


DOE/ER-0313/28

Distribution

Categories

UC-423, -424

\section{FUSION MATERIALS \\ SEMIANNUAL PROGRESS REPORT \\ FOR THE PERIOD ENDING \\ June 30,2000}

Prepared for
DOE Office of Fusion Energy Sciences

(AT 6020000 )

DATE PUBLISHED: SEPTEMBER 2000

Prepared for

OAK RIDGE NATIONAL LABORATORY Oak Ridge, Tennessee 37831

Managed by

U.T.-Battelle, LLC

for the

U.S. DEPARTMENT OF ENERGY

under Contract DE-AC05-00OR22725 



\section{FOREWORD}

This is the tweny-eighth in a series of semiannual technical progress reports on fusion materials. This report combines the full spectrum of research and development activities on both metallic and non-metallic materials with primary emphasis on the effects of the neutronic and chemical environment on the properties and performance of materials for in-vessel components. This effort forms one element of the materials program being conducted in support of the Fusion Energy Sciences Program of the U.S. Department of Energy. The other major element of the program is concerned with the interactions between reactor materials and the plasma and is reported separately.

The Fusion Materials Program is a national effort involving several national laboratories, universities, and industries. A large fraction of this work, particularly in relation to fission reactor experiments, is carried out collaboratively with our partners in Japan, Russia, and the European Union. The purpose of this series of reports is to provide a working technical record for the use of the program participants, and to provide a means of communicating the efforts of materials scientists to the rest of the fusion community, both nationally and worldwide.

This report has been compiled and edited under the guidance of $A$. F. Rowcliffe by Gabrielle Burn, Oak Ridge National Laboratory. Their efforts, and the efforts of the many persons who made technical contributions, are gratefully acknowledged.

S. E. Berk

International and Technology Division 
Reports previously listed in this series are as follows:

DOE/ER-0313/1

DOE/ER-0313/2

DOE/ER-0313/3

DOE/ER-0313/4

DOE/ER-0313/5

DOE/ER-0313/6

DOE/ER-0313/7

DOE/ER-0313/8

DOE/ER-0313/9

DOE/ER-0313/10

DOE/ER-0313/11

DOE/ER-0313/12

DOE/ER-0313/13

DOE/ER-0313/14

DOE/ER-0313/15

DOE/ER-0313/16

DOE/ER-0313/17

DOE/ER-0313/18

DOE/ER-0313/19

DOE/ER-0313/20

DOE/ER-0313/21

DOE/ER-0313/22

DOE/ER-0313/23

DOE/ER-0313/24

DOE/ER-0313/25

DOE/ER-0313/26

DOE/ER-0313/27

DOE/ER-0313/100
Period ending September 30, 1986

Period ending March 31, 1987

Period ending September 30, 1987

Period ending March 31, 1988

Period ending September 30, 1988

Period ending March 31, 1989

Period ending September 30, 1989

Period ending March 31, 1990

Period ending September 30, 1990

Period ending March 31, 1991

Period ending September 30, 1991

Period ending March 31, 1992

Period ending September 30, 1992

Period ending March 31, 1993

Period ending September 30, 1993

Period ending March 31, 1994

Period ending September 30, 1994

Period ending March 31, 1995

Period ending December 31, 1995

Period ending June 30, 1996

Period ending December 31, 1996

Period ending June 30, 1997

Period ending December 31, 1997

Period ending June 30, 1998

Period ending December 31, 1998

Period ending June 30, 1999

Period ending December 31, 1999

Technical Evaluation of the Technology of Vanadium Alloys for Use as Blanket Structural Materials in Fusion Power Systems 


\section{CONTENTS}

\subsection{VANADIUM ALLOYS}

1.1 OXIDATION OF V-4Cr-4Ti AT LOW PRESSURES - B. A. Pint, R. DiStefano, and L. D. Chitwood (Oak Ridge National Laboratory)

Specimens of $\mathrm{V}-4 \mathrm{Cr}-4 \mathrm{Ti}$ have been exposed to low pressure oxygen and high purity helium and argon environments to determine oxidation kinetics. After exposure, mechanical properties were measured at 25 and $600^{\circ} \mathrm{C}$. Oxidation at $600-700^{\circ} \mathrm{C}$ generally produced linear kinetics when the oxygenpressure was $\leq 10^{-5} \mathrm{~Pa}$. Higher oxygen partial pressures and lower temperatures can result in external film formation and parabolic kinetics. Internal oxidation resulting in oxygen concentrations $>2000$ wppm generally led to significant tensile embrittlement. Higher total oxygen levels could be tolerated (without significant embrittlement) in cases where an external oxide layer formed. However, when specimens which formed an external layer were given an additional vacuum anneal for $2000 \mathrm{~h}$ at $700^{\circ} \mathrm{C}$, embrittlement occurred. This indicates that, rather than being protective, surface oxides on vanadium are a source of oxygen for further internal oxidation and thus embrittlement.

\subsection{HYDROGEN SOLUBILITY IN VANADIUM ALLOYS AND LITHIUM ALLOYS -}

D. L. Smith (Argonne National Laboratory), R. E. Buxbaum (REB Research), and

C. B. Reed (Argonne National Laboratory)

A systematic investigation was conducted to provide an accurate determination of the hydrogen solubility in the $\mathrm{V}-4 \mathrm{Cr}-4 \mathrm{Ti}$ alloy at temperatures in the range 400$600^{\circ} \mathrm{C}$, which is of primary interest for fusion applications. Results habe been obtained by the method of hydrogen absorption and desorption into flowing helium with controlled concentrations of hydrogen to provide accurate measurements of the Sieverts' constants for the alloy. In the procedure used, the alloy specimen was maintained at constant temperature for each test to avoid the rapid redistribution of hydrogen that occurs during cooling down of the specimens. The results indicate a hydrogen solubility for $\mathrm{V}-4 \mathrm{Cr}-4 \mathrm{Ti}$ about $30 \%$ higher than that reported for unalloyed vanadium.

1.3 LASER WELDING OF V-4Cr-4Ti ALLOY - Z. Xu, d. L. Smith, Y. Yan, and C. B. Reed (Argonne National Laboratory)

Laser welding offers potential advantages for welding vanadium alloys, including increased flexibility for field and large component welding with acceptable atmospheric control. A pulsed Nd:YAG laser with a fiber optic delivery system is used to conduct a systematic investigation of the weld parameters and environmental control requirements to obtain high intergrity laser welds of vanadium alloys. Ths current effort is focused on determination of laser weld parameters for welding $\sim 4-\mathrm{mm}$-thick plate of $\mathrm{V}-4 \mathrm{Cr}-4 \mathrm{Ti}$ alloys and evaluation of various approaches for providing adequate environmental control. Laser weld specimens have been produced on two heats of $\mathrm{V}-4 \mathrm{Cr}-4 \mathrm{Ti}$ alloys and preliminary evaluations of weld integrity have been performed. Parameters for obtaining full penetration of welds have been defined and weld specimens have been prepared 
for mechanical testing in a related study. Results from preliminary bend tests on weld specimens indicate good ductility.

\subsection{MICROSTRUCTURAL CHARACTERIZATION AND IMPACT PROPERTIES} OF V-4Cr-4Ti LASER WELDMENTS - Y. Yan, H. Tsai, A. D. Storey, D. L. Smith, and Z. Xu (Argonne National Laboratory)

Microstructure and Charpy-impact properties of laser weldments of the $500-\mathrm{kg}$ \#832665 heat $\mathrm{V}-4 \mathrm{Cr}$-4Ti alloy were investigated. Optical metallography shows the grain sizes in the weld to be greater than those in the base materials. The grains are equiaxed near the middle of the weld and elongated (oriented in the direction of freeze progression) near the edge. The banded structure in the base metal seems to disappear in the weld zone, and density of secondary phase particles in the weld is much lower than that in the base metal. Impact testing was performed with specimens as-machined (by electric discharge machining with water as the flushing fluid), as well as after a degassing heat treatment at $400^{\circ} \mathrm{C}$ for $1 \mathrm{~h}$. In the asmachined condition, the ductile-to-brittle-transition temperature (DBTT) for both the base metal and the laser weld is about $-20^{\circ} \mathrm{C}$. While the DBTT of the base metal was decreased significantly with the degassing operation, that of the weldment was relatively unaffected. Additional characterization and testing, including oxygen analysis is under way.

\subsection{IMPURITY EFFECTS ON GAS TUNGSTEN ARC WELDS IN V-Cr-Ti} ALLOYS - M. L. Grossbeck, J. F. King, and D. T. Hoelzer (Oak Ridge National Laboratory)

\section{Extended Abstract}

1.6 STUDY OF THE LONG-TERM STABILITY OF MHD COATINGS FOR FUSION REACTOR APPLICATIONS - B. A. Pint, L. D. Chitwood, J. H. DeVan, and J. R. DiStefano (Oak Ridge National Laboratory)

Two candidate materials for insulating coatings in a lithium-cooled fusion reactor have been exposed to lithium in $100 \mathrm{~h}$ isothermal tests from 400 to $800^{\circ} \mathrm{C}$ to determine their maximum compatibility temperature. Bulk samples of AIN $+5 w+\% Y_{2} \mathrm{O}_{3}$ showed significant mass loss at $600^{\circ} \mathrm{C}$ and higher temperatures. The amount of attack was reduced when $A I N+0.4 Y$ was tested. Characterization by auger spectroscopy of a AIN+-0.4Y specimen exposed at $600^{\circ} \mathrm{C}$ indicated the possibility of a lithium aluminate compound formation. Bulk specimens of $\mathrm{CaO}$ (99.9\% purity) showed mass losses above $500^{\circ} \mathrm{C}$ indicating a possible dissolution problem that had not been observed in previous short-term screening tests. Doping of the lithium with oxygen (in the case of $\mathrm{CaO}$ ) did not appear effective in reducing the attack at $600^{\circ} \mathrm{C}$. However, doping with nitrogen (with AIN) did show a possible beneficial effect in conjunction with a Mo capsule. Based on these results, future testing also will consider alternative candidates such as $\mathrm{Y}_{2} \mathrm{O}_{3}$ and $\mathrm{Er}_{2} \mathrm{O}_{3}$. 
1.7 DEVELOPMENT OF ELECTRICALLY INSULATING CaO COATINGS K. Natesan, Z. Zeng, W. E. Ruther, M. Uz, and D. L. Smith (Argonne National Laboratory)

A systematic study has been initiated to develop electrically insulating $\mathrm{CaO}$ coating by in-situ formation in a liquid $\mathrm{Li}$ environment. Twelve capsule tests were conducted at several temperatures and with different concentrations of $\mathrm{Ca}$ in $\mathrm{Li}-\mathrm{Ca}$ mixtures. Specimens included in the run were annealed $\mathrm{V}-4 \mathrm{Cr}-4 \mathrm{Ti}$ alloy without and with a grit-blasted surface, O-precharged in 99.999 vol.\% Ar environment,

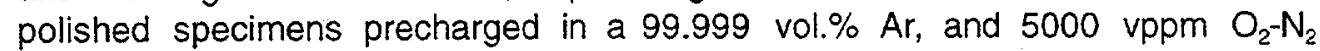
mixture. CaO coatings of $2-3 \mu \mathrm{m}$ in thickness were obtained. Detailed microstructural and compositional analyses were performed on the exposed specimens. The coatings exhibited a resistance of $=44 \Omega / \mathrm{cm}^{2}$ on the surface of $V$ $4 \mathrm{Cr}-4 \mathrm{Ti}$ alloys.

A systematic vapor transport study has been in progress to develop electrically insulating $\mathrm{CaO}$ coatings that are compatible with use in a liquid $\mathrm{Li}$ environment. Several additional experiments were conducted to study how the deposition of $\mathrm{Ca}$ on $\mathrm{V}-4 \mathrm{Cr}-4 \mathrm{Ti}$ substrate alloys is affected by variations in process temperature and time, and specimen location, surface preparation, and pretreatment. During this reporting period, several specimens were prepared with a coating of $\mathrm{CaO}$ by thermal/chemical deposition and the coatings were characterized before and after exposure to an $\mathrm{Li}$ environment.

1.8 UNIAXIAL CREEP BEHAVIOR OF V-4Cr-4Ti ALLOY - K. Natesan, W. K. Soppet, and D. L. Rink (Argonne National Laboratory)

A systematic study is currently being conducted at Argonne National Laboratory (ANL) to evaluate the uniaxial creep behavior of V-Cr-Ti alloys as a function of temperature in the range of $650-800^{\circ} \mathrm{C}$ and at applied stress levels of $75-380 \mathrm{MPa}$. At present, the principal effort has focused on the $\mathrm{V}-4 \mathrm{Cr}-4 \mathrm{Ti}$ alloy of Heat 832665 ; however, another heat of a similar alloy from General Atomics (GA) will also be used in the study. The Larson-Miller approach is used to correlate several creep parameters such as time to rupture, time-to-inset of tertiary creep, and times for 1 and $2 \%$ strain accumulation with applied stress and temperature. Best-fit equations are presented for several creep parameters.

1.9 EVALUATION OF THERMAL CREEP OF V-4Cr-4Ti IN A LITHIUM ENVIRONMENT - M. L. Grossbeck (Oak Ridge National Laboratory)

Thermal creep in vanadium alloys can be measured by pressurized tubes. The tubes are pressurized with helium at a series of pressures to give the desired stresses in the tube wall. The diameter of the tubes is very precisely measured before and after high temperature exposure to determine creep deformation. A pair of high temperature furnaces and retorts have been fitted into an inert gas glove box system. Liquid lithium will be contained in the retorts which will contain the pressurized tubes of the vanadium alloy to be tested. The refractory metal retorts have been equipped with pressure sensors to determine to time of tube failure. This system will be used to determine time of failure and strain to failure as a function of stress. 
viii

1.10DEFORMATION BEHAVIOR OF UNALLOYED VANADIUM - D. T. Hoelzer and A. F. Rowcliffe

The tensile deformation behavior of unalloyed vanadium has been determined at 200 and $300^{\circ} \mathrm{C}$ for strain rates in the range $10^{-2} / \mathrm{s}$ to $10^{-5} / \mathrm{s}$. The occurrence of serrated flow effects in the Lüders extension and work hardening regimes of tensile stress-strain curves is associated with negative strain rate sensitivity of stress parameters.

1.11 TENSILE PROPERTIES OF $\mathrm{V}-(\mathrm{Cr}, \mathrm{Fe})$-Ti ALLOYS AFTER IRRADIATION IN THE HFIR-11J EXPERIMENT - Y. Yan, H. Tsai, D. O. Pushis, and D. L. Smith (Argonne National Laboratory), K. Fukumoto, H. Matsui (IMR/Tohoku University)

Postirradiation tensile tests at room temperature and $300^{\circ} \mathrm{C}$ were performed on $\mathrm{V}$ $(\mathrm{Cr}, \mathrm{Fe})-\mathrm{Ti}$ alloy specimens that had been irradiated in the HFIR-11J experiment. The specimens were of the SSJ design. Irradiation temperature was $\approx 300^{\circ} \mathrm{C}$ and the attained neutron damage was $\approx 6 \mathrm{dpa}$. Results from these tensile tests show significant radiation hardening and ductility reduction in all of the materials. In comparison, hardening was substantially lower in the same materials after the $500^{\circ} \mathrm{C}$ $12 \mathrm{~J}$ experiment. These results are consistent with previous findings that the demarcation for low-temperature radiation embrittlement in vanadium alloys is $\approx 400^{\circ} \mathrm{C}$.

\subsection{IMPACT AND TENSILE PROPERTIES OF VANADIUM ALLOY AFTER} LONG-TERM EXPOSURE IN THE DIII-D EXPERIMENTAL TOKAMAK H. Tsai, Y. Yan, D. O. Pushis, A. Storey, D. L. Smith (Argonne National Laboratory), and W. R. Johnson (General Atomics)

Tensile and Charpy specimens of Heat 832665 of $\mathrm{V}-4 \mathrm{Cr}-4 \mathrm{Ti}$ alloy were exposed in the DIII-D experimental tokamak to investigate the effect of environment on the impact and tensile properties of this alloy. In this last test of the four-test series, specimens were mounted next to the chamber wall behind a divertor baffle plate and received an exposure of $\approx 3 \mathrm{yr}$. The results of this test, consistent with the results of the previous three tests, indicate no significant degradation of the mechanical properties of the alloy.

\subsection{EFFECT OF HEAT TREATMENT ON MICROSTRUCTURE OF V-4Cr-4Ti} MATERIALS - Y. Yan, H. Tsai, W. C. Kettman, and D. L. Smith (Argonne National Laboratory)

A banded structure containing Ti-rich particles has been observed in an extruded $\mathrm{V}-4 \mathrm{Cr}-4 \mathrm{Ti}$ bar from the ANL's 832665 heat and in a swaged rod from the GA's 832864 heat. Because these two materials may be used as feedstocks for the upcoming creep tubing fabrication, this task was undertaken to determine whether this secondary-phase structure could be removed by dissolution at elevated temperature. Small pieces of the two mateirals were heat treated at $1150^{\circ} \mathrm{C}$ for $3 \mathrm{~h}$ and then characterized. The preliminary results show that this heat treatment did not redissolve the banded structure in either the extruded 832665 bar or the swaged 832864 rod. 


\subsection{TOUGHNESS-TEMPERATURE CURVES IN OXIDE DISPERSION STRENGTHENED MA957 -- M.J. Alinger, G.R. Odette and G.E. Lucas (University of California, Santa Barbara)}

Iron based alloys strengthened with a very high density and fine dispersion of ultrafine scale yttria-titanium-oxygen particles for improved high temperature creep strength, coupled with chromium additions for corrosion resistance, offer great promise for elevated temperature applications in fusion reactors. These alloys are usually referred to as oxide dispersion strengthened (ODS) steels. They are typically produced through mechanical alloying by mixed powder attrition, followed by consolidation and hot deformation, which may include the production of near net shape components. Given their engineered microstructural architectures and low carbon content (a key factor in their success), we feel it is more appropriate to refer to this class of materials as nano-composited ferritic alloys (NFAs).

Mechanically alloyed $14 \mathrm{Cr}-1 \mathrm{Ti}-0.3 \mathrm{Mo}-0.025 \mathrm{Y}_{2} \mathrm{O}_{3}$ MA957 in the form of extrusions, were produced and extensively characterized for the breeder reactor program [1]. This material showed very promising creep and tensile properties. However, limited Charpy testing demonstrated that this MA957 product has highly anisotropic grain structures and manifests extremely brittle behavior, particularly in certain orientations. Brittle behavior was attributed to the presence of alumina stringers. The objective of the present work is to characterize the fracture toughnesstemperature curves for MA957 in various orientations relative to the grain and inclusion structures. Small, pre-cracked, 1/3-sized Charpy specimens of MA957 tested in three point bending under quasi-static conditions showed low minimum toughness (<20MPa $\sqrt{\mathrm{m}}$ ) and lower transition cleavage up to temperatures around $50-70^{\circ} \mathrm{C}$ in both the $\mathrm{C}-\mathrm{R}$ and $\mathrm{C}-\mathrm{L}$ orientations. At higher temperatures these orientations also manifested low resistance to stable crack growth, with maximum load toughness values ranging from about 50-100 MPa $\sqrt{\mathrm{m}}$. However, the cleavage regime is shifted to much lower temperatures of around $-70^{\circ} \mathrm{C}$ for the $L-R$ orientation; and at high temperature maximum load toughness increased to about 125 to $145 \mathrm{MPa}$. At intermediate temperatures the fracture process was complex, typically involving out of plane cracking and combinations of stable extension and small cleavage pop-in events. The latter results are very encouraging and suggest that with proper development, NFA systems offer great promise to combine very high strength with good toughness and corrosion resistance.

\subsection{SILICON CARBIDE COMPOSITE MATERIALS}

\subsection{POLYMER DERIVED SIC MATERIALS FOR JOINING SILICON CARBIDE COMPOSITES FOR FUSION ENERGY - C. A. Lewinsohn and R. H. Jones (Pacific Northwest National Laboratory), T. Nozawa, M. Kotani, Y. Katoh and A. Kohyama (Institute of Advanced Energy, Kyoto University)}

The fabrication of large or complex silicon carbide-fiber-reinforced sillicon carbide $(\mathrm{SiC} / \mathrm{SiC})$ components for fusion energy systems requires a method to assemble smaller components that are limited in size by manufacturing constraints. Recently families of polymers that yield inorganic materials subsequent to pyrolysis have been a subject of extensive international research [2-9]. One such polymer, allylhydridopolycarbosilane (aHPCS), has been shown to have good high temperature 
mechanical properties as well as requiring relatively low temperature for pyrolysis [5]. In this study the mechanical properties of joints fabricated by aHPCS were measured. Preliminary results indicate that the strength value of the aHPCS joints are slightly lower than those of reaction-based methods.

\subsection{TENSILE STRENGTH AND FRACTURE SURFACE CHARACTERIZATION} OF HI-NICALON ${ }^{T M}$ SiC FIBERS - G. E. Youngblood, Charles Lewinsohn, and R. H. Jones (Pacific Northwest National Laboratory), and A. Kohyama (Institute of Advanced Energy, Kyoto University)

Extended Abstract

2.3 TRANSMUTATIONS IN SIC IRRADIATED IN ARIES-IV FIRST WALL H. L. Heinisch (Pacific Northwest National Laboratory)

The change in concentrations of elements due to transmutations resulting from neutron irradiation in the first wall of the ARIES-IV conceptual fusion energy device were determined as a function of neutron dose. $\mathrm{SiC}$ burns out at a rate of about $0.5 \%$ per effective full power year. The largest impurity concentration is that of $\mathrm{He}$, but several other elements burn in at rates of hundreds of appm/efpy.

2.4 THE KFIB EXPERIMENT - G. E. Youngblood, D J. Senor and R. H. Jones (Pacific Northwest National Laboratory), W. Kowbel (MER Corporation), and A. Kohyama (Kyoto University)

Several rod-shaped specimens with uniaxially packed fibers (Hi-Nicalon ${ }^{\mathrm{TM}}$, Hi-

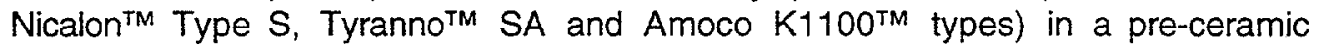
polymer matrix were fabricated. By using appropriate analytic models, the bare fiber thermal conductivity $\left(K_{1}\right)$ will be determined as a function of temperature up to $1000^{\circ} \mathrm{C}$ before and after irradiation for samples cut from these rods. Preliminary thermal conductivity data for unirradiated fibers (Hi-Nicalon ${ }^{T M}$ and Tyranno ${ }^{T M}$ SA-B $\mathrm{SiC}$ and $\mathrm{K} 1100^{\mathrm{TM}}$ graphite) and for three types of unirradiated composites made from these fibers (2D-Nicalon S/SiC multilayer/CVI-SiC, 3D-Nicalon S/PIP-SiC, and 2D-8HS Tyrannohex ${ }^{\mathrm{TM}} \mathrm{HP}$ ) are presented.

2.5 THE TRANSVERSE THERMAL CONDUCTIVITY OF 2D-SIC $/$ /SIC COMPOSITES - G. E. Youngblood, David J. Senor, R. H. Jones (Pacific Northwest National Laboratory), and Samuel Graham (Sandia National Laboratories)

Extended Abstract

2.6 A NEW TYPE OF SIC COMPOSITE FOR FUSION - G. E. Youngblood and R. H. Jones (Pacific Northwest National Laboratory)

A new type of $\mathrm{SiC}$ composite called Tyrannohex ${ }^{\mathrm{TM}}$ is potentially suitable as a fusion reactor structural material. Tyrannohex ${ }^{\mathrm{TM}}$ composite plates are made by hotpressing layups of Tyranno ${ }^{\mathrm{TM}} \mathrm{SA}$ precursor fibers into various $1 D$ and $2 D$ configurations. The fiber-bonded composite plates contain nearly $100 \%$ fiber volume, so take advantage of the outstanding high temperature strength and creep properties of the Tyranno ${ }^{\mathrm{TM}} \mathrm{SA}$ fiber, a nearly stoichiometric SiC fiber. The hot- 
pressed plates are dense, strong, rigid, tough, thermally conductive and have high temperature stability.

The microstructure and thermal conductivity of a SA-Tyrannohex ${ }^{\top M}$ material with a 2D-woven configuration was evaluated prior to irradiation testing. The microstructure contained some small, flat interlaminar pores and intrabundle needle-like pores, and the transverse thermal conductivity was 25 and $21 \mathrm{~W} / \mathrm{mK}$ at ambient and $1000^{\circ} \mathrm{C}$, respectively. These results suggest that careful control of the fiber-bonded interlayers and the fiber architecture are critical to achieve both high thermal conductivity and toughness in Tyrannohex ${ }^{\mathrm{TM}}$ type materials.

\section{O FERRITIC MARTENSITIC STEELS}

3.1 MICROSTRUCTURE AND MECHANICAL PROPERTIES OF OXIDE DISPERSION-STRENGTHENED STEELS - R. L. Klueh, P. J. Maziasz, D. J. Larson, N. Hashimoto, L. Heatherly, M. K. Miller (Oak Ridge National Laboratory), I-S. Kim, and K. Miyahara (Nagoya University)

The microstructure and the tensile and creep behavior of two oxide dispersionstrengthened (ODS) steels-F.E-12Cr-0.25 $\mathrm{Y}_{2} \mathrm{O}_{3}$ (designated 12Y1) and $\mathrm{Fe}-12 \mathrm{Cr}$ $3 \mathrm{~W}-0.4 \mathrm{Ti}-0.25 \mathrm{Y}_{2} \mathrm{O}^{3}$ (12WWT) - were investigatd. Optical microscopy, transmission electron microscopy, and atom probe field ion microscopy studies indicated that the $12 \mathrm{YWT}$ contained a high density of extremely fine Y-Ti-O clusters, compared to the much larger oxide particles in the 12Y1. The fine dispersion of particles in the $12 Y W T$ gave it superior tnesile and creep properties.

\subsection{TENSILE RESULTS OF LOW-ACTIVATION MARTENSITIC STEEL} IRRADIATED IN HFIR RB-11J AND 12J SPECTRALLY TAILORED CAPSULTS - K. Shiba (Japan Atomic Energy Research Inatitute), R. L. Klueh (Oak Ridge National Laboratory), Y. Miwa, N. Igawa (Japan Atomic Energy Research Institute), and J. P. Robertson (Oak Ridge National Laboratory)

Post-irradiation tensile test results for F82H IEA heat base metal (BM) and TIG weldments are reported. Tensile specimens were irradiated to about $5 \mathrm{dpa}$ at 300 and $500^{\circ} \mathrm{C}$. Irradiation caused significant hardening at $300^{\circ} \mathrm{C}$. The TIG weld metal (WM) exhibited almost the same amount of irradiation hardening as the $\mathrm{BM}$, but the TIG weld joint (WJ) showed less hardening than BM and WM. Increasing the strain rate caused a slight increase in yield strength, while a decreasing strain rate caused a sharper stress drop after yielding for BM specimens irradiated at $500^{\circ} \mathrm{C}$. However, a decrease in strain rate caused a reduction in elongation.

\subsection{POSTIRRADIATION DEFORMATION MICROSTRUCTURES IN FERRITIC} Fe-9Cr - D. S. Gelles, M. L. Hamilton (Pacific Northwest National Laboratory) and R. Schäublin (EPFL-CRPP Fusion Technology, Switzerland)

The deformed microstructures of both irradiated and unirradiated $\mathrm{Fe}-9 \mathrm{Cr}$ uniaxial tensile specimens have been examined to identify controlling mechanisms. Deformation following irradiation is found to ossur in poorly defined channels, causing formation of discrete steps at surfaces and delineated by nonuniformly distributed highly elongated voids. Deformation is by motion of $a / 2<111\rangle$ dislocations, which interact with and decompose irradiation-induced $a<100>100 p s$. 
The structure formed after extensive deformation consists of highly complex cell walls and moderate densities of individual slip dislocations.

\subsection{MICROSTRUCTURAL EVOLUTION OF 9Cr-2WVTa STEELS IN HFIR- CTR-62/63 EXPERIMENT - N. Hashimoto and R.L. Klueh (Oak Ridge National Laboratory)}

The microstructures of reduced-activation ferritic/martensitic steels, 9Cr-2WVTa and $9 \mathrm{Cr}-2 \mathrm{WVTa}$ doped with $2 \% \mathrm{Ni}$, irradiated at $400^{\circ} \mathrm{C}$ up to $12 \mathrm{dpa}$ in the High Flux Isotope Reactor (HFIR), were investigated by transmission electron microscopy. Specimens were tempered at two different temperatures in order to investigate the effects of tempering on microstructural evolution during irradiation. Before irradiation, the lath width of Ni-doped 9Cr-2WVTa was somewhat narrower and the dislocation density tended to be higher compared with 9Cr-2WVTa. Dislocation density of specimens tempered at $750^{\circ} \mathrm{C}$ was lower than that tempered at $700^{\circ} \mathrm{C}$. In all steels, precipitates on grain and/or lath boundaries were mainly $M_{23} C_{6}$, and there were a few $\mathrm{TaC}$ along dislocations in the matrices. Irradiation-induced cavities were observed in all the steels. The cavity number density of the Ni-doped $9 \mathrm{Cr}-2 \mathrm{WVTa}$ was higher than that of $9 \mathrm{Cr}-2 \mathrm{WVT}$ a due to the higher concentration of helium; however, swelling in each steels was $<0.001 \%$ because cavity sizes were so small. There was no difference of cavity number density between the steels tempered at $700^{\circ} \mathrm{C}$ and $750^{\circ} \mathrm{C}$, but the mean size of the cavities in the steels tempered at $750^{\circ} \mathrm{C}$ was larger than that tempered at $700^{\circ} \mathrm{C}$. Irradiation-induced $a_{0}<100>$ and $\left(a_{0} / 2\right)<111>$ type dislocation loops were observed in all steels; number density and mean diameter of $a_{0}<100>$ type loops was higher and larger than that of $\left(a_{0} / 2\right)<111>$ type loops. There was a tendency for the number density of loops in Ni-doped 9Cr-2WVTa to be higher than that in 9Cr-2WVTa. In addition, the mean size of loops in the steels tempered at $750^{\circ} \mathrm{C}$ was larger than for those tempered at $700^{\circ} \mathrm{C}$, while there was not much difference of number density between them. In the steels doped with $\mathrm{Ni}$, irradiation-produced precipitates, identified as $\mathrm{M}_{6} \mathrm{C}(\eta)$ type carbide, were found in the matrices. Precipitation during irradiation might affect cavity and dislocation loop growth. In this experiment, the $9 \mathrm{Cr}-2 \mathrm{VWTa}-2 \mathrm{Ni}$ steel showed a larger increase of the transition temperature and a significant reduction in the upper shelf energy compared with the 9Cr-2WVTa steel. From these results, it might be suggested that the high density of cavities and precipitation in irradiated $9 \mathrm{Cr}-2 \mathrm{VWTa}-2 \mathrm{Ni}$ could affect Charpy properties, especially the reduction of upper shelf energy.

\subsection{INVESTIGATION OF THE MICROSTRUCTURE OF FRACTURE SPECIMENS FROM FIVE DIFFERENT PLATES OF THE $500 \mathrm{KG}$ PROGRAM HEAT OF V-4Cr-4Ti -- E.G. Donahue, G.R. Odette, G.E. Lucas (University of California, Santa Barbara)}

Four of the five plates of $\mathrm{V}-4 \mathrm{Cr}-4 \mathrm{Ti}$ had similar microstructures. They exhibited banding of Ti-OCN particles, which were distributed in planar arrays parallel to the rolling plane. The grain sizes were reduced in the vicinity of the particles. The plates differed in the size reduction of these grains and the thickness and spacing of the bands. The fifth plate had a more uniform distribution of Ti-OCN particles and no evidence of bands of reduced-size grains. The microstructures are considered in relation to fracture behavior. 
4.1 TENSILE PROPERTIES OF HIGH-STRENGTH, HIGH-CONDUCTIVITY COPPER ALLOYS AT HIGH TEMPERATURES - S. J. Zinkle (Oak Ridge National Laboratory)

The unirradiated tensile properties of wrought GlidCop AL25 (ITER grade zero, IGO), solutionized and aged CuCrZr, and wrought and aged CuCrNb have been measured at temperatures up to $700^{\circ} \mathrm{C}$ at strain rates between $4 \times 10^{-4} \mathrm{~s}^{-1}$ and $0.02 \mathrm{~s}$ ${ }^{1}$. GlidCop Al25 exhibited rapid softening with increasing test temperature $\geq 300^{\circ} \mathrm{C}$, whereas the CuCrZr and CuCrNb precipitation hardened alloys decreased more slowly with increasing temperature. The difference in tensile behavior of the GlidCop and precipitation-hardened alloys is attributed to the small grain size in GlidCop, which allows grain boundary sliding (Coble creep) to become the dominant deformation mode at temperatures above $\sim 400^{\circ} \mathrm{C}$.

4.2 OVERAGING OF OUTOKUMPU CuCrCr - D. J. Edwards (Pacific Northwest National Laboratory) and B. N. Singh (Risø National Laboratory)

Aging at $850^{\circ} \mathrm{C}$ for four hours essentially removed the fine-scale precipitates produced during the prime aging treatment. Aging at $700^{\circ} \mathrm{C}$ led to large scale coarsening that produced denuded zones along grain and twin boundaries, grain boundary precipitates, and removed all of the fine-scale- defects to produce precipitates $20 \mathrm{~nm}$ in size or larger. Aging at $600^{\circ} \mathrm{C}$ led to somewhat similar microstructure compared to the $700^{\circ} \mathrm{C}$ aged specimens, however, the average size of the precipitates was not quite as large and the density appears to be somewhat higher. Denuded zones formed along all boundaries, but the grain boundary precipitation was not as extensive as in the case of the specimens aged at $700^{\circ} \mathrm{C}$. Further characterization will be conducted to determine the identity and chemistry of the precipitates observed in the aged microstructures.

\subsection{AUSTENITIC STAINLESS STEELS}

No contributions.

\subsection{INSULATING CERAMICS AND OPTICAL MATERIALS}

\subsection{GAS ASSISTED CAVITY FORMATION AND BLISTERING IN CERAMICS -}

Single- or poly-crystalline specimens of $\mathrm{SiC}, \mathrm{Si}_{3} \mathrm{~N}_{4}, \mathrm{MgO}, \mathrm{Al}_{2} \mathrm{O}_{3}$ and $\mathrm{MgAl}_{2} \mathrm{O}_{4}$ were implanted with 0.4-1 $\mathrm{MeV} \mathrm{H}^{+}$or $0.4-1 \mathrm{MeV} \mathrm{He}^{+}$ion beams at room temperature and $650^{\circ} \mathrm{C}\left(\sim 0.1\right.$ and $\left.0.4 T_{M}\right)$ up to fluences of $-1 \times 10^{22} / \mathrm{m}^{2}$. This produced peak implanted gas and displacement damage levels as high as $\sim 50$ at. $\%$ and 21 displacements per atom (dpa). The specimens were subsequently examined optically, and in cross-section using transmission electron microscopy. Subsurface blistering occurred for specimens irradiated to $\mathrm{H}^{+}$or $\mathrm{He}^{+}$fluences greater than about $3 \times 10^{21} / \mathrm{m}^{2}(\sim 15$ at. \% implanted gas concentration), and surface exfoliation occurred for fluences above $\sim 1 \times 10^{22} / \mathrm{m}^{2}$. Helium was more effective at inducing blistering and exfoliation than $\mathrm{H}$ on an atomic basis. The threshold blistering and 
exfoliation fluences for both ions decreased with increasing temperature. Both $\mathrm{H}^{+}$ and $\mathrm{He}^{+}$were found to be very effective in inducing matrix cavity formation, due to their low solubility in these ceramics. Cavity formation was observed to initiate at the periphery of dislocation loops in several cases. The bubble formation and blistering behavior of the ceramics was similar to that observed for metals irradiated at comparable homologous temperatures.

\section{O BREEDING MATERIALS}

No contributions.

\section{O RADIATION EFFECTS, MECHANISTIC STUDIES, AND EXPERIMENTAL} METHODS

8.1 COMPOSITIONAL AND TEMPERATURE DEPENDENCE OF VOID SWELLING IN MODEL FE-CR BASE ALLOYS IRRADIATED IN THE EBR-II FAST REACTOR - B. H. Sencer and F. A. Garner (Pacific Northwest National Laboratory)

A series of annealed and aged $\mathrm{Fe}-\mathrm{xCr}, \mathrm{Fe}-12 \mathrm{Cr}-\mathrm{yC}$ and $\mathrm{Fe}-12 \mathrm{Cr}-0.1 \mathrm{C}-\mathrm{zMo}$ model alloys were irradiated in EBR-II at eight temperatures between 400 and $650^{\circ} \mathrm{C}$ and dose levels ranging from 35 to $131 \mathrm{dpa}$. Swelling-induced density changes observed in the binary alloys generally peaked at mid-chromium levels, with the chromium and temperature dependence expressed primarily in the duration of the transient regime. The steady state swelling rate at the lower irradiation temperatures was much higher than previous estimates, reaching $\sim 0.2 \% / \mathrm{dpa}$ and possibly still climbing at higher neutron exposures.

The dependence of swelling on molybdenum and carbon was more complex, depending on whether the temperature was relatively low or high. At temperatures of $482^{\circ} \mathrm{C}$ and above the effect of carbon additions was very pronounced, with swelling of $\mathrm{Fe}-12 \mathrm{Cr}$ jumping dramatically from near zero at $0.002 \% \mathrm{C}$ to $6-10 \%$ at $0.1 \% \mathrm{C}$. This indicates that the major determinant of the composition and temperature dependence probably lies in the duration of the nucleation-dominated transient regime of swelling and not primarily in the steady-state swelling rate as previously envisioned. This raises the possibility that significant swelling may occur earlier in fusion and spallation neutron spectra where high gas generation rates may assist void nucleation.

\subsection{RADIATION HARDENING IN HCP TITANIUM ALLOYS - D. J. Edwards}

Two titanium alloys were irradiated at 50 and $350^{\circ} \mathrm{C}$ to $\sim 0.3 \mathrm{dpa}$. Tensile properties were determined for both alloys and related to the observed microstructure before and after deformation. Radiation hardening occurred in both alloys when irradiated at $50^{\circ} \mathrm{C}$ due to the presence of fine-scale defects, whereas at $350^{\circ} \mathrm{C}$ only the Ti-6Al$4 \mathrm{~V}$ alloy showed significant hardening. Radiation-induced precipitation occurred in this alloy, yielding a high strength, lower ductile condition compared to the unirradiated condition. 


\subsection{PASSIVE TEMPERATURE MONITORS FOR THE HFIR METS} EXPERIMENT - S. D. Connery (Rennselaer Polytechnic Institute), L. L. Snead (Oak Ridge National Laboratory), and D. Steiner (Renssalaer Polytechnic Institute)

The purpose of this work is to provide a method of indicating the maximum temperature in the uninstrumental Mapping Elevated Temperature Swelling (METS) capsules. Small heats of selected alloys and pure metals ("melt blocks") were fabricated with a range of melting temperatures to be included in the METS capsules. Visual inspection and/or radiography of the melt blocks after irradiation will indicate the maximum temperature attained to within $\sim 20^{\circ} \mathrm{C}$. METS subcapsules expected to remain below $1000^{\circ} \mathrm{C}$ will also include $\mathrm{SiC}$ temperature monitors. Postirradiation annealing and dimensional analysis of the $\mathrm{SiC}$ temperature monitors will provide an estimate of the temperature at the end of irradiation to within $\sim 45^{\circ} \mathrm{C}$.

\subsection{DOSIMETRY, DAMAGE PARAMETERS, AND ACTIVATION CALCULATIONS}

\subsection{SIMULATION OF PRIMARY DAMAGE FORMATION IN IRRADIATED}

MATERIALS - Roger E. Stoller (Oak Ridge National Laboratory) and Lawrence R. Greenwood (Pacific Northwest National Laboratory)

An extensive database of atomic displacement cascades in iron has been developed using the method of molecular dynamics (MD). More than 300 simulations have been completed at $100 \mathrm{~K}$ with energies between 0.1 and 100 $\mathrm{keV}$, with a more limited range of simulations at 600 and $900 \mathrm{~K}$. This encompasses nearly all energies relevant to fission and fusion reactor irradiation environments since a $100 \mathrm{keV}$ MD cascade corresponds to the average event following a collision with a $5.1 \mathrm{MeV}$ neutron and an iron atom. Extensive statistical analysis of the database has determined representative average values for several primary damage parameters: the total number of surviving point defects, the fraction of the surviving point defects conatined in clusters formed during cascade cooling, and a measure of the size distribution of the in-cascade point defect clusters. The energy dependence of the MD-based primary damage parameters has been used to obtain spectrum-averaged defect productiong cross sections for typical fission and fusion reactor neutron energy spectra. Total point defect survival and the total fraction of either interstitials or vacancies in clusters exhibit little dependence on neutron energy spectrum, while the fraction of point defects in large clusters exhibits a potentially-significant spectrum dependence.

\subsection{MATERIALS ENGINEERING AND DESIGN REQUIREMENTS}

No contributions. 
xvi

\subsection{HFIR-MFE-RB-14J SPECIMEN LOADING LISTING AND OPERATIONAL SUMMARY - A. L. Qualls (Oak Ridge National Laboratory}

The specimens are housed in three cylindrical holders within the experiment. The holders are centered about the HFIR mid-plane in a large unshielded RB irradiation location (approximately $21 \mathrm{~cm}$ from the reactor centerline) during irradiation.

The three holders are the main components of three independently controlied temperature regions. The upper region is positioned from $21.1 \mathrm{~cm}$ to $12.9 \mathrm{~cm}$ above the reactor centerline and is controlled to irradiate the specimens at $500^{\circ} \mathrm{C}$. The middle region irradiates the specimens at $800^{\circ} \mathrm{C}$. It is twice as long as the other two zones and is centered on the reactor mid-plane extending from $8.8 \mathrm{~cm}$ above the reactor centerline to $-9.2 \mathrm{~cm}$ below the reactor centerline. The lower region is controlled to irradiate the specimens at approximately $300^{\circ} \mathrm{C}$ and is positioned from $-12.4 \mathrm{~cm}$ to $-21.4 \mathrm{~cm}$ below the reactor centerline. A schematic of the experimental region of the capsule is shown in Figure 1.

\subsection{SUMMARY OF THE OPERATION OF THE VARYING TEMPERATURE EXPERIMENT - A. L. Qualls (ORNL), T. Muroga (NIFS)}

The Varying Temperature Experiment (HFIR-MFE-RB-13J) ended irradiation after eight cycles in a europium shielded Removable Beryllium position in the HFIR reactor. The irradiation was terminated two cycles short of a planned ten-cycle irradiation due to a break in one of the capsule's gas supply lines, which occurred while the capsule was being handled during an outage. The break made it impossible to maintain constant operating pressure and steady temperature control could not be guaranteed. It was considered prudent to terminate the irradiation after 8 cycles, rather than risk a temperature excursion with $80 \%$ of the irradiation complete. 
1.0 VANADIUM ALLOYS 

OXIDATION OF V-4Cr-4TIAT LOW PRESSURES -- B. A. Pint, J. R. DiStefano, and L.D. Chitwood (Oak Ridge National Laboratory)

\section{OBJECTIVE}

The objective of this task is to assess the high temperature oxidation behavior of $\mathrm{V}-4 \mathrm{Cr}-4 \mathrm{Ti}$ in low oxygen pressure environments and any related effect on mechanical properties. Many reactor designs involve vanadium alloys in high temperature environments such as vacuum or helium which will contain some level of oxygen and hydrogen impurities. Testing is being conducted in vacuum with low oxygen pressures, $10^{-3}-10^{-6} \mathrm{~Pa}\left(10^{-5}-10^{-8} \mathrm{Torr}\right)$, and in high-purity helium and argon at $400-700^{\circ} \mathrm{C}$. Recent emphasis has been on determining kinetics of oxidation at $600-$ $700^{\circ} \mathrm{C}$.

\section{SUMMARY}

Specimens of $\mathrm{V}-4 \mathrm{Cr}-4 \mathrm{Ti}$ have been exposed to low pressure oxygen and high purity helium and argon environments to determine oxidation kinetics. After exposure, mechanical properties were measured at $25^{\circ}$ and $600^{\circ} \mathrm{C}$. Oxidation at $600^{\circ}-700^{\circ} \mathrm{C}$ generally produced linear kinetics when the oxygen pressure was $\leq 10^{-5} \mathrm{~Pa}$. Higher oxygen partial pressures and lower temperatures can result in external film formation and parabolic kinetics. Internal oxidation resulting in oxygen concentrations $>2000 \mathrm{wppm}$ generally led to significant tensile embrittlement. Higher total oxygen levels could be tolerated (without significant embrittlement) in cases where an external oxide layer formed. However, when specimens which formed an external layer were given an additional vacuum anneal for $2000 \mathrm{~h}$ at $700^{\circ} \mathrm{C}$, embrittlement occurred. This indicates that, rather than being protective, surface oxides on vanadium are a source of oxygen for further internal oxidation and thus embrittlement.

\section{PROGRESS AND STATUS}

\section{Experimental Procedure}

All of the experiments were conducted on V-4Cr-4Ti (Heat\#832665). Prior to exposure, the specimens were annealed at $1050^{\circ} \mathrm{C}$ to produce a uniform grain size. Specimens were $0.76 \mathrm{~mm}$ thick tensile specimens. Low pressure exposures were conducted in an ultra high vacuum system in which a base vacuum of $10^{-7} \mathrm{~Pa}\left(10^{-9} \mathrm{Torr}\right)$ could be achieved. A leak valve was used to achieve oxygen partial pressures of $10^{-3}-10^{-6} \mathrm{~Pa}\left(10^{-5}-10^{-8} \mathrm{Torr}\right)$. For testing in helium at $76,000 \mathrm{~Pa}$ ( $1 \mathrm{~atm}$ ), the pumping system was closed and excess gas pressure was removed through an oil bubbler. Oxygen content was determined by weighing the samples before and after exposure. $A$ power law was used to fit the data at each pressure and temperature where $n=1$ is linear reaction kinetics and $n=2$, parabolic.

\section{Results and Discussion}

\section{Reaction Kinetics $600^{\circ}-700^{\circ} \mathrm{C}$}

The reaction kinetics of $\mathrm{V}-4 \mathrm{Cr}-4 \mathrm{Ti}$ at $600^{\circ}$ and $700^{\circ} \mathrm{C}$ were previously determined ${ }^{1}$ at oxygen 
partial pressures from $10^{-3}-10^{-6} \mathrm{~Pa}\left(10^{-5}-10^{-8} \mathrm{Torr}\right)$. Similar experiments to these conducted at $700^{\circ} \mathrm{C}$ were repeated at $10^{-6} \mathrm{~Pa}\left(10^{-8} \mathrm{Torr}\right)$ for 100,250 and $500 \mathrm{~h}$ using material with the same thermo-mechanical history as that used to obtain the data at $10^{-4}-10^{-5} \mathrm{~Pa}$. Mass gain data are shown in Table I. The mass gains of the new data set at $10^{-6} \mathrm{~Pa}$ averaged about $10 \mathrm{X}$ less than that at $10^{-5} \mathrm{~Pa}$ and $100 \mathrm{X}$ less than at $10^{-4} \mathrm{~Pa}$ which is in agreement with the linear pressure relation on reaction rate that has been proposed for high temperature/low pressure oxidation where a significant surface film does not form. These data fit a nearly linear relationship with time $(n=1.02)$. The previous data set ${ }^{1}$ had a value of $n=2.85$ but included specimens that had received a different thermo-mechanical treatment. No further investigation of why these materials behaved differently has been conducted.

Mass gain results from tests at $600^{\circ}$ and $700^{\circ} \mathrm{C}$ in helium at $76,000 \mathrm{~Pa}(1 \mathrm{~atm})$ or argon (10 Pa) are also reported in Table I. Data from tests in pure helium ( $<0.1 \mathrm{vppm}$ oxygen) had $\mathrm{n}$ values of 1.39 at $600^{\circ} \mathrm{C}$ and 3.02 at $700^{\circ} \mathrm{C}$. These deviations from linear behavior are similar to observations in tests conducted in vacuum with high $\left(10^{-3} \mathrm{~Pa}\right)$ oxygen pressures ${ }^{1}$ and have been observed when the mass gains are extremely high. A linear rate is associated with a reaction limited by a surface reaction such as oxygen absorption. However, when the mass gain becomes very high and the near-surface region becomes saturated with oxygen, the rate limiting step may switch to another process such as diffusion in the metal, which would result in a parabolic relationship ( $n=2)$. Values of $n$ between 1 and 2 suggest a time period when there is a change in the rate controlling mechanism. Thus, when the mass gains become very high, it is not surprising to observe parabolic kinetics. However, when the mass gains are high, the material is usually already embrittled and subsequent oxidation behavior is of less interest. Of more technological importance are the periods where the oxygen uptake is relatively low and the material retains

Table I. Oxidation data for $\mathrm{V}-4 \mathrm{Cr}-4 \mathrm{Ti}$ at low pressure and in high purity helium*.

\begin{tabular}{|c|c|c|c|c|c|c|c|}
\hline Temp. & $\begin{array}{l}\text { Pressure } \\
(\mathrm{Pa})\end{array}$ & $\begin{array}{l}\text { Time } \\
\text { (h) }\end{array}$ & $\begin{array}{c}\text { Mass } \\
\text { Gain } \\
\left(\mathrm{mg} / \mathrm{cm}^{2}\right)\end{array}$ & $\begin{array}{c}\text { Rate of } \\
\text { Mass Gain } \\
\left(\mathrm{mg} / \mathrm{cm}^{2} \mathrm{~h}\right)\end{array}$ & \multicolumn{2}{|c|}{$\begin{array}{l}\text { Ave. Mass Gain Rate } \\
\text { Normalized to }\end{array}$} & $\begin{array}{c}\text { power } \\
\text { law fit } \\
(n)\end{array}$ \\
\hline \multicolumn{8}{|c|}{ Vacuum: } \\
\hline $700^{\circ} \mathrm{C}$ & $10^{-6}$ & $\begin{array}{l}100 \\
250 \\
500\end{array}$ & $\begin{array}{l}0.021 \\
0.058 \\
0.100\end{array}$ & $\begin{array}{l}2.1 \times 10^{-4} \\
2.3 \times 10^{-4} \\
2.0 \times 10^{-4}\end{array}$ & 0.002 & 0.012 & 1.02 \\
\hline \multicolumn{8}{|c|}{ Helium* } \\
\hline $600^{\circ} \mathrm{C}$ & $7.6 \times 10^{4}$ & $\begin{array}{c}24 \\
48 \\
100\end{array}$ & $\begin{array}{l}0.69 \\
1.1 \\
1.9\end{array}$ & $\begin{array}{l}2.9 \times 10^{-2} \\
2.3 \times 10^{-2} \\
1.9 \times 10^{-2}\end{array}$ & $\begin{array}{l}0.97 \\
0.86\end{array}$ & $\begin{array}{c}2 \\
1.6\end{array}$ & 1.39 \\
\hline $700^{\circ} \mathrm{C}$ & $7.6 \times 10^{4}$ & $\begin{array}{c}24 \\
48 \\
100\end{array}$ & $\begin{array}{l}1.4 \\
1.9 \\
2.3\end{array}$ & $\begin{array}{l}6.0 \times 10^{-2} \\
3.9 \times 10^{-2} \\
2.3 \times 10^{-2}\end{array}$ & $\begin{array}{l}0.67 \\
0.49\end{array}$ & $\begin{array}{c}3.1 \\
2\end{array}$ & 3.02 \\
\hline
\end{tabular}

Argon

$600^{\circ} \mathrm{C} \quad 10 \quad 100$

$0.06 \quad 1.3 \times 10^{-3} \quad 1.7$

$700^{\circ} \mathrm{C} \quad 10 \quad 100 \quad 2.9 \quad 2.9 \times 10^{-2}$

1.7

1.5

* research grade $\mathrm{He}$ with $<0.1 \mathrm{vppm}$ oxygen 


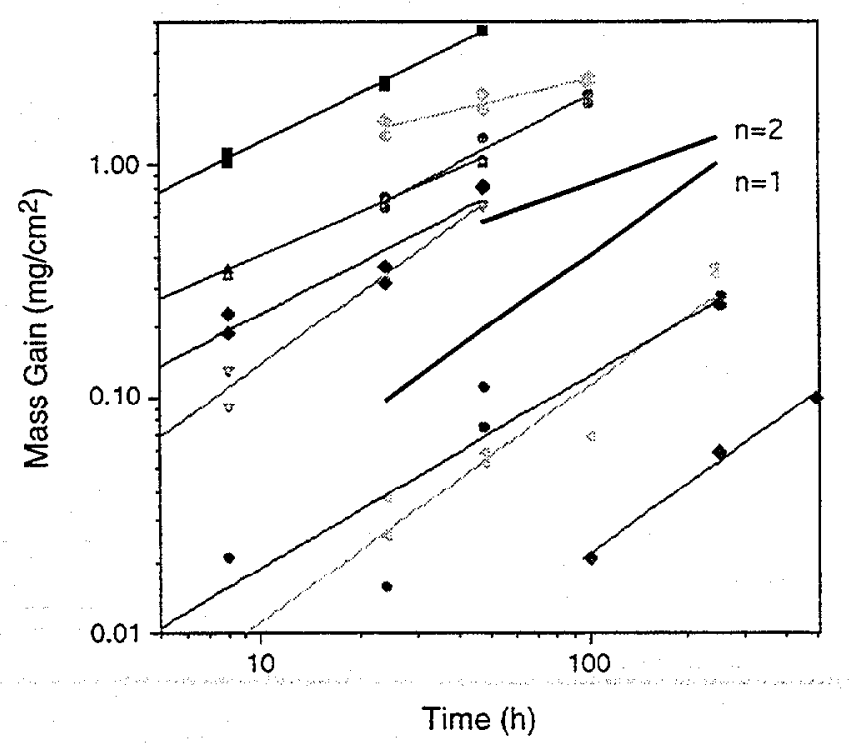

Figure 1. Log-log plot of the mass gains observed in this work at $600^{\circ}$ (open symbols) and $700^{\circ} \mathrm{C}$ (closed symbols) in $\mathrm{He}$ and in oxygen pressures of $10^{-3}-10^{-6} \mathrm{~Pa}$. At lower oxygen pressures, the data fit a linear relationship ( $n=1)$ whereas at higher pressures the value of $n$ increased.

some ductility. During these periods, the oxidation reaction tends to follow linear kinetics. This distinction is illustrated in Figure 1 using data from Table 1 and from previousiy reported data for V-4Cr-4Ti'.

The mass gains after $100 \mathrm{~h}$ in helium were similar to those obtained in low pressure (10Pa) argon which contained $10 \mathrm{vppm} \mathrm{O}_{2}$. Mass gains were similar to those obtained at oxygen partial pressures of $10^{-3}-10^{-4} \mathrm{~Pa}\left(10^{-5}-10^{-6} \mathrm{Torr}\right)$ in vacuum. In the low pressure argon tests, the oxygen partial pressure was $\sim 4 \times 10^{-4} \mathrm{~Pa}\left(4 \times 10^{-6} \mathrm{Torr}\right)$. In pure helium at $1 \mathrm{~atm}$, the oxygen concentration would have to be in the $1-10 \mathrm{vppb}$ range for its partial pressure of oxygen to be in that same range; otherwise the volume of helium present had some type of shielding effect that reduced the oxidation rate, as has been reported for $\mathrm{Nb}-1 \mathrm{Zr} .^{2}$

\section{Mechanical Properties}

As previously reported, ${ }^{3}$ sub-size sheet tensile specimens (SS-3) of unoxidized, annealed V-4 Cr4 Ti have a room temperature elongation of $\sim 30 \%$, but internal oxidation can significantly lower this value. Post-oxidation, tensile data at room temperature and $600^{\circ} \mathrm{C}$ are reported in Table 11 . Although elongation was initially lower at $600^{\circ} \mathrm{C}(9-13 \%)$, values as low as $2-5 \%$ uniform elongation were obtained after oxidation. Furthermore, the room temperature tensile data indicated that internal oxidation was more important to embrittling V-4Cr-4Ti than the oxide scale since samples with a surface oxide retained significant ductility $(\sim 10 \%$ elongation) for total mass gains up to $-6000 \mathrm{wppm}$ oxygen, whereas samples with no visible surface oxide had little ductility ( $-2 \%$ elongation) after mass increases of $\sim 2000 \mathrm{wppm}$ oxygen. However, although the surface film may not initially contribute to tensile embrittlement, over time it is a source of oxygen for further internal oxidation to occur. For example, two samples exposed to He picked up 2944 and 
Table II. Mechanical properties at $25^{\circ}$ and $600^{\circ} \mathrm{C}$ of $\mathrm{V}-4 \mathrm{Cr}-4 \mathrm{Ti}$ after exposure

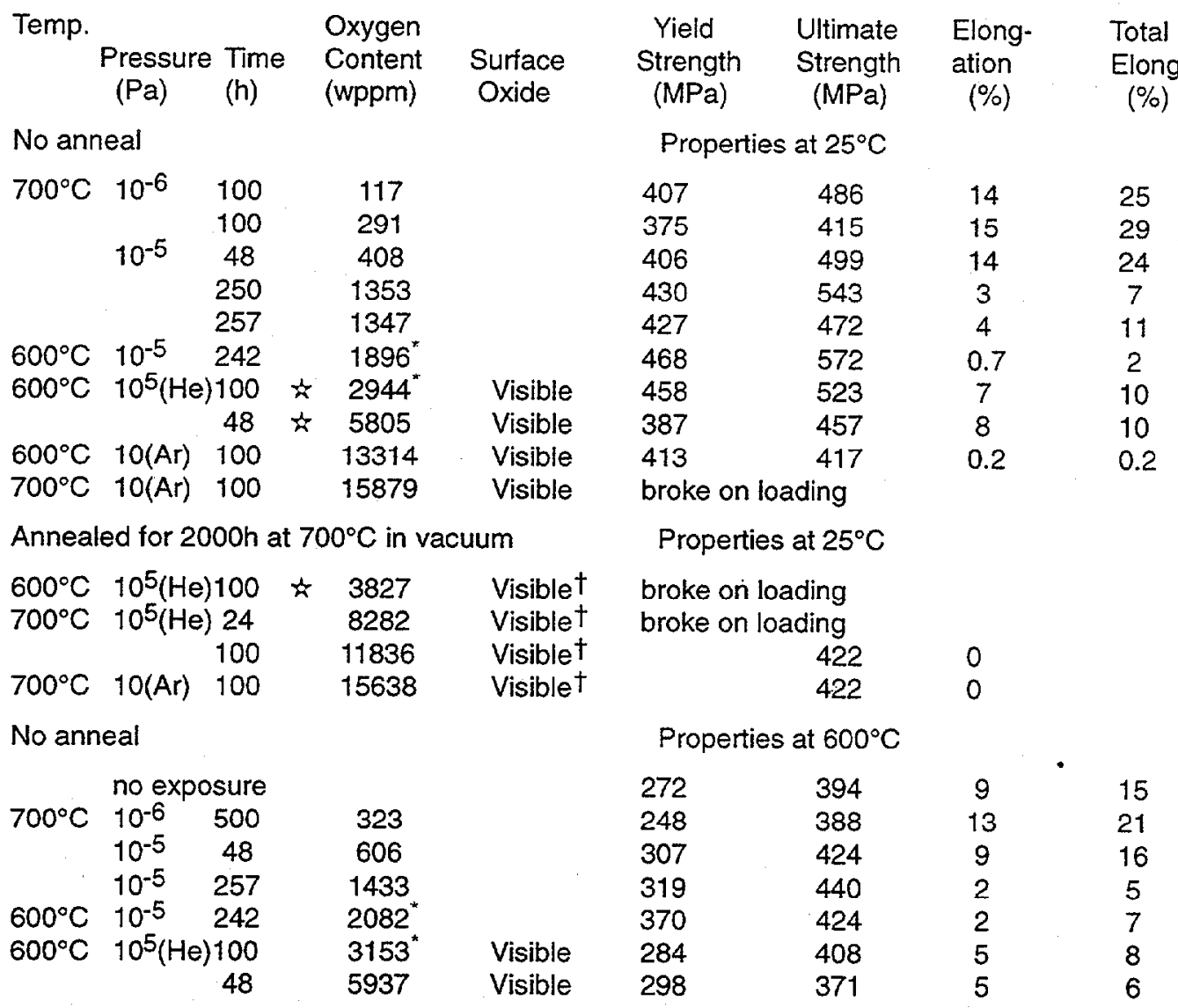

* different heat of $\mathrm{V}-4 \mathrm{Cr}-4 \mathrm{Ti}$ which relatively higher mass gains

$\dagger$ after annealing, the surface oxide was no longer visible

5805 wppm oxygen, respectively (marked by stars in Table II), and both contained a visible surface oxide. When tensile tested at room temperature, total elongation of either sample was $10 \%$. Another sample with 3827 wppm oxygen (marked by a star in Table II) also had a visible surface oxide; but it was subsequently heat treated for $2000 \mathrm{~h}$ at $700^{\circ} \mathrm{C}$ in static argon. This heat treatment was conducted in order to examine if the surface oxide layer was truly protective, i.e prevented oxygen embrittlement of the alloy. Because of the high solubility of oxygen in vanadium, it is possible that this anneal would allow the surface oxide to react with the alloy to further internally oxidize the sample. After this heat treatment there was no longer a visible surface oxide but the sample had such low ductility that it failed on loading during the tensile test. This result and another for a sample with $8382 \mathrm{wppm}$ indicate that the formation of a surface oxide does not represent a long-term protective state for $\mathrm{V}-4 \mathrm{Cr}-4 \mathrm{Ti}$. During prolonged high temperature exposure even in the absence of further oxidation, the presence of a surface oxide provides a source for oxygen which can embrittle the underlying substrate. 
Considering both the oxidation and mechanical properties data, these results indicate that $\mathrm{V}-4 \mathrm{Cr}$ $4 \mathrm{Ti}$, after relatively short exposures to oxidizing environments containing oxygen partial pressures of $\geq 10^{-4} \mathrm{~Pa}$ at $600^{\circ}-700^{\circ} \mathrm{C}$, picked up sufficient oxygen (either internally or as a scale) to significantly reduce the tensile ductility. Thus, even though $n$ values greater than 1 were observed under these conditions the material already contained enough oxygen to be embrittled. The conditions where low mass gains were observed, and the $\mathrm{V}-4 \mathrm{Cr}-4 \mathrm{Ti}$ specimens were not severely embrittled, showed linear kinetics. However, one area of concern is that all of the tensile data in this study used $0.76 \mathrm{~mm}$ thick, SS-3 specimens. For a fixed exposure time, temperature and pressure, an increase in specimen thickness would reduce the amount of oxygen uptake, because the surface area to volume ratio would decrease and the oxidation rate per unit surface area should be constant. In contrast, a specimen geometry with a higher surface area to volume ratio should result in a higher oxygen concentration given the same oxidation conditions. Thus, extrapolating the present data to another design geometry and wall thickness represents a modification in the surface area to volume ratio that has not yet been considered experimentally. Future work should examine the effect of specimen thickness on the oxidation kinetics to provide more reliable predictions for fusion reactor applications.

As a final note, it has been argued that a purification system in conjunction with a recirculating inert gas can reduce the oxygen partial pressure in the gas many orders of magnitude to levels comparable with or better than ultra high vacuum systems can produce. However, to date high vacuum has been the system of choice for protecting refractory metal/alloys at high temperature, and there is little, if any, experimental evidence that has been reported attesting to successful operation of a niobium, tantalum or vanadium system in a recirculating gas for long times at the temperatures of interest.

\section{REFERENCES}

1. B. A. Pint, J. R. DiStefano, J. Bentley and L.D. Chitwood, DOE/ER-0313/27 (1999) 40.

2. H. Inouye, Refractory Metal Alloys, Ed. By I. Machlin, R. T. Bagley, and E. D. Weisert, Plenum Press, New York 1968, p.165.

3. J. R. DiStefano and J. H. DeVan, J. Nucl. Mater. 249 (1997) 150. 
HYDROGEN SOLUBILITY IN VANADIUM ALLOYS AND LITHIUM ALLOYS. *

D.L. Smith (Argonne National Laboratory), R.E. Buxbaum (REB Research), and C.B. Reed (Argonne National Laboratory)

\section{OBJECTIVE}

The objective of this program is to provide baseline solubility data for hydrogen in selected vanadium-base alloys and lithium alloys that will provide a basis for evaluating the hydrogen and tritium distribution in candidate fusion blanket systems.

\section{SUMMARY}

A systematic investigation was conducted to provide an accurate determination of the hydrogen solubility in the $\mathrm{V}-4 \mathrm{Cr}-4 \mathrm{Ti}$ alloy at temperatures in the range $400-600^{\circ} \mathrm{C}$, which is of primary interest for fusion applications. Results have been obtained by the method of hydrogen absorption and desorption into flowing helium with controlled concentrations of hydrogen to provide accurate measurements of the Sieverts' constants for the alloy. In the procedure used, the alloy specimen was maintained at constant temperature for each test to avoid the rapid redistribution of hydrogen that occurs during cooling down of the specimens. The results indicate a hydrogen solubility for $\mathrm{V}-4 \mathrm{Cr}-4 \mathrm{Ti}$ about $30 \%$ higher than that reported for unalloyed vanadium.

\section{INTRODUCTION}

The self-cooled lithium system with a vanadium alloy structure offers a potential for a high performance, environmentally attractive first-wall/blanket system for fusion applications. One of the key issues associated with this system relates to the development of an electrically insulating coating on the vanadium alloy channel walls to mitigate the magnetohydrodynamic (MHD) induced pressure drop in the recirculating lithium coolant. Calcium oxide-based coatings are a leading candidate for this insulator application. Since tritium production in the lithium is essential for the fuel cycle, hydrogen transmutations will occur in the vanadium alloy structure, and hydrogen isotopes are highly mobile in most materials at elevated temperatures; tritium/hydrogen interactions are an important safety related issue and effects of hydrogen isotopes on the stability of the coating and integrity of the structure are important performance considerations for the V/Li system.

A procedure previously used at both ANL and REB Research to accurately determine the hydrogen solubility in metals and alloys involves quantitative absorption and desorption of specimens at various hydrogen partial pressures while maintaining the system at constant temperature. This procedure avoids the difficulties of obtaining accurate data caused by rapid redistribution of the hydrogen during cooling.

This task involves the accurate determination of hydrogen as a function of temperature and pressure in selected vanadium alloys, LiCa alloys and a SnLi alloy. Results for the vanadium alloys are important for evaluating the performance of these alloys in a fusion system, as baseline data for the distribution of hydrogen/tritium in the DHCE experiment to evaluate He effects in neutron irradiation tests, and to provide an accurate blank for the vanadium alloy capsules used for the hydrogen solubility tests for LiCa and SnLi. The effects of Ca in Li on the solubility of

- This work has been supported by the U.S. Department of Energy, Office of Fusion Energy Sciences, under Contract W-31-109-Eng-38.

hydrogen/tritium are important to evaluate tritium inventory, tritium recovery, and the stability of the $\mathrm{CaO}$ coatings in lithium cooled systems. The measurements of hydrogen solubility in $\mathrm{SnLi}$ will provide baseline data for further evaluation of this alloy system for fusion applications. 


\section{EXPERIMENTAL PROCEDURE}

We have used the method of hydrogen absorption and desorption into flowing helium to provide accurate measurements of the Sieverts' constant for V-4Cr-4Ti. A schematic diagram of the apparatus used for the hydrogen solubility measurements

is shown in Fig. 1. It is a slightly modified version of the system described previously [1]. The main changes have been to place the cut off valves closer to the furnace and to add a flow controller to more effectively control pressure drop instead of using the pressure regulator to determine the pressure and flow rate. This new control strategy makes the system less subject to atmospheric pressure variations. We also attached redundant thermocouple and pressure gauges to assure that we were getting the right values for these parameters.

Figure 1: Apparatus for measuring hydrogen absorption and Sieverts constants.

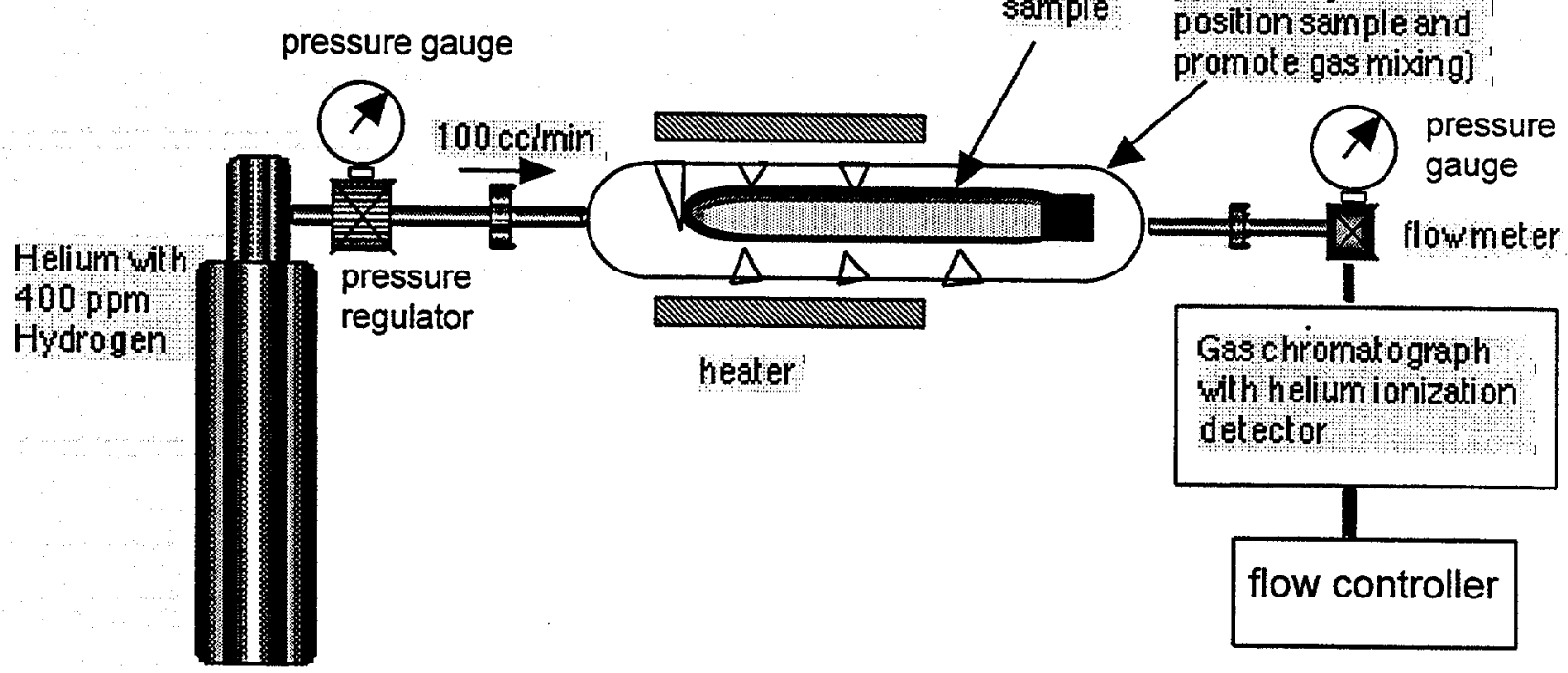

The test sample of $\mathrm{V}-4 \mathrm{Cr}-4 \mathrm{Ti}$ for this test was fabricated from alloy heat \#832665 and was annealed at $1050^{\circ} \mathrm{C}$ for 2 hours. In the current series of tests cylindrical specimens $(-4.75 \mathrm{~mm}$ dia $\times 100 \mathrm{~mm}$ long) are used. The weight of the $\mathrm{V}-4 \mathrm{Cr}-4 \mathrm{Ti}$ specimen was $10.0251 \mathrm{~g}$, which corresponds to 0.1971 mols of metal atoms.

The V-alloy rod was then coated with palladium to increase the hydrogen absorption/ desorption rates and to prevent any oxidation of the vanadium from impurities in the helium gas. The weight of the specimen after coating was $10.0962 \mathrm{~g}$. Assuming a uniform palladium distribution over the entire surface area, this weight gain corresponds to a coating thickness of 5.22 microns thick. The sample was then placed in the apparatus shown and exposed to flowing helium and to a helium-hydrogen mixture at a flow rate of 53.1 standard cc's per minute. This flow rate was maintained constant within $\pm 1 \%$. The pressure was measured at the cylinder and again at the gas chromatograph (GC). For hydrogen-helium mixture, the measured pressure corresponded to an average pressure of $1.253 \mathrm{~atm}$. The concentration of hydrogen in the gas mixture was determined by the gas supplier (BOC) to be 394 parts per million. The input hydrogen partial 
pressure is thus 0.000494 atmospheres or 50.01 Pascals.

A series of runs were used to calibrate the gas chromatograph to determine the peak area corresponding to a given concentration and pressure. We maintained a constant total pressure to minimize any error that might have been created during sample insertion, and also used the time of peak maximum to check that the sweep gas flow rate was at a constant level. A low sweep gas flow would increase the peak area for a given hydrogen concentration and could cause errors if not detected and corrected for any difference. A decrease in the GC sweep gas rate also shows up as an increase in the peak arrival time. During these experiments, the hydrogen peak arrived at 4.5 minutes \pm 0.1 minute. This variation was included in the data analysis. At normal flow conditions this concentration produced an average peak area $1,267,091$ counts on the $\mathrm{GC} \pm 1 \%$.

\section{RESULTS}

Before beginning the experiments, the sample was heated to $400{ }^{\circ} \mathrm{C}$ under flowing helium to degas any hydrogen it contained. A significant amount of hydrogen degassed from the sample. The helium gas was then switched off and replaced by the hydrogen-helium mixture. The peak areas were measured and plotted as shown in Fig. 2. Each data point ( $x$ ) represents one reading of the gas chromatograph, which occurred every 22 minutes. The sample absorbed virtually every molecule of hydrogen for the first 4 hours. The specimen then rapidly approaches saturation, and after 10 to 15 hours the sample appears to be saturated with the hydrogen in helium mixture at 1.253 atmospheres.

The rapidity of the ascent suggests that the long thin sample produced some chromatographic saturation. This behavior is exploited in later degassing experiments to get two values for the Sieverts constant from each run.

The rate of hydrogen absorption is calculated from the flow rate and the difference between the GC count area with absorption and without. This relation is shown below.

$$
\mathrm{H}_{2} \text { absorption rate }=\frac{(\text { peak area })\left(\text { original } \mathrm{H}_{2} \text { conc. }\right)(\text { gas flow rate })}{\text { (original peak area) }}
$$

The total absorption is the integral of the absorption rates from the beginning of the experiment until saturation. In this way we determined that the sample absorbed $0.0004788 \mathrm{mols}_{2}$. Given the sample mass, this corresponds to a Sieverts' constant of 0.2186 atom ratio/atm ${ }^{5}$ at $400^{\circ} \mathrm{C}$.

For the second experiment, we raised the sample temperature to $500^{\circ} \mathrm{C}$ while keeping the same hydrogen and helium mixture flowing at the same pressure and flow rate. This produced the hydrogen peak areas shown in Fig. 3. The hydrogen concentration measured increased approximately 4 times that shown previously, which corresponds to a hydrogen partial pressure of $0.00132 \mathrm{~atm}$ This corresponds to a Sieverts' constant at $500^{\circ} \mathrm{C}$ of 0.1098 atom ratio/atm ${ }^{5}$, or approximately half that at $400^{\circ} \mathrm{C}$

A better measure of the Sieverts' constant is found from the complete data at $500^{\circ} \mathrm{C}$, particularly from the total amount of hydrogen at the end of the degassing run and the hydrogen partial pressure at this point, which is $0.000494 \mathrm{~atm}$. The integral of the desorption data in Figs. 2 and 3 are combined to give 0.0002484 mols of hydrogen at this pressure, or a Sieverts' constant of 0.1134 atom ratio/atm ${ }^{5}$, which is in good agreement with the value obtained above. Figure 3 also shows that the peak area after saturation at $500^{\circ} \mathrm{C}$ is that same as that after saturation at 
$400^{\circ} \mathrm{C}$ at the end of the previous experiment. This demonstrates that no baseline creep occurred, which provides increased confidence in the data. A similar procedure was followed to obtain the Sieverts' constant at $600^{\circ} \mathrm{C}$ (see Fig. 4). The hydrogen desorption experiment shown in Fig. 4 also serve as a check on the other sorption experiments.

The results from all these experiments are summarized in Table 1 and the Sieverts' values from these experiments are plotted in Fig. 5 and given by the following equation.

$$
K_{s}=0.00120 \exp (3500 / T), \text { atom fraction } / a^{0.5}
$$

Also plotted in Fig. 5 are earlier correlations from Park et al. [2] for $\mathrm{V}-4 \mathrm{Cr}-4 \mathrm{Ti}$, a revised correlation of Park's data, a correlation from Zaluzhnyi et al. [3] and the solubility curve for unalloyed vanadium. The results from this series of experiments indicate that the solubility of hydrogen in the $\mathrm{V}-4 \mathrm{Cr}-4 \mathrm{Ti}$ alloy is only slightly higher, approximately $10 \%$, than that in unalloyed vanadium.

\section{REFERENCES}

1. D. L Smith, R.E Buxbaum, and C.B. Reed, US/DOE Report DOE/ER-0313/27, p. 62 (March 2000)

2. J. H. Park, G. D. Ragel, R.A. Erck, D.L. Smith, and R. E. Buxbaum, USIDOE Report DOEJER-0313/19 ,p. 59 (April 1995)

3. A. G. Zaluzhnyi et al., Fusion Engr. \& Design 41 (1998) 181-185.

Table 1: Values of the Sieverts' constant of V4\%Cr4\%Ti measured in these experiments. Sample size $=\mathbf{1 0 . 0 2 5 1} \mathrm{gms}$.

\begin{tabular}{|c|c|c|c|c|}
\hline Temperature & Exp't type & $\begin{array}{l}\text { mols } \mathrm{H} 2 \text { in } \\
\text { sample }\end{array}$ & $\begin{array}{c}\text { partial pres. H2 } \\
\text { atmospheres }\end{array}$ & $\begin{array}{c}\text { sieverts value } \\
\text { atom ratio/atm.5 }\end{array}$ \\
\hline $400^{\circ} \mathrm{C}$ & hydrogen sorption & $4.788 \mathrm{e}-4$ & $4.937 \mathrm{e} \cdot 4$ & $2.186 \mathrm{e}-1$ \\
\hline $500^{\circ} \mathrm{C}$ & temperature spike & $4.788 \mathrm{e} \cdot 4$ & $1.959 \mathrm{e} \cdot 3$ & $1.098 \mathrm{e}-1$ \\
\hline $500^{\circ} \mathrm{C}$ & hydrogen sorption & $2.484 \mathrm{e}-4$ & $4.937 e-4$ & $1.134 \mathrm{e} \cdot 1$ \\
\hline $595^{\circ} \mathrm{C}$ & temperature spike & $2.484 \mathrm{e}-4$ & $1.320 \mathrm{e} \cdot 3$ & $6.936 e-2$ \\
\hline $600^{\circ} \mathrm{C}$ & hydrogen sorption & $1.478 \mathrm{e}-4$ & $4.972 \mathrm{e}-4$ & $6.723 e \cdot 2$ \\
\hline $600^{\circ} \mathrm{C}$ & degassing into $\mathrm{He}$ & $1.435 \mathrm{e} \cdot 4$ & $4.972 \mathrm{e}-4$ & $6.530 \mathrm{e} \cdot 2$ \\
\hline
\end{tabular}




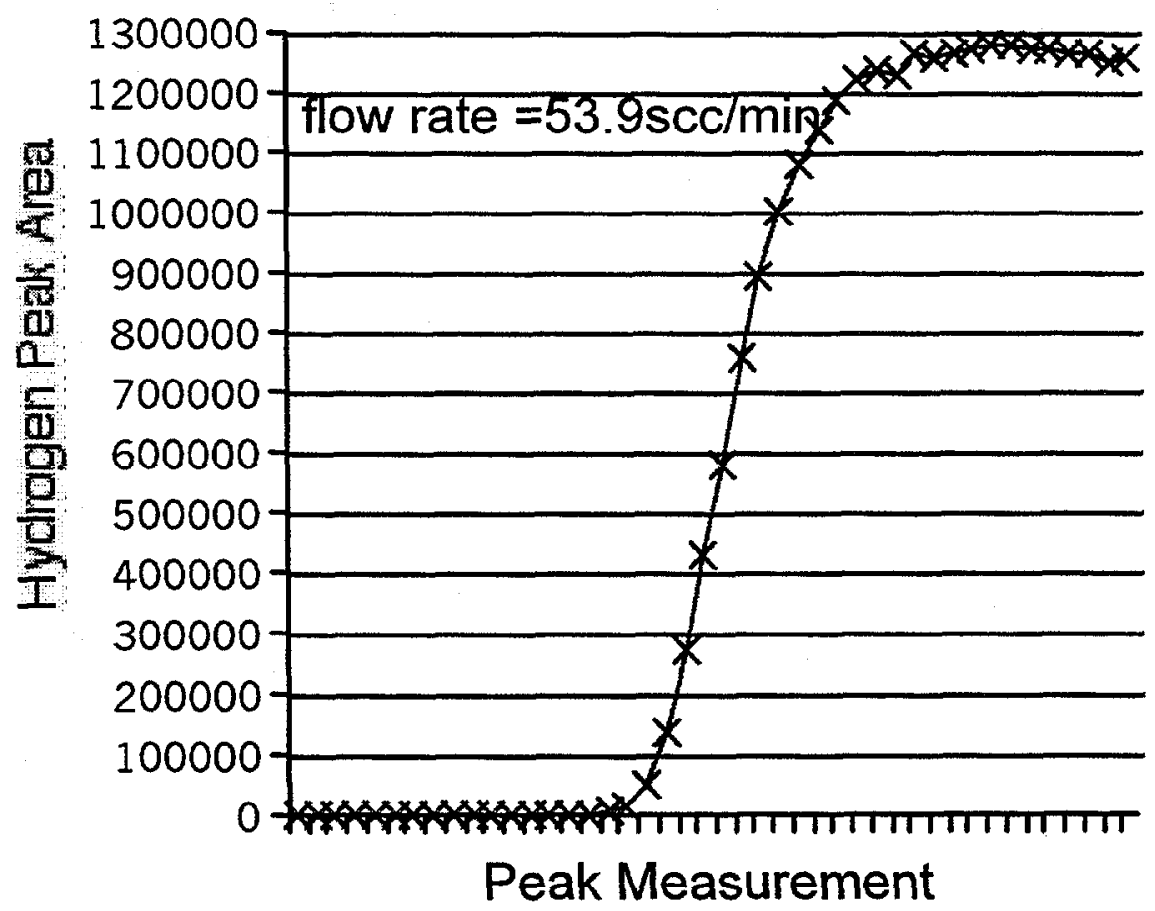

Figure 2: Hydrogen sorption by $\mathrm{V} 4 \% \mathrm{Cr} 4 \% \mathrm{Ti}$ at $400^{\circ} \mathrm{C}$ from a $\mathrm{He}, 394 \mathrm{ppm} \mathrm{H2}$ mix at 1.253 atm.

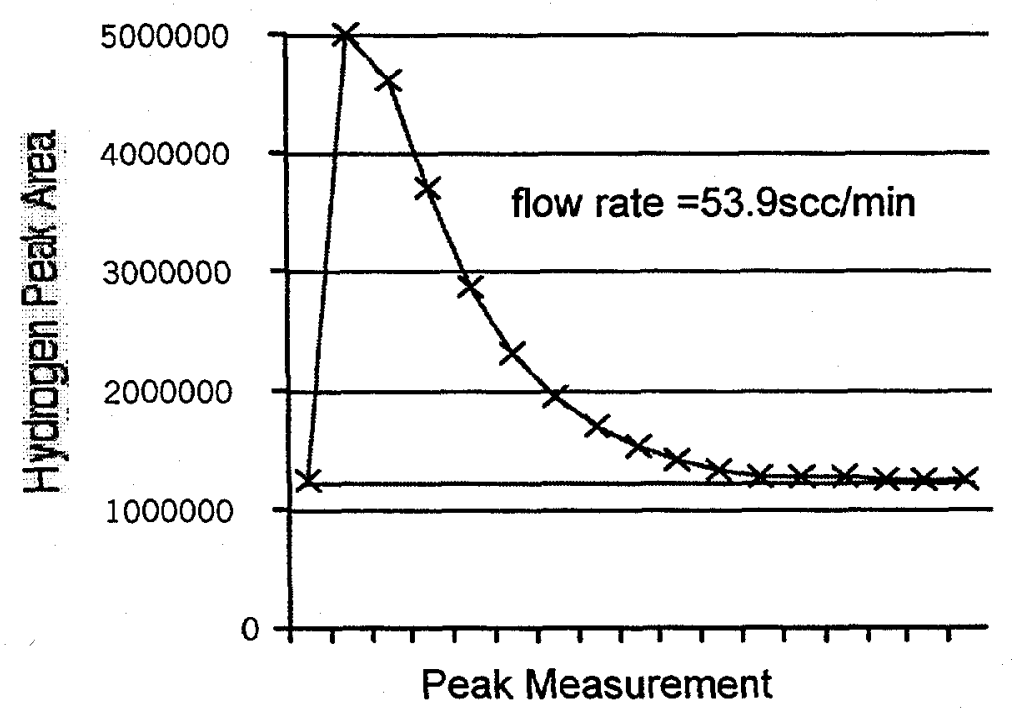

Figure 3: Hydrogen desorption by $\mathrm{V} 4 \% \mathrm{Cf} 4 \% \mathrm{Ti}$ at $500^{\circ} \mathrm{C}$ into a $\mathrm{He}, 394 \mathrm{ppm} \mathrm{H2}$ mix at 1.253 atm. 

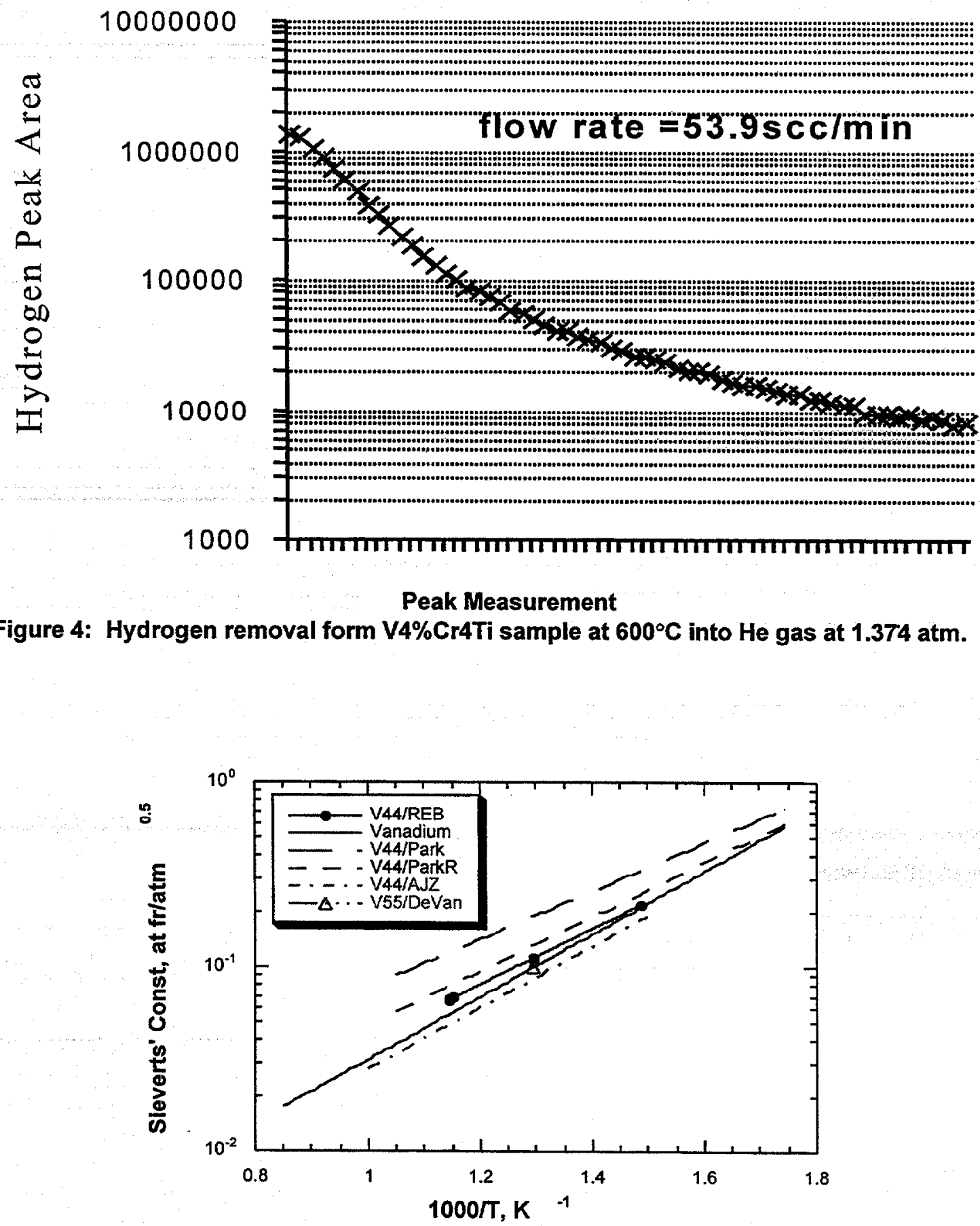

Figure 5: Sievert's Constant for $\mathrm{V} 4 \% \mathrm{Cf} 4 \% \mathrm{Ti}$, atom ratio/atm ${ }^{.5}$ 


\section{LASER WELDING OF V-4Cr-4Ti ALLOY}

Z. Xu, D. L. Smith, Y. Yan and C. B. Reed (Argonne National Laboratory)

\section{OBJECTIVE}

The objective of this research is to evaluate the potential of laser welding for joining vanadium-base alloys and to determine the effects of weld parameters on the properties of weldments.

\section{SUMMARY}

Laser welding offers potential advantages for welding vanadium alloys, including increased flexibility for field and large component welding with acceptable atmospheric control. A pulsed Nd:YAG laser with a fiber optic delivery system is used to conduct a systematic investigation of the weld parameters and environmental control requirements to obtain high integrity laser welds of Vanadium alloys. The current effort is focused on determination of laser weld parameters for welding $\sim 4-\mathrm{mm}$-thick plate of $\mathrm{V}-4 \mathrm{Cr}-4 \mathrm{Ti}$ alloys and evaluation of various approaches for providing adequate environmental control. Laser weld specimens have been produced on two heats of $\mathrm{V}-4 \mathrm{Cr}-4 \mathrm{Ti}$ alloys and preliminary evaluations of weld integrity have been performed. Parameters for obtaining full penetration welds have been defined and weld specimens have been prepared for mechanical testing in a related study. Results from preliminary bend tests on weld specimens indicate good ductility.

\section{EXPERIMENTAL PROGRAM}

\section{$\underline{\text { Materials }}$}

The materials used for the study were obtained from the $500 \mathrm{~kg}$ heat \#832665 of V-4Cr4Ti alloy produced by TWC and a $30 \mathrm{~kg}$ heat \#PX906 produced in Japan. The $500 \mathrm{~kg}$ heat was in the form of 3.8-mm-thick plate cold-rolled and annealed by the vendor at $1050^{\circ} \mathrm{C}$ for 2 hours and the $30 \mathrm{~kg}$ heat was in the form of $4.0-\mathrm{mm}$-thick plate cold-rolled and annealed in Japan at $1000^{\circ} \mathrm{C}$ for 1 hour. Small plates of $50.8 \times 15 \mathrm{~mm}$ in dimensions were saw cut from the plate stock with the short side of the plate along the rolling direction. For the first series of tests the long edges of the plates were mille to provide better edge fitup for butt welds. The microstructure of the as-annealed plate from heat \#832555 is shown in Fig. 1

\section{Pulsed YAG laser butt welding}

An Electrox $1.6 \mathrm{~kW}$ pulsed Nd:YAG laser with fiber optic beam delivery was used for the current laser welding studies. This facility is located in the ANL laser laboratory. The laser schedule power settings were E4L3R66 (Alternative). This indicates that the energy per unit time (E) was 4 Joules/ms, the pulse length (L) was $3 \mathrm{~ms}$, and the 
repetition rate was $132 / \mathrm{s}$. The calculated power is $\mathrm{E}^{*} \mathrm{~L}^{*}(2 \mathrm{R})=1.58 \mathrm{~kW}$, while the actual measured power is $1.30 \mathrm{~kW}$. The difference is mainly due to losses in the fiber optic delivery and the fact that at low energies $(4 \mathrm{~J} / \mathrm{ms})$ the laser does not put out full power. The above laser schedule power settings within the capabilities of the equipment were based on previous studies which showed that they produced relatively deep, smooth and stable welds [1]. The two workpieces for a butt weld were mounted on a Wessel 5-axis $\mathrm{CNC}$ workstation which moved the workpieces under the stationary laser beam. The seam-line of the two pieces was carefully aligned with the laser beam with the help of a He-Ne alignment laser that is co-axial with the YAG beam. The laser beam was focused by a 77-mm focal length Gradium glass lens (LightPath Technologies, Inc., Albuquerque, NM.). Welds with different beam focal positions relative to the workpiece surface were made to study the effect of focal position on weld penetration. Beam travel speeds ranging from $4 \mathrm{~mm} / \mathrm{s}$ to $10 \mathrm{~mm} / \mathrm{s}$ were used. Slight changes of the beam travel speed were used to compensate for the energy loss or gain from the power fluctuations of the laser system.

\section{Environmental shielding technique}

Welding of vanadium alloys must be performed in an inert atmosphere to prevent $\mathrm{O}_{2}$ and $\mathrm{N}_{2}$ contamination. A major feature of the laser welding approach is the potential to use a flexible containment chamber with an inert gas purge to avoid atmospheric contamination. This capability will allow for on-site welding of large components. An environmental control box (ECB) used in early welding tests provided adequate protection for good welds with a clean silvery weld-bead appearance if flow rates of all the shielding gases were well balanced at the open slit [2]. In this study, a flexible polyethylene containment (Fig. 2) was utilized to achieve consistent prevention from atmospheric contamination. High purity argon (99.995\%) was purged into the ECB/bag for 4 minutes prior to welding to displace any air in the ECB/bag.

\section{Weld-bend test}

A simplified bend test was performed on selected weld specimens to provide a preliminary evaluation of the weld integrity. A slow strain rate bend of the welded specimen with a standard vice was used to produce a $\sim 90^{\circ}$ bend with an inside radius of approximately twice (2t) the specimen thickness $(t)$.

\section{RESULTS AND DISCUSSION}

\section{Focal position effect on weld depth}

Figure 3 shows the results of a systematic study to investigate the weld depth as a function of beam focal position with respect to the workpiece surface for a fixed laser schedule of power settings and beam travel speed. The maximum weld depth was obtained when the laser beam was focussed at $0-0.5 \mathrm{~mm}$ into the workpiece. Figure 4 


\section{REFERENCES}

1. K. Natesan, C. B. Reed, Z. Xu, and D. L. Smith, "Laser-Welded V-Cr-Ti Alloys: Microstructural and Mechanical Properties," Fusion Reactor Materials Progress Report for the Period Ending December 31, 1998, DOE/ER-0313/25, pp. 64-68.

2. Z. Xu, C. B. Reed, K. Natesan, and D. L. Smith, "Improvement of laser weld quality of V-Cr-Ti alloys," Fusion Reactor Materials Progress Report for the Period Ending June 30, 1999, DOE/ER-0313/26.

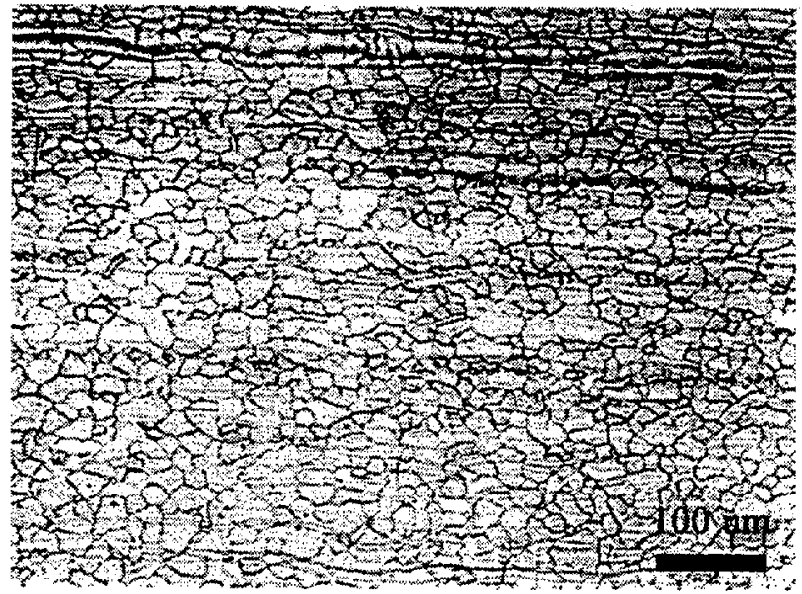

Figure 1. Microstructure of cold-rolled and annealed base metal $\mathrm{V}-4 \mathrm{Cr}-4 \mathrm{Ti}$. 
MICROSTRUCTURAL CHARACTERIZATION AND IMPACT PROPERTIES OF $\mathrm{V}-4 \mathrm{Cr}-4 \mathrm{TI}$ LASER WELDMENTS - Y. Yan, H. Tsai, A. D. Storey, D.L. Smith, and Z. Xu (Argonne National Laboratory)

\section{OBJECTIVE}

The objective of this task is to assess the quality of laser welds on $\mathrm{V}-4 \mathrm{Cr}-4 \mathrm{Ti}$ alloys and to evaluate the effects of weld parameters on the properties of weldments. This activity includes evaluation of methods for controlling the atmospheric contamination of welds.

\section{SUMMARY}

Microstructure and Charpy-impact properties of laser weldments of the $500-\mathrm{kg} \# 832665$ heat $\mathrm{V}-4 \mathrm{Cr}-4 \mathrm{Ti}$ alloy were investigated. Optical metallography shows the grain sizes in the weld to be greater than those in the base material. The grains are equiaxed near the middle of the weld and elongated (oriented in the direction of freeze progression) near the edge. The banded structure in the base metal seems to disappear in the weld zone, and density of secondary phase particles in the weld is much lower than that in the base metal. Impact testing was performed with specimens as-machined (by electric discharge machining with water as the flushing fluid), as well as after a degassing heat treatment at $400^{\circ} \mathrm{C}$ for $1 \mathrm{~h}$. In the as-machined condition, the ductile-to-brittletransition temperature (DBTT) for both the base metal and the laser weld is about $-20^{\circ} \mathrm{C}$. While the DBTT of the base metal was decreased significantly with the degassing operation, that of the weldment was relatively unaffected. Additional characterization and testing, including oxygen analysis, is underway.

\section{BACKGROUND}

Laser welding offers potential advantages for welding vanadium alloys, including increased flexibility for field and large component welding with acceptable atmospheric control. A pulsed $\mathrm{Nd}$ :YAG laser with a fiber optic delivery system is used to conduct a systematic investigation of the weld parameters and environmental control requirements for obtaining high-integrity laser welds of vanadium alloys. The current effort is focused on evaluation of laser welds on $\approx 4-\mathrm{mm}$ thick plate of $\mathrm{V}-4 \mathrm{Cr}-4 \mathrm{Ti}$ alloy. The postwelding characterization includes Charpy-impact testing and microstructural characterization of the welds. Because of the relatively large number of samples in this recent welding effort and the different objectives for the various subtasks, the postwelding characterization work will be carried out in several phases.

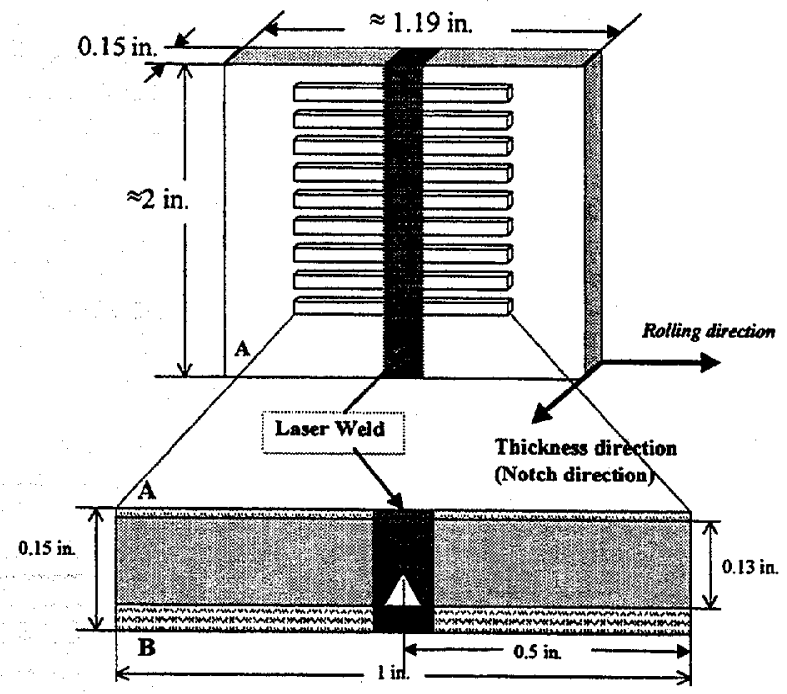

Fig. 1 Schematic illustration of the fabrication of Charpy specimens. 


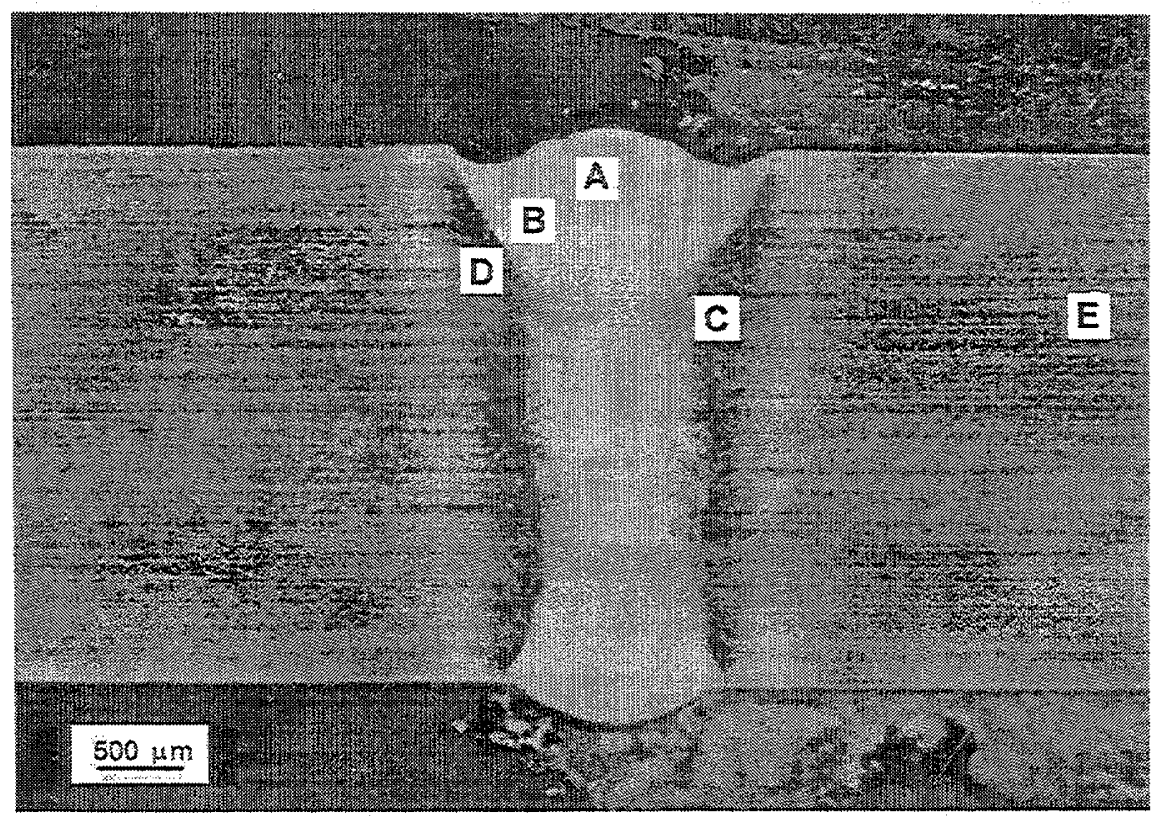

Fig. 2. Low magnification micrograph showing laser butt weld. Details of areas $A$ through $E$ are given in Figs. 3-6.

One objective of the Phase I effort, described in this paper, is to determine whether there is notable hydrogen uptake during test specimen preparation, which could affect the results of the Charpy tests. In conventional tests, the specimens are vacuum-annealed after machining, which would remove any hydrogen from the alloy. For the weld specimens, it is necessary to anneal the material before welding and machining of the test specimens. During specimen cutting with an electric discharge machine, the work piece is inundated in water and thus could pick up hydrogen. A low-temperature hydrogen degassing heat treatment at $400^{\circ} \mathrm{C}$ for $1 \mathrm{~h}$ was performed on some of the weldment and base metal specimens after they were machined to determine if hydrogen uptake occurred or had any effect on the impact properties of the materials. Similar tests were conducted on as-received material to further validate the results with respect to hydrogen effects. The material used for this investigation was from the $500 \mathrm{~kg}$ heat $\# 832665$ of $\mathrm{V}$ $4 \mathrm{Cr}-4 \mathrm{Ti}$ alloy with a supplier annealing at $1050^{\circ} \mathrm{C}$ for $2 \mathrm{~h}$.

\section{EXPERIMENTAL PROCEDURE}

\section{Fabrication of Charpy Specimens}

The starting material for this series of tests was obtained from the $500 \mathrm{~kg}$ heat $\# 832665$ of $\mathrm{V}-4 \mathrm{Cr}$ $4 \mathrm{Ti}$ alloy, which was annealed by the vendor for $2 \mathrm{~h}$ at $1050^{\circ} \mathrm{C}$. Laser welding was performed on a Nd:YAG laser welding facility [1]. The laser weldment was produced by butt welding of two annealed plates of $3.8 \mathrm{~mm}$ thickness. Direction of the weld travel was perpendicular to the rolling direction of the plate. Details of the welding procedure are given in Ref. 1.

An electric discharge machine was used to cut all of the Charpy-impact specimens. The specimens were $1 / 3$-size, i.e., $3.3 \mathrm{~mm}$ thick $\times 3.3 \mathrm{~mm}$ wide $\times 25.4 \mathrm{~mm}$ long, with a $30^{\circ}, 0.61-\mathrm{mm}$ deep, $0.08-\mathrm{mm}$-root-radius $\mathrm{V}$ notch. The base metal specimens were machined from an annealed plate. Notch orientation (i.e., crack propagation direction) was perpendicular to the final rolling 
direction and into the thickness of the plate. The weld specimens were prepared with the $V$-notch in the weldment in the thickness direction, as shown in Fig. 1. The specimens were not exposed to other hydrogenous materials (cleaning fluids, etc.) after they were cut.

\section{Impact Testing}

In addition to the weld specimens, several base alloy specimens were tested to confirm that hydrogen pickup during specimen preparation was not a problem. Under standard test procedures, specimens were cut from cold-worked material and then annealed before testing. In addition to the annealing, this procedure would remove any hydrogen that might have been picked up during machining. For investigation of the weld properties, it was necessary to weld annealed material and then machine the specimens. Some specimens were given a hydrogen degassing treatment at $400^{\circ} \mathrm{C}$ for $1 \mathrm{~h}$ in vacuum to remove any hydrogen that might have been picked up.

Charpy tests were conducted with a Dynatup drop-weight tester. The tester was verified before these tests by using a 1/3-size high-energy ferritic steel calibration specimen supplied by Oak Ridge National Laboratory. The calibration showed good agreement (within 1\%) between the ANL measured absorbed energy and the published ORNL data [2].

Fifteen Charpy-impact tests, eight for the base metal and seven for the laser weld (\#031300B), have been completed. Specimen temperature during impact testing was measured with a thermocouple that was spot-welded to the end of the specimen. For tests in which temperatures were above ambient, a hot-air blower provided the heating; for tests in which temperatures were below ambient, argon gas prechilled with a mixture of dry ice, acetone, and liquid nitrogen provided the cooling. In both cases, the specimens were held at the test temperature for a significant period before the test. Five specimens, three for the base metal and two for the laser weld, were degassed for hydrogen before the impact tests.

\section{RESULTS}

\section{Microstructural Characterization of Laser Weld}

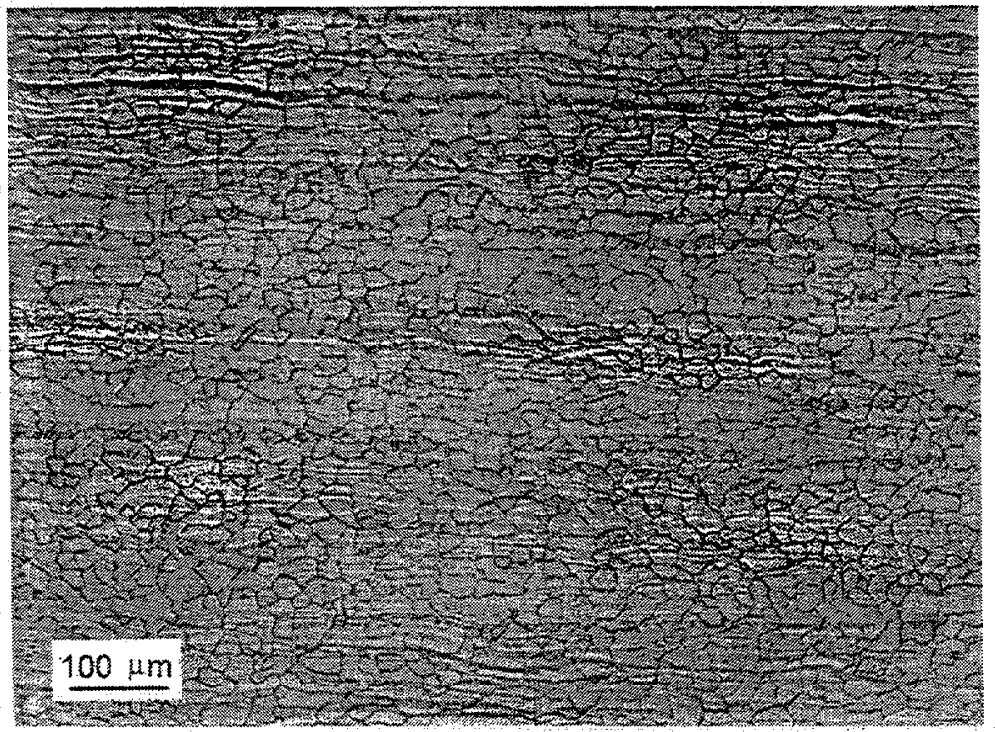

Fig. 3. High-magnification bright-field image of $\mathrm{V}-4 \mathrm{Cr}-4 \mathrm{Ti}$ matrix, labeled as area $\mathrm{E}$ in Fig. 2. 

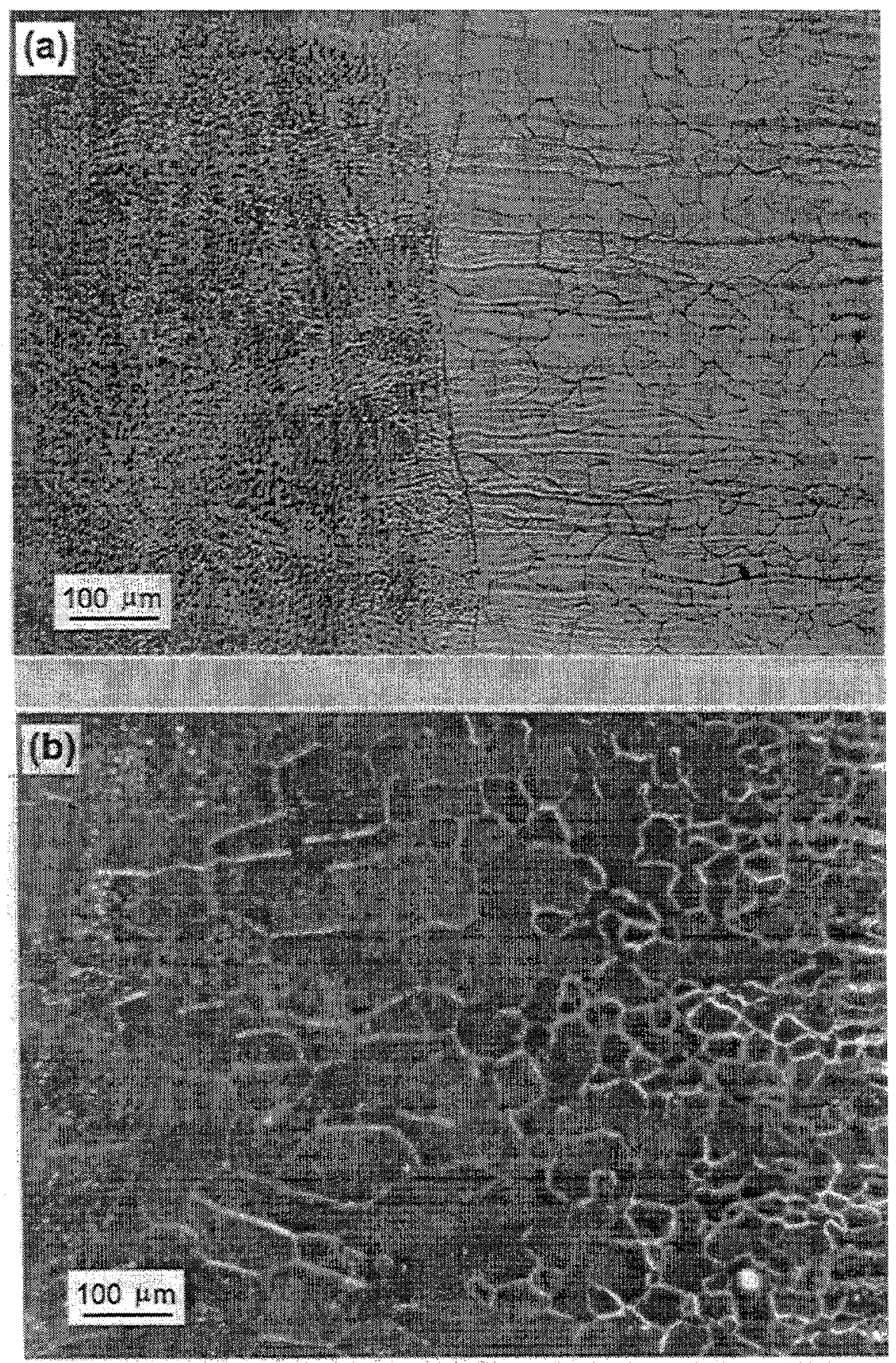

Fig. 4. High-magnification (a) bright-field and (b) dark-field images of laser weld (left part) and matrix (right part) interface area, labeled as area $\mathrm{C}$ in Fig. 2.

To elucidate the microstructure of the weld zone, metallographic specimens were cut in the orientation perpendicular to the direction of the weld and perpendicular to the rolling direction. After polishing and etching, optical microscopy was conducted to investigate grain morphology and possible microstructural inhomogeneities. An area containing the base metal, the heataffected zone (HAZ), and the weldment, is shown in Fig. 2. The weld appears to be sound, with 
good depth of penetration and no noticeable voids. Areas of interest are denoted as $A$ through $E$ in Fig. 2 and are shown in detail in Figs. 3-6.

Figure 3 is a high-magnification micrograph of the base metal of Area $E$ in Fig. 2. The grains are small $(\approx 20-50 \mu \mathrm{m})$ and show some indication of the characteristic banded structure aligned in the direction of rolling. Using bright-field imaging, one can see a sharp interface between the weld zone and the HAZ. This is shown in Fig. $4 a$ of the region denoted as Area $\mathrm{C}$ in Fig. 2. The darkfield image, Fig. $4 \mathrm{~b}$, of the same area, reveals the grain boundaries in the weld. The grains in the weld are elongated in the direction perpendicular to the interface as shown in Figs. 4 and 5.

Figures $6 \mathrm{a}$ and $6 \mathrm{~b}$ are high-magnification micrographs of the laser weld, denoted as Areas $A$ and $B$ in Fig. 2, respectively. The grains are equiaxed in the middle of the weld and are elongated, oriented in the direction of freeze progression, near the edge. The grain size in the weld is increased to $\approx 50 \mu \mathrm{m}$ in the center of the weld and to $\approx 50 \times 100-200 \mu \mathrm{m}$ elongated grains near the edge of the weld. The banded structure in the base metal disappears in the weld zone, but is still present in the HAZ, see Fig. 4a. Densities of the small secondary phase particles in the weld are much lower than those in the base metal. There is also noticeable equiaxed grain growth in the $\mathrm{HAZ}$ adjacent to the weld, as shown in Figs. $4 a$ and 5.

\section{Impact Tests}

Fifteen Charpy-impact tests (eight for the base alloy and seven for the laser weld) have been completed this period. The initial series of impact tests was conducted on base alloy specimens to evaluate the potential for hydrogen effects associated with the specimen-processing procedures required for the weld specimens. Charpy-impact tests were conducted on specimens machined from the as received heat $\# 832665$ alloy annealed at $1050^{\circ} \mathrm{C}$ for $2 \mathrm{~h}$ by the vendor. The list of Charpy specimens is shown in Table 1. Results shown in Fig. 7 indicate a DBTT of $-20^{\circ} \mathrm{C}$, which is much higher than observed previously on specimens annealed at $950-1100^{\circ} \mathrm{C}$ after machining. Additional specimens from this series were hydrogen-degassed at $400^{\circ} \mathrm{C}$ for 1 $\mathrm{hr}$. Results from these tests (Fig. 7) indicate a DBTT of $<-190^{\circ} \mathrm{C}$, in agreement with prior results. These tests indicate that significant hydrogen was present in the nondegassed specimens. Although not verified, it was assumed that the hydrogen pickup most likely occurred during the machining process. Further tests will be conducted to determine the source of hydrogen.

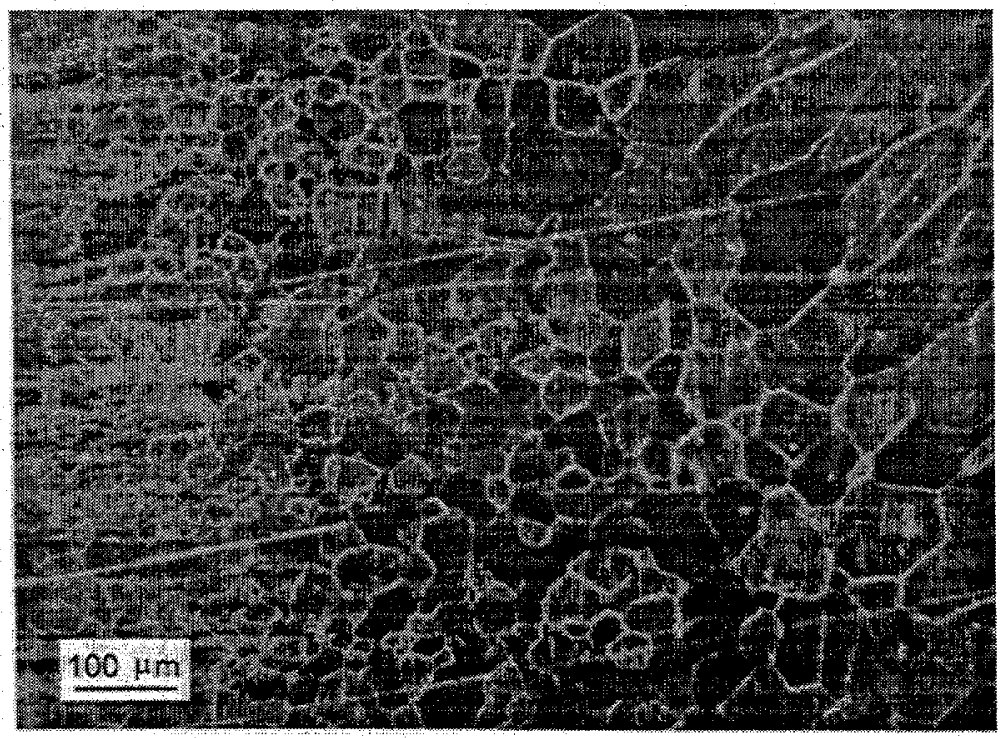

Fig. 5. High-magnification dark-field image of area D in Fig. 2. 

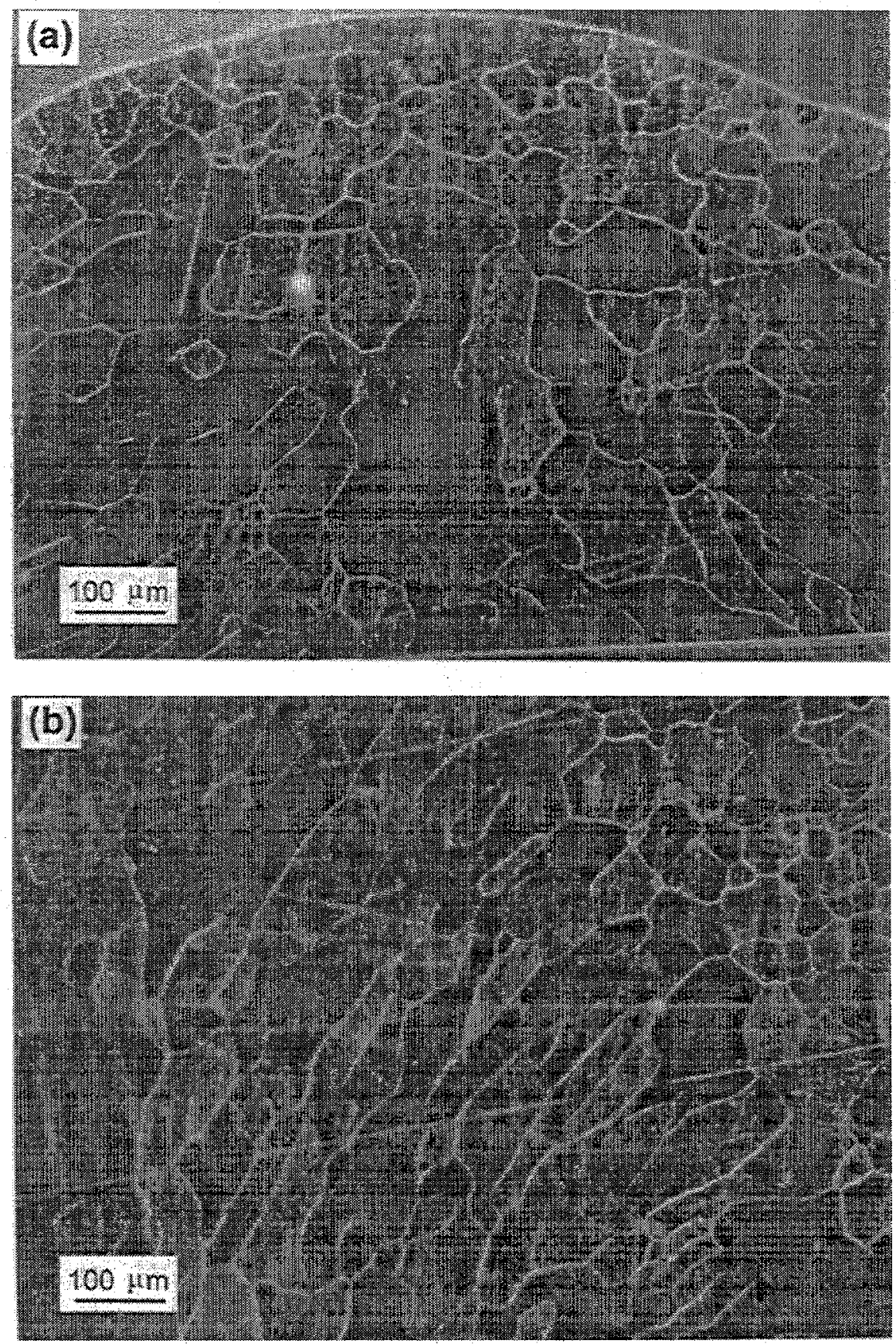

Fig. 6. High-magnification dark-field images of laser welded areas (a) for area $A$ and (b) for area B in Fig. 2.

Specimens from the weldment shown in Fig. 2 were tested in the as-machined condition and the results are included in Fig. 7 . The DBTT for the weld is $\approx 0^{\circ} \mathrm{C}$, only slightly above the DBTT of the as-machined base metal. Two remaining weld specimens were hydrogen-degassed at $400^{\circ} \mathrm{C}$ for 
$1 \mathrm{~h}$. In this case, the DBTT of the weld specimens increased slightly to about room temperature. It appears that the hydrogen in the base metal must not have been picked up in the machining process and that any hydrogen in the alloy must have been degassed during the welding process. The results so far indicate that the DBTT of the laser weldments from heat \#832665 is at or below room temperature. Oxygen analyses are being performed on the weldments to determine the extent of oxygen pickup during the welding and to evaluate effects of oxygen concentration on the properties. Further investigations are in progress to determine these various effects on the laser welds.

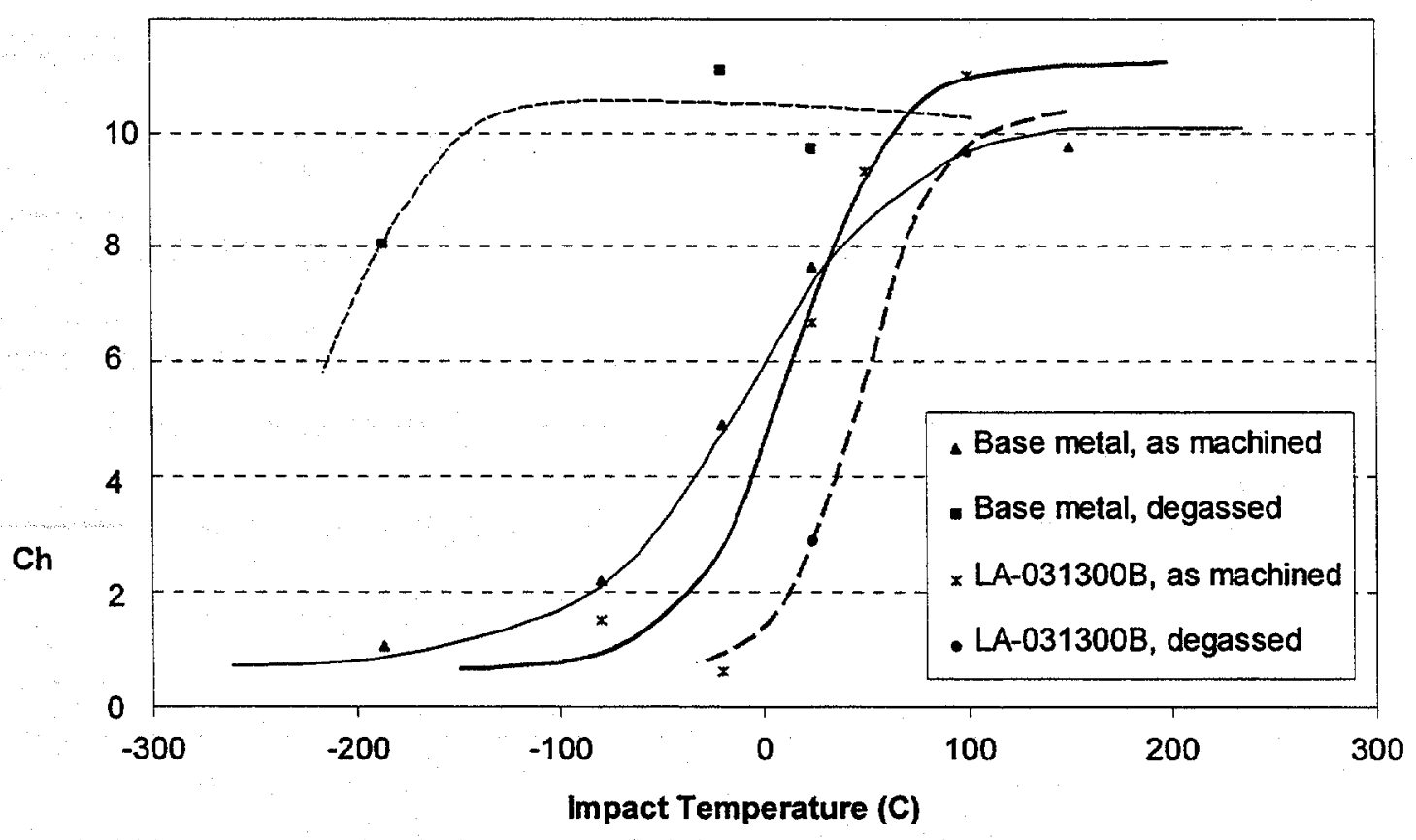

Fig. 7. Charpy-impact data for base metal and laser weld specimens showing ductile behavior.

\section{Future Activities}

Charpy specimens of Japanese material $\mathrm{V}-4 \mathrm{Cr}-4 \mathrm{Ti}$ alloy with a lower oxygen content are being fabricated and will be tested to evaluate the effect of oxygen concentration on impact properties. The fracture surface of selected specimens will be examined by scanning electron microscopy to delineate the fracture mode. Oxygen and hydrogen analyses on the laser weldments are underway and will be reported in the future.

\section{REFERENCES}

[1] Z. Xu, D.L. Smith, Y. Yan, and C.B. Reed, Laser welding of $\mathrm{V}-4 \mathrm{Cr}-4 \mathrm{Ti}$ alloy, (this progress report).

[2] D. J. Alexander, W. R. Corwin, and T. D. Owings, "The Production of Calibration Specimens for Impact Testing of Subsize Charpy Specimens," ASTM STP 1248, p. 32. 


\section{IMPURITY EFFECTS ON GAS TUNGSTEN ARC WELDS IN V-Cr-Ti ALLOYS -

\author{
M. L. Grossbeck, J. F. King, and D. T. Hoelzer (Oak Ridge National Laboratory)
}

\section{Summary}

Recent research on welding vanadium alloys at ORNL has centered on gas tungsten arc welding of $6.4 \mathrm{~mm}$ plate of $\mathrm{V}-4 \mathrm{Cr}-4 \mathrm{Ti}$. Previous research has demonstrated that the level of oxygen in the glove box atmosphere can be correlated with embrittlement of the weld, higher levels being more deleterious. Efforts to reduce the oxygen level by means of a heated titanium getter resulted in elevated levels of hydrogen in the weld with corresponding embrittlement as measured by Charpy impact testing and the tendency to crack prior to testing. A cold getter of $\mathrm{Zr}$-Al was introduced to control the level of hydrogen. A residual gas analyzer installed to monitor the argon atmosphere showed that an important source of hydrogen is dissociation of water vapor by the electric welding arc. Use of the hydrogen getter and repeated pumping and backfilling with high purity argon resulted in an atmosphere with less than one wt. ppm of moisture and oxygen. Hydrogen was still a major contaminant but nonetheless reduced from that of previous welds.

The Charpy impact tests on miniature specimens $25.4 \mathrm{~mm}$ in length and $3.33 \mathrm{~mm}$ on a side were used to evaluate brittleness of the weld. In all cases, the root of the blunt notch was positioned at the center of the fusion zone. In early welds of $\mathrm{V}-4 \mathrm{Cr}-4 \mathrm{Ti}$, ductile to brittle transition temperatures, DBTT, as high as $250^{\circ} \mathrm{C}$ were observed. In the recent welds, DBTT's as low as $-28^{\circ} \mathrm{C}$ were attained.

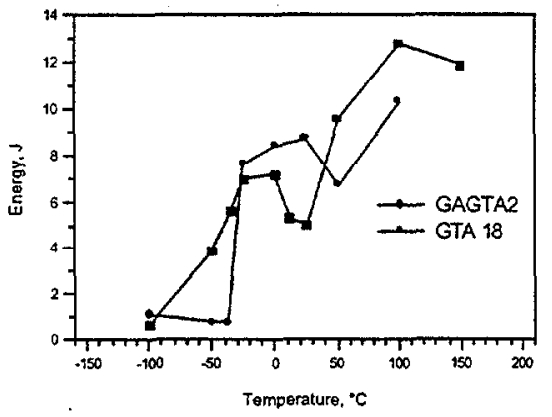

Figure 1 Charpy energy data plotted such as to show the high-temperature minima for two GTA welds in $\mathrm{V}-4 \mathrm{Cr}-4 \mathrm{Ti}$. This is a significant improvement, but electron beam welds have demonstrated DBTT's of $90^{\circ} \mathrm{C}$. This suggests that impurity control might result in further reduction of the DBTT.

Figure 1 shows the Charpy results of two of the most recent welds, both using filler metal of Wah Chang heat 832665 but different heats of similar base metal. Most interesting is perhaps not the low DBTT but rather the minima in the curves near $50^{\circ} \mathrm{C}$. This minimum has been observed previously, often following a postt-weld heat treatment to precipitate oxygen. In the case of the two recent welds shown in Fig. 1, a matrix with a low interstitial concentration was achieved, not by precipitation but by a clean welding atmosphere. This minimum is believed to result from twinning which permits plastic deformation after the initial restriction of slip as temperature is reduced. Twinning is enhanced by high strain rates, low interstitial concentrations, and large grain size, all of which are present in the high purity welds. Twinning has been observed in vanadium at low temperatures and high strain rates ${ }^{1-3}$. In addition, twinning has been observed in welds in the present research by TEM, and what appear to be twins have been observed following Charpy testing at temperatures below the minimum.

Further research will focus on determination of the mechanism of the high temperature minimum and, more importantly, on control of grain size as an additional mechanism of reduction of embrittlement in welds. 


\section{REFERENCES}

1. C.J. McHargue, Trans, AIME 224 (1962) 334.

2. W.R. Clough and A.S. Pavlonic, Trans. ASM 52 (1960) 948.

3. C.J. McHargue, Acta Met. 8 (1960) 900. 


\author{
STUDY OF THE LONG-TERM STABILITY OF MHD COATINGS FOR FUSION REACTOR \\ APPLICATIONS -- B. A. Pint, L.D. Chitwood, J. H. DeVan and J. R. DiStefano (Oak Ridge \\ National Laboratory)
}

\title{
OBJECTIVE
}

The objective of this task is to assess the long-term, high-temperature compatibility of high electrical resistance coatings with lithium at high temperatures. Electrically insulating, magnetohydrodynamic (MHD) coatings on the first wall of magnetic confinement reactors are essential to reduce the MHD force that would otherwise inhibit the flow of the lithium coolant. Initial experimental work is being conducted on bulk ceramics to determine basic lithium compatibility and maximum-use temperatures of candidate ceramics such as AIN and CaO.

\section{SUMMARY}

Two candidate materials for insulating coatings in a lithium-cooled fusion reactor have been exposed to lithium in $1000 \mathrm{~h}$ isothermal tests from $400^{\circ}-800^{\circ} \mathrm{C}$ to determine their maximum compatibility temperature. Bulk samples of $A I N+5 w t \% Y_{2} \mathrm{O}_{3}$ showed significant mass loss at $600^{\circ} \mathrm{C}$ and higher temperatures. The amount of attack was reduced when AIN+0.4Y was tested. Characterization by auger spectroscopy of a $\mathrm{AIN}+0.4 \mathrm{Y}$ specimen exposed at $600^{\circ} \mathrm{C}$ indicated the possibility of a lithium aluminate compound formation. Bulk specimens of $\mathrm{CaO}(99.9 \%$ purity) showed mass losses above $500^{\circ} \mathrm{C}$ indicating a possible dissolution problem that had not been observed in previous short-term screening tests. Doping of the lithium with oxygen (in the case of $\mathrm{CaO}$ ) did not appear effective in reducing the attack at $600^{\circ} \mathrm{C}$. However, doping with nitrogen (with AIN) did show a possible beneficial effect in conjunction with a Mo capsule. Based on these results, future testing also will consider alternative candidates such as $\mathrm{Y}_{2} \mathrm{O}_{3}$ and $\mathrm{Er}_{2} \mathrm{O}_{3}$.

\section{PROGRESS AND STATUS}

\section{Experimental Procedure}

Two types of aluminum nitride were tested, one with nominally $5 w t \% \mathrm{Y}_{2} \mathrm{O}_{3}$ from Goodfellow Corp. and the other with 400 wppm $Y$ and $0.9 w t \%$ oxygen from Tokuyama Corp (Shapal SH-50). The AIN $+0.4 Y$ material was produced by reducing and nitriding aluminum oxide and had a average grain size of $7-8 \mu \mathrm{m}$. Both had a density of $3.25 \mathrm{~g} / \mathrm{cm}^{3}$. Specimens of AIN $+Y_{2} \mathrm{O}_{3}$ measured $\approx 0.6 \times 12 \times 12 \mathrm{~mm}$ while Y-free AIN measured $\approx 2 \times 8 \times 12 \mathrm{~mm}$. Calcium oxide $(99.9 \%$ purity) was obtained from Cerac Corp. in the form of a sputtering target that was cut into specimens approximately $\approx 6 \times 6 \times 13 \mathrm{~mm}$. To avoid degradation from reaction with moisture, $\mathrm{CaO}$ was cut with a diamond blade and handled in dry air or in an argon glove box before and after testing. Dimensions and mass were measured before and after exposure with an accuracy of $0.02 \mathrm{mg} / \mathrm{cm}^{2}$.

The experimental procedure for lithium exposures has been outlined previously ${ }^{1,2}$. Bulk ceramic specimens were exposed for $1000 \mathrm{~h}$ at $400^{\circ}-800^{\circ} \mathrm{C}$. In three tests, additions of $\mathrm{Li}_{3} \mathrm{~N}$ and $\mathrm{Li} \mathrm{i}_{2} \mathrm{O}$ were made to increase the impurity levels in the lithium to nominally 1000 ppmw of nitrogen or oxygen. In order to explore the effect of the vanadium inner capsule on the experiment, a molybdenum capsule was used for one experiment with $\mathrm{Li}_{3} \mathrm{~N}$. In some cases, a final alcohol cleaning of AIN (but not $\mathrm{CaO}$ ) was done to remove any residual lithium or distillation residue. However, it was 
determined that this left a carbon residue on the specimen and inhibited further characterization.

Initial characterization has been performed on selected specimens. In order to detect lithium, Auger electron spectroscopy (AES) and X-ray photoelectron spectroscopy (XPS) were used to characterize the specimens after exposure. Because of the heavy attack on many of the specimens, electrical resistance measurements have not yet been made.

\section{Results and Discussion}

Mass changes after the $1000 \mathrm{~h}$ exposures to lithium are shown in Table I. Both materials have similar densities; thus a mass loss of $\approx 3.2 \mathrm{mg} / \mathrm{cm}^{2}$ corresponds to a $10 \mu \mathrm{m}$ loss in material thickness. Some of the mass change results were confounded by the inadvertent use of Ni wire (rather than the desired Mo wire) to restrain the specimens in the capsule. This resulted in some nickel being deposited on the surface of the ceramic specimen (determined by AES) due to dissolution of the wire. The amount of deposition appeared to increase with temperature with little Ni observed at $400^{\circ} \mathrm{C}$.

At $400^{\circ} \mathrm{C}$, the mass changes were slight for all of the materials tested which is in agreement with previous $100 \mathrm{~h}$ tests at $400^{\circ} \mathrm{C}^{3}$ and $450^{\circ} \mathrm{C}^{4}$ As reported previously, ${ }_{1,2}^{1,2}$ AIN with $5 \mathrm{wt} \% \mathrm{Y}_{2} \mathrm{O}_{3}$ showed increasing attack over the temperature range $400^{\circ}-700^{\circ} \mathrm{C}$, Table I. In order to avoid the complication of the $\mathrm{Y}_{3} \mathrm{Al}_{5} \mathrm{O}_{12}$ (YAG) grain boundary phase, additional tests were performed on AIN+0.4Y.

The results for AlN $+0.4 Y$ showed mass gains up until $800^{\circ} \mathrm{C}$ where a large mass loss was measured, Table I. However, the mass gain at $500^{\circ} \mathrm{C}$ and $700^{\circ} \mathrm{C}$ was in part due to a visible $\mathrm{Ni}$ deposition. Examination of the AIN surface after exposure at $500^{\circ} \mathrm{C}$ by AES showed $70 \%$ of the signal from Ni. A slight mass gain was observed for the $A I N+0.4 Y$ at $600^{\circ} \mathrm{C}$, rather than the mass loss observed for $\mathrm{AIN}+5 \mathrm{w}+\% \mathrm{Y}_{2} \mathrm{O}_{3}$. This indicates a beneficial effect of reducing the yttrium content in the AIN.

Table 1. Mass changes of bulk ceramic specimens after $1000 \mathrm{~h}$ exposures to lithium in a vanadium alloy capsule at various temperatures.

\begin{tabular}{lcccccc} 
Conditions & \multicolumn{2}{c}{$\mathrm{AIN}_{+} \mathrm{Y}_{2} \mathrm{O}_{3}$} & \multicolumn{3}{c}{$\mathrm{AIN}+0.4 \mathrm{Y}$} & $\mathrm{CaO}$ \\
$\mathrm{mg} / \mathrm{cm}^{2}$ & $\%$ & $\mathrm{mg} / \mathrm{cm}^{2}$ & $\%$ & $\mathrm{mg} / \mathrm{cm}^{2}$ \\
$400^{\circ} \mathrm{C}$ & $-0.18^{*}$ & $-0.17^{*}$ & $+0.1^{*}$ & $+0.23^{*}$ & $+0.08^{*}$ & $+0.22^{*}$ \\
$500^{\circ} \mathrm{C}$ & $+1.7^{*}$ & $+1.9^{*}$ & $+1.1^{*}$ & $+2.4^{*}$ & $-3.1^{*}$ & $-8.56^{*}$ \\
$600^{\circ} \mathrm{C}$ & -1.9 & -1.8 & +0.1 & +0.26 & -3.6 & -10.3 \\
$600^{\circ} \mathrm{C}+1000 \mathrm{ppm} \mathrm{N}$ & & & +0.6 & +1.36 & & \\
$600^{\circ} \mathrm{C}+1000 \mathrm{ppm} \mathrm{NT}$ & & -0.1 & -0.17 & & \\
$600^{\circ} \mathrm{C}+1000 \mathrm{ppm} \mathrm{O}$ & & & & -3.3 & -9.51 \\
$700^{\circ} \mathrm{C}$ & specimen broke & $+5.4^{*}$ & $+12.5^{*}$ & $-2.7^{*}$ & $-7.18^{*}$ \\
$800^{\circ} \mathrm{C}$ & not tested & -8.6 & -26.5 & -8.0 & -23.3
\end{tabular}

* specimen suspended by Ni wire which dissolved and redeposited on specimen during test + tested in a Mo capsule 
In order to saturate the lithium with nitrogen and possibly improve compatibility, nitrogen was added to the lithium for two tests. A higher mass gain was observed for $\mathrm{AIN}+0.4 \mathrm{Y}$ when 1000ppm nitrogen was added to the lithium (Table I), but the specimen appeared to have a thicker residue on the surface that was not removed by distillation. Previous testing of the lithium after reaction with $\mathrm{AlN}+5 \mathrm{wt} \% \mathrm{Y}_{2} \mathrm{O}_{3}$ showed that, while the $\mathrm{Al}$ content of the lithium increased with temperature (i.e. the amount of reaction), the nitrogen content did not. This suggested a possible reaction with the vanadium capsule. Thus, a Mo capsule also was used in one test. In this case, the specimen lost a small amount of weight $\left(0.17 \mathrm{mg} / \mathrm{cm}^{2}\right)$. Additional testing and characterization will further explore this result.

The AlN $+0.4 \mathrm{Y}$ specimen exposed to lithium at $600^{\circ} \mathrm{C}$ (followed by distillation at $500-600^{\circ} \mathrm{C}$ ) was sputter depth profiled by AES in order to characterize the reaction product. Figure 2 shows a complex distribution of elements to a depth of almost $2 \mu \mathrm{m}$ below which there appeared to be largely $\mathrm{Al}$ and $\mathrm{N}$ present. There appeared to be an outer layer (labeled I) of mainly $\mathrm{Li}$ and $\mathrm{O}$ and a second layer (II) where there were large amounts of $\mathrm{Li}$, Al and $\mathrm{O}$ above the substrate (III). This indicates that there is probably a reaction where the AIN is transforming to an oxide, such as lithium aluminate. The specimen exposed at $800^{\circ} \mathrm{C}$ showed a surface composition of 42at.\%O$32 \% \mathrm{Al}-12 \% \mathrm{Li}-14 \% \mathrm{C}$ beneath a patchy layer of $\mathrm{Li}-\mathrm{C}-\mathrm{O}$ which appeared to spall off of some areas. (Lithium exposed to air will readily form a carbonate.) In this case, it was believed that the oxygenrich layer was too thick to be sputtered through by AES. The presence of an aluminate reaction product could degrade the electrically properties of the coating and lithium aluminate is not stable in $\mathrm{Li}$ at $450^{\circ} \mathrm{C} .4$

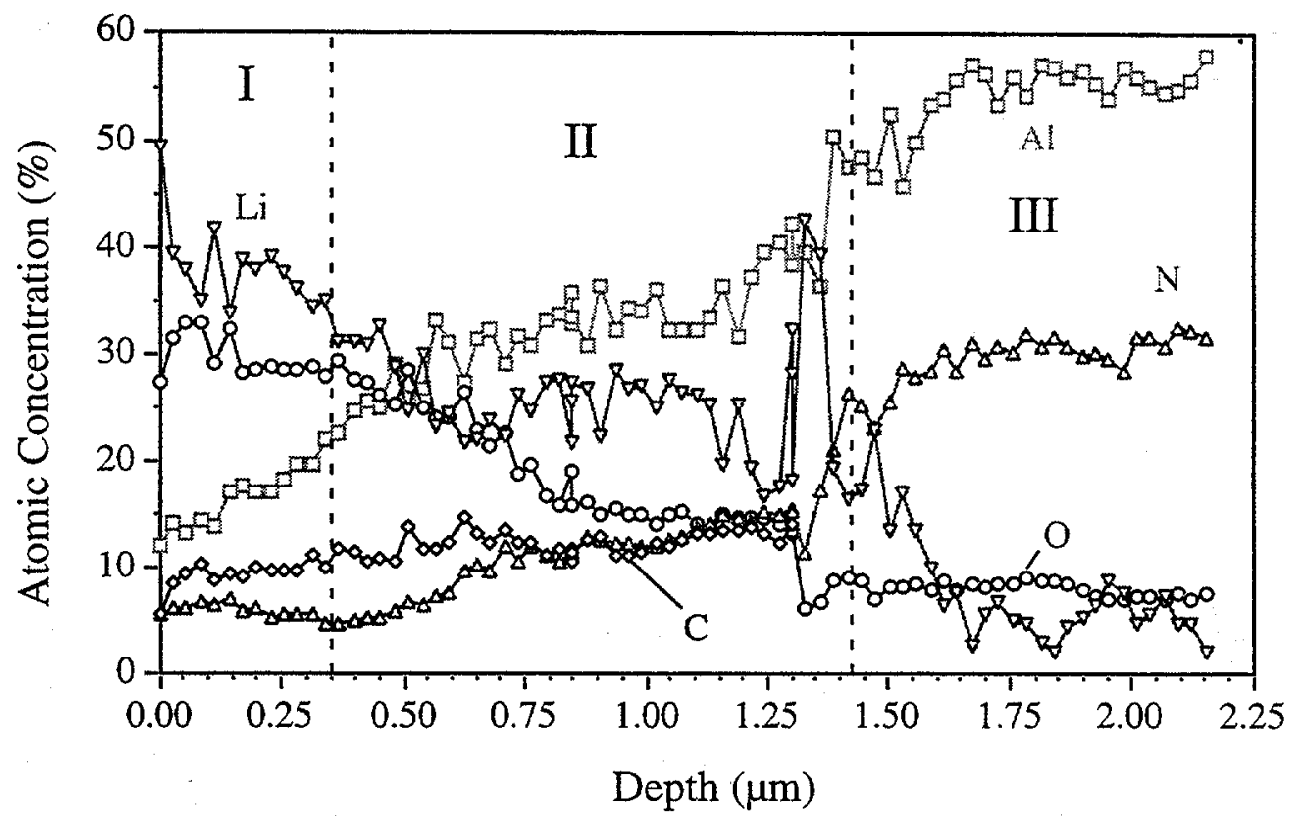

Figure 2. Sputter depth profile from the surface of AIN+0.4Y after $1000 \mathrm{~h}$ at $600^{\circ} \mathrm{C}$ determined by Auger electron spectroscopy. A layer of largely Li and $O(I)$ was observed above a layer with large amounts of $\mathrm{Li}, \mathrm{Al}$ and $\mathrm{O}$ (II). Further sputtering appeared to reveal the substrate (III). 
The source of the oxygen in the Li-containing reaction layer (Figure 2) could be the AIN-0.4Y material $(0.9 \mathrm{wt} \%)$, impurities in the lithium or the vanadium walls. In the presence of lithium, any oxygen in the $\mathrm{V}-4 \mathrm{Cr}-4 \mathrm{Ti}$ is likely to diffuse out. However, this process would be relatively slow at temperatures below $600^{\circ} \mathrm{C}$. More testing is required to confirm this behavior over the temperature range $500^{\circ}-700^{\circ} \mathrm{C}$ and additional characterization by $x$-ray diffraction is warranted. These results suggest that a thin AIN MHD coating may be substantially attacked by a similar process in a flowing lithium system. The change in electrical properties of AIN after exposure to lithium may indicate the severity of this problem. The presence of oxygen in the outer layer indicates that the lithium may need to be further purified in order to avoid oxidation of AIN. Neither alumina ${ }^{3}$ or $\mathrm{LiAlO}_{2}{ }^{4}$ is compatible with lithium.

At $500^{\circ}-800^{\circ} \mathrm{C}$, significant mass losses were recorded for $\mathrm{CaO}$ that generally increased with temperature. These specimens were very brittle and some mass loss may have resulted from small pieces breaking off. However, the consistency of the losses and similar general appearance of the specimens after testing suggested that these results are accurate and that substantial dissolution occurred at higher temperatures. An attempt was made to saturate the lithium with oxygen in order to slow the rate of dissolution. However, the addition of $1000 \mathrm{ppm} O$ to the lithium showed little change in reaction rate and did not appear to affect the reaction. Due to charging problems, $\mathrm{CaO}$ specimens could not be analyzed by AES. XPS was used to detect $\mathrm{Li}$ on the surface but it could not be determined if it was residual Li not removed during distillation. The $400^{\circ} \mathrm{C}-450^{\circ} \mathrm{C}$ experimental results ${ }^{3,4}$ and thermodynamic calculations ${ }^{5-7}$ indicate $\mathrm{CaO}$ should be a good candidate material. However, based on these results, $\mathrm{CaO}$ does not appear to be a viable candidate material for the higher temperature range desired.

In general, the results are not promising for $\mathrm{CaO}$ or $\mathrm{AlN}+5 \mathrm{wt} \% \mathrm{Y}_{2} \mathrm{O}_{3}$ at $600^{\circ}-800^{\circ} \mathrm{C}$; however, more work is required to better characterize the performance of AIN+0.4Y in this temperature range and further investigate the effect of $\mathrm{N}$ doping in conjunction with a Mo capsule. Future work also will focus on single crystals of $\mathrm{CaO}$ in attempt to further confirm these results for its long-term, high temperature compatibility. Single crystals will eliminate issues such as accelerated grain boundary attack or the role of porosity on these tests. Also single crystals of other oxides such as $\mathrm{Sc}_{2} \mathrm{O}_{3}, \mathrm{Y}_{2} \mathrm{O}_{3}$ and $\mathrm{Er}_{2} \mathrm{O}_{3}$, which have similar stabilities as $\mathrm{CaO},{ }^{8}$ will be considered. Recent work suggests that oxides such as these may be stable in lithium in this temperature range. ${ }^{9}$

\section{REFERENCES}

1. B. A. Pint, L.D. Chitwood, J. H. DeVan and J.R. DiStefano, DOE/ER-0313/27 (1999) 49.

2. B. A. Pint, L. D. Chitwood and J. R. DiStefano, J. Nucl. Mater. in press.

3. R. J. Lauf and J. H. DeVan, J. Electrochem. Soc. 139 (1992) 2087.

4. J. E. Battles, Intern. Mater. Rev. 34 (1989) 1.

5. I. Schreinlechner and F. Holub, in: Materials Behavior and Physical Chemistry in Liquid Metal Systems, H. U. Borgstedt (Ed.), Plenum Press, N.Y. 1982, p.105.

6. R. N. Singh, J. Amer. Ceram. Soc. 59 (1976) 112.

7. P. Hubberstey and T. Sample, J. Nucl. Mater. 248 (1997) 140.

8. K. Cvetkovic and A. Petric, Amer. Ceram. Soc. Bull. 79-4 (2000) 65.

9. T. Mitsuyama, T. Terai, T. Yoneoka and S. Tanaka, Fusion Eng. Design 39-4 (1998) 811. 
DEVELOPMENT OF ELECTRICALLY INSULATING CaO COATINGS*

K. Natesan, Z. Zeng, W. E. Ruther, M. Uz and D. L. Smith (Argonne National Laboratory)

\section{OBJECTIVE}

The objectives of this task are to (a) develop electrically insulating coatings, with emphasis on the basic understanding of the thermodynamic conditions and kinetics of coating development needed to achieve stable coatings of $\mathrm{CaO}$ that are compatible in an $\mathrm{Li} / \mathrm{Li}-\mathrm{Ca}$ environment; (b) perform detailed postexposure analysis of the surface layers by several electron/optical techniques to characterize the elemental and phase compositions, quantify stratification in the layers, and establish the role of compositional changes in the coating defects and microstructure; (c) measure the electrical resistance of the coatings, before and after exposure external to Li; and (d) establish optimal procedures from the standpoint of sample preparation procedures, exposure time and temperature, and sequence of operations in order to obtain reliable and reproducible coatings with adequate electrical resistance for use in an Li environment.

\section{SUMMARY}

A systematic study has been initiated to develop electrically insulating $\mathrm{CaO}$ coating by in-situ formation in a liquid $\mathrm{Li}$ environment. Twelve capsule tests were conducted at several temperatures and with different concentrations of $\mathrm{Ca}$ in $\mathrm{Li}-\mathrm{Ca}$ mixtures. Specimens included in the run were annealed $\mathrm{V}-4 \mathrm{Cr}-4 \mathrm{Ti}$ alloy without and with a grit-blasted surface, O-precharged in $99.999 \mathrm{vol} \% \mathrm{Ar}$ environment, polished specimens precharged in a 99.999 vol.\% $\mathrm{Ar}$ and $5000 \mathrm{vppm} \mathrm{O}_{2}-\mathrm{N}_{2}$ mixture. $\mathrm{CaO}$ coatings of $2-3 \mu \mathrm{m}$ in thickness were obtained. Detailed mirostructural and compositional analyses were performed on the exposed specimens. The coatings exhibited a resistance of $\approx 44 \Omega / \mathrm{cm}^{2}$ on the surface of $\mathrm{V}-4 \mathrm{Cr}-4 \mathrm{Ti}$ alloys.

A systematic vapor transport study has been in progress to develop electrically insulating $\mathrm{CaO}$ coatings that are compatible with use in a liquid Li environment. Several additional experiments were conducted to study how the deposition of $\mathrm{Ca}$ on $\mathrm{V}-4 \mathrm{Cr}-4 \mathrm{Ti}$ substrate alloys is affected by variations in process temperature and time, and specimen location, surface preparation, and pretreatment. During this reporting period, several specimens were prepared with a coating of $\mathrm{CaO}$ by thermal/chemical deposition and the coatings were characterized before and after exposure to an Li environment.

\section{EXPERIMENTAL PROGRAM}

The present work on in-situ development of insulator coatings emphasizes a basic understanding of the thermodynamic conditions and kinetics of coating development in $\mathrm{Li}-\mathrm{Ca}$ mixtures to achieve stable coatings of $\mathrm{CaO}$ in-situ in a $\mathrm{Li} / \mathrm{Li}-\mathrm{Ca}$ environment. Among the key variables that influence coating formation and its chemical and mechanical integrity are test temperature, test time, $\mathrm{Li}$ chemistry (including $\mathrm{Ca}$ content and trace element concentrations), and alloy chemistry and specimen

\footnotetext{
*This work has been supported by the U.S. Department of Energy, Office of Fusion Energy Research, under Contract W-31-109-Eng-38.
} 
surface preparation.

To understand the mechanism of in-situ formation of $\mathrm{CaO}$ coatings in an $\mathrm{Li}$ environment and to establish the optimal experimental conditions, a series of capsule experiments were performed with specimens of $\mathrm{V}-4 \mathrm{Cr}-4 \mathrm{Ti}$ alloy that were bare (identified as B) or pretreated by several methods: gritblasted surface and O-precharged in 99.999 vol.\% Ar (identified as G), polished specimens $\mathrm{O}$ precharged in 99.999 vol.\% Ar (identified as A) or in a 5000 vppm $\mathrm{O}_{2}-\mathrm{N}_{2}$ mixture (identified as O), and prealuminization and $O$-precharged in a $5000 \mathrm{vppm} \mathrm{O}_{2}-\mathrm{N}_{2}$ mixture (identificd as $L$ ). The $O$ precharging was done for $100 \mathrm{~h}$ at $500^{\circ} \mathrm{C}$.

The pretreated $\mathrm{V}-4 \mathrm{Cr}-4 \mathrm{Ti}$ coupons, which measured $10 \times 5 \times 1 \mathrm{~mm}$, were immersed in an Li-Ca mixture in a stainless steel capsule lined with $\mathrm{V}$-alloy. To ensure flexibility in adjusting the $\mathrm{Li}-\mathrm{Ca}$ chemistry in these experiments, capsules that contained $\approx 50-60 \mathrm{~mL}$ of $\mathrm{Li}-\mathrm{Ca}$ mixture are used for specimen exposure. Table 1 lists the exposure conditions for different capsule experiments. Figure 1 shows the specimen assembly used in the capsule experiments in Li. The temperature of the in-situ coating varied from 800 to $450^{\circ} \mathrm{C}$; the concentration of Ca varied from 40 to 85 wt. $\%$ (10 to 50 at. \%) in the Ca-Li mixture. At Ca contents of $>30 \mathrm{wt} . \%$, the CaLi2 phase is expected to deposit as the specimens are cooled, whereas at a Ca content of $10 \mathrm{wt} \%, \beta-\mathrm{Ca}$ and $\alpha$-Ca deposits are expected. A furnace that could accommodate at least five capsules simultaneously at a given temperature was used for exposure of the capsules. The capsules were subjected to a rocking action to enable mixing of the Ca-Li mixture at elevated temperature. Upon exposure, the capsules were inverted at temperature to drain the specimens of $\mathrm{Li}$ and were then cooled to room temperature. Subsequently, the capsules were cut open, the sample holder was retrieved, the microstructures of the coatings were examined with a JOEL 6400 scanning microscope, and the compositions were analyzed by energy-dispersive X-ray (EDX) analysis. Resistances of the coated specimens were measured by a two-probe method.

Table 1. Exposure conditions for capsule tests

\begin{tabular}{ccccc}
\hline Capsule Number & Temperature $\left(^{*} \mathrm{C}\right)$ & Exposure time $(\mathrm{h})$ & Capsule condition & $\begin{array}{c}\text { Wt.\% Ca in } \\
\text { Ca-Li mixture }\end{array}$ \\
\hline 1 & 800 & 500 & rocking & 40 \\
2 & 800 & 500 & rocking & 60 \\
3 & 800 & 500 & rocking & 85 \\
4 & 800 & 210 & rocking & 85 \\
5 & 650 & 1050 & rocking & 40 \\
6 & 650 & 1050 & rocking & 60 \\
7 & 650 & 1050 & rocking & 85 \\
8 & 650 & 500 & rocking & 85 \\
9 & $650 / 450$ & $1004 / 1848$ & static & 40 \\
10 & $650 / 450$ & $1004 / 1848$ & static & 60 \\
11 & $650 / 450$ & 1004 & static & 85 \\
12 & $650 / 450$ & $1004 / 1848$ & static & 85 \\
\hline
\end{tabular}




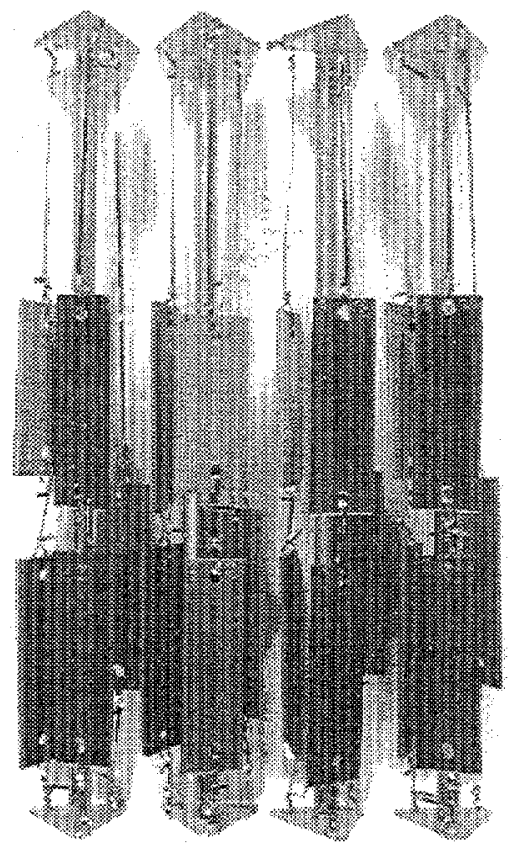

Fig. 1. Macrophotograph of specimen assembly used for in-situ coating development in liquid $\mathrm{Li}$.

Experiments were also conducted to develop Ca-rich coatings by using the thermal/chemical deposition process. The experiments involved exposure of $\mathrm{V}$ alloy specimens to a pack of fine $\mathrm{Ca}$ pellets at $700-800^{\circ} \mathrm{C}$. The specimens were either completely enclosed within the pack or hung above the pack material in a static Ar environment. Above $700^{\circ} \mathrm{C}$, the vapor pressure of $\mathrm{Ca}$ is $>0.1$ torr and is sufficient to deposit a layer of $\mathrm{Ca}$ on the specimens. Several geometrical arrangements were examined to obtain a uniform coating of $\mathrm{Ca}$ on the specimens, which were typically coupons that measured 5 to $10 \times 5 \times 1 \mathrm{~mm}$. Effort during this period concentrated on developing procedures to develop a thick adherent coating of $\mathrm{CaO}$ on a $\mathrm{V}-4 \mathrm{Cr}-4 \mathrm{Ti}$ alloy substrate and on measuring the electrical resistance of the coated specimens as a function of temperature up to $\approx 710^{\circ} \mathrm{C}$.

\section{RESULTS AND DISCUSSION}

Coatings by in-situ method in $\mathrm{Li}$

EDX analysis of the in-situ-developed coatings showed that the major elements in the coating are $\mathrm{Ca}$, $\mathrm{V}$, and $\mathrm{O}$. Small amounts of $\mathrm{Ti}$ and $\mathrm{Cr}$ from the $\mathrm{V}-4 \mathrm{Cr}-4 \mathrm{Ti}$ alloy and $\mathrm{Al}$ from the prealuminized samples were also detected in the coatings. For the coating to be a good electrical insulator, a high $\mathrm{Ca}$ content is required. The $\mathrm{Ca}$ content of the present coatings increases with increasing $\mathrm{Ca}$ content of the Ca-Li mixture (see Fig. 2). Therefore, high Ca content in the Ca-Li mixture is advantageous in formulating a $\mathrm{CaO}$ coating. Several of the specimens were precharged with $\mathrm{O}$. In these specimens, several surface interactions (which can lead to $\mathrm{CaO}$ coating) are possible upon exposure to the $\mathrm{Ca}-\mathrm{Li}$ mixture:

$$
\mathrm{VO}_{\mathrm{x}}+\mathrm{xCa}=\mathrm{xCaO}+\mathrm{V}
$$


Table 2. Ca concentrations in coated specimens, with different initial pretreatments, after exposure in $\mathrm{Ca}$-Li mixtures

\begin{tabular}{|c|c|c|c|c|c|}
\hline \multirow[b]{2}{*}{ Capsule No. } & \multicolumn{5}{|c|}{ Ca concentration (in at. \%) in specimen } \\
\hline & A & $\mathrm{B}$ & $G$ & 0 & $L$ \\
\hline \multirow{4}{*}{1} & 29.7 & 1.1 & 43.8 & 31.4 & 4.9 (Al $0.4 \%)$ \\
\hline & 34.5 & 1.1 & 25.0 & 16.9 & $14.4(\mathrm{Al} 0.4 \%)$ \\
\hline & 26 & 0.5 & 44.1 & 29.9 & $12.6(\mathrm{Al} 0.3 \%)$ \\
\hline & 46.7 & $4.4(\mathrm{Al} 9.6 \%)$ & 38.1 & $5.9(\mathrm{Al} 4.4 \%)$ & $33.9(\mathrm{Al} 0.3 \%)$ \\
\hline \multirow{4}{*}{2} & 26.2 & $7.7(\mathrm{Al} 7.1 \%)$ & 4.6 & $3.6(\mathrm{Al} 4.6 \%)$ & 28.9 (Al $0.48 \%$ \\
\hline & 38.8 & $3.1(\mathrm{~A} \mid 7.4 \%)$ & 4.8 & $3.7(\mathrm{Al} 2.8 \%)$ & $28.4(\mathrm{Al} 0.4 \%)$ \\
\hline & 1.0 & 0.6 & 6.0 & 22.6 & 12.7 \\
\hline & 4.8 & 0.3 & 6.6 & 24.6 & 5.2 \\
\hline \multirow[t]{4}{*}{5} & 2.1 & 1.2 & 6.9 & 22.4 & 4.7 \\
\hline & - & - & - & 19.7 & - \\
\hline & - & - & - & 17.1 & - \\
\hline & 10.6 & 2.1 & 30.9 & 2.2 & 19.0 \\
\hline \multirow[t]{3}{*}{6} & 9.9 & 2.6 & 22.9 & 1.7 & 4.9 \\
\hline & 6.6 & 0.5 & 20.7 & 1.7 & 9.7 \\
\hline & 13.6 & 3.9 & 15.9 & 0.7 & 4.3 \\
\hline \multirow[t]{4}{*}{7} & 11.9 & 0.6 & 22.1 & 1.3 & 5.4 \\
\hline & 19.1 & 2.0 & 18.6 & 0.5 & 7.7 \\
\hline & - & - & 16.5 & - & - \\
\hline & 10 & 0.55 & 4.7 & 0.4 & - \\
\hline \multirow[t]{2}{*}{9} & 25.9 & 0.82 & 9.1 & 0.4 & $\therefore$ \\
\hline & 17.2 & & - & - & - \\
\hline \multirow[t]{4}{*}{10} & 1.2 & 0.8 & 0.8 & 0.8 & - \\
\hline & 12.6 & - & 30 & - & . \\
\hline & 12.5 & 5.9 & 5.3 & 0.5 & - \\
\hline & 39.4 & 3.6 & 12.1 & 1.5 & - \\
\hline \multirow[t]{5}{*}{11} & 18.1 & 0.7 & 8.7 & 2.3 & - \\
\hline & 4 & - & - & 23.1 & - \\
\hline & - & • & - & 37.6 & - \\
\hline & 16.1 & 3.2 & 18.4 & 9.0 & - \\
\hline & 16.4 & - & 7.7 & 9.6 & - \\
\hline \multirow[t]{3}{*}{12} & 14.6 & - & 1.3 & 11.7 & - \\
\hline & - & - & 25.9 & 8.1 & - \\
\hline & - & - & 3.7 & - & - \\
\hline
\end{tabular}

If $\mathrm{Ca}$ content is too low, $\mathrm{VO}_{\mathrm{x}}$ may first react with the $\mathrm{Li}$ in the $\mathrm{Ca}-\mathrm{Li}$ mixture. Then, $\mathrm{Li}_{2} \mathrm{O}$ reacts with $\mathrm{Ca}$ to form CaO. However, in the two-step (Eqs. 2 and 3) exchange process, the volume change may lead to cracks in the coating. Higher $\mathrm{Ca}$ content can increase the chance of the one-step reaction, Eq. 1, and can lead to a coating with good mechanical integrity. Table 2 lists the Ca concentrations in the coatings developed on different specimens that were exposed in various capsules. Figure 3 shows the $\mathrm{Ca}$ content of the coatings that increases with an increase in exposure temperature. Higher exposure temperature may help increase the Ca content of the coating. 


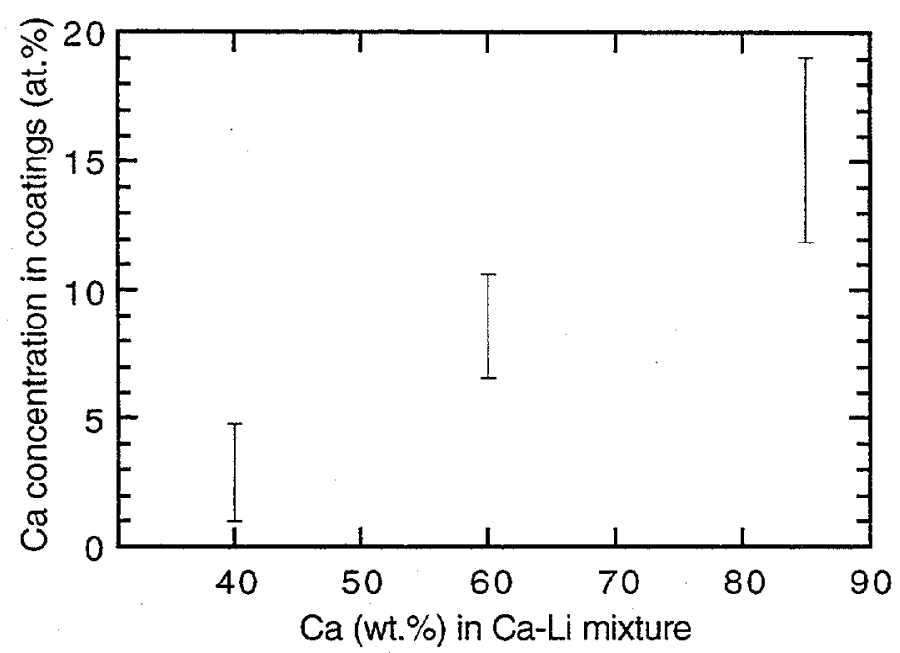

Fig. 2. Ca concentration in coatings, developed in-situ in $\mathrm{Ca}-\mathrm{Li}$ mixture at $650-800^{\circ} \mathrm{C}$, as a function of $\mathrm{Ca}$ content of the liquid.
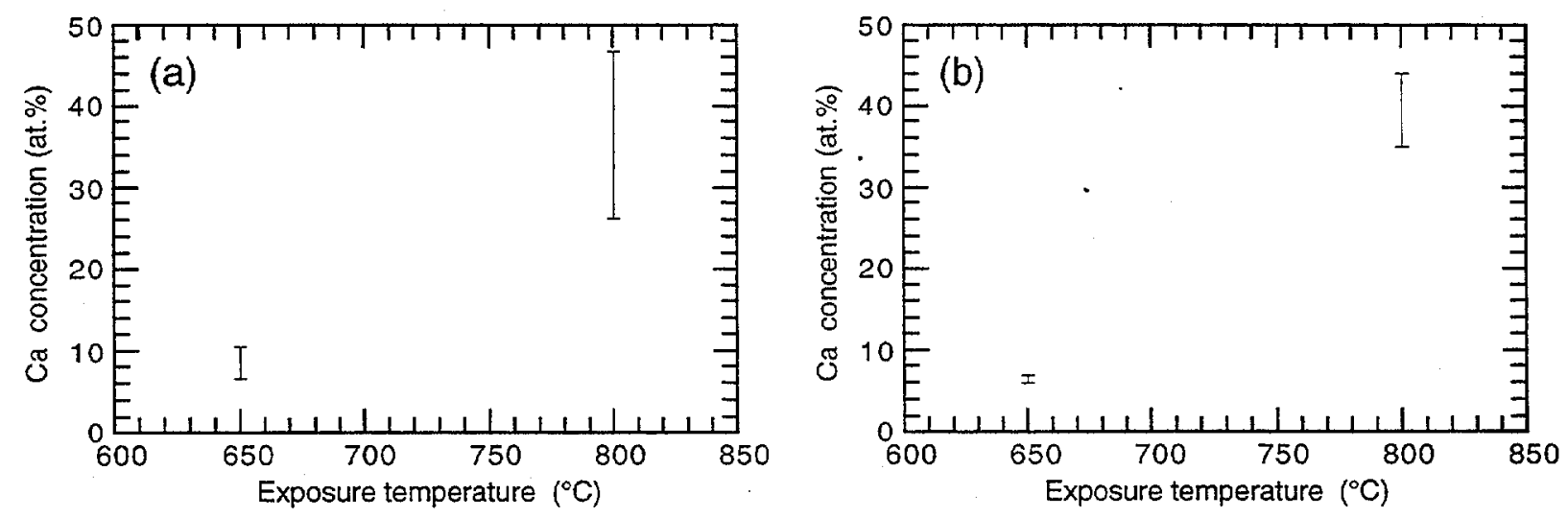

Fig. 3. Ca concentration in two coatings developed in-situ in $\mathrm{Ca}-\mathrm{Li}$ mixture on $\mathrm{V}-4 \mathrm{Cr}-4 \mathrm{Ti}$ alloy: (a) polished surface, O-pretreated in 99.999 vol. $\%$ Ar at $650^{\circ} \mathrm{C}$ for $17 \mathrm{~h}$ and (b) grit blast surface, Opretreated in $99.999 \mathrm{vol} \% \mathrm{Ar}$ at $650^{\circ} \mathrm{C}$ for $17 \mathrm{~h}$, as a function of exposure temperature.

The Ca content of the coating is strongly affected by the pretreatment of the specimens. The bare $\mathrm{V}$ 4Cr-4 $\mathrm{Ti}$ samples always showed the lowest $\mathrm{Ca}$ content (Fig. 4). This is probably because the $\mathrm{O}$ content of the surface of the bare specimen is low enough that the reaction in Eq. 1 does not occur. The specimens pretreated at $650^{\circ} \mathrm{C}$ in 99.999 vol.\% Ar exhibited higher Ca content in the coating when compared to specimens with other pretreatments. The oxygen in Ar gas formed a layer of oxide on the surface of the alloy, and the layer was converted to CaO coating according to Eq (1). 

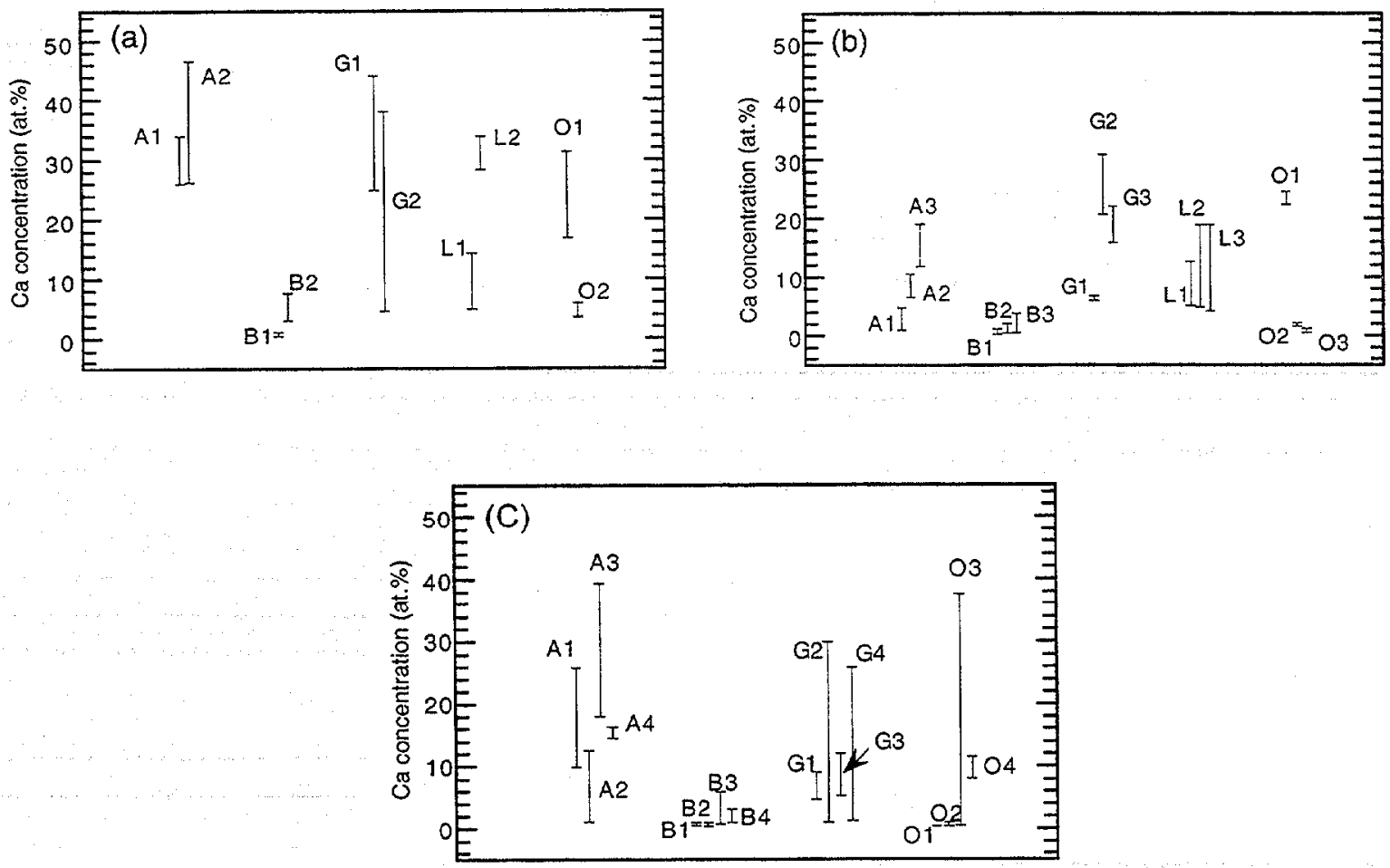

Fig. 4. Effect of specimen pretreatment on the $\mathrm{Ca}$ concentration in coatings developed in-situ in Ca$\mathrm{Li}$ mixtures by exposure at (a) $800^{\circ} \mathrm{C}$ for $500 \mathrm{~h}$, (b) $650^{\circ} \mathrm{C}$ for $1050 \mathrm{~h}$, and (c) $650 / 450^{\circ} \mathrm{C}$ for $1004 / 1848 \mathrm{~h}$. The letters $A, B, G, O$, and $L$ signify specimen pretreatments of exposure in 99.999 vol.\% Ar for $17 \mathrm{~h}$, no treatment, grit blast, exposure in $5000 \mathrm{vppm} \mathrm{O}_{2}-\mathrm{N}_{2}$ mixture, and prealuminization, respectively. The numbers $1,2,3$, and 4 signify exposure in Ca-Li mixtures containing $40,60,85$, and 85 wt. $\% \mathrm{Ca}$, respectively.

Some areas of the sample treated by grit blasting exhibited a high $\mathrm{Ca}$ content but it was not uniformly high on the entire surface, indicating probable spallation of the coating. The results also indicated that surface roughness can play a large role in the adhesion of the coating to the substrate. An alternate approach, which involves chemical etching is being examined as a pretreatment for the specimens prior to exposure in a Ca-Li mixture.

The Ca content of prealuminized samples was higher than that of the bare samples, but lower than that in specimens pretreated in 99.999 vol.\% Ar. Specimens pretreated in a $5000 \mathrm{vppm}$ O-N gas mixture exhibited higher $\mathrm{Ca}$ content but also significant cracking of the coating; the cracked regions exhibited low $\mathrm{Ca}$ content. It is probable that the pretreatment led to a thick oxide layer that cracked upon reaction with $\mathrm{Ca}$ in the liquid mixture. The average thickness of the coating for the sample pretreated in 99.999 vol.\% Ar is $\approx 3 \mu \mathrm{m}$. A sharp change in $\mathrm{Ca}$ and $\mathrm{V}$ content, shown in Fig. 5 , is noted at the coating/substrate interface, indicating a lack of diffusion of $\mathrm{Ca}$ into the substrate alloy. Figure 6 shows the resistance of the coated specimen as a function of temperature. Resistance is $\approx 44 \Omega / \mathrm{cm}^{2}$ at room temperature; it decreases with increasing temperature, but the values are much lower than desired for application in the first wall/blanket system. 


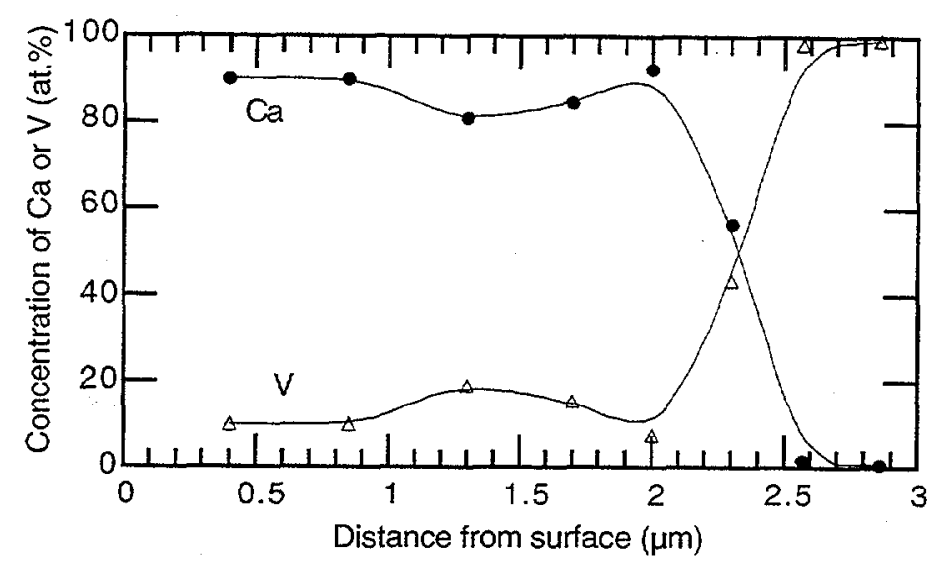

Fig. 5. Ca and $V$ concentrations as a function of coating thickness for a typical in-situ-developed coating on a V$4 \mathrm{Cr}-4 \mathrm{Ti}$ alloy specimen.

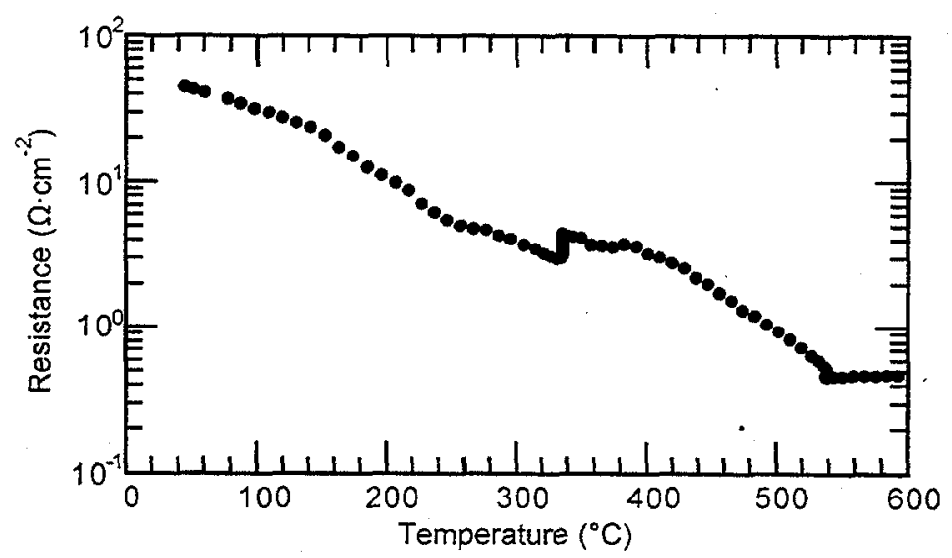

Fig. 6. Resistance of an in-situ-developed coating as a function of temperature, measured by a two-probe method.

In conclusion, CaO coatings on the surface of $\mathrm{V}-4 \mathrm{Cr}-4 \mathrm{Ti}$ alloy were made by in-situ coating. The results showed that specimen pretreatment had a strong influence on the composition, mechanical integrity, and thickness of the coating developed by exposure in a Ca-Li mixture.

Coatings by thermal/chemical vapor phase transport

In previous reports, we discussed the procedure for deposition of $\mathrm{Ca}$ by thermal/chemical vapor transport and subsequent oxidation to convert the $\mathrm{Ca}$ into $\mathrm{CaO} .1,2$ Based on an extensive analysis of the coated specimens, it was concluded that the coating thickness and the adhesive bonding of the coating to the substrate after a single deposition/oxidation procedure was not adequate to produce the desired insulating characteristics. Subsequently, a double Ca deposition/oxidation treatment was developed for producing $\mathrm{CaO}$ coatings. 3,4 During this reporting period, several additional specimens were coated by this procedure and the coatings were characterized for their chemical composition, 
microstructure, and electrical resistance. Figure 7 shows typical scanning electron microscopy (SEM) secondary-electron and backscattered-electron images of cross sections of two $\mathrm{V}-4 \mathrm{Cr}-4 \mathrm{Ti}$ alloy specimens after a double $\mathrm{Ca}$ deposition/oxidation treatment. Coating thicknesses in these specimens were 30-34 $\mu \mathrm{m}$. EDX analysis of the specimen surfaces showed the coatings to be $\mathrm{CaO}$ and also revealed the virtual absence of any elements from the substrate alloy. EDX analysis of the coating surface indicated primarily $\mathrm{Ca}$ and $\mathrm{O}$ peaks. Cross sections of several specimens were analyzed as a function of depth for constituent elements of the coating and substrate. Depth profiles for two of the coated specimens are shown in Figs. $8 \mathrm{a}$ and $8 \mathrm{~b}$. The coating composition was predominantly CaO in both specimens, and negligible amounts of substrate elements were detected in the coating region. The results also showed that consistently reproducible coatings with uniform thickness can be developed by this procedure.

Additional experiments are in progress to develop coatings on rod specimens with rounded ends (to minimize stress concentration and cracking of the coating at the corners of coupon specimens). These specimens will be used for in-situ measurement of resistance of the coating in an $\mathrm{Li}$ environment at temperatures up to $700^{\circ} \mathrm{C}$. For this purpose, an $\mathrm{Li}$ facility is being built and is in the final stages of assembly.

\section{REFERENCES}

1. K. Natesan, C. B. Reed, M. Uz, and D. L. Rink, "Development of Electrically Insulating CaO Coatings," Fusion Reactor Materials Progress Report for the Period Ending June 30, 1998, Argonne National Laboratory, DOE/ER-0313/24, p. 82, Sept.1998.

2. K. Natesan, M. Uz, and S. Wieder, "Development of Electrically Insulating CaO Coatings," Fusion Reactor Materials Progress Report for the Period Ending December 31, 1998, Argonne National Laboratory, DOE/ER-0313/25, p. 69, April 1999.

3. K. Natesan, M. Uz, and S. Wieder, "Development of Electrically Insulating CaO Coatings," Fusion Reactor Materials Progress Report for the Period Ending June 30, 1999, Argonne National Laboratory, DOE/ER-0313/26, p. 57, Sept. 1999.

4. K. Natesan, C. B. Reed, M. Uz, J. H. Park, and D. L. Smith, "Electrically Insulating Coatings for $\mathrm{V}-\mathrm{Li}$ Self-Cooled Blanket in a Fusion System," Argonne National Laboratory Report ANLTD/TMO0-10, May 2000. 

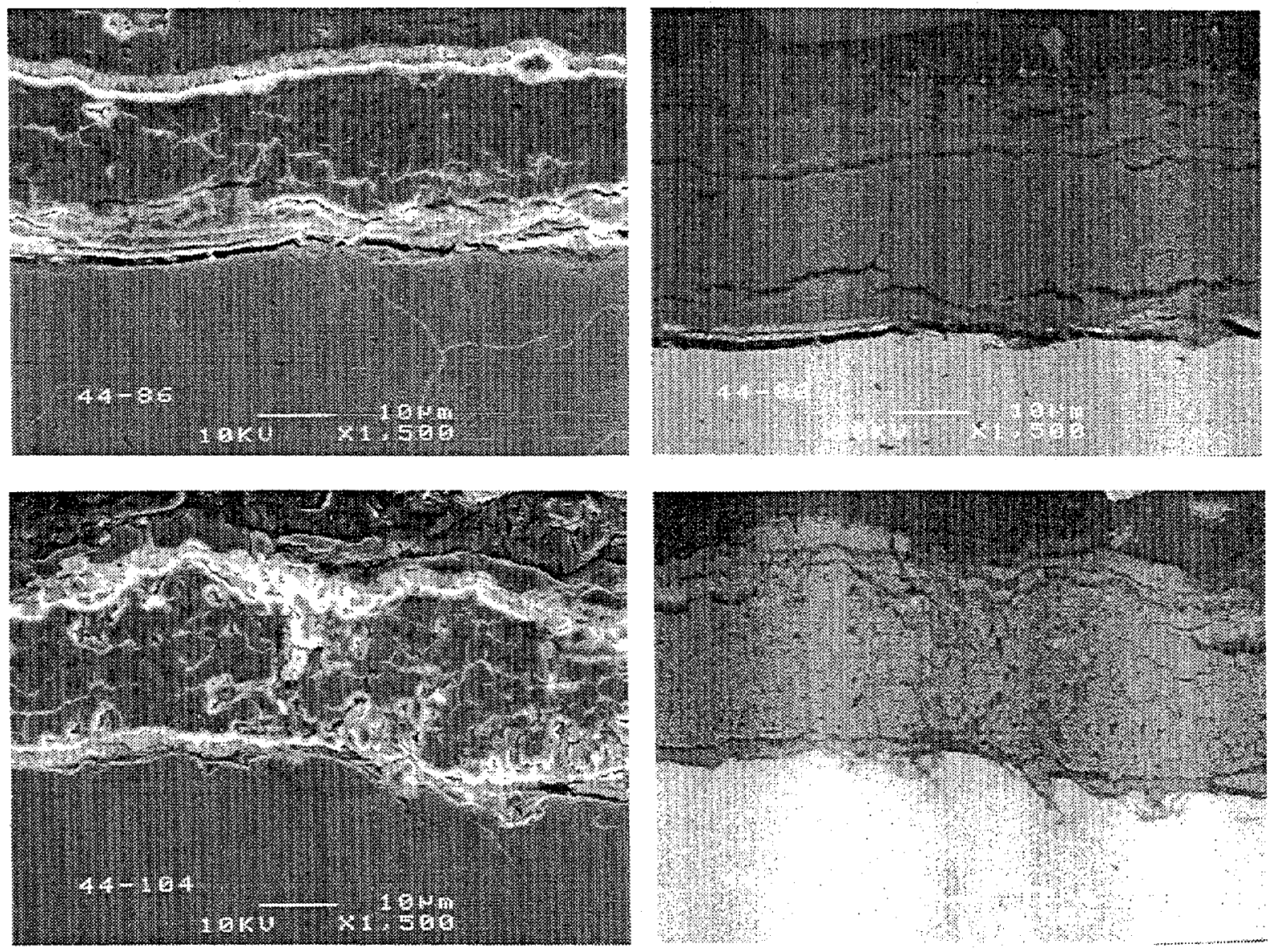

Fig. 7. SEM photomicrographs of cross sections of two $\mathrm{V}-4 \mathrm{Cr}-4 \mathrm{Ti}$ alloy specimens after double $\mathrm{Ca}$ deposition/oxidation treatment. Photographs on the left are secondary-electron images, those on the right are backscattered-electron images.
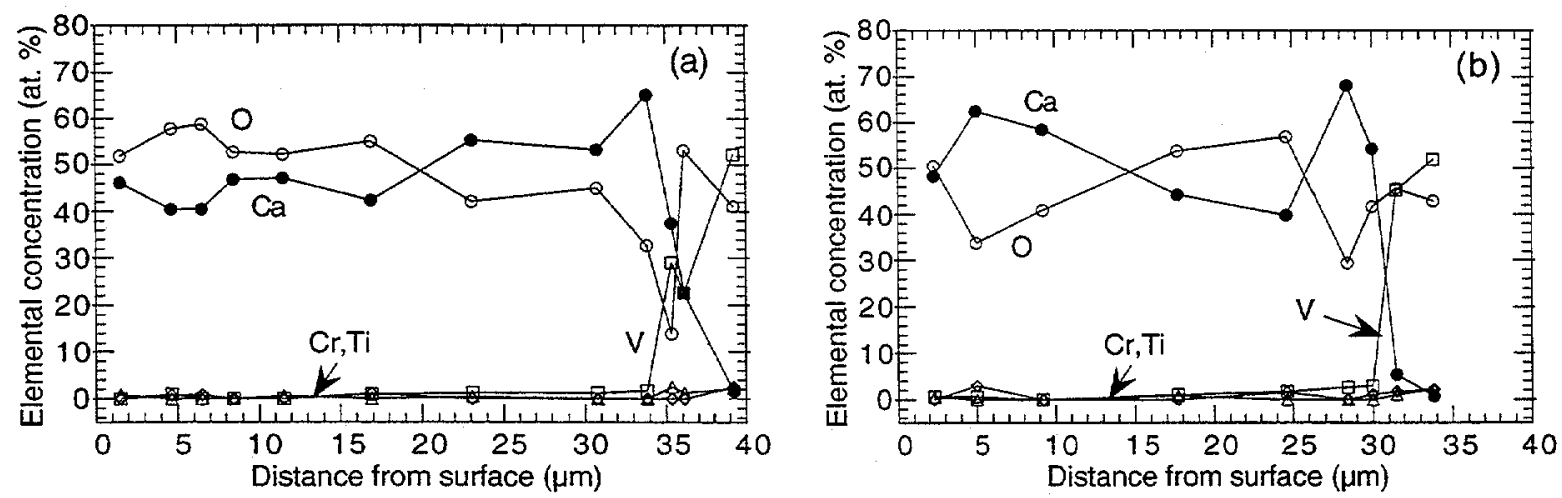

Fig. 8. Elemental concentrations as a function of coating thickness for $\mathrm{V}-4 \mathrm{Cr}-4 \mathrm{Ti}$ alloy specimens after (a) double $\mathrm{Ca}$ /deposition/oxidation treatment and (b) after exposure to $\mathrm{Li}$ at $500^{\circ} \mathrm{C}$ for $68 \mathrm{~h}$. 
UNIAXIAL CREEP BEHAVIOR OF V-4Cr-4TI Alloy*

K. Natesan, W. K. Soppet, and D. L. Rink (Argonne National Laboratory)

\section{OBJECTIVE}

The objectives of the creep test program are to (a) to establish time/temperature relationships for creep properties, such as creep rupture strength, $1 \%$ creep in $10,000 \mathrm{hr}$, onset of third-stage creep, etc., all of which are key parameters in designing structural components for service at elevated temperatures; (b) provide a basis to establish the upper-use temperature associated with creep limits for application of V-base alloys; and (c) evaluate the influence of variations in the concentrations of substitutional and interstitial elements on the creep properties of fusion-reactor-relevant $V$-base alloys.

\section{SUMMARY}

A systematic study is currently being conducted at Argonne National Laboratory (ANL) to evaluate the uniaxial creep behavior of $\mathrm{V}-\mathrm{Cr}-\mathrm{Ti}$ alloys as a function of temperature in the range of $650-800^{\circ} \mathrm{C}$ and at applied stress levels of $75-380 \mathrm{MPa}$. At present, the principal effort has focused on the $\mathrm{V}-4 \mathrm{Cr}-4 \mathrm{Ti}$ alloy of Heat 832665; however, another heat of a similar alloy from General Atomics (GA) will also be used in the study. The Larson-Miller approach is used to correlate several creep parameters such as time to rupture, time-to-onset of tertiary creep, and times for 1 and $2 \%$ strain accumulation with applied stress and temperature. Best-fit equations are presented for several creep parameters.

\section{INTRODUCTION}

Refractory alloys based on V-Cr-Ti are being considered for use in first-wall structures in advanced blanket concepts that use liquid $\mathrm{Li}$ as a coolant and breeding material. Furthermore, advanced concepts that involve $\mathrm{He}$ as a coolant also require structural alloys such as $\mathrm{V}-\mathrm{Cr}-\mathrm{Ti}$, which can withstand thermal loading at high temperature. It is important that for advanced fusion systems, design concepts establish the upper temperature limits for structural components based on various design criteria. At temperatures above $600^{\circ} \mathrm{C}$, the time-dependent creep properties of $\mathrm{V}$ alloys must be considered when evaluating performance limits.

The long-term creep properties of the $V$-base alloys will be influenced by the time-dependent nucleation and growth of precipitates that contain nonmetallic elements such as $O, N$, and $C$. Several microstructural studies of $\mathrm{V}$-base alloys have identified precipitates such as face-centered-cubic Ti(O, $\mathrm{N}, \mathrm{C}$ ) with variable $\mathrm{O}, \mathrm{N}$, and $\mathrm{C}$ ratios. To correlate microstructual development with creep properties, It is essential to establish the time-dependent evolution of type, number, and location of precipitates in V-base alloys. Furthermore, development of several of these precipitates can be influenced by the exposure environment during creep testing. Over the long term, creep data are needed for environments with a wide range of chemistry and that encompass high vacuum to low partial pressures of $\mathrm{O}$ and $\mathrm{H}$, as well as $\mathrm{He}$ of various purities.

"This work has been supported by the U.S. Department of Energy, Office of Fusion Energy Research, under Contract W-31-109-Eng-38. 


\section{SCOPE OF WORK}

In the near term, the program will experimentally evaluate uniaxial creep properties of $\mathrm{V}-\mathrm{Cr}-\mathrm{Ti}$ materials in high-vacuum environments at temperatures of $650-800^{\circ} \mathrm{C}$, with emphasis on baseline creep behavior of the alloys and correlations between microstructures and properties. Furthermore, the test program will examine the effects of specimen geornetry and heat-to-heat variation on the creep properties. Another aspect of the program will be creep tests on heats of $V$-base alloys that represent a range of variations in the concentrations of both substitutional and interstitial elements to provide an understanding of the effects of these variables on creep behavior.

\section{EXPERIMENTAL PROGRAM}

The effort is focused on the ANL-procured large heat of nominal composition V-4Cr-4Ti and on the GA heat of a similar composition. 1, 2 Flat creep specimens, $1 \mathrm{~mm}$ in thickness (see Fig. 1 for details), were used in the initial phase of the program. A few specimens with cylindrical cross sections (2.5 $\mathrm{mm}$ diameter; see Fig. 2 for details) are being tested to validate the effects, if any, of specimen geometry on creep properties. All specimens were fabricated according to ASTM Standard E8-96a with the gauge length oriented parallel to the rolling direction. Initial tests were conducted on specimens annealed at $1000^{\circ} \mathrm{C}$ for $1 \mathrm{~h}$ in vacuum. During this reporting period, several tests were conducted at $650,700,725$, and $800^{\circ} \mathrm{C}$. The specimens were wrapped in Ti foil to minimize contamination of the sample, especially by $O$.

The creep-test procedure is in accordance with ASTM E139-96. Four ATS model 2140 uniaxial direct constant-load creep-test machines are used for this program. All of the machines are equipped with high-vacuum systems and furnaces capable of $900^{\circ} \mathrm{C}$. Creep strain in the specimen is measured by a linear-variable-differential transducer (LVDT) attached between the fixed and movable pull rods of the creep assembly. Displacements of $5 \times 10^{-3} \mathrm{~mm}$ could be accurately determined with the LVDT over an operating range of $25 \mathrm{~mm}$. Before each test, the LVDT was calibrated by measuring its voltage output for displacements that were set manually on a standard micrometer. The LVDT is operated over the linear portion of the calibration curve to measure specimen strain during creep testing. Each creep-test system is monitored with a dedicated $66 \mathrm{MHz}$ Intel-486-based PC data acquisition system (DAS) that records LVDT displacement versus time and fracture event. The strain measurements are made at sufficiently frequent intervals during a test to define the creep strain/time curve. The DAS software provides a continuously variable data-sampling rate that adapts for transients and different creep-rate stages.

A three-zone resistance-heated furnace with three-mode proportional-integral-derivative temperature controller is used in each testing machine to conduct creep tests at elevated temperatures. ChromelAlumel thermocouples with small beads are used to measure specimen temperature. Ceramic insulators are used on the thermocouples in the hot zone. In general, three thermocouples are fed through the specimen chamber, one spot-welded onto each end of the specimen grips near the 


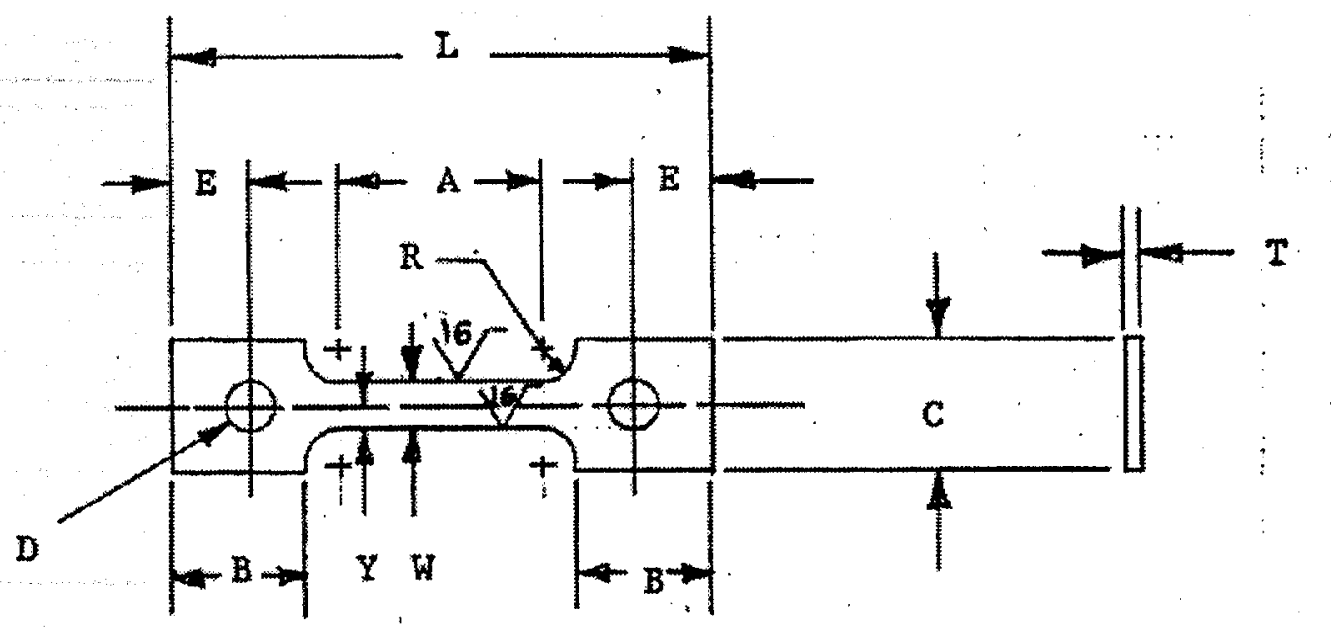

Dimensions in $\mathrm{mm}$

$\begin{array}{ll}A=19 \pm 0.50 & Y=2.2 \\ B=12.7 & W=4.5 \\ C=12.7 & T=1.0 \\ D=4.0 & R=3.175 \\ E=7.6 & L=50.8\end{array}$

Fig. 1. Schematic diagram of flat creep specimen designed according to ASTM Standard E8-96a.

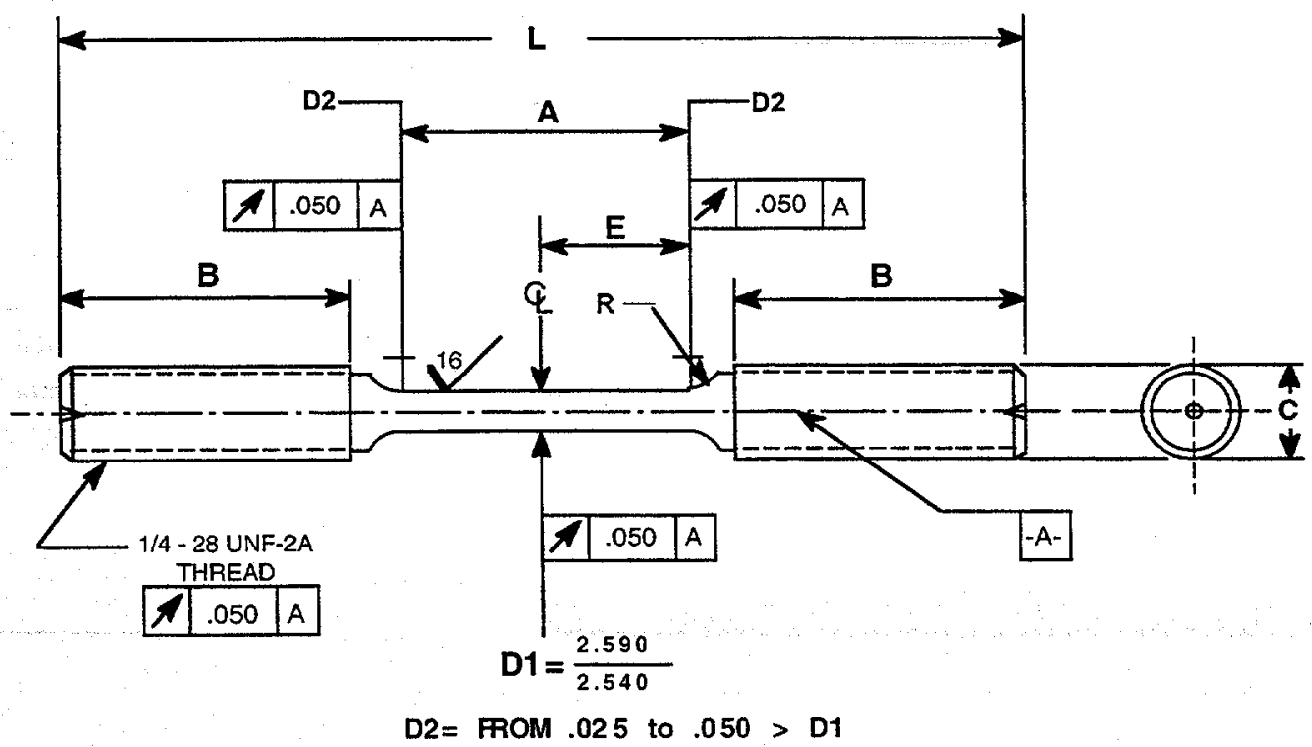

Dimensions in $\mathrm{mm}$

$\begin{array}{ll}A=19.05 & E=9.52 \\ B=19.05 & R=4.75 \\ C=6.35 & L=63.50 \\ D 1=2.54+0.05 & \end{array}$

Fig. 2. Schematic diagram of round creep specimen designed according to ASTM Standard E8-96a. 
shoulder region and the third held in the vacuum environment adjacent to the gauge section of the specimen. Temperature is maintained within $\pm 2^{\circ} \mathrm{C}$ of the desired value for each test. The specimens are loaded at a constant rate to full load after test-temperature equilibrium is achieved.

A detailed microstructural evaluation of the tested specimens is planned to characterize the morphologies as a function of exposure temperature and time and to establish the mechanisms of creep deformation and failure. The test program is aimed at obtaining the steady-state creep rate, onset of tertiary creep, rupture strain, and rupture life. At least four stress levels are planned at each temperature to obtain sufficient data to develop Larson-Miller correlations between time, temperature, and applied stress. The information will be used to assess the upper-use temperature for the material, based on appropriate design criteria and as a basis for alloy improvement.

\section{RESULTS}

During this period, several creep tests were conducted at $650,700,725$, and $800^{\circ} \mathrm{C}$. Two additional creep tests were completed at $700^{\circ} \mathrm{C}$ to complement and allow comparison with the data generated in the biaxial creep test program at $700^{\circ} \mathrm{C}$ conducted at Pacific Northwest National Laboratory. ${ }^{3}$ Figure 3 shows creep strain/time plots for $\mathrm{V}-4 \mathrm{Cr}-4 \mathrm{Ti}$ alloy specimens that we tested in vacuum at 650,700 , 725 , and $800^{\circ} \mathrm{C}$ at ANL. The data indicate that the primary creep period is negligible for all tests, and the secondary (or linear) creep portion of the curve is small. The curves show an accelerating creep behavior over the range of the present tests, especially at 725 and $800^{\circ} \mathrm{C}$. Since the last reporting period, the creep strain/time curves have been reanalyzed with KaleidaGraph graphical analysis software (Version 3.5 from Synergy Software). A linear least-squares analysis (LLSA) function is used to provide a consistent method to extract minimum creep rate, onset of tertiary creep, and creep strain at the onset of tertiary creep. Figure 4 shows an example of a typical LLSA applied to a creep strain/time curve. Data are given in Table 1 for completed tests. Figure 5 shows variation in rupture time and minimum creep rate as a function of applied stress for the $\mathrm{V}-4 \mathrm{Cr}-4 \mathrm{Ti}$ alloy creep tested in vacuum at $650-800^{\circ} \mathrm{C}$.

To examine the extent of $O$ contamination, if any, in the creep specimen, cross sections of the tested specimen were mounted and polished, after which Vickers hardness measurements were made along the thickness direction. Figure 6 shows hardness profiles for several specimens after testing at 725 and $800^{\circ} \mathrm{C}$. Hardness values ranged from 145 to 195 , with negligible variation within a given specimen, indicating that the contamination is minimal over the range of the current study. Examination of the fracture surfaces of tested specimens showed a ductile mode of fracture in all of the specimens. The specimens tested at $800^{\circ} \mathrm{C}$ showed rupture strains of $30-61 \%$, and significant thinning of the cross section is seen in the fracture zone. Detailed examination of the tested specimens by scanning and transmission electron microscopy is planned.

The Larson-Miller parameter approach is used to correlate time to rupture, exposure temperature, and applied stress. Similar correlations have been developed for time to onset of tertiary creep and times for $1 \%$ or $2 \%$ strain accumulation. The Larson-Miller parameter is given by: 

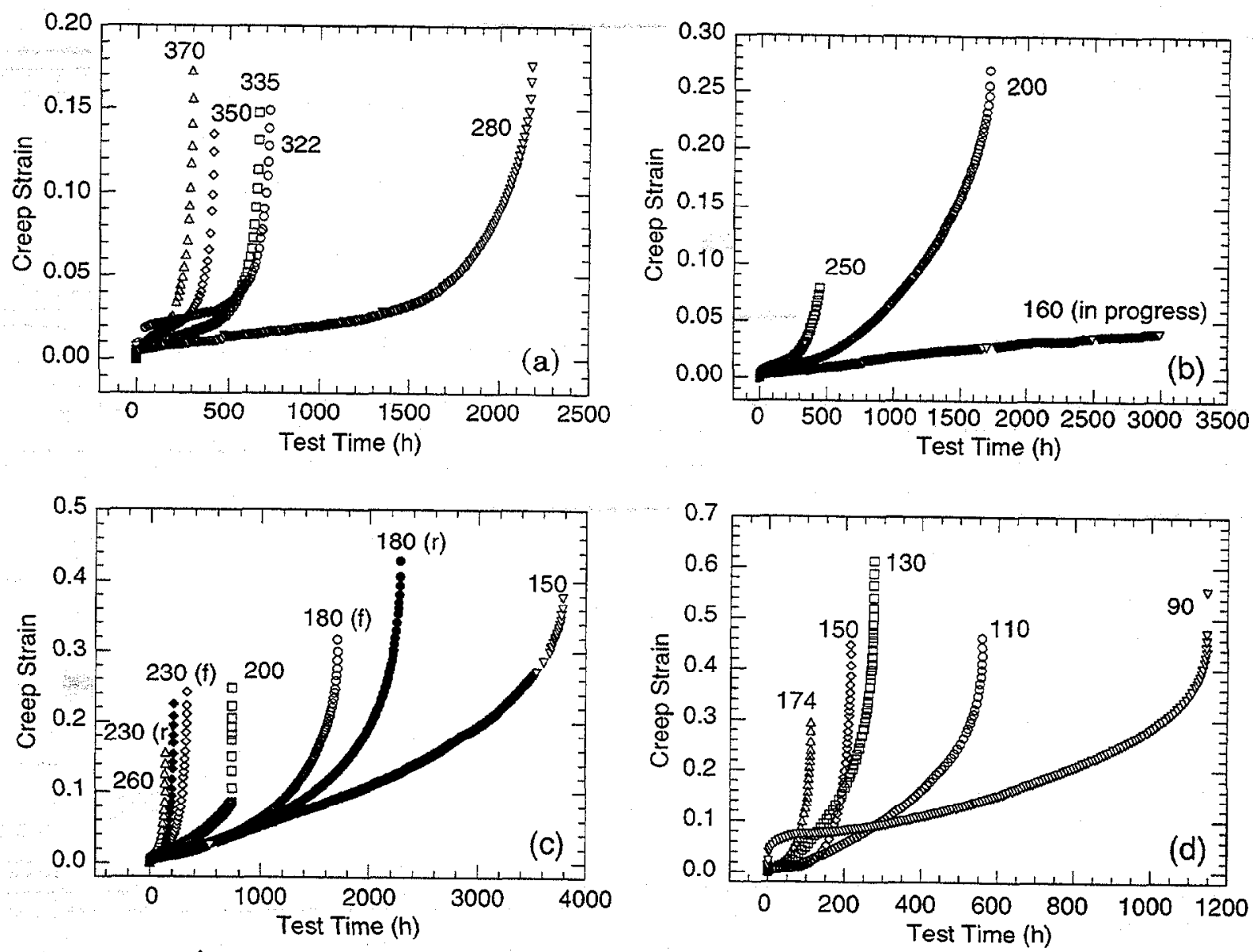

Fig. 3. Creep strain versus time plots for $\mathrm{V}-4 \mathrm{Cr}-4 \mathrm{Ti}$ alloys tested at (a) 650 , (b) 700 , (c) 725 , and (d) $800^{\circ} \mathrm{C}$ in vacuum environment.
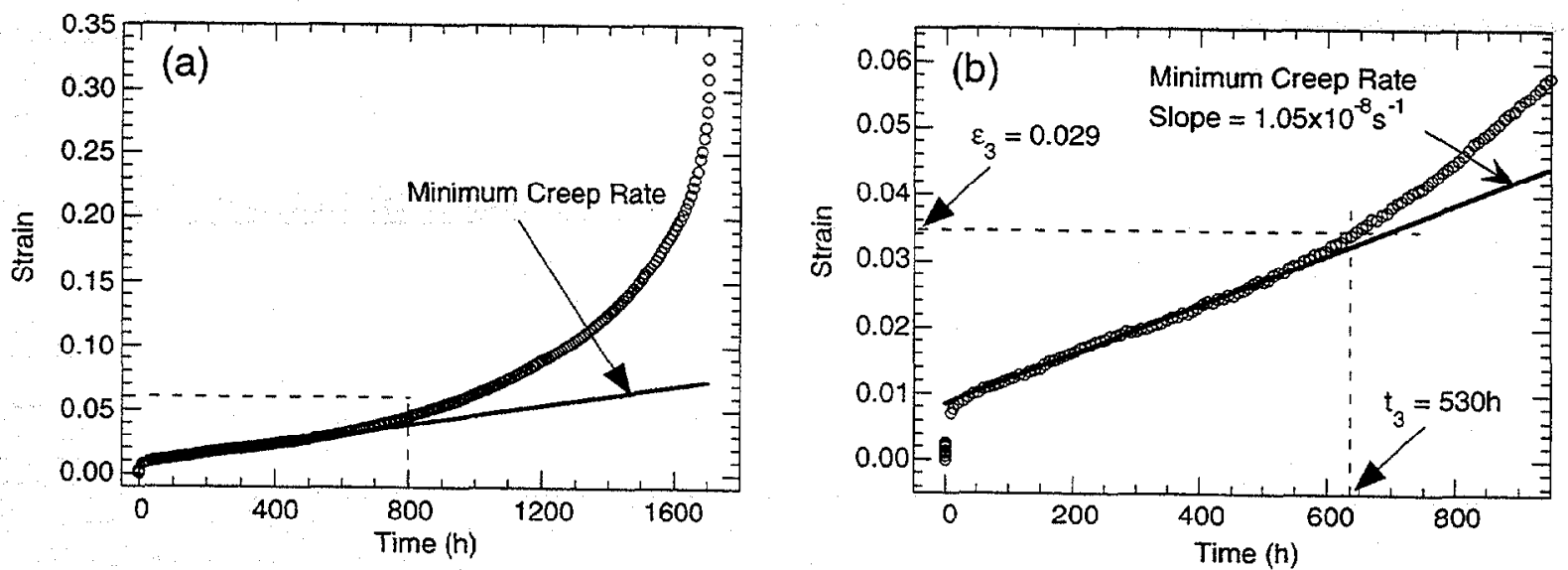

Fig. 4. (a) Typical creep strain versus time curve obtained for $\mathrm{V}-4 \mathrm{Cr}-4 \mathrm{Ti}$ alloy at $725^{\circ} \mathrm{C}$ and $180 \mathrm{MPa}$ and (b) magnified plot of portion of curve indicated by rectangular box shown in (a), along with application of linear least-squares analysis to extract minimum creep rate, onset of tertiary creep, and creep strain at onset of tertiary creep. 
Table 1. Creep test data obtained for $\mathrm{V}-4 \mathrm{Cr}-4 \mathrm{Ti}$ alloy at $650-800^{\circ} \mathrm{C}$

\begin{tabular}{|c|c|c|c|c|c|c|c|c|}
\hline $\mathrm{T}\left({ }^{\circ} \mathrm{C}\right)$ & $\begin{array}{l}\text { Applied stress } \\
\text { (MPa) }\end{array}$ & $\begin{array}{l}\text { Time to } \\
\text { rupture (h) }\end{array}$ & $\begin{array}{l}\text { Rupture } \\
\text { strain }\end{array}$ & $\begin{array}{l}\text { Minimum creep } \\
\text { rate }\left(s^{-1}\right)\end{array}$ & $\begin{array}{l}\text { Time to onset } \\
\text { of tertiary }(\mathrm{h})\end{array}$ & $\begin{array}{c}\text { Strain to onset } \\
\text { of tertiary }\end{array}$ & $\begin{array}{l}\text { Time for } 1 \% \\
\text { strain }(h)\end{array}$ & $\begin{array}{l}\text { Time for } \\
2 \% \text { strain } \\
\text { (h) }\end{array}$ \\
\hline \multirow[t]{5}{*}{650} & 370 & 300 & 0.18 & $2.2 \times 10^{-8}$ & 160 & 0.021 & 41 & 156 \\
\hline & 350 & 415 & 0.14 & $2.0 \times 10^{-8}$ & 252 & 0.023 & 76 & 212 \\
\hline & 335 & 661 & 0.15 & $9.3 \times 10^{-9}$ & 325 & 0.017 & 118 & 400 \\
\hline & 322 & 719 & 0.16 & $7.0 \times 10^{-9}$ & 440 & 0.029 & - & - \\
\hline & 280 & 2176 & 0.18 & $4.2 \times 10^{-9}$ & 1250 & 0.024 & 360 & 1025 \\
\hline \multirow[t]{3}{*}{700} & 250 & 530 & 0.27 & $1.3 \times 10^{-8}$ & 250 & 0.016 & 120 & 282 \\
\hline & 200 & 1715 & 0.28 & $6.1 \times 10^{-9}$ & 325 & 0.013 & 230 & 510 \\
\hline & $160^{\mathrm{a}}$ & - & - & - & - & - & - & - \\
\hline \multirow[t]{7}{*}{725} & 260 & 139 & 0.17 & $7.2 \times 10^{-8}$ & 75 & 0.024 & 20 & 63 \\
\hline & 230 & 280 & 0.25 & $3.3 \times 10^{-8}$ & 106 & 0.024 & 58 & 130 \\
\hline & $230^{\circ}$ & 215 & 0.23 & $2.4 \times 10^{-8}$ & 105 & 0.014 & 61 & 127 \\
\hline & 200 & 737 & 0.27 & $2.2 \times 10^{-8}$ & 265 & 0.023 & 78 & 220 \\
\hline & 180 & 1701 & 0.32 & $1.0 \times 10^{-8}$ & 530 & 0.029 & 50 & 315 \\
\hline & $180^{b}$ & 2281 & 0.43 & $1.2 \times 10^{-8}$ & 475 & 0.024 & 140 & 379 \\
\hline & 150 & 3783 & 0.38 & $6.6 \times 10^{-9}$ & 270 & 0.012 & 211 & 458 \\
\hline \multirow[t]{5}{*}{800} & 174 & 112 & 0.30 & $1.1 \times 10^{-7}$ & 45 & 0.023 & 14 & 38 \\
\hline & 150 & 215 & 0.46 & $2.3 \times 10^{-8}$ & 85 & 0.011 & 77 & 115 \\
\hline & 130 & 275 & 0.61 & $5.3 \times 10^{-8}$ & 45 & 0.013 & 37 & 59 \\
\hline & 110 & 559 & 0.46 & $2.6 \times 10^{-8}$ & 67 & 0.012 & 61 & 101 \\
\hline & 90 & 1147 & 0.55 & $1.2 \times 10^{-8}$ & 150 & 0.075 & $\mathrm{c}$ & $\mathrm{c}$ \\
\hline
\end{tabular}

In progress.

${ }^{\text {b}}$ Round cross-section specimen.

'Times for 1 and $2 \%$ strain could not be deduced because of a large scatter in strain/time data in the early part of the test.

$$
P=\left(t \text { in }{ }^{\circ} \mathrm{C}+273\right)[20+\log (t \text { in } h)] \times 0.001
$$

where $t$ is time to rupture or time to onset of tertiary creep or time for 1 or $2 \%$ strain accumulation.

The best-fit equations that relate the applied stress with the Larson-Miller parameters for different creep parameters are:

$$
\begin{aligned}
& \log \sigma(\mathrm{MPa})=0.81177+0.41488 \times \mathrm{P} 1-0.01219 \times \mathrm{P}^{2} \\
& \log \sigma(\mathrm{MPa})=0.79354+0.30003 \times \mathrm{P} 2-0.01219 \times \mathrm{P}^{2} \\
& \log \sigma(\mathrm{MPa})=8.9903-0.46601 \times \mathrm{P} 3+0.00729 \times \mathrm{P}^{2}
\end{aligned}
$$




$$
\log \sigma(M P a)=6.4342-0.2228 \times P 4-0.00168 \times P 4^{2}
$$

where $\mathrm{P} 1, \mathrm{P} 2, \mathrm{P} 3$, and $\mathrm{P} 4$ are the Larson-Miller parameters based on time (in hours) to rupture and to-onset of tertiary creep, for $1 \%$ strain and $2 \%$ strain, respectively. The values for the Larson-Miller parameters calculated from data from various tests are given in Table 2. Figure 7 shows the best-fit curves for Larson-Miller correlations, along with data from individual tests for time to rupture and timeto onset of tertiary creep, for 1 and $2 \%$ strain accumulation, respectively.

Table 2. Larson-Miller parameters calculated from creep test data developed in vacuum for $\mathrm{V}-4 \mathrm{Cr}-4 \mathrm{Ti}$ alloy at $650-800^{\circ} \mathrm{C}$ in the ANL program

\begin{tabular}{|c|c|c|c|c|c|}
\hline $\begin{array}{c}\text { Test } \\
\text { temperature } \\
\left({ }^{\circ} \mathrm{C}\right) \\
\end{array}$ & $\begin{array}{l}\text { Applied } \\
\text { stress } \\
\text { (MPa) }\end{array}$ & $\begin{array}{l}\text { P1 } \\
\text { (Time to } \\
\text { rupture) }\end{array}$ & $\begin{array}{c}\mathrm{P} 2 \\
\text { (Time to } \\
\text { tertiary) }\end{array}$ & $\begin{array}{c}\text { P3 } \\
\text { (Time for } \\
1 \% \text { strain) }\end{array}$ & $\begin{array}{c}\text { P4 } \\
\text { (Time for } \\
2 \% \text { strain) }\end{array}$ \\
\hline \multirow[t]{5}{*}{650} & 370 & 20.746 & 20.494 & 19.949 & 20.484 \\
\hline & 350 & 20.876 & 20.676 & 20.196 & 20.607 \\
\hline & 335 & 21.063 & 20.778 & 20.372 & 20.862 \\
\hline & 322 & 21.097 & 20.900 & - & - \\
\hline & 280 & 21.541 & 21.318 & 20.819 & 21.239 \\
\hline \multirow[t]{2}{*}{700} & 250 & 22.111 & 21.793 & 21.483 & 21.844 \\
\hline & 200 & 22.607 & 21.904 & 21.758 & 22.094 \\
\hline \multirow[t]{7}{*}{725} & 260 & 22.099 & 21.831 & 21.258 & 21.756 \\
\hline & 230 & 22.402 & 21.981 & 21.720 & 22.070 \\
\hline & $230^{\mathrm{b}}$ & 22.288 & 21.977 & 21.742 & 22.060 \\
\hline & 200 & 22.822 & 22.378 & 21.848 & 22.298 \\
\hline & 180 & 23.184 & 22.679 & 21.656 & 22.453 \\
\hline & $180^{b}$ & 23.311 & 22.631 & 22.102 & 22.533 \\
\hline & 150 & 23.531 & 22.387 & 22.280 & 22.616 \\
\hline \multirow[t]{5}{*}{800} & 174 & 23.659 & 23.234 & 22.690 & 23.155 \\
\hline & 150 & 23.963 & 23.530 & 23.484 & 23.671 \\
\hline & 130 & 24.077 & 23.234 & 23.143 & 23.360 \\
\hline & 110 & 24.408 & 23.419 & 23.376 & 23.611 \\
\hline & 90 & 24.743 & 23.795 & 22.690 & - \\
\hline
\end{tabular}



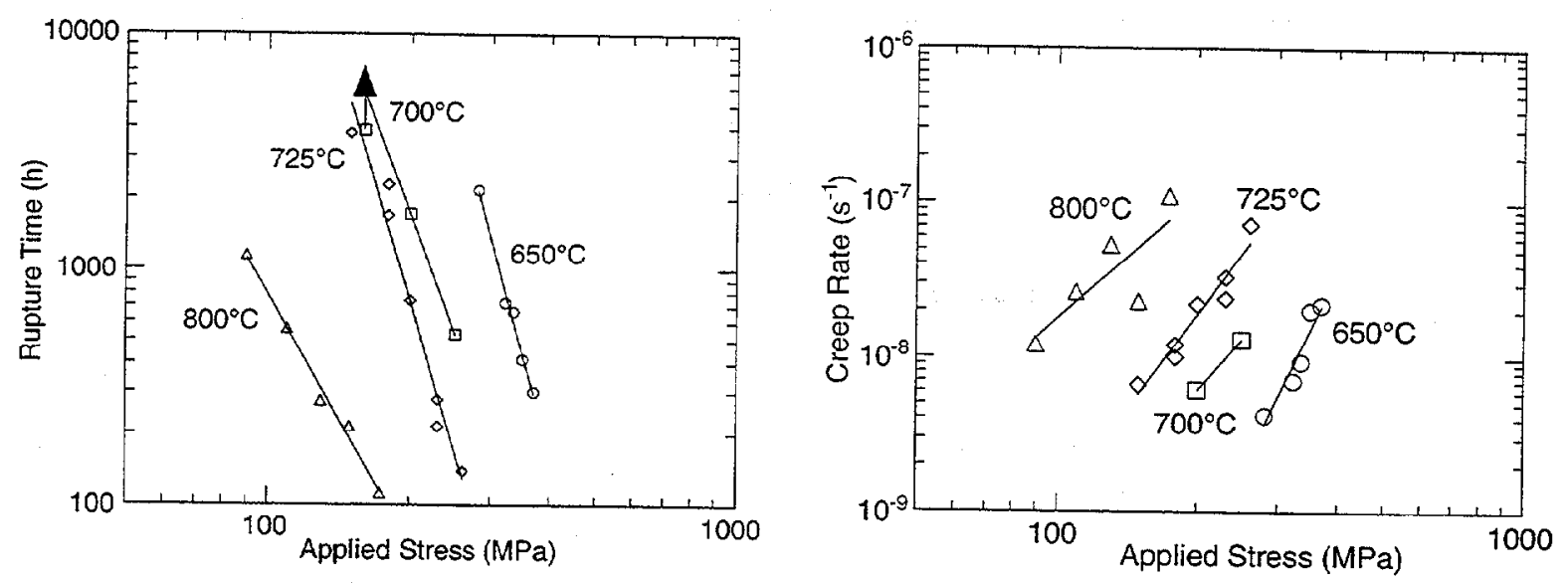

Fig. 5. Variation in (a) rupture life and (b) minimum creep rate as a function of applied stress for $\mathrm{V}-4 \mathrm{Cr}-4 \mathrm{Ti}$ alloy tested in vacuum at $650-800^{\circ} \mathrm{C}$.
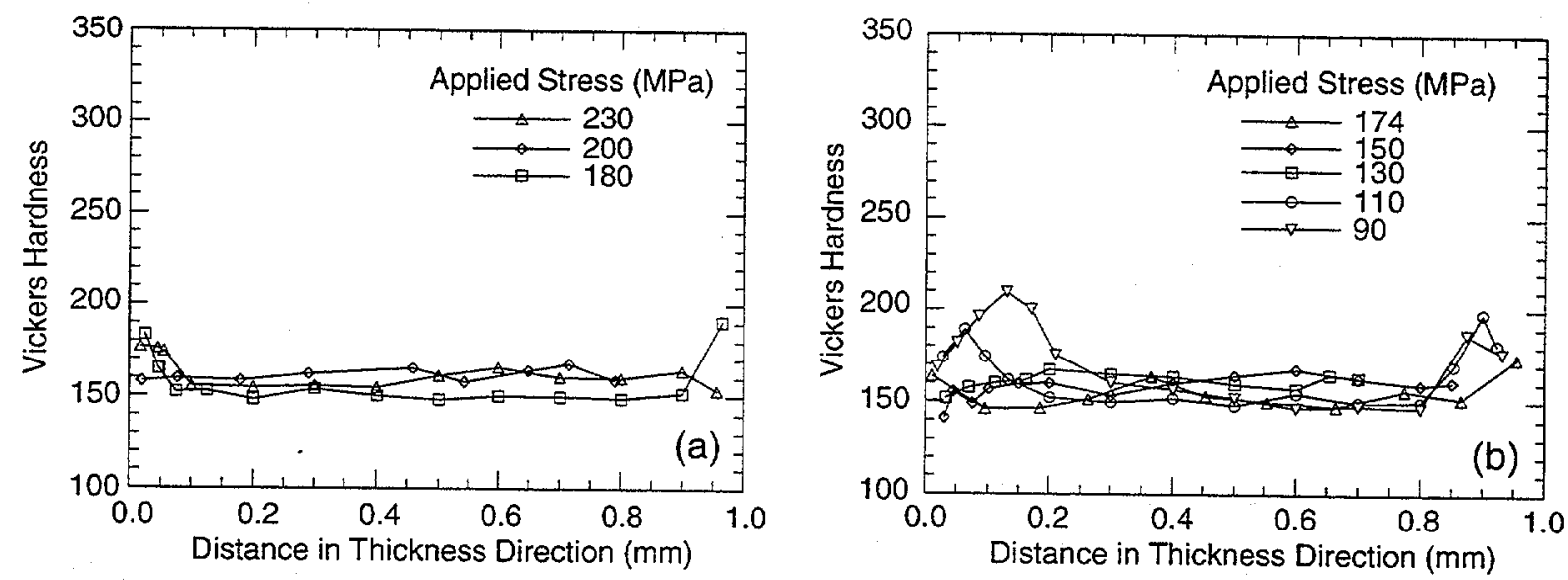

Fig. 6. Vickers hardness profiles across specimen gauge section obtained for several $\mathrm{V}-4 \mathrm{Cr}-4 \mathrm{Ti}$ specimens after creep testing at (a) 725 and (b) $800^{\circ} \mathrm{C}$ in vacuum environment.

\section{REFERENCES}

1. K. Natesan, W. K. Soppet, and D. L. Rink, Uniaxial Creep Behavior of V-Cr-Ti Alloys, Semiannual Progress Report for Period Ending June 30, 1999, DOE/ER-0313/26, Sept. 1999, p. 20.

2. K. Natesan, W. K. Soppet, and D. L. Rink, Uniaxial Creep Behavior of V-Cr-Ti Alloys, Semiannual Progress Report for Period Ending December 31, 1999, DOE/ER-0313/27, March 2000, p. 17.

3. R. J. Kurtz and M. L. Hamilton, Biaxial Thermal Creep of V-4Cr-4Ti at 700 and $800^{\circ} \mathrm{C}$, ibid, p. 3 . 


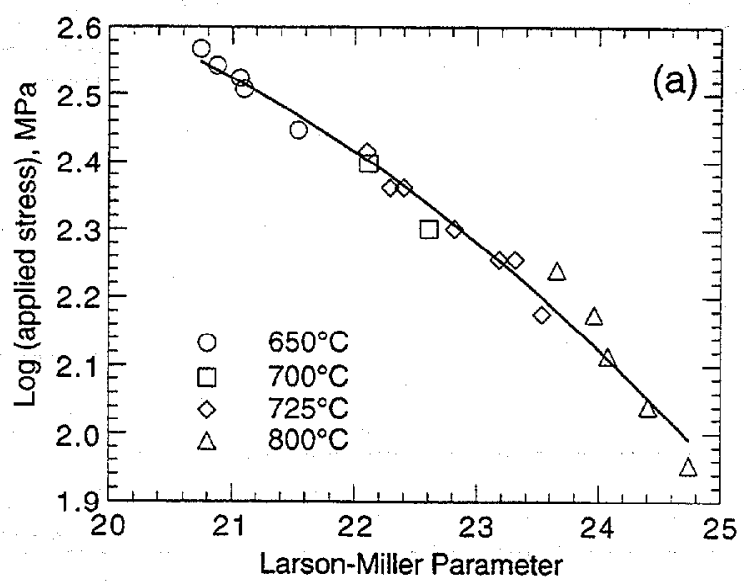

$\left(\mathrm{T}\right.$ in $\left.{ }^{\circ} \mathrm{C}+273\right) \times\left[20+\log \left(t_{\mathrm{r}}\right.\right.$ in $\left.\left.\mathrm{h}\right)\right] \times 0.001$

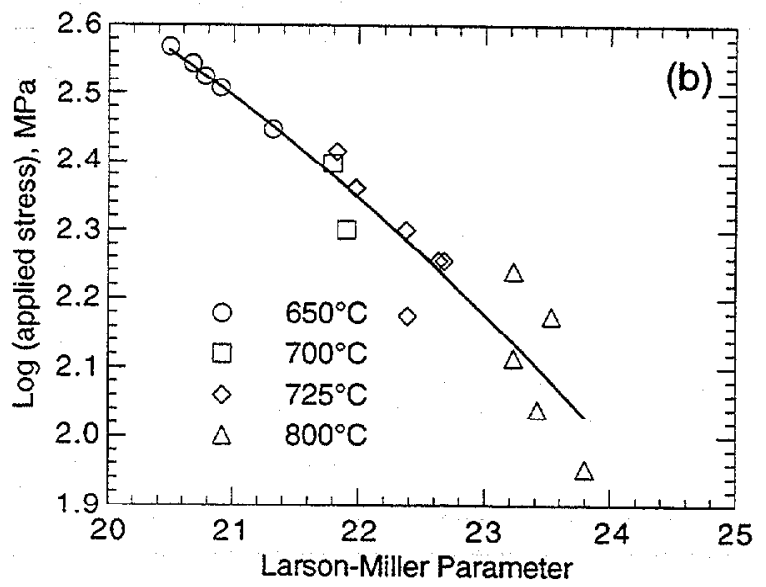

( $T$ in $\left.{ }^{\circ} \mathrm{C}+273\right) \times\left[20+\log \left(t_{3}\right.\right.$ in $\left.\left.h\right)\right] \times 0.001$

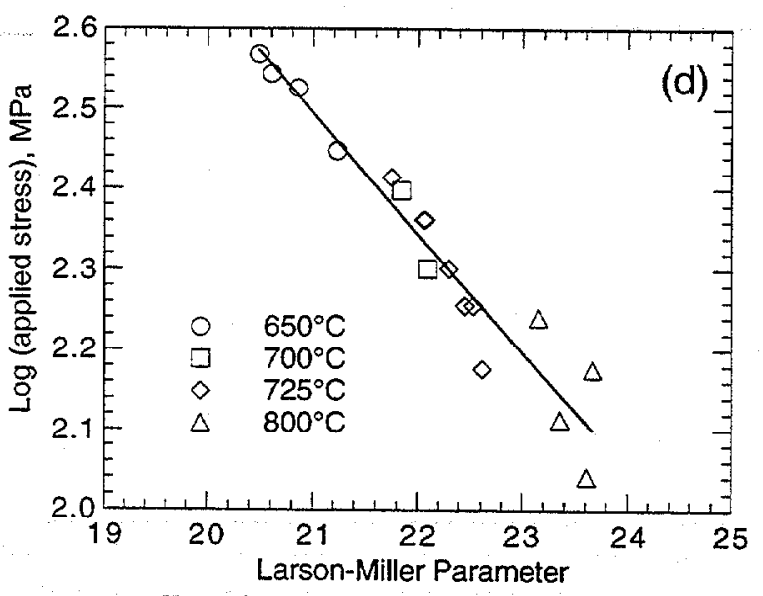

( $\mathrm{T}$ in $\left.{ }^{\circ} \mathrm{C}+273\right) \times\left[20+\log \left(\mathrm{t}_{2 \%}\right.\right.$ in $\left.\left.\mathrm{h}\right)\right] \times 0.001$

Fig. 7. Larson-Miller plots for (a) time to rupture, (b) time-to-onset of tertiary creep, (c) time for $1 \%$ strain accumulation, and (d) time for $2 \%$ strain accumulation for $\mathrm{V}-4 \mathrm{Cr}-4 \mathrm{Ti}$ alloy creep tested in vacuum at $650-800^{\circ} \mathrm{C}$. 
EVALUATION OF THERMAL CREEP OF V-4Cr-4Ti IN A LITHIUM ENVIRONMENT M. L. Grossbeck (Oak Ridge National Laboratory)

\section{OBJECTIVE}

The goal of this research is to evaluate the creep behavior of $\mathrm{V}-4 \mathrm{Cr}-4 \mathrm{Ti}$ under conditions where oxygen is not increased during the test. This will allow thermal creep to be separated from irradiation and helium effects in DHCE experiments and will aid in interpretation of the vacuum thermal creep experiments now being performed.

\section{SUMMARY}

Thermal creep in vanadium alloys can be measured by pressurized tubes. The tubes are pressurized with helium at a series of pressures to give the desired stresses in the tube wall. The diameter of the tubes is very precisely measured before and after high temperature exposure to determine creep deformation. A pair of high temperature furnaces and retorts have been fitted into an inert gas glove box system. Liquid lithium will be contained in the retorts which will contain the pressurized tubes of the vanadium alloy to be tested. The refractory metal retorts have been equipped with pressure sensors to determine to time of tube failure. This system will be used to determine time of failure and strain to failure as a function of stress.

\section{INTRODUCTION}

In order to design a fusion device using a vanadium alloy, thermal and irradiation creep must be known for the conditions of application. Experiments have been done using helium pressurized tubes under neutron irradiation, and deformation has been determined for low exposure levels. One experiment was carried out in the HFIR in a shielded experiment to reduce transmutation of vanadium to chromium to acceptable levels. ${ }^{1}$ Another experiment was carried out in EBR-II in a dynamic helium charging experiment (DHCE). ${ }^{2}$ In this experiment, helium was introduced through the production and decay of tritium. This was a preliminary experiment, and the desired levels of helium were not achieved, but future such experiments are expected to simulate fusion parameters.

The difficulty in complex experiments is sorting out the effects of each component of the environment. The effect of temperature alone, of helium, and of atomic displacements must be separated in order to interpret the results to the extent of permitting extrapolation to reallife exposure levels. Helium by itself has been shown to decrease ductility in vanadium alloys. An example of this behavior is shown in Fig. 1 where V-20Ti was cyclotron injected with helium to levels of 90 and 200 at. ppm. ${ }^{3}$ Helium embrittlement is evident at test temperatures above about $600^{\circ} \mathrm{C}$. The effect of helium as a function of temperature and concentration must be understood in order to predict behavior in the presence of high energy fusion neutrons. Fluence and temperature dependence of helium embrittlement is very different from irradiation embrittlement which is predominant at lower temperatures in refractory metals as shown in Fig. 2 for $\mathrm{V}-4 \mathrm{Cr}-4 \mathrm{Ti}^{4}{ }^{4}$

As a first step to understand deformation in vanadium alloys, thermal creep tests have been conducted with $\mathrm{V}-4 \mathrm{Cr}-4 \mathrm{Ti}$ in an ultra-high vacuum environment with early results shown in Fig. $3 .^{5}$ For refractory metals such as vanadium, even the highest vacuua attainable will not prevent oxygen from diffusing into vanadium. The result is that the alloy is continuously hardened during the test. The increase in oxygen was in fact documented for a specimen exposed to the vacuum environment at $800^{\circ} \mathrm{C}$ for 2812 hours. $^{5}$ 


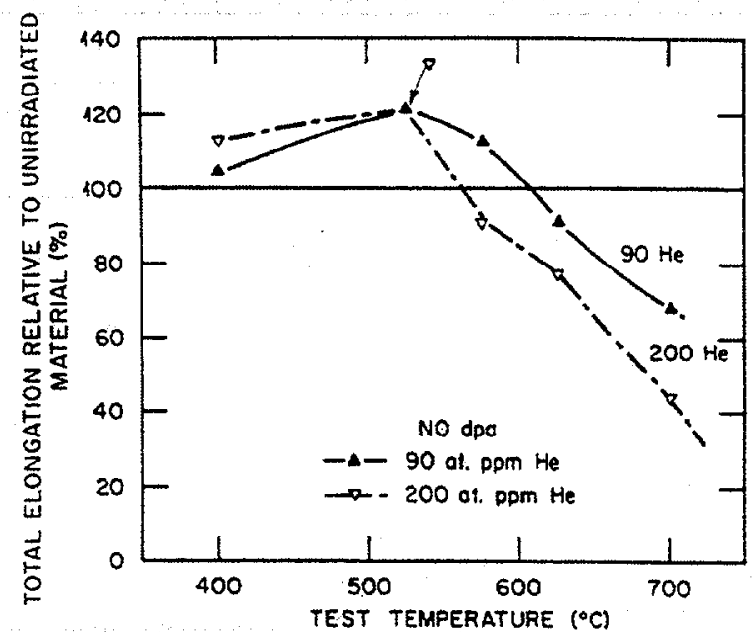

Fig. 1. Relative tensile elongation of $\mathrm{V}-20 \mathrm{Ti}$ following cyclotron implantation of helium.

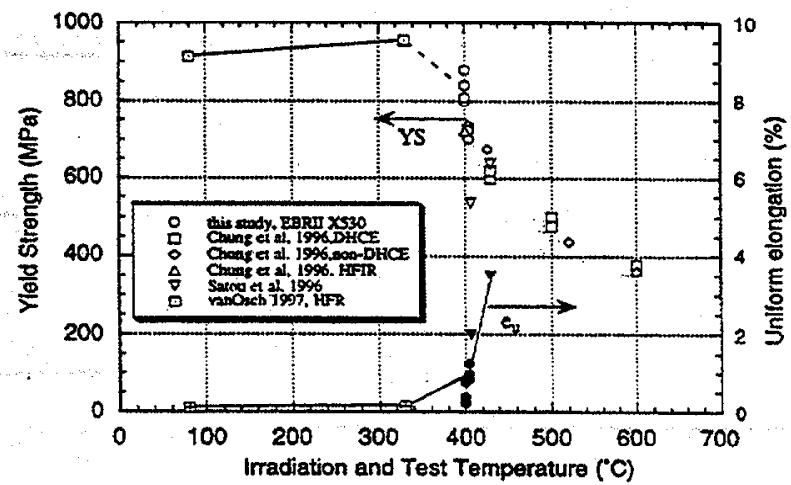

Fig. 2. Yield strength and uniform elongation of $\mathrm{V}-(4-5) \mathrm{Cr}-4-5) \mathrm{Ti}$ alloys irradiated and tested at temperatures in the range of $80-600^{\circ} \mathrm{C}$. Displacement levels are in the range of 4-6 dpa.

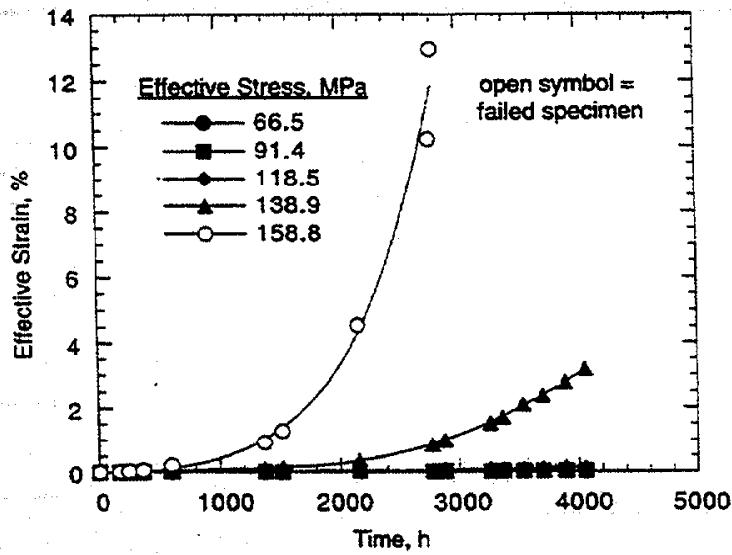

Fig. 3. Thermal creep strain from pressurized tubes of $\mathrm{V}-4 \mathrm{Cr}-4 \mathrm{Ti}$ exposed to a vacuum environment at $700^{\circ} \mathrm{C}$. 
The present experiment is designed to make similar measurements, at the same temperatures, in a liquid lithium environment. In this environment, the oxygen level is expected to slowly decrease. This effect has been demonstrated rather dramatically for the case of $\mathrm{Nb}-1 \mathrm{Zr}$ which was irradiated in EBR-II for a period of about 2 years in lithium at about $1200^{\circ} \mathrm{C} .{ }^{6}$ Results are shown in Fig. 4 where strength clearly decreased during the irradiation. Ductility correspondingly increased as can be seen in Fig. 5 . Since the fusion environment will expose vanadium alloys to liquid lithium, used as a coolant, this is the relevant environment. Comparison of the Li environment tests with the vacuum tests will determine the effect of oxygen. It will also support future tests where helium is introduced in the absence of irradiation.

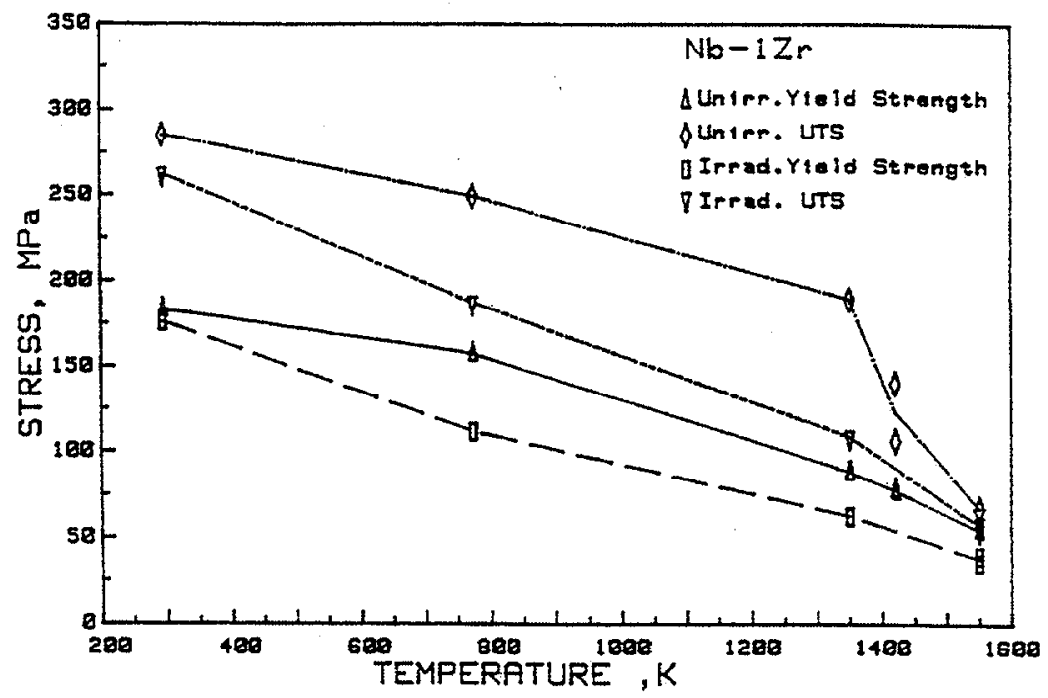

Fig. 4. Yield and ultimate tensile strength of $\mathrm{Nb}-1 \mathrm{Zr}$ irradiated at $1200-1340^{\circ} \mathrm{C}$ to a fluence of $1.9 \times 10^{26} \mathrm{n} / \mathrm{cm}^{2}(\mathrm{E}>0.1 \mathrm{MeV})$.

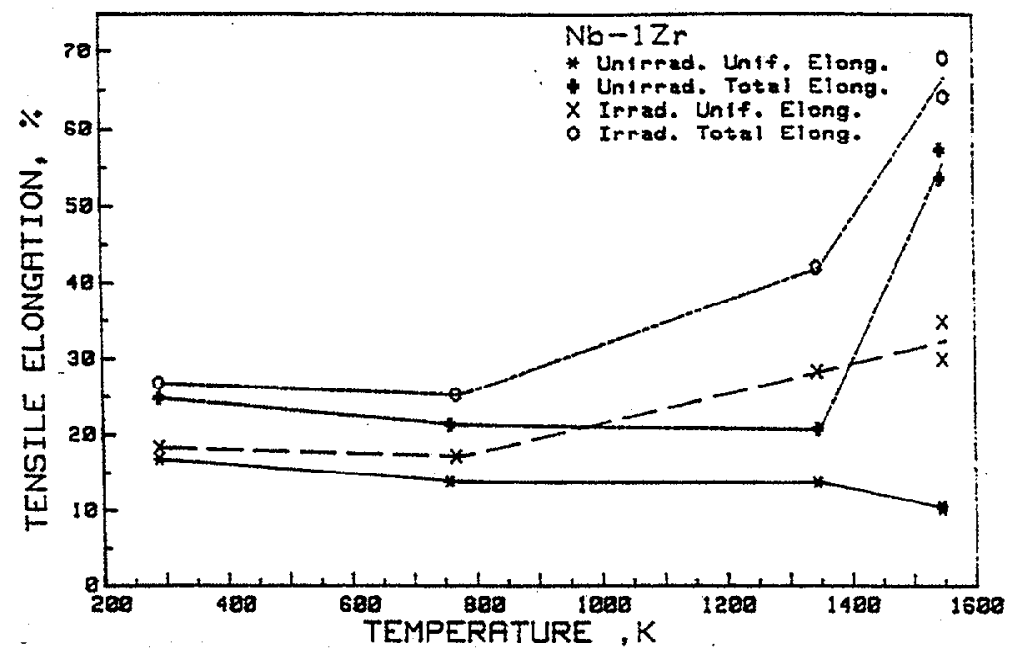

Fig. 5. Uniform and total tensile elongation of $\mathrm{Nb}-1 \mathrm{Zr}$ irradiated at $1200-1340^{\circ} \mathrm{C}$ to a fluence of $1.9 \times 10^{26} \mathrm{n} / \mathrm{cm}^{2}$ ( $\left.\mathrm{E}>0.1 \mathrm{MeV}\right)$. 


\section{EXPERIMENTAL METHODS AND PROGRESS}

The Li creep program will employ the methods used for study of irradiation creep, pressurized tubes. Specimen preparation and measurement are done in the same manner using helium as a fill gas and making a series of 500 diameter measurements in a helical pattern on the central $12.7 \mathrm{~mm}$ of the $25.4 \mathrm{~mm}$ long tube.

The pressurized tubes will be exposed to liquid lithium contained in a retort of molybdenum. The retort is sealed with a vanadium gasket. Figure 6 shows the first prototype of the retort. The lithium is contained entirely in a refractory metal vessel. As a prototype for the next phase of the project, exposure to tritium to form helium, a tritium barrier of quartz is in place around the molybdenum retort. At a temperature of $800^{\circ} \mathrm{C}, 4 \times 10^{5} \mathrm{Ci} / \mathrm{yr}$ are expected to diffuse through the Mo tube. The quartz barrier, which has a tritium permeation rate several orders of magnitude lower, is necessary to prevent tritium escape. A gage is connected to indicate when the partial vacuum in the quartz tube has been spoiled by diffusion of tritium through the molybdenum. A KF flange is used to seal the retort so that it can be easily removed. The retort is put in place in a vertical tube furnace.

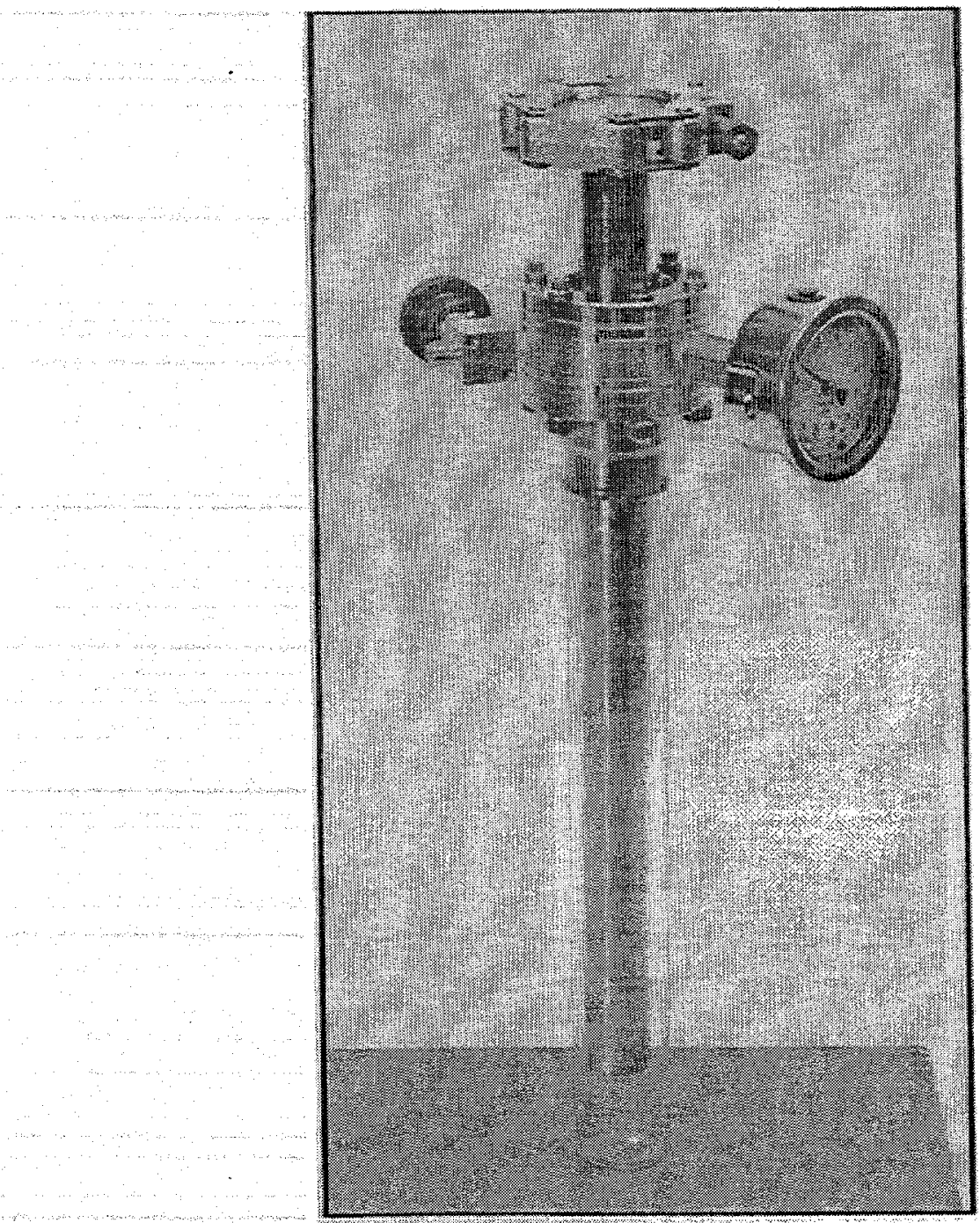

Fig. 6. Retort for liquid Li containment. A later modification had a pressure sensor added. 
Two units are shown in Fig. 7 which shows a newer design in which a pressure sensor has been added to the retort. A small molybdenum tube extends above the retort and connects to a stainless steel elbow connecting to a digital pressure sensor. It was not desired to have stainless steel in the retort, but a refractory metal pressure sensor was not available for the required pressure range. The stainless steel is in a region that is well below $100^{\circ} \mathrm{C}$ so that $\mathrm{Li}$ is expected to condense and solidify well before reaching the stainless steel. The $90 \%$ bend was introduced to avoid a direct path for high temperature black body radiation to impinge on the pressure diaphragm. The pressure sensors are incorporated to indicate failure of a pressurized tube. The pressure is recorded at short intervals on a magnetic medium so that the time of tube failure can be determined.

The furnaces and retort can operate in air. However, for ease of removing specimens for measurement and for safety reasons, the furnaces are operated in a glove box with an argon atmosphere. The glove box, pictured in Fig. 8 has purification systems for oxygen, water, and nitrogen with the capability of reaching levels of each below $1 \mathrm{ppm}$. At the present time, only oxygen and moisture are monitored, by electrochemical sensors. Moisture is below 1 $\mathrm{ppm}$, and oxygen is at $1 \mathrm{ppm}$. Further evaluation of the atmosphere is being made at the present time.

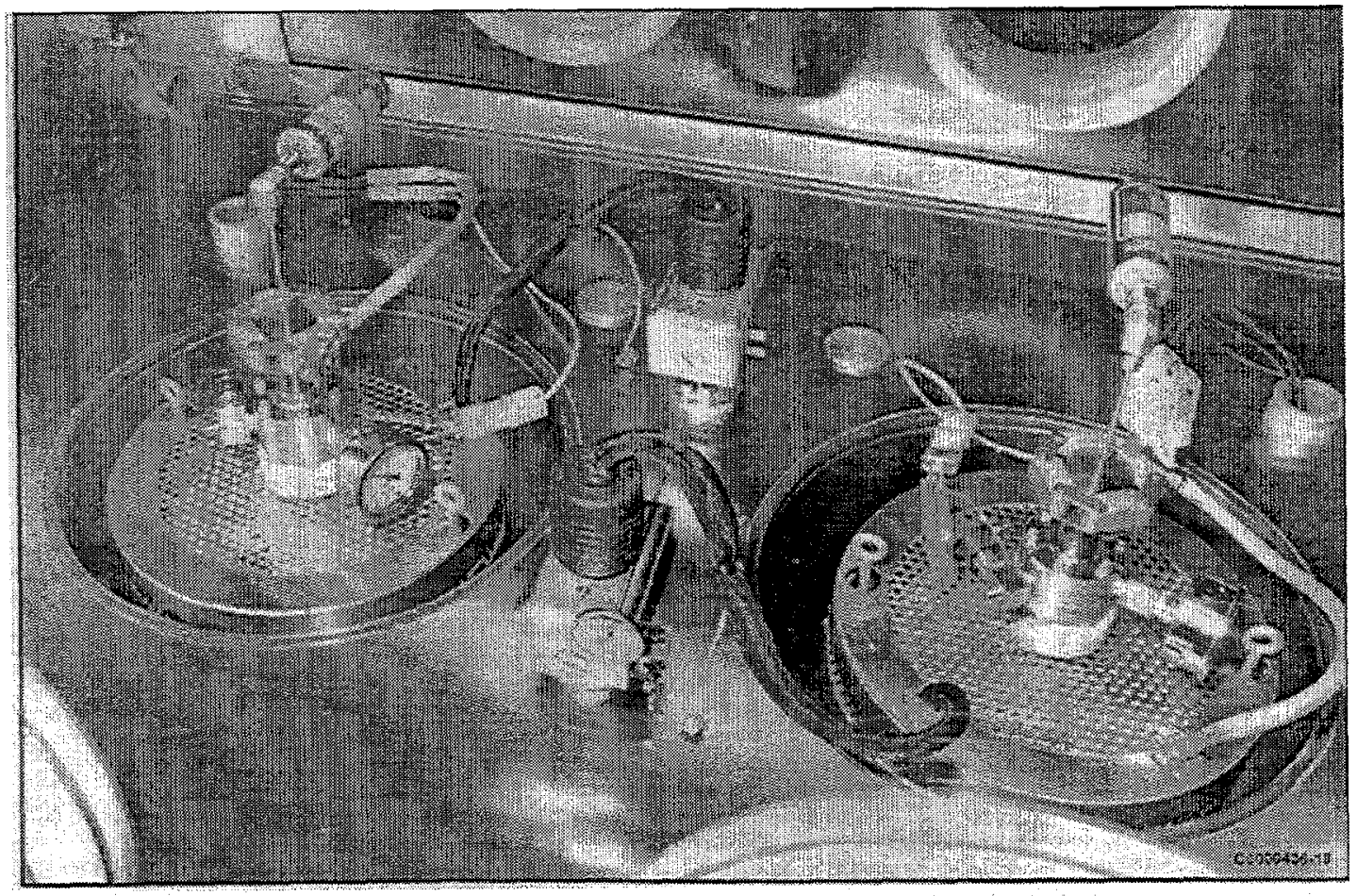

Fig. 7. Two retorts in place in furnaces positioned in an inert gas glove box. Pressure sensors appear above the retort flanges. 


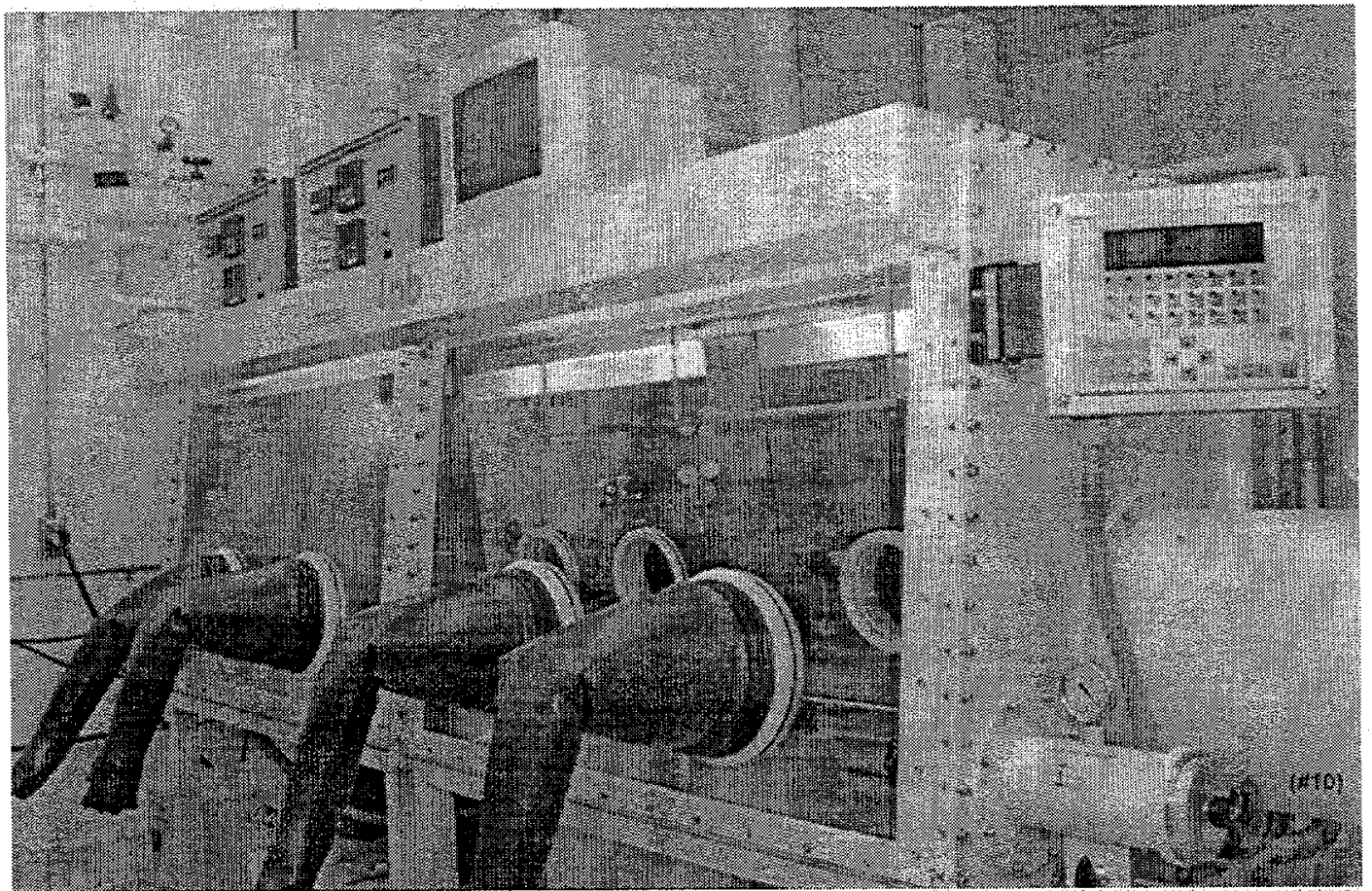

Fig. 8. Inert glove box with water cooled wells for furnaces in the left half. The right half of the glove box is for handling the tubes when removed from the liquid $\mathrm{Li}$.

The glove box permits the specimens to be removed while the $\mathrm{Li}$ is liquid. It is planned to reduce the temperature of the $\mathrm{Li}$ to about $200^{\circ} \mathrm{C}$, just above the melting point, and remove the KF flange seal. The specimen rack can then be lifted out of the retort. It is expected that the residual Li will be removed by dipping in hot silicone oil. With this method, the Li can be removed inside the glove box.

The stress levels have been selected based on the results of the vacuum thermal creep tests. Most of the tubes have been pressurized to fail in several hundred hours, a few for a longer duration. This will allow early data to become available which will further guide the following tests. The stresses and fill pressures are shown in Table 1. 
Table 1. Stresses and fill pressures for the first phase of pressurized tube samples

\begin{tabular}{|c|c|c|}
\hline Hoop Stress & Fill Pressure & Predicted Life \\
\hline (MPa) & (psig) & (Hours) \\
\hline $700^{\circ} \mathrm{C}$ & & \\
\hline 185 & 884 & $<2000$ \\
\hline 160 & 772 & 2500 \\
\hline 140 & 660 & 3500 \\
\hline 115 & 549 & $>5000$ \\
\hline 105 & 493 & \\
\hline 80 & 381 & \\
\hline & & \\
\hline $800^{\circ} \mathrm{C}$ & & \\
\hline 115 & 497 & 600 \\
\hline 105 & 447 & 900 \\
\hline 80 & 345 & 4000 \\
\hline 80 & 345 & 4000 \\
\hline 60 & 244 & $>4000$ \\
\hline 35 & 142 & \\
\hline
\end{tabular}

\section{FUTURE DIRECTIONS}

The tests are planned to begin in the next reporting period. To complete the understanding of deformation behavior, the $\mathrm{Li}$ and vacuum tests must be conducted. Irradiation tests to determine the effect of atomic displacements have been conducted and continue to explore higher fluences and an appropriate range of temperatures. The effect of helium generated during the test by tritium decay is now being planned. This series of tests in intended to be done in conjunction with a DHCE experiment designed to reach fusion He/dpa ratios. The resulting set of data should permit understanding vanadium deformation in a fusion environment.

\section{CONCLUSIONS}

1. In order to understand the mechanisms of deformation under irradiation in the fusion environment, the fusion effects must be separated.

2. The present experiment is designed to evaluate thermal creep without the interference of oxygen. This is essential to evaluating the true thermal creep and to evaluating creep in a lithium cooled fusion blanket.

3. Temperature and stresses have been selected based on data from the vacuum creep effort. The two phases of the project will continue to be coordinated and conducted interactively.

4. A Li environment creep system has been designed and built and is in the final testing phase prior to introduction of lithium. 


\section{REFERENCES}

1. H. Tsai, R.V. Strain, M.C. Billone, T.S. Bray, D.L. Smith, M.L. Grossbeck, K. Fukumoto, and H. Matsui, "Study of Irradiation Creep of Vanadium Alloys," Fusion Materials Semiannual Progress Report for Period Ending December 31, 1999, DOE/ER-0313/27 (2000) pg. 65.

2. H. M. Chung, B.A. Loomis, and D.L. Smith, "Prpoerties of Vanadium-base Alloys Irradiated in the Dynamic Helium Charging Experiment," J. Nucl. Mater. 233-237 (1996) 446.

3. M. P. Tanaka, E. E. Bloom, and J. A. Horak, "Tensile Properties and Microstructure of Helium Injected and Reactor Irradiated V-20Ti," J. Nucl. Mater. 103 \& 104 (1981) 895.

4. S. J. Zinkle et al. "Effect of Fast Neutron Irradiaiton to $4 \mathrm{dpa}$ at $400^{\circ} \mathrm{C}$ on the Properties of $\mathrm{V}$-(4-5) Cr-(4-5)Ti Alloys," Fusion Materials Semiannual Progress Report for Period Ending December 31, 1996, EOE/ER-0313/21 (1997) 73.

5. R. J. Kurtz and M. L. Hamilton, "Biaxial Thermal Creep of V-4Cr-4Ti at $700^{\circ} \mathrm{C}$ and $800^{\circ} \mathrm{C}$," Fusion Materials Semiannual Progress Report for Period Ending June 30, 1999, DOE/ER0313/26 (1999) 3.

6. M. L. Grossbeck, R. L. Heestand, and S. D. Atkin, "Effect of Irradiation on the Tensile Properties of Niobium-Base Alloys," $4^{\text {th }}$ Symposium on Space Nuclear Power Systems (1997) 151. 


\section{DEFORMATION BEHAVIOR OF UNALLOYED VANADIUM - D.T. Hoelzer and A. F. Rowcliffe}

\section{OBJECTIVE}

The broad objective of this work is to investigte the influence of the interstitial elements on the deformation behavior of BCC alloys.

\section{SUMMARY}

The tensile deformation behavior of unalloyed vanadium has been determined at $200^{\circ} \mathrm{C}$ and $300^{\circ} \mathrm{C}$ for strain rates in the range $10^{-1} / \mathrm{s}$ to $10^{-5} / \mathrm{s}$. The occurrence of serrated flow effects in the Lüders extension and work hardening regimes of tensile stress-strain curves is associated with negative strain rate sensitivity of stress parameters.

\section{PROGRESS AND STATUS}

\section{Introduction}

The work described here is from a study of the deformation behavior of vanadium and is a continuation of an investigation of the strain rate sensitivity of $\mathrm{V}-4 \mathrm{Cr}-4 \mathrm{Ti}$ (No. 832665). In previous studies [1-3], the deformation behavior of the $\mathrm{V}-4 \mathrm{Cr}-4 \mathrm{Ti}$ alloy was shown to exhibit dynamic strain aging (DSA) during tensile testing, typically at temperatures ranging from $300^{\circ} \mathrm{C}$ to $750^{\circ} \mathrm{C}$ and strain rates ranging from $10^{-1} / \mathrm{s}$ to $10^{-5} / \mathrm{s}$. Dynamic strain aging has been observed by the appearance of serrated yielding (continuous) and jerky flow (discontinuous) in the Lüders strain and work hardening regimes of stress strain curves and a concomitant negative value in strain rate sensitivity (SRS) for flow stresses. The shape, spacing, and magnitude of the serrations and jerky flow depended on temperature, strain, and strain rate.

Dynamic strain aging is associated with the migration of interstitial and substitutional solute atoms to dislocations during deformation [4,5]. Interstitial atoms have a dominant effect on DSA at low temperatures due to their higher diffusion coefficients compared to substitutional atoms. In the $V$ $4 \mathrm{Cr}-4 \mathrm{Ti}$ alloy, DSA was attributed to interstitial $\mathrm{O}, \mathrm{C}$, and $\mathrm{N}$ at temperatures below $\sim 500^{\circ} \mathrm{C}$ since $\mathrm{Ti}$ and $\mathrm{Cr}$ solute atoms are generally immobile below this temperature. Although interstitial atoms can be removed from solid solution by forming Ti-OCN precipitates a sizable fraction remain in solution since DSA was observed in the alloy at $300^{\circ} \mathrm{C}$. In order to investigate the interaction between $\mathrm{Ti}$ solute atoms and interstitial atoms, an investigation was conducted on the unalloyed vanadium used in the production of the $500 \mathrm{~kg}$ heat of $\mathrm{V}-4 \mathrm{Cr}-4 \mathrm{Ti}$. The reason for using this vanadium was to ensure a similar interstitial content with $\mathrm{V}-4 \mathrm{Cr}-4 \mathrm{Ti}$ but without the $\mathrm{Ti}$ and $\mathrm{Cr}$ alloying atoms. The purpose of this study is to investigate the temperature range of DSA in vanadium in order to develop a better understanding of the Ti-OCN precipitation process and the interaction between $\mathrm{Ti}$ and interstitial atoms.

\section{Experimental Procedure}

Sheet tensile specimens of the type SS-3 (nominal gage dimensions $0.76 \times 1.52 \times 7.6 \mathrm{~mm}$ ) were prepared from unalloyed vanadium (Teledyne Wah-Chang heat no. 832665). A 0.25 in thick plate was cut from the vanadium ingot, hot rolled at $-1050^{\circ} \mathrm{C}$ to a thickness of $0.10 \mathrm{in}(60 \%$ reduction) and then cold rolled to $0.06 \mathrm{in}$ (40\% reduction). Specimens were electro-discharge machined from the 0.06 in thick plate and annealed at $1000^{\circ} \mathrm{C}$ for 1 hour in a vacuum of $<-3 \times 10^{-7}$ torr followed by furnace cooling. This procedure resulted in a uniform microstructure consisting of recrystallized grains with an average grain size of $89 \pm 5 \mu \mathrm{m}$, which is shown in Figure 1 . Tensile testing was carried out under a vacuum of $\sim 2 \times 10^{-7}$ torr using a screw-driven machine. Specimens 


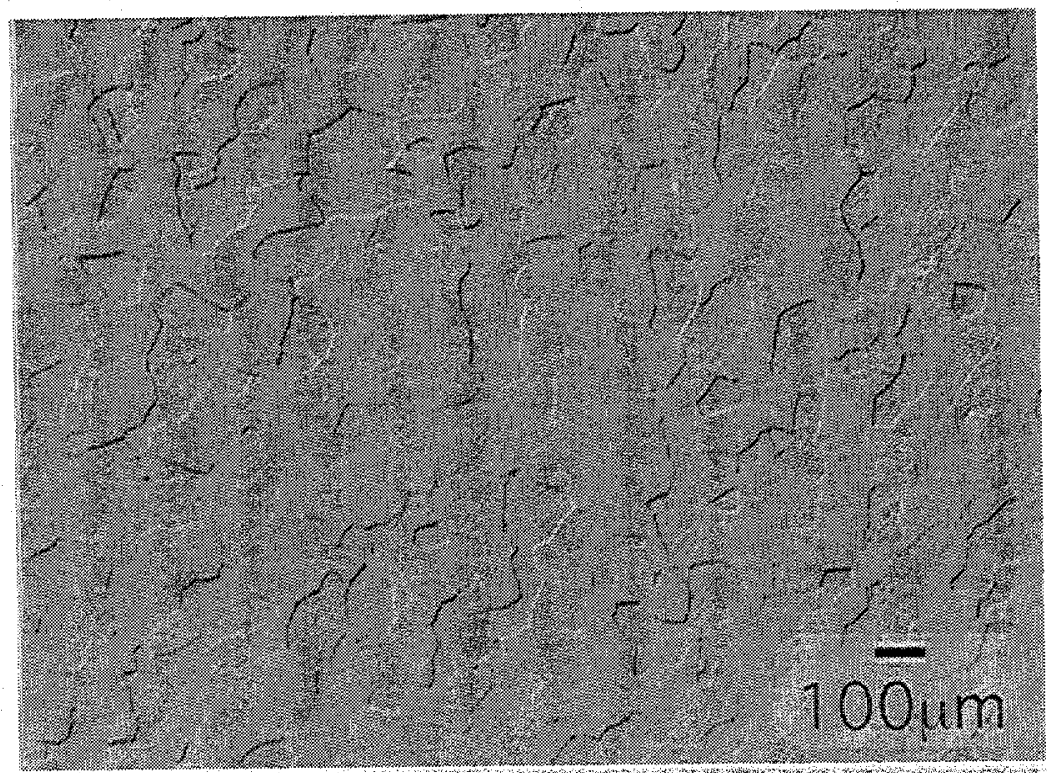

Figure 1. Light micrograph of vanadium annealed at $1000^{\circ} \mathrm{C}$.

were held at the test temperature for 20-30 minutes before starting the test. Data were acquired digitally at rates of 20 points per second (pts) for tests conducted at $10^{-1} / \mathrm{s}$ and $10^{-3} / \mathrm{s}$ strain rates and $0.2 p$ ts at $10^{-5} / \mathrm{s}$ strain rate.

\section{Results}

Data obtained from testing the specimens at $200^{\circ} \mathrm{C}$ and $300^{\circ} \mathrm{C}$ with strain rates of $10^{-1}, 10^{-3}$, and $10^{-5}$ are summarized in Table 1. The engineering stress-strain curves for $200^{\circ} \mathrm{C}$ and $300^{\circ} \mathrm{C}$ are shown in Figures 2 and 3 , respectively. The curves have been offset along the normalized crosshead displacement axis for comparison of the elastic and Lüders extension regimes. The results show Lüders extensions typically ranging from 0.4 to $1.4 \%$ following an initial yield stress, $\sigma_{i}$ in all of the specimens. A small permanent strain of the order of 0.1 to $0.2 \%$ usually occurred after $\sigma_{i}$. Serrations associated with the Luders extension are propagated by an average stress

Table 1. Temperature and Strain Rate Dependence of Unalloyed Vanadium Tensile Properties.

\begin{tabular}{|c|c|c|c|c|c|c|c|c|c|}
\hline Specimen & $\begin{array}{c}\text { Test } \\
\text { Temp. }\end{array}$ & $\begin{array}{l}\text { Strain } \\
\text { Rate }\end{array}$ & $\begin{array}{c}\text { Initial } \\
\text { Yield } \\
\text { Stress } \\
\sigma_{i}\end{array}$ & $\begin{array}{c}\text { Lower } \\
\text { Yield } \\
\text { Stress } \\
\sigma_{y}\end{array}$ & $\begin{array}{c}\text { Ultimate } \\
\text { Tensile } \\
\text { Strength } \\
\sigma_{u}\end{array}$ & $\begin{array}{c}\text { Stress } \\
\text { for } 8 \% \\
\text { Strain } \\
\sigma_{s}\end{array}$ & $\begin{array}{c}\text { Luders } \\
\text { Strain } \\
\varepsilon_{\mathrm{b}}\end{array}$ & $\begin{array}{c}\text { Uniform } \\
\text { Strain } \\
\varepsilon_{u}\end{array}$ & $\begin{array}{c}\text { Total } \\
\text { Strain } \\
\varepsilon_{1}\end{array}$ \\
\hline ID & ${ }^{\circ} \mathrm{C}$ & $\mathrm{s}^{-3}$ & \multicolumn{4}{|c|}{$\mathrm{MPa}$} & \multicolumn{3}{|c|}{$\%$} \\
\hline PV46 & 200 & $10^{-1}$ & 93 & 124 & 193 & 172 & 1.4 & 29.0 & 42.8 \\
\hline PV44 & 200 & $10^{-3}$ & 105 & 105 & 188 & 161 & 0.8 & 24.1 & 36.2 \\
\hline PV45 & 200 & $10^{-5}$ & 88 & 100 & 194 & 187 & 0.8 & 11.1 & 17.6 \\
\hline PV41 & 300 & $10^{-1}$ & 90 & 116 & 183 & 174 & 0.4 & 14.2 & 20.6 \\
\hline PV42 & 300 & $10^{-3}$ & 105 & 115 & 240 & 213 & 0.8 & 15.2 & 21.1 \\
\hline PV43 & 300 & $10^{-5}$ & 118 & 118 & 297 & 238 & 1.4 & 19.4 & 27.8 \\
\hline
\end{tabular}


which is defined as the lower yield stress, $\sigma_{y}$. Upon completion of the Lüders extension, the deformation proceeds with initially an increase in the work hardening rate on the stress-strain curve that eventually decreases until the ultimate stress, $\sigma_{y}$, is achieved. Tests performed at high temperatures and/or low strain rates exhibited both continuous (serrated yielding) and discontinuous (jerky flow) behavior in the plastic flow regimes of stress strain curves. These types of deformation are related to the phenomenon of dynamic strain aging (DSA). The results indicated that both the shape and magnitude of the serrations changed with temperature, strain, and strain rate. For tests carried out at a rate of $10^{-1} / \mathrm{s}$, the data acquisition system was not sufficiently rapid to detect load drops associated with the serrations. Therefore, determination of jerky flow could not be ascertained at this strain rate.

The testing temperature had an effect on the dependency of elongation with strain rate. At $200^{\circ} \mathrm{C}$, the largest elongations (uniform and total) occurred at a rate of $10^{-1} / \mathrm{s}$ and the smallest at

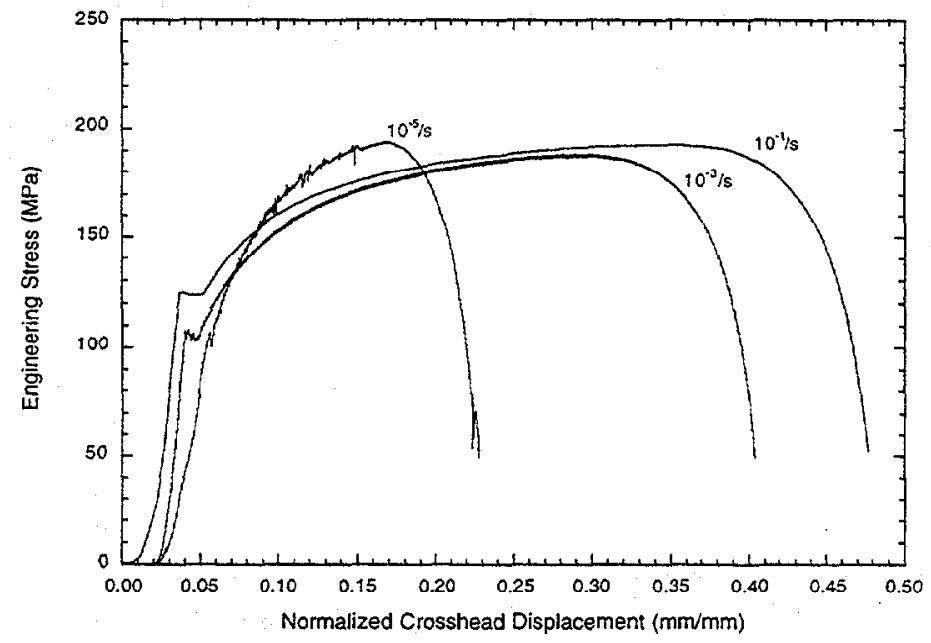

Figure 2. The stress-strain curves for vanadium at $200^{\circ} \mathrm{C}$.

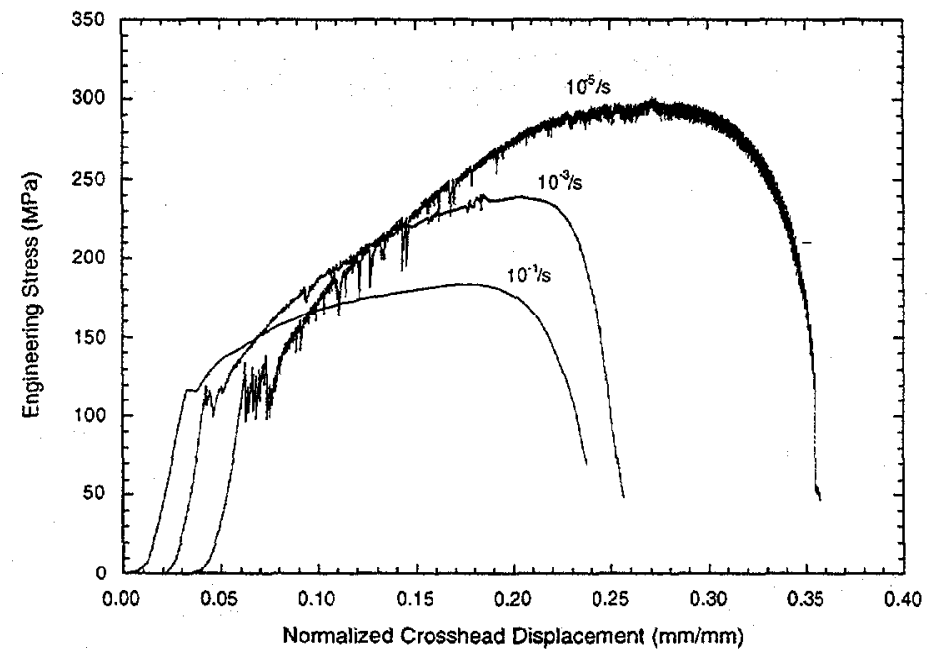

Figure 3. The stress-strain curves for vanadium at $300^{\circ} \mathrm{C}$. 
$10^{-5} / \mathrm{s}$ (Fig. 2). This was opposite to that at $300^{\circ} \mathrm{C}$, which showed the largest elongations at $10^{-5} / \mathrm{s}$ and the smallest at $10^{-1} / \mathrm{s}$ (Fig. 3).

The strain-rate dependence was determined for the lower yield stress, $\sigma_{y}$, and for a parameter, $\sigma_{s}$, which is the stress required to produce a strain of $8 \%$ after the completion of the Lüders extension. The $8 \%$ strain is an arbitrary value selected to represent material in the strainhardening regime. The strain-rate sensitivities of these parameters are presented in Figures 4 and 5.

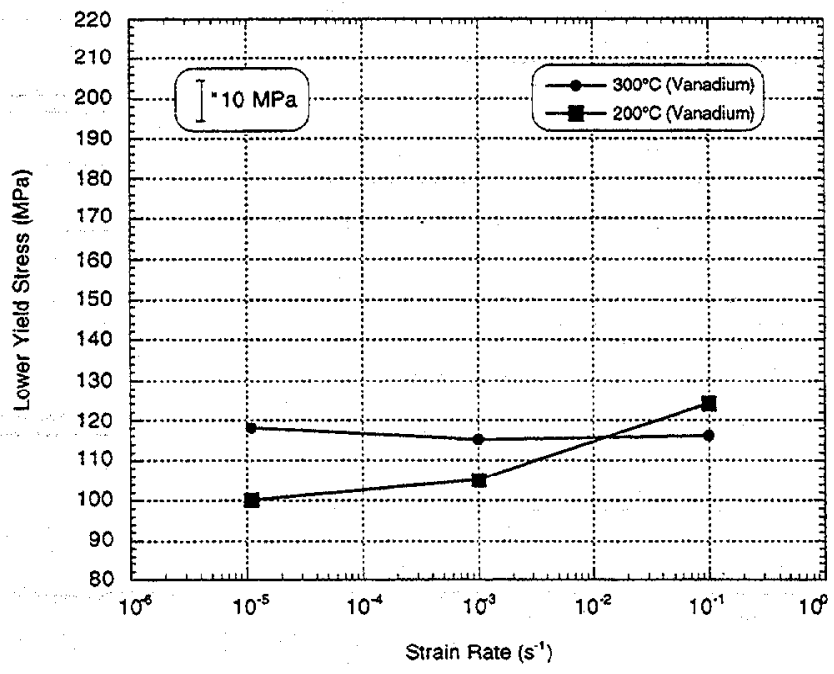

Figure 4. Effect of strain rate on the lower yield strength of vanadium tested at temperatures of 200 and $300^{\circ} \mathrm{C}$.

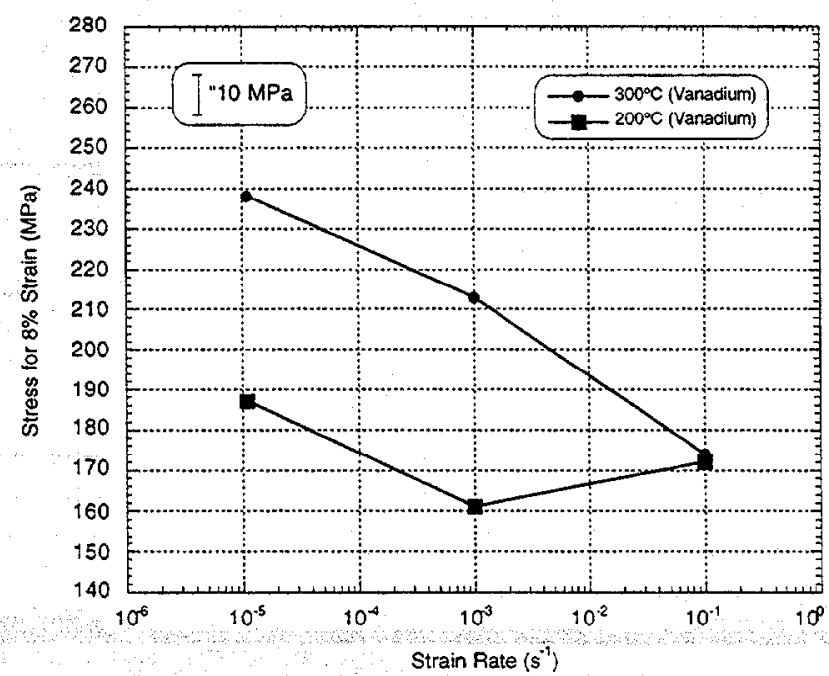

Figure 5. Effect of strain rate on the tensile strength (measured at $8 \%$ strain in the strainhardening regime) of vanadium tested at temperatures of 200 and $300^{\circ} \mathrm{C}$. 
The data shows that changes in temperature, strain, and strain rate produced significant variations in strain rate sensitivity, $m$, of vanadium, where $m$ is defined as

$$
m=\left.\frac{1}{\sigma} \frac{\partial \sigma}{\partial \ln \dot{\varepsilon}}\right|_{\varepsilon, T}
$$

where $\sigma$ is the stress and $\dot{\varepsilon}$ is the strain rate. Figure 4 shows that $\sigma_{y}$ exhibits a positive SRS at $200^{\circ} \mathrm{C}(\mathrm{m}=0.023)$, but is virtually independent of strain rate at $300^{\circ} \mathrm{C}(\mathrm{m}=-0.002)$. A different behavior in SRS was observed for the $\sigma_{\mathrm{s}}$ (Fig. 5). At $200^{\circ} \mathrm{C}$, the SRS of $\sigma_{\mathrm{s}}$ transitions from a positive value over the range $10^{-1}$ to $10^{-3} / \mathrm{s}$ to a negative value as the strain rate is decreased below $-10^{-3} / \mathrm{s}$. A negative value for $\mathrm{m}$ was observed at $300^{\circ} \mathrm{C}(\mathrm{m}=-0.034)$ for the full range of strain rates examined.

The appearance of serrations and jerky flow in stress-strain curves at $200^{\circ} \mathrm{C} \mathrm{(Fig.} \mathrm{2)} \mathrm{and} 300^{\circ} \mathrm{C}$ (Fig. 3) coincided with negative values for $m$ of $\sigma_{s}$. From these figures, jerky flow is observed at $200^{\circ} \mathrm{C}$ for the strain rate of $10^{-5} / \mathrm{s}$ while at $300^{\circ} \mathrm{C}$ it is observed for strain rates at $10^{-3} / \mathrm{s}$ and $10^{-5} / \mathrm{s}$. It is possible that serrations or jerky flow were present at $300^{\circ} \mathrm{C}$ for the strain rate of $10^{-1} / \mathrm{s}$, but was not resolved due to the data acquisition problem described above. These observations of the deformation behavior correlated with the negative value of $m$ at $300^{\circ} \mathrm{C}(m=-0.034)$ for strain rates ranging from $10^{-1} / \mathrm{s}$ to $10^{-5} / \mathrm{s}$ and at $200^{\circ} \mathrm{C}$ for strain rates below $10^{-3} / \mathrm{s}$.

\section{Discussion}

The phenomenon of strain aging (static and dynamic). arises in vanadium due to the segregation of interstitial carbon, nitrogen, and oxygen solutes to dislocations to form Cottrell atmospheres $[4,6,7]$. In vanadium, these interstitial solutes have moderate solubility levels and high diffusion coefficients, which allows them to be mobile at low temperatures [8]. The results showing serrated yielding and jerky flow in stress strain curves at $200^{\circ} \mathrm{C}$ and a strain rate of $10^{-5} / \mathrm{s}$ (Fig. 2) are consistent with these assessments of vanadium. An analysis of the jerky flow in the stress strain curve obtained at $200^{\circ} \mathrm{C}$ and $10^{-5} / \mathrm{s}$ indicated that the average time duration between yield drops was $\sim 129 \mathrm{sec}$. This duration represents the time it takes for a sufficient number of interstitial atoms to diffuse to dislocations to form atmospheres, which either pins or subjects a drag on them, and for the dislocation to then break free with an increase in stress. Using the diffusion data for $\mathrm{C}, \mathrm{N}$, and $O$ in vanadium [8], it was determined that only $C$ and $O$ possessed limited mobilities at $200^{\circ} \mathrm{C}$, with calculated diffusion lengths for $-129 \mathrm{sec}$ of $4 \mathrm{~nm}(C)$ and $2.9 \mathrm{~nm}(O)$. These values are for bulk diffusion and should be larger for diffusion along dislocation cores. At $300^{\circ} \mathrm{C}$ and a strain rate of $10^{-5} / \mathrm{s} \mathrm{(Fig.} \mathrm{3),} \mathrm{the} \mathrm{frequency} \mathrm{of} \mathrm{the} \mathrm{serrations} \mathrm{increases} \mathrm{and} \mathrm{the} \mathrm{calculated} \mathrm{time} \mathrm{duration} \mathrm{between}$ the yield drops decreases to $-37.5 \mathrm{sec}$. This decrease in time is due to the increased mobilities for the interstitial solutes. The calculated diffusion distance for a time duration of $37.5 \mathrm{sec}$ is $28.7 \mathrm{~nm}(\mathrm{C}), 22.8 \mathrm{~nm}(\mathrm{O})$, and $2.2 \mathrm{~nm}(\mathrm{~N})$. From these calculations, the interstitial atoms responsible for causing DSA in vanadium at $200^{\circ} \mathrm{C}$ and $300^{\circ} \mathrm{C}$ are interstitial $\mathrm{O}$ and $\mathrm{C}$ atoms in solid solution. Contributions to DSA in vanadium by $\mathrm{N}$ should occur only at temperatures above $300^{\circ} \mathrm{C}$.

The correlation between the appearance of serrations and jerky flow in stress strain curves and negative values of strain rate sensitivity, $m$, is consistent with previous investigations of strain aging effects in vanadium $[6,7]$. The results showed that this correlation occurred at $300^{\circ} \mathrm{C}$ for the full range of strain rates $\left(m=-0.034\right.$ for $\sigma_{\mathrm{s}}$ at $10^{-1} / \mathrm{s}$ to $\left.10^{-5} / \mathrm{s}\right)$ and at $200^{\circ} \mathrm{C}$ for strain rates below $10^{-3} / \mathrm{s}$. A negative $\mathrm{m}$ value was also measured for the ultimate stress, $\sigma_{\mathrm{u}}$, at $300^{\circ} \mathrm{C}$, which was -0.053 . Systematic studies by Bradford and Carlson [6] and Thompson and Carlson [7] have shown that oxygen and nitrogen, respectively, can cause strain aging in vanadium but that the minimum values in $m$ are smaller and occur at higher temperatures compared to the results of this study. Bradford and Carlson [6] observed serrations in stress strain curves along with negative 
values of $m\left(\sigma_{u}\right)$ in vanadium containing 265 wppm $O$ and 150 wppm $C$ for temperatures ranging from $175^{\circ} \mathrm{C}-425^{\circ} \mathrm{C}$. They measured a minimum value in $\mathrm{m}$ of -0.023 at $340^{\circ} \mathrm{C}$. A similar correlation was observed by Thompson and Carlson [7] in vanadium containing $210 \mathrm{wppm} N$ for temperatures ranging from $250^{\circ} \mathrm{C}-550^{\circ} \mathrm{C}$, with a minimum value in $\mathrm{m}$ of -0.011 at $400^{\circ} \mathrm{C}$. The reason for these differences is related to the interstitial content in vanadium. It was determined from chemical analysis that the vanadium plate used to make the SS-3 specimens contained 340 wppm O, $177 \mathrm{wppm} \mathrm{N}$, and $198 \mathrm{wppm} \mathrm{C}$, or a total interstitial content of $715 \mathrm{wppm}$. This level is higher than the combined $\mathrm{C}, \mathrm{N}$, and $\mathrm{O}$ contents of vanadium used by Bradford and Carison and by Thompson and Carlson, which were 420 wppm and $365 \mathrm{wppm}$, respectively, for the vanadium cited above. Additional tensile tests will be performed on vanadium at temperatures above $300^{\circ} \mathrm{C}$, which pertain to temperatures that DSA has been observed in the V-4Cr-4Ti alloy.

For temperatures investigated in this study, results showing differences in the SRS of $\sigma_{\mathrm{s}}$ for strain rates between vanadium and $\mathrm{V}-4 \mathrm{Cr}-4 \mathrm{Ti}[1-3]$ suggest that $\mathrm{Ti}$ and $\mathrm{Cr}$ solutes raise the temperature range over which DSA occurs by $-100^{\circ} \mathrm{C}$. This was determined from the $\mathrm{u}$-shape dependence of $\sigma_{s}$ (and $\sigma_{u}$ ) on changes in strain rate that was observed for vanadium at $200^{\circ} \mathrm{C}$ (Fig. 5) and for $V$. $4 \mathrm{Cr}-4 \mathrm{Ti}$ at $300^{\circ} \mathrm{C}$ (see Fig. 3 in ref. 2). For the SRS of $\sigma_{\mathrm{s}}, \mathrm{m}$ was -0.034 for vanadium and was within the range between -0.014 to -0.021 for $\mathrm{V}-4 \mathrm{Cr}-4 \mathrm{Ti}$ at all test temperatures (i.e $400^{\circ} \mathrm{C}$ to $700^{\circ} \mathrm{C}$ ). These results indicate that interstitial atoms are removed from solid solution by interacting with the solutes such as Ti to form precipitates. However, the effectively lower interstitial content of $\mathrm{V}-4 \mathrm{Cr}-4 \mathrm{Ti}$ can account for less negative values of $\mathrm{m}$ but cannot account for differences in the temperature range showing the DSA effect. This behavior suggests that an interaction occurs between $\mathrm{Ti}$ and interstitial solutes that decreases the mobility of the interstitials at temperatures below $-500^{\circ} \mathrm{C}$, which is the temperature that Ti solutes start to become mobile. Further research using stereology to determine the volume fraction of precipitates is currently being performed on $\mathrm{V}-4 \mathrm{Cr}-4 \mathrm{Ti}$ in order to estimate the amount of interstitials in solid solution and to quantify their contribution to the DSA effect.

\section{REFERENCES}

1. A.N. Gubbi, A.F. Rowcliffe, W.S. Eatherly, and L.T. Gibson, "Effects of Strain Rate, Test Temperature, and Environment on the Tensile Properties of Vanadium Alloys," Fusion Materials Semiannual Progress Report, DOE/ER-0313/20, June 1996, p. 38.

2. A.F. Rowcliffe, D.T. Hoelzer, and S.J. Zinkle, "High Temperature Tensile Properties and Deformation Behavior of V-4Cr-4Ti," Fusion Materials Semiannual Progress Report, DOE/ER0313/26, June 1999, p. 25.

3. A.F. Rowcliffe, S.J. Zinkle, and D.T. Hoelzer, "Effect of Strain Rate on the Tensile Properties of Unirradiated and Irradiated V-4Cr-4Ti," To be published in the Journal of Nuclear Materials as Proceedings of the $9^{\text {th }}$ International Conference on Fusion Reactor Materials, Oct. 10-15, 1999, Colorado Springs.

4. J. D. Baird, Metallurgical Reviews 5, 1971, p. 1.

5. B.J. Brindley and P.J. Worthington, 4, 1970, p. 101.

6. S. A. Bradford and O. N. Carlson, Trans. AIME, 224, 1962, p. 738.

7. R. W. Thompson and O. N. Carlson, J. Less Common Metals 7, 1964, p. 321.

8. F.A. Schmidt and J.C. Warner, J. Less-Common Metals, 26, 1972, p. 325. 


\author{
TENSILE PROPERTIES OF V-(Cr,Fe)-Ti ALLOYS AFTER IRRADIATION IN THE HFIR-11J \\ EXPERIMENT - Y. Yan, H. Tsai, D. O. Pushis, and D. L. Smith (Argonne National Laboratory), \\ K. Fukumoto, H. Matsui (IMR/Tohoku Univ.) \\ OBJECTIVE
}

The objective of this work is to develop further understanding of the effects of neutron irradiation on the tensile properties of $\mathrm{V}-(\mathrm{Cr}, \mathrm{Fe})-\mathrm{Ti}$ alloys with compositional variations near the reference $\mathrm{V}-4 \mathrm{Cr}-4 \mathrm{Ti}$. The current focus is on moderate-fluence irradiation in the temperature range of $300-500^{\circ} \mathrm{C}$.

\title{
SUMMARY
}

Postirradiation tensile tests at room temperature and $300^{\circ} \mathrm{C}$ were performed on $\mathrm{V}-(\mathrm{Cr}, \mathrm{Fe})-\mathrm{Ti}$ alloy specimens that had been irradiated in the HFIR-11J experiment. The specimens were of the SSJ design. Irradiation temperature was $\approx 300^{\circ} \mathrm{C}$ and the attained neutron damage was $\approx 6 \mathrm{dpa}$. Results from these tensile tests show significant radiation hardening and ductility reduction in all of the materials. In comparison, hardening was substantially lower in the same materials after the $500^{\circ} \mathrm{C}$ $12 \mathrm{~J}$ experiment. These results are consistent with previous findings that the demarcation for low-temperature radiation embrittlement in vanadium alloys is $\approx 400^{\circ} \mathrm{C}$.

\section{INTRODUCTION}

Data on mechanical properties for $V$-base alloys are needed to establish guidelines for the design and operation of fusion devices utilizing this class of materials for in-vessel structures. Two experiments, RB-11J and RB-12J, were performed recently in the HFIR to investigate the effects of irradiation at 300 and $500^{\circ} \mathrm{C}$, respectively [1], on the mechanical properties of vanadium alloys with a range of compositions. These experiments were conducted in a collaboration of the Japanese-Monbusho and the U.S.JDOE Fusion Energy Sciences Programs.

In this study, ten V-base alloys (six with $\mathrm{Cr}, \mathrm{Ti}$, and $\mathrm{Si}$ additions and four with $\mathrm{Fe}, \mathrm{Ti}$, and $\mathrm{Si}$ additions) were irradiated in the $11 \mathrm{~J}$ and $12 \mathrm{~J}$ experiments. While the reference alloy has been $\mathrm{V}-4 \mathrm{Cr}-4 \mathrm{Ti}$, effects of variations in $\mathrm{Cr}$ and $\mathrm{Ti}$ are of interest and replacement of $\mathrm{Cr}$ with $\mathrm{Fe}$ is being explored because iron atoms appear to be a more effective trap for the helium atoms produced in transmutation by neutron reaction [2]. The goals of the present work are to evaluate tensile properties of these alloys after the $300^{\circ} \mathrm{C} 11 \mathrm{~J}$ irradiation and to compare with the data from the $12 \mathrm{~J}$ experiment reported in Ref. 3.

\section{EXPERIMENTAL PROCEDURES}

Six small heats of $\mathrm{V}-(4-5) \mathrm{Cr}-(3-5) \mathrm{Ti}-(0-0.1) \mathrm{Si}$ and four small heats of $\mathrm{V}-(3-4) \mathrm{Fe}-4 \mathrm{Ti}-(0-0.1) \mathrm{Si}$ alloys were produced by arc melting. Chemical analyses of the heats are shown in Table 1 . The SSJ tensile specimens, with overall dimensions of $16.0 \times 4.0 \times 0.2 \mathrm{~mm}$ and gauge dimensions of $5.0 \times$ $1.2 \times 0.2 \mathrm{~mm}$, were punched from 0.2-mm-thick as-rolled sheets with the longitudinal direction parallel to the final sheet rolling direction. All specimens were vacuum-degassed at $600^{\circ} \mathrm{C}$ for $0.5 \mathrm{~h}$ and then vacuum-annealed at $1100^{\circ} \mathrm{C}$ for $2 \mathrm{~h}$. An impurity getter made of $\mathrm{Zr}$ and Ta foils was used to protect the specimens during the degassing and annealing. According to previous studies, the mechanical properties of these materials, in terms of yield stress, uniform elongation, and ultimate tensile stress, are not strongly influenced by annealing temperatures in the range of 950 to $1100^{\circ}$ [4]. In the $11 \mathrm{~J}$ experiment, the specimens were irradiated in a temperature range from $274 \pm 9$ to 
$307 \pm 19^{\circ} \mathrm{C}$ and attained a dose of 4.2 to $6.2 \mathrm{dpa}$. Details of the operating history are given in Ref. 1 .

Table 1. Composition of Alloys Studied

\begin{tabular}{ccccccccc}
\hline Heat & Nominal Comp & $\begin{array}{c}\mathrm{Cr} \\
\text { (wt.\%) }\end{array}$ & $\begin{array}{c}\mathrm{Fe} \\
\text { (wt.\%) }\end{array}$ & $\begin{array}{c}\mathrm{Ti} \\
\text { (wt.\%) }\end{array}$ & $\begin{array}{c}\mathrm{Si} \\
\text { (wppm) }\end{array}$ & $\begin{array}{c}\mathrm{O} \\
\text { (wppm) }\end{array}$ & $\begin{array}{c}\mathrm{N} \\
\text { (wppm) }\end{array}$ & $\begin{array}{c}\mathrm{S} \\
\text { (wppm) }\end{array}$ \\
\hline VM9401 & V-4Cr-4Ti-0.1Si & 4.43 & - & 4.07 & 640 & 240 & 5.5 & 3 \\
VM9402 & V-4Cr-4Ti & 4.39 & - & 4.08 & 5 & 595 & 305 & 3 \\
VM9403 & V-5Cr-4Ti & 5.56 & - & 4.05 & 7 & 515 & 4.5 & 2 \\
VM9404 & V-4Cr-3Ti & 4.35 & - & 3.05 & 6 & 515 & 10 & 3 \\
VM9405 & V-5Cr-3Ti & 5.53 & - & 3.07 & 4 & 490 & 5.5 & 3 \\
VM9406 & V-5Cr-5Ti & 5.43 & - & 5.06 & 5 & 495 & 7 & 9 \\
VM9407 & V-4Fe-4Ti-0.1Si & 0.06 & 3.94 & 4.03 & 210 & 370 & 7.5 & 4 \\
VM9408 & V-4Fe-4Ti & 0.05 & 3.92 & 3.99 & 8 & 470 & 7.5 & 3 \\
VM9409 & V-3Fe-4Ti & 0.05 & 3.01 & 3.97 & 6 & 515 & 7.5 & 2 \\
VM9502 & V-3Fe-4Ti-0.1Si & - & 2.92 & 3.96 & 400 & 1478 & 21 & 8 \\
\hline
\end{tabular}

Postirradiation tensile tests were conducted in the Irradiation Materials Laboratory at Argonne National Laboratory (ANL). The tests were conducted at room temperature and $300^{\circ} \mathrm{C}$, the nominal irradiation temperature, at a strain rate of $6.67 \times 10^{-4} / \mathrm{s}(0.2 \mathrm{~mm} / \mathrm{min})$. The $300^{\circ} \mathrm{C}$ tests were performed in a high-purity flowing argon environment with the specimen protected in a Ti getter foil enclosure. After the tensile tests, fractography was performed with a SEM in ANL's Alpha-Gamma Hot Cell Facility. For reduction-in-area determinations, specimens were mounted in a vertical clip holder and oriented with crosssection parallel to the image plane. For side-view observations, specimens were tilted.

\section{RESULTS}

Nine of the ten materials have been tested; the results are summarized in Table 2. Also shown in the table are the sums of weight percentages of the major alloying components, Ti plus $\mathrm{Cr}$ or $\mathrm{Fe}$.

Table 3. Summary results of $11 \mathrm{~J}$ tensile tests ${ }^{\mathrm{a}}$.

\begin{tabular}{|c|c|c|c|c|c|c|c|c|}
\hline Heat/ Material & $\begin{array}{c}(\mathrm{Cr}, \mathrm{Fe})+\mathrm{Ti} \\
(\text { wt. \%) }\end{array}$ & $\begin{array}{c}\text { Spec. } \\
\text { No. }\end{array}$ & $\begin{array}{c}\text { Test Temp. } \\
\left({ }^{\circ} \mathrm{C}\right)\end{array}$ & $\begin{array}{c}0.2 \% \text { YS } \\
(\mathrm{MPa})\end{array}$ & $\begin{array}{l}\text { UTS } \\
\text { (MPa) }\end{array}$ & $\begin{array}{l}\text { UE } \\
(\%)\end{array}$ & $\begin{array}{l}\text { TE } \\
(\%)\end{array}$ & $\begin{array}{l}\mathrm{RA} \\
(\%)\end{array}$ \\
\hline VM9401 & 8.65 & TH12 & $R T$ & 1051 & 1044 & 0.6 & 2.4 & 61 \\
\hline $\mathrm{V}-4 \mathrm{Cr}-4 \mathrm{Ti}-0.1 \mathrm{Si}$ & 8.00 & TH11 & 300 & 928 & 937 & 0.4 & 1.5 & 55 \\
\hline VM9402 & 862 & TD24 & RT & 927 & 950 & 0.5 & 2.1 & 63 \\
\hline $\mathrm{V}-4 \mathrm{Cr}-4 \mathrm{Ti}$ & 8.62 & TD21 & 300 & 890 & 903 & 0.3 & 3.3 & 58 \\
\hline VM9403 & 973 & TD34 & RT & 870 & 941 & 0.7 & 2.1 & 76 \\
\hline $\mathrm{V}-5 \mathrm{Cr}-4 \mathrm{Ti}$ & & TD30 & 300 & 890 & 894 & 0.2 & 3.0 & 65 \\
\hline VM9404 & & TD45 & $\mathrm{RT}$ & 930 & 1023 & 0.8 & 3.1 & 54 \\
\hline $\mathrm{V}-4 \mathrm{Cr}-3 \mathrm{Ti}$ & 1.49 & TD40 & 300 & 777 & 787 & 0.4 & 1.2 & 66 \\
\hline VM9405 & 866 & TD50 & $\mathrm{RT}$ & 1082 & 1082 & 0.2 & 3.7 & 65 \\
\hline $\mathrm{V}-5 \mathrm{Cr}-3 \mathrm{Ti}$ & 8.66 & TD56 & 300 & 821 & 843 & 0.3 & 3.6 & 65 \\
\hline VM9406 & 10.67 & TD60 & RT & 1020 & 1023 & 0.2 & 3.5 & 63 \\
\hline V-5Cr-5Ti & 10.08 & TD64 & 300 & 915 & 915 & 0.2 & 2.9 & 68 \\
\hline VM9407 & 7.86 & TD72 & RT & 862 & 989 & 0.7 & 3.7 & 67 \\
\hline V-4Fe-4Ti-0.1Si & & TD70 & 300 & 885 & 900 & 0.3 & 3.5 & 72 \\
\hline VM9408 & 7.80 & TD83 & RT & 1202 & 1208 & 0.3 & 3.8 & 66 \\
\hline
\end{tabular}




\begin{tabular}{ccccccccc} 
V-4Fe-4Ti & & TD80 & 300 & 728 & 925 & 1.2 & 3.7 & 72 \\
VM9409 & \multirow{2}{*}{6.95} & TD96 & RT & 1080 & 1118 & 0.4 & 3.8 & 74 \\
V-3Fe-4Ti & & TD92 & 300 & 918 & 947 & 0.5 & 2.9 & 73 \\
\hline
\end{tabular}

${ }^{2} 0.2 \%$ offset yield stress (YS), ultimate tensile strength (UTS), uniform elongation (UE), total elongation (TE), and reduction-in-area (RA).

For all materials tested, substantial hardening (manifested in the increased tensile strength) resulted from the $300^{\circ} \mathrm{C}$ irradiation in the $11 \mathrm{~J}$ experiment. Compared to the nonirradiated baseline, the strengths are approximately doubled. Concomitantly, ductility of the materials shows a substantial decrease to $<\approx 1 \%$ uniform elongation and $<\approx 4 \%$ total elongation. All materials show respectable reduction in area, however. Most of the reduction occurred in the thickness direction; necking in the width direction of the gauge was minimal.

Figure 1 shows the stress-strain curves for the VM9407 material (V-4Fe-4Ti-0.1Si) tested at room temperature and $300^{\circ} \mathrm{C}$. At both temperatures, the material showed little work-hardening capability and fractured soon after reaching the yield point. Similar behavior was seen in essentially all of the other materials tested. In contrast, as shown in Fig. 2, the VM9407 materials displayed substantially more ductility and less hardening after the $500^{\circ} \mathrm{C} 12 \mathrm{~J}$ irradiation. The substantial difference in irradiation behavior of vanadium-base alloys at 300 and $500^{\circ} \mathrm{C}$ highlights the issue of low-temperature embrittlement, which has been observed at temperatures below $\approx 400^{\circ} \mathrm{C}$.

Fig. 1 Stress-strain curves for VM9407N-4Fe-4Ti-0.1Si from HFIR/11J experiment.

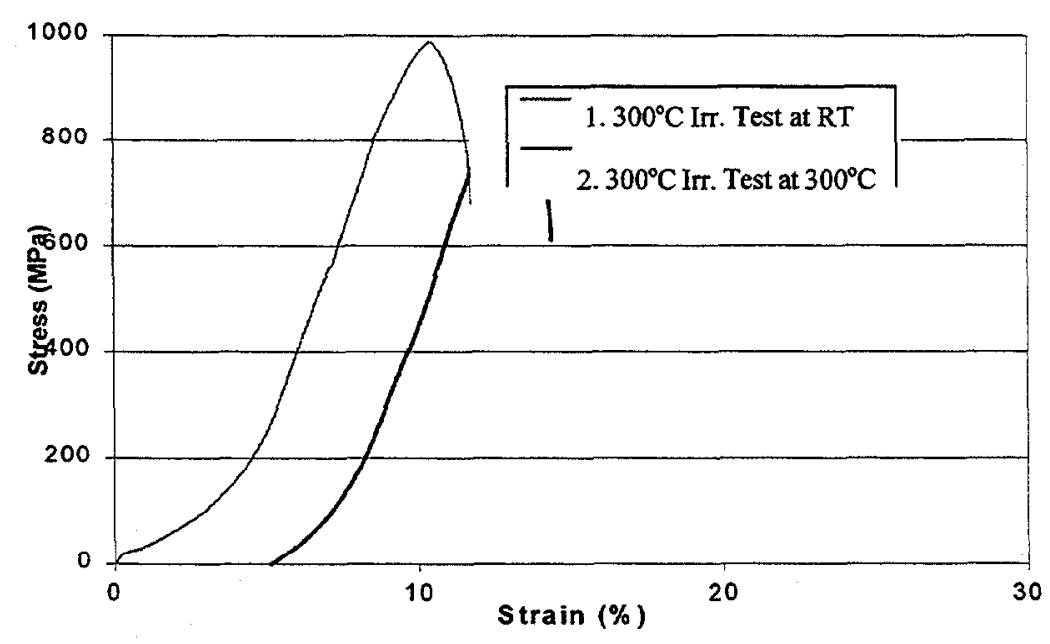




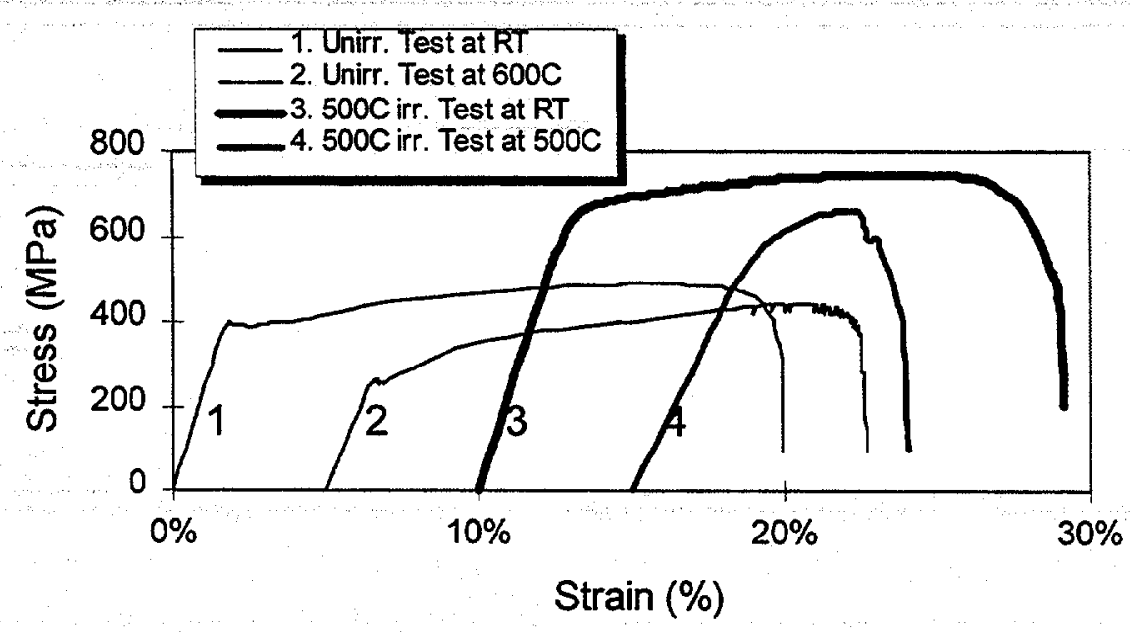

Fig. 2. Stress-strain curves for VM9407N-4Fe-4Ti-0.1Si from $12 \mathrm{~J}$ experiment.

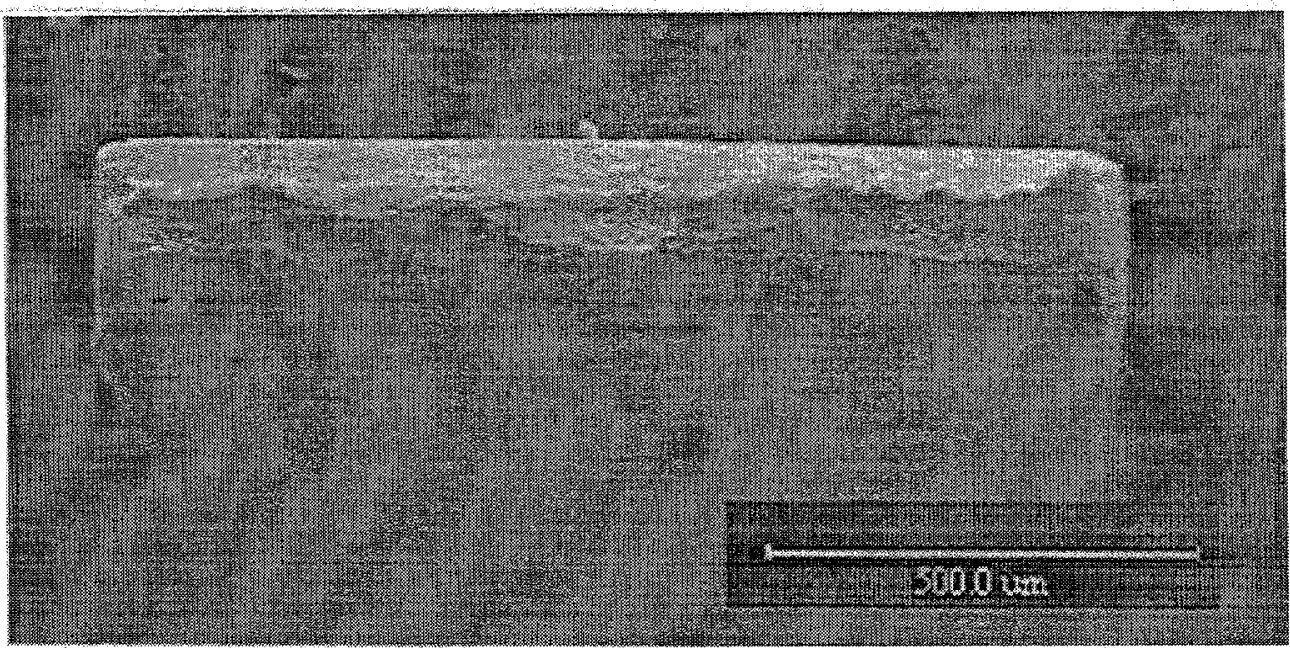

Fig. 3. Perspective view of tip of fractured tensile specimen TD45 with nominal composition of $\mathrm{V}-4 \mathrm{Cr}-3 \mathrm{Ti}$. Irradiation was $300^{\circ} \mathrm{C}$ and test temperature was RT. 


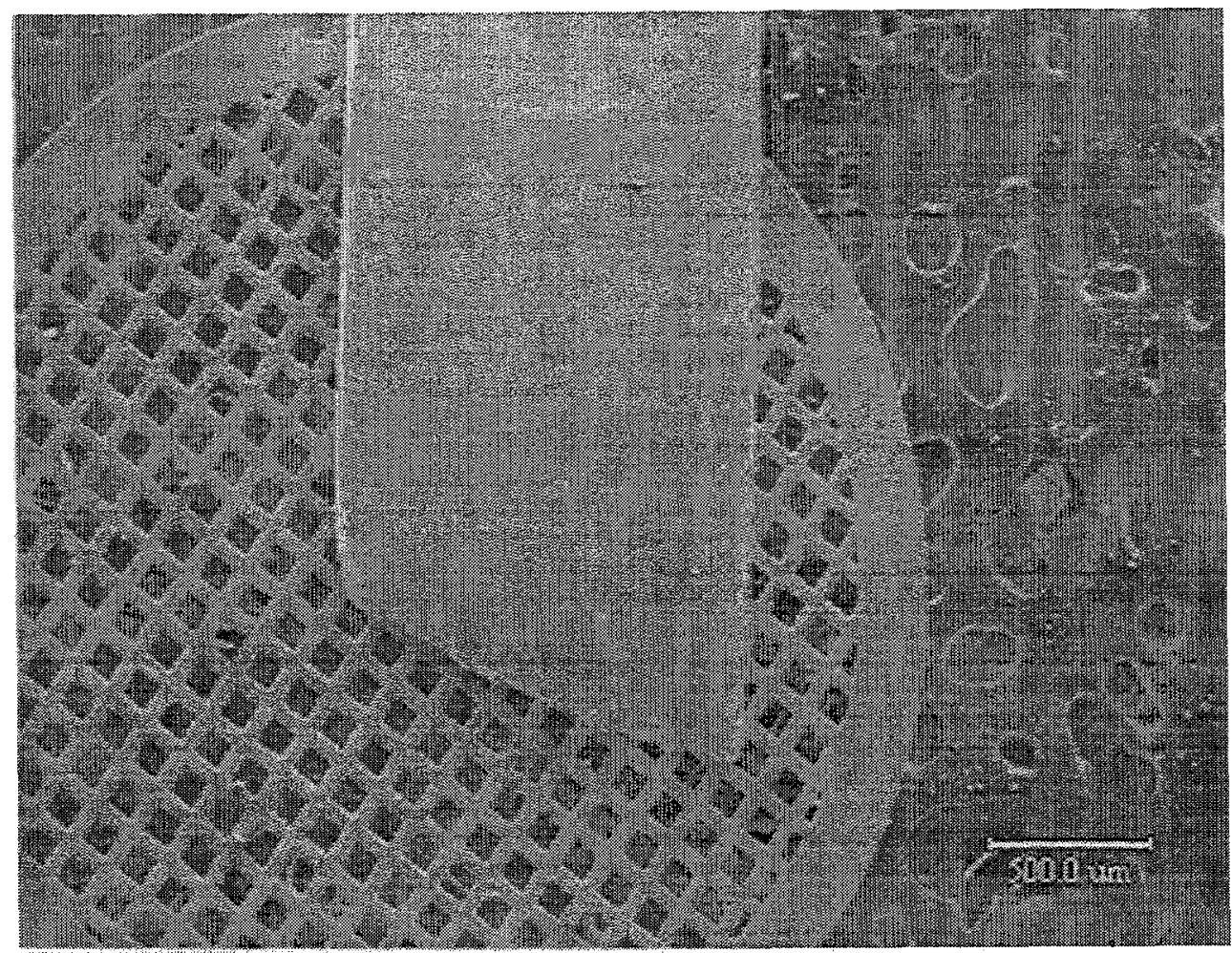

Fig. 4. SEM image showing gauge area of same TD45 specimen.

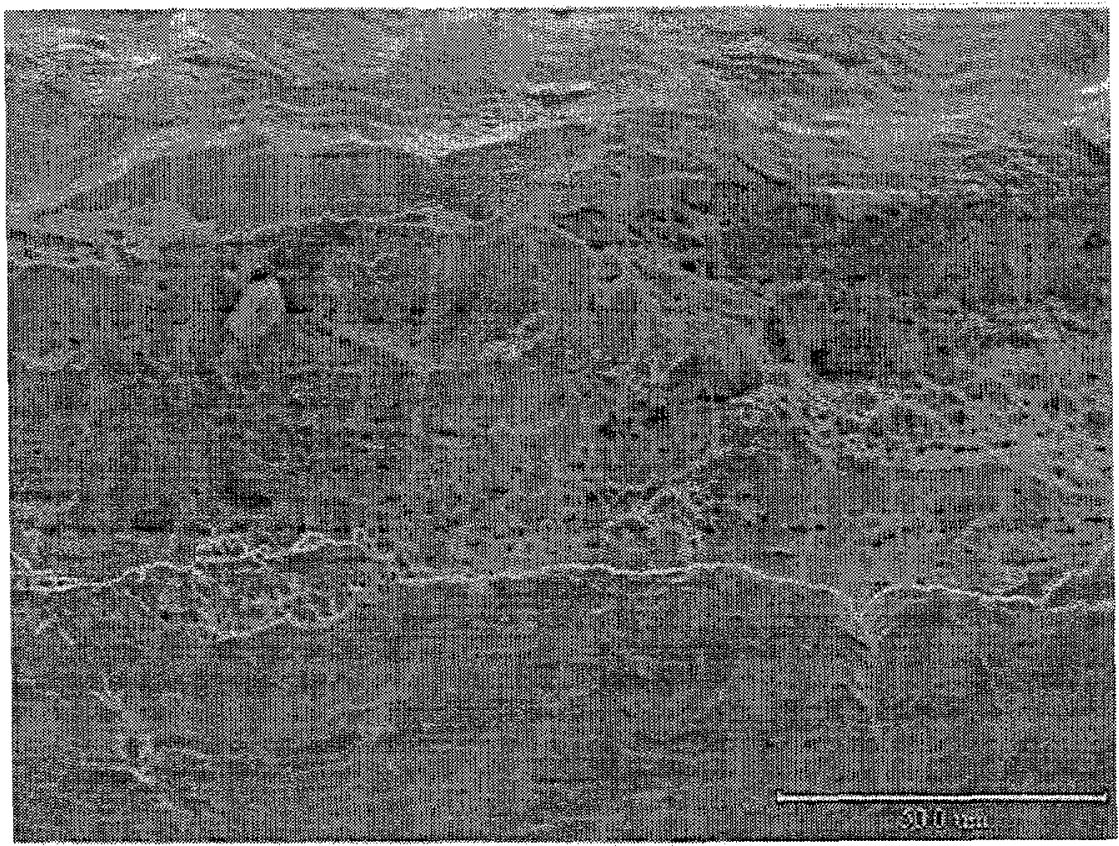

Fig. 5. Higher-magnification SEM fractograph of same TD45 specimen

Figure 3 is perspective view of the fractured tip of a representative specimen, TD45 (VM9404, $\mathrm{V}-4 \mathrm{Cr}-3 \mathrm{Ti}$ ). Reductions in area of the $11 \mathrm{~J}$ specimens were $\approx 55-75 \%$, less than those of the $12 \mathrm{~J}$ 
specimens ( $\approx 85-95 \%)$. As can be seen in Fig. 4, there was very little necking in the width direction of the gauge. A higher-magnification SEM fractograph of the same TH36 specimen is shown in Fig. 5. Surface cracks are visible, but, these cracks and slip bands are observed only in the necked region.

\section{FUTURE WORK}

Tensile testing for the VM9502 specimens will be completed. Microstructural examination of tested tensile specimens with TEM will be completed to determine the mechanisms of irradiation hardening.

\section{REFERENCES}

[1] Operating history of the HFIR MFE-RB-11J and 12J (P3-2 and P3-3) experiments, K. E.Lenox and M.L. Grossbeck; Fusion Materials Semianual Progress Report for Period Ending December 31, 1998 (DOE/ER-0313/25) p. 307.

[2] Effects of implanted helium on the mechanical properties of vanadium-based alloys, $M$. Tanaka and H. Matsui, Materials Transactions, JIM, Vol. 34 (1993) 1083.

[3] Tensile Properties of $\mathrm{V}-(\mathrm{Cr}, \mathrm{Fe})-\mathrm{Ti}$ Alloys after Irradiation in the HFIR-12J Experiment, K. Fukumoto, H. Matsui, Y. Yan, H. Tsai, R.V. Strain, and D. L. Smith, Fusion Materials Semianual Progress Report for Period Ending December 31, 1999 (DOE/ER-0313/27).

[4] Mechanical properties of vanadium based alloys for fusion reactor, $K$. Fukumoto, T. Morimura, T. Tanaka, A. Kimura, K. Abe, H. Takahashi and H. Matsui, J.Nucl.Mater., 239 (1996) 170. 


\begin{abstract}
IMPACT AND TENSILE PROPERTIES OF VANADIUM ALLOY AFTER LONG-TERM EXPOSURE IN THE DIII-D EXPERIMENTAL TOKAMAK,' ${ }^{1}$ H. Tsai, Y. Yan, D. O. Pushis, A.
\end{abstract} Storey, D. L. Smith (Argonne National Laboratory), and W. R. Johnson (General Atomics)

\title{
OBJECTIVE
}

In service, components in fusion vessels will be exposed to a range of temperature and impurity conditions, including alternating vacuum/low-pressure hydrogen plasma operation, thermal cycles and periodic bakeout, glow discharge cleaning, and occasional reexposure to air during vents for maintenance. The objective of this task is to determine the effects of these exposures on the performance of components made of vanadium-base alloys. Of particular importance is the determination of whether the absorption of interstitial impurities would lead to material embrittlement.

\section{SUMMARY}

Tensile and Charpy specimens of Heat 832665 of $\mathrm{V}-4 \mathrm{Cr}-4 \mathrm{Ti}$ alloy were exposed in the DIII-D experimental tokamak to investigate the effect of environment on the impact and tensile properties of this alloy. In this last test of the four-test series, specimens were mounted next to the chamber wall behind a divertor baffle plate and received an exposure of $\approx 3 \mathrm{yr}$. The results of this test, consistent with the results of the previous three tests, indicate no significant degradation of the mechanical properties of the alloy.

\section{TEST PROCEDURE}

The present test, designated $W 2$, was the fourth and last test of the series. It was discharged in 1999 after $\approx 3$ yr of exposure in the DIII-D experimental tokamak. During the test, the specimens experienced several full DIII-D operating cycles, which included multiple air and nitrogen vents, postvent bakeouts at $150-350^{\circ} \mathrm{C}$, and boronizations at $280^{\circ} \mathrm{C}$. The five $1 / 3$-size Charpy and five SS-3 tensile specimens were mounted in a bracket on the vessel wall behind a divertor baffle plate, as shown in Fig. 1. The Charpy specimens measured $3.3 \times 3.3 \times 25.4 \mathrm{~mm}$ and contained a $0.6 \mathrm{~mm}$-depth, $30^{\circ}$ blunt notch with a root radius of $0.08 \mathrm{~mm}$. The direction of the crack plane was perpendicular to the rolling direction and through the thickness of the plate from which the specimens were prepared. The tensile specimens were $25.4 \mathrm{~mm}$ long, with a gauge section that measured 7.62 $\times 1.52 \times 0.76 \mathrm{~mm}$. The long direction of the gauge section was parallel to the final rolling direction of the plate. All specimens were vacuum-annealed at $1000^{\circ} \mathrm{C}$ for $1.0 \mathrm{~h}$ before testing in the DIII-D. Thermocouples were welded onto two each of the tensile and Charpy specimens to monitor temperatures during the exposure. All specimens were made from Heat 832665 of the $\mathrm{V}-4 \mathrm{Cr}-4 \mathrm{Ti}$ material.

\section{RESULTS}

The results of the previous three exposure tests, of shorter exposure duration than the present one, were reported earlier $[1,2]$. After the discharge from the DIII-D in the present investigation, two specimens were subjected to tensile tests: one at $350^{\circ} \mathrm{C}$, the peak temperature experienced in the DIII-D; the other at room temperature. To preclude oxidation, the $350^{\circ} \mathrm{C}$ test was performed in highpurity argon. The specimens were tested as-discharged, i.e., without a hydrogen outgassing operation before the tensile tests. The strain rate for both tests was $1.1 \times 10^{-3} / \mathrm{s}$. Machine operation and tensile data acquisition were controlled by commercially acquired software. The test conduct for both was good. Fig. 2 shows the engineering stress and strain curves for the tests. Serration, possibly due to enhanced solute mobility at the higher temperature, can be seen in the $350^{\circ} \mathrm{C}$ data.

\footnotetext{
${ }^{1}$ This work has been supported by the U.S. Department of Energy, Office of Fusion Energy Research, under Contract W-31-109-Eng-38.
} 


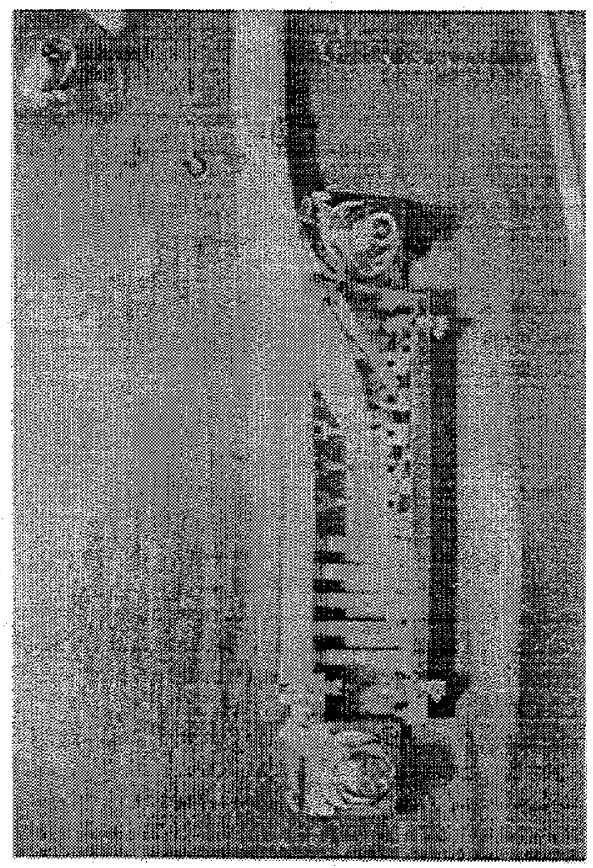

Figure 1. Mounting of W2 test specimens on DIII-D vessel wall behind a divertor baffle plate.

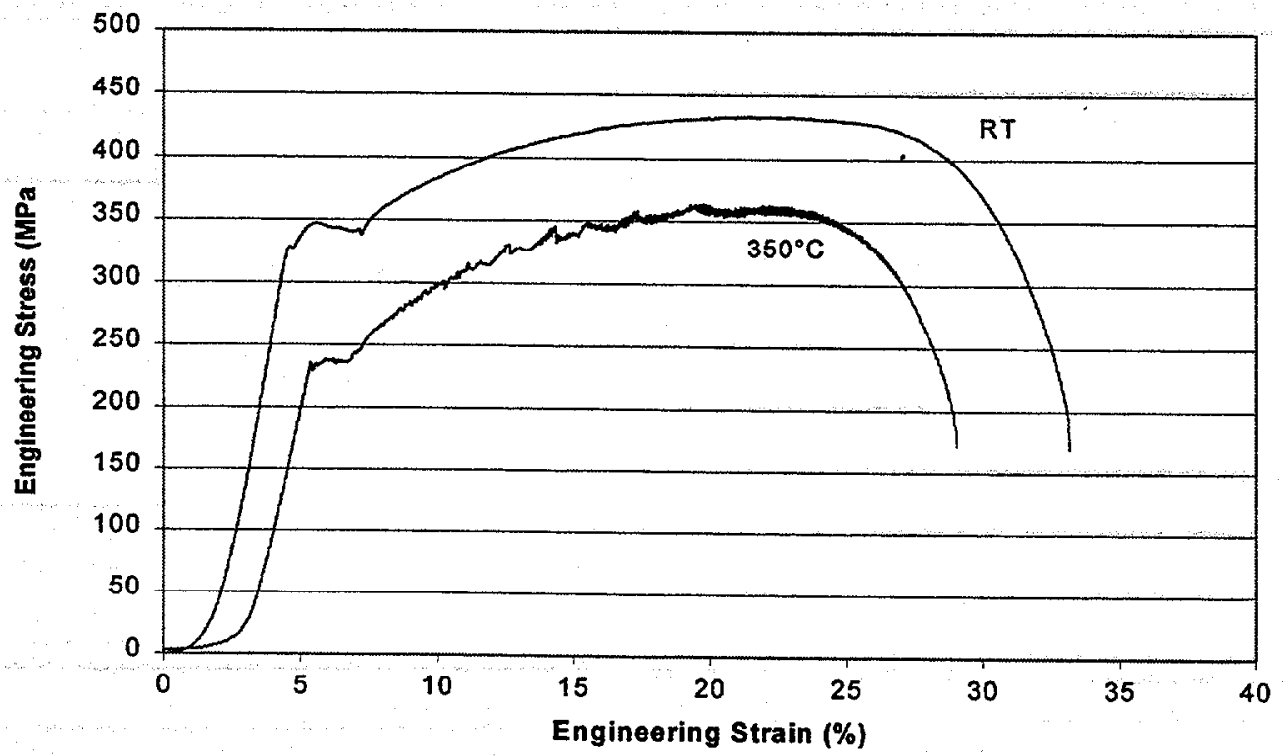

Figure 2. Engineering stress and strain curves for specimens tested at room temperature and $350^{\circ} \mathrm{C}$ after DIII-D exposure. Data are consistent with those of the nonexposed control, indicating little or no degradation due to exposure.

The calculated engineering tensile data are summarized in Table 1, along with nonexposed baseline data for Heat 832665. Also shown in Table 1 are the results of the $W 1$ test in which the exposure duration was $1 \mathrm{yr}$. The results indicate no significant degradation of tensile properties due to the DIII- 
D exposure, after either 1 or 3 yr. All specimens exhibit high uniform and total elongation and little change in yield and ultimate strength.

Table 1 Tensile properties at 25 and $350^{\circ} \mathrm{C}$ of Heat 832665 of $\mathrm{V}-4 \mathrm{Cr}-4 \mathrm{Ti}$ alloy before (baseline) and after one year (W1) the three years (W2) of exposure test in DIII-D tokamak.

\begin{tabular}{|c|c|c|c|c|c|c|}
\hline \multirow[b]{3}{*}{ Properties $^{a}$} & \multicolumn{6}{|c|}{ Test temperature $\left({ }^{\circ} \mathrm{C}\right)$} \\
\hline & \multicolumn{3}{|c|}{25} & \multicolumn{3}{|c|}{350} \\
\hline & Baseline & W1 & W2 & Baseline & W1 & $W_{2}$ \\
\hline YS (MPa) & 357 & 334 & 327 & 205 & 241 & 235 \\
\hline UTS (MPa) & 428 & 449 & 434 & 359 & 377 & 365 \\
\hline UE (\%) & 19.1 & 19.0 & 16.0 & 17.6 & 14.8 & 16.3 \\
\hline TE (\%) & 29.2 & 27.0 & 29.5 & 25.4 & 22.0 & 24.4 \\
\hline
\end{tabular}

${ }^{a}$ YS: $0.2 \%$ offset yield stress; UTS: engineering ultimate tensile stress; UE: uniform elongation; TE: total elongation.

Charpy impact properties of the W2 specimens were determined in a temperature range of -180 to $200^{\circ} \mathrm{C}$ with a Dynatup impact tester. Tests were conducted on the specimens "as removed," without hydrogen degasssing. The results are summarized in Fig. 3, along with the data of the nonexposed base metal and those from the previous two DIII-D exposure tests, D2 and W1. (Test D2 utilized the DIII-D's Divertor Materials Evaluation System, DiMES; exposure was $\approx 1$ mo. W1 was a wallmounted experiment similar to $W 2$; exposure was $\approx 1$ yr.) The $W 2$ specimens indicate that the ductile-brittle transition temperature remains below $-180^{\circ} \mathrm{C}$ after three years of exposure in the DIIID. The upper-shelf energies are slightly lower than those of the baseline material, but similar to the results from the previous $\mathrm{D} 2$ and $\mathrm{W} 1$ tests.

\section{CONCLUSIONS}

This series of four DIII-D exposure tests has been concluded successfully. The results from the four tests, including those from Test W2 with a 3-yr exposure reported in this article, suggest no significant degradation of either the tensile properties at room temperature or $350^{\circ} \mathrm{C}$ or the ductilebrittle transition temperature of $\mathrm{V}-4 \mathrm{Cr}-4 \mathrm{Ti}$ alloy by environment of the DIII-D chamber. By design, the test specimens were not exposed directly to the plasma. Conditions permitting, experiments in which specimens are exposed to the plasma may be of value for the next phase of the investigation to further demonstrate the suitability of V-base alloys for tokamak in-vessel applications.

\section{ACKNOWLEDGMENTS}

The authors acknowledge the able staff at General Atomics for conducting the experiments in the DIII-D. 


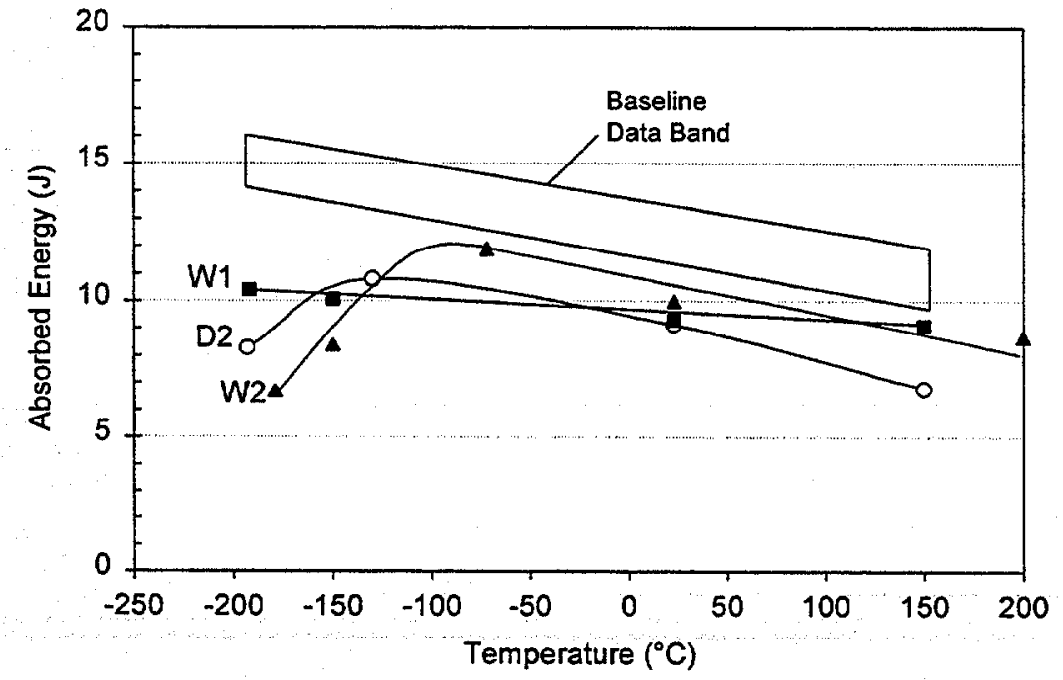

Figure 3. Charpy impact data for the DIII-D-exposed specimens showing ductile behavior.

\section{References}

1. H. Tsai, H. M. Chung, D. L. Smith, W. R. Johnson and J. P. Smith "Performance of V-4Cr-4Ti Material Exposed to DIII-D Tokamak Environment," Fusion Reactor Materials Semiannual Progress Report for Period Ending December 31, 1996, DOE/ER-0313/21, pp. 10-14.

2. H. Tsai, W. R. Johnson, D. L. Smith, W. R. Johnson, J. P. Smith and H. M. Chung, "Performance of V-4Cr-4Ti Material Exposed to DIII-D Tokamak Environment," Journal of Nuclear Materials, 258-263 (1998) 1466-1470. 
EFFECT OF HEAT TREATMENT ON MICROSTRUCTURE OF V-4Cr-4TI MATERIALS

- Y. Yan, H. Tsai, W. C. Kettman, and D. L. Smith (Argonne National Laboratory)

\section{OBJECTIVE}

The objective of this task is to determine whether the banded structure observed in an extruded $\mathrm{V}-4 \mathrm{Cr}-4 \mathrm{Ti}$ bar from ANL's 832665 heat and in a swaged rod from the General Atomic (GA)'s 832864 heat can be effectively removed by dissolution at elevated temperature.

\section{SUMMARY}

A banded structure containing Ti-rich particles has been observed in an extruded $\mathrm{V}-4 \mathrm{Cr}-4 \mathrm{Ti}$ bar from the ANL's 832665 heat and in a swaged rod from the GA's 832864 heat [1]. Because these two materials may be used as feedstocks for the upcoming creep tubing fabrication, this task was undertaken to determine whether this secondary-phase structure could be removed by dissolution at elevated temperature. Small pieces of the two materials were heat treated at $1150^{\circ} \mathrm{C}$ for $3 \mathrm{~h}$ and then characterized. The preliminary results show that this heat treatment did not redissolve the banded structure in either the extruded 832665 bar or the swaged 832864 rod.

\section{EXPERIMENTAL PROCEDURE}

A rectangular bar of $2.5 \times 1.2 \times 1.0 \mathrm{~cm}$ from ANL's 832665 heat and a rod section of $1.0 \mathrm{~cm}$ diameter $\times 1.2 \mathrm{~cm}$ long from GA's 832864 heat were used in the heat treatment. Before the annealing, the specimen surfaces were carefully prepared to remove impurities introduced in specimen cutting. The preparation process included grinding with 600-grit silicon carbide paper, polishing with $6-\mu \mathrm{m} \mathrm{Al}_{2} \mathrm{O}_{3}$ or diamond powder, and then cleaning with acetone and methanol. The specimens were then wrapped in a Ti getter foil and annealed in a high vacuum $\left(>3 \times 10^{-7}\right.$ torr $)$ at $1150^{\circ} \mathrm{C}$ for $3 \mathrm{~h}$, as suggested by Rowcliffe and Hoelzer [2].

Following the heat treatment, metallographic specimens were cut perpendicular to the extrusion direction of the bars to elucidate the microstructure, particularly the distribution of the banded structure. After mechanical polishing and electropolishing (see Fig. 1), optical microscopy was used to delineate grain morphology and microstructural imhomogeneity.

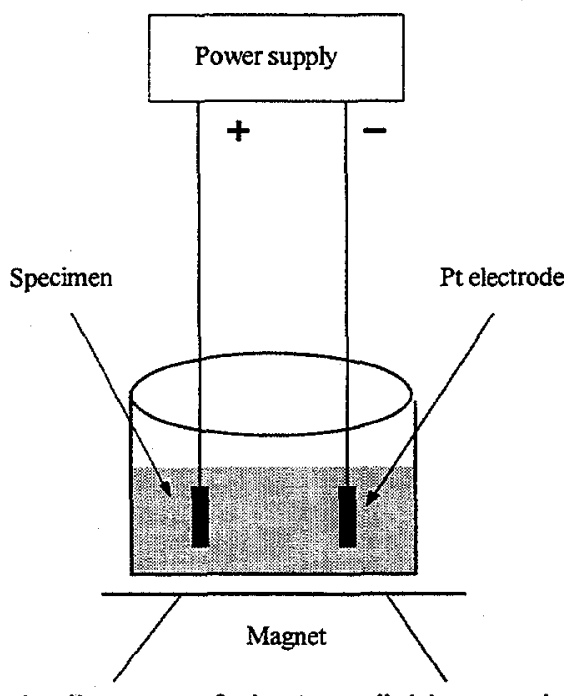

Fig.1. Schematic diagram of electropolishing equipment 


\section{RESULTS AND DISCUSSION}

As reported previously [1], there were significant microstructural differences, including grain sizes, between the extruded 832665 and the swaged 832864 materials. The microstructure of the extruded 832665 material consists of an inhomogeneous mixture of small $(5-20 \mu \mathrm{m})$ and coarse grains $(25-50 \mu \mathrm{m})$. The grains are mostly equiaxed. In the swaged 832864 material, the grains are elongated in the longitudinal direction and the average grain size is larger than that of the 832665 material. In both materials, banded structure parallel to the work direction was observed before the heat treatment, as shown in Figs. $2 a$ and $3 a$ [1].
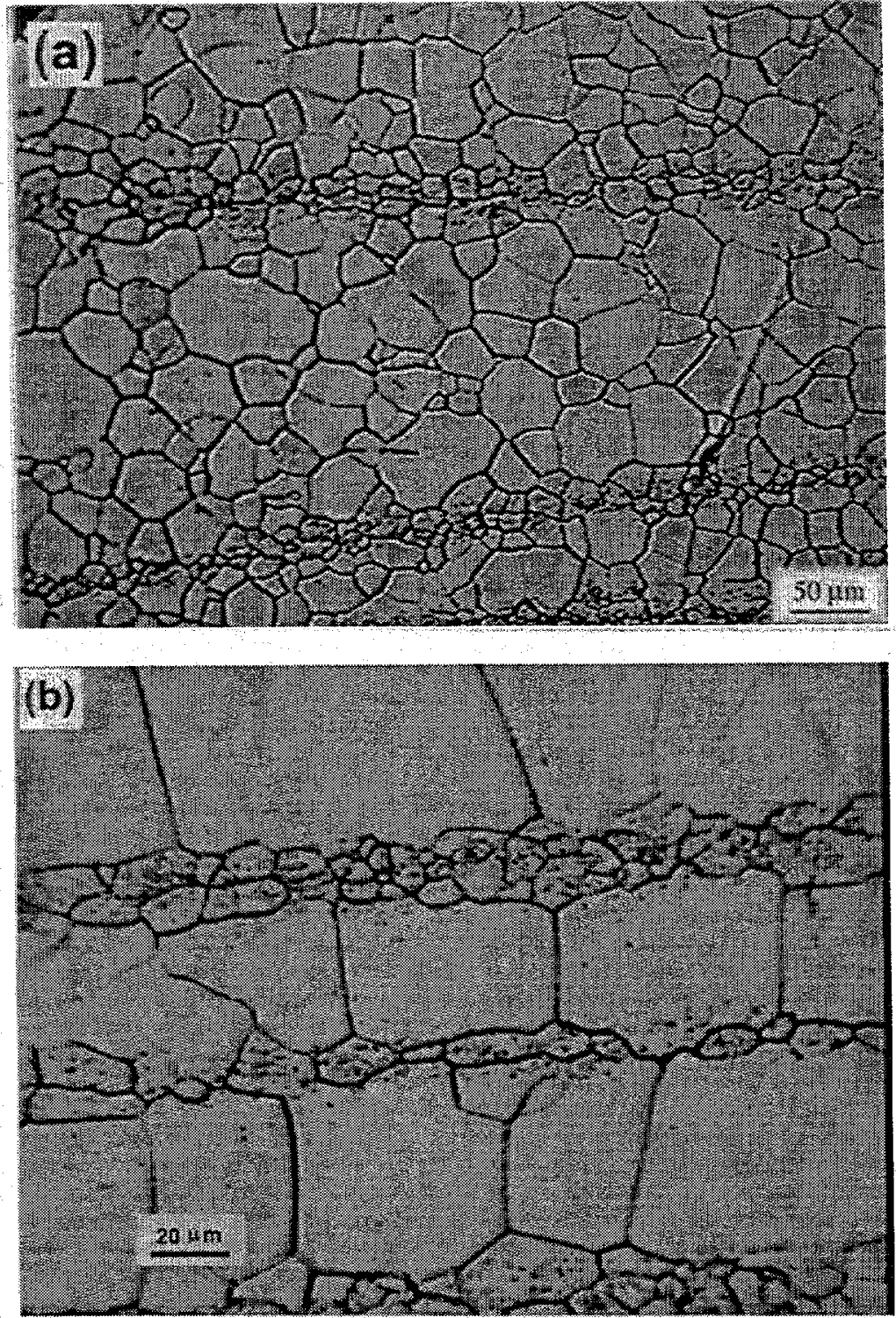

Fig. 2. Micrographs of local area with banded structure in extruded 832665 material (a) before and (b) after the heat treatment. 

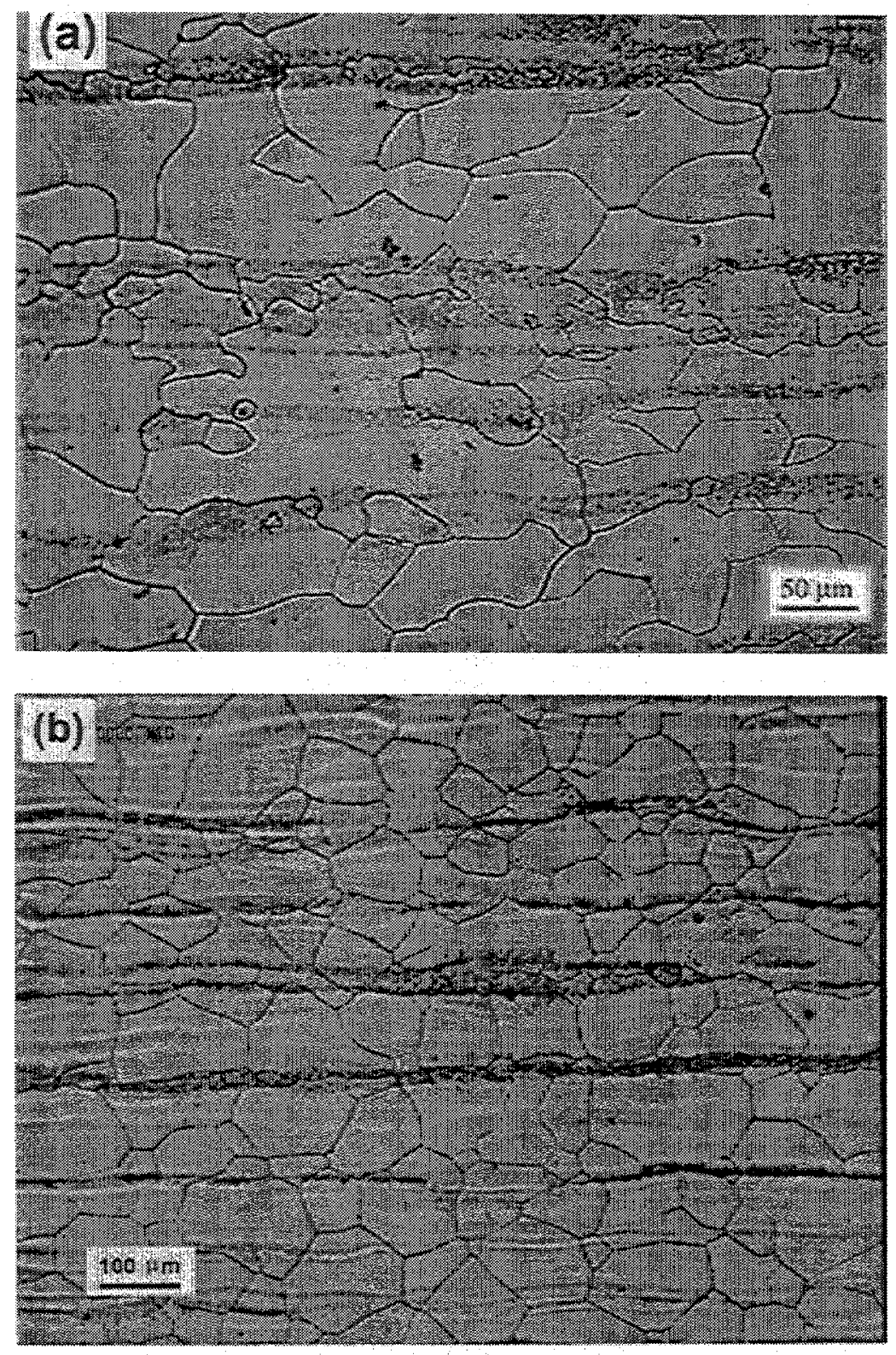

Fig. 3. Low magnification micrograph of banded structure in heat-treated 832864 materials (a) before and after (b) heat treatment.

Metallography after the heat treatment showed that the $1150^{\circ} \mathrm{C}$ annealing did not redissolve the banded structure in either the extruded 832665 bar or the swaged 832864 rod. Figure 2(b) shows a local area with the banded structure in the extruded 832665 material after heat treatment. Similar to the as-received specimens, Fig. 2(a), the average grain size in the banded region is considerably smaller than that in the unbanded region. Detailed analyses indicate that the width of the bands and the spacing between them vary from region to region. The observed width of the bands in the post-heat-treatment specimens ranges from 25 to $75 \mu \mathrm{m}$ (pre-heat-treatment specimen: 25 to $100 \mu \mathrm{m}$ ), and the distances between the bands range from 100 up to a few hundred $\mu \mathrm{m}$ (pre-heat-treatment specimen: $\approx 50-150 \mu \mathrm{m}$ ) in the regions examined. 


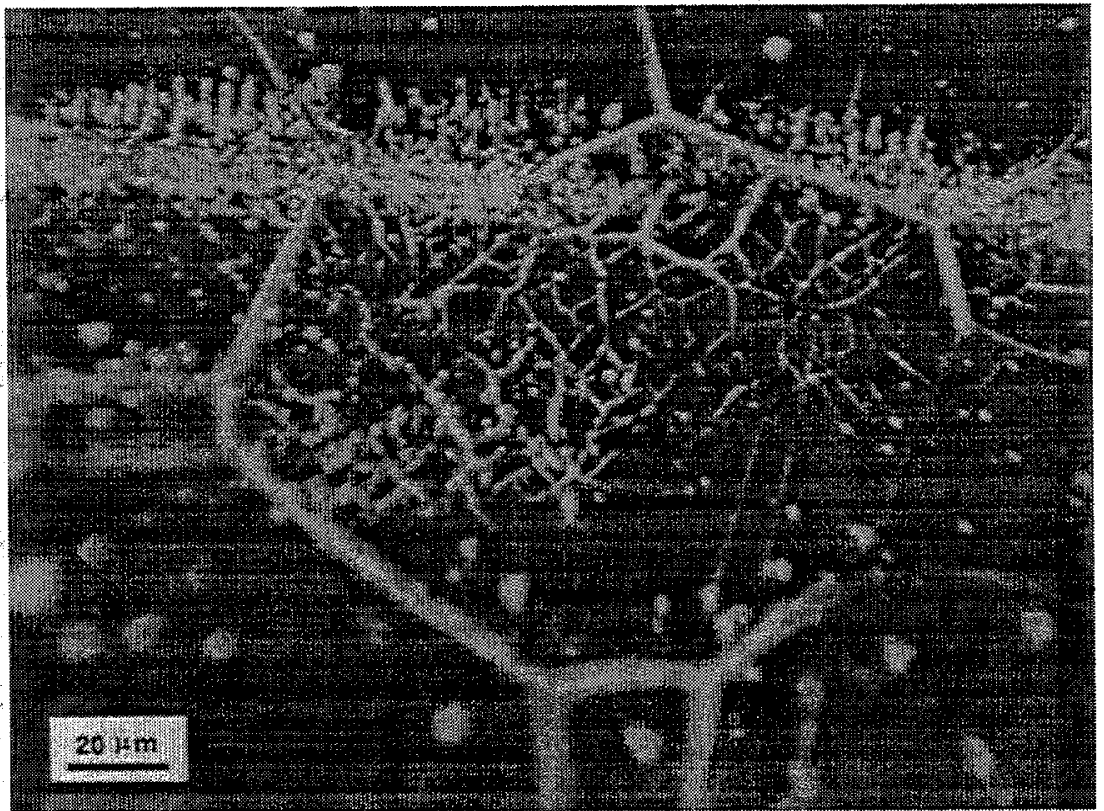

Fig. 4a. 'Branched" structure associated with Ti-rich secondary particles within band structure in heat-treated 832864 materials after heat treatment.

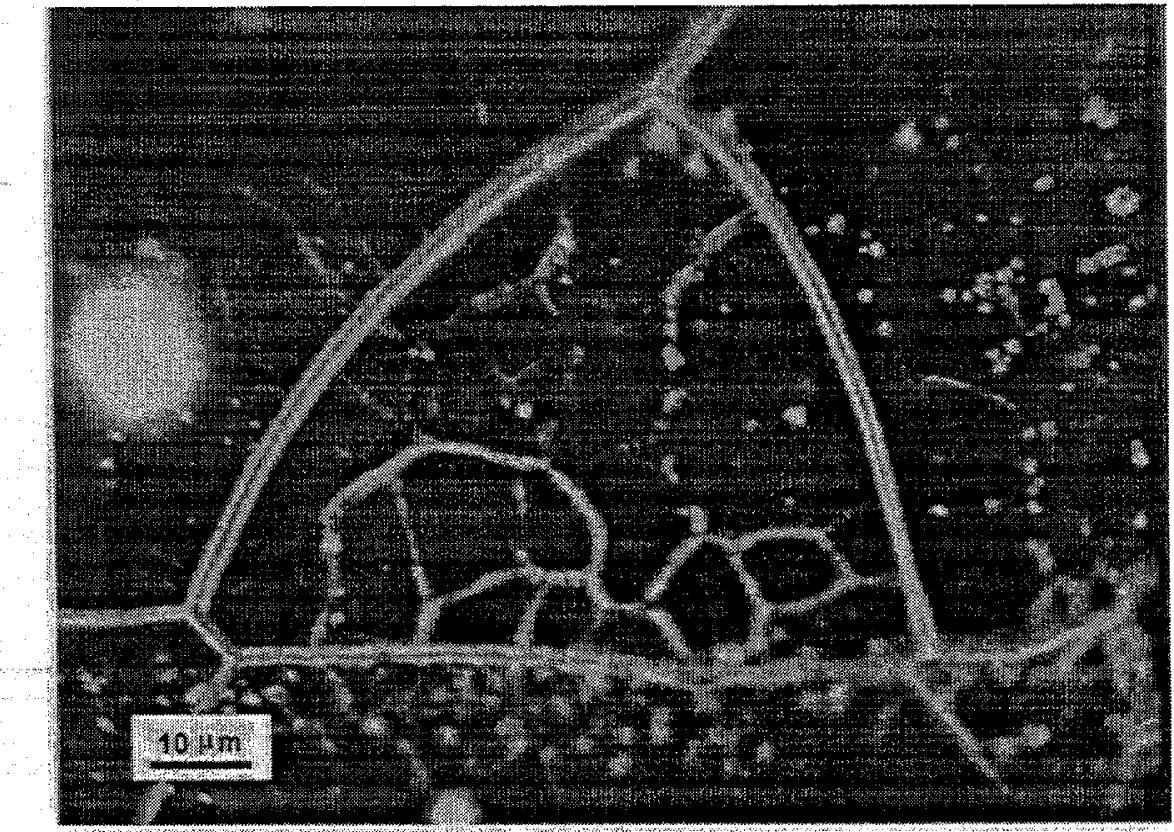

Fig. 4b. Subgrains in original grain of heat-treated 832864 materials.

Fig $3(\mathrm{~b})$ is a lower-magnification micrograph of the banded structure in the heat-treated 832864 material. For comparison, a micrograph of the as-received specimens is shown in Fig. 3(a). It appears that the heat treatment did not dissolve the banded structure although it did cause the previously elongated grains to become more equiaxed. As in the 832665 material, Fig.3(b) shows that the grain size in the banded region is smaller than in the unbanded region, and the width of 
the bands and the spacing between them are also varied from region to region. A new characteristic microstructure was observed in higher-magnification micrographs of swaged 832864 material after the heat treatment. Fig. 4(a) shows a "branched" structure associated with the Ti-rich secondary particles in the banded structure. The branches are apparently formed by joining associated with secondary particles. Directions of the branches are mostly parallel to the faceted interfaces of the grain, which is usually a low-index plan of the material. In addition, subgrains are found within grains of the heat-treated 832864 materials, as shown in Fig. 4(b). Subgrain size ranges from a few $\mu \mathrm{m}$ to $15 \mu \mathrm{m}$ and there is a strong tendency for the subgrain boundary interfaces to be faceted similarly to those of the original grain surfaces. The branched structure appears to be related to dissolution and diffusion of secondary particles. More detailed study is required to completely understand the mechanism of such structure.

\section{FUTURE ACTIVITIES}

In addition to the extruded bar and swaged rod, a piece of rolled 3.8-mm-thick plate from the 832665 heat has been heat treated under similar conditions. The microstructure of this plate material will be characterized and compared with that of the untreated material. Result will be presented in a future report.

\section{REFERENCES}

1. Y. Yan, H. Tsai, and D.L. Smith, Fusion Materials Semiannual Progress Report DOE/ER-0313/27, Dec. 1999.

2. F. Rowcliffe and D. T. Hoelzer, Fusion Materials Semiannual Progress Report, DOE/ER0313/25, Dec. 1998, pp. 42-58. 
Toughness-Temperature Curves in Oxide Dispersion Strengthened MA957- M.J. Alinger, G.R. Odette and G.E. Lucas (University of California, Santa Barbara)

\section{OBJECTIVE}

The objective of this work is to asses the fracture toughness as a function of test temperature and crack orientation in oxide dispersion strengthened (ODS) MA957 as a baseline for developing high performance nano-composited ferritic alloys.

\section{SUMMARY}

Iron based alloys strengthened with a very high density and fine dispersion of ultra-fine scale yttria-titanium-oxygen particles for improved high temperature creep strength, coupled with chromium additions for corrosion resistance, offer great promise for elevated temperature applications in fusion reactors. These alloys are usually referred to as oxide dispersion strengthened (ODS) steels. They are typically produced through mechanical alloying by mixed powder attrition, followed by consolidation and hot deformation, which may include the production of near net shape components. Given their engineered microstructural architectures and low carbon content (a key factor in their success), we feel it is more appropriate to refer to this class of materials as nano-composited ferritic alloys (NFAs).

Mechanically alloyed $14 \mathrm{Cr}-1 \mathrm{Ti}-0.3 \mathrm{Mo}-0.025 \mathrm{Y}_{2} \mathrm{O}_{3} \mathrm{MA957}$ in the form of extrusions, were produced and extensively characterized for the breeder reactor program [1]. This material showed very promising creep and tensile properties. However, limited Charpy testing demonstrated that this MA957 product has highly anisotropic grain structures and manifests extremely brittle behavior, particularly in certain orientations. Brittle behavior was attributed to the presence of alumina stringers. The objective of the present work is to characterize the fracture toughness-temperature curves for MA957 in various orientations relative to the grain and inclusion structures. Small, precracked, 1/3-sized Charpy specimens of MA957 tested in three point bending under quasi-static conditions showed low minimum toughness (<20MPa $\sqrt{ } \mathrm{m})$ and lower transition cleavage up to temperatures around $50-70^{\circ} \mathrm{C}$ in both the $\mathrm{C}-\mathrm{R}$ and $\mathrm{C}-\mathrm{L}$ orientations. At higher temperatures these orientations also manifested low resistance to stable crack growth, with maximum load toughness values ranging from about 50-100 MPa $/ \mathrm{m}$. However, the cleavage regime is shifted to much lower temperatures of around $-70^{\circ} \mathrm{C}$ for the $\mathrm{L}-\mathrm{R}$ orientation; and at high temperature maximum load toughness increased to about 125 to $145 \mathrm{MPaVm}$. At intermediate temperatures the fracture process was complex, typically involving out of plane cracking and combinations of stable extension and small cleavage pop-in events. The latter results are very encouraging and suggest that with proper development, NFA systems offer great promise to combine very high strength with good toughness and corrosion resistance.

\section{PROGRESS AND STATUS}

\section{Introduction}

Ferritic and martensitic steels are attractive candidates for structural applications in fusion reactors owing to their resistance to swelling under irradiation and inherent low activation character. Unfortunately, the creep resistance of steels such as $\mathrm{F} 82 \mathrm{H}$ is insufficient for temperatures above about $600^{\circ} \mathrm{C}$. However, the creep strength of ferritic (and other metal based) systems can be greatly increased by mechanical alloying (MA) iron and chromium powders with fine scale dispersants $\left[Y(T i)_{2} \mathrm{O}_{3}\right]$. The MA powders can then be consolidated, hot deformed and thermally treated by a variety of methods to yield desired product forms. Recently is has been observed that MA and consolidation of ferritic powders with $\mathrm{Y} 2 \mathrm{O} 3$ and Ti can produce ultra fine, $\mathrm{nm}$-scale, coherent $\mathrm{Y}-\mathrm{O}-\mathrm{Ti}$ clusters, as well as more typical fine-to-coarser scale incoherent 
$\mathrm{Y}(\mathrm{Ti})_{2} \mathrm{O}_{3}$ dispersed oxide particles [2]. The processing route and engineered reinforcement architecture produce what we call nano-composited ferritic alloys (NFAs). A current challenge to studying NFAs is that they are not currently commercially available, and generally exist only in small laboratory batch-sized quantities that are restricted in use. An exception is patented (U.S. Patent 4,075,010 [3]) MA957. Several forms of MA957 were procured for characterization of their basic mechanical properties in the 1980 s by the US Breeder Reactor Alloy Development Program [1]. However, data on the fracture resistance of MA957 is limited to a small number of Charpy Vnotch tests. Fortunately, though the efforts of Dr. D. Gelles of Pacific Northwest National Laboratory (PNNL), a residual stock of MA957 has been located, and he has supplied material to UCSB in the form of approximately $103 \mathrm{~mm}$ of a $25 \mathrm{~mm}$ diameter extrusion. This MA957 product is being used to develop a baseline understanding of the performance of NFAs, with initial emphasis on fracture toughness.

Indeed, low toughness is a potential problem with NFAs, since in common with other BCC metals and alloys, they exhibit a transition from 'ductile' stable crack growth to brittle cleavage fracture in a characteristic low temperature regime. Further, the very high strength (the yield stress for MA957 used in this study is more than $1100 \mathrm{MPa}$ at room temperature) would be expected to decrease toughness relative to conventional steels. In addition, during extrusion processing the MA957 (and similar alloys) develop highly anisotropic grain structures and corresponding variations in properties with specimen orientation. Moreover, MA processing routes are vulnerable to impurity contamination. Unfortunately, the current MA957 product was contaminated with alumina $\left(\mathrm{Al}_{2} \mathrm{O}_{3}\right)$ stringers deriving from impurities in the ferrochrome powder used to supply the chromium to the alloy [1]. These stringers are extremely detrimental to the mechanical properties of this MA957 product.

The objective of the current study is to characterize the toughness-temperature behavior of the MA957 product as a function of specimen orientation. Coupled with other measurements, which are in progress, these data will provide insight on the fracture mechanisms in this material system as well as guidance regarding approaches to improving the performance and ultimate potential of NFAs in general.

\section{Experiment}

The MA957 was procured from PNNL in the form of a hot-extruded bar produced by International Nickel Company (INCO). The chemical composition is shown in Table 1, and details of the processing can be found in Reference 1.

Table 1. Nominal Chemical Composition of MA957 (wt\%)

\begin{tabular}{|c|c|c|c|c|c|}
\hline & $\mathrm{Cr}$ & $\mathrm{Ti}$ & $\mathrm{Mo}$ & $\mathrm{Y}_{2} \mathrm{O}_{3}$ & $\mathrm{Fe}$ \\
\hline MA957 & 14.0 & 1.0 & 0.3 & 0.25 & Bal. \\
\hline
\end{tabular}

Previous microstructure characterization showed highly anisotropic structures with equiaxed grains in the transverse direction $(\approx 0.5 \mu \mathrm{m})$ but with significant elongation in the longitudinal direction resulting in $a \approx 10: 1$ aspect ratio; alumina stringers aligned in the longitudinal direction were also observed [1].

Small, 1/3-sized Charpy specimens $(3.33 \times 3.33 \times 25.4 \mathrm{~mm})$ were electro-discharge machined from the as-received bar in three orientations with respect to the extrusion direction as shown in Figure 1. Per ASTM Standard E399, these orientations included: a) circumferential specimen length-longitudinal crack plane (C-L); b) circumferential specimen length-radial crack plane ( $C$ $R$ ); and c) longitudinal specimen length-radial crack plane (L-R). Micro-hardness measurements 
$\left(\approx 355 \mathrm{~kg} / \mathrm{mm}^{2}\right)$ revealed little variation in strength through the cross-section of the bar. Fatigue pre-cracking was carried out at a final $\Delta K \leq 15 \mathrm{MPa} / \mathrm{m}$ to a nominal crack length (a) to specimen width $(W)$ ratio $a / N=0.5$.
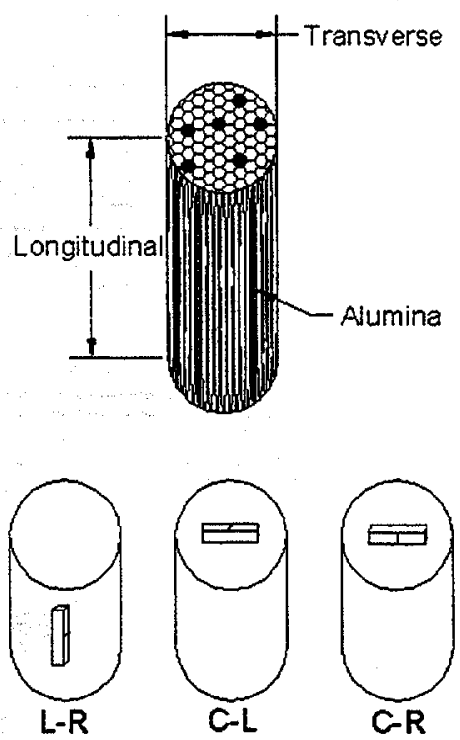

Figure 1. Specimen orientation showing grain anisotropy and alumina $\left(\mathrm{Al}_{2} \mathrm{O}_{3}\right)$ stringers.

The specimens were tested in three point bending over a temperature range from -196 to $150^{\circ} \mathrm{C}$ at approximate loading rates of $2.5 \times 10^{-6} \mathrm{~m} / \mathrm{s}$ in accordance with testing guidelines in ASTM Standard E1921-97 [4]. Load and load line displacement were monitored during testing. Depending on specimen orientation and temperature, the failure event was either a result of unstable cleavage crack propagation, cleavage pop-ins and unstable crack tearing or some combination of these. In all cases, $K_{J c}$ was determined from: $K_{J_{c}}=\left(E^{\prime} J_{1 c}\right)^{1 / 2}$, where $E^{\prime}$ is the plane strain elastic modulus and $J_{\mathrm{IC}}$ is the elastic-plastic energy release rate determined from the elastic stress intensity and the compliance corrected area under the stress-displacement curve up to the fracture or pop-in load drop per ASTM 1921-97. In several cases, a maximum load was exhibited without a pop-in event. In these cases, an effective maximum load toughness, $K_{m}$, was determined from the stress-displacement curve. The high yield stress $\left(\sigma_{\mathrm{y}}\right)$ resulted in sufficient (although not totally full) constraint up to $K_{\mathrm{Jc}}$ values near the ASTM 1921-97 censoring criteria for cleavage nucleation of $\sigma_{y} E^{\prime} b / K_{j c}{ }^{2}>30$. Note that cases with extensive stable crack growth and complex fracture path are not technically 'valid' but nevertheless represent useful measures of effective toughness.

\section{Results}

Figures 2-4 summarize the $K_{\mathrm{J} / \mathrm{m}}$ versus temperature data for the specimens tested in three orientations. The filled triangles indicate linear elastic cleavage fracture. The filled circles indicate elastic-plastic cleavage, including cases where some stable crack growth was mixed with pop-ins. The filled diamonds correspond to $K_{m}$, where some form of stable crack growth was exhibited along with minimal pop-ins. It is evident that the toughness and the cleavage transition temperature regime are highly dependent on orientation. These large toughness variations are believed to be due to the alumina stringers and anisotropic grains. 
80

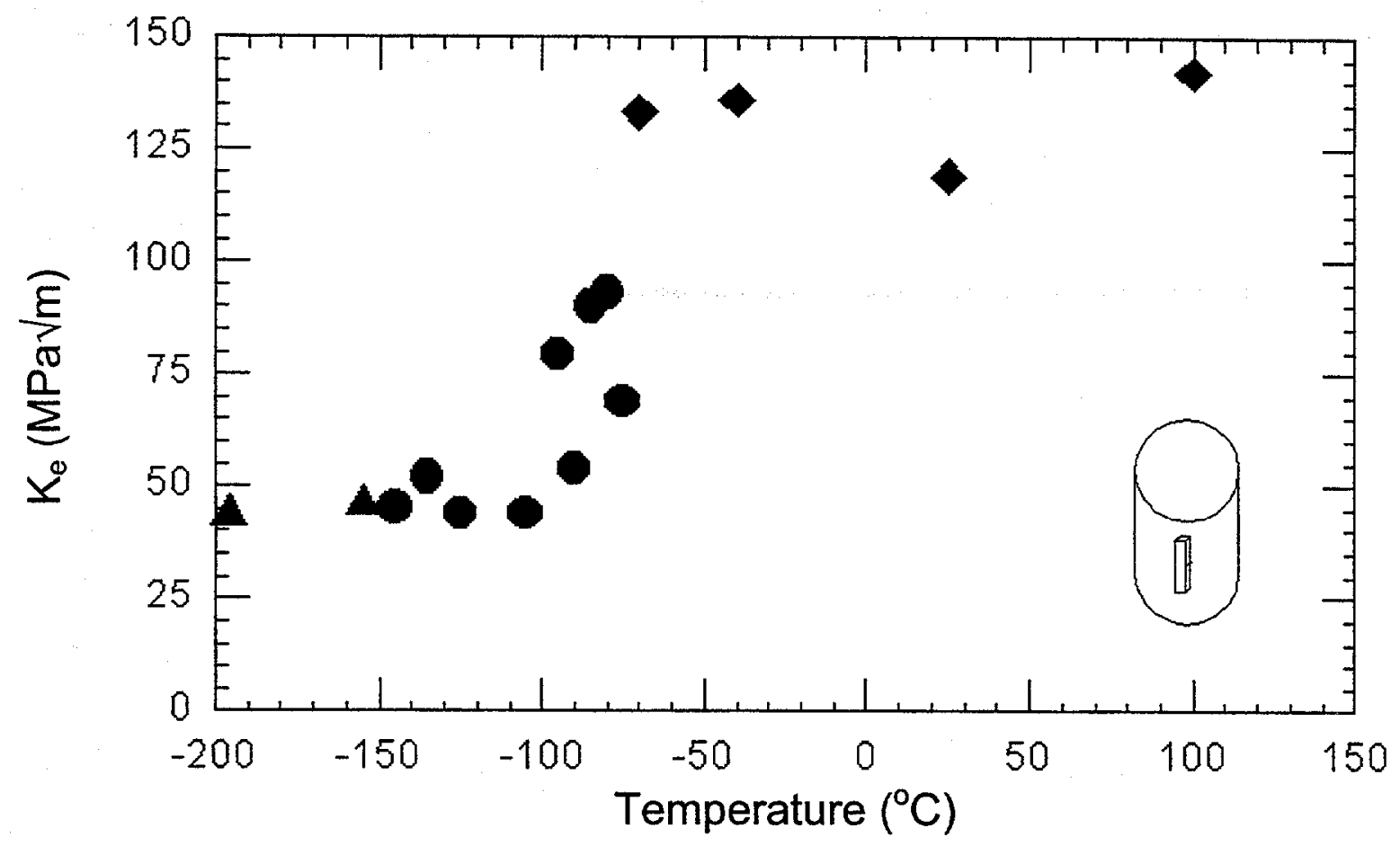

Figure 2. $\quad K_{e} V s$. Temperature for L-R orientation.

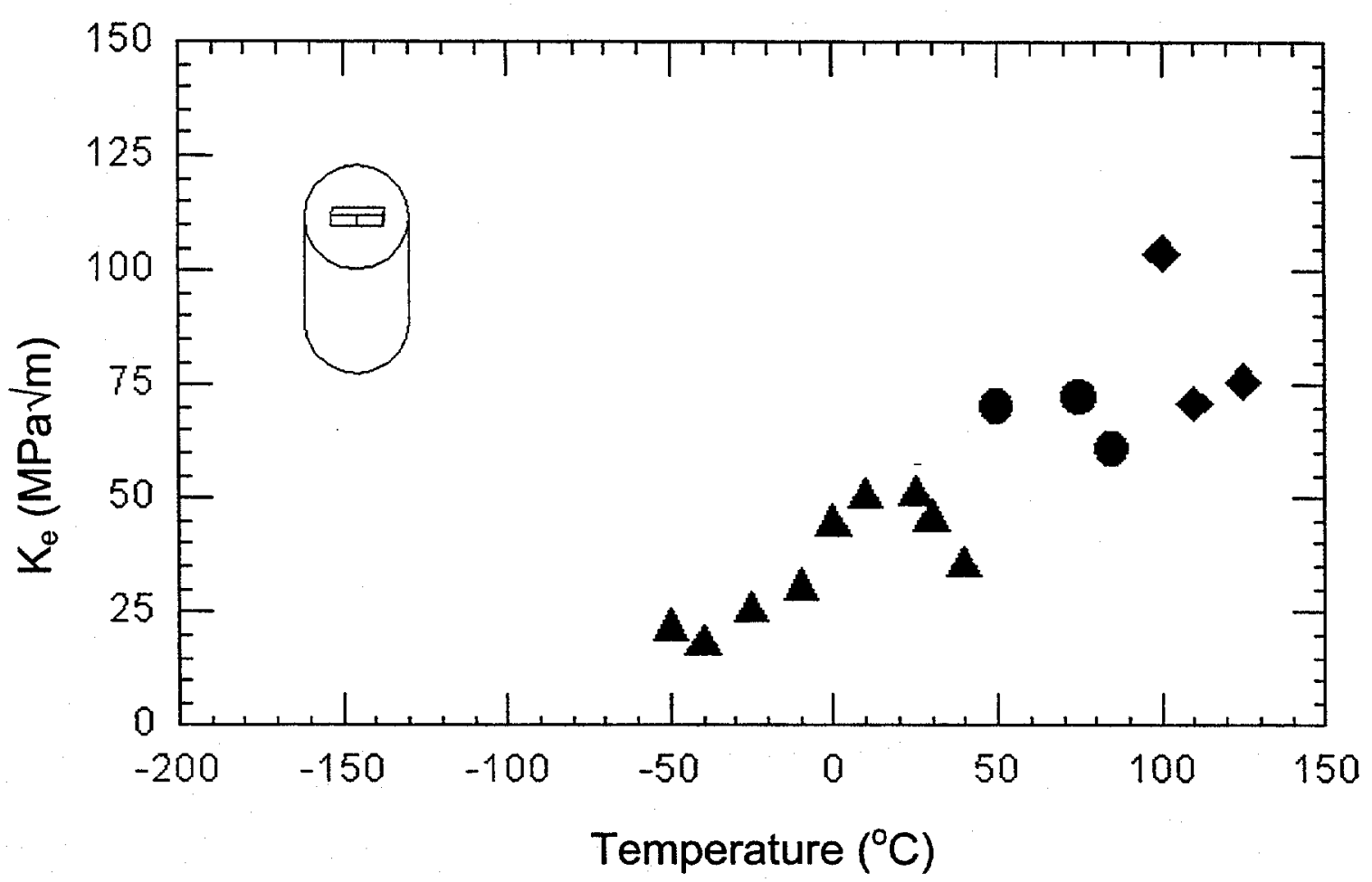

Figure 3. $\quad K_{e}$ Vs. Temperature curve for C-R orientation. 


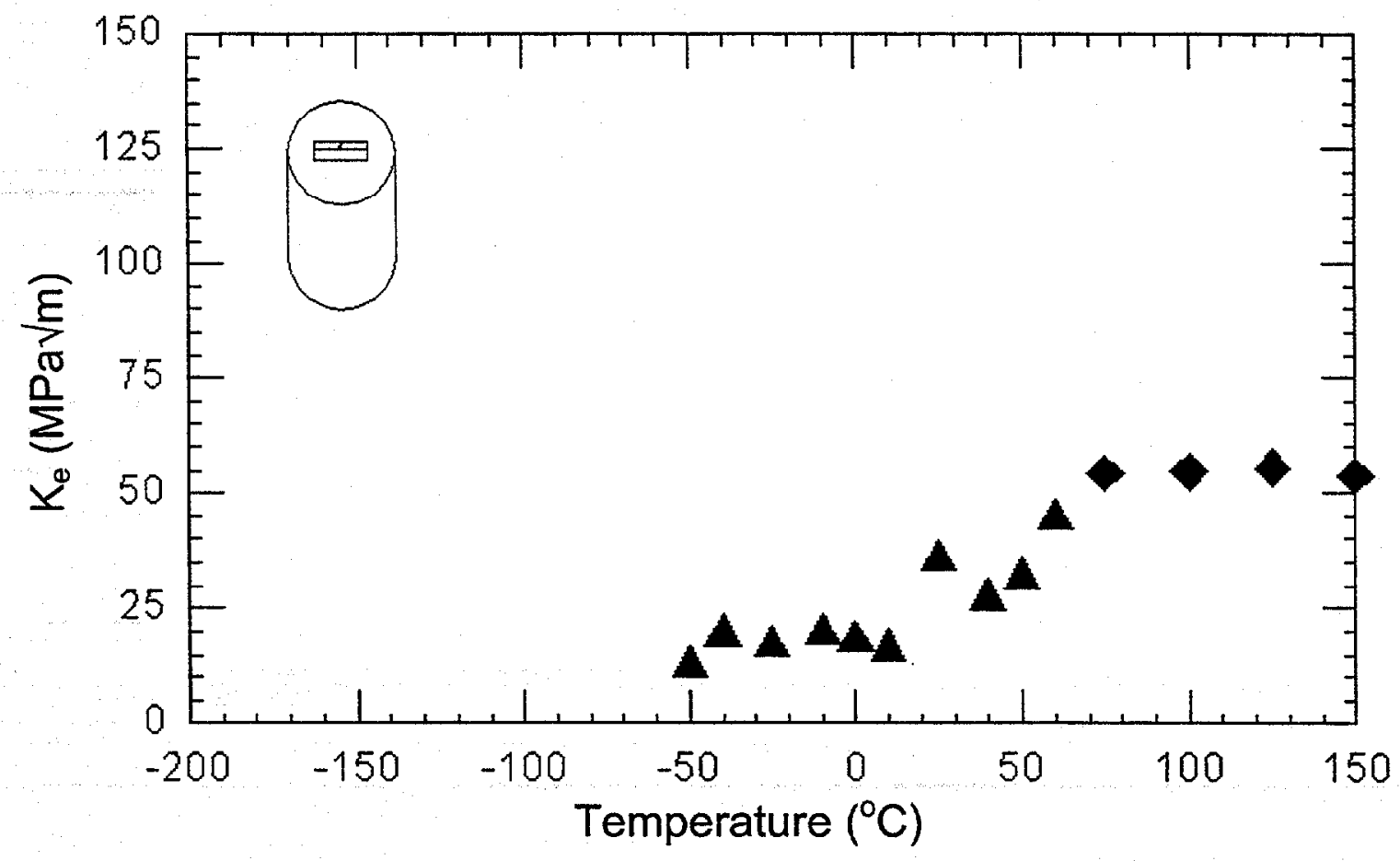

Figure 4. $\quad K_{e}$ Vs. Temperature for C-L orientation.

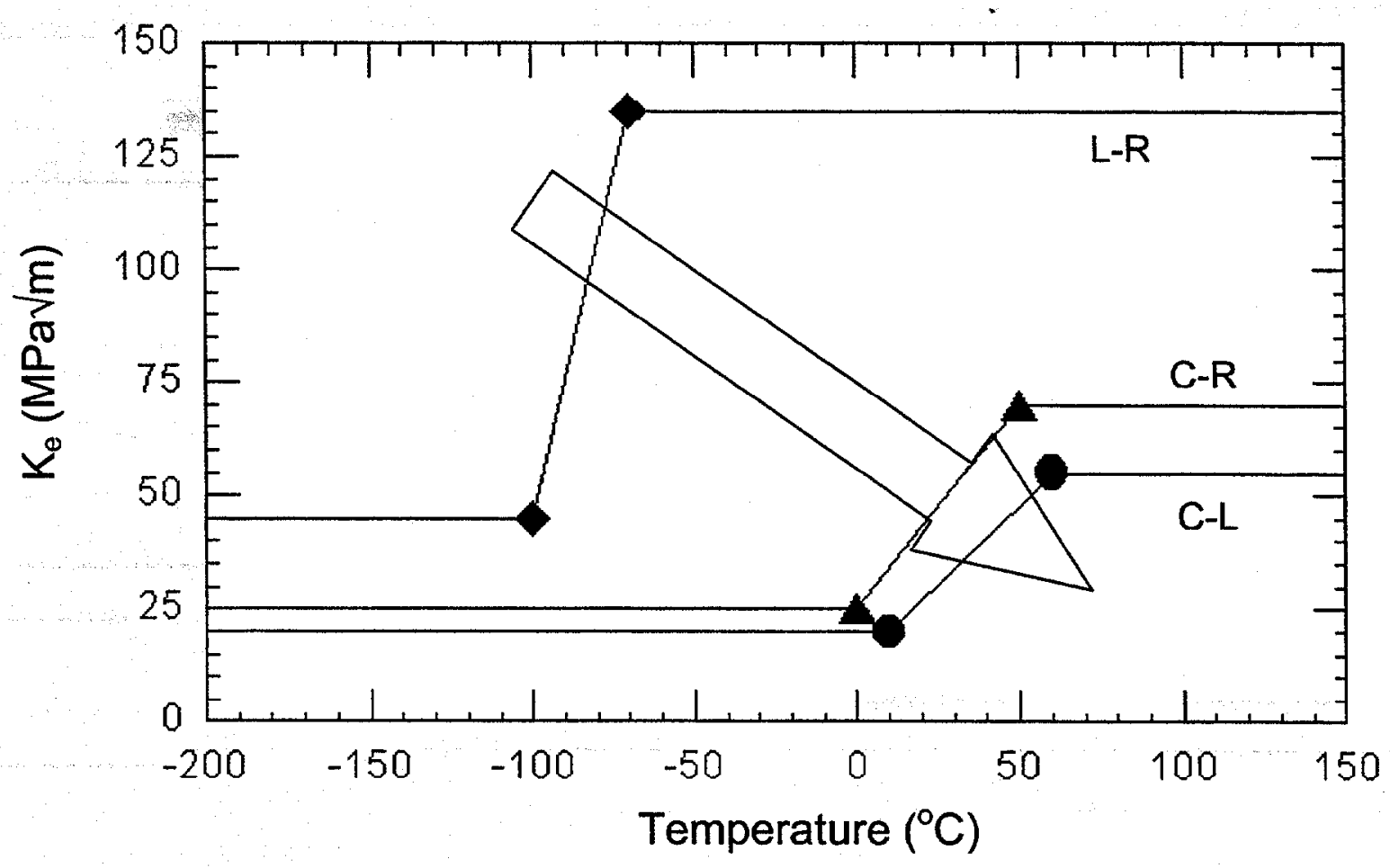

Figure 5. Ke Vs Temperature Summary for All Orientations. 
As shown in Figure 2, the L-R orientation exhibits the highest toughness levels and the lowest cleavage transition temperature range. The transition to stable crack growth occurs at about $70^{\circ} \mathrm{C}$. However, even at much lower temperatures (down to about $-145^{\circ} \mathrm{C}$ ) fracture occurs by a series of small pop-ins between arrest events with what appears to be a minimum of intervening stable growth.

The toughness levels for both circumferential orientations are much lower. Figure 3 shows the results for the C-R orientation, with intermediate toughness. Below about $50^{\circ} \mathrm{C}$ fracture is linear elastic with $\mathrm{K}_{\mathrm{lc}}<60 \mathrm{MPa} / \mathrm{m}$. Between 70 and $100^{\circ} \mathrm{C}$ there is some plasticity prior to cleavage, but the toughness remains low with $\mathrm{K}_{\mathrm{Jc}} \leq 75 \mathrm{MPa} \sqrt{\mathrm{m}}$. Ductile tearing occurs above about $100^{\circ} \mathrm{C}$ at about $75 \mathrm{MPa} / \mathrm{m}$. Note, the $\mathrm{K}_{\mathrm{m}} \approx 110 \mathrm{MPa} \sqrt{\mathrm{m}}$ point is misleading since crack tearing starts below general yield in this case.

Figure 4 shows results for the C-L orientation, which has the lowest toughness. While the toughness increases with temperature, fracture is linear elastic up to $50^{\circ} \mathrm{C}$ and has only a very small amount of plasticity up to $75^{\circ} \mathrm{C}$. Above $100^{\circ} \mathrm{C}$ it appears that stable crack tearing occurs close to or even before general yield at a very low $\mathrm{K}_{\mathrm{m}}\left(=\mathrm{K}_{\mathrm{lc}}\right)$ of about $60 \mathrm{MPa} / \mathrm{m}$. The magnitude of the upper and lower shelves decrease as well to about $20 \mathrm{MPa}$ m and $55 \mathrm{MPaVm}$, respectively.

\section{DISCUSSION}

Figure 5 summarizes the effect of specimen orientation on the transition temperature range as well as the respective calculated effective toughnesses. The fracture toughness trends reflect the high degree of microstructural anisotropy and the deleterious effects of the alumina stringers on cleavage fracture. The highest toughness occurred when the crack grew across the short dimension of the elongated grains and orthogonal to the alumina stringers, thereby intersecting the smallest cross section area of the inclusions. The lowest toughness occurred when crack growth was along the longitudinal direction, parallel to the long dimension of the grains and the quasi-continuous length of the inclusions. Intermediate behavior occurred when the inclusion stringers ran parallel to the crack front. This suggests that cleavage fracture is promoted by crack growth in directions of large grain dimension and by a high density in the crack path of alumina inclusions, which act as trigger particles for cleavage.

These conclusions are supported by SEM Fractography shown in Figures 6 to 11 . Cracking in the L-R orientation is primarily out-of-plane, transverse to the fracture surface, which shows what appear to be substantial levels of deformation (Figures 6 and 7). The fracture in the C-R orientation also has transverse components and a somewhat torturous path with ductile dimples mixed with cleavage facets on the surface (Figures 8 and 9). In contrast, the C-L orientation shows a very flat fracture surface with only limited indications of ductile fracture, split inclusions and a minimal difference between the pre-crack and predominantly cleavage surface (Figures 10 and 11). These detailed examinations are continuing and will be described in future reports.

Clearly, the generally low, and highly orientation-dependent toughness of this MA957 product do not provide acceptable levels of performance for fusion applications. However, the results in the $C-R$ and $C-L$ orientation are important primarily for fundamental reasons. The much better results for the L-R orientation are more technologically important, since they probe conditions of crack growth in the direction of small grain dimension and of minimum density in the crack path of impurity inclusions that act as the trigger particles for cleavage. These results indicate that removal of the brittle alumina stringers as well as a reduction in the 10:1 aspect ratio of the grain morphology will likely provide a material with both good toughness and very high strength as well as good corrosion resistance. 


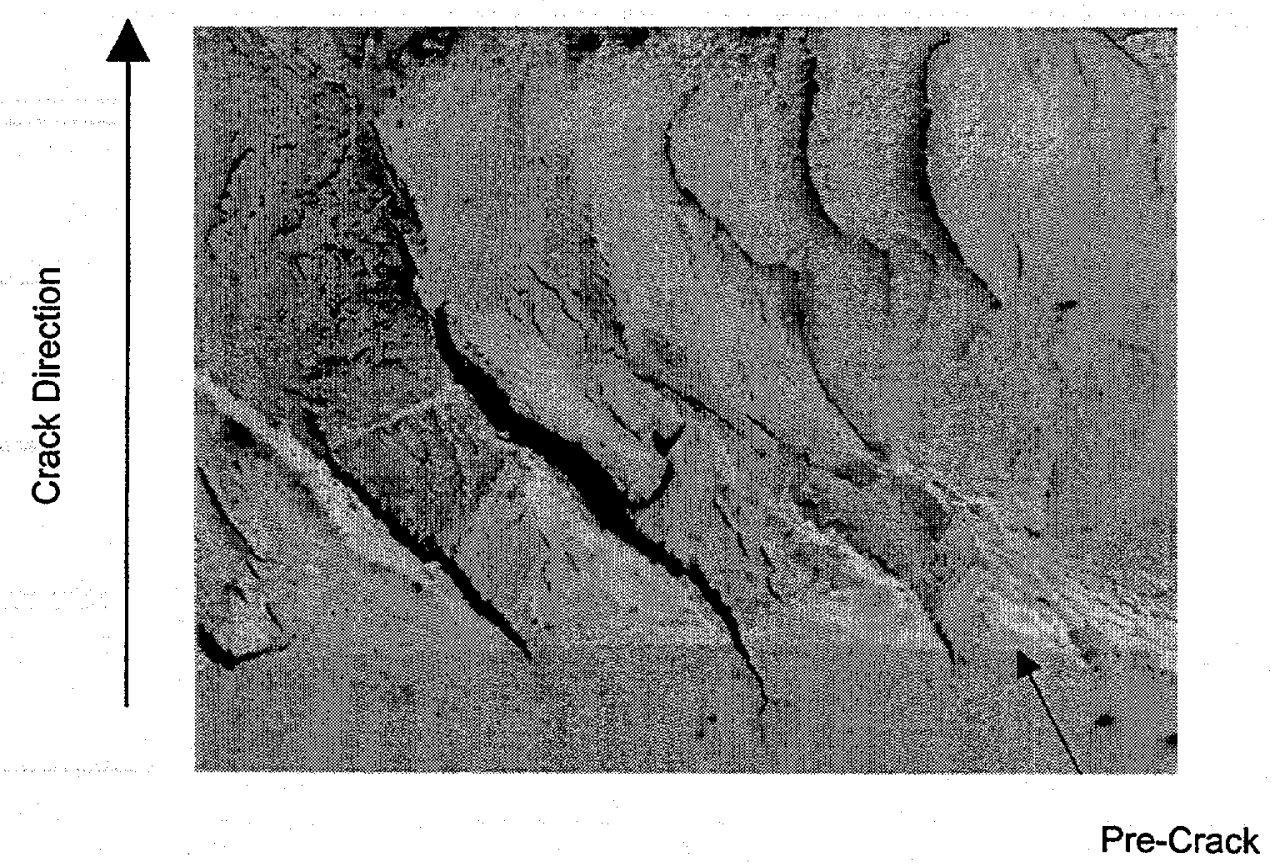

Figure 6. SEM image of fracture surface in L-R orientation tested at $-80^{\circ} \mathrm{C}$.

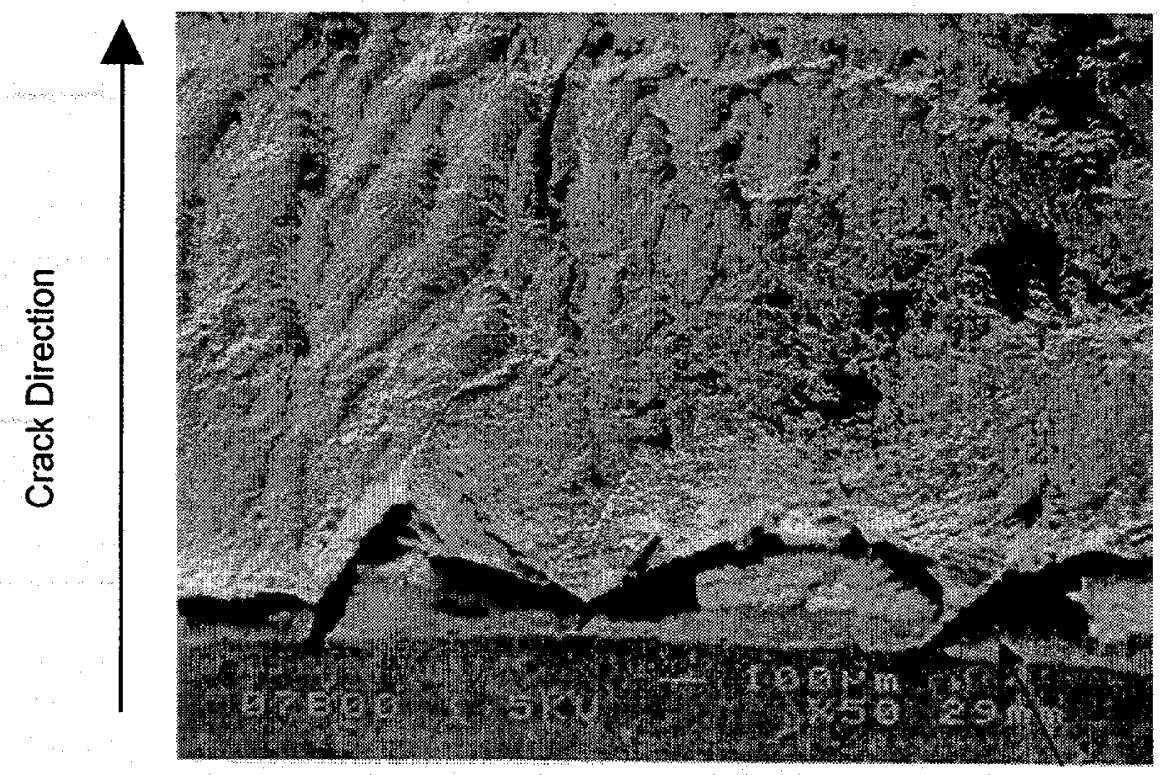

Pre-Crack

Figure 7. SEM image of fracture surface in L-R orientation tested at $-70^{\circ} \mathrm{C}$. 


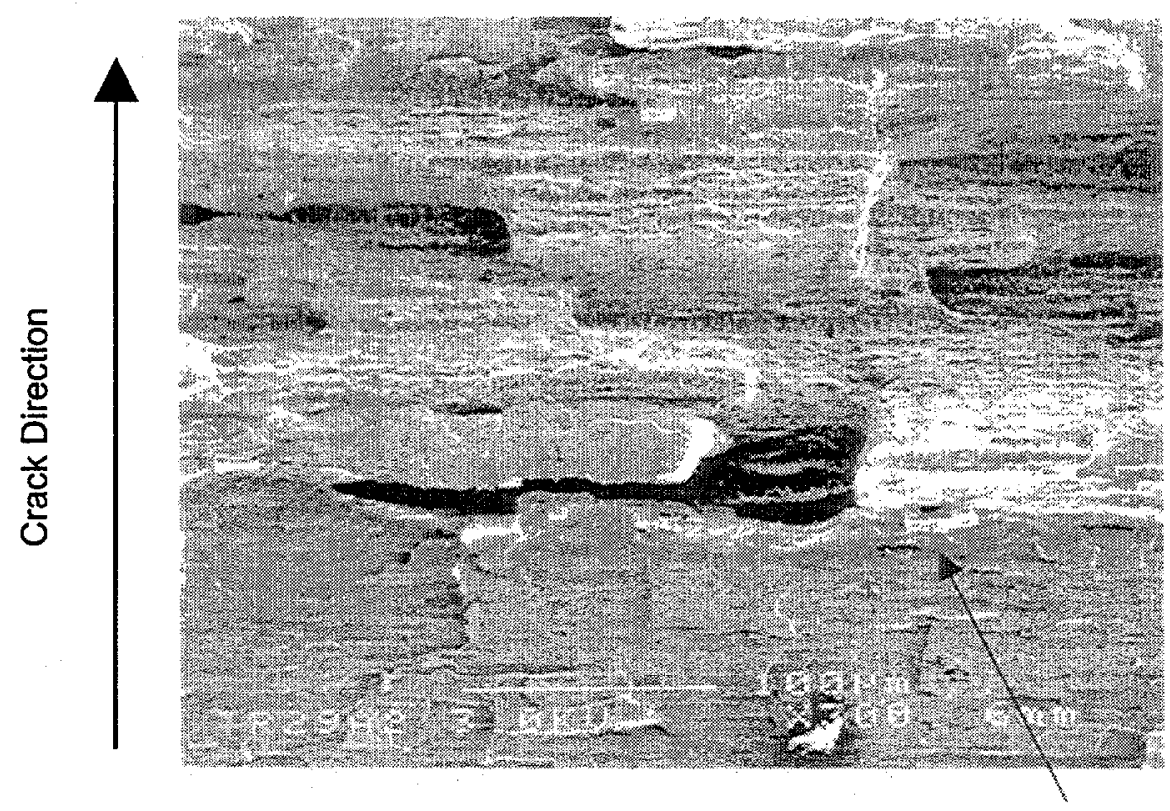

Pre-Crack

Figure 8. SEM image of fracture surface in C-R orientation tested at $-40^{\circ} \mathrm{C}$.

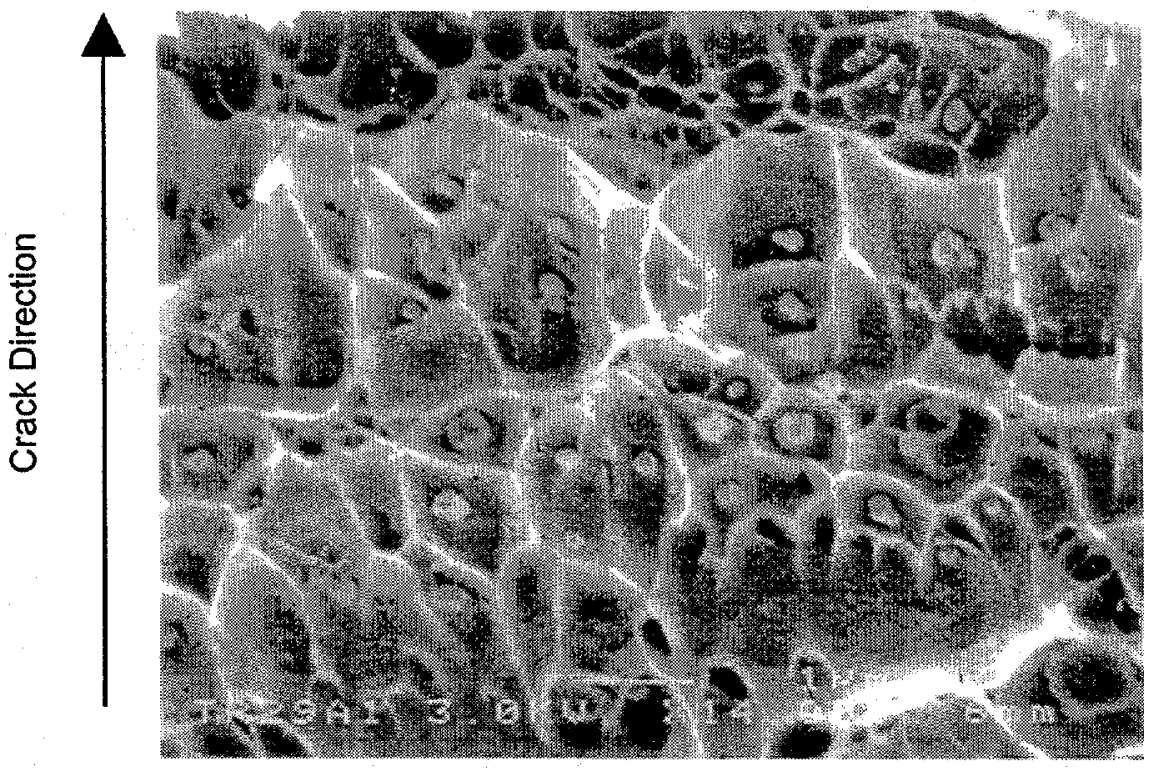

Figure 9. SEM image of fracture surface in C-R orientation tested at $-80^{\circ} \mathrm{C}$. 


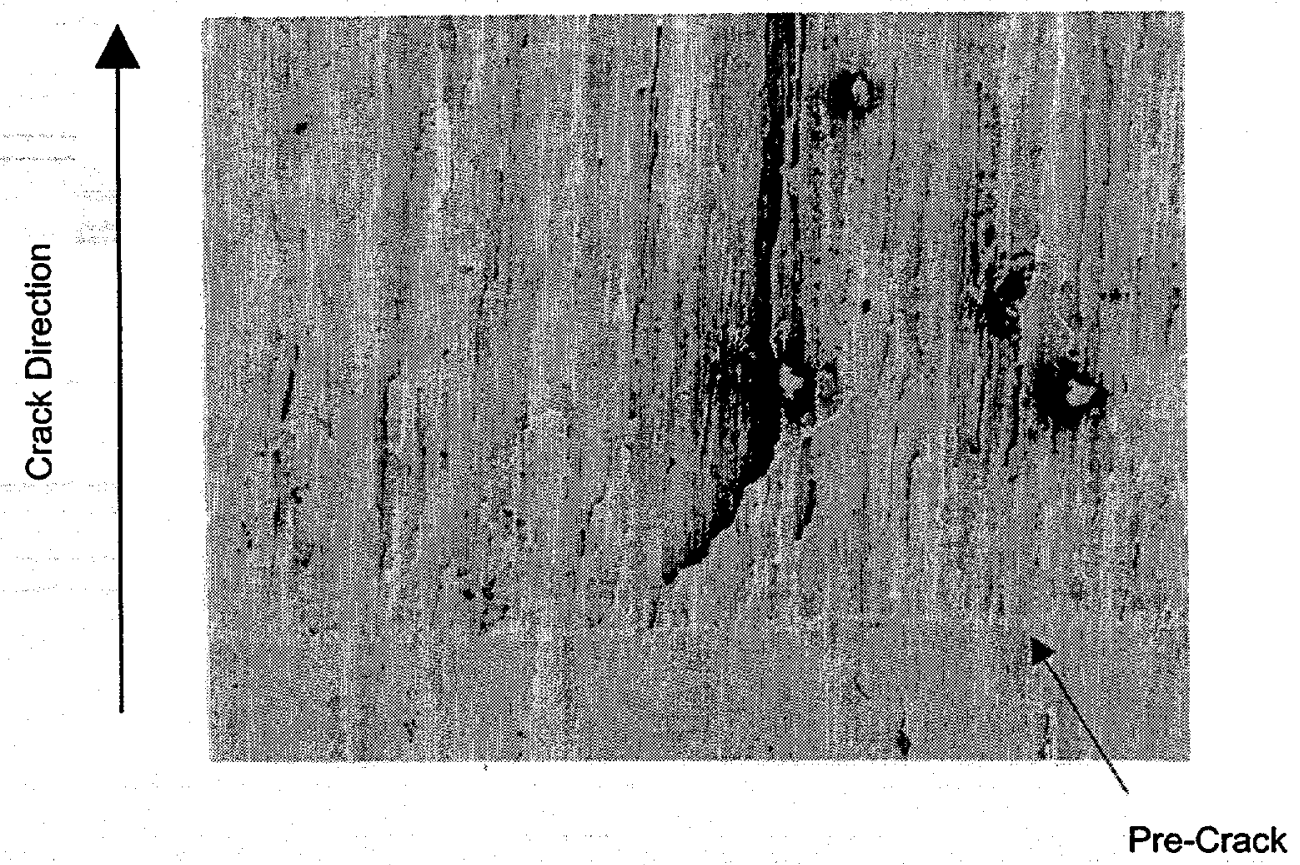

Figure 10. SEM image of fracture surface in $\mathrm{C}-\mathrm{L}$ orientation tested at $25^{\circ} \mathrm{C}$.

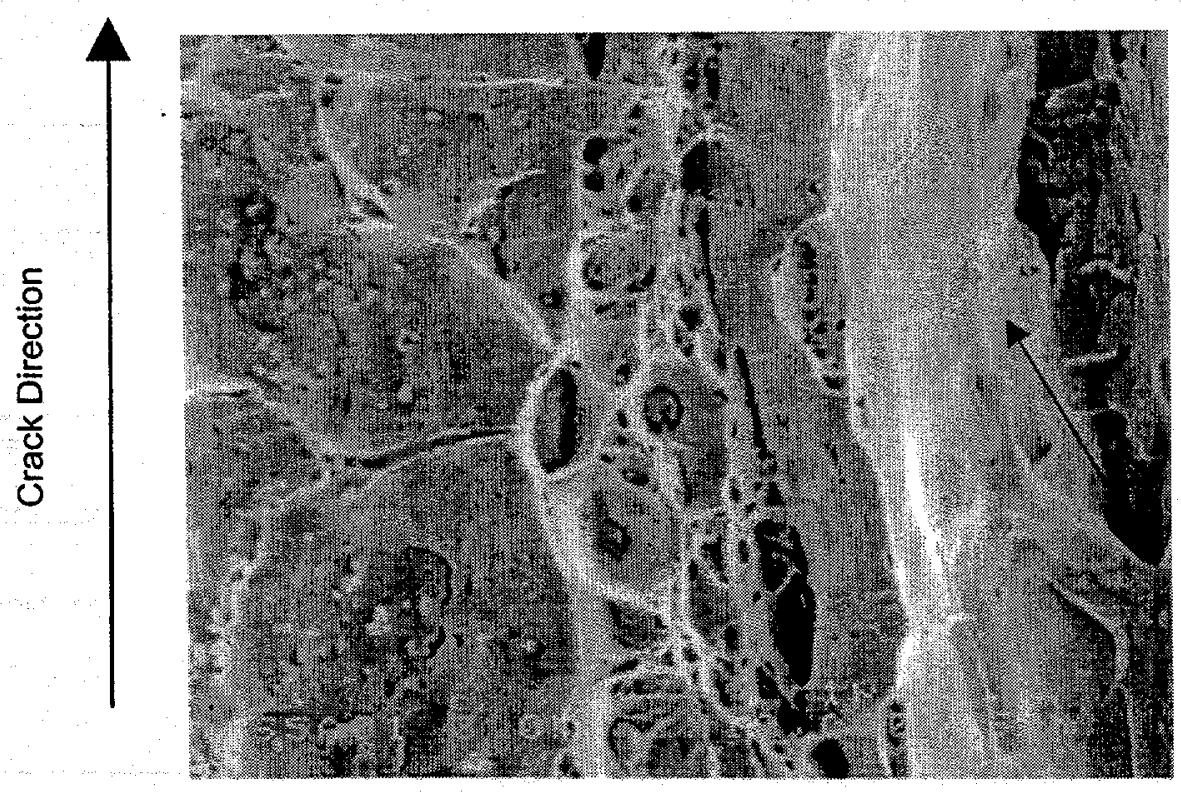

Figure 11. SEM image of fracture surface in $C-L$ orientation tested at $25^{\circ} \mathrm{C}$. 


\section{FUTURE WORK}

Investigation of some details of fracture of the MA957 product examined in this study will continue with emphasis on high resolution Fractography to characterize the mix of fracture mechanisms and to identify crack nucleation sites and the role of inclusions in crack propagation. However, given the very promising results for the L-R orientation, efforts will be initiated to procure some new high purity and more isotropic NFAs in the MA957 class with the intention of baselining what is expected to be their superior toughness performance. Further optimizations of the balance of properties using a materials system design approach will follow.

\section{ACKNOWLEDGMENTS}

This work was supported in part by the Office of Fusion Energy, DOE, Grant No. DE-FG03-87ER52143.

\section{REFERENCES}

1. Hamilton, M.L. et al, "Fabrication Technological Development of the Oxide Dispersion Strengthened Alloy MA957 for Fast Reactor Applications", PNNL-13168, PNL, Richland, WA, 2000.

2. Okuda, T. and M. Fujiwara, "Dispersion Behavoiur of Oxide Particles in Mechanically Alloyed ODS Steel", Journal of Materials Science Letters, V14, pp 1600-1603, 1995.

3. Fischer, J.J., U.S. Patent 4,075,010, "Dispersion Strengthened Ferritic Alloy for use in Liquid Metal Fast Breeder Reactors", issued Feb. 21, 1978.

4. E 1921-97, "Standard Test Method for Determination of Reference Temperature, To, for Ferritic Steels in the Transition Range", American Society for Testing and Materials, Philadelphia, 1997. 


\subsection{SILICON CARBIDE COMPOSITE MATERIALS}


POLYMER DERIVED SIC MATERIALS FOR JOINING SILICON CARBIDE COMPOSITES FOR FUSION ENERGY - C. A. Lewinsohn and R. H. Jones (Pacific Northwest National Laboratory*), T. Nozawa, M. Kotani, Y. Katoh and A. Kohyama (Institute of Advanced Energy, Kyoto University)

\section{OBJECTIVE}

Reliable and practical joining techniques are required to enable the use of silicon carbide composites in fusion energy systems. Based on criteria relevant to fusion applications, silicon carbide has been selected as a promising joint material [1]. The objective of this work is to evaluate the thermal stability and mechanical properties of silicon carbide joints fabricated via preceramic polymer precursor pyrolysis.

\section{SUMMARY}

The fabrication of large or complex silicon carbide-fiber-reinforced silicon carbide ( $\mathrm{SiC} / \mathrm{SiC}$ ) components for fusion energy systems requires a method to assemble smaller components that are limited in size by manufacturing constraints. Recently families of polymers that yield inorganic materials subsequent to pyrolysis have been a subject of extensive international research [2-9]. One such polymer, allyl-hydridopolycarbosilane (aHPCS), has been shown to have good high temperature mechanical properties as well as requiring a relatively low temperature for pyrolysis [5]. In this study the mechanical properties of joints fabricated by aHPCS were measured. Preliminary results indicate that the strength value of the aHPCS joints are slightly lower than those of reaction-based methods.

\section{PROGRESS AND STATUS}

\section{Introduction}

A limitation of $\mathrm{SiC} / \mathrm{SiC}$ composite materials is that they can only be produced in limited sizes and shapes. Therefore, to fabricate a complete fusion energy system a method of joining $\mathrm{SiC} / \mathrm{SiC}$ components is required. In fusion energy systems utilizing silicon carbide first-wall materials it would be undesirable to use a joining technique that introduces dissimilar materials at the inner face of the first wall. In addition, to avoid poisoning the plasma the first wall must be hermetic. Therefore, two attractive methods of joining silicon carbide with other forms of silicon carbide have been developed: reaction bonding [10-13], and preceramic polymer adhesives [2-9]. In this report, preliminary results obtained from joints formed by a preceramic polymer adhesive will be presented. These results were obtained during collaborative work by $\mathrm{Dr}$. Lewinsohn during a one month stay at the Institute of Advanced Energy, Kyoto University (June 15 - July 11, 2000). Plans for additional study of joining and joint testing techniques were also made and are summarized in Tables I and II (experiments already conducted are underlined).

\footnotetext{
- Pacific Northwest National Laboratory (PNNL) is operated for the U.S. Department of Energy by Battelle Memorial Institute under Contract DE-AC06-76RLO-1830.
} 
Table I

Summary of Required Number of Test Specimens

\begin{tabular}{|l|l|l|l|l|l|l|l|}
\hline Joint Material & CREST-PP & \multicolumn{2}{l|}{ CREST-RB } & Torino-CA & Starfire \\
\hline Substrate & CVD-SiC & $\begin{array}{l}\mathrm{CVI} \\
\mathrm{SiC}_{\mathrm{f}} / \mathrm{SiC}_{\mathrm{m}}\end{array}$ & CVD-SiC & $\begin{array}{l}\mathrm{CVI} \\
\mathrm{SiC}_{\mathrm{f}} / \mathrm{SiC}_{\mathrm{m}}\end{array}$ & CVD-SiC & $\begin{array}{l}\text { CVI } \\
\mathrm{SiC}_{\mathrm{f}} / \mathrm{SiC}_{\mathrm{m}}\end{array}$ & $\begin{array}{l}\mathrm{CVD}- \\
\mathrm{SiC}\end{array}$ \\
\hline F1 & 5 & 5 & 5 & 5 & 5 & 5 & 5 \\
\hline A1 & & 5 & & 5 & & 5 & \\
\hline F2 & & 15 & & 15 & & 15 & 5 \\
\hline A2 & & 15 & & 15 & & 15 & \\
\hline D & & & & & & & 10 \\
\hline
\end{tabular}

Table II

Matrix of Mechanical Test Conditions and Required Number of Specimens

\begin{tabular}{|c|c|c|c|c|c|c|c|c|}
\hline \multirow{2}{*}{\multicolumn{2}{|c|}{$\begin{array}{l}\text { Joint Material } \\
\text { Substrate }\end{array}$}} & \multicolumn{2}{|c|}{ CREST-PP } & \multicolumn{2}{|c|}{ CREST-RB } & \multicolumn{2}{|l|}{ Torino-CA } & \multirow{2}{*}{$\begin{array}{l}\text { Starfire } \\
\text { CVD- } \\
\mathrm{SiC}\end{array}$} \\
\hline & & $\begin{array}{l}\text { CVD- } \\
\text { SiC }\end{array}$ & $\begin{array}{l}\text { CVI } \\
\text { SiC/SiC }\end{array}$ & $\begin{array}{l}\text { CVD- } \\
\text { Sir }\end{array}$ & $\begin{array}{l}\text { CVI } \\
\text { Sirsir }\end{array}$ & CVD-SiC & $\begin{array}{l}\text { CVI } \\
\mathrm{SiC} / \mathrm{SiC}\end{array}$ & \\
\hline Test & $\begin{array}{l}\text { Treat- } \\
\text { ment }\end{array}$ & & & & & & & \\
\hline F1 & $\mathrm{N}$ & 5 & 5 & 5 & 5 & 5 & 5 & 3 \\
\hline A1 & $\mathrm{N}$ & & 5 & & 5 & & 5 & \\
\hline F2 & $N$ & & 5 & & 5 & & 5 & 5 \\
\hline A2 & $\mathrm{N}$ & & 5 & & 5 & & 5 & \\
\hline $\mathrm{D}$ & $\mathrm{N}$ & & 5 & & & & & 5 \\
\hline D & $\mathrm{A}$ & & & & & & & 5 \\
\hline F1 & A & & & & & & & 3 \\
\hline F2 & $\mathrm{A}$ & & 5 & & 5 & & 5 & \\
\hline $\mathrm{A} 2$ & $\mathrm{~A}$ & & 5 & & 5 & & 5 & \\
\hline F2 & B & & 5 & & 5 & & 5 & \\
\hline A2 & B & & 5 & & 5 & & 5 & \\
\hline
\end{tabular}

Legend:

CREST-PP: Joint material derived from pre-ceramic polymer.

CREST-RB: Joint material consisting of reaction-bonded silicon carbide.

Torino-CA: Joint material consisting of calcium-aluminosilicate glass.

Starfire: Joint material derived from alyll-hydropolcarbosilane preceramic polymer.

$\mathrm{F} 1=1 / 4$, four-point bend test. $2 \times 3 \times 50 \mathrm{~mm}$ specimen.

$F 2=1 / 4$, four point bend test. $2 \times 2 \times 25 \mathrm{~mm}$ specimen.

$\mathrm{A} 1=$ asymmetric four-point bend test. $2 \times 2 \times 50 \mathrm{~mm}$ specimen .

$\mathrm{A} 2$ = asymmetric four-point bend test. $2 \times 2 \times 25 \mathrm{~mm}$ specimen.

$\mathrm{D}=$ double notch shear test. $8 \times 15 \times 30 \mathrm{~mm}$ specimen.

$\mathrm{N}=$ no heat treatment.

$A=1373 \mathrm{~K}, 100 \mathrm{~h}$, argon.

$B=1373 \mathrm{~K}$, ten $10 \mathrm{~h}$ cycles, vacuum. 


\section{Experimental Technique}

\section{Task 1-specimen preparation}

To evaluate the suitability of joints formed by aHPCS, butt-joined, flexural specimens for four point bend testing [14] were fabricated from plates of monolithic, chemically vapor deposited (CVD) silicon carbide (Morton. Advanced Materials, Woburn, MA) were joined by Starfire Systems, Inc. (Watervliet, NY), developers of the aHPCS polymer. Two plates of CVD silicon carbide, approximately $4 \mathrm{~mm}$ thick, were cut into $25 \mathrm{~mm}$-long by $30 \mathrm{~mm}$-wide pieces. The polymer was applied to the $30 \times 4 \mathrm{~mm}$ faces and held in a special fixture. The material was cured and pyrolysed by Starfire Systems, Inc.. The pyrolysis temperature was $1000 \mathrm{C}$. The joined materials were sent to Chand inc. (Worcester, MA), for additional machining into mechanical test specimens.

IAE, Kyoto University procured $\mathrm{SiC}_{f} / \mathrm{SiC}_{\mathrm{m}}$ composite, fabricated by a preceramic polymer impregnation method (PIP). Initial steps to join the $\mathrm{SiC}_{\mathrm{f}} / \mathrm{SiC}_{\mathrm{m}}$ composite with a preceramic precursor, polyvinylsilane (PVS), were made by researchers at IAE. In addition, the $\mathrm{SiC}_{\mathrm{f}} / \mathrm{SiC}_{\mathrm{m}}$ composite will be joined, at $\mathrm{IAE}$, using two other techniques: reaction sintering of silicon carbide and the use of glass ceramic materials. Mechanical test specimens will be fabricated from these materials.

\section{Task II - mechanical testing}

The details of the experimental program were coordinated during Dr. Lewinsohn's visit to IAE. Specimens, with dimensions of $2 \times 2 \times 50 \mathrm{~mm}$, of all joint compositions will be tested in $1 / 4$, four point bending at room temperature to establish baseline properties. Specimens of this dimension, with $\mathrm{SiC}_{f} / \mathrm{SiC}_{\mathrm{m}}$ composite substrates only, will also be tested in asymmetric four point bending. Subsequently, the suitability of using smaller test specimens will be evaluated using $\mathrm{SiC}_{\mathrm{f}} / \mathrm{SiC}_{\mathrm{m}}$ specimens with dimensions of $2 \times 2 \times 25 \mathrm{~mm}$. The number and type of each specimen that will be tested are shown in Table I and II. Underlined numbers represent experiments that were performed during Dr. Lewinsohn's visit to IAE.

The high-temperature durability of joining materials will be evaluated by heat treating various specimens at $1373 \mathrm{~K}$ for 100 hours. The number and type of specimens that will be heat treated is shown in Table II. Numbers in bold type indicate specimens that were heat treated during the visit of Dr. Lewinsohn to IAE. The effect of thermal cycling on joint materials will be evaluated by testing materials after cycling the materials between 298 and $1373 \mathrm{~K}$ ten times. The number and type of specimens that will be subject to the thermal cycling treatment is shown in Table II.

\section{Results}

The flexural strength of specimens joined with aHPCS by Starfire Systems, Inc. was tested at room temperature, before and after heat treatment at $1373 \mathrm{~K}$, in argon, for $100 \mathrm{~h}$. Prior to heat treatment, the value of the flexural strength was $85 \mathrm{MPa}$ with a standard deviation of 11 $\mathrm{MPa}$ (Fig. 1). Subsequent to heat treatment the value of the flexural strength was $79 \mathrm{MPa}$ with a standard deviation of $21 \mathrm{MPa}$ (Fig. 2). Therefore, it appears as if the strength of the joint material was unaffected by the heat treatment that was performed. In contrast, as reported in the prior semi-annual report [14], the strength of joints made from a reactionbased silicon carbide increased from $134 \pm 25 \mathrm{MPa}$ to $212 \pm 108 \mathrm{MPa}$ after an identical heat treatment. 
The room temperature strength of reaction-formed silicon carbide joints between Hexoloy SA silicon carbide has been reported as $255 \pm 3.2 \mathrm{MPa}$, by researchers at the NASA Glenn Research Center [11]. Materials fabricated at NASA Glenn were provided to PNNL and a flexural strength of $53 \mathrm{MPa}$ with a standard deviation of $6 \mathrm{MPa}$ (3 specimens) was measured, as reported in the prior semi-annual report [14]. Two specimens, from the same batch of materials supplied by NASA Glenn, were provided to an independent investigator (Dr. O. Unal, Ames Laboratory, Ames, IA) who had earlier measured values similar to those that had been reported by investigators at NASA Glenn Research Center. These specimens exhibited $1 / 4$, four-point flexural loading of $72 \mathrm{MPa}$ and $122 \mathrm{MPa}$ [14]. These results indicate that although there may be some experimental error in the measurements made at PNNL, the material provided by NASA Glenn Research Center had a lower than expected strength. Additionally, the value of the strength of the joints made from the aHPCS material were in the same range as the joints made from reaction-based and reaction-formed $\mathrm{SiC}$ materials (Fig. 1). It must be noted that the aHPCS joints were between CVD SiC material, whereas the other joints were between sintered $\alpha$-SiC. Furthermore, Starfire systems claims that aHPCS containing nano-sized SiC filler material exhibits a higher strength than pure aHPCS derived material.

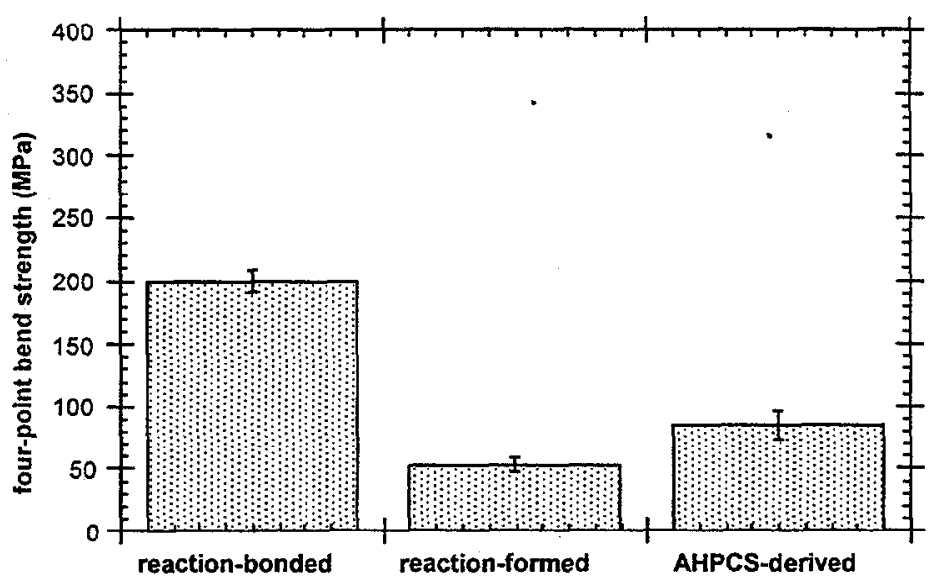

Figure 1. A comparison of strength values for joints tested at room temperature.

Scanning electron microscopy (SEM) and energy dispersive $X$-ray analysis (EDX) were used to investigate the fracture surfaces of specimens joined by aHPCS. In all samples, both fracture surfaces were covered by aHPCS material (as determined from the presence of oxygen detected by EDX analysis) indicating that failure occurred in the aHPCS layer and not at the interfaces between the aHPCS and the SiC. In the untreated specimens there were some areas that were not covered by aHPCS. These areas appeared as continuous channels and were likely due to the evolution of gas during pyrolysis.

The failure origin was located at a corner of the fracture surface of each specimen joined by aHPCS. Although this means that the true strength of the joint was not obtained (due to the stress intensification by the corners and free surfaces), this also indicates that there were no large strength limiting defects in the microstructure. The entire surface of the aHPCS material contained cracks (Fig. 3), but the crack opening in the area around the failure origin was greater than that observed at other locations on the fracture surface (Fig. 4). The cracks 
were likely due to shrinkage during curing and pyrolysis. It could not be determined whether the cracks were the cause of failure, or caused by it. Either hypothesis can be justified, but since the regions of larger crack opening were located at the corners, rather than along an entire surface, it is more likely that the fracture was initially more tortuous and then became

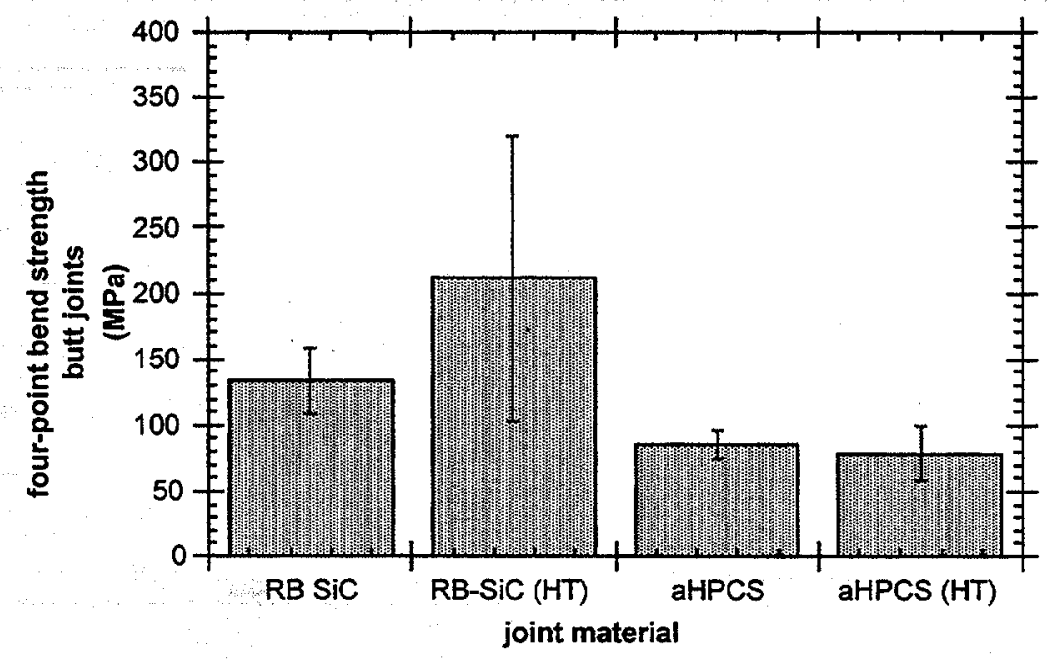

Figure 2. A comparison of the strength, before and after heat treatment at $1373 \mathrm{~K}$ for $100 \mathrm{~h}$, of sintered $\mathrm{SiC}$ (Hexalloy ${ }^{\mathrm{TM}}$, Carborundum $\mathrm{Co}$.) joined by reaction-bonded $\mathrm{SiC}$ (Busek, Inc.) with CVD SiC (Morton Advanced Materials, Inc.) joined by aHPCS derived SiC.

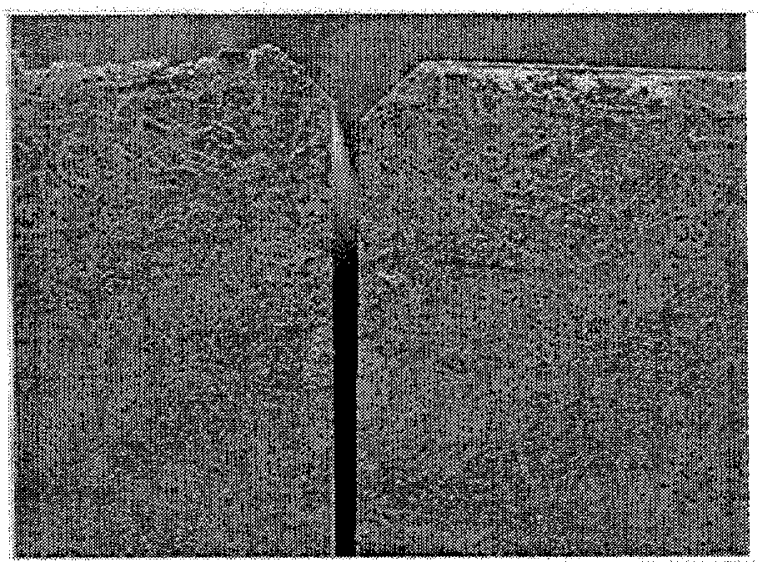

Figure 3. A micrograph $(50 \mathrm{x})$ of the matching surfaces of a typical fractured specimen joined by aHPCS derived material.

more planar as the crack velocity increased. If an entire side of the specimen had contained cracks with a larger opening than the rest of the specimen this may have been due to asymmetrical heat loss or transport of product gases during pyrolysis. 


\section{Conclusions}

Initial studies have shown that joints between silicon carbide can be fabricated from preceramic polymer precursors. The strength of joints made from aHPCS were within the range of values obtained for joints made from reaction based methods. Preliminary results

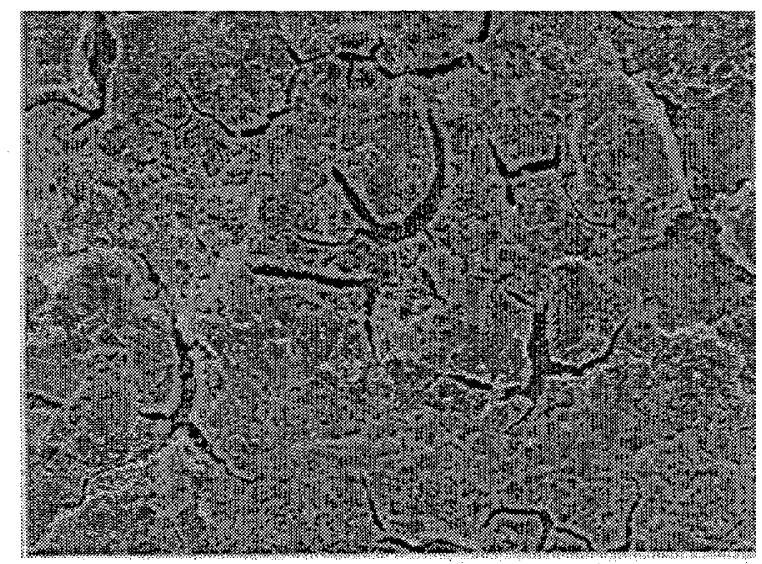

Figure 4. Higher magnification $(500 \mathrm{x})$ view of a typical fracture surface showing cracks in aHPCS material.

indicate that failure occurs in the aHPCS layer and that the bonding between the aHPCS and $\mathrm{SiC}$ is relatively strong.

\section{REFERENCES}

[1] C. A. Lewinsohn, R. H. Jones, "A Review of Joining Techniques for $\mathrm{SiC}_{f} / \mathrm{SiC}_{\mathrm{m}}$ Composites for First Wall Applications," Fusion Materials Semiannual Progress Report for the Period Ending June 30, 1998, DOE/ER.

[2] R. Riedel, L. Ruswich, L. An, and R. Raj, "Amorphous Silicoboron Carbonitride Ceramic with Very High Viscosity at Temperatures above $1500^{\circ} \mathrm{C}$," J. Am. Ceram. Soc., 81 [12], 3341-3344 (1998).

[3] S. Yajima, K. Okamura, T. Shishido, Y. Hasegawa, and T. Matsuzawa, "Joining of SiC to $\mathrm{SiC}$ Using Polyborosiloxane," Am. Ceram. Soc. Bull., 60, 253, (1981).

[4] A. Donato, P. Colombo, and M. O. Abadirashid, "Joining of SiC to SiC using a preceramic Polymer," pp. 471-476 in High-Temperature Ceramic -Matrix Composites I, A. G. Evans and R. Naslain (eds.), Ceram. Trans., 57, The American Ceramic Society, Westerville, Ohio, USA, 1995.

[5] W. J. Sherwood, C. K. Whitmarsh, J. M Jacobs, and L. V. Interrante, "Joining Ceramic Composites Using Active Metal/HCPS Preceramic Polymer Slurries," Cer. Eng. Sci. Proc., 18, 177-184 (1997).

[6] O. Unal, I .E. Anderson, M. Nostrati, S. ljadi-Maghsoodi, T. J. Barton, and F. C. Laabs, "Mechanical Properties and Microstructure of a Novel SiC/SiC Joint," pp. 185-194 in Ceramic Joining, I. E. Reimanis, C. H. Henager, Jr., and A. P. Tomsia (Eds.), Ceramic Transactions, vol. 77, The American Ceramic Society, Westerville, Ohio, USA, 1997. 
[7] P. Colombo, "Joining Ceramics Using Preceramic Polymers," in Interfacial Science in Ceramic Joining, NATO Advanced Research Workshop, Bled, Slovenia, November 12 $15,1997$.

[8] P. Colombo, V. Sglavo, E. Pippel, and J. Woltersdorf, "Joining of Reaction-Bonded Silicon Carbide Using a Preceramic Polymer," J. Mat. Sci., 33, 2409-2416 (1998).

[9] E. Pippel, J. Woltersdorf, P. Colombo, and A. Donato, "Structure and Composition of Interlayers in Joints Between SiC Bodies," J. Eur. Ceram. Soc., 17, 1259-1265 (1997).

[10] B. H. Rabin, and G. A. Moore, "Joining of SiC-Based Ceramics by Reaction Bonding Methods," J. Mat. Synth. \& Proc., 1 [3], 195-201 (1993).

[11] M. Singh, "A Reaction Forming Method for Joining of Silicon Carbide-Based Ceramics," Scripta Mater., 37 [8], 1151-1154 (1997).

[12] M. Singh, S. C. Farmer, and J. D. Kiser, "Joining of Silicon Carbide-Based Ceramics by Reaction Forming Approach," Cer. Eng. Sci. Proc. 18 [3], 161-166 (1997).

[13] M. Singh, "Joining of Sintered Silicon Carbide Ceramics For High Temperature Applications," J. Mat. Sci. Lett, in press.

[14] C. A. Lewinsohn, R. H. Jones, M. Singh, H. Serizawa, Y. Katoh, and A. Kohyama, "Reaction Based SiC Materials for Joining Silicon Carbide Composites for Fusion Energy," Fusion Materials Semiannual Progress Report for the Period Ending December 31, 1999, DOE/ER. 
Tensile Strength and Fracture Surface Characterization of Hi-Nicalon ${ }^{\mathrm{TM}} \mathrm{SiC}$ Fibers G. E. Youngblood, Charies Lewinsohn and R. H. Jones (Pacific Northwest National Laboratory*,) and Akira Kohyama (Institute of Advanced Energy, Kyoto University)

\section{EXTENDED ABSTRACT}

Presented at the $102^{\text {nd }}$ annual meeting of the American Ceramic Society, April 30 - May 3, 2000, St. Louis, Missouri and submitted to the Journal of Nuclear Materials, August, 2000.

Dimensional, tensile strength and fracture surface characterizations were carried out for a particular batch ( 51 samples) of unirradiated Hi-Nicalon ${ }^{\mathrm{TM}} \mathrm{SiC}$ fiber. This batch of SiC fibers is included in the radiation test matrix as part of the JUPITER $12 \mathrm{~J}$ and $14 \mathrm{~J}$ experiments. In general, filaments of $\mathrm{Hi}-\mathrm{Nicalon}^{\mathrm{TM}}$ fiber with larger cross-sectional areas (equivalent diameters) had lower strengths than filaments with smaller cross-sectional areas. During tensile tests at room temperature, fracture originated at critical flaws that typically consisted of internal pores or carbonaceous inclusions. Well-demarcated mirror and hackle regions usually surrounded the critical flaws (See Fig. 1(a-b)). With a few exceptions, the critical flaw size $\left(a_{c}\right)$ was linearly related to the mirror size $\left(r_{m}\right)$ by $a_{c} \approx 0.33 r_{m}$. From fracture mechanics principles, values for the average mirror constant $\left(A_{m}\right)$ and effective fracture toughness for this batch of Hi-Nicalon ${ }^{\mathrm{TM}}$ fiber were estimated to be $2.99 \pm 0.33 \mathrm{MPa} \mathrm{m}^{1 / 2}$ and $1.1 \pm 0.2 \mathrm{MPa} \mathrm{m}^{1 / 2}$, respectively (See Fig. 2).
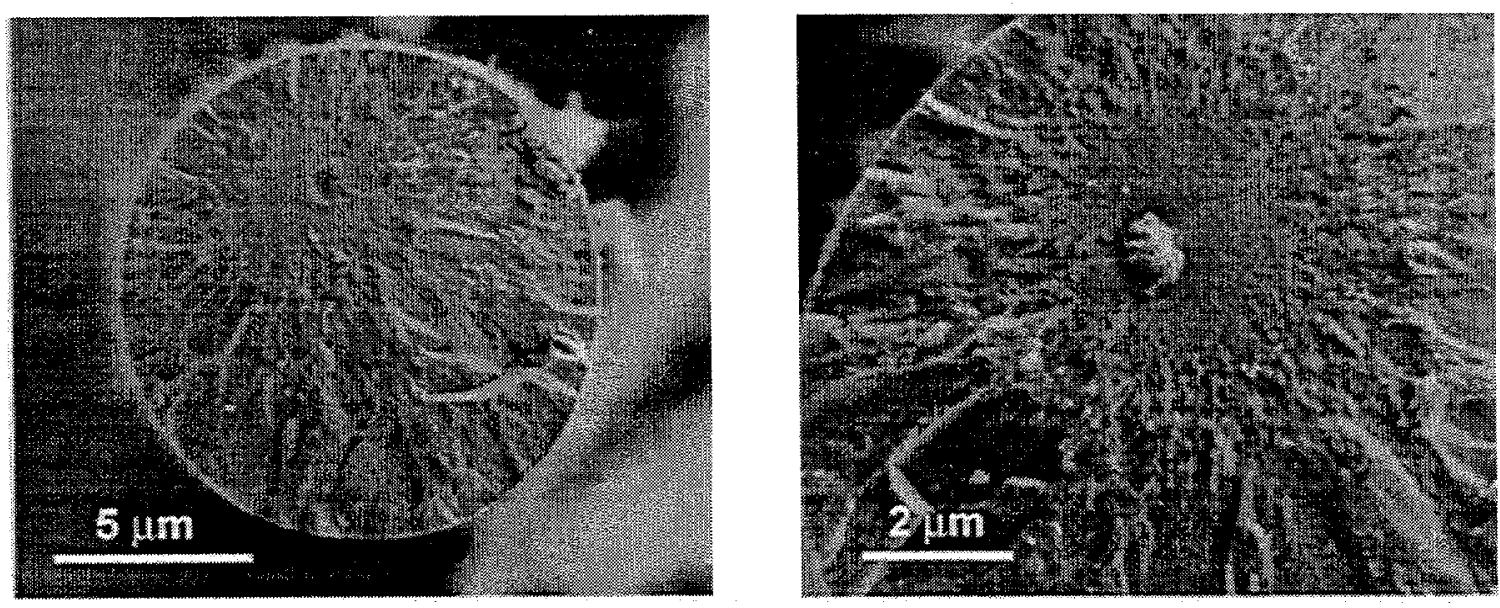

*Pacific Northwest National Laboratory (PNNL) is operated for the U.S. Department of Energy by Battelle Memorial Institute under contract DE-AC06-76RL0-1830 
Figure 1(a-b) An SEM of a typical pair of mating fracture surfaces showing in (a) an internal pore and the surrounding mirror and hackle regions, and in (b) the actual critical flaw was a carbonaceous inclusion that popped free from the opposite pore site during fracture. For this filament, the diameter, strength, flaw location parameter and the mirror and flaw radius values were $12.8 \mu \mathrm{m}, 2.89 \mathrm{GPa}, 0.44,1.34 \mu \mathrm{m}$ and $0.61 \mu \mathrm{m}$, respectively.

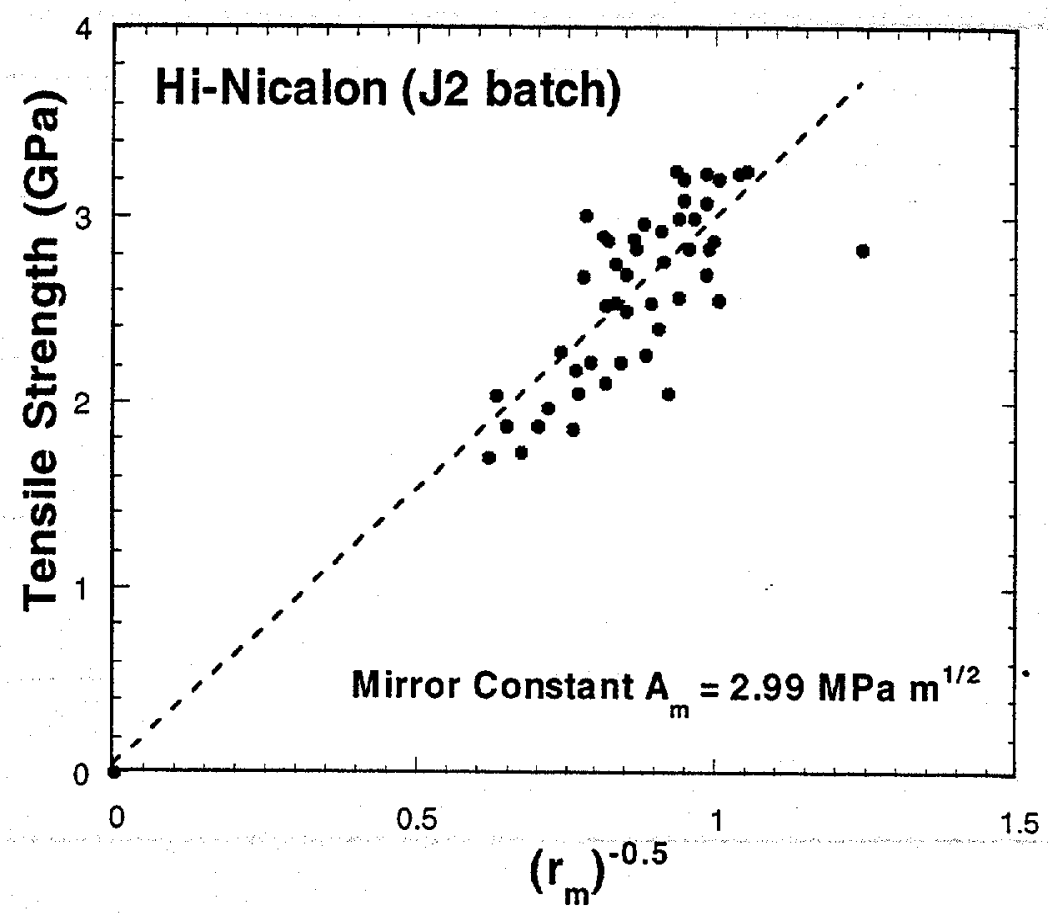

Figure 2. The fiber tensile strength versus the square root of the fracture mirror radius for the $\mathrm{Hi}$ Nicalon (batch J2) set of 51 fiber filaments.

\section{FUTURE WORK}

The fiber characterization protocol established by this work should be appropriate for assessing degradation in $\mathrm{SiC}$ fibers due to neutron irradiation. 
TRANSMUTATIONS IN SiC IRRADIATED IN ARIES-IV FIRST WALL- H. L. Heinisch (Pacific Northwest National Laboratory")

\section{OBJECTIVE}

The objective of this task is to determine the burn-out limit of neutron irradiated SiC.

\section{SUMMARY}

The change in concentrations of elements due to transmutations resulting from neutron irradiation in the first wall of the ARIES-IV conceptual fusion energy device were determined as a function of neutron dose. $\mathrm{SiC}$ burns out at a rate of about $0.5 \%$ per effective full power year. The largest impurity concentration is that of $\mathrm{He}$, but several other elements burn in at rates of hundreds of appm/efpy.

\section{PROGRESS AND STATUS}

Transmutation calculations were performed for pure SiC irradiated in the neutron spectrum of the first wall of the ARIES-IV conceptual fusion energy device using the REAC-3 code with FENDL-2.0 nuclear cross sections.

The ARIES-IV first wall has a total neutron flux of $3.6 \times 10^{15} \mathrm{n} / \mathrm{cm}^{2}-\mathrm{s}$ and a fast flux (E>0.1 $\mathrm{MeV}$ ) of $1.9 \times 10^{15} \mathrm{n} / \mathrm{cm}^{2}$-s. Calculations were performed for a continuous irradiation of up to 12 effective full power years (efpy) to a total neutron dose of $1.37 \times 10^{24} \mathrm{n} / \mathrm{cm}^{2}$. The elemental composition of the material is not significantly affected by the post-irradiation decay of radioactive isotopes, since they are either too short-lived or too long-lived to affect the composition over a reactor lifetime.

SiC Burn out. In this neutron spectrum, Si burns out somewhat more rapidly than $\mathrm{C}$ (Fig. 1), so the Si content controls the stoichiometry of neutron irradiated $\mathrm{SiC}$. Si, hence $\mathrm{SiC}$, burns out at a rate of about $0.0047 /$ efpy. A $3 \%$ burnout of $\mathrm{SiC}$ has been suggested as a desirable design goal for SiC composites. In ARIES-IV a 3\% burnout occurs in about 6.5 efpy (total neutron fluence $7.4 \times 10^{23} \mathrm{n} / \mathrm{cm}^{2}$ ).

The differing burnout rates of $\mathrm{Si}$ and $\mathrm{C}$ result in an excess concentration of carbon totaling about 3500 appm after 6.5 efpy. The $\mathrm{Si}$ and $\mathrm{C}$ burnout rates are constant, and the excess $\mathrm{C}$ increases at the rate of 540 appm excess C/efpy.

Impurity Burn in. The most abundant transmutation products, which burn in at constant rates (Fig. 2), are the following:

Element Burn-in Rate (appm/efpy) Concentration at 6.5 efpy (at\%)

$\begin{array}{lrr}\mathrm{He} & 6384 & 4.2 \\ \mathrm{H} & 2307 & 1.5 \\ \mathrm{Mg} & 1630 & 1.1 \\ \mathrm{Be} & 632 & 0.4 \\ \mathrm{Al} & 469 & 0.3 \\ \mathrm{P} & 146 & 0.1\end{array}$

\footnotetext{
"Pacific Northwest National Laboratory is operated for the U.S. Department of Energy by Battelle Memorial Institute under contract DE-AC06-76RLO-1830.
} 


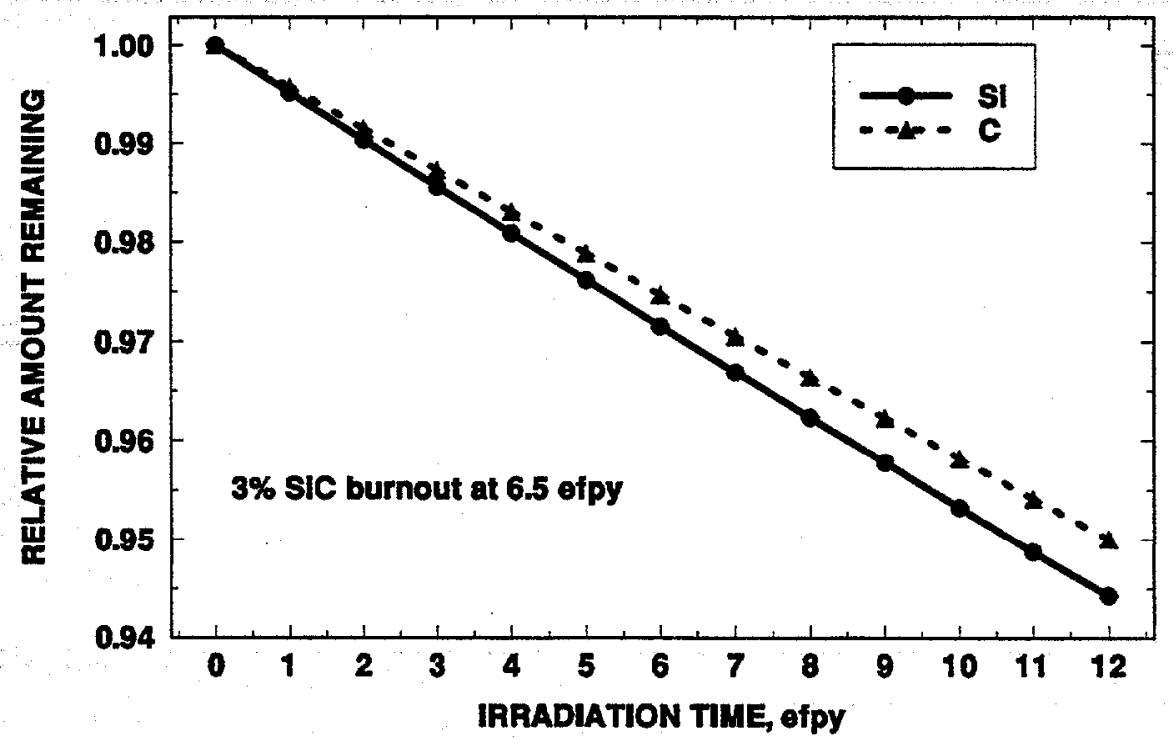

Figure 1. The burnout of $\mathrm{Si}$ and $\mathrm{C}$ in $\mathrm{SiC}$ irradiated in ARIES-IV first wall as a function of dose in effective full power years.

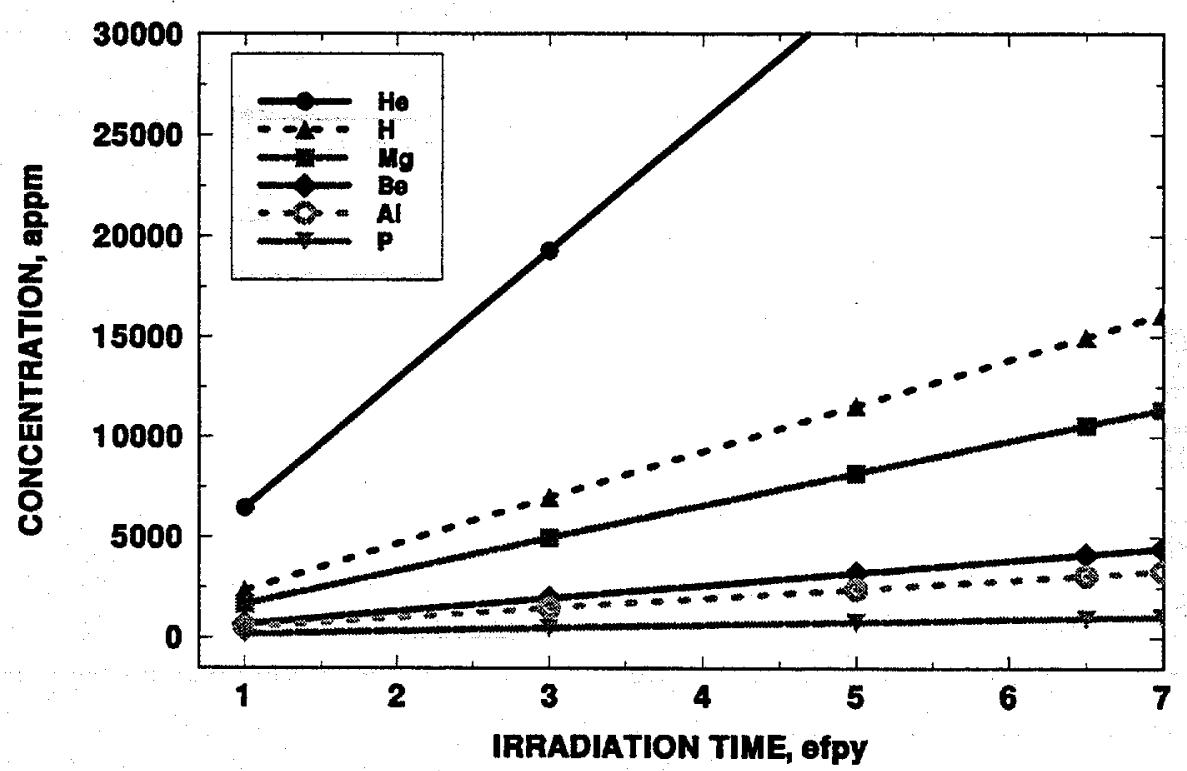

Figure 2. Concentrations of transmutation products in $\mathrm{SiC}$ irradiated in ARIES-IV first wall as a function of irradiation time in effective full power years. 
After 6.5 efpy, although $3 \%$ of the SiC burns out, the concentration of transmutant atoms totals almost $8 \%$. This is because many transmutation reactions create additional $\mathrm{H}$ or $\mathrm{He}$ atoms, which causes the total number of atoms in the system to increase.

Several other elements burn in through two-step transmutations, so they accumulate nonlinearly as the square of the irradiation time. Their concentrations are relatively small compared to the transmutants discussed above (Fig. 3). The concentrations of elements produced by two-step transmutations after 6.5 efpy are listed below.

\section{Element $\quad$ Concentration at 6.5 efpy (appm)}

$\begin{array}{lr}\mathrm{Ne} & 78 \\ \mathrm{~S} & 8 \\ \mathrm{Na} & 7 \\ \mathrm{Li} & 4\end{array}$

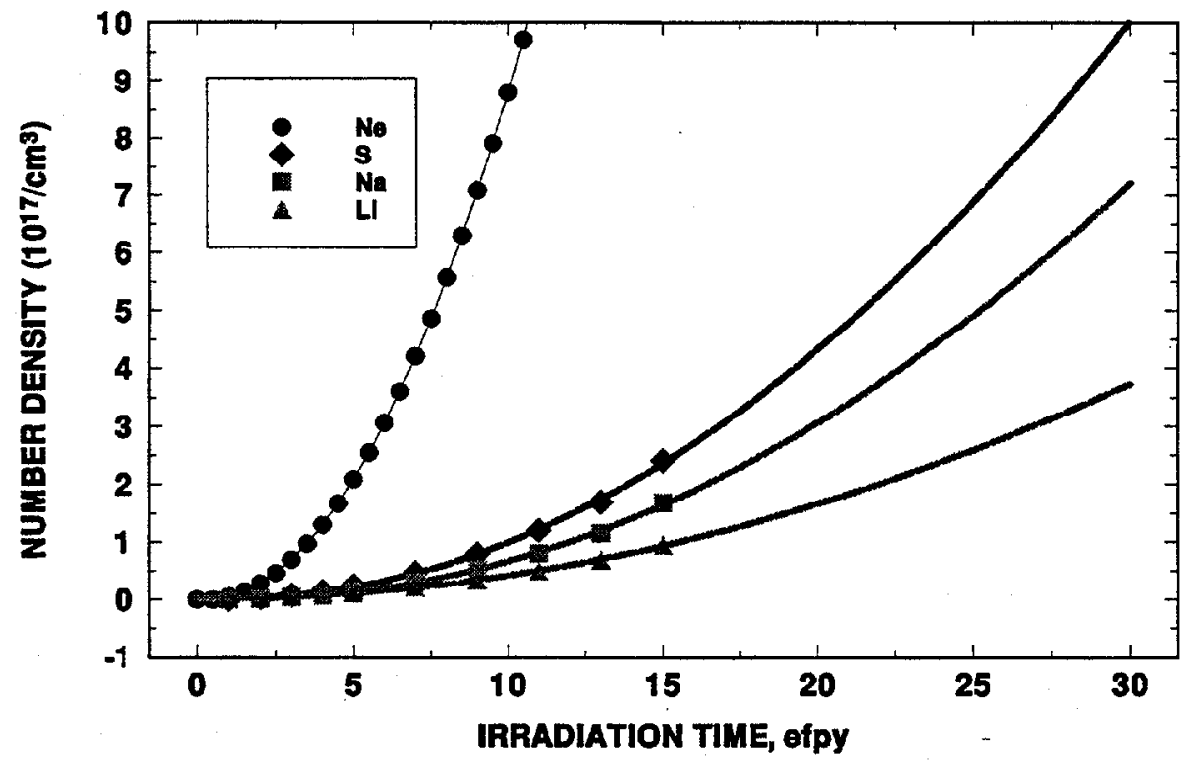

Figure 3. Number density of transmutation products in SiC that result from multiple interactions of a nucleus with neutrons in the ARIES-IV first wall as a function of irradiation time in effective full power years

Of the elements identified as transmutation products in this report, only $\mathrm{Al}$ and $\mathrm{Na}$ are also considered as possible intrinsic impurities in unirradiated SiC. After only one effective full power day the concentration of $\mathrm{Al}$ due to transmutation is greater than its typical concentration as an intrinsic impurity. The same is true for $\mathrm{Na}$ after 4 efpy Thus, transmutations are responsible for creating an additional set of radiation-induced impurities, 
having dose-dependent concentrations, that is entirely different from the set of intrinsic impurities.

\section{FUTURE WORK}

The effect on the phase stability of SIC due to the burnout of SiC and the build up of excess $C$ under fusion first wall neutron irradiation needs to be examined. Additional calculations have shown that the burnout rate of SiC in neutron spectra typical of fission reactor test facilities (HFIR PTP and EBR-II Row 2) is about one tenth the burn out rate in fusion reactors at the same fast fluence $(\mathrm{E}>0.1 \mathrm{MeV})$. The effects of impurities produced in $\mathrm{SiC}$ by nuclear transformations also need to be assessed.

\section{ACKNOWLEDGEMENTS}

The author is indebted to Laila El-Guebaly, Fusion Technology Institute, University of Wisconsin - Madison, for providing a copy of the ARIES-IV first wall neutron spectrum. 
THE KFIB EXPERIMENT - G. E. Youngblood, D J. Senor and R. H. Jones (Pacific Northwest National Laboratory), W. Kowbel (MER Corporation), and A. Kohyama (Kyoto University)

\section{OBJECTIVE}

The primary objective of the experiment called "KFIB" is to assess the thermal conduction (K) properties of several advanced SiC FIBers before and after irradiation. A secondary goal is to assess the thermal conductivity of $\mathrm{SiC} / \mathrm{SiC}$ composites made from these fibers (with various SiC-type matrices and architectures) before and after irradiation and to model the transverse and in-plane thermal conductivity of these composites as a function of temperature and dose.

\section{SUMMARY}

Several rod-shaped specimens with uniaxially packed fibers (Hi-Nicalon ${ }^{\mathrm{M}}$, Hi-Nicalon ${ }^{\mathrm{TM}}$ Type S, Tyranno ${ }^{\mathrm{TM}} \mathrm{SA}$ and Amoco $\mathrm{K} 1100^{\mathrm{TM}}$ types) in a pre-ceramic polymer matrix were fabricated. By using appropriate analytic models, the bare fiber thermal conductivity $\left(\mathrm{K}_{\mathrm{f}}\right)$ will be determined as a function of temperature up to $1000^{\circ} \mathrm{C}$ before and after irradiation for samples cut from these rods. Preliminary thermal conductivity data for unirradiated fibers (Hi-Nicalon ${ }^{\mathrm{TM}}$ and Tyranno ${ }^{\mathrm{TM}} \mathrm{SA}-\mathrm{B}$ $\mathrm{SiC}$ and $\mathrm{K} 1100^{\mathrm{m}} \mathrm{graphite}$ ) and for three types of unirradiated composites made from these fibers (2D-Nicalon S/SiC multilayer/CVI-SiC, 3D-Nicalon S/PIP-SiC, and 2D-8HS Tyrannohex ${ }^{\mathrm{TM}} \mathrm{HP}$ ) are presented.

\section{PROGRESS AND STATUS}

The KFIB experiment is coordinated at the Pacific Northwest National Laboratory (PNNL), but involves several other organizations. Other organizations have furnished materials, materials analysis or irradiation facilities for the experiment. The cooperating organizations and points of contact are:

Pacific Northwest National Laboratory (PNNL) in Richland, WA; contact Jerry Youngblood, (ge.youngblood@pnl.gov)

Knolls Atomic Power Laboratory (KAPL) in Schenectady, NY; contact George Newsome (newsome@kapl.gov).

MER Corporation in Tucson, AZ; contact Witold Kowbel (kowbel@opus1.com)

Monbusho Fusion Energy Materials Program, Kyoto University, Japan; contact Akira Kohyama, (kohyama@iae.kyoto-u.ac.jp)

JAERI Fusion Energy Materials Program, Tokai-mura, Japan; contact Reiji Yamada, (reiji@popsvr.tokai.jaeri.go.jp)

ATR Reactor, Idaho Falls, ID; contact George Newsome, (newsome@kapl.gov)

NRG Petten, Petten, The Netherlands; contact Paul de Heij, (heij@nrg-nl.com)

UBE Industries Ltd., Kogushi-Ube-City, Japan; contact Toshihiro Ishikawa (24613u@ube-ind.co.jp).

\section{$\underline{\text { SiC Fibers }}$}

The thermal conductivity of the following advanced $\mathrm{SiC}$ and $\mathrm{C}$ fibers will be assessed before and after irradiation: Hi-Nicalon ${ }^{T M}$, Hi-Nicalon ${ }^{\mathrm{TM}}$ Type S, Tyranno ${ }^{\mathrm{TM}} \mathrm{SA}$, and Amoco $\mathrm{K}^{\mathrm{N}} 100^{\mathrm{TM}}$ as described previously [1]. These fibers will be used to make $\mathrm{SiC} / \mathrm{SiC}$ (or $\mathrm{C} / \mathrm{SiC}$ ) composites with

\footnotetext{
"Pacific Northwest National Laboratory (PNNL) is operated for the U.S. Department of Energy by Battelle Memorial Institute under contract DE-AC06-76RLO-1830.
} 
uniaxial alignment of the fibers. The composites will be fabricated into rod shapes that conveniently can be sliced into several discs for measurement of the thermal diffusivity along the fiber axial direction. The matrix component will purposely be made amorphous from pre-ceramic polymers (Ceraset ${ }^{\mathrm{TM}}$ or $\mathrm{KION}^{\mathrm{TM}}$ ) so that the fiber contribution to the overall composite $\mathrm{K}$-value will be dominated by the fiber contribution. To further enhance the accuracy of the fiber K-value determinations, the composite rods will contain a relatively high $(>60 \%)$ fiber packing fraction.

\section{SiC/SiC Composites and Monolithic CVD-SiC}

Several types of SiC/SiC composites made with the advanced fibers and with different architectures will be included in the experimental matrix. Samples of Morton high-purity CVD-SiC will also be included in each capsule to serve as passive temperature and radiation damage monitors [2].

\section{Irradiation Tests and Schedule}

Two irradiation tests are planned. A low temperature irradiation test will take place in the ATR reactor at $300^{\circ} \mathrm{C}$ to a dose of $3.6 \mathrm{dpa}-\mathrm{SiC}$. A moderate and a high temperature irradiation test will take place in the HFR Petten reactor at $627^{\circ} \mathrm{C}$ and $1027^{\circ} \mathrm{C}$ to a dose of about $2.5 \mathrm{dpa}$-SiC. The ATR irradiation will commence in November, 2000 and will be completed by May, 2001; the HFR Petten irradiation will commence in January, 2001 and will be completed by July, 2001. The sample test matrix is given in Table 1.

Table 1. KFIB sample test matrix

\begin{tabular}{|l|c|c|}
\hline Fiber Discs (6.2 mm dia x 2.0 mm thk) & HFR Petten & ATR \\
\hline Hi-Nicalon (parallel) & 4 & 2 \\
\hline Hi-Nicalon (perpendicular) & 2 & 2 \\
\hline Tyranno SA-B (parallel) & 4 & 2 \\
\hline Nicalon Type S (parallel) & 6 & 2 \\
\hline Amoco K1100 graphite (parallel) & 0 & 2 \\
\hline Composite Discs (6.2 mm dia x 2.0 mm thk) & & 4 \\
\hline 2D-Nicalon S/SiC multilayer/CVI-SiC & 6 & 4 \\
\hline 3D-Nicalon S/PIP (Ceraset 1400C) & 4 & 3 \\
\hline 2D-8HS Tyrannohex HP (100\% transverse) & 4 & 2 \\
\hline 2D-8HS Tyrannohex HP (50\% transverse) & 0 & 0 \\
\hline 2D-5HS Nicalon S/CVI-SiC w K1100(z-stitch) & 2 & \\
\hline Morton High-Purity CVD-SiC Reference & & 3 \\
\hline CVD-SiC (6.0 mm dia x 2 mm thk discs) & 3 & 0 \\
\hline CVD-SiC (25.5 mm long x 1.85 mm sq bars) & 6 & \\
\hline
\end{tabular}

Ten fiber, thirteen composites made with these fibers and three CVD-SiC thermal diffusivity disc samples have been inserted into the ATR reactor. Sixteen fiber and sixteen composite disc samples made with these fibers and nine CVD-SiC reference samples will be irradiated in the HFR Petten reactor.

The Hi-Nicalon ${ }^{\mathrm{TM}}$ and Hi-Nicalon ${ }^{\mathrm{TM}}$ Type $\mathrm{S}$ SiC fibers were fabricated by the Nippon Carbon Co. (Yokohama, Japan) using an electron-beam radiation curing process. The Tyranno ${ }^{\mathrm{TM}} \mathrm{SA}-\mathrm{B}$ fiber was fabricated by Ube Industries Ltd. (Ube City, Japan) using an oxidative curing process and high temperature $\left(1800^{\circ} \mathrm{C}\right)$ sintering. It is noted that the tested Tyranno ${ }^{\text {TM }}$ SA-B fiber, a new smaller diameter version of Tyranno ${ }^{T M} \mathrm{SA}$, has improved thermal creep and high temperature 
strength compared to the Tyanno ${ }^{\mathrm{TM}}$ SA fiber version [3].

The 2D-Nicalon ${ }^{\mathrm{TM}} \mathrm{S} / \mathrm{SiC}$ multilayer/CVI-SiC composite was made by Hypertherm High Temperature Composites, Inc. (Huntington Beach, CA) by the same procedure as a similar composite examined by Snead, et al [4], except the Hi-Nicalon ${ }^{\mathrm{MM}}$ fiber was replaced with HiNicalon ${ }^{T M}$ type $S$ fiber. Snead reported that the Hi-Nicalon ${ }^{\mathrm{TM}}$ multilayer composite, where the fibers were coated by CVD with four alternate layers of C/SiC prior to matrix infiltration, exhibited the least strength degradation after low temperature neutron irradiation compared to composites with either a single layer PyC or a "porous SiC" fiber coating. Replacing the Hi-Nicalon "M fiber with the more radiation resistant $\mathrm{Hi}$-Nicalon ${ }^{\mathrm{TM}}$ type $S$ fiber may improve the radiation strength stability of the multilayer composite even further. However, thermal conductivity results have not been reported for the Hi-Nicalon ${ }^{\mathrm{MM}}$ multilayer composite until now.

The fabrication and mechanical properties of the 3D-Nicalon ${ }^{\mathrm{mM}}$ S/PIP-SiC composite, contributed by JAERI, were reported earlier by Yamada, et al [5]. The 3D fiber architecture for this composite had an $X Y Y / Z$ pattern with either $1 / 1 / 0.1$ or $1 / 1 / 0.2$ relative fiber volume ratios. The thermal conductivity was determined in the Z-direction.

The fabrication and characteristics of the 2D-8HS Tyrannohex ${ }^{\mathrm{TM}}$ HP composite are fully described in an accompanying paper in this volume [6].

A 2D composite with Hi-Nicalon ${ }^{\mathrm{TM}}$ type $\mathrm{S}$ SiC fiber in the $X-Y$ plane but studded with $\mathrm{K} 1100^{\mathrm{TM}}$ graphite fiber rods in the Z-direction is the final composite included in the KFIB test matrix. This composite, fabricated by MER Corp. using a special PIP matrix and a high temperature treatment, is an attempt to improve the transverse thermal conductivity by inserting highly conductive $\mathrm{K} 1100^{\mathrm{TM}}$ fibers in the Z-direction [7].

The thermal diffusivity and conductivity for a representative number of disc-shaped composite samples were determined by the laser flash method described in detail previously [8].

\section{$\underline{\text { Results }}$}

During the latest period, data for the unirradiated thermal conductivity of Tyranno ${ }^{\mathrm{TM}} \mathrm{SA}-\mathrm{B}$ fiber were obtained and added to the previously reported fiber conductivity data for unirradiated $\mathrm{Hi}-$ Nicalon ${ }^{\mathrm{MM}} \mathrm{SiC}$ fiber and $\mathrm{K} 1100^{\mathrm{TM}}$ graphite fiber as shown in Fig. 1 [1]. The thermal conductivity for the unirradiated Tyranno ${ }^{\mathrm{TM}} \mathrm{SA}-\mathrm{B}$ SiC fibers ranges from about $45 \mathrm{~W} / \mathrm{mK}$ at ambient down to $18 \mathrm{~W} / \mathrm{mK}$ at $1000^{\circ} \mathrm{C}$ and are considerably higher than similar values for the Hi-Nicalon ${ }^{\mathrm{TM}}$ fiber. The thermal conductivity of the Tyranno ${ }^{\mathrm{m}} \mathrm{SA}$ fiber version, reported to be $65 \mathrm{~W} / \mathrm{mK}$ at ambient, is higher still [9].

The transverse thermal conductivity results for the 2D-Nicalon ${ }^{\mathrm{TM}} \mathrm{S} / \mathrm{SiC}$ multilayer/CVI-SiC and the 3D-Nicalon ${ }^{\mathrm{TM}}$ S/PIP-SiC materials are presented in Figs. 2(a-b), respectively.

In Fig. 2(a), the thermal conductivity values for different samples of the 2D multilayer composite (CVI-SiC matrix) are distributed over a wide range between 5-14 W/mK. In general, samples with higher bulk density values exhibited the higher thermal conductivity values. The sample densities, which are used as labels to identify corresponding data in the figure, ranged from a high value of $2.59 \mathrm{~g} / \mathrm{cc}$ down to $2.31 \mathrm{~g} / \mathrm{cc}$. Usually high quality $\mathrm{SiC} / \mathrm{SiC}$ made with a CVI-SiC matrix exhibits a bulk density of $2.5 \mathrm{~g} / \mathrm{cc}$ or better. The thermal conductivity of such material when made with Nicalon CG fiber is about $10 \mathrm{WmK}$ at ambient, and when made with Hi-Nicalon it is about $13 \mathrm{~W} / \mathrm{mK}$ [8]. Only for one multilayer sample did the density exceed $2.5 \mathrm{~g} / \mathrm{cc}$, and for that sample the thermal conductivity at ambient was slightly more than $14 \mathrm{~W} / \mathrm{mK}$. All samples 
with densities less than $2.5 \mathrm{~g} / \mathrm{cc}$ exhibited thermal conductivity values less than $10 \mathrm{~W} / \mathrm{mK}$ at ambient. These results suggest that achieving high quality composite by the CVI-method might be more difficult when multilayer coatings are used. Perhaps when using multilayer coatings there is a greater tendency to seal off the fiber bundles and prevent adequate infiltration. Even when the infiltration was adequate, the thermal conductivity values for this type of $2 \mathrm{D} \mathrm{SiC/SiC}$ composite were significantly below desired values for the fusion application [10].

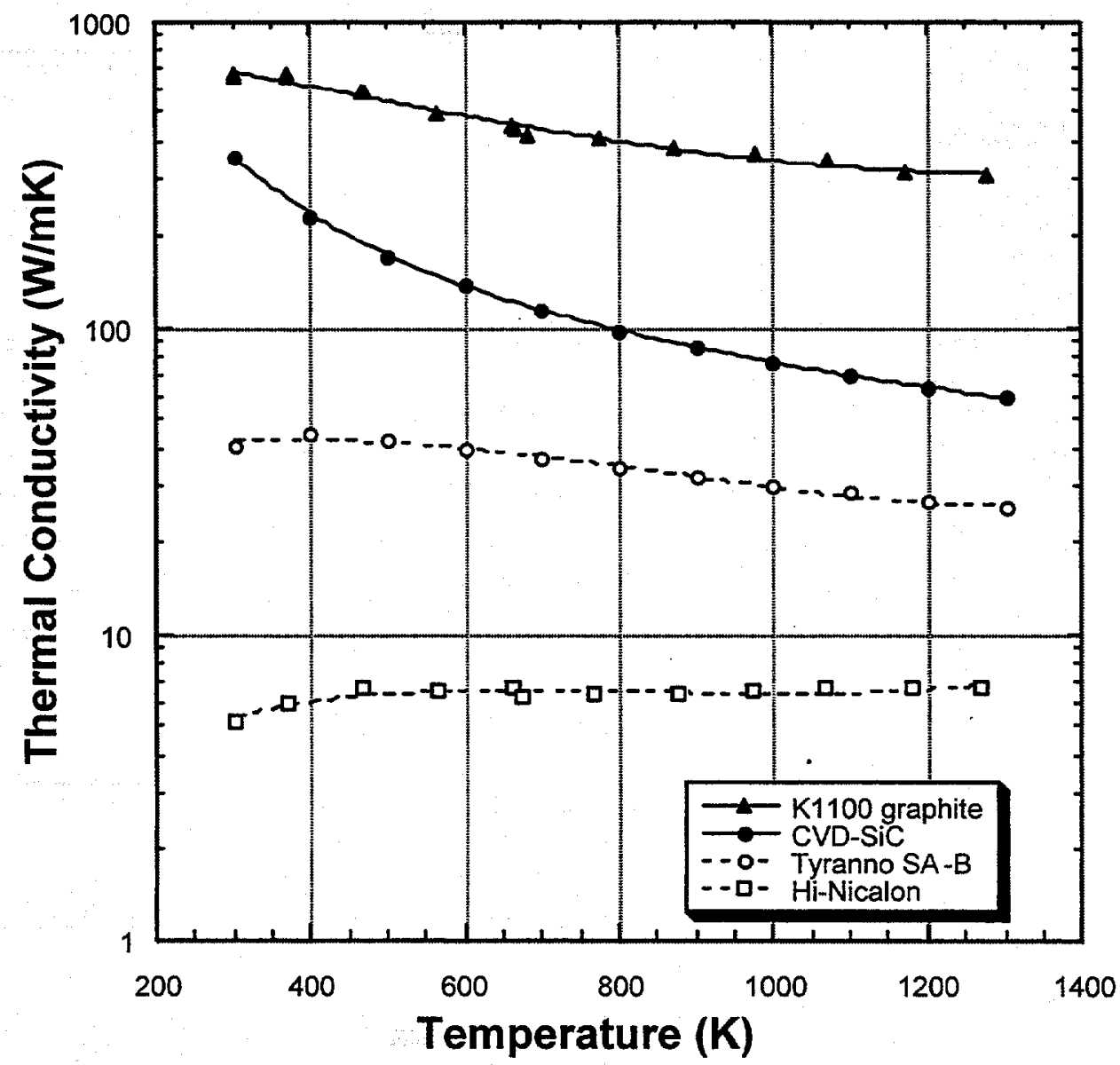

Figure 1. The measured thermal conductivity values for $K 1100^{7 M}$ graphite, Tyranno ${ }^{T M} S A-B$ and Hi-Nicalon ${ }^{T M}$ fibers compared to the thermal conductivity of high-purity, monolithic CVD-SiC.

In Fig. 2(b), the average thermal conductivity values for the 3D-Nicalon S composite (PIP-SiC matrix) are plotted as a function of temperature. The values all fall within a narrow range of about 5-6 W/mK with little temperature dependence indicated. The thermal conductivity values for the composite made with 0.2 relative fiber volume ratio in the Z-direction were only slightly larger than values for composite with a 0.1 volume ratio. The conductivity values representing materials with each fiber volume ratio $(0.2$ or 0.1$)$ were determined by averaging values made for three different samples selected from each group. The resulting values agree fairly well with values measured by Yamada for similar materials, except Yamada's values exhibited a slightly larger spread between composites with different fiber volume ratios [5]. As expected, Yamada observed higher thermal conductivity values (by $\approx 20 \%$ ) for the $Z=0.2$ group which contained approximately twice as many Nicalon $S$ fibers aligned in the heat flow direction as the $Z=0.1$ group. The bulk density 
values for our $Z=0.1$ and 0.2 groups were 2.40 and $2.24 \mathrm{~g} / \mathrm{cc}$, respectively. The lower average density observed for our $Z=0.2$ group likely counteracted the benefit of having additional fibers aligned in the Z-direction; so only slight differences in thermal conductivity values were observed between the two groups.

In general, the observed thermal conductivity values for these 3D-composites with a PIP-SiC matrix were considerably less than values observed for $2 \mathrm{D}-\mathrm{SiC} / \mathrm{SiC}$ composites made with a CVI$\mathrm{SiC}$ matrix. Apparently, the low thermal conductivity of the continuous PIP-SiC matrix phase dominates the conduction process in these materials, and any benefits derived from the Zstitching were minimal. These results suggest that a PIP-SiC matrix must be annealed at high enough temperature to completely crystallize the matrix before the thermal conductivity will be significantly improved. At the same time the formation of shrinkage cracks in the matrix must also be avoided (highly unlikely). Only then is there a possibility for attaining fusion thermal conductivity goals for $\mathrm{SiC} / \mathrm{SiC}$ composites made with a PIP-type matrix.

The results for the 2D-8HS Tyrannohex HP are presented in a separate paper in this volume [6]. The thermal conductivity results for the 2D-5HS Nicalon S/CVI-SiC w K1100 (z-rods) will be reported later.

\section{FUTURE WORK}

The thermal conductivity for advanced $\mathrm{SiC}$ fibers (Hi-Nicalon ${ }^{\mathrm{TM}}$, Hi-Nicalon ${ }^{\mathrm{T} M}$ Type $\mathrm{S}$ and Tyranno $\left.{ }^{\mathrm{TM}} \mathrm{SA}-\mathrm{B}\right)$ and for graphite fibers $\left(\mathrm{K} 1100^{\mathrm{TM}}\right)$ will be analyzed before and after irradiation. Similar analysis will be performed for composites made with these.fibers by using appropriate thermal conductivity models. The results should be available by the end of 2001 .

\section{ACKNOWLEDGEMENTS}

This work is a joint effort funded by the US DOE Fusion Energy and the Japan Monbusho programs. Also, part of this work is being supported by a DOE-SBIR, Phase I (Contract DEFG03-99ER82823) with the MER Corporation, Tucson, AZ. The capsule loading and irradiation in the ATR reactor are being managed by KAPL (George Newsome). The capsule loading and irradiation in the HFR Petten reactor are being managed by NRG Petten (Paul de Heij). 

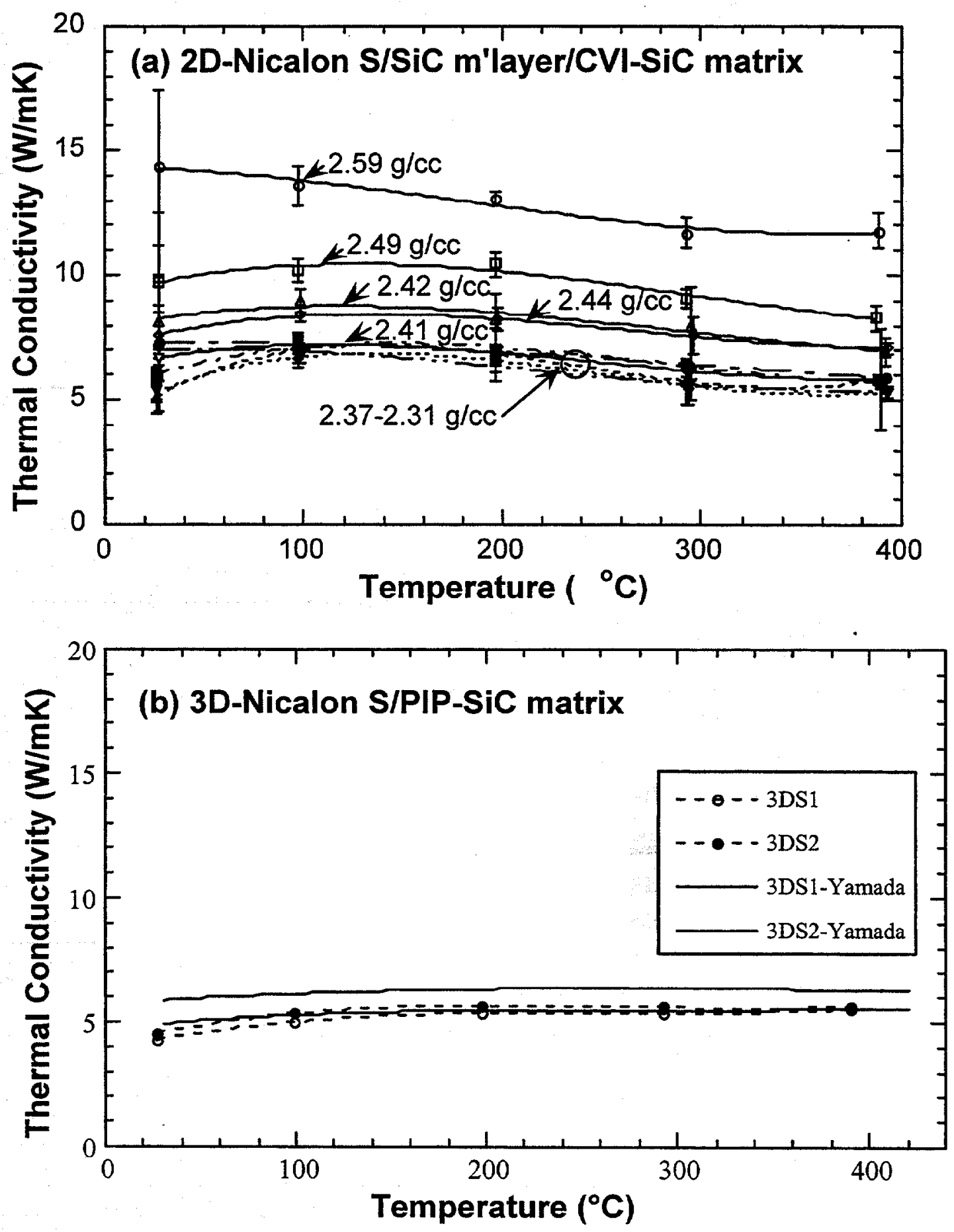

Figures 2(a-b). Thermal conductivity of (a) 2D-Nicalon S/SiC multilayer/CVI-SiC and (b) 3DNicalon S/PIP-SiC. In Fig. 2(b), the X-Y-Z fiber volume ratios were 1-1-0.1 and 1-1-0.2 for the samples labeled 3DS1 and 3DS2, respectively. 


\section{REFERENCES}

[1] G. E. Youngblood, D. J. Senor, W. Kowbel, J. Webb and Akira Kohyama, "Thermal conductivity of SiC and C fibers," p. 113 in Fusion Materials Semiannual Progress Report (FMSPR) for period ending December 31, 1999 (DOE/ER-031327).

[2] G. E. Youngblood, "Passive SiC irradiation temperature monitor," p. 324 in FMSPR for period ending December 31, 1995 (DOE/ER-0313/19).

[3] Toshihiro Ishikawa, Shinji Kajii, Terumi Hisayuki and Yasuhiko Kohtoku, "SiC Polycrystalline Fiber and the Fiber-Bonded Ceramic," Proc. $6^{\text {th }}$ Japan International SAMPE Symposium, Oct. 26-29, 1999.

[4] L. L. Snead, M. C. Osborne, R. A. Lowden, J. Strizak, R. J. Shinavski, K.L. More, W.S. Eatherly, J. Bailey and A. M. Williams, "Low dose irradiation performance of SiC interphase SiC/SiC composite," J. Nucl. Mater. 253 (1998) 20-29.

[5] R. Yamada, T. Taguchi and N. Igawa, "Mechanical and thermal properties of 2D and 3D $\mathrm{SiC/SiC} \mathrm{composites,"} \mathrm{presented} \mathrm{at} \mathrm{ICFRM9,} \mathrm{Colorado} \mathrm{Springs,} \mathrm{Co.,} \mathrm{Oct.} \mathrm{10-15,} 1999$.

[6] G. E. Youngblood and R. H. Jones, "A new type of SiC composite for fusion," in this report.

[7] "Hybrid 3D SiC/C high thermal conductivity composites," USDOE Phase II SBIR for FY 2000 , issued to MER Corp., Tucson, AZ.

[8 D. J. Senor, G. E. Youngblood, D. V. Archer and C. E. Chamberlin, "Recent Progress in Thermal Conductivity Testing of SiC-based Materials for Fusion Reactor Applications," p. 102 in the Proceedings of the Third IEA Workshop on SiC/SiC Ceramic Composites for Fusion Structural Applications, January 29-30, 1999, Cocoa Beach, FL.

[9] Masaki Shibuya, Tyranno Fiber Project, Ube Industries Ltd., 1978-10 Kagushi, Ube City, Yamaguchi Prefecture, 755-8633 Japan.

[10] R. H. Jones, "IEA Agreement - Performance requirements for structural applications of $\mathrm{SiC} / \mathrm{SiC}, "$ p. 196 in the Proceedings of the IEA International Workshop on SiC/SiC Ceramic Composites for Fusion Structural Applications, 28-29 October 1996, Ispra (Va), Italy. 
THE TRANSVERSE THERMAL CONDUCTIVITY OF 2D-SIC $/$ SIC COMPOSITES - G. E. Youngblood, David J. Senor, R. H. Jones (Pacific Northwest National Laboratory)", and Samuel Graham (Sandia National Laboratories).

Submitted to the Journal of Nuclear Materials $5 / 26 / 00$.

\section{EXTENDED ABSTRACT}

A model for predicting the effective transverse thermal conductivity $\left(\mathrm{K}_{\text {eff }}\right)$ of a $2 \mathrm{D}-\mathrm{SiC} / \mathrm{SiC}$ composite with a fiber-matrix thermal barrier was assessed experimentally and by comparison to numerical finite element model (FEM) predictions.

The Hasselman and Johnson model [1] is described by an expression for $K_{\text {eff }}$ based on a composite configuration that consists of dispersed uniaxial fibers in a matrix with thermal barriers (fiber coatings or fiber/matrix debonds) and is given by:

$$
\begin{aligned}
K_{\text {eff }}=K_{m}\left[\left(K_{f} / K_{m}-1-K_{f} / a h\right) V_{f}+\left(1+K_{f} / K_{m}+K_{f} / a h\right)\right] x \\
\\
{\left[\left(1-K_{f} / K_{m}+K_{f} / a h\right) V_{f}+\left(1+K_{f} / K_{m}+K_{f} / a h\right)\right]^{-1} }
\end{aligned}
$$

In Eq. (1), " $h$ " is the effective interfacial conductance, $K_{m}$ and $K_{f}$ are the thermal conductivity values of the matrix and fiber constituents, and $V_{f}$ and "a" are the fiber volume fraction and radius, respectively. Examination of Eq. (1) indicates that the value of the non-dimensional parameter, $\mathrm{K}_{\mathrm{f}} /$ ah, relative to the ratio $\mathrm{K}_{\mathrm{f}} / \mathrm{K}_{\mathrm{m}}$ controls the overall effect of interfacial barrier resistances on $\mathrm{K}_{\text {eff }}$.

Agreement between predictions of Eq. (1) and the FEM were within $5 \%$ for composites with simple unidirectional or cross-ply architectures with fiber volume fractions of 0.5 or less and with ratios $\mathrm{K}_{\mathrm{f}} / \mathrm{K}_{\mathrm{m}}<10$. For a woven $2 \mathrm{D}-\mathrm{SiC}_{\mathrm{f}} / \mathrm{SiC}$ composite, inhomogeneous fiber packing and numerous direct fiber-fiber contacts would introduce deviations from model predictions. Nevertheless, the analytic model should be very appropriate to examine the degradation in $\mathrm{K}_{\text {eff }}$ due to neutron irradiation or to other mechanical or environmental treatments [2].

The expected effects of temperature dependence and irradiation on $K_{\text {eff }}$ were examined for a hypothetical $2 \mathrm{D}-\mathrm{SiC}_{f} / \mathrm{SiC}$ composite made with a high conductivity fiber (Tyranno ${ }^{\mathrm{TM}} \mathrm{SA}$ ) and a CVI-SiC matrix. In Figs. 1(a-b), the analytical solutions predicted by Eq. (1) are plotted for such a hypothetical composite for a fiber volume fraction of 0.4 and for selected $h$-values of 5000,500 and $50 \mathrm{~W} / \mathrm{cm}^{2} \mathrm{~K}$. For example, it is predicted that before irradiation this composite with an optimized interfacial heat transfer coefficient $\left(\mathrm{h} \approx 5000 \mathrm{~W} / \mathrm{cm}^{2} \mathrm{~K}\right) \mathrm{K}_{\text {eff }}$ would range from 34 down to $26 \mathrm{~W} / \mathrm{mK}$ at 200 and $1000^{\circ} \mathrm{C}$, respectively. After irradiation to saturation doses at those temperatures, the $\mathrm{h}$-value would likely decrease to $500 \mathrm{~W} / \mathrm{cm}^{2} \mathrm{~K}$ or less and the respective $\mathrm{K}_{\text {eff }}$ values would decrease to 6 or $10 \mathrm{~W} / \mathrm{mK}$ (or less) at 200 or $1000^{\circ} \mathrm{C}$, respectively.

\section{FUTURE WORK}

The theoretical model predictions will be compared to measured thermal conductivity values for unirradiated and irradiated $\mathrm{SiC} / \mathrm{SiC}$ composites made with advanced $\mathrm{SiC}$ fibers and for various matrices and fiber architectures (see the article "KFIB EXPERIMENT" in this volume).

\footnotetext{
"Pacific Northwest National Laboratory (PNNL) is operated for the U.S. Department of Energy by Battelle Memorial Institute under contract DE-AC06-76RLO-1830.
} 


\section{ACKNOWLEDGEMENTS}

Work supported by the Nuclear Energy Research Initiative (NERI), and the U.S. Department of Energy.
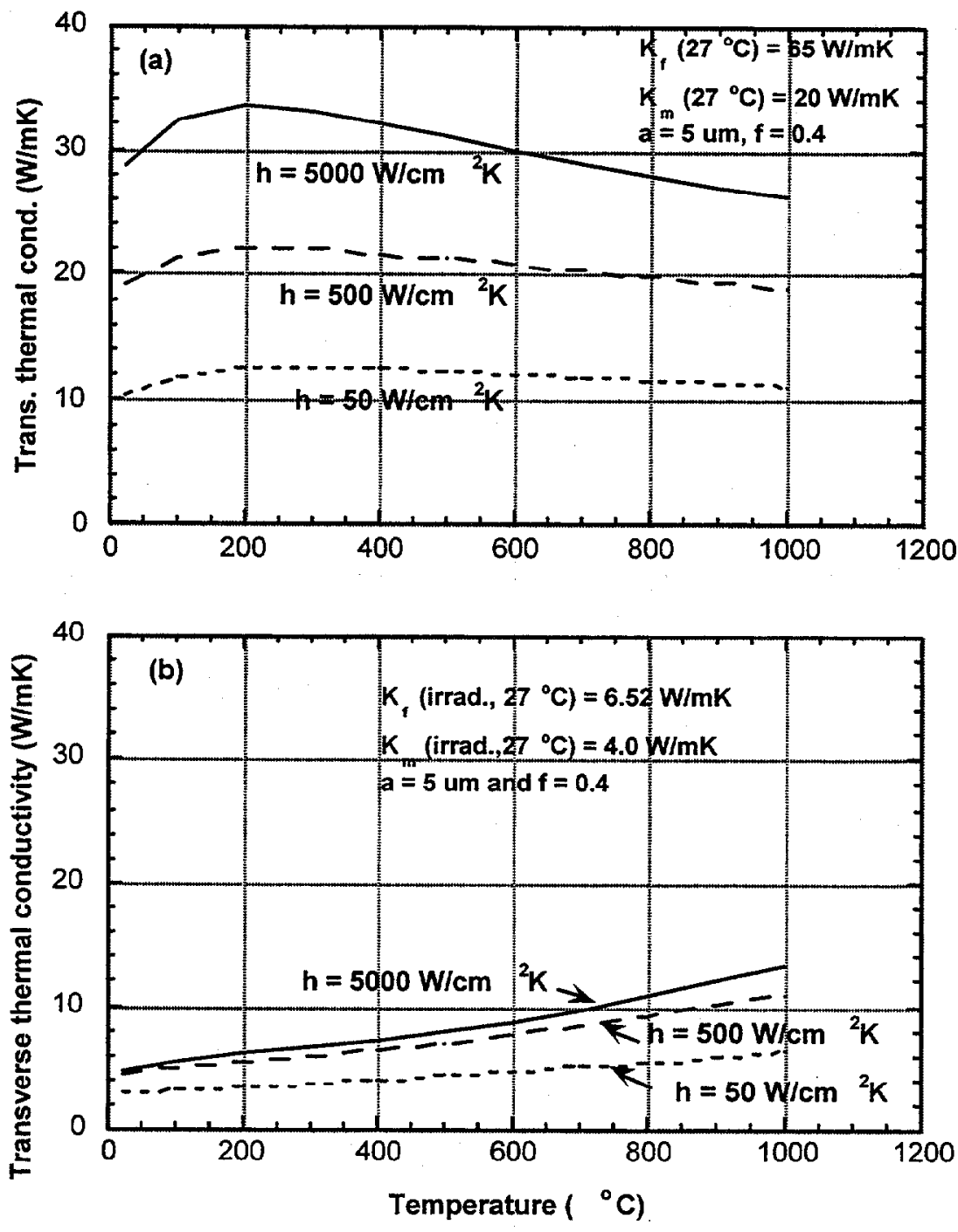

Figures 1(a-b). The transverse thermal conductivity predicted by Eq. (1) for a hypothetical (a) unirradiated and (b) irradiated 2D-Tyranno ${ }^{T M}$ SA/CVI-SiC composite as a function of temperature. The selected values for $a, K_{f}$ and $K_{m}$ correspond to expected constituent values at $27^{\circ} \mathrm{C}$ for a hypothetical composite with $V_{f}=0.4$ and $h=50,500$ and $5000 \mathrm{~W} / \mathrm{cm}^{2} \mathrm{~K}$. 


\section{REFERENCES}

[1] D. P. H. Hasselman and Lloyd F. Johnson, "Effective thermal conductivity of composites with interfacial thermal barrier resistance," J. Comp. Mater. 21 (1987) 508.

[2] Samuel Graham, David L. McDowell, Edgar Lara-Curzio, Ralph B. Dinwoodie and Hsin Wang, "The effects of microstructural damage on the thermal diffusivity of continuous fiberreinforced ceramic matrix composites," ASTM STP 1392, West Conshocken, PA, 2000. 
A NEW TYPE OF SIC COMPOSITE FOR FUSION - G. E. Youngblood and R. H. Jones (Pacific Northwest National Laboratory")

\section{OBJECTIVE}

The objective of this task is to examine $\mathrm{SiC}$ fibers and $\mathrm{SiC} / \mathrm{SiC}$ composites fabricated by various processing methods designed to improve the composite thermal conductivity. Specifically, it is desired to increase the thermal conductivity of these composites to meet expected thermal transport requirements for advanced fusion energy systems.

\section{SUMMARY}

A new type of $\mathrm{SiC}$ composite called Tyrannohex ${ }^{\mathrm{TM}}$ is potentially suitable as a fusion reactor structural material. Tyrannohex ${ }^{T M}$ composite plates are made by hot-pressing layups of Tyranno $^{T M}$ SA precursor fibers into various $1 \mathrm{D}$ and $2 \mathrm{D}$ configurations. The fiber-bonded composite plates contain nearly $100 \%$ fiber volume, so take advantage of the outstanding high temperature strength and creep properties of the Tyranno ${ }^{\mathrm{TM}} \mathrm{SA}$ fiber, a nearly stoichiometric $\mathrm{SiC}$ fiber. The hot-pressed plates are dense, strong, rigid, tough, thermally conductive and have high temperature stability.

The microstructure and thermal conductivity of a SA-Tyrannohex ${ }^{\mathrm{TM}}$ material with a 2D-woven configuration was evaluated prior to irradiation testing. The microstructure contained some small, flat interlaminar pores and intrabundle needle-like pores, and the transverse thermal conductivity was 25 and $21 \mathrm{~W} / \mathrm{mK}$ at ambient and $1000^{\circ} \mathrm{C}$, respectively. These results suggest that careful control of the fiber-bonded interlayers and the fiber architecture are critical to achieve both high thermal conductivity and toughness in Tyrannohex ${ }^{\mathrm{TM}}$ type materials.

\section{PROGRESS AND STATUS}

Considerable radiation performance data now exist for a two-dimensional (2D), woven $\mathrm{SiC}_{f} / \mathrm{SiC}$ composite made with Hi-Nicalon ${ }^{T M}$ fiber and a chemical vapor infiltrated (CVI) matrix [1]. Therefore, this composite serves as a useful standard even though its properties appear to be unacceptable for the most demanding (first wall) fusion reactor application [2]. In particular, its transverse thermal conductivity $\left(K_{t}\right)$ is expected to degrade from about 13 and $10 \mathrm{~W} / \mathrm{mK}$ unirradiated to about $5 \mathrm{~W} / \mathrm{mK}$ irradiated at $300 \mathrm{~K}$ and $1273 \mathrm{~K}$, respectively [3]. Several conceptual fusion reactor designs utilizing $\mathrm{SiC} / \mathrm{SiC}$ call for $\mathrm{K}_{\mathrm{t}}$-values above $15 \mathrm{WmK}$ at $1000^{\circ} \mathrm{C}$ for the first wall structure [4]. Since the $\mathrm{K}_{\mathrm{t}}$-values for monolithic $\mathrm{SiC}$ or $\mathrm{SiC} / \mathrm{SiC}$ irradiated at $1000^{\circ} \mathrm{C}$ to saturation doses or above have been observed to degrade about $50 \%$ [3], unirradiated $1000^{\circ} \mathrm{C}$ $\mathrm{K}_{\mathrm{t}}$-values must exceed $30 \mathrm{~W} / \mathrm{mK}$. Obviously, the thermal conductivity performance of the $2 \mathrm{D}$ woven $\mathrm{SiC} / \mathrm{SiC}$ composite made with Hi-Nicalon fiber is far below this goal. In fact, it is unlikely that any $2 \mathrm{D}$-woven $\mathrm{SiC} / \mathrm{SiC}$ composite made by either the CVI-process or by polymer infiltration pyrolysis (PIP-process) will attain the $K_{t}$-values required for fusion (see reference [5]). To attain the thermal conductivity goal for fusion, a "new" type of SiC/SiC composite should be considered.

Currently, MER Corporation (Tucson, AZ) is pursuing the design and testing of SiC/SiC with a special 3D-type architecture to meet the fusion $K_{t}$ goal [6]. Ube Industries Ltd. (Ube City, JP) also is currently developing a new type of $\mathrm{SiC}$ composite that potentially could meet fusion

- Pacific Northwest National Laboratory (PNNL) is operated for the U.S. Department of Energy by Battelle Memorial Institute under contract DE-AC06-76RLO-1830. 
requirements for $K_{t}[7]$. This report presents a description and some test results for the latter material.

\section{Description of a "new type" of SiC composite for fusion}

The fabrication and properties of a new type of SiC composite developed by Ube Industries, called Tyrannohex ${ }^{\mathrm{TM}}$, have been described in recent papers $[7,8-10]$. This new SiC composite consists of a $100 \%$ fiber-bonded ceramic made by hot-pressing sheets of polycrystalline $\mathrm{SiC}$ fibers (precursor fibers for Tyranno $\mathrm{SA}^{\mathrm{TM}}$ ) at temperatures over $1800^{\circ} \mathrm{C}$ and at a pressure of about $50 \mathrm{MPa}$.

The sintered Tyranno $S A^{T M}$ fiber itself exhibits outstanding high temperature tensile strength retention (2.8 $\mathrm{GPa}$ up to $1900^{\circ} \mathrm{C}$ in argon), and even in air chemical stability and creep resistance [11]. In Fig. 1, creep curves of representative $\mathrm{SiC}$ fibers in air at $1300^{\circ} \mathrm{C}$ for a $1 \mathrm{GPa}$ applied stress are presented [12]. The creep resistance of the Tyranno ${ }^{\mathrm{TM}} \mathrm{SA}$ fiber is significantly better than that of Hi-Nicalon ${ }^{T M}$ fiber and earlier versions of the Tyranno ${ }^{\mathrm{TM}} \mathrm{SiC}$ fiber. Furthermore, the SA fiber has a relatively high thermal conductivity ( $64 \mathrm{~W} / \mathrm{mK}$ at ambient), which is 13 times higher than the thermal conductivity value for Hi-Nicalon ${ }^{\top M}$ fiber. These favorable properties are related to the densified and sintered fiber structure, which is composed of nearly stoichiometric SiC grains. The $\mathrm{SA}$ fiber composition $\left(\mathrm{Si}_{1} \mathrm{C}_{1.08} \mathrm{Al}_{0.009} \mathrm{O}_{0.006}\right)$ contains a small amount of aluminum $(\leq 1 \%)$ which apparently controls grain growth during densification. Because oxidative rather than electron beam radiation curing is utilized, it is expected that fiber processing costs for the SA fiber also can be reduced. Preliminary estimates place the cost of SA fiber at about $1 / 3$ that of $\mathrm{Hi}$ Nicalon ${ }^{\mathrm{TM}}$ type $\mathrm{S}$ fiber, which is a comparable near-stoichiometric $\mathrm{SiC}$ fiber made using electron beam curing [13].

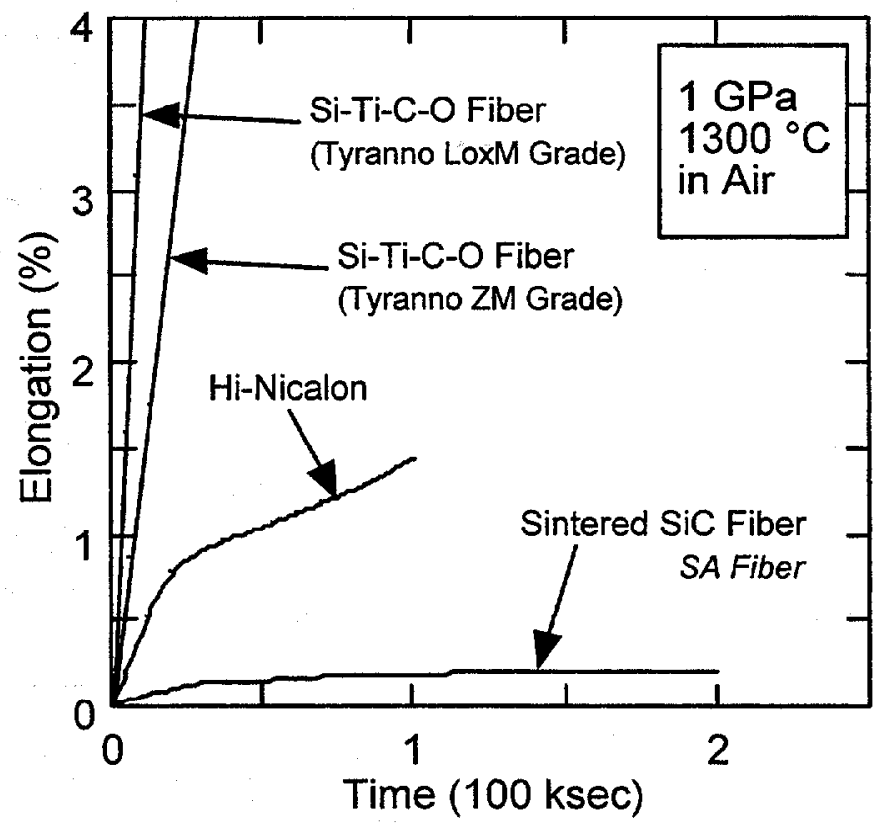

Figure 1. Creep curves for representative $\mathrm{SiC}$ fibers in air at $1300^{\circ} \mathrm{C}$ for $1 \mathrm{GPa}$.

${ }^{7 m}$ Tyrannohex and Tyranno SA are trademarks of Ube Industries, Ltd., Ube City, Japan. 
One version of the new type of SiC composite is synthesized by hot-pressing stacked sheets $(\approx 100 \mu \mathrm{m}$ thick) of the Tyranno SA precursor fibers. The precursor fibers actually are amorphous Si-Al-C-O fibers, which have been cured but not sintered by heating in inert gas up to $1300^{\circ} \mathrm{C}$. During hot-pressing, the amorphous Si-Al-C-O fibers deform and convert into sintered SiC fiber by way of a decomposition, which releases $\mathrm{CO}$ gas over the $1500-1700^{\circ} \mathrm{C}$ temperature range before completion of the sintering at temperatures over $1800^{\circ} \mathrm{C}$. The sintered composite consists of a highly ordered, close-packed structure of fine hexagonal columnar fibers with a 100-400 nm grain size and a thin interfacial carbon layer between fibers. When made with the fibers aligned uniaxially in the sheets, this material had a tensile strength of $600 \mathrm{MPa}$ in the longitudinal direction, which was retained when tested up to $1600^{\circ} \mathrm{C}$. Because of the very thin interfacial carbon layer, the $\mathrm{SiC}$ fiber-bonded ceramic also exhibits fibrous fracture behavior similar to that exhibited by a conventional 2D-woven $\mathrm{SiC} / \mathrm{SiC}$ composite. Likewise, the stress-strain curves for a $2 D$ cross-plied version of the ceramic exhibit nonlinear fracture behavior, a maximum bend strength of $210 \mathrm{MPa}$, a maximum strain of $0.09 \%$, a proportional limit of $120 \mathrm{MPa}$, a high elastic stiffness of $300 \mathrm{GPa}$, and a relatively high fracture energy of $2000 \mathrm{~J} / \mathrm{m}^{2}$. These properties are almost equivalent or better than comparable properties obtained for $2 \mathrm{D}$-woven $\mathrm{SiC} / \mathrm{SiC}$ made with Hi-Nicalon ${ }^{\mathrm{TM}}$ fiber and a CVI-SiC matrix (see Table 1). Furthermore, the fiber-bonded ceramic exhibits a desired high transverse thermal conductivity $\left(20-65 \mathrm{~W} / \mathrm{mK}\right.$ at $1000^{\circ} \mathrm{C}$, depending on configuration). The dense, low porosity structure made up of nearly $100 \%$ high quality, sintered crystalline $\mathrm{SiC}$ fibers accounts for the outstanding mechanical and thermal properties exhibited by the Tyrannohex ${ }^{\mathrm{TM}}$ fiber-bonded ceramic.

Generally, large improvements in mechanical properties of other types of SiC/SiC composites made with advanced fibers have been limited because of the high temperature strength limitation of the fiber. As an example, one way to improve the thermal conductivity of a SiC/SiC composite, especially one made by PIP-processing, is to give the composite a high temperature treatment (HTT). However, the HTT temperature required to achieve a significant improvement in the

Table 1. Comparison of properties for three types of $\mathrm{SiC}$ composites

\begin{tabular}{|c|c|c|c|}
\hline Property & $\begin{array}{c}\mathrm{Hi}-\mathrm{Nic} / \mathrm{PyC} / \mathrm{CV} I-\mathrm{SiC} \\
(2 \mathrm{D}-\mathrm{PW})\end{array}$ & $\begin{array}{c}\text { Tyrannohex }^{\mathrm{TM}} 1 \mathrm{D} \\
\text { (parallel plies) }\end{array}$ & $\begin{array}{c}\text { Tyrannohex }{ }^{\mathrm{TM}} 2 \mathrm{D} \\
(8 \mathrm{HS})\end{array}$ \\
\hline Bulk density ( $g / c c)$ & 2.6 & 3.1 & 3.0 \\
\hline Porosity (\%) & $10-15$ & $<3$ & $<6$ \\
\hline Bend strength (MPa) & $\begin{array}{c}350[7] \\
\text { (up to } 1000^{\circ} \mathrm{C} \text { ) }\end{array}$ & $\begin{array}{c}600[7] \\
\text { (up to } 1600^{\circ} \mathrm{C} \text { ) }\end{array}$ & $\begin{array}{c}280 \\
210(X-p l y)[14]\end{array}$ \\
\hline Young's Modulus (GPa) & 200 (est) & NM & 320 (X-ply) [14] \\
\hline Proportional limit (MPa) & NM & NM & $120(X-p l y)[14]$ \\
\hline Ultimate strain (\%) & 0.9 & NM & 0.09 (X-ply) [14] \\
\hline Thermal conductivity $(\mathrm{W} / \mathrm{mK})$ & 13 & 37 (63 in plane) [7] & 25 (80 in plane) \\
\hline @ $1000^{\circ} \mathrm{C}$ & 10 & 27 (35 in plane) [7] & 21 ( 42 in plane) \\
\hline
\end{tabular}

PNNL measurements shown in bold type. 
thermal conductivity is about $1800^{\circ} \mathrm{C}$, which exceeds the stability limit of other advanced SiC fibers. Thus, at the expense of improving the thermal conduction properties of a composite the mechanical properties will be degraded by an $1800^{\circ} \mathrm{C} \mathrm{HTT}$. However, the high temperature stability of the Tyranno ${ }^{\mathrm{TM}} \mathrm{SA}$ fiber allows an $1800^{\circ} \mathrm{C} H T$ without sacrificing composite mechanical properties [11].

Recently, Ube discovered that by reducing the mean diameter of the SA fiber from 10 to $7.5 \mu \mathrm{m}$ during processing the fiber tensile strength could be further improved [10]. Apparently, when starting with smaller diameter precursor fibers the gas evolution stage and grain growth are better controlled so that the resulting microstructure is made up of smaller ( $\approx 50$ rather than 200 $\mathrm{nm}$ ) grains, and the fiber surface is smoother. Contrary to expectation for a fiber with a smaller average grain size, the resulting creep resistance for this new version of Tyranno fiber (called SA-B) also is improved as depicted in Fig. 2 [12].

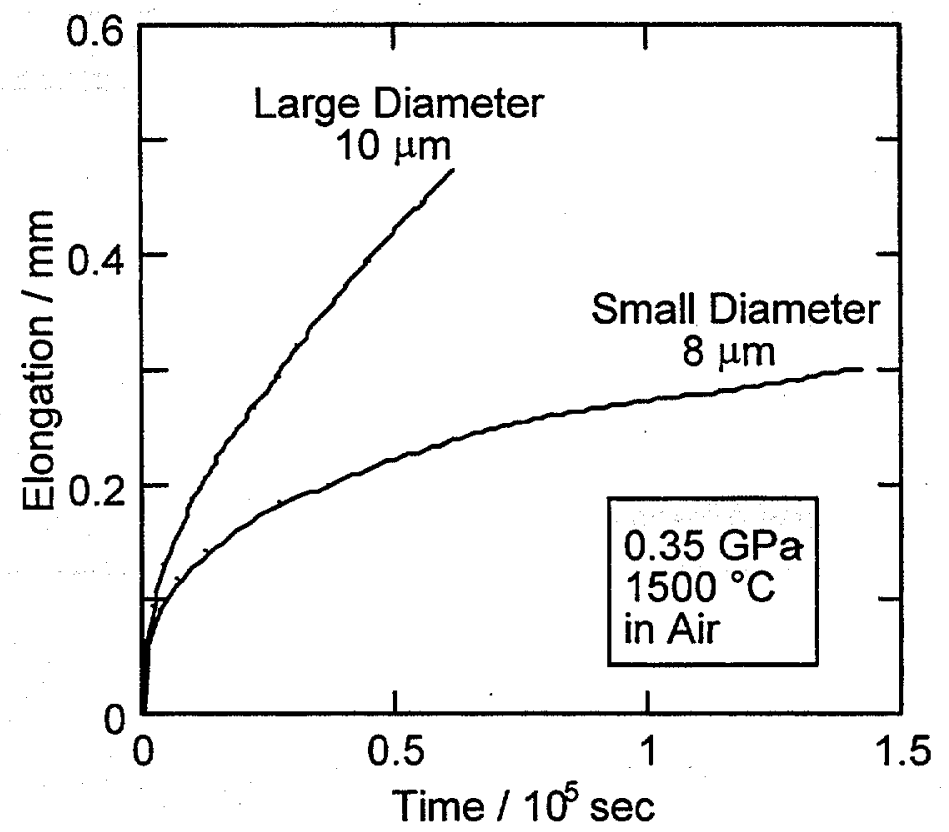

Figure 2. Creep resistance difference between two types of sintered $\mathrm{SiC}$ fiber (Tyranno ${ }^{\mathrm{TM}} \mathrm{SA}$ ) with different diameters.

By starting with smaller diameter fiber precursors, the strength of the fiber-bonded Tyrannohex ${ }^{T M}$ composite also was improved. For instance, the 4-point bending strength of a cross-plied specimen increased from 300 to $500 \mathrm{MPa}$ by using the $7.5 \mu \mathrm{m}$ rather than the 10 $\mu \mathrm{m}$ fiber [10]. Other improvements in Tyrannohex ${ }^{\mathrm{TM}}$ composite properties are expected as fiber and composite development continues.

The Tyrannohex ${ }^{\mathrm{TM}}$ fiber-bonded $\mathrm{SiC}$ composite is dense, strong and rigid, tough, thermally conductive and has high temperature stability, all of which are desired attributes of a fusion grade $\mathrm{SiC} / \mathrm{SiC}$. The irradiation performance of this new type of $\mathrm{SiC}$ composite now needs to be assessed. 


\section{Pre-irradiation experimental results}

A plate $\left(50 \times 16 \times 2.0 \mathrm{~mm}^{3}\right.$, code UD-786) and two discs $(6.5 \mathrm{~mm}$ dia $\times 2.0 \mathrm{~mm}$ thick, code UD722) of 2D SA-Tyrannohex ${ }^{7 M}$ were obtained from Ube Industries for testing (courtesy of $T$. Ishikawa). The plate contained 22 fabric layers stacked and bonded together. Each layer was woven in a $0 / 90$ satin weave (8HS) pattern, which is a different architecture option from that discussed previously. The surfaces of the as-received plate were lightly machined. The nominal density and bending strength were given as $3.1 \mathrm{~g} / \mathrm{cc}$ and $280 \mathrm{MPa}$, respectively [12].

Seven discs $(6.2 \mathrm{~mm}$ dia $\times 2.0 \mathrm{~mm}$ thick) for thermal diffusivity testing were core-drilled from the plate with the fabric layers normal to the heat flow direction. The remainder of the plate was cut into two flexure bars $\left(50 \times 3.6 \times 2.0 \mathrm{~mm}^{3}\right)$. The two as-received discs were cut from a thicker piece of stock so that the heat flow direction was parallel to alternate fabric layers (i.e., $50 \%$ rather than $100 \%$ of the fibers were normal to the heat flow direction). These discs will be irradiated in the ATR and the HFR Petten reactors as part of the KFIB experiment (see Ref. [14] in this report). The thermal diffusivity was determined as a function of temperature up to $1000^{\circ} \mathrm{C}$ for each type of architecture by the laser flash technique described elsewhere [15].

SEM micrographs of polished pieces of the SA-Tyrannohex plate sample are presented in Figs. $3(a-b)$. In Fig. 3(a), the fibers on the left-hand side exhibit deformed hexagonal cross-sections with intervening thin carbon interfacial layers. However, sometimes needle-like pores remain between individual filaments. Such a pore is observed aligned parallel to the fiber axis in the right-hand side while two end-on views of pores are noted in the left-hand side of Fig. 3(a), respectively. Importantly, large interlaminar pores characteristic of $2 \mathrm{D}$-woven $\mathrm{SiC} / \mathrm{SiC}$ with a CVI$\mathrm{SiC}$ matrix were not observed. However, for these SA-Tyrannohex samples made from layers of 8HS fabric a few smaller "interlaminar-type" pores were observed, as depicted in Fig. 3(b). Because of the more undulating weave pattern in this SA-Tyrannohex material, as compared to the unidirectional or simple 2D-layered architectures, porosity was low but not completely eliminated by hot-pressing. In fact, the average bulk density determined by weighing and dimensioning each disc sample was $2.97 \pm 0.03 \mathrm{~g} / \mathrm{cc}$, a value slightly less than the given nominal $3.1 \mathrm{~g} / \mathrm{cc}$ value.

In Figures 4(a-b), the measured pre-irradiation thermal diffusivities and calculated thermal conductivities for the individual disc samples are given as a function of temperature. The heat flow in the samples labeled THt\# was transverse to $100 \%$ of the fibers; in the samples labeled THp\#, heat flow was transverse to $50 \%$ and parallel to the other $50 \%$ of the fibers. As expected, the thermal diffusivity values for samples with either architecture decreased with increasing temperature up to $1000^{\circ} \mathrm{C}$, in a manner characteristic of thermal transport being governed by phonon conductivity. For the two samples with heat flow parallel to $50 \%$ of the fibers, the thermal conductivity ranged from about $80 \mathrm{~W} / \mathrm{mK}$ at ambient down to $42 \mathrm{~W} / \mathrm{mK}$ at $1000^{\circ} \mathrm{C}$. However, in samples with the heat flow transverse to $100 \%$ of the fibers the thermal conductivity ranged from only $25 \mathrm{~W} / \mathrm{mK}$ at ambient down to $21 \mathrm{~W} / \mathrm{mK}$ at $1000^{\circ} \mathrm{C}$.

The large difference in the thermal conductivity values between samples with the two different architectures is due primarily to the high conduction along the axis of $50 \%$ of the fibers for the THp material because the axial thermal conductivity of the Tyranno SA fibers is quite high (64 W/mK at ambient). Furthermore, the THt material contains approximately twice as many intervening carbon interlayers, which effectively act as thermal barriers.

Using a simple series-parallel combination model, the thermal conductivity of an interlayer $\left(\mathrm{K}_{\mathrm{i}}\right)$ can be estimated from the difference in the thermal conductivity values for the two architectures. If the interlayer is assumed to be 50 or $100 \mathrm{~nm}$ thick, $\mathrm{K}_{\mathrm{i}} \approx 0.2$ or $0.4 \mathrm{~W} / \mathrm{mK}$, respectively. These 


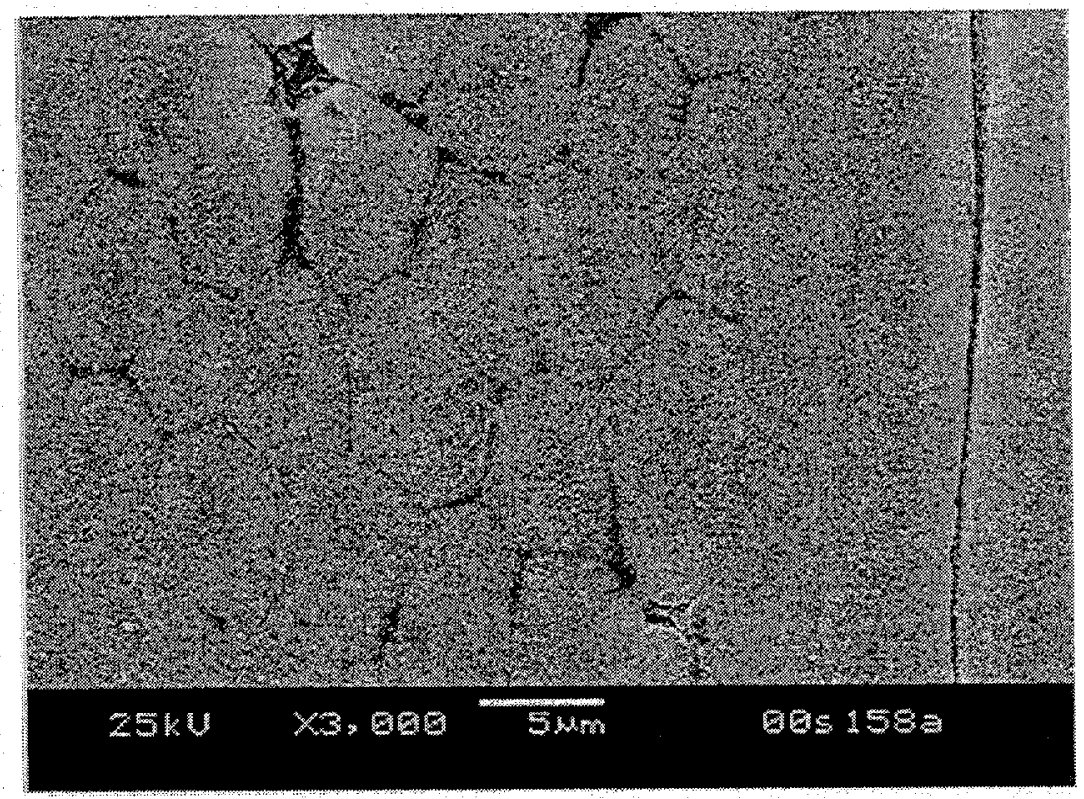

(a)

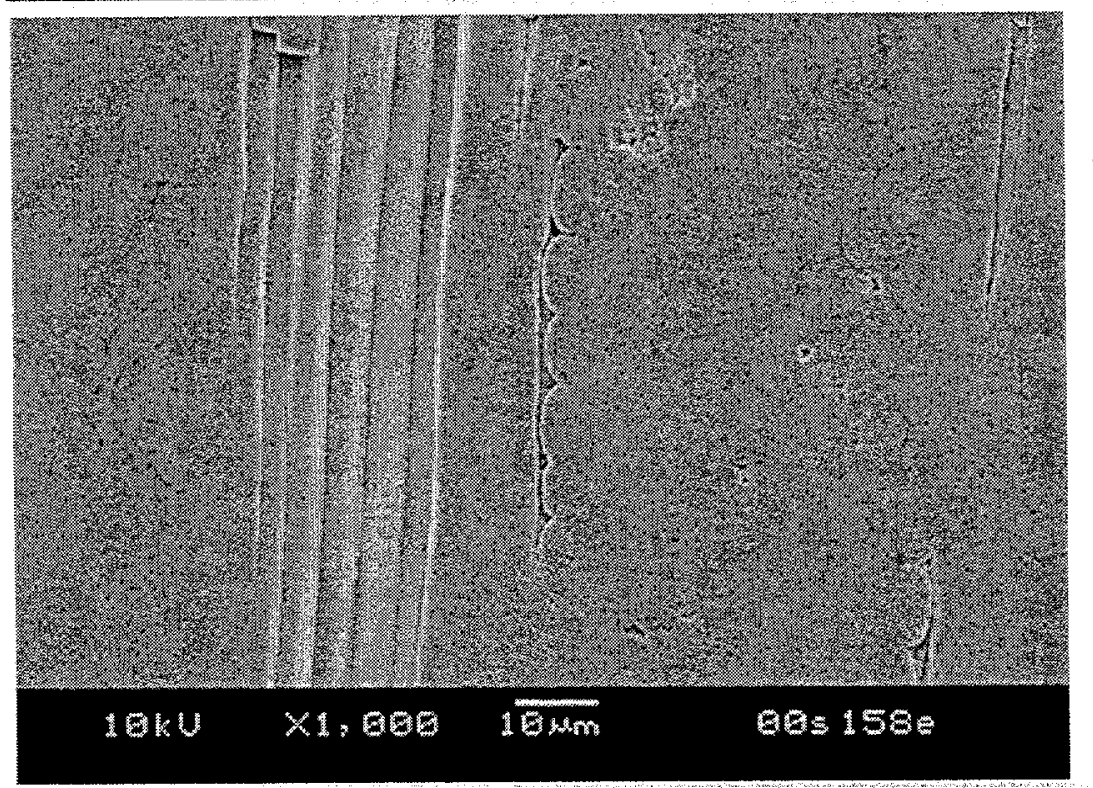

(D)

Figures 3(a-b). Typical SEM images of 2D SA-Tyrannohex showing crosssectional views of material made by hot-pressing a layup of $8 \mathrm{HS}$ fabric layers. (a) Typical fiber-bonding arrangement with residual intrabundle needle-like porosity observed in both $0^{\circ}$ and $90^{\circ}$ bundles and (b) limited amount of small interlaminar type porosity observed between $0 / 90$ layers.

low values confirm that the interlayers act as effective thermal barriers for transverse thermal conduction in the Tyrannohex ${ }^{T M} 1 \mathrm{D}$ - or $2 \mathrm{D}$-type materials. 

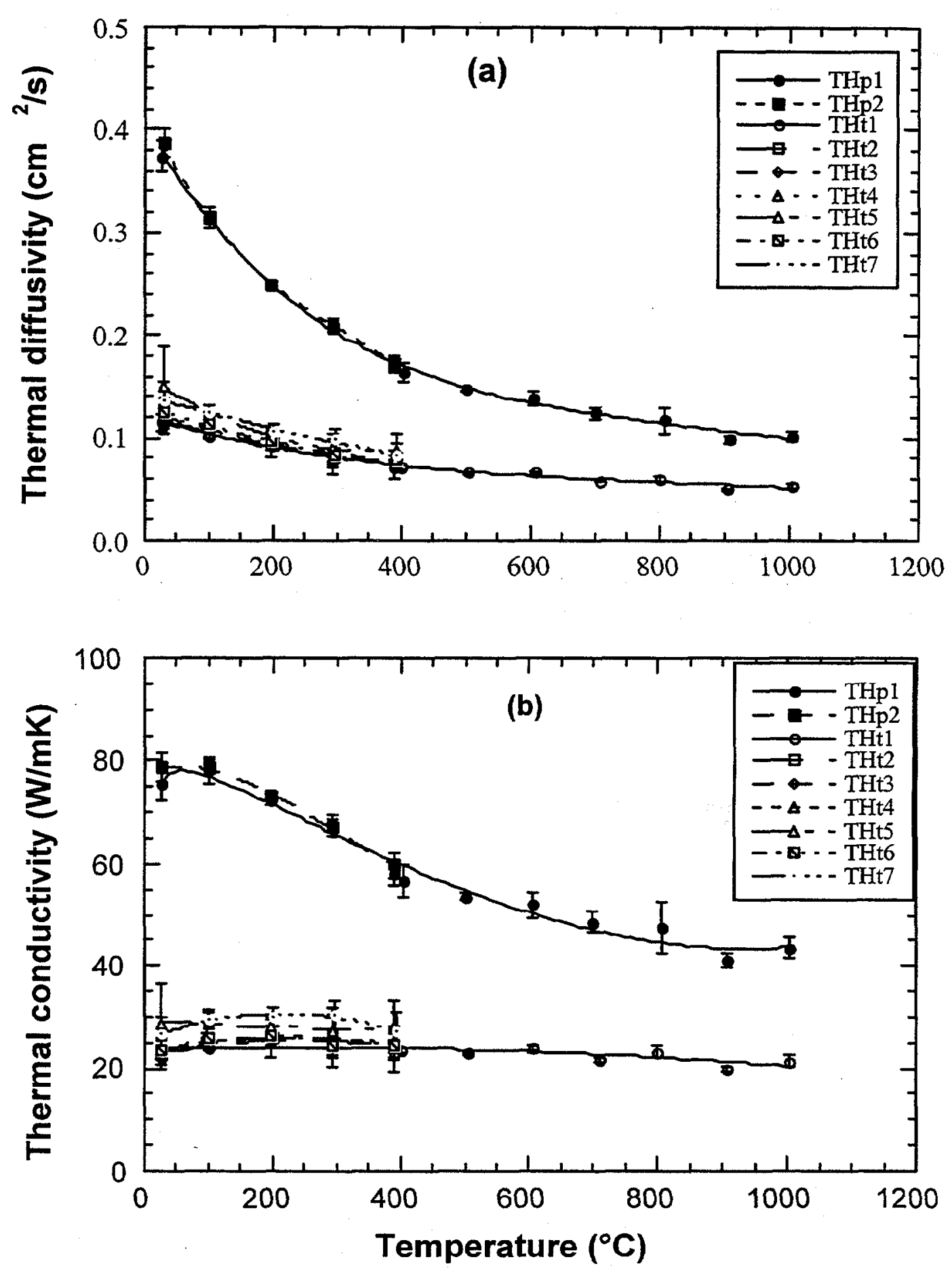

Figures 4(a-b). Tyrannohex-SA (2D-HP from 8HS Tyranno SA fiber) pre-irradiation (a) measured thermal diffusivity and (b) calculated thermal conductivity for "KFIB Experiment" disc samples (see Ref. [14]). The heat flow was normal to $100 \%$ or $50 \%$ of the fibers for the samples labeled THE\# or THp\#, respectively. 
If the interlayer is carbon, as is suggested by detailed chemical and microscopic analysis by Ube [10], the carbon must exist in a fairly unorganized form to exhibit such low thermal conductivity values. Of course, the small amount of porosity contained in the SA-Tyrannohex ${ }^{\mathrm{TM}}$ material with an initially woven fiber layup may also contribute to the low $\mathrm{K}_{\mathrm{i}}$ estimates. However, a carbon interlayer is necessary to provide the fibrous fracture and toughness in these materials so cannot be eliminated. The somewhat lower $21 \mathrm{~W} / \mathrm{mK}$ transverse conductivity value observed at $1000^{\circ} \mathrm{C}$ for the THt material is only about two times comparable values for a conventional 2D-PW $\mathrm{SiC} / \mathrm{CVI}-\mathrm{SiC}$ made with Hi-Nicalon ${ }^{\mathrm{TM}}$ fibers. However, the $1000^{\circ} \mathrm{C}$ thermal conductivity of other types of the Tyrannohex material has been reported to be as high as $65 \mathrm{~W} / \mathrm{mK}$ [10]. These results suggest that careful control of the fiber-bonded interlayers and the fiber architecture are critical to achieve both high thermal conductivity and toughness in Tyrannohex ${ }^{\mathrm{TM}}$ type materials.

\section{FUTURE WORK}

The dimensional stability and transverse thermal conductivity of the 2D SA-Tyrannnohex ${ }^{\mathrm{TM}}$ material will be assessed after irradiation as part of the KFIB experiment.

\section{ACKNOWLEDGEMENTS}

This work is a joint effort funded by the US DOE Fusion Energy and the Japan Monbusho fusion materials programs.

\section{REFERENCES}

[1] L. L. Snead, M. C. Osborne, R. A. Lowden, J. Strizak, R. J. Shinavski, K. L. More, W. S. Eatherly, J. Bailey and A. M. Williams, "Low dose irradiation performance of SiC interphase SiC/SiC composites," J. Nucl. Mater. 253 (1998) 20-30.

[2] L. L. Snead and E. Lara-Curzio, "Neutron irradiated Hi-Nicalon/CVD silicon carbide composites," p. 132 in the Proceedings of the IEA International Workshop on SiC/SiC Ceramic Composites for Fusion Structural Applications, 28-29 October 1996, Ispra (Va), Italy. Also p. 100 in Fusion Materials Semiannual Progress Report (FMSPR), December 31, 1999 (DOE/ER-0313/27).

[3] D. J. Senor, G. E. Youngblood, C. E. Moore, D. J. Trimble, G. A. Newsome and J. J. Woods, "Effects of Neutron Irradiation on Thermal Conductivity of SiC-Based Composites and Monolithic Ceramics," Fusion Technology 30(3), 943-955 (1996).

[4] R. H. Jones, "IEA Agreement - Performance Requirements for Structural Applications of $\mathrm{SiC} / \mathrm{SiC}$," p. 196 in the Proceedings of the IEA International Workshop on SiC/SiC Ceramic Composites for Fusion Structural Applications, 28-29 October 1996, Ispra (Va), Italy.

[5] G. E. Youngblood, David J. Senor, R. H. Jones and Samuel Graham, "The transverse thermal conductivity of $2 \mathrm{D}-\mathrm{SiC} / \mathrm{SiC}$ composites," extended abstract in this report, submitted to J. Nucl. Mater. for publication.

[6] "Hybrid 3D SiC/C high thermal conductivity composites," USDOE Phase II SBIR for FY 2000 , issued to MER Corp., Tucson, AZ.

[7] Toshihiro Ishikawa, Shinji Kajii, Kenji Matsunaga, Toshihiko Hogami, Yasuhiko Kohtoku, and Toshio Nagasawa, "A tough, thermally conductive silicon carbide composite with high 
strength up to $1600^{\circ} \mathrm{C}$ in air," Science, 282, 1295-1297, 13 November 1998.

[8] Toshihiro Ishikawa, "Crack-resistant Fiber-bonded Ceramic," Advanced Engineering Materials, 1, No. 1, 59-61, 1999.

[9] T. Ishikawa, S. Kajii, T. Hisayuki, K. Matsunaga, T. Hogami and Y. Kohtoku, "New Type of Sintered SiC Fiber and Its Composite Material," Key Engineering Materials, 164-165, 15-18, 1999.

[10] Toshihiro Ishikawa, Shinji Kajii, Terumi Hisayuki and Yasuhiko Kohtoku, "SiC Polycrystalline Fiber and the Fiber-Bonded Ceramic," Proc. $6^{\text {th }}$ Japan International SAMPE Symposium, Oct. 26-29, 1999.

[11] Toshihiro Ishikawa, Yasuhiko Kohtoku, Kiyoshi Kumagawa, Takemi Yamamura and Toshio Nagasawa, "High-strength, alkali-resistant sintered SiC fibre stable to $2200^{\circ} \mathrm{C}$," Nature, 391, No 6669, 773-775, 19 February 1998.

[12] Masaki Shibuya, Tyranno Fiber Project, Ube Industries Ltd., 1978-10 Kagushi, Ube City, Yamaguchi Prefecture, 755-8633 Japan.

[13] Quoted domestic fiber costs: Tyranno ${ }^{\mathrm{TM}} \mathrm{SA}-\$ 5000 / \mathrm{kg}$ and Hi-Nicalon ${ }^{\mathrm{TM}}$ type $\mathrm{S}$ $\$ 13,600 / \mathrm{kg}$.

[14] G. E. Youngblood, R. H. Jones, W. Kowbel and Akira Kohyama, "The KFIB Experiment," this report.

[15]D. J. Senor, G. E. Youngblood, D. V. Archer and C. E. Chamberlin, "Recent Progress in Thermal Conductivity Testing of SiC-based Materials for Fusion Reactor Applications," p. 102 in the Proceedings of the Third IEA Workshop on SiC/SiC Ceramic Composites for Fusion Structural Applications, January 29-30, 1999, Cocoa Beach, FL. Also see Ref. [3]. 


\subsection{FERRITIC/MARTENSITIC STEELS}


Microstructure and Mechanical Properties of Oxide Dispersion-Strengthened SteelsR. L. Klueh, P. J. Maziasz, D. J. Larson, N. Hashimoto, L. Heatherly, M. K. Miller (Oak Ridge National Laboratory), I-S. Kim, and K. Miyahara (Nagoya University)

\section{OBJECTIVE}

The objective of this work is to explore the possibility of using oxide dispersion-strengthened ferritic steels as a structural material for fusion, which would allow for an increase in the operating temperature over that available with conventional ferritic/martensitic steels.

\section{SUMMARY}

The microstructure and the tensile and creep behavior of two oxide dispersion-strengthened (ODS) steels-Fe-12Cr-0.25 $\mathrm{Y}_{2} \mathrm{O}_{3}$ (designated $12 \mathrm{Y} 1$ ) and $\mathrm{Fe}-12 \mathrm{Cr}-3 \mathrm{~W}-0.4 \mathrm{Ti}-0.25 \mathrm{Y}_{2} \mathrm{O}_{3}$ (12YWT)-were investigated. Optical microscopy, transmission electron microscopy, and atom probe field ion microscopy studies indicated that the 12YWT contained a high density of extremely fine Y-Ti-O clusters, compared to the much larger oxide particles in the $12 Y 1$. The fine dispersion of particles in the 12YWT gave it superior tensile and creep properties.

\section{PROGRESS AND STATUS}

\section{Introduction}

If the conventional high-chromium ferritic/martensitic steels, such as modified $9 \mathrm{Cr}-1 \mathrm{Mo}$ and Sandvik $\mathrm{HT}$, or the reduced-activation steels, such as F82H, ORNL 9Cr-2WVTa, and JLF-1, were used for a fusion power plant first wall and blanket structure, the upper operating temperature would be limited to $550-600^{\circ} \mathrm{C}$. One way suggested to increase this limit to $650^{\circ} \mathrm{C}$ or higher and still maintain the advantages inherent in ferritic/martensitic steels (1. e. high thermal conductivity and low swelling) is to use oxide dispersion-strengthened (ODS) steels. Elevated temperature strength in these steels is obtained through microstructures that contain a high density of small $\mathrm{Y}_{2} \mathrm{O}_{3}$ or $\mathrm{TiO}_{2}$ particles dispersed in a ferrite matrix.

ODS steels are being developed for fission and fusion applications in Japan [1,2], Europe [3,4], and the United States [5]. This report will summarize some preliminary work conducted on three ODS steels produced by Kobe Steel Ltd. in Japan. Some work carried out at the Oak Ridge National Laboratory (ORNL) on the characterization of microstructure and mechanical properties of these ODS steels is presented in this report. The work to be discussed was carried out in conjunction with Nagoya University, Nagoya, Japan.

\section{Experimental Procedure}

The ODS steels examined were (compositions are in wt.\%): $\mathrm{Fe}-12 \mathrm{Cr}-0.25 \mathrm{Y}_{2} \mathrm{O}_{3}$ (designated 12Y1) and Fe-12Cr-3W-0.4Ti-0.25 $\mathrm{Y}_{2} \mathrm{O}_{3}(12 \mathrm{YWT})$; chemical analyses of the steels are given in Table 1.

Table 1. Chemical composition of ODS steels

\begin{tabular}{|c|c|c|c|c|c|c|c|c|c|c|}
\hline Steel & $\mathrm{C}$ & $\mathrm{Mn}$ & $\mathrm{Si}$ & $\mathrm{Ni}$ & $\mathrm{Cr}$ & $\mathrm{Mo}$ & $\mathrm{Ti}$ & $\mathrm{W}$ & $\mathrm{O}$ & $\mathrm{Y}$ \\
\hline $12 \mathrm{Y} 1$ & 0.045 & 0.04 & 0.03 & 0.24 & 12.85 & 0.03 & 0.003 & $<0.01$ & 0.15 & 0.2 \\
\hline $12 \mathrm{YWT}$ & 0.052 & 0.05 & 0.10 & 0.27 & 12.58 & 0.02 & 0.35 & 2.44 & 0.16 & 0.16 \\
\hline
\end{tabular}

Both alloys contained $0.25 \% \mathrm{Y}_{2} \mathrm{O}_{3}$ and were prepared by mechanical alloying $70 \mu \mathrm{m}$ diameter, argonatomized, pre-alloyed metal powders and $20 \mathrm{~nm} \mathrm{Y}_{2} \mathrm{O}_{3}$ powder. The process involved milling in a high-energy attritor in an argon atmosphere. After the mechanical alloying step, the flakes were 
degassed and consolidated into a bar by hot extrusion at $1150^{\circ} \mathrm{C}$. Further processing by hot and cold rolling interspersed with annealing treatments were used to convert the extruded bar into sheet with a final thickness of $2 \mathrm{~mm}$.

Transmission electron microscopy (TEM) specimens were prepared and examined using a Philips $\left.\mathrm{CM} 30\left(\mathrm{LaB}_{6}\right), 300 \mathrm{KV}\right)$ microscope. In addition to the TEM, atom probe field ion microscopy was performed on the 12YWT material, and three-dimensional atom-probe (3-DAP) analysis was performed. Sheet tensile specimens $1.5 \mathrm{~mm}$ thick and $0.38 .1 \mathrm{~mm}$ long with a $12.7 \mathrm{~mm} \times 3.1 \mathrm{~mm} \times$ $1.5 \mathrm{~mm}$ gage section were prepared for uniaxial tensile and creep tests. Tensile tests were conducted over the range room temperature to $900^{\circ} \mathrm{C}$, and creep tests were made over the range $600-850^{\circ} \mathrm{C}$.

\section{Results and Discussion}

\section{Microstructure}

Optical microstructures of the $12 Y 1$ (Fig. 1) and 12YWT (Fig. 2) showed some differences. The $12 Y W T$ had a much smaller grain size compared to the 12Y1. Both steels showed indications of elongated grains that resulted from the way the steels were processed. Because of the smaller grain size of the 12YWT, this effect would not be expected to have as large an effect on the anisotropy of the mechanical properties.

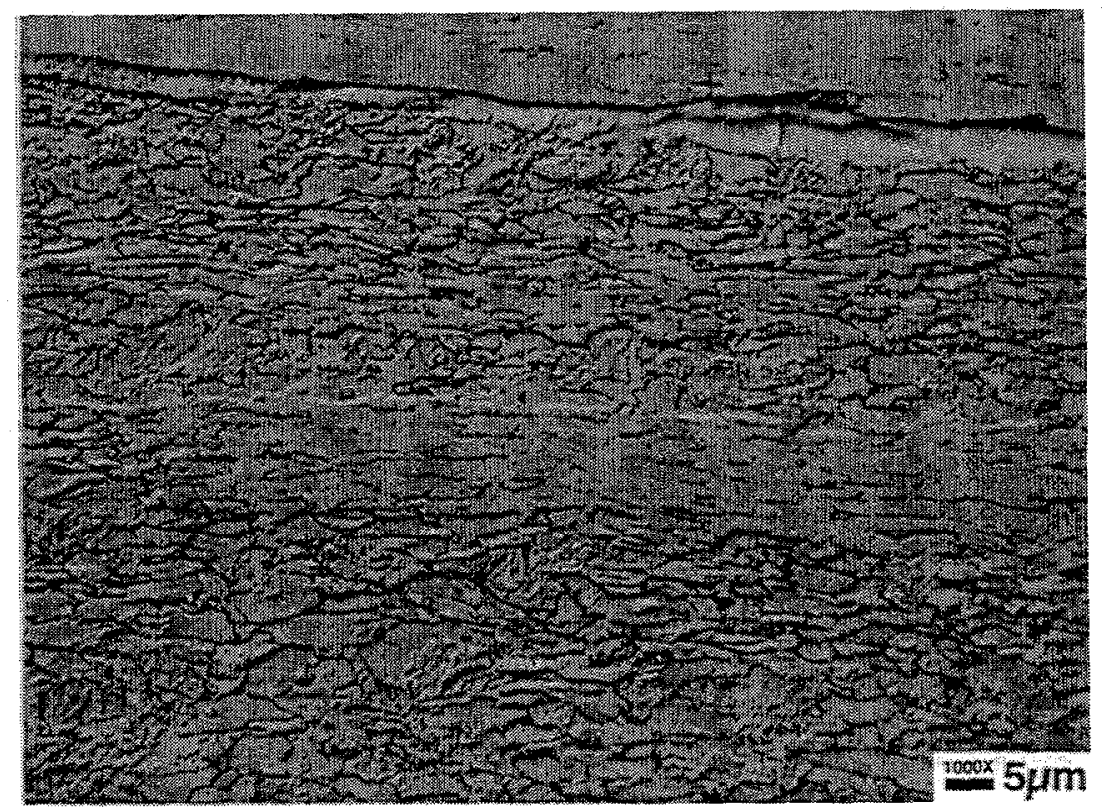

Fig. 1. Microstructure of the $\mathrm{Fe}-12 \mathrm{Cr}-0.25 \mathrm{Y}_{2} \mathrm{O}_{3}(12 \mathrm{Y} 1) \mathrm{ODS}$ steel.

TEM microstructures of the as-processed $12 Y 1$ and $12 Y W T$ are considerably different (Fig. 3). The 12YWT contained about an order of magnitude more dislocation pinned by a fairly uniform distribution of very fine particles, whereas the $12 Y 1$ contained much larger particles non-uniformly distributed. For the 12Y1, the particles were estimated to be $10-40 \mathrm{~nm}$ in diameter at a number density of $10^{20}-10^{21} \mathrm{~m}^{-3}$; the dislocation density was estimated at $\approx 10^{15} \mathrm{~m} / \mathrm{m}^{3}[6]$. Diffraction studies indicated that the particles in the $12 \mathrm{Y} 1$ were crystalline (presumably $\mathrm{Y}_{2} \mathrm{O}_{3}$ ). For the 12YWT, the dislocation density, particle size, and particle number density were estimated at $10^{15}-10^{16} \mathrm{~m} / \mathrm{m}^{3}$, 


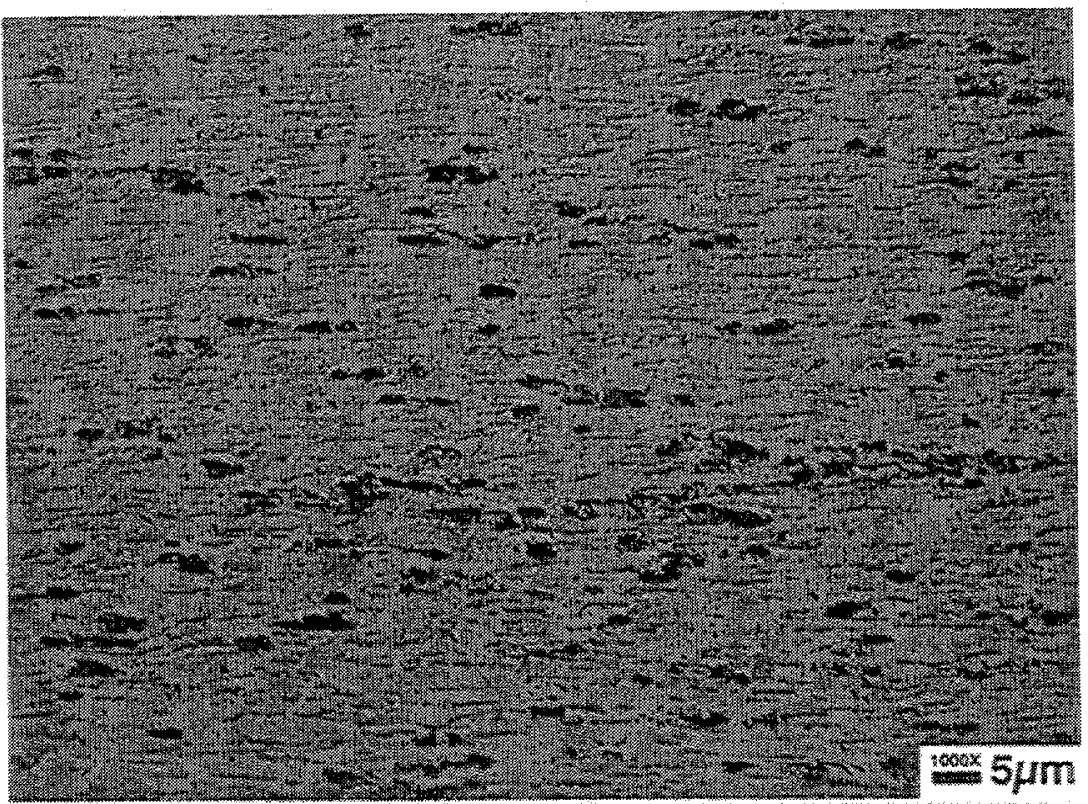

Fig. 2. Microstructure of the Fe-12Cr-3W-0.4Ti-0.25 $\mathrm{Y}_{2} \mathrm{O}_{3}(12 \mathrm{YWT})$ ODS steel.

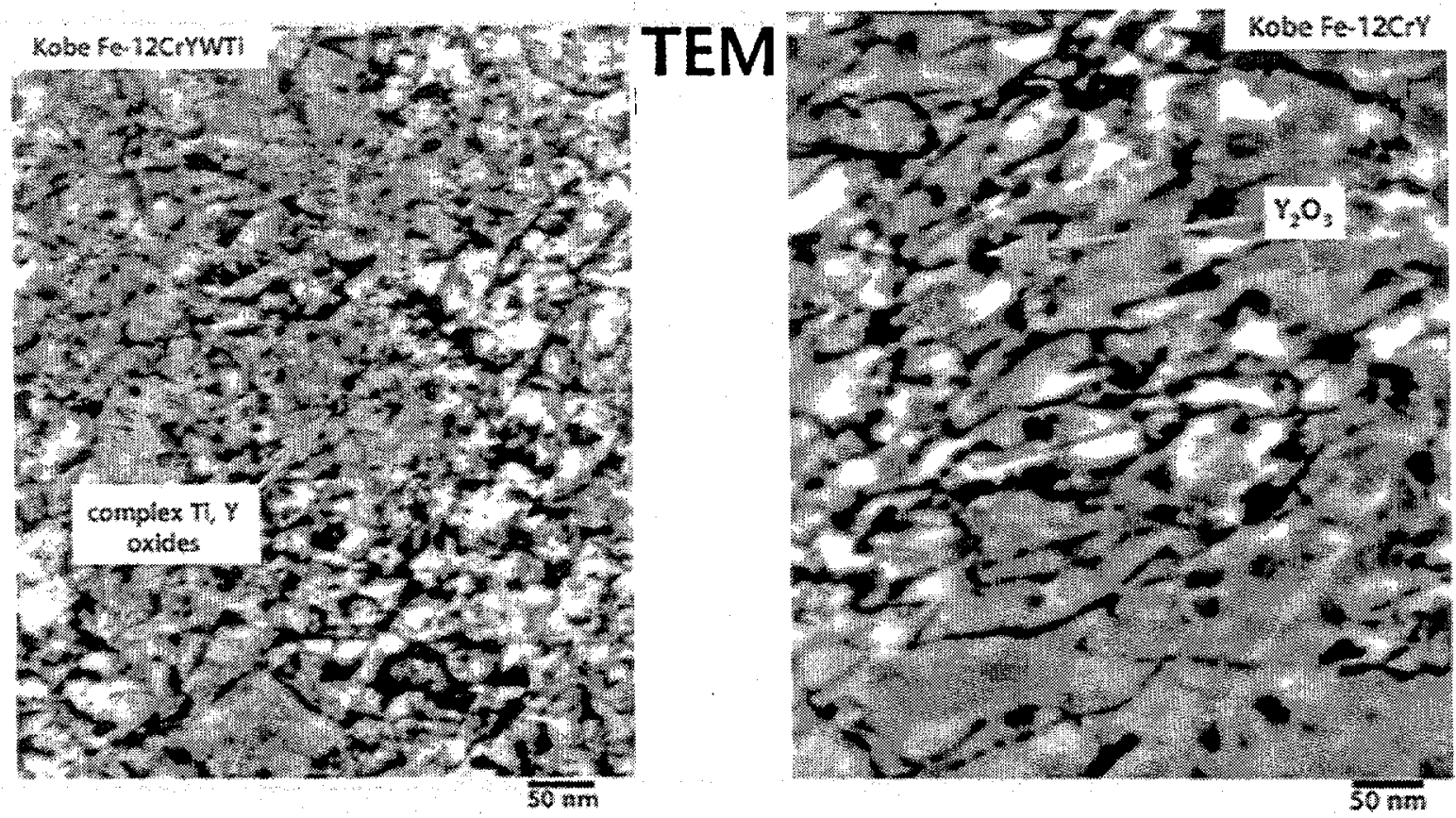

Figure 3. Transmission electron micrographs of Fe-12Cr-3W-0.4Ti-0.25Y $\mathrm{O}_{3}(12 \mathrm{YWT}$ ) (left) and Fe$12 \mathrm{Cr}-0.25 \mathrm{Y}_{2} \mathrm{O}_{3}(12 \mathrm{Y} 1)$ (right) steels 
3-5 $\mathrm{nm}$ diameter, and $1-2 \times 10^{23} \mathrm{~m}^{-3}$, respectively. It was not possible to identify the particles by electron diffraction because of their size; no spots or amorphous rings were observed [6].

To determine the nature of the small particles in the 12VWT, atom probe field ion microscopy studies were conducted. The 3-DAP analysis of random volumes revealed compositional clustering in the 12YWT that was not present in the 12Y1 [7]. The matrix of the 12Y1 contained low levels of $Y$ and $O$ but no indication of clustering. In contrast to this, the 12YWT contained clusters enriched in $\mathrm{Y}, \mathrm{Ti}$, and $O$ (there was some indication of $C$ and $B$ enrichment), slightly enriched in $C r$, and slightly depleted in Fe and $W$. The cluster diameters were estimated at $2-5 \mathrm{~nm}[7]$, in agreement with TEM.

From the atom probe results, it was concluded that the original $\mathrm{Y}_{2} \mathrm{O}_{3}$ particles had evidently dissolved during the processing of the alloy, and then the new, small clusters formed. The appearance of the titanium in the clusters indicates that it must play a critical role in the dissolution process. At what point in the processing of the ODS steel the dissolution and subsequent clustering occurs still needs to be determined.

\section{Tensile Properties}

In Fig. 4, the $0.2 \%$ yield stress from room temperature to $900^{\circ} \mathrm{C}$ is shown for $12 Y 1$ and $12 \mathrm{YWT}$. For comparison, data for the reduced-activation $9 \mathrm{Cr}-2 \mathrm{WVT}$ a steel is also shown for tests from room temperature to $600^{\circ} \mathrm{C}$ [8], the latter temperature being near or above the limit for the application of such a steel. The superior strength of the 12YWT over the $12 \mathrm{Y} 1$ is obvious in this figure. This might be expected based on the difference in the microstructures. Indeed, because of the much larger and less evenly distributed oxide particles in the 12Y1, the yield stress of this steel is only higher than that of the $9 \mathrm{Cr}-2 \mathrm{WVTa}$ steel below $\approx 550^{\circ} \mathrm{C}$, while the $12 \mathrm{YWT}$ continues to show excellent strength above this temperature.

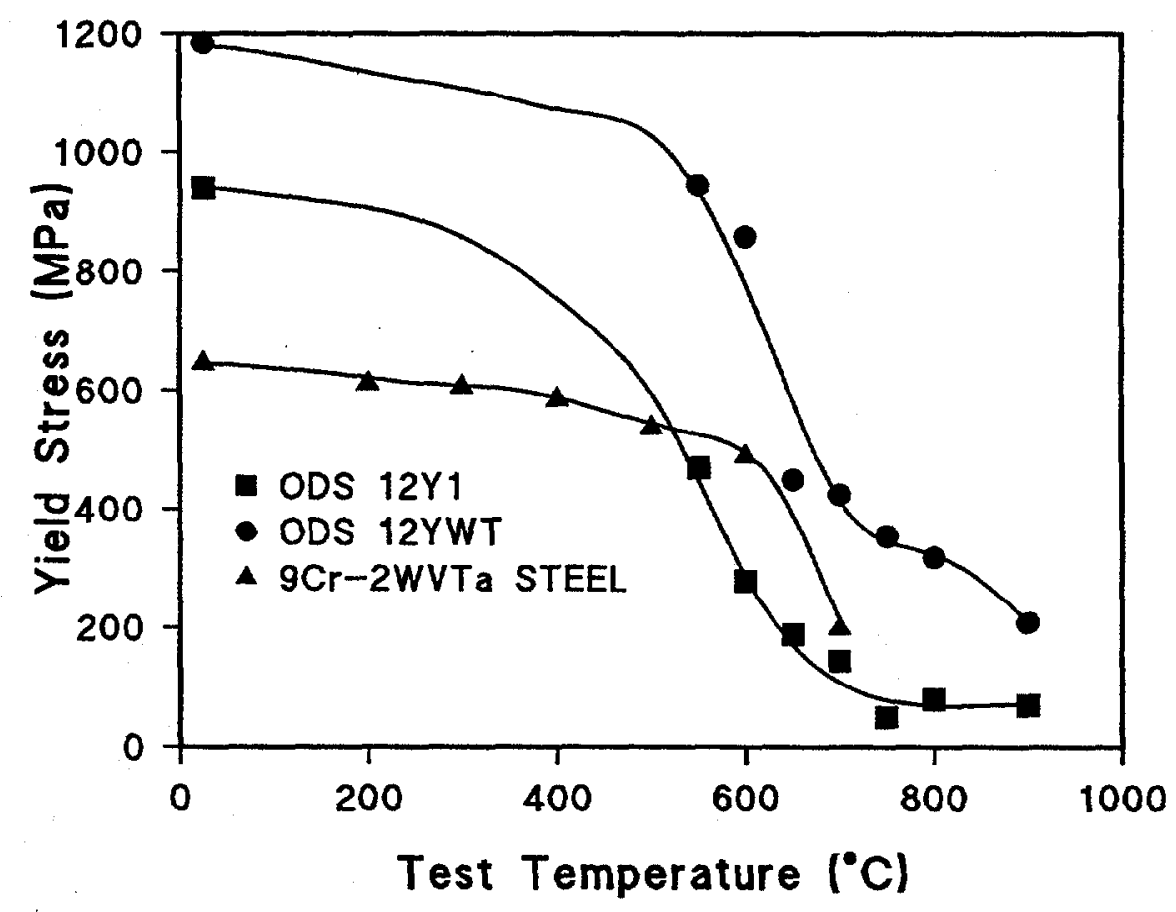

Figure 4. The $0.2 \%$ yield stress of the $12 Y 1$ and $12 \mathrm{YWT}$ ODS steels and the reduced-activation $9 \mathrm{Cr}$ 2WVTa steel. 
The total elongations for $12 Y 1$ and $12 Y W T$ are shown in Figure 5 (no elongations are shown for the $9 \mathrm{Cr}-2 \mathrm{WVT}$ a because this steel was tested in another experiment [8], and different specimen geometries were used). As expected from the relative yield stress behavior, the elongation of the weaker $12 Y 1$ exceeds that of the 12YWT. However, despite the higher strength, the 12YWT also shows good ductility.

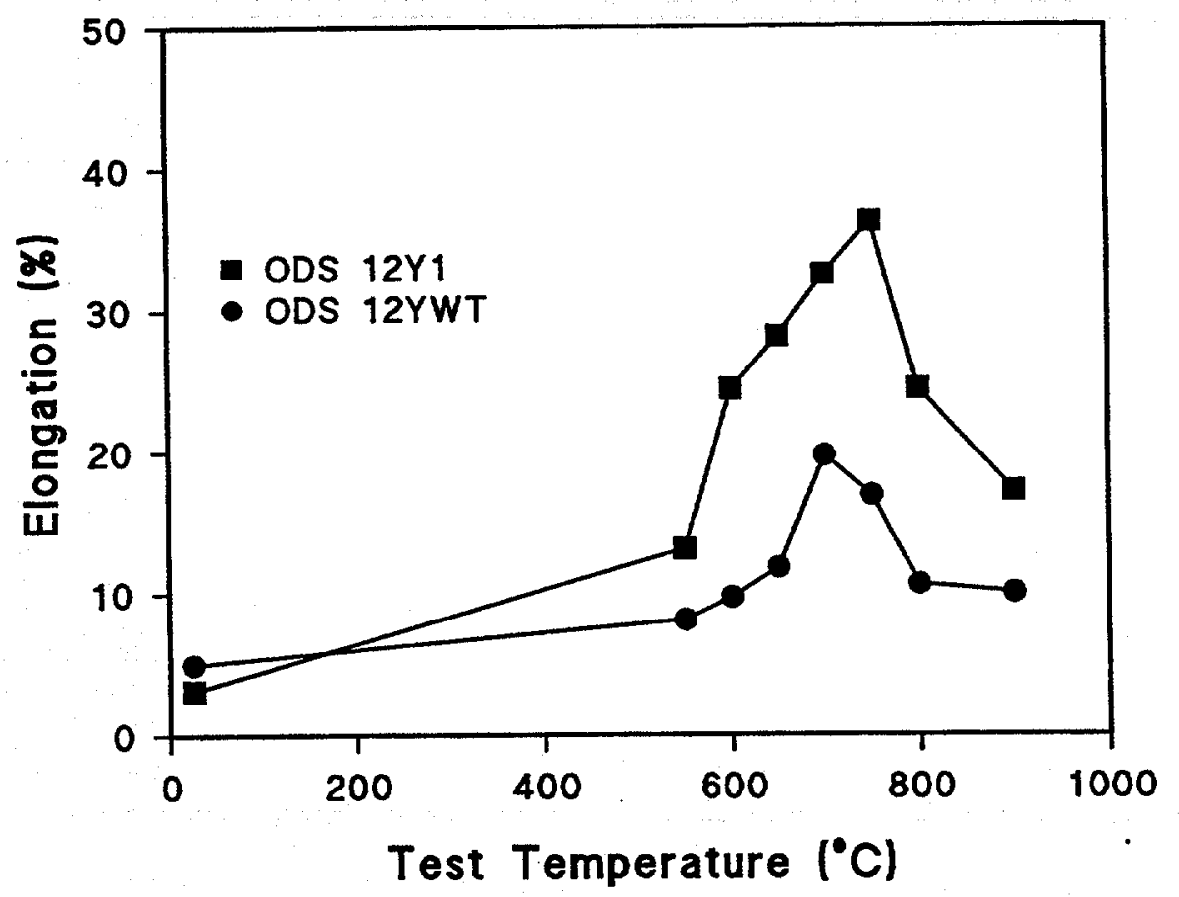

Figure 5. The tensile total elongation of the $12 \mathrm{Y} 1$ and $12 \mathrm{YWT}$ ODS steels.

\section{Creep Properties}

The most important property for any material that is expected to operate at elevated temperatures is creep. Creep tests have been conducted on the $12 \mathrm{Y} 1$ and $12 \mathrm{YWT}$ at $600-850^{\circ} \mathrm{C}$, and indications are that the 12YWT has excellent creep resistance over this temperature range. Figure 6 presents a Larson-Miller diagram that compares the 12YWT with other ODS and conventional steels. In this figure, the stress to rupture is plotted against the Larson-Miller Parameter (LMP), which is defined as $L M P=T(25+\log t)$, where $T$ is the temperature in Kelvin and $t$ is the rupture time in hours.

From the Larson-Miller dlagram it is obvious that the creep behavior of the $12 \mathrm{YWT}$ is superior to the other materials to which it is compared. Those other materials are: 12Y1, MA956 (Fe-19Cr-0.33Ti$5 \mathrm{Al}-0.4 \mathrm{Y}-0.15 \mathrm{O}-0.02 \mathrm{C}$ ) and MA957 (Fe-14Cr-0.3Mo-1Ti-0.3Y-0.20-0.03C), the latter two being commercial ODS steels, and $9 \mathrm{Cr}-\mathrm{WMOVNb}$, being a commercial ferritic/martensitic steel. Since few of the tests for $12 \mathrm{YWT}$ shown in Fig. 5 have ruptured, the curve for the 12YWT should eventually exceed that of all the other materials for all test conditions.

A typical creep curve for $12 \mathrm{YWT}$ is shown in Fig. 7 for a test at $800^{\circ} \mathrm{C}$ at $138 \mathrm{MPA}$. Even after almost $5000 \mathrm{~h}$ of creep, the strain is still $<0.6 \%$. In Fig. 8 , the creep curve for $12 \mathrm{YWT}$ is compared with a curve for the $\mathrm{V}-4 \mathrm{Cr}-4 \mathrm{Ti}$ alloy [9], another candidate for fusion applications. The $\mathrm{V}-4 \mathrm{Cr}-4 \mathrm{Ti}$ was also tested at $800^{\circ} \mathrm{C}$ but at a much lower stress $-77 \mathrm{MPa}$ (the $\mathrm{V}-4 \mathrm{Cr}-4 \mathrm{Ti}$ alloy test is from a biaxial creep test using a pressurized tube). Whereas the vanadium alloy is in the tertiary creep stage prior 


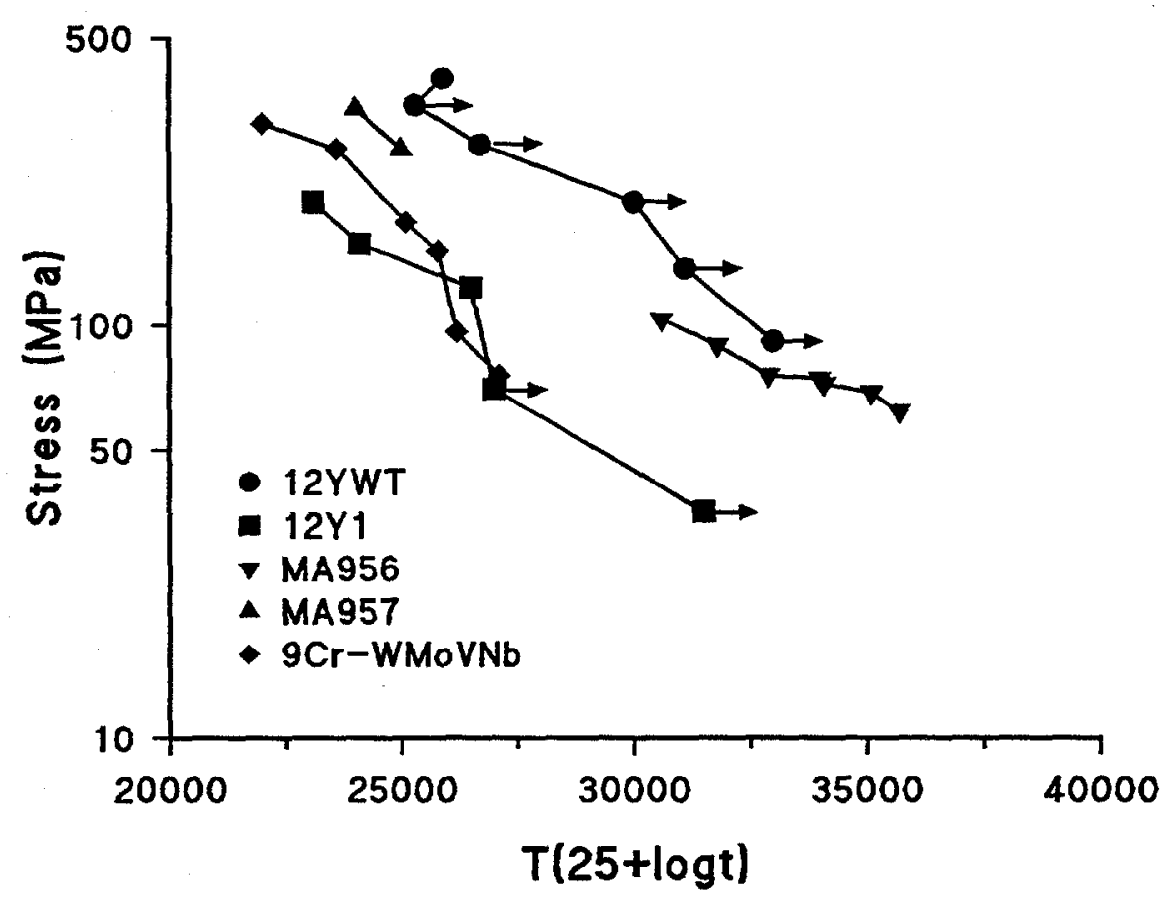

Figure 6. Larson-Miller diagram for the four ODS steels and a conventional ferritic/martensitic steel. The arrows indicate that the test is still in progress.

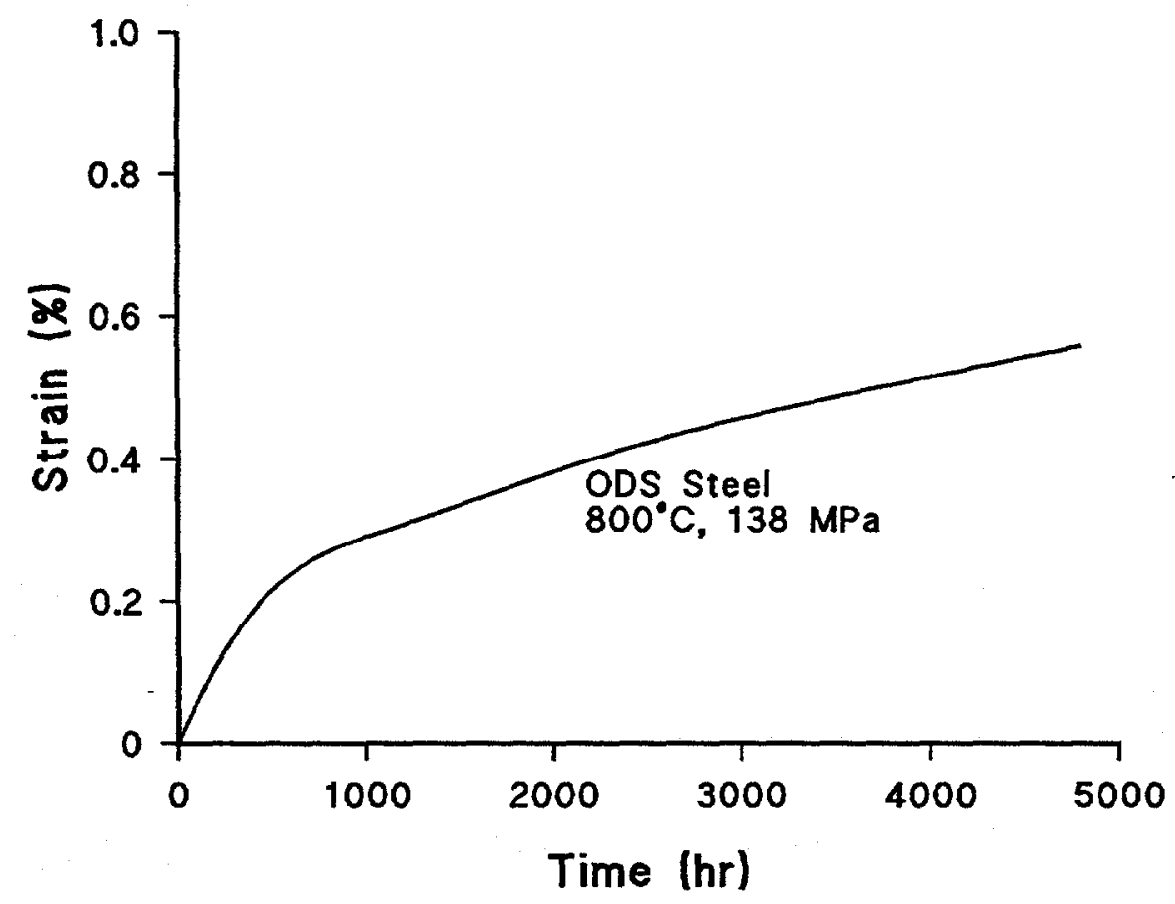

Figure 7. Creep curve for $12 \mathrm{YWT}$ at $800^{\circ} \mathrm{C}$ and $138 \mathrm{MPa}$. 


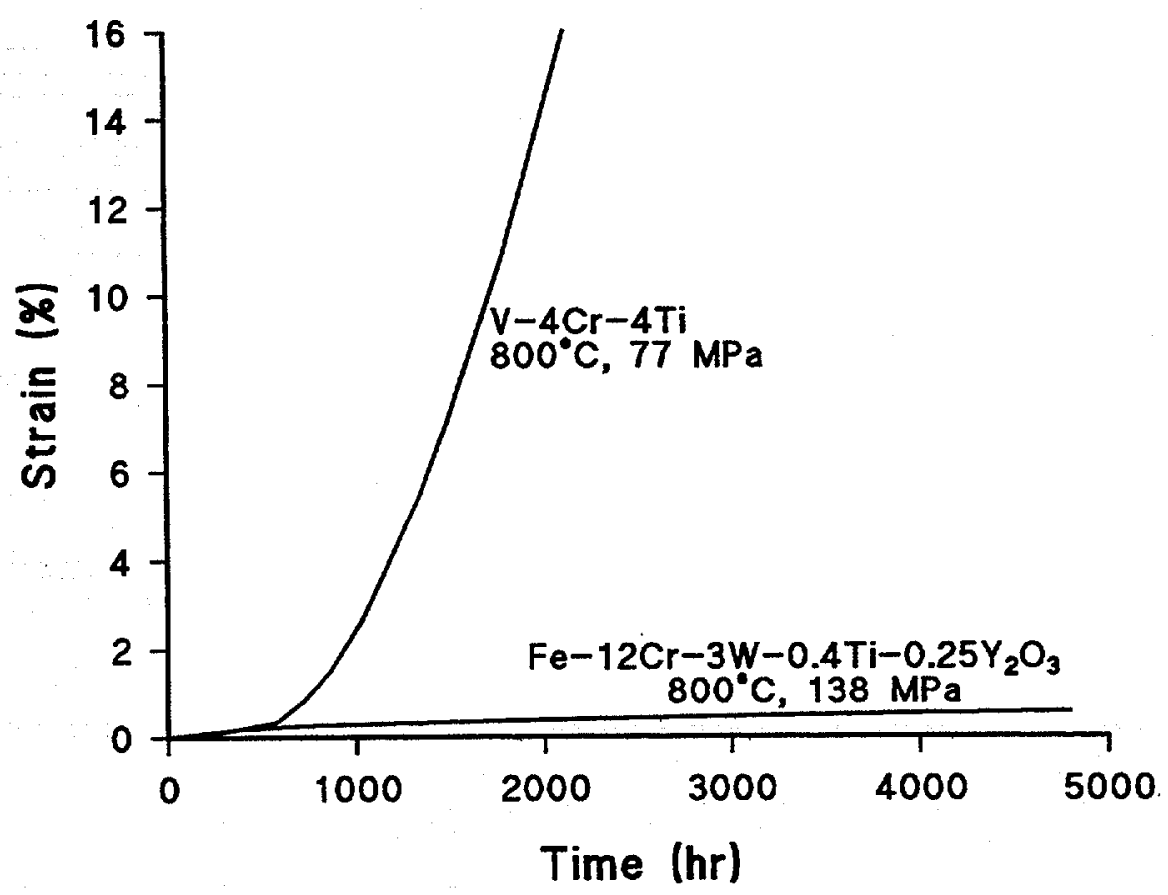

Figure 8. A comparison of the creep behavior of the ODS steel $12 \mathrm{YWT}$ and the $\mathrm{V}-4 \mathrm{Cr}-4 \mathrm{Ti}$ alloy at $800^{\circ} \mathrm{C}$.

to rupture (the specimen failed after $4029 \mathrm{~h}$ and $\approx 52 \%$ ), the $12 \mathrm{YWT}$ steel appears to be in the steadystate stage (Fig. 7), although it may still be only in the primary creep stage.

\section{Conclusion}

Preliminary microstructural studies of an Fe-12Cr-3W-0.4Ti-0.25 $\mathrm{Y}_{2} \mathrm{O}_{3}$ ODS steel demonstrated that this steel has a distribution of extremely fine atom clusters that give the steel excellent elevatedtemperature tensile and creep properties relative to other ODS steels and conventional and reducedactivation ferritic/martensitic steels. The preliminary creep properties of $12 \mathrm{YWT}$ also appear to be superior to those of the $\mathrm{V}-4 \mathrm{Cr}-4 \mathrm{Ti}$ alloy.

It must be emphasized that even though the 12YWT steel displays these excellent properties, such ODS steels for fusion are still at an early development stage, similar to the vanadium alloys. Neither of these materials is at a stage of development comparable to that of conventional and reducedactivation ferritic/martensitic steels for which the technology (including final fabrication and welding) is advanced to the point that a fusion plant could be constructed. Some of the problems still to be solved for the ODS steels include the anisotropy of mechanical properties that derives from the way the steels are processed. The question of producing large sections and joining the steels in a large structure needs to be addressed. Finally, there is the question of irradiation resistance, for which very little information is available.

\section{References}

1. S. Ukai, T. Nishida, H. Okada, T. Okuda, M. Fujiwara, and K. Asabe, J. Nucl. Sci. \& Tech. 34 (1997) 256. 
2. S. Ukai, T. Yoshitake, S. Mizuta, Y. Matsudaira, S. Hagi, and T. Kobayashi, J. Nucl. Sci. \& Tech. 36 (1999) 710.

3. A. Alamo, J. Decours, M. Pigoury, C. Foucher, in: Structural Applications of Mechanical Alloying (ASM international, Materials Park, OH, 1990).

4. A. Alamo, H. Regle, G. Pons, and L. L. Bechade, Materials Science Forum, 88-90 (1992) 183.

5. D. K. Mukhopadhyay, F. H. Froes, and D. S. Gelles, J. Nucl. Mater. 258-263 (1998) 1209-1215.

6. I-S. Kim, J. D. Hunn, N. Hashimoto, D. L. Larson, P. J. Maziasz, K. Miyahara, and E. H. Lee, J. Nucl. Mater., to be published.

7. D. J. Larson, P. J. Maziasz, I-S. Kim, and K. Miyahara, Scripta Met., to be published.

8. R. L. Klueh, Met. Trans. 20A (1989) 463.

9. R. J. Kurtz and M. L. Hamilton, in: Fusion Materials Semiannual Progress Report for Period Ending June 30, 1999, DOE/ER-0313/26, September 1999, p. 3. 
TENSILE RESULTS OF LOW-ACTIVATION MARTENSITIC STEEL IRRADIATED IN HFIR RB11J AND RB-12J SPECTRALLY TAILORED CAPSULES, K. Shiba (Japan Atomic Energy Research institute), R. L. Klueh (Oak Ridge National Laboratory), Y. Miwa, N. Igawa (Japan Atomic Energy Research Institute) and J. P. Robertson (Oak Ridge National Laboratory)

\section{Objective}

The objective of this investigation is to examine post-irradiation tensile behavior of low-activation martensitic steel F82H IEA heat base metal and weidments irradiated at 300 and $500^{\circ} \mathrm{C}$ in HFIR. Additionally, strain rate effects on the tensile properties of F82H IEA base metal were examined.

\section{Summary}

Post-irradiation tensile test results for F82H IEA heat base metal (BM) and TIG weldments are reported. Tensile specimens were irradiated to about $5 \mathrm{dpa}$ at 300 and $500^{\circ} \mathrm{C}$. Irradiation caused significant hardening at $300^{\circ} \mathrm{C}$. The TIG weld metal (WM) exhibited almost the same amount of irradiation hardening as the BM, but the TIG weld joint (WJ) showed less hardening than BM and WM. Increasing the strain rate caused a slight increase in yield strength, while a decreasing strain rate caused a sharper stress drop after yielding for $\mathrm{BM}$ specimens irradiated at $300^{\circ} \mathrm{C}$. No difference in strength was observed for the $\mathrm{BM}, \mathrm{WM}$, and WJ specimens irradiated at $500^{\circ} \mathrm{C}$. However, a decrease in strain rate caused a reduction in elongation.

\section{Progress and status}

\section{Introduction}

Investigation of irradiation behavior of low activation martensitic steel has been conducted using the HFIR. Previous irradiation experiments dealt with mainly base metal (BM). Irradiation behavior of weldment joints, such as TIG welded joints, is also important for a fusion reactor design. Tensile, Charpy and other specimens have been irradiated in US/JAERI phase 3 experiment. Postirradiation tensile test results of F82H IEA heat BM and TIG weldments are presented in this report.

\section{Experimental Procedure}

F82H IEA heat (F82H IEA) BM and its TIG weldments were used for the irradiation. F82H IEA was hot-rolled at $1200^{\circ} \mathrm{C}$ and then normalized at $1040^{\circ} \mathrm{C}$ for $0.63 \mathrm{~h}$ and tempered at $750^{\circ} \mathrm{C}$ for $1 \mathrm{~h}$. TIG weldments were annealed at $720^{\circ} \mathrm{C} 1 \mathrm{~h}$ after welding. The chemical compositions of the F82H IEA heat and TIG wire are shown in Table 1, and TIG welding conditions have been previously reported [1]. Microstructure and Vickers' hardness of a TIG welded joint are shown in Figure 1. Weld joint (WJ), weld metal (WM) and heat affected zone (HAZ) type specimens were fabricated as shown in Figure 2. SS-3 sheet tensile specimens with gauge section of $7.62 \mathrm{~mm} \times 0.76 \mathrm{~mm} \times 1.5 \mathrm{~mm}$ were irradiated. Tensile tests on the BM, WM, and HAZ were carried out at a strain rate of $1 \times 10^{-3} \mathrm{~s}^{-1}$ at room temperature and the nominal irradiation temperature. Some F82H IEA BM specimens were 
also tested at strain rates of $1 \times 10^{-2} \mathrm{~s}^{-1}$ and $1 \times 10^{-4} \mathrm{~s}^{-1}$ at room temperature to examine strain rate effects. The irradiation was performed in the HFIR RB-11 $J$ and $-12 \mathrm{~J}$ capsules, which had Europium thermal neutron shields for neutron spectrum tailoring. Irradiation conditions of these capsules are summarized in Table 2, and further information on the capsules can be found elsewhere [2-5].

Table 1 Chemical composition of the steels (wt.\%).

\begin{tabular}{cccccccc}
\hline & $\mathrm{Fe}$ & $\mathrm{Cr}$ & $\mathrm{W}$ & $\mathrm{V}$ & $\mathrm{Ta}$ & $\mathrm{C}$ & $\mathrm{B}$ \\
\hline F82H IEA heat & $\mathrm{Bal}$ & 7.71 & 1.95 & 0.16 & 0.02 & 0.090 & 0.0002 \\
TIG wire & $\mathrm{Bal}$ & 7.34 & 2.04 & 0.22 & 0.026 & 0.08 & $<0.0002$ \\
\hline & $\mathrm{Si}$ & $\mathrm{Mn}$ & $\mathrm{P}$ & $\mathrm{S}$ & $\mathrm{Al}$ & $\mathrm{N}$ \\
\hline F82H IEA heat & 0.11 & 0.16 & 0.002 & 0.002 & 0.003 & 0.006 \\
TIG wire & 0.10 & 0.49 & 0.004 & 0.004 & $<0.002$ & 0.0064 \\
\hline
\end{tabular}
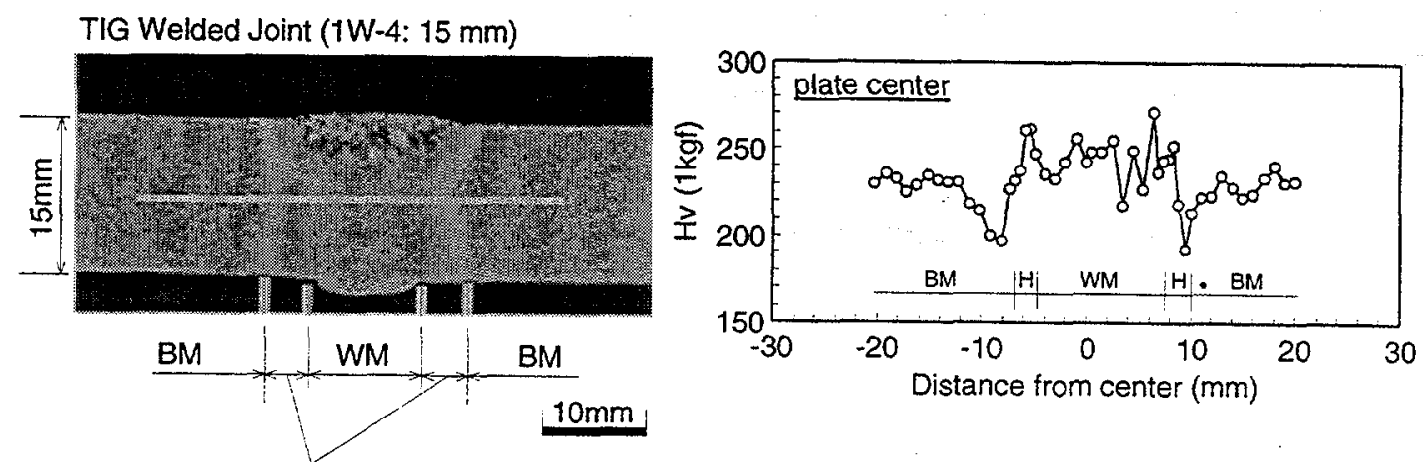

HAZ

Figure 1 Microstructure and Vickers' hardness of F82H IEA TIG welded joint.

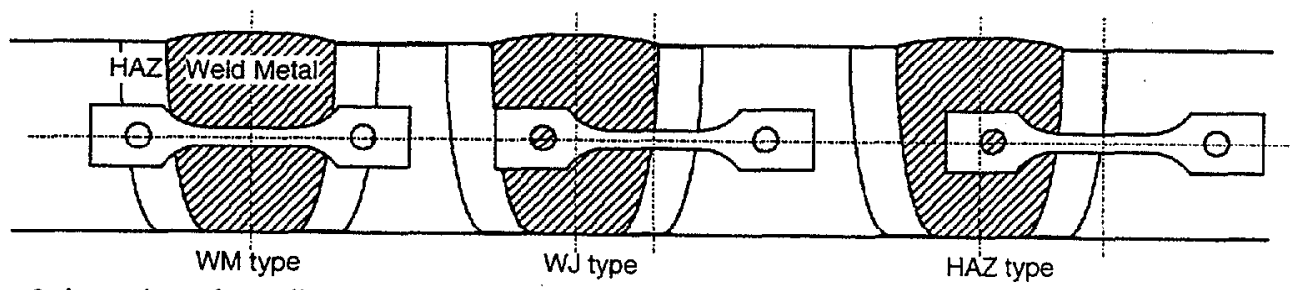

Figure 2 Location of tensile specimens in TIG welded joint.

Table 2 Summary of irradiation conditions. (*: Estimation)

\begin{tabular}{|c|c|c|c|c|c|c|}
\hline \multirow{2}{*}{\multicolumn{2}{|c|}{ Capsule }} & \multirow{2}{*}{$\begin{array}{l}\text { Nominal Irradiation } \\
\text { Temperature } \\
\left({ }^{\circ} \mathrm{C}\right)\end{array}$} & \multicolumn{2}{|c|}{ Neutron fluence $\left(\mathrm{n} / \mathrm{cm}^{2}\right)^{\star}$} & \multirow[b]{2}{*}{$\begin{array}{l}\text { Damage } \\
\text { (dpa) }\end{array}$} & \multirow[b]{2}{*}{$\begin{array}{c}\mathrm{He} \\
(\mathrm{appm})\end{array}$} \\
\hline & & & $\begin{array}{c}\text { Thermal } \\
(\mathrm{E}<0.5 \mathrm{eV})\end{array}$ & $\begin{array}{c}\text { Fast } \\
(E>0.1 \mathrm{MeV})\end{array}$ & & \\
\hline $11 \mathrm{~J}$ & Shielded & 300 & $1 \times 10^{21}$ & $1 \times 10^{22}$ & 5 & 3 \\
\hline $12 \mathrm{~J}$ & Shielded & 500 & $1 \times 10^{21}$ & $1 \times 10^{22}$ & 5 & 3 \\
\hline
\end{tabular}




\section{Results and Discussion}

Tensile test results are summarized in Table 3. Increases in yield stresses of F82H IEA BM and weldments are plotted in Figure 3. Significant hardening occurred by irradiation at $300^{\circ} \mathrm{C}$ for tests at both room temperature and $300^{\circ} \mathrm{C}$. In contrast, irradiation at $500^{\circ} \mathrm{C}$ did not cause apparent hardening. Stress-strain curves of $F 82 \mathrm{H} I E A$ and weldments irradiated at $300^{\circ} \mathrm{C}$ and tested at room temperature are shown in Figure 4. BM and WM have almost the same character of stress-strain curves; however, the stress-strain curves of the $W J$ and $H A Z$ are apparently different. As shown in Figure 3, TIG weld metal exhibited a higher yield strength than base metal before and after irradiation. The increase in yield stress of WM is almost the same as that of BM. On the other hand, the increase in yield stress in WJ is less than half of that of the BM and WM. Yield strength and elongation of the TIG weld joint were lower than those of base metal, because it contains heat affected zone with lower strength.

Table 3 Tensile test results from RB-11J and $-12 \mathrm{~J}$ capsules.

\begin{tabular}{|c|c|c|c|c|c|c|c|c|c|}
\hline Material & $\begin{array}{l}\text { Specimen } \\
\text { ID }\end{array}$ & dpa & $\begin{array}{l}\text { Irrad. } \\
\text { Temp. } \\
\left({ }^{\circ} \mathrm{C}\right)\end{array}$ & $\begin{array}{l}\text { Test } \\
\text { Temp. } \\
\left({ }^{\circ} \mathrm{C}\right) \\
\end{array}$ & $\begin{array}{c}\text { Strain } \\
\text { Rate } \\
\left(s^{-1}\right) \\
\end{array}$ & $\begin{array}{c}\text { Yield } \\
\text { Stress } \\
\text { YS } \\
(\mathrm{MPa}) \\
\end{array}$ & $\begin{array}{l}\text { Ultimate } \\
\text { Tensile } \\
\text { Stress } \\
\text { UTS } \\
\text { (MPa) } \\
\end{array}$ & $\begin{array}{c}\text { Uniform } \\
\text { Elongation } \\
\text { Eu } \\
(\%) \\
\end{array}$ & $\begin{array}{c}\text { Total } \\
\text { Elongation } \\
\text { Et } \\
(\%) \\
\end{array}$ \\
\hline \multirow{8}{*}{ F82H IEA std. } & A025 & 4.9 & 307 & 28 & $1 \times 10^{-2}$ & 960 & 968 & 0.47 & 7.62 \\
\hline & $\mathrm{A023}$ & 4.9 & 307 & 25 & $1 \times 10^{-3}$ & 898 & 911 & 0.45 & 7.76 \\
\hline & A026 & 4.9 & 307 & 25 & $1 \times 10^{-4}$ & 889 & 896 & 0.38 & 8.23 \\
\hline & $\mathrm{A} 024$ & 4.9 & 307 & 300 & $1 \times 10^{-3}$ & 762 & 770 & 0.32 & 7.31 \\
\hline & A038 & 4.8 & 497 & 25 & $1 \times 10^{-2}$ & 510 & 630 & 6.66 & 18.22 \\
\hline & $\mathrm{A} 033$ & 4.8 & 497 & 25 & $1 \times 10^{-3}$ & 527 & 637 & 7.54 & 18.31 \\
\hline & A039 & 4.8 & 497 & 25 & $1 \times 10^{-4}$ & 535 & 620 & 4.30 & 14.51 \\
\hline & A035 & 4.9 & 497 & 500 & $1 \times 10^{-3}$ & 401 & 444 & 1.92 & 11.16 \\
\hline \multirow{4}{*}{$\begin{array}{c}\text { F82H IEA std } \\
\text { TIG WM }\end{array}$} & TW01 & 4.7 & 307 & 25 & $1 \times 10^{-3}$ & 963 & 1011 & 0.55 & 8.54 \\
\hline & TWO2 & 4.7 & 307 & 300 & $1 \times 10^{-3}$ & 821 & 867 & 0.67 & 7.83 \\
\hline & TW05 & 4.5 & 497 & 25 & $1 \times 10^{-3}$ & 605 & 714 & 4.90 & 13.61 \\
\hline & TW06 & 4.5 & 497 & 500 & $1 \times 10^{-3}$ & 460 & 515 & 1.96 & 10.71 \\
\hline \multirow{4}{*}{$\begin{array}{l}\text { F82H IEA std } \\
\text { TIG WJ }\end{array}$} & TJ01 & 4.7 & 307 & 25 & $1 \times 10^{-3}$ & 665 & 685 & 0.96 & 8.92 \\
\hline & TJ02 & 4.7 & 307 & 300 & $1 \times 10^{-3}$ & 532 & 552 & 1.00 & 8.08 \\
\hline & TJ08 & 4.7 & 497 & 25 & $1 \times 10^{-3}$ & 528 & 597 & 2.85 & 12.30 \\
\hline & TJ06 & 4.7 & 497 & 500 & $1 \times 10^{-3}$ & 347 & 373 & 1.57 & 9.37 \\
\hline \multirow{4}{*}{$\begin{array}{c}\text { F82H IEA std } \\
\text { TIG HAZ }\end{array}$} & THO2 & 4.8 & 307 & 25 & $1 \times 10^{-3}$ & 652 & 670 & 1.15 & 9.32 \\
\hline & $\mathrm{THO} 3$ & 4.8 & 307 & 300 & $1 \times 10^{-3}$ & 550 & 568 & 1.03 & 8.62 \\
\hline & THO8 & 4.3 & 478 & 25 & $1 \times 10^{-3}$ & 422 & 569 & 5.30 & 13.96 \\
\hline & THOS & 4.3 & 478 & 500 & $1 \times 10^{-3}$ & 320 & 370 & 2.10 & 11.65 \\
\hline
\end{tabular}


(a) $300^{\circ} \mathrm{C}$ irradiation, RT test

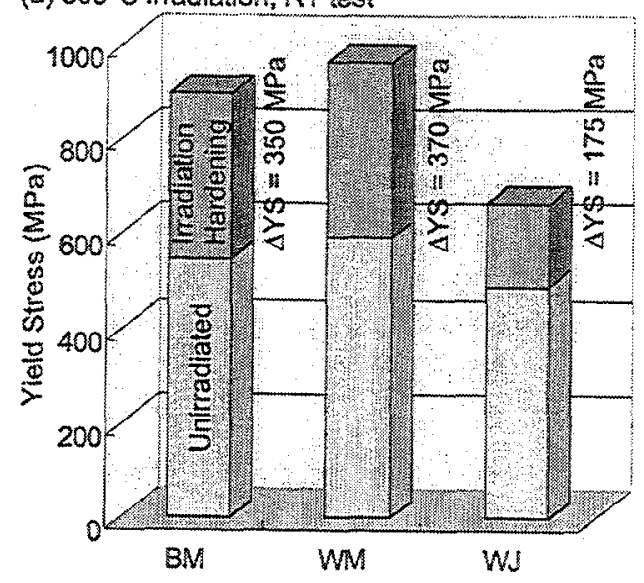

(c) $500^{\circ} \mathrm{C}$ irradiation, RT test

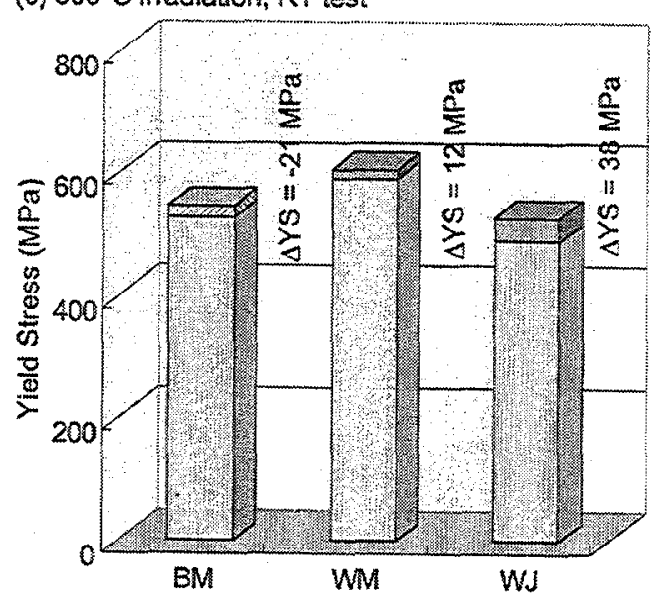

(b) $300^{\circ} \mathrm{C}$ irradiakion, $300^{\circ} \mathrm{C}$ sest

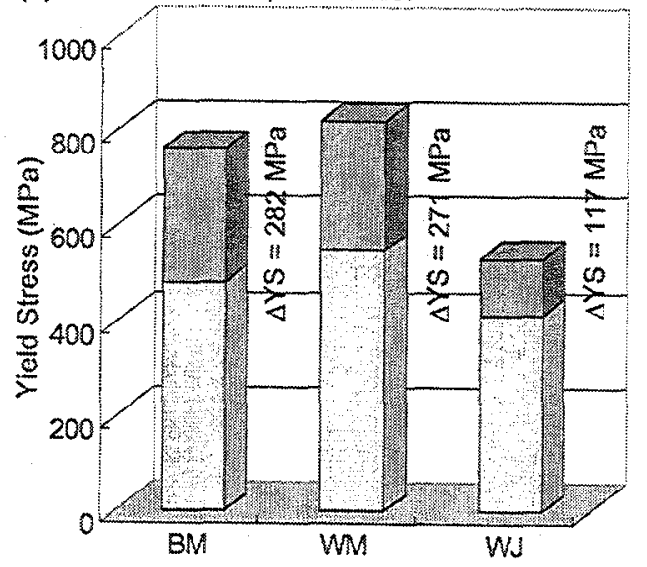

(d) $500^{\circ} \mathrm{C}$ irradiation, $500^{\circ} \mathrm{C}$ test

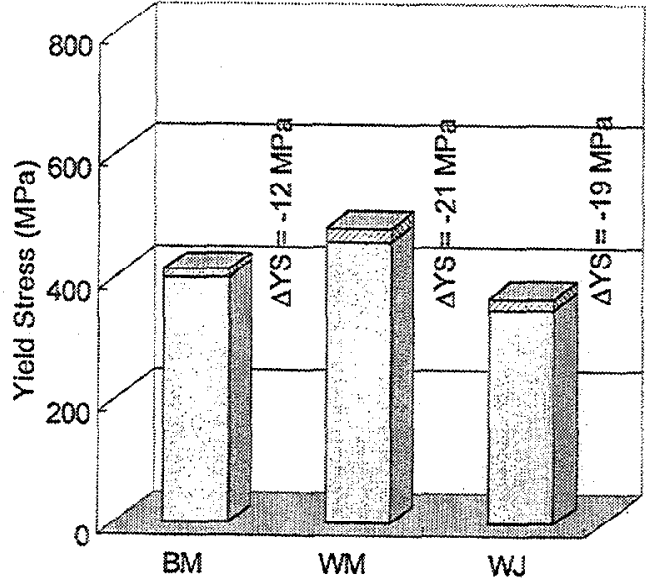

Figure 3 Irradiation hardening in F82H IEA and TIG weldments (HFIR RB-11J and 12J).

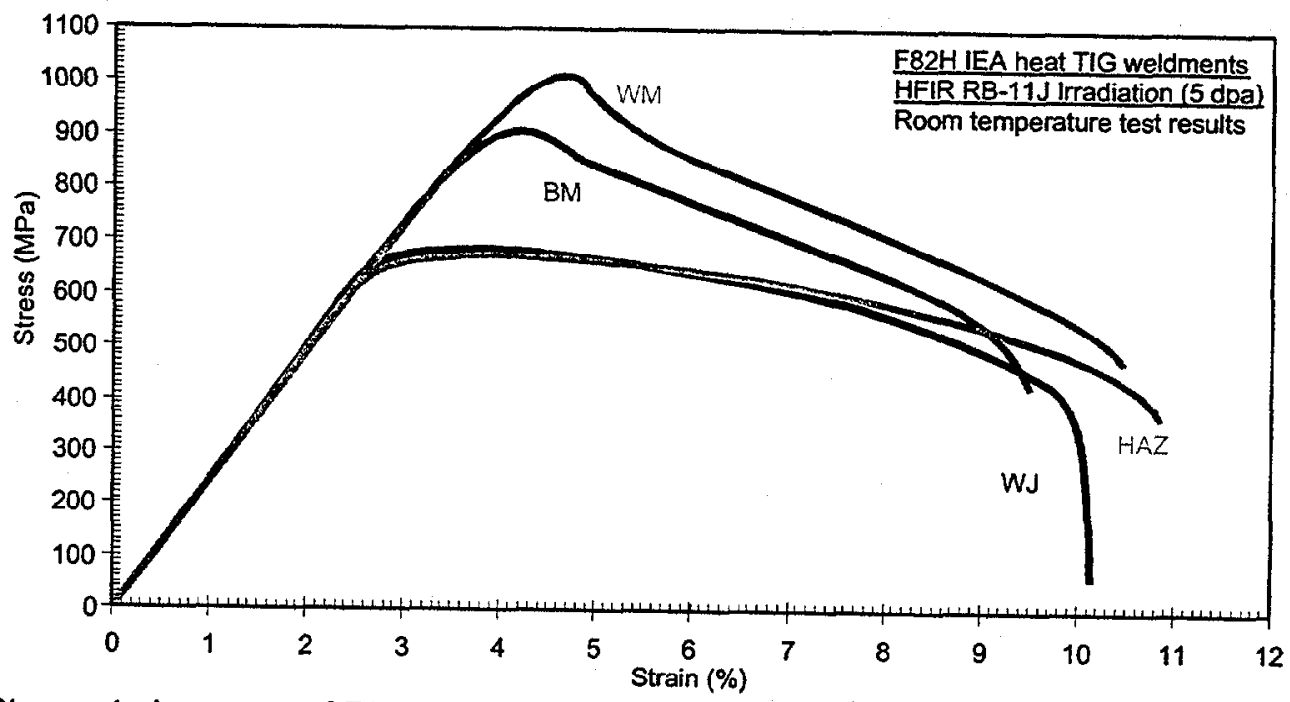

Figure 4 Stress-strain curves of F82H IEA and TIG weldments. 
Stress-strain curves of F82H IEA BM specimens tested with different strain rates are shown in Figure 5. Stress levels for the specimens irradiated at $300^{\circ} \mathrm{C}$ were affected by strain rate, when the strain rates were changed from $1 \times 10^{-3} \mathrm{~s}^{-3}$ used for the tests discussed above. A higher strain rate $\left(1 \times 10^{-2} \mathrm{~s}^{-1}\right)$ caused some increase in yield strength, and a slower strain rate $\left(1 \times 10^{-4} \mathrm{~s}^{-1}\right)$ caused a sharper stress drop after yielding for the specimens irradiated at $300^{\circ} \mathrm{C}$. The specimens irradiated at $500^{\circ} \mathrm{C}$ did not exhibit any difference in strength due to strain rate, but the slowest strain rate caused less elongation.
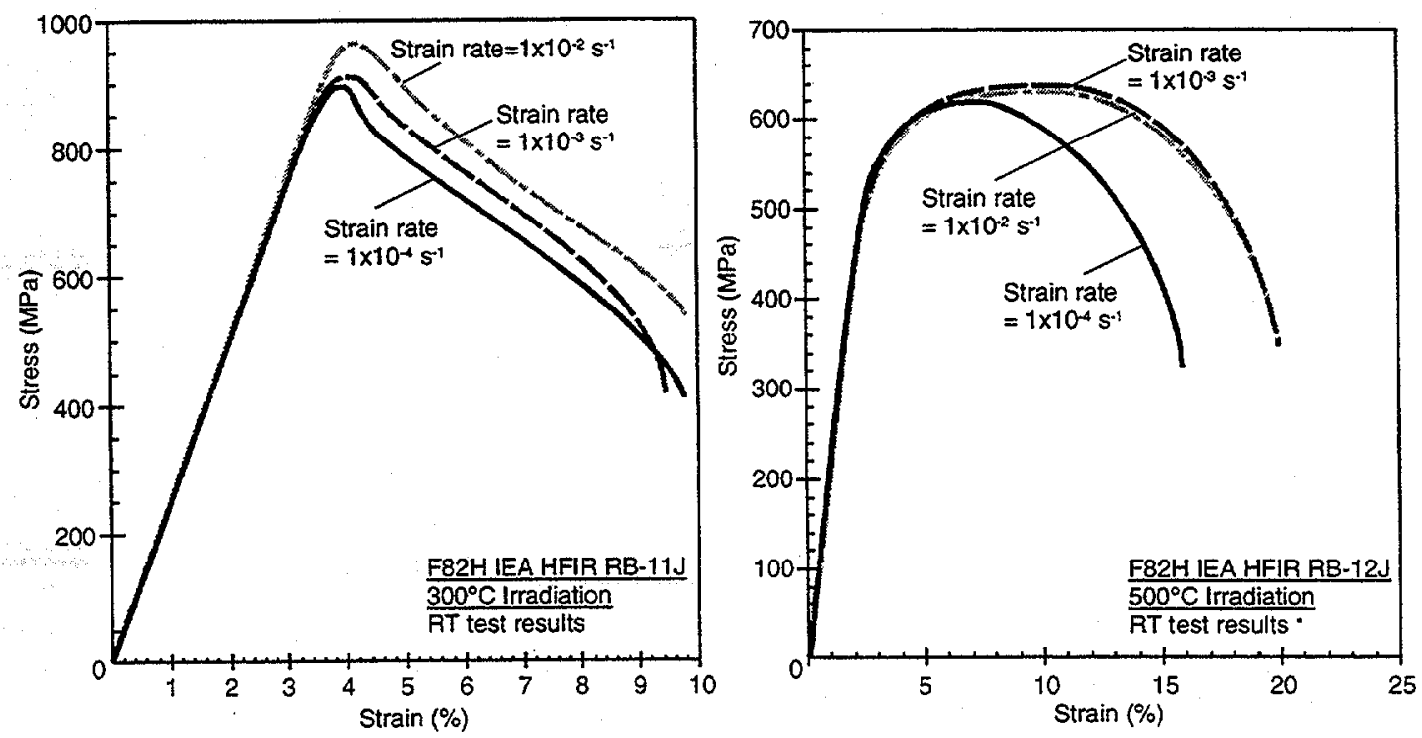

Figure 5 Stress-strain curves of F82H IEA tested at different strain rates.

\section{Future Work}

TEM observation of the HAZ region of the weldment is needed to understand the reason for the low irradiation hardening in this material irradiated in the $11 \mathrm{~J}$ capsule. Ion irradiation experiments on TIG weldments using the TIARA facility (JAERI, Takasaki) is scheduled to examine the changes in microstructure and hardness due to ion irradiation. Some more tensile tests to determine the strain rate effect using F82H IEA specimens irradiated in $11 \mathrm{~J}$ and $12 \mathrm{H}$ are planned at JAERI.

\section{References}

[1] K. Shiba, Proc. of the IEA Working Group Meeting on Ferritic/Martensitic Steels, September 19-20, 1995, Barden, Switzerland, ORNL/M-4939 (1995).

[2] J.E. Pawel, -et al., DOE/ER-0313/19 Fusion Materials (Sep. 30 1995), p312.

[3] J.E. Pawel, et al., DOE/ER-0313/21 Fusion Materials (Dec. 31 1996), p249.

[4] M.L. Grossbeck, et al., DOE/ER-0313/22 Fusion Materials (June 30 1997), p254.

[5] L.E. Lenox and M.L. Grossbeck, DOE/ER-0313/25 Fusion Materials (Dec. 31 1998), p307. 
POSTIRRADIATION DEFORMATION MICROSTRUCTURES IN FERRITIC Fe-9Cr - D. S. Gelles, M. L. Hamilton (Pacific Northwest National Laboratory) and R. Schäublin (EPFLCRPP Fusion Technology, Switzerland)

\section{OBJECTIVE}

The objective of this effort is to provide further understanding of postirradiation deformation mechanisms controlling in ferritic/martensitic steels.

\section{SUMMARY}

The deformed microstructures of both irradiated and unirradiated $\mathrm{Fe}-9 \mathrm{Cr}$ uniaxial tensile specimens have been examined to identify controlling mechanisms. Deformation following irradiation is found to occur in poorly defined channels, causing formation of discrete steps at surfaces and delineated by nonuniformly distributed highly elongated voids. Deformation is by motion of $\frac{a}{2}<111>$ dislocations, which interact with and decompose irradiation-induced $a<100>100 p s$. The structure formed after extensive deformation consists of highly complex cell walls and moderate densities of individual slip dislocations.

\section{PROGRESS AND STATUS}

\section{Introduction}

Post-irradiation deformation behavior on a microstructural scale in ferritic/martensitic steels represents an important field for research that has been largely ignored. This is in part due to limitations imposed by specimen availability, imaging challenges, and as will be shown, localized flow limitations. We have previously attempted to examine postirradition deformation in $\mathrm{Fe}-6 \mathrm{Cr}$ and $-12 \mathrm{Cr}$ specimens, without success [1], but are unaware of any other similar efforts. In this previous attempt, specimens of deformed miniature sheet tensile specimens were prepared about $1.5 \mathrm{~mm}$ from the fracture surface, but the microstructures found were characteristic of undeformed material. This topic is of importance because martensitic steels are considered candidate materials for fusion structural applications, and postirradiation deformation in general, and embrittlement in particular are expected to define the low temperature limits for application. The topic is of particular interest because ferritic steels provide an unusual example where irradiation produces a Burger's vector $(a<100>)$ that is not normally encountered in unirradiated ferritic steels, nor is it found in most other body centered cubic metals. Also, it is not clear how slip dislocations of type $\frac{a}{2}\langle 111\rangle$ can interact with $a<100>$ Burger's vectors so as to annihilate all a<100> segments.

\section{Experimental Procedures}

Miniature sheet tensile specimens of $\mathrm{Fe}-\mathrm{Cr}$ alloys were irradiated in fusion irradiations in the FFTF, and were tested to provide understanding of postirradiation deformation response in simple alloys $[1,2]$. Later irradiation experiments duplicated these conditions, but did not exceed them because FFTF was shut down prematurely. Because the conditions were duplicates, they were ignored and deformation testing was terminated. From the available specimen conditions, the two listed in Table 1 were easily accessible and were chosen for study. It was decided to limit the present study to $\mathrm{Fe}-9 \mathrm{Cr}$ ( $\mathrm{Fe}-9.6 \mathrm{Cr}-0.002 \mathrm{C}-0.022 \mathrm{O}-$

\footnotetext{
*Pacific Northwest National Laboratory (PNNL) is operated for the U.S. Department of Energy by Battelle Memorial Institute under contract DE-AC06-76RLO-1830.
} 
$0.0017 \mathrm{~N}$ in wt\% [3]) in order to best match the low activation candidate alloy compositions. This meant that two specimens were available from capsule ZP-1 and four were available from ZR1. Unirradiated control duplicates could not be found, so SS-3 control samples with identical heat treatment were substituted to provide control condition microstructures.

Table 1. Irradiation Conditions for miniature sheet tensile specimens.

\begin{tabular}{|c|c|c|c|c|}
\hline Capsule ID & MOTA/Basket & Irr. Temp $\left({ }^{\circ} \mathrm{C}\right)$ & Fluence $\left(\mathrm{n} / \mathrm{cm}^{2}\right)$ & Dose (dpa) \\
\hline ZP1 & 1E/BCB-1 & 370 & $2.79 \times 10^{22}$ & 10.4 \\
\hline ZR1 & 1E/2C-3 & 403 & $9.46 \times 10^{22}$ & 40.5 \\
\hline
\end{tabular}

Specimen flats were mechanically polished to Linde 600 grit and deformed at room temperature either to failure on the first test or to $\sim 2 \%$ for the irradiated specimens and $\sim 8 \%$ for the unirradiated specimens using procedures previously described [2]. Testing details are given in Table 2 with elongations estimated from test traces. If uniform elongation (UE) and total elongation (TE) are not provided, the test was stopped prior to failure.

Table 2. Test Details for Deformed Tensile Specimens.

\begin{tabular}{|c|c|c|c|c|}
\hline Specimen ID & Condition & YS (MPa) & UTS (MPa) & Elongation (\%) \\
\hline 6721 & unirradiated & 194 & 326 & 16.4 UE, 27.3 TE \\
\hline 6720 & " & 139 & 250 & 8.5 \\
\hline 6724 & " & 142 & 239 & 7.2 \\
\hline ZR01 & 40 dpa at 403 & 534 & 534 & 0.02 UE, 4.1 TE \\
\hline ZR02 & " & 540 & 554 & 2.3 \\
\hline ZP01 & 10 dpa at 370 & 619 & 619 & 2.6 \\
\hline
\end{tabular}

Maximum load response as shown in reference 2, page 1240.

Following deformation, specimens were examined by SEM to identify regions that were deformed. Unirradiated SS-3 specimens were then ground from $0.030^{\prime \prime}(0.75 \mathrm{~mm})$ to about the thickness of the miniature specimens: $0.010^{\prime \prime}(0.25 \mathrm{~mm})$. Disks $1 \mathrm{~mm}$ in diameter were then punched from promising areas so that the edge of the specimen was retained on one side to allow determination of the stress axis. Each disk was then mounted in a $3 \mathrm{~mm}$ stainless steel disk using recently developed procedures [4] and prepared using normal polishing procedures. TEM was performed on a JEOL 1200EX transmission electron microscope operating at $120 \mathrm{KeV}$ and using a double tilting $\pm 45^{\circ}$ goniometer stage. Imaging included procedures for identifying each of the $a<100>$ and $\frac{a}{2}<111>$ Burgers vectors in a field of view [5]. All micrographs were digitized and stereo images were prepared as anaglyphs, available on request.

Results

\section{Surface Features}

SEM revealed that surfaces of both irradiated and unirradiated specimens had developed clearly defined steps. The vertical surfaces of these steps were not flat, but instead showed fine structure. However, the irradiated specimens showed no other features whereas the unirradiated specimens developed more rounded step edges and more structure on the original surfaces. Examples are provided in Figures 1 and 2. Figure 1 compares the specimens at low magnification and Figure 2 shows examples of specimen surfaces at higher magnifications. 


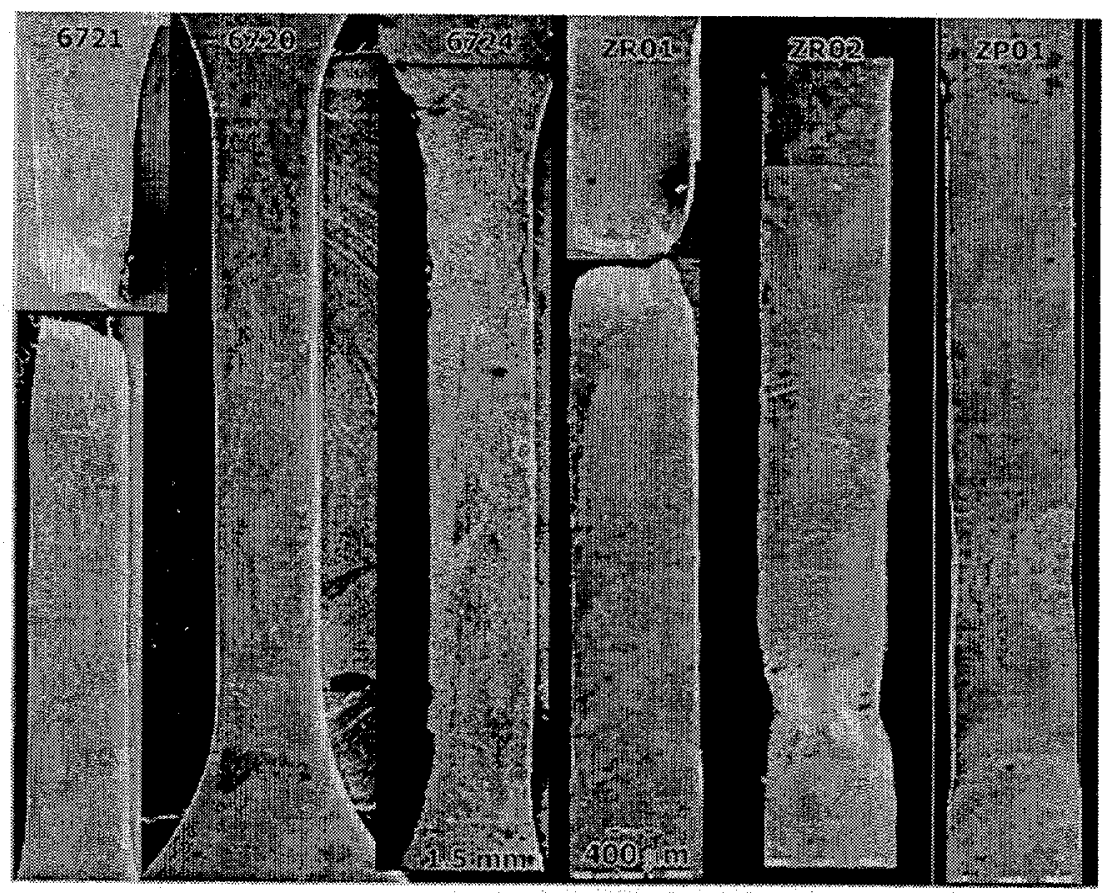

Figure 1. Low magnification examples of deformed tensile specimens with unirradiated specimens on the left. Note differences in magnification.

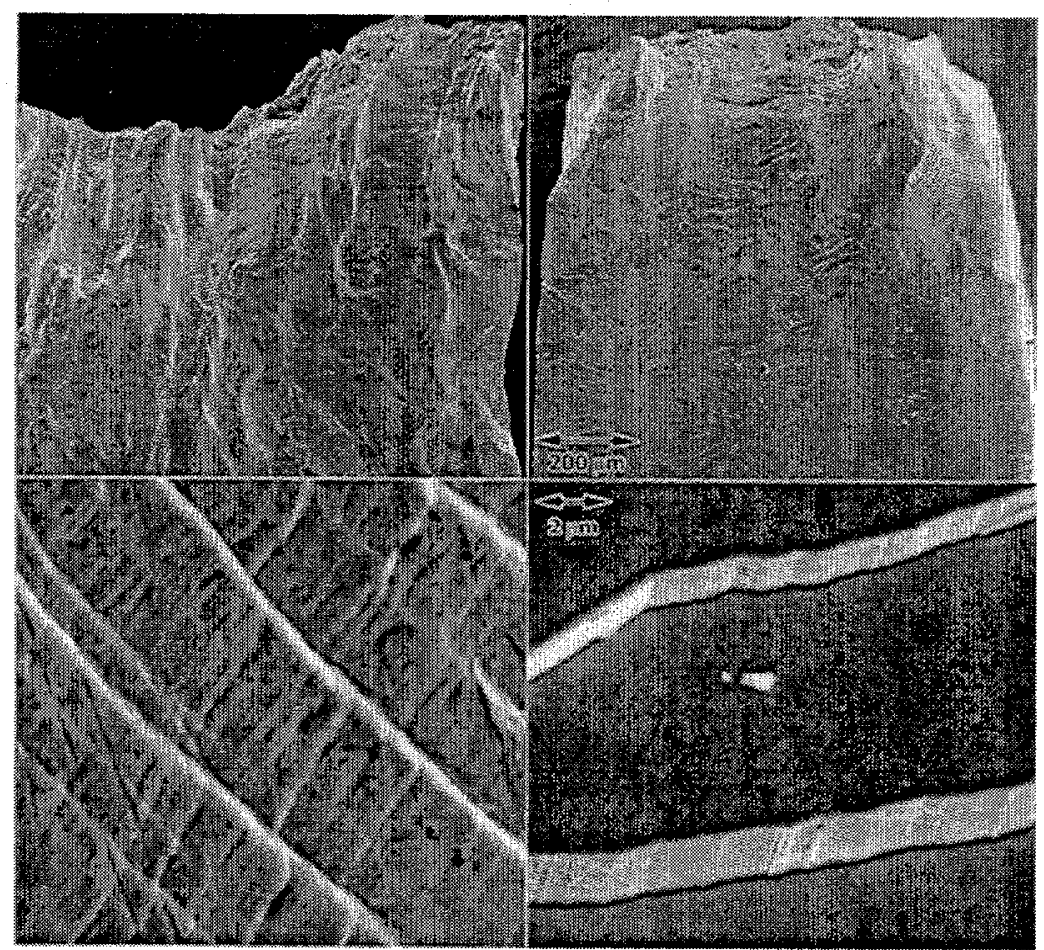

Figure 2. Higher magnification examples of the fracture surfaces and slip steps, with the unirradiated condition on the left. 


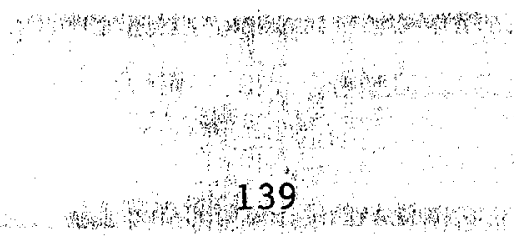

Figure 1 shows the unirradiated specimens on the left and the irradiated samples on the right at decreasing strain from left to right. From Figure 1 it can be shown that strain is much more localized following irradiation. In fact, specimen ZP02, second from right is about to fail in the necked region with little indication of deformation elsewhere. Slip steps can be identified in the gauge sections only towards the grips, even in the failed specimen. From this figure, the reason for the previous inablility to find deformation in reference 1 microstructural studies is apparent; deformation is so localized that material $1.5 \mathrm{~mm}$ from the fracture surface shows few slip steps. Deformation in the unirradiated specimens is much more uniform.

Figure 2 shows the fracture surfaces at higher magnification with unirradiated specimen 6721 on the left and irradiated specimen ZR01 on the right. Dimple rupture is apparent on the fracture surface following irradiation. The grain size is on the order of $200 \mu \mathrm{m}$ and each grain contains slip steps appearing as wavy lines, but these lines are difficult to resolve in the unirradiated condition at lower magnification. Slip step spacing increases with distance from the fracture surface. At higher magnification in the lower images, it is apparent that in the irradiated case, the surface is stepped with no features on the original surface and fine structure on the step surfaces. In general, the fine structure is ridged, but several examples can be found where steps appear on this surface. Therefore, once deformation initiates on a plane, it tends to continue without change on that plane. In comparison, the unirradiated sample shows undulations on the original surface, step edges that are rounded and step surfaces that are more uneven. (Scratches are on the lower left and should be ignored.) Therefore, in the unirradiated case, deformation is less restricted to deformation channels.

\section{Microstructural Examination}

The unirradiated deformed condition was found to contain a moderate density of straight screw $\frac{a}{2}<111>$ dislocation line segments, but $\frac{a}{2}<111>$ loops produced by deformation were also found. An example demonstrating procedures that allow identification of all $\frac{a}{2}\langle 111\rangle$ Burgers vectors, is given in Figure 3 for an area in specimen 6724 deformed approximately $7 \%$. Figure 3 provides comparison of the same area imaged using $\bar{g}=011$ (vertical) in Figure $3 \mathrm{a}$ and 200 (horizontal) in Figure $3 \mathrm{~b}$ taken near (011) orientations and $\overline{\mathrm{g}}=10 \overline{1}$ (with $\overline{\mathrm{g}}$ as shown) in Figure $3 c$ taken near (131) [5]. In Figure $3 a$ only $\frac{a}{2}[1 \overline{1} 1]$ and $\frac{\operatorname{a}}{2}[11 \overline{1}]$ are in contrast, in Figure $3 \mathrm{~b}$, all $\frac{3}{2}<111>$ dislocations are in contrast and in Figure $3 \mathrm{c}$, only $\frac{3}{2}[111]$ and $\frac{2}{2}[11 \overline{1}]$ are in contrast. Therefore, those dislocations that appear in Figures $3 a$ and $3 b$, but not in $3 c$ that tend to lie on the diagonal from lower left to upper right are of type $\frac{a}{2}\left[1{ }^{1} 1\right]$ and are of screw configuration. A small loop, most visible in Figure $3 a$ and marked with an arrow, appears to be an edge loop with $\frac{3}{2}[111]$ Burgers vector.

Except in samples that were taken where necking was occurring, the microstructures observed in irradiated samples were typical of the as-irradiated structure, as found in earlier work [1]. That structure consisted of equiaxed voids, a $<100>$ loops, $\frac{a}{2}<111>$ line segments, and perhaps large $\frac{a}{2}<111>$ loops. Examples are provided in Figure 4 from specimens ZP0 1 away from the necked area and ZRO1 near the fracture surface, showing bright field images with $\overline{\mathrm{g}}=01 \overline{1}$ (horizontal) and 200 (vertical) taken near (011) orientations, the lower dose and temperature on the left. For Figure 4 , it can be noted that in $\bar{g}=200$ contrast, all $\frac{a}{2}<111>$ dislocations are weakly visible and one set of $a<100>$ are visible in strong contrast, those on the $(200)$ plane, whereas in $\bar{g}=01 T$ contrast, only two sets of $\frac{a}{2}<111>$ dislocations and the remaining a $<100>$ dislocations are visible (with a[100] invisible) [1,5]. Therefore, Figure 4 shows loops on the order of $50 \mathrm{~nm}$ predominantly of $a<100>$ type with a few $\frac{\theta}{2}<111>$ dislocation segments. Similar response was previously reported in undeformed specimens $[1,3,6-8]$. 

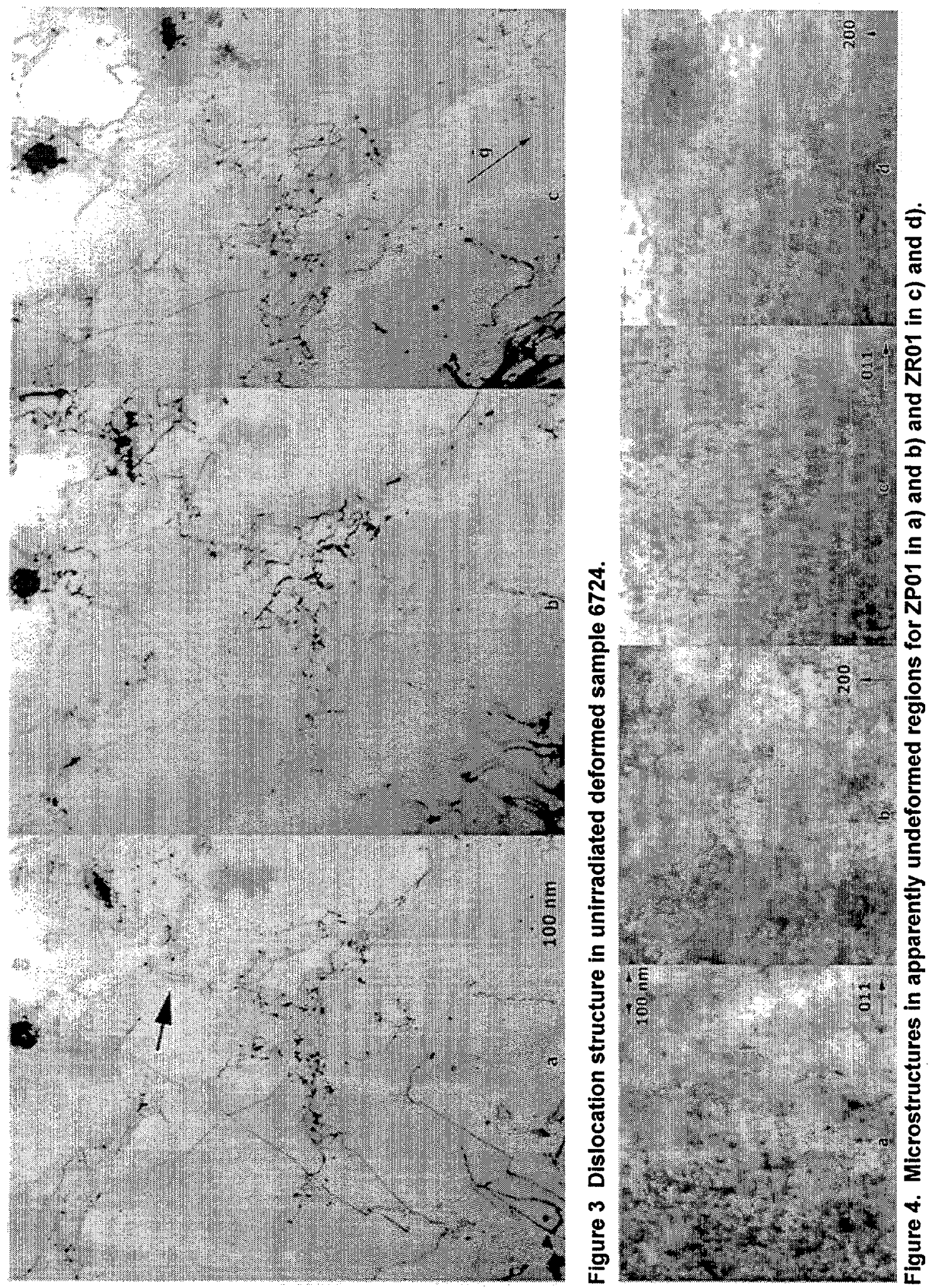

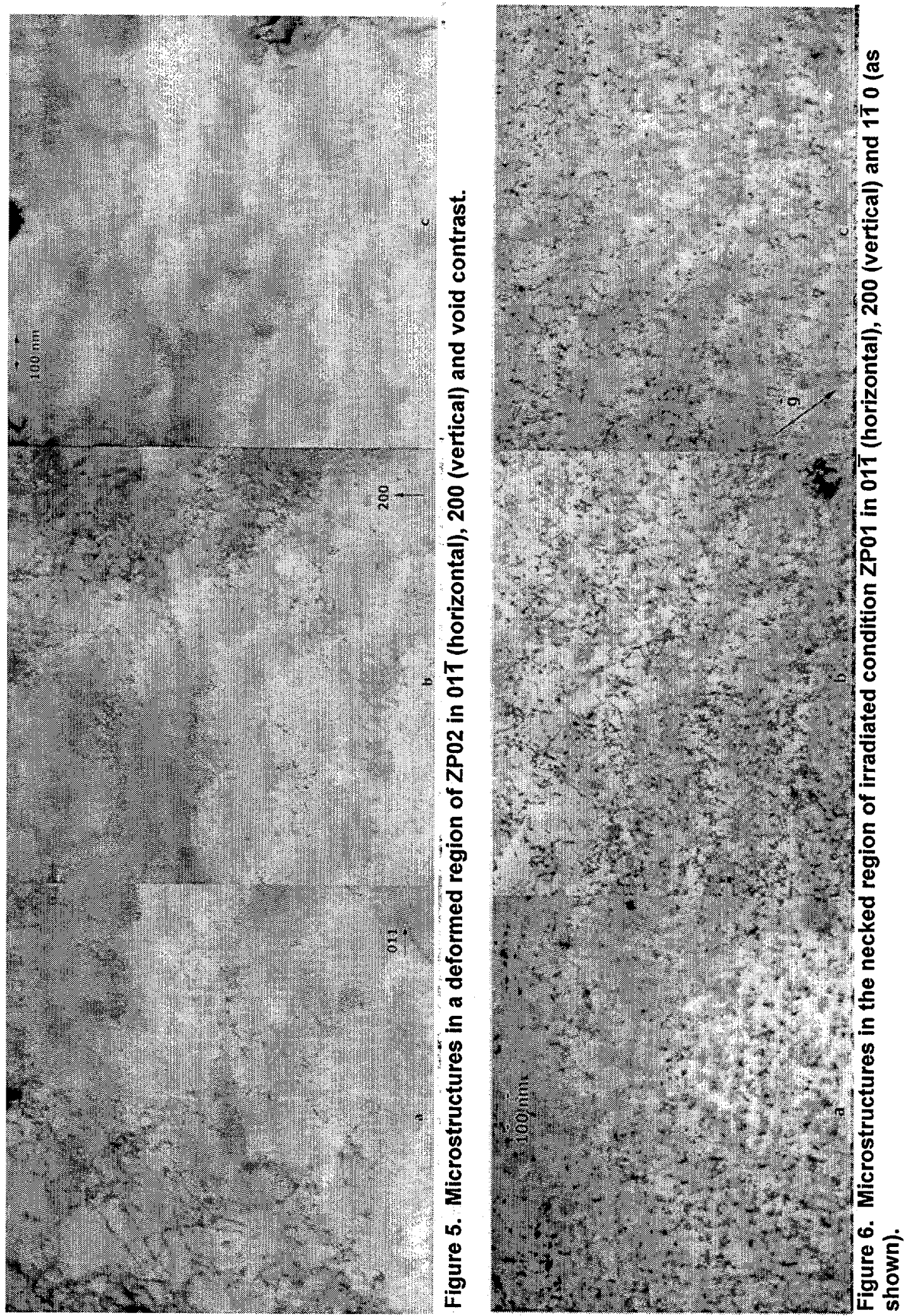
Nom

143

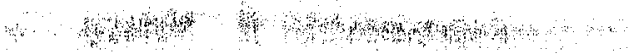

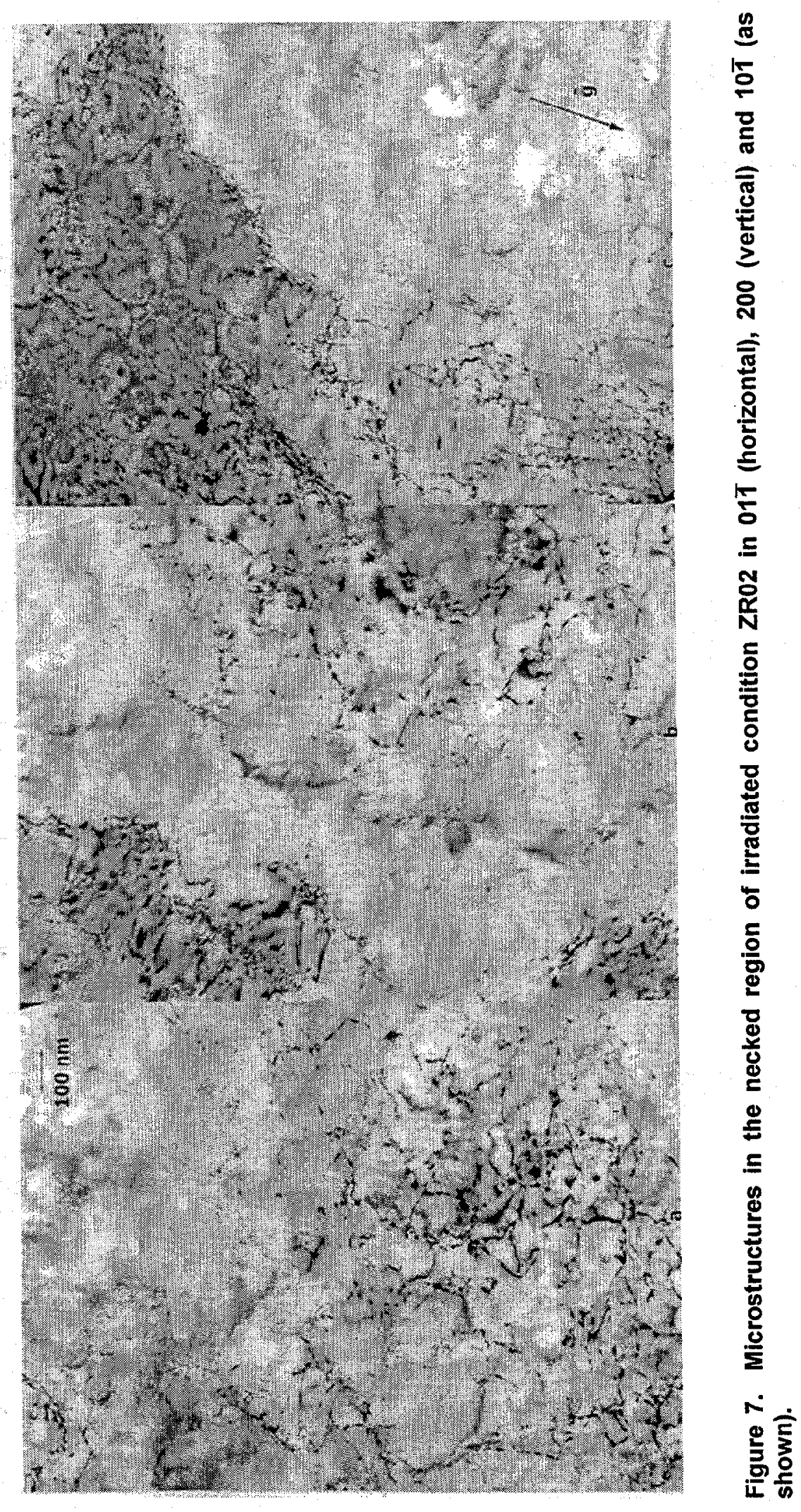




$$
\frac{3}{2}[\overline{1} 11]+\mathrm{a}[100]=\frac{\mathrm{a}}{2}[111]
$$

Replacement of a section of the $a[100]$ loop with an $\frac{a}{2}[111]$ line segment therefore can take place with significant reduction in energy. This process can be expected to continue rapidly, replacing the $a[100]$ loop with an $\frac{a}{2}[111]$ loop lying on the (100) plane. This replacement reaction can occur with any moving $\frac{a}{2}<111>$ dislocation but its sense will determine which side of the a[100] loop it will be attracted to. Stereoscopic examination of features in Figure $6 \mathrm{~b}$ reveals however that most of the $\frac{a}{2}<111>$ loops present are not on $\{100\}$ planes, and therefore, once formed, the loops are able to glide to more favorable configurations.

Reduction in dislocation density then occurs with further interaction between the newly formed $\frac{3}{2}<111>$ loops and moving dislocations of similar Burgers vector. However, interactions between $\frac{3}{2}<111>$ loops and dislocations of a different Burgers vector will not be energetically favorable, representing the reverse of the above interaction, and therefore, such loops will represent barriers to dislocation slip.

It is apparent that with sufficient deformation, all irradiation induced loops can be destroyed, leaving a dislocation structure with screw component characteristics similar to those created in deformed unirradiated conditions. Even after the irradiation-induced dislocation structure is removed, localized deformation continues, resulting in a higher density of surface steps and a transition into necking response. This may be a consequence of favorable dislocation nucleation or enhanced dislocation glide because the remaining microstructural obstacles to dislocation glide, the voids, are distorted.

It has been shown that some voids are elongated or, at least, deformed from the original equiaxed and faceted shape. The deformed elongated cavities are located in regions that form narrow bands that are about $100 \mathrm{~nm}$ wide as shown in Figure 8. The analysis of the shape of the elongated cavities allowed measurement of localized strains. The local strain is given by the ratio of length of the cavity, measured from top to bottom in the direction of the strain, and the original size, as measured by the size of the cavity at mid-height perpendicular to the strain axis. The average strain for highly elongated voids is about $300 \%$, which represents the passage across a $25 \mathrm{~nm}$ cavity of about 100 dislocations.

Even though these bands are poorly defined, they clearly indicate deformation of the material occurring by localized shear. When these bands are correlated with the stepped traces revealed

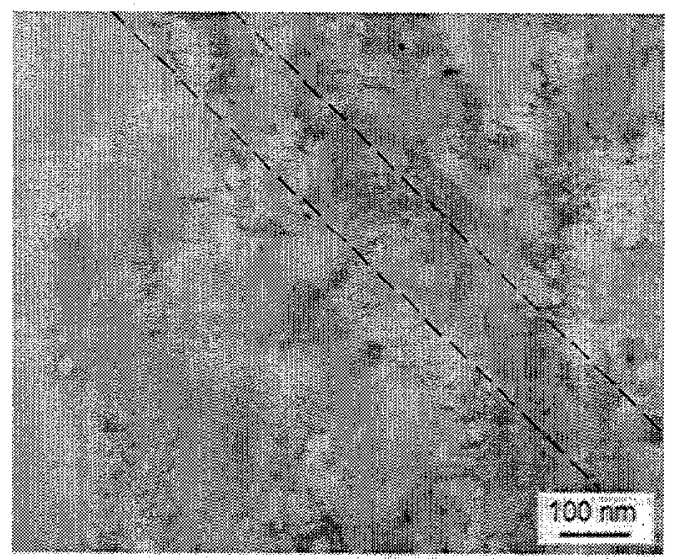

Figure 8. Microstructure in the necked region of irradiated condition ZR02 showing typical elongated cavities in poorly defined narrow bands. $A$ band is delineated by the dashed lines.

by the SEM analysis, it is clear that the irradiated material can deform via a channeling mechanism. Although channeling has been demonstrated in a number of irradiated fcc and ferritic materials [9-10], this is to our knowledge the first evidence for this mechanism in a Fe-9Cr type ferritic alloy. 


\section{Conclusions}

A novel specimen preparation procedure has made it possible to examine postirradiation deformation in $\mathrm{Fe}-9 \mathrm{Cr}$ minature sheet tensile specimens. It is found that

1) Deformation in irradiated specimens is highly localized so that specimens prepared more than $1 \mathrm{~mm}$ from the fracture surface usually showed no effects of deformation.

2) Surface slip steps created during postirradiation deformation are clearly defined with no other apparent surface damage whereas in unirradiated specimens the steps are more poorly defined and other surfaces show evidence of local deformation. The surface steps in irradiated specimens are nonplanar but features created early in the deformation are reproduced during further deformation creating ridges on the steps that are rarely altered with further deformation. Therefore, once localized slip is established in irradiated specimens, it generally continues without change. Localized necking occurs in irradiated specimens as slip steps get larger and slip planes increase in density.

3) Transformation of a $<100>$ loops created during irradiation of ferritic alloys appears to proceed easily based on observed rapid disappearance of such features. It is proposed that this transformation is based on the reaction

$$
\frac{a}{2}[111]+a[100]=\frac{a}{2}[111]
$$

4) Continued postirradiation deformation removes all irradiation induced dislocation structure, replacing it eventually with $\frac{2}{2}[111]$ screw dislocations typical of deformation in unirradiated specimens.

5) Evidence for highly localized plasticity is found in the void structure so that some voids become highly elongated but nearby voids remain undistorted. Strains as high as $300 \%$ were identified in narrow bands that are about $100 \mathrm{~nm}$ wide. The controlling deformation mechanism is by channeling.

6) As local strains increase during postirradiation deformation, highly defined subgrain structure develops, whereas such structure is not found in unirradiated specimens deformed to about $8 \%$ uniform elongation.

\section{FUTURE WORK}

This work will be continued as needed.

\section{REFERENCES}

[1] M. L. Hamilton, D. S. Gelles, and P. L. Gardner in Effects of Radiation on Materials: $16^{\text {th }}$ International Symposium, ASTM STP 1175 , A. S. Kumar, D. S. Gelles, R, Nanstad and E. A. Little, Eds., ASTM Philadelphia (1993) 545.

[2] M. L. Hamilton and D. S. Gelles in Effects of Radiation on Materials: $15^{\text {th }}$ International Symposium, ASTM STP 1125, R. E. Stoller, A. S. Kumar, and D. S. Gelles, Eds., ASTM, Philadelphia (1992) 1234.

[3] D. S. Gelles, J. Nucl. Mater., $108 \& 109(1982) 515$.

[4] D. S. Gelles, S. Ohnuki, K. Shiba, Y. Kohno, A. Kohyama, J. P. Robertson, and M. L. Hamilton, in DOE/ER-0313/25 (1999) 143. 
[5] D. S. Gelles, A. Kimura and T. Shibayama in Effects of Radiation on Materials: $19^{\text {th }}$ International Symposium, ASTM STP 1366, M. L. Hamilton, A. S. Kumar, S. T. Rosinski and M. L. Grossbeck, Eds. ASTM, W. Conshohocken, PA (2000) 535.

[6] D. S. Gelles in Effects of Radiation on Materials: 14th International Symposium, Vol. 1, ASTM STP 1046, N. H. Packan, R. E. Stoller and A. S. Kumar, Eds., ASTM, Philadelphia 1990, 73-97.

[7] D. S. Gelles, IBID Reference 1, 66.

[8] D. S. Gelles, J. Nucl. Mater., 225 (1995) 163.

[9] R. L. Fish, J. L. Straalsund, C. W. Hunter, and J. J. Holmes in Effects of Radiation on Substructure and Mechanical Properties of Metals and Alloys, ASTM STP 529, ASTM 1973, 149-164.

[10] M. Victoria, N. Baluc, C. Bailat, Y. Dai, M.I. Luppo, R. Schäublin, B.N. Singh, J. Nucl. Mater., 276 (1-3) (2000) 114-122. 


\section{MICROSTRUCTURAL EVOLUTION OF 9Cr-2WVTa STEELS IN HFIR-CTR-62/63 EXPERIMENT -}

N. Hashimoto and R.L. Klueh (Oak Ridge National Laboratory)

\section{OBJECTIVE}

The objective of this work is to investigate microstructural evolution of nickel-doped and undoped ferritic/martensitic steels irradiated in HFIR-CTR-62/63 experiment in order to clarify the effect of helium generation rate on swelling and the change of the mechanical properties.

\section{SUMMARY}

The microstructures of reduced-activation ferritic/martensitic steels, 9Cr-2WVTa and 9Cr-2WVTa doped with $2 \% \mathrm{Ni}$, irradiated at $400^{\circ} \mathrm{C}$ up to $12 \mathrm{dpa}$ in the High Flux Isotope Reactor (HFIR), were investigated by transmission electron microscopy. Specimens were tempered at two different temperatures in order to investigate the effects of tempering on microstructural evolution during irradiation. Before irradiation, the lath width of Ni-doped $9 \mathrm{Cr}$-2WVTa was somewhat narrower and the dislocation density tended to be higher compared with $9 \mathrm{Cr}-2 \mathrm{WVTa}$. Dislocation density of specimens tempered at $750^{\circ} \mathrm{C}$ was lower than that tempered at $700^{\circ} \mathrm{C}$. In all steels, precipitates on grain and/or lath boundaries were mainly $\mathrm{M}_{23} \mathrm{C}_{6}$, and there were a few $\mathrm{TaC}$ along dislocations in the matrices. Irradiation-induced cavities were observed in all the steels. The cavity number density of the Ni-doped $9 \mathrm{Cr}-2 \mathrm{WVT}$ a was higher than that of $9 \mathrm{Cr}-2 \mathrm{WVT}$ a due to the higher concentration of helium; however, swelling in each steels was $<0.001 \%$ because cavity sizes were so small. There was no difference of cavity number density between the steels tempered at $700^{\circ} \mathrm{C}$ and $750^{\circ} \mathrm{C}$, but the mean size of the cavities in the steels tempered at $750^{\circ} \mathrm{C}$ was larger than that tempered at $700^{\circ} \mathrm{C}$. Irradiation-induced $a_{0}<100>$ and $\left(a_{0} / 2\right)<111>$ type dislocation loops were observed in all steels; number density and mean diameter of $a_{0}<100>$ type loops was higher and larger than that of $\left(a_{0} / 2\right)<111>$ type loops. There was a tendency for the number density of loops in Ni-doped $9 \mathrm{Cr}-2 \mathrm{WVTa}$ to be higher than that in 9Cr-2WVTa. In addition, the mean size of loops in the steels tempered at $750^{\circ} \mathrm{C}$ was larger than for those tempered at $700^{\circ} \mathrm{C}$, while there was not much difference of number density between them. In the steels doped with $\mathrm{Ni}$, irradiation-produced precipitates, identified as $\mathrm{M}_{6} \mathrm{C}(\eta)$-type carbide, were found in the matrices. Precipitation during irradiation might affect cavity and dislocation loop growth. In this experiment, the $9 \mathrm{Cr}-2 \mathrm{VWTa}-2 \mathrm{Ni}$ steel showed a larger increase of the transition temperature and a significant reduction in the upper shelf energy compared with the $9 \mathrm{Cr}-2 \mathrm{WVTa}$ steel. From these results, it might be suggested that the high density of cavities and precipitation in irradiated $9 \mathrm{Cr}-2 \mathrm{VWTa}-2 \mathrm{Ni}$ could affect Charpy properties, especially the reduction of upper shelf energy. 


\section{PROGRESS AND STATUS}

\section{Introduction}

Ferritic/martensitic steels are attractive candidate structural first wall materials for fusion energy systems [1]. The high-energy neutrons produced by the D-T fusion reaction induce displacement damage and generate gas atoms in the materials from $(n, p)$ and $(n, \alpha)$ reactions. It is considered positible that the simultaneous production of helium atoms from $(n, \alpha)$ reactions could strongly influence the nucleation of cavities. Therefore, to clarify the effect of helium atoms on the microstructural development and mechanical property change in martensitic steels under fast neutron irradiation, $9 \mathrm{Cr}-2 \mathrm{WVTa}$ and $9 \mathrm{Cr}$-2WVTa with $2 \% \mathrm{Ni}$ added were irradiated with neutrons in the High Flux Isotope Reactor (HFIR). In this experiment, specimens tempered at different temperature were prepared in order to investigate the effect of tempering on microstructural evolution during irradiation. Irradiation of Ni-doped steels in a mixed spectrum reactor like the HFIR results in the following transmutation reaction with the thermal neutrons: ${ }^{58} \mathrm{Ni}(\mathrm{n}, \gamma)^{59} \mathrm{Ni}(\mathrm{n}, \alpha)^{56} \mathrm{Fe}$, thus providing the possibility of studying the effects of the simultaneous production of displacement damage and helium production.

\section{Experimental Procedure}

$9 \mathrm{Cr}-2 \mathrm{WVTa}$ and $9 \mathrm{Cr}-2 \mathrm{WVTa}-2 \mathrm{Ni}$, normalized $0.5 \mathrm{~h}$ at $1050^{\circ} \mathrm{C}$ and tempered $1 \mathrm{~h}$ at $700^{\circ} \mathrm{C}(-\mathrm{A})$ or $750^{\circ} \mathrm{C}(-\mathrm{B})$, were prepared for this experiment; the compositions are given in Table 1. Standard $3-\mathrm{mm}$ diameter transmission electron microscopy (TEM) disks were punched from $0.25-\mathrm{mm}$ thick sheet stock. Irradiation was at $400^{\circ} \mathrm{C}$ in the HFIR-CTR-63 capsule in the High Flux Isotope Reactor (HFIR) to a neutron fluence of about $1.68 \times 10^{22} \mathrm{n} / \mathrm{cm}^{2}(E>0.1 \mathrm{MeV})$ [2], resulting in a displacement dose of about $12 \mathrm{dpa}$. The details of the design, construction, and installation of HFIR-CTR-62/63 have been reported [3]. The irradiation conditions and the calculated helium concentrations in the steels are given in Table 2. TEM specimens were thinned using an automatic Tenupol electropolishing unit located in a shielded glove box. TEM disks were examined using a JEM-2000FX $\left(\mathrm{LaB}_{6}\right)$ transmission electron microscope. The foil thicknesses were measured by thickness fringes in order to evaluate quantitative defect density values.

\section{Results and discussion}

Before irradiation, the lath width of the 9Cr-2WVTa-2Ni steels was somewhat narrower and the dislocation density somewhat higher compared with the 9Cr-2WVTa steels. The dislocation density of specimens tempered at $750^{\circ} \mathrm{C}$ were lower than for the tempered at $700^{\circ} \mathrm{C}$. In all steels, precipitates on grain boundaries were mainly $\mathrm{M}_{23} \mathrm{C}_{6}$, which were identified from the diffraction pattern, and there were a few TaC along dislocations in the matrices. The spacing of moiré fringes was used to identify the $\mathrm{TaC}$. Figure 1 shows the unirradiated microstructures of the steels and the TaC carbides on dislocations. 
Table 1. Chemical compositions of the specimens (wt\%)

\begin{tabular}{ccc}
\hline & 9 Cr-2WVTa & 9 Cr-2WVTa-2Ni \\
\hline $\mathrm{Cr}$ & 8.71 & 8.55 \\
$\mathrm{Ni}$ & 0.02 & 2.01 \\
$\mathrm{~W}$ & 2.17 & 2.15 \\
$\mathrm{~V}$ & 0.23 & 0.23 \\
$\mathrm{Ta}$ & 0.06 & 0.06 \\
$\mathrm{Mn}$ & 0.39 & 0.38 \\
$\mathrm{Al}$ & 0.021 & 0.021 \\
$\mathrm{Mo}$ & $<0.01$ & $<0.01$ \\
$\mathrm{Nb}$ & $<0.01$ & $<0.01$ \\
$\mathrm{Cu}$ & $<0.001$ & $<0.001$ \\
$\mathrm{Ti}$ & $<0.01$ & $<0.01$ \\
$\mathrm{C}$ & 0.098 & 0.098 \\
$\mathrm{P}$ & 0.014 & 0.014 \\
$\mathrm{~S}$ & 0.003 & 0.003 \\
$\mathrm{Si}$ & 0.19 & 0.19 \\
$\mathrm{~B}$ & $<0.001$ & $<0.001$ \\
$\mathrm{~N}$ & 0.016 & 0.016 \\
$\mathrm{Fe}$ & $\mathrm{Bal}$ & $\mathrm{Bal}$ \\
\hline
\end{tabular}

Table 2. Irradiation conditions and helium concentration

\begin{tabular}{lccc}
\hline & dpa & appm He & He/dpa \\
\hline 9Cr-2WVTa & 12.0 & 25 & 2.1 \\
9Cr-2WVTa-2Ni & 12.3 & 150 & 12.2 \\
\hline
\end{tabular}
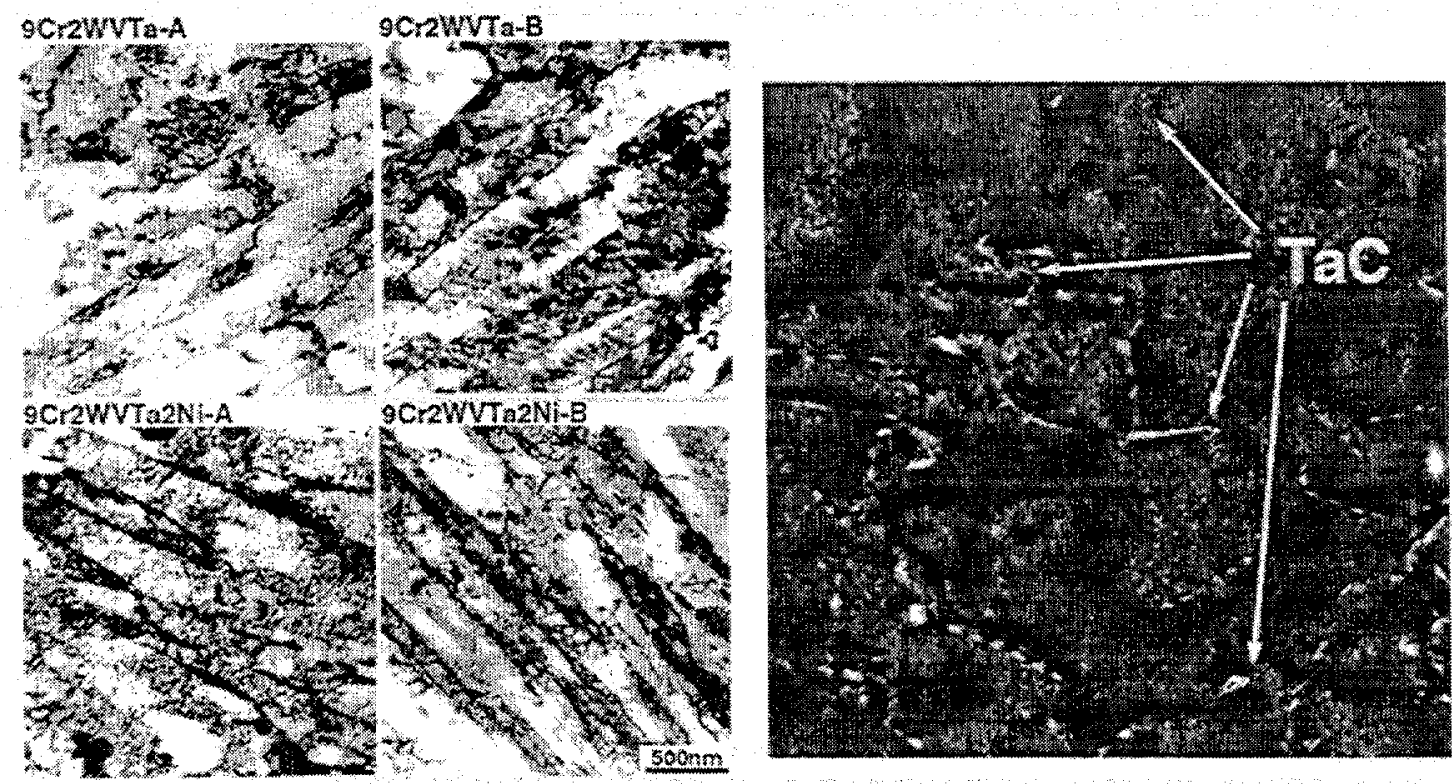

Fig.1. Microstructures of the unirradiated steels and $\mathrm{TaC}$ on dislocation. 


\subsection{Dislocations and dislocation loops}

During irradiation of $\mathrm{Fe}-\mathrm{Cr}$ binary alloys, dislocation evolution in an initially almost dislocation-free condition proceeds by the formation of interstitial-type dislocation loops with an $a_{0}<100>$ and/or $\left(a_{0} / 2\right)<111>$ Burgers vector $[4,5]$. Figure 2 shows the dislocation segments and loops in the specimens after irradiation at $400^{\circ} \mathrm{C}$ to 12 dpa using the diffraction conditions: $\mathbf{g}=110,(\mathbf{g}, 4 \mathbf{g})$. Table 3 summarizes the quantitative results of dislocation loops. The number density and the mean diameter of $a_{0}<100>$ type loops are higher and smaller than that of $\left(a_{0} / 2\right)<111>$ type loops, respectively. In addition, there is a tendency for the number density of irradiation-induced $\left(a_{0} / 2\right)<111>$ type dislocation loops in $9 \mathrm{Cr}-2 \mathrm{WVTa}-2 \mathrm{Ni}$ to be somewhat higher than those in the $9 \mathrm{Cr}-2 \mathrm{WVTa}$. With respect to the two different tempering temperatures, the mean size of the loops in the steels tempered at $750^{\circ} \mathrm{C}$ was larger than for those tempered at $700^{\circ} \mathrm{C}$, while there was little difference in the number density between them. Before irradiation, the dislocation density of specimens tempered at $700^{\circ} \mathrm{C}$ were higher than for those tempered at $750^{\circ} \mathrm{C}$, and higher dislocation density tends to cause a smaller size of loops during irradiation. This suggests that the growth of irradiation-induced loops is controlled by heat treatment before irradiation.

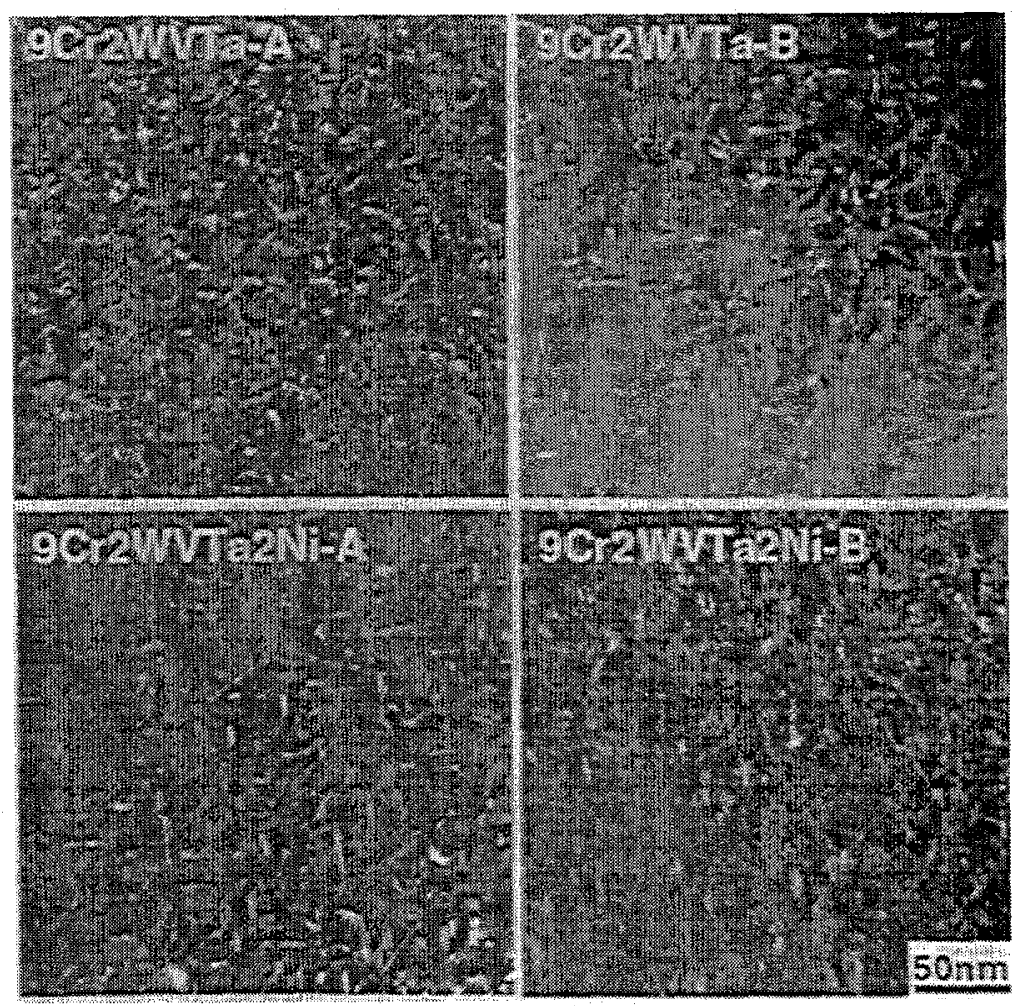

Figure 2. Dislocation segments and loops in $9 \mathrm{Cr}-2 \mathrm{WVTa}-\mathrm{A}, 9 \mathrm{Cr}-2 \mathrm{WVTa}-\mathrm{B}, 9 \mathrm{Cr}-$ 2WVTa-2Ni-A and $9 \mathrm{Cr}-2 \mathrm{WVTa}-2 \mathrm{Ni}-\mathrm{B}$ after irradiation at $400^{\circ} \mathrm{C}$ to $12 \mathrm{dpa}$ using the diffraction conditions: $g=110,(g, 4 g)$. 
Table 3. Summary of dislocation structure before and after irradiation

\begin{tabular}{|c|c|c|c|c|c|}
\hline \multirow[t]{2}{*}{ Steel } & \multicolumn{2}{|c|}{$a_{0}<100>$ type loops } & \multicolumn{2}{|c|}{$\left(a_{0} / 2\right)<111>$ type loops } & \multirow{2}{*}{$\begin{array}{l}\text { Before irradiation } \\
\text { Line density }\end{array}$} \\
\hline & $\begin{array}{l}\text { Number } \\
\text { density } \\
\left(\mathrm{m}^{-3}\right)\end{array}$ & $\begin{array}{l}\text { Mean } \\
\text { diameter } \\
(\mathrm{nm})\end{array}$ & $\begin{array}{l}\text { Number } \\
\text { density } \\
\left(\mathrm{m}^{-3}\right)\end{array}$ & $\begin{array}{l}\text { Mean } \\
\text { diameter } \\
(\mathrm{nm}) \\
\end{array}$ & \\
\hline 9Cr-2WVTa-A & $1 \times 10^{22}$ & 18 & $5 \times 10^{21}$ & 28 & $5 \times 10^{14}$ \\
\hline 9Cr-2WVTa-B & $1 \times 10^{22}$ & 23 & $4 \times 10^{21}$ & 30 & $2 \times 10^{14}$ \\
\hline $9 \mathrm{Cr}-2 \mathrm{WVTa}-2 \mathrm{Ni}-\mathrm{A}$ & $1 \times 10^{22}$ & .17 & $6 \times 10^{21}$ & 16 & $7 \times 10^{14}$ \\
\hline 9Cr-2WVTa-2Ni-B & $1 \times 10^{22}$ & 23 & $6 \times 10^{21}$ & 28 & $5 \times 10^{14}$ \\
\hline
\end{tabular}

\subsection{Cavities}

Figure 3 shows cavities of the specimens irradiated at $400^{\circ} \mathrm{C}$ to $12 \mathrm{dpa}$. Distribution of cavities is homogeneous in the matrices, and no cavities were observed on grain boundaries. Neutron irradiation induced tiny cavities with number densities of $3 \times 10^{21}$ in $9 \mathrm{Cr}-2 \mathrm{WVTa}-2 \mathrm{Ni}-\mathrm{A}$, and $-\mathrm{B}$. In $9 \mathrm{Cr}-2 \mathrm{WVTa}-\mathrm{A}$ and $-\mathrm{B}$, somewhat larger cavities were observed even though this steel contained very little helium compared with the Ni-doped steels. Swelling of each steel was estimated to be $<0.001 \%$, suggesting the difference in helium concentrations did not affect swelling in this experiment, even though the cavity number densities correlated with the helium concentrations. Table 4 summarizes the quantitative results of the observations on the cavities.

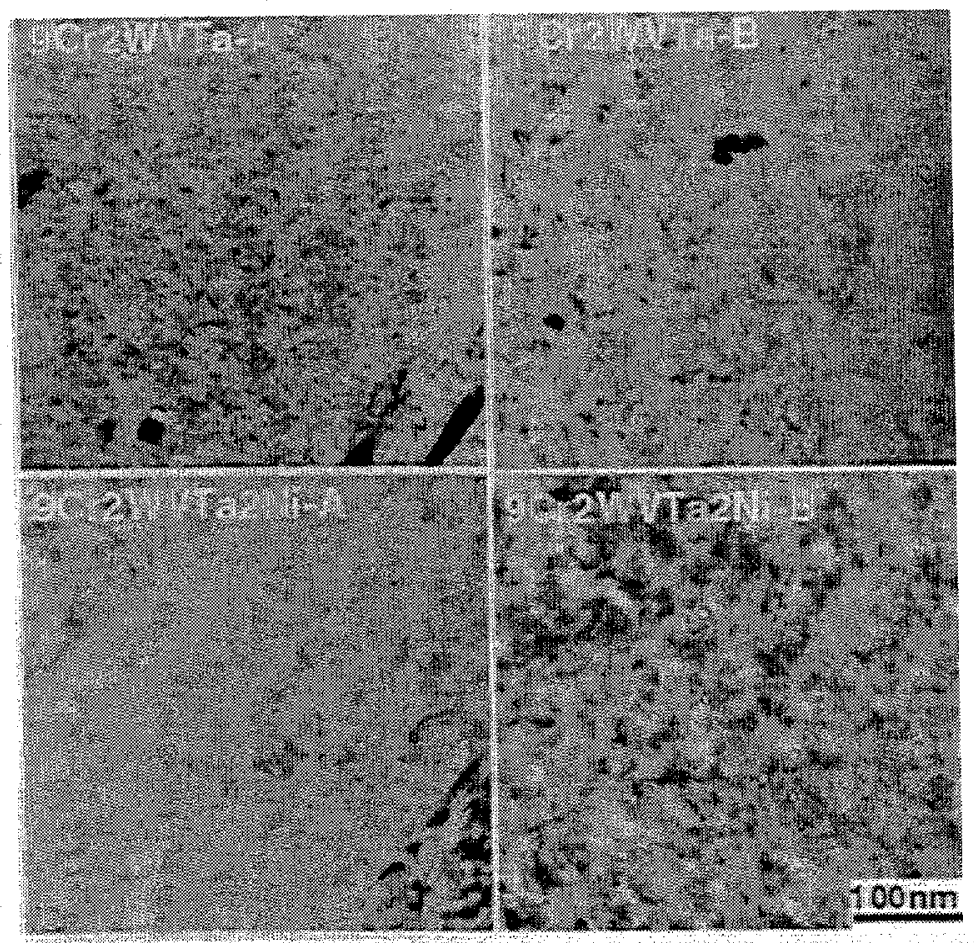

Figure 3. Cavities in 9Cr-2WVTa-A, 9Cr-2WVTa-B, 9Cr-2WVTa-2Ni-A and 9Cr2WVTa-2Ni-B after irradiation at $400^{\circ} \mathrm{C}$ to $12 \mathrm{dpa}$. 
Table 4. Summary of cavities formed during irradiation

\begin{tabular}{lccc}
\hline Steel & $\begin{array}{c}\text { Mean Size } \\
(\mathrm{nm})\end{array}$ & $\begin{array}{c}\text { Number Density } \\
\left(\mathrm{m}^{-3}\right)\end{array}$ & $\begin{array}{c}\text { Swelling } \\
(\%)\end{array}$ \\
\hline 9Cr-2WVTa-A & 3 & $1 \times 10^{21}$ & $<0.001$ \\
9Cr-2WVTa-B & 9 & $1 \times 10^{21}$ & $<0.001$ \\
9Cr-2WVTa-2Ni-A & 3 & $3 \times 10^{21}$ & $<0.001$ \\
9Cr-2WVTa-2Ni-B & 4 & $3 \times 10^{21}$ & 0.001 \\
\hline
\end{tabular}

\subsection{Precipitates}

Before irradiation, the alloys used in this study include a few TaC on dislocations and $\mathrm{M}_{23} \mathrm{C}_{6}$ on grain and/or lath boundaries, with the number density and the mean diameter of $<1 \times 10^{20} \mathrm{~m}^{-3}$ and about $100 \mathrm{~nm}$, respectively. There was little difference in $\mathrm{M}_{23} \mathrm{C}_{6}$ before and after irradiation in terms of size and distribution, but neutron irradiation did produce precipitates in the matrices of the Ni-doped steels. The spacing of moiré fringes was used to identify the irradiation-produced precipitates, which were identified as $M_{6} C(\eta)$-type carbide. Figures 4 shows the irradiationinduced $\mathrm{M}_{6} \mathrm{C}(\eta)$-type carbides in the $9 \mathrm{Cr}-2 \mathrm{WVTa}-2 \mathrm{Ni}-\mathrm{A}$ and $-\mathrm{B}$ steels after irradiation at $400^{\circ} \mathrm{C}$ to 12 dpa. Precipitation of a $\mathrm{Cr}$ - and Ni-rich $\mathrm{M}_{6} \mathrm{C}(\eta)$ has been observed in a number of $8-12 \mathrm{Cr}$ steels that contain $>0.3 w t \%$ Ni during FBR (Fast Breeder Reactor) and HFIR irradiation at about $400^{\circ} \mathrm{C}$ [6-9]. Table 5 summarizes the quantitative results of precipitates.

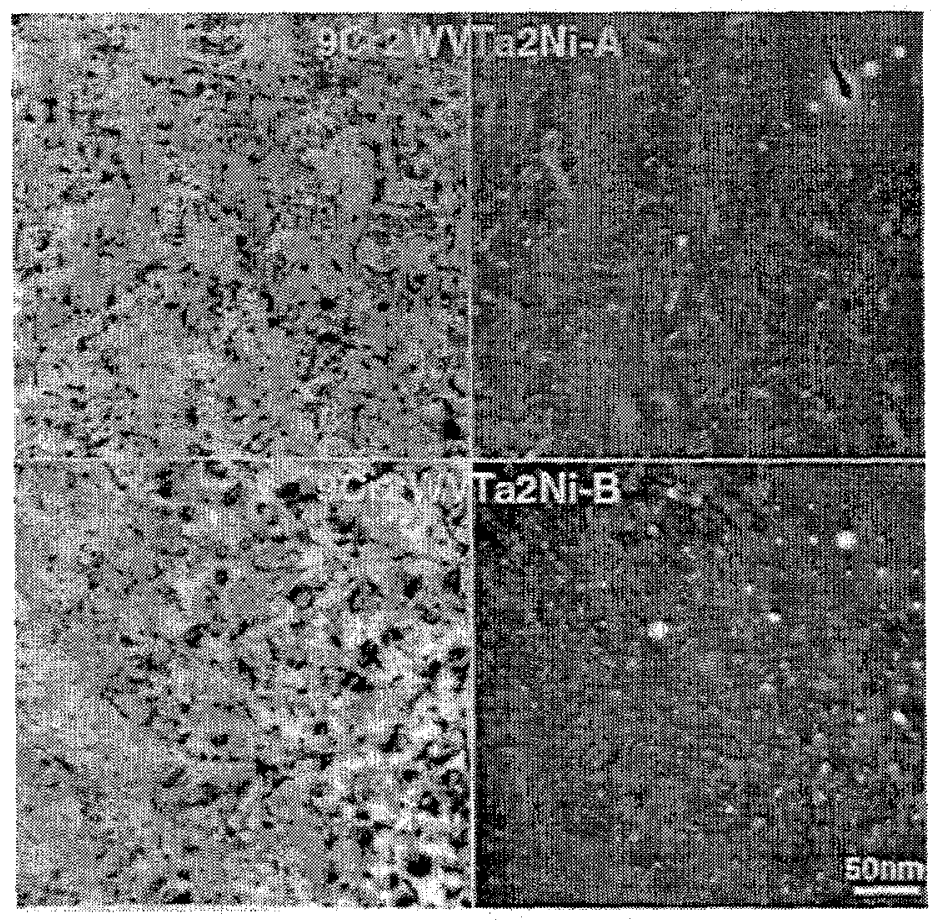

Figure 4. Irradiation-induced precipitates in 9Cr-2VWTa-2Ni-A and 9Cr-2VWTa$2 \mathrm{Ni}-\mathrm{B}$ after irradiation at $400^{\circ} \mathrm{C}$ to $12 \mathrm{dpa}$. 
Table 5. Summary of precipitates in the steels after irradiation at $400^{\circ} \mathrm{C}$

\begin{tabular}{lcccc}
\hline Steel & \multicolumn{3}{c}{$\mathrm{M}_{23} \mathrm{C}_{6}$} & \multicolumn{3}{c}{$\mathrm{M}_{6}(\eta)$} \\
\cline { 2 - 5 } & $\begin{array}{l}\text { Mean Size } \\
(\mathrm{nm})\end{array}$ & $\begin{array}{l}\text { Number } \\
\text { Density } \\
\left(\mathrm{m}^{-3}\right)\end{array}$ & $\begin{array}{l}\text { Mean Size } \\
(\mathrm{nm})\end{array}$ & $\begin{array}{l}\text { Number Density } \\
\left(\mathrm{m}^{-3}\right)\end{array}$ \\
\hline 9Cr-2WWTa-A & 95 & $<1 \times 10^{20}$ & - & - \\
9 9r-2VWTa-B & 102 & $<1 \times 10^{20}$ & - & - \\
9 Cr-2VWTa-2Ni-A & 92 & $<1 \times 10^{20}$ & 7 & $2 \times 10^{21}$ \\
9 Cr-2VWTa-2Ni-B & 98 & $<1 \times 10^{20}$ & 6 & $2 \times 10^{21}$ \\
\hline
\end{tabular}

The Charpy specimens from HFIR-CTR-62/63 experiment showed some differences between $9 \mathrm{Cr}-2 \mathrm{VWTa}$ and $9 \mathrm{Cr}-2 \mathrm{VWTa}-2 \mathrm{Ni}$ steel [10]. Table 6 and 7 summarize the Charpy properties and the tensile properties of the specimens, respectively. The 9Cr-2VWTa-2Ni steel showed larger increase of the strength and the transition temperature and a significant reduction in the uppershelf energy compared with $9 \mathrm{Cr}-2 \mathrm{WVT}$ a steel. As mentioned above, precipitation of $\mathrm{M}_{6} \mathrm{C}(\eta)$-type carbide and a higher number density of cavities were observed in the irradiated $9 \mathrm{Cr}-2 \mathrm{VWTa}-2 \mathrm{Ni}$ steel. From these results, it might be suggested that a high density of cavities and precipitation in the irradiated $9 \mathrm{Cr}-2 \mathrm{WWTa}-2 \mathrm{Ni}$ could affect the yield and tensile strength and Charpy properties.

Table 6. Charpy properties of steels in HFIR-CTR-62/63 experiment [10].

\begin{tabular}{lcccc}
\hline Steel & Irrad. Temp. & $\begin{array}{c}\text { Trans. Temp. } \\
\left({ }^{\circ} \mathrm{C}\right)\end{array}$ & $\begin{array}{c}\Delta \mathrm{DBTT} \\
\left({ }^{\circ} \mathrm{C}\right)\end{array}$ & $\begin{array}{c}\text { Upper-Shelf Energy } \\
(\mathrm{J})\end{array}$ \\
\hline 9Cr-2VWTa & Unirrad. & -94 & & 10.8 \\
& 400 & -15 & 79 & 6.5 \\
\hline 9Cr-2VWTa-2Ni & Unirrad. & -113 & & 10.8 \\
& 400 & 21 & 133 & $\mathrm{n} / \mathrm{m}$ \\
\hline
\end{tabular}

Table 7. Tensile properties of steels in HFIR-CTR-62/63 experiment [10].

\begin{tabular}{lcccccc}
\hline Steel & Irrad. Temp. Test Temp. & \multicolumn{2}{c}{ Strength $(\mathrm{MPa})$} & \multicolumn{2}{c}{ Elongation (\%) } \\
& $\left({ }^{\circ} \mathrm{C}\right)$ & $\left({ }^{\circ} \mathrm{C}\right)$ & Yield & Tensile & Uniform & Total \\
\hline 9Cr-2VWTa & Unirrad. & 400 & 715 & 817 & 1.6 & 4.5 \\
& 400 & 400 & 963 & 983 & 0.6 & 5.8 \\
\hline \multirow{2}{*}{$9 \mathrm{Cr}-2 \mathrm{VWTa}-2 \mathrm{Ni}$} & Unirrad. & 400 & 733 & 824 & 1.6 & 4.3 \\
& 400 & 400 & 1034 & 1075 & 0.6 & 5.7 \\
\hline
\end{tabular}




\section{ACKNOWLEDGMENTS}

The authors would like to thank Messrs. J.W. Jones and J.J. Duff for technical support. Particular thanks go to Mr. L.T. Gibson for the preparation of TEM specimens for microstructural examination. This research was supported in part by an appointment to the Oak Ridge National Laboratory Postdoctoral Research Associates Program administered jointly by the Oak Ridge Institute for Science and Education and Oak Ridge National Laboratory.

\section{REFERENCES}

1. R.L. Klueh, K. Ehrlich, and F Abe, J. Nucl. Mater. 191-194 (1992) 116.

2. L.R. Greenwood and C.A. Baldwin, "Neutron Dosimetry and Damage Calculations for the HFIR-CTR-62 and 63 Irradiations", Fusion Reactor Materials Semiannual Report for Period Ending June 30, 1999, DOE/ER-0313/26, 1999, p. 199.

3. K.E. Lenox, R.L. Klueh, and R.L. Senn, "Continuing Irradiation of Ferritic Steels: Experiments HFIR-CTR-62 and -63", Fusion Reactor Materials Semiannual Report for Period Ending March 31, 1995, DOE/ER-0313/18, 1995, p. 7.

4. N. Yoshida, et al., J. Nucl. Mater. 155-157 (1988) 1232.

5. D.S. Gelles, Annual Progress Report for Fusion Year, (1991), 348.

6. E.A. Little and L.P. Stoter, Effects of Radiation on Materials: 11th Conf., ASTM STP-782 (American Society for Testing and Materials, Philadelphia, 1982) p. 207.

7. P.J. Maziasz, R.L. Klueh and J.M. Vitek, J. Nucl. Mater. 141-143 (1986) 929.

8. P.J. Maziasz and R.L. Klueh, Effects of Radiation on Materials: 14th Conf., ASTM STP-1046 (American Society for Testing and Materials, Philadelphia, 1989) p. 35.

९. P.J. Maziasz, J. Nucl. Mater. 169 (1989) 95-115.

10. R.L. Klueh, M.A. Sokolov, K. Shiba, Y. Miwa and J.P. Robertson, J. Nucl. Mater. to be published. 
INVESTIGATION OF THE MICROSTRUCTURE OF FRACTURE SPECIMENS FROM FIVE DIFFERENT PLATES OF THE 500 KG PROGRAM HEAT OF V4CR-4TI. -- E.G. Donahue, G.R. Odette, G.E. Lucas (University of California, Santa Barbara)

\section{OBJECTIVE}

The objective of this study was to determine and compare microstructures of five plates of $\mathrm{V}-4 \mathrm{Cr}-4 \mathrm{Ti}$ that have been used to obtain fracture toughness and tensile data in a program to develop fracture assessment methods.

\section{SUMMARY}

Four of the five plates of $\mathrm{V}-4 \mathrm{Cr}-4 \mathrm{Ti}$ had similar microstructures. They exhibited banding of Ti-OCN particles, which were distributed in planar arrays parallel to the rolling plane. The grain sizes were reduced in the vicinity of the particles. The plates differed in the size reduction of these grains and the thickness and spacing of the bands. The fifth plate had a more uniform distribution of Ti-OCN particles and no evidence of bands of reduced-size grains. The microstructures are considered in relation to fracture behavior.

\section{PROGRESS AND STATUS}

\section{Introduction}

We have undertaken an effort to understand the mechanisms of fracture in vanadiumbased alloys and to develop fracture assessment methods for structures comprised of vanadium alloys $[1,2]$. As part of this effort, we have been testing unirradiated and irradiated fracture specimens of $\mathrm{V}-4 \mathrm{Cr}-4 \mathrm{Ti}$ alloys [1-4]. However, the specimens have been fabricated from various plates produced from the $500 \mathrm{~kg}$ program heat of $\mathrm{V}-4 \mathrm{Cr}$ $4 \mathrm{Ti}$, and differences in fracture behavior have been found between various batches of specimens made from the different plates. This is believed to be due to microstructural differences. An inhomogeneous distribution of titanium-oxycarbonitrides (Ti-OCN) often forms in the solid solution matrix of $\mathrm{V}-\mathrm{Cr}$-Ti alloys during thermo-mechanical processing $[5,6]$ The formation of these precipitates can be significant since they have been shown to influence the fracture behavior of $\mathrm{V}-\mathrm{Cr}$-Ti alloys by removing interstitial elements from the matrix [7]. Therefore, in order to compare fracture data from different plates of this heat of $\mathrm{V}-4 \mathrm{Cr}-4 \mathrm{Ti}$, it is necessary to know what, if any, differences exist in the microstructure and distribution of precipitates exist.

While some microstructural investigations have been conducted on this heat at ORNL [5], there has been no comprehensive metallographic study of all the fabrication products of this heat. Hence, we have undertaken an effort to augment the existing microstructural data, and work to date is presented here. 


\section{Experiment}

Material from fracture specimens machined from plates of the $500 \mathrm{~kg}$ program heat of V4Cr-4Ti was used to investigate the microstructural differences among the plates. The plates were M150, Q250, Q150, V250, and V150, as identified by Oak Ridge National Laboratory (ORNL) [5]. Table 1 summarizes the relationship between ORNL and Argonne National Laboratory (ANL) identification codes and the final plate thicknesses. The plates were all prepared by Teledyne Wah Chang, Albany (TWCA) from parent stock of plate V250, which was fabricated by warm rolling a rectangular extrusion in the extrusion direction to $6.35 \mathrm{~mm}$, with intermediate $1050^{\circ} \mathrm{C} / 2 \mathrm{~h}$ vacuum anneals. The subsequent steps in producing the other plates are shown in Schematic 1. All of the anneals shown in Schematic 1 were performed at TWCA. Subsequent to plate fabrication, 1/3-sized Charpy V-notch (MCVN) and compact tension (CT) specimens were machined from the plates, and the specimens were then vacuum annealed at ORNL for $2 \mathrm{~h}$ at $1000^{\circ} \mathrm{C}$. For all plates this was done to remove any hydrogen picked up during machining. For plates V150 and Q150 this also served as a recrystallization anneal following the previous warm roll.

Samples of material from each plate were derived from the broken halves of the MCVN specimens following testing. Samples were mounted for metallography in each of three orientations: view plane parallel to the rolled surface (LT), view plane orthogonal to the rolling direction (TS), and view plane orthogonal to the transverse direction (LS), as described in ASTM-E3 [8]. Sample orientations are illustrated in Figure.1. Mounted samples were ground and polished through $0.05 \mu \mathrm{m}$ alumina and etched using a solution of $10 \% \mathrm{HF}, 30 \% \mathrm{HNO}_{3}$, and $60 \% \mathrm{H}_{2} \mathrm{O}$ applied to the samples with a cotton swab for four minutes. An optical metallograph was used to inspect the etched surfaces for grain boundaries and inclusion distribution patterns. Samples were also inspected with a JEOL $6300 \mathrm{~F}$ scanning electron microscope (SEM).

Table 1. Summary of the plate identification codes and thicknesses.

\begin{tabular}{ccc}
\hline ORNL I.D. & ANL I.D. & Thickness (mm) \\
\hline V250 & Plate D & 6.4 \\
Q250 & Plate A, Ann. & 6.4 \\
Q150 & - & 3.8 \\
M150 & Plate A & 3.8 \\
V150 & Plate DD & 3.8 \\
\hline
\end{tabular}




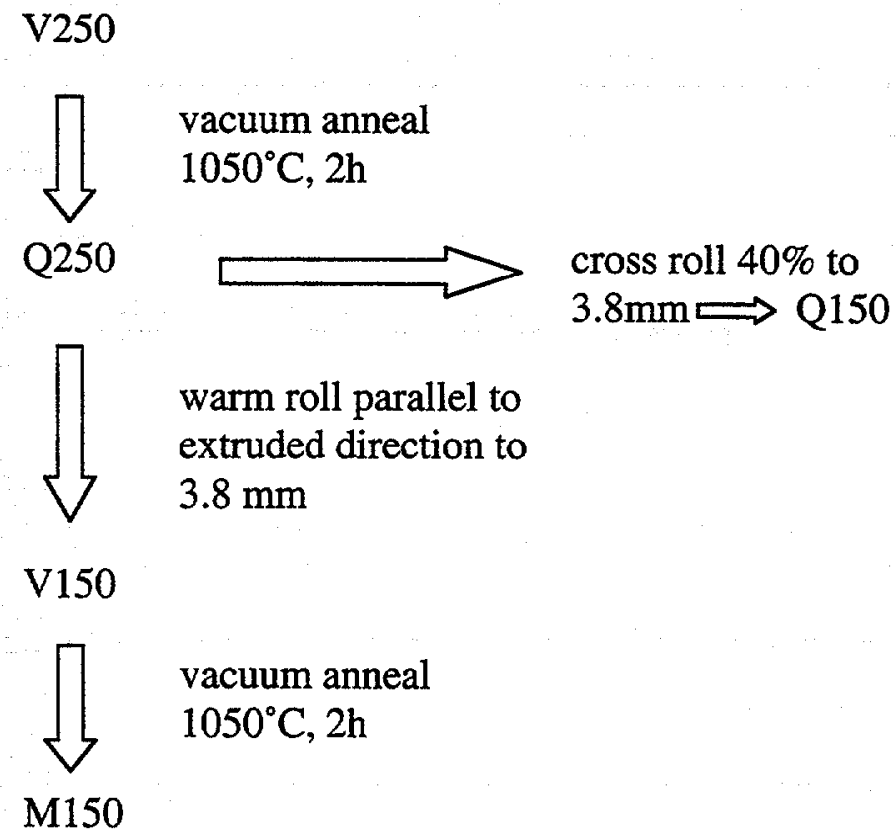

Schematic 1. Processing histories for plates

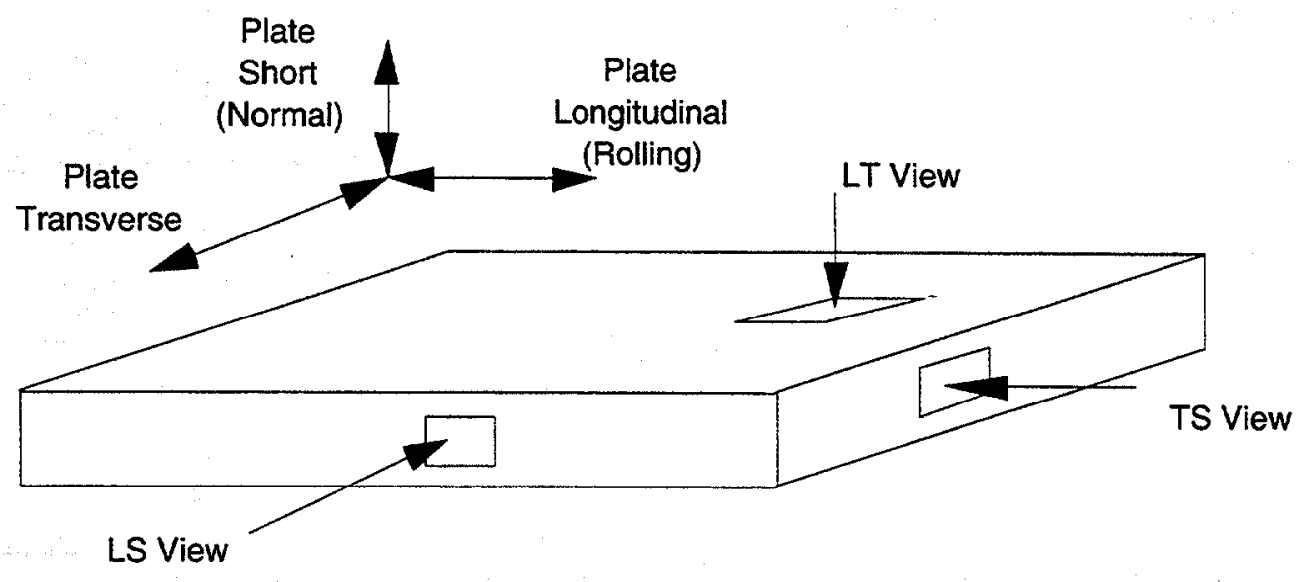

Figure 1. Diagram of the plate directions and views used in metallography. 


\section{$\underline{\text { Results }}$}

Figure 2 shows the optical micrographs of the etched samples from V250 in each of the three orientations at low- and higher- magnification. The LT view ( $a$ and $b$ ) of the V250 sample shows generally uniform grain sizes of $25-50 \mu \mathrm{m}$ in diameter. The TS (c and d) and LS ( $e$ and $f$ ) views are characterized by bands of particles throughout the thickness of the plate. The particles are presumed to be Ti-OCN precipitates. The bands are typically $25-100 \mu \mathrm{m}$ thick and extend as roughly planar arrays parallel to the rolling plane. Within the particle-rich regions grains are smaller resulting in a bimodal grain-size distribution of alternating coarse- and fine-grained regions through the plate thickness. Grain sizes in the banded, finer grain regions are typically $10-20 \mu \mathrm{m}$ in diameter; grains in the coarse regions are typically $25-50 \mu \mathrm{m}$ in diameter. The bands of finer grains are typically $20-30 \mu \mathrm{m}$ thick and $75-100 \mu \mathrm{m}$ apart.

Figure 3 shows the LT ( $a$ and b), TS ( $c$ and d), and LS (e and $f$ ) views of the Q250 plate. The Q250 plate has a microstructure very similar to that of V250. The LT view shows uniform grain sizes of $\sim 25 \mu \mathrm{m}$ diameter. The LS and TS views show the banding and the associated course $(25-50 \mu \mathrm{m}$ diameter) and fine $(10-20 \mu \mathrm{m}$ diameter $)$ grain regions. The bands of finer grains are typically $25-50 \mu \mathrm{m}$ thick and $100-125 \mu \mathrm{m}$ apart. The banding appears to be somewhat more severe, and the bands thicker than in the V250 plate.

Figure $4 \mathrm{a}$ and $\mathrm{b}$ show the LT view of Q150 material at low- and higher-magnification; in this view the grains are uniform in size, $-25 \mu \mathrm{m}$ diameter, similar to V250 and Q250. There are also particle-rich bands in this plate, as shown in Figure 4 in the TS (c and d) and LS (e and $f$ ) views. However, there is less severe banding and reduction of grain sizes associated with the banded Ti-OCN particle distribution than in Q250. The bands of finer grains are typically thin, $\sim 25 \mu \mathrm{m}$, compared to the Q250 plate; and they are $\sim 50 \mu \mathrm{m}$ apart.

Figure 5 shows the optical micrographs of the etched samples from M150 in each of the three orientations at low- and higher-magnification. The LT view (a and b) of the M150 sample shows generally uniform grain sizes of $25-50 \mu \mathrm{m}$ in diameter. The TS (c and d) and LS (e and $f$ ) views are characterized by bands of particles typically $25-100 \mu \mathrm{m}$ throughout the thickness of the plate. Grain sizes in the banded, finer grain regions are typically $10-20 \mu \mathrm{m}$ in diameter; grains in the coarse regions are typically $25-50 \mu \mathrm{m}$ in diameter. The bands of finer grains are typically $50-100 \mu \mathrm{m}$ thick and $100-125 \mu \mathrm{m}$ apart. The structure is quite similar to that observed in Q250.

Figure 6 shows optical micrographs of V150. As in the other plates, in the LT view (6 and $b)$ the grains are uniform in size $(\sim 25 \mu \mathrm{m}$ diameter). However, unlike the other plates, V150 does not exhibit the well-defined banding in the TS (6 c and d) or LS (6 e and f) views, but similar and relatively uniform grain sizes. 
a)

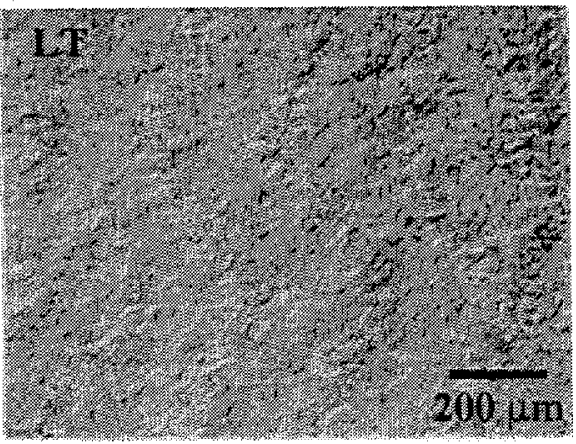

c)

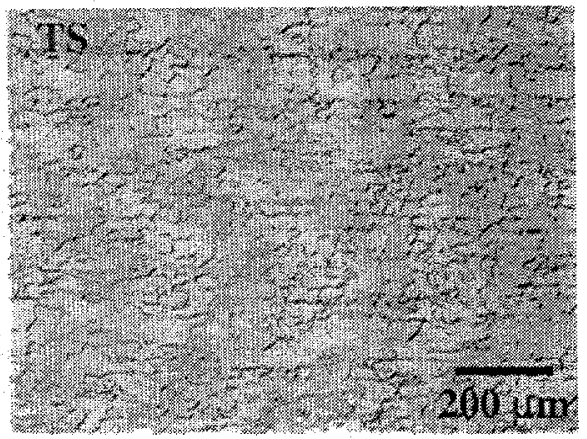

e)

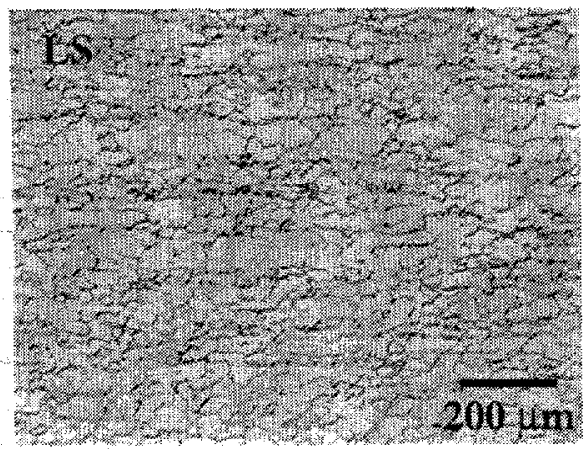

b)

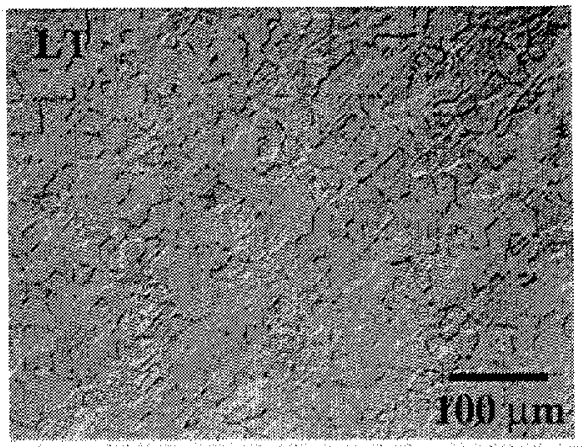

d)

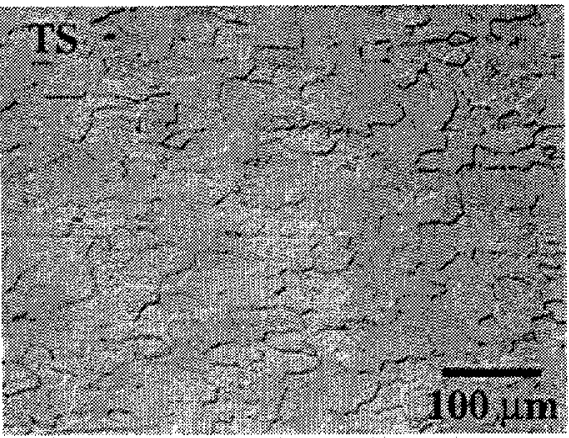

f)

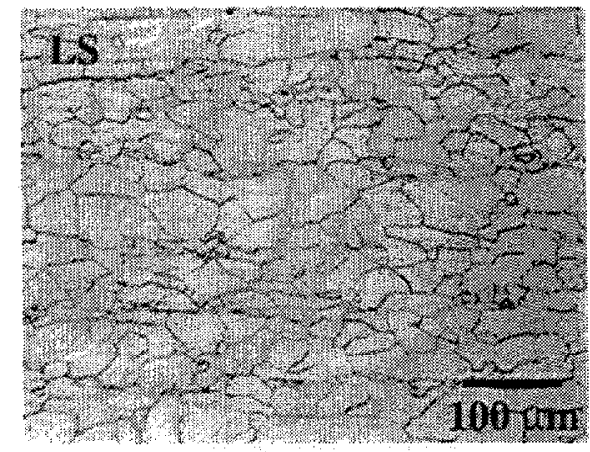

Figure 2. Low- and higher-magnification optical micrographs of V250. The LT view (a and b) shows uniform grain sizes while the TS (c, d) and LS $(e, f)$ views show a banded grain size distribution associated with a non-uniform, banded distribution of particles. 
a)

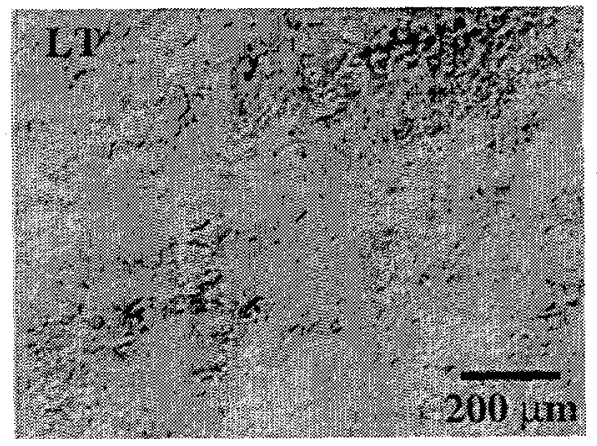

c)

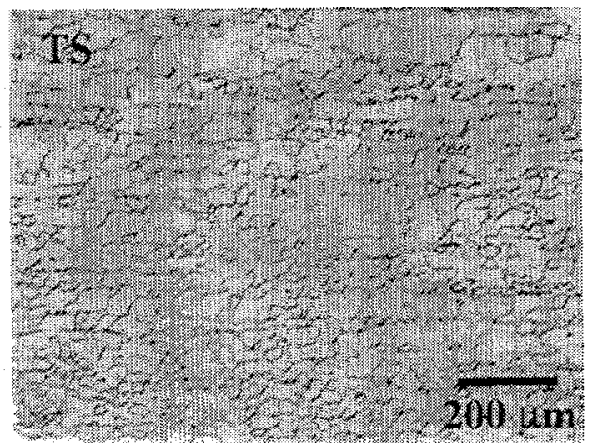

e)

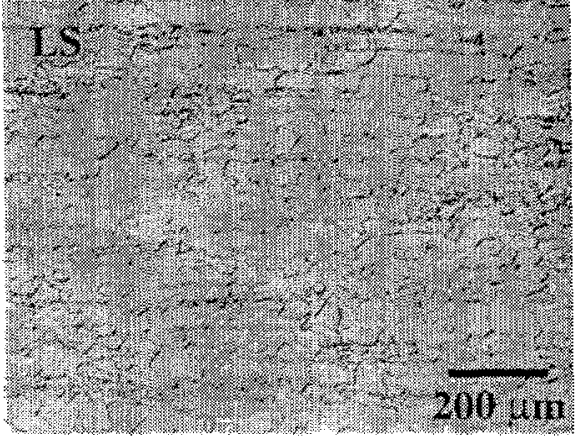

b)

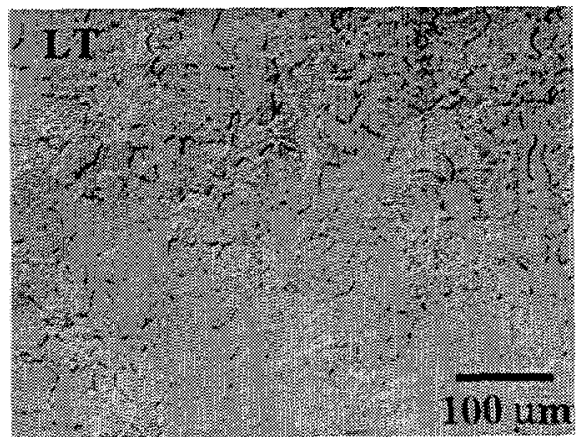

d)

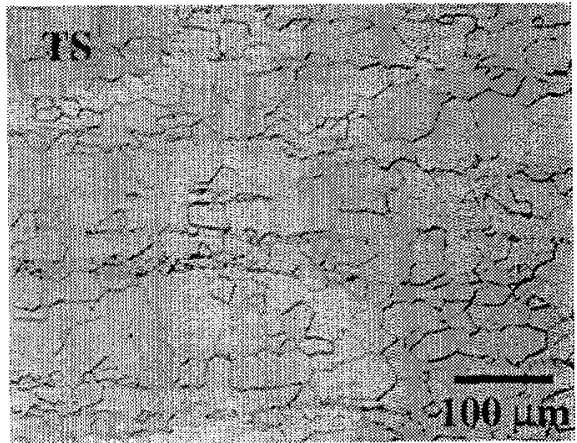

f)

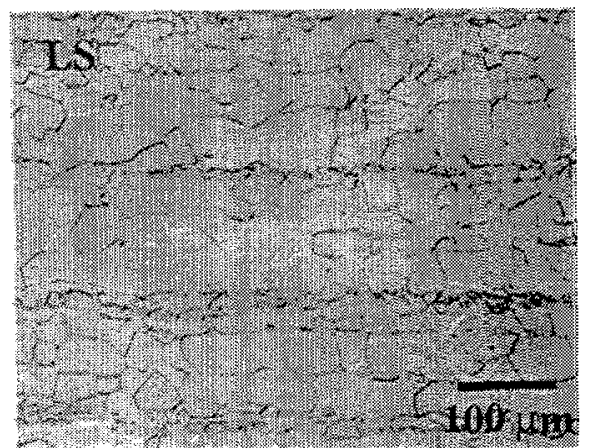

Figure 3. Low- and higher-magnification optical micrographs of Q250. The LT view ( $a$ and $b$ ) shows uniform grain sizes while the TS (c, d) and LS $(e, f)$ views show a banded grain size distribution associated with a non-uniform, banded distribution of particles, similar to that in V250, but slightly more severe. 
a)

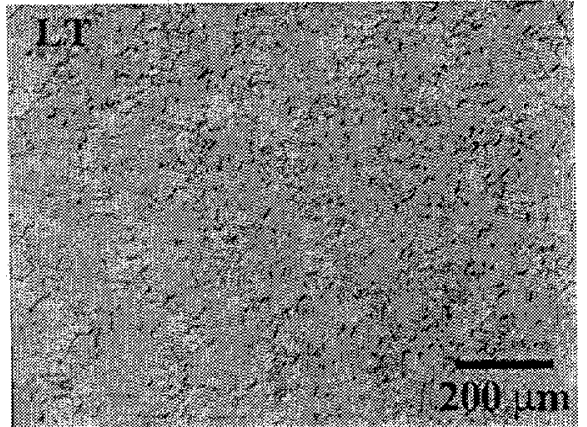

c)

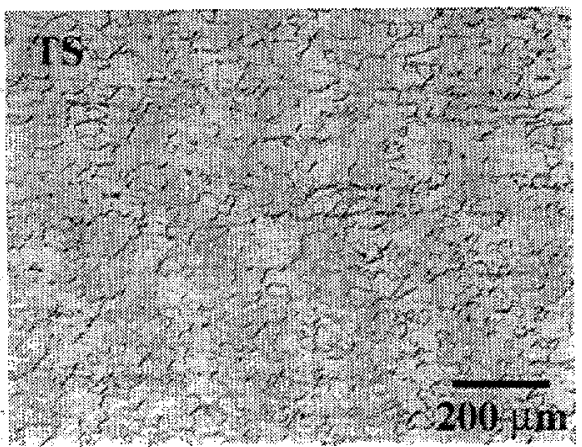

e)

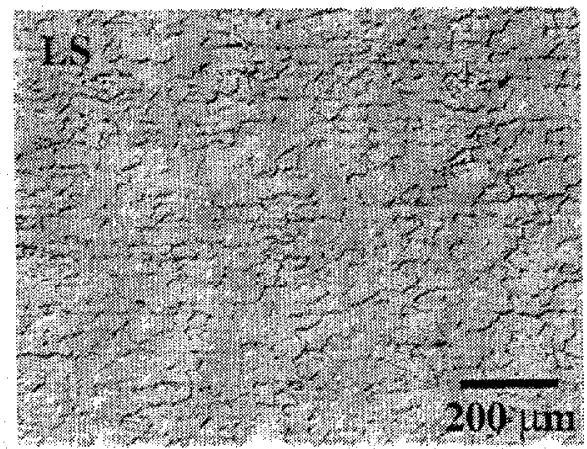

b)

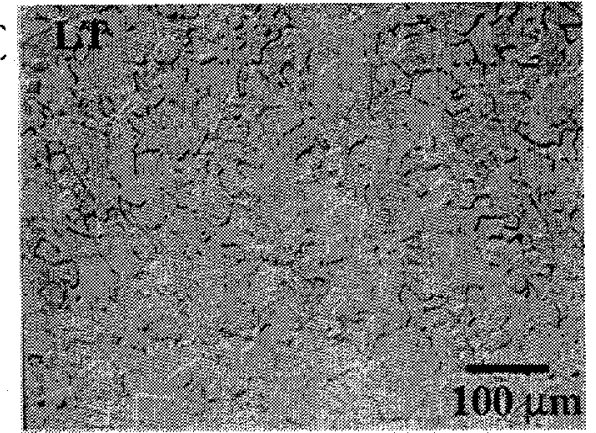

d)

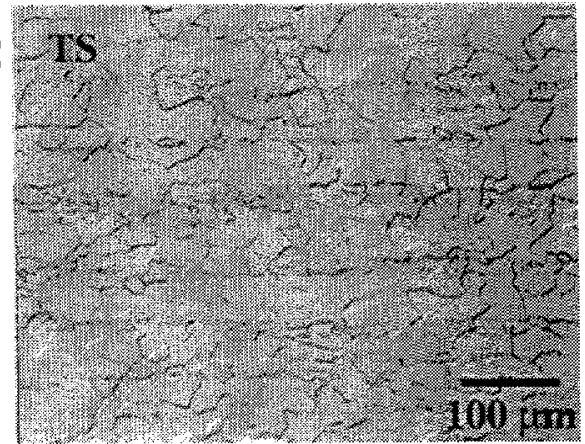

f)

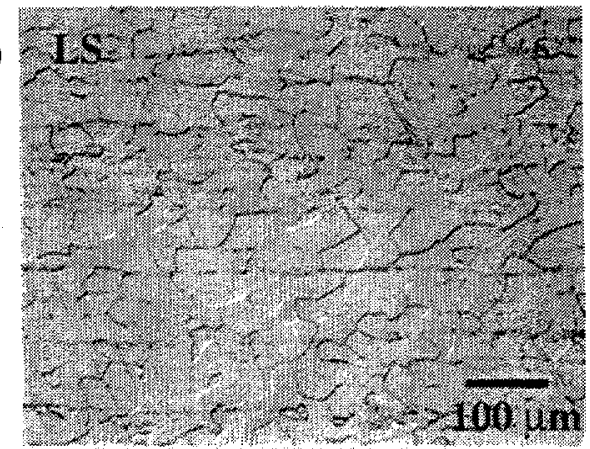

Figure 4. Low- and higher-magnification optical micrographs of Q150. The LT view ( $a$ and $b$ ) shows homogeneous grain size distribution while the TS (c and d) and LS (e and f) views show banding of Ti-OCN particles, but a much less pronounced reduction of grain sizes in the bands than seen in $\mathrm{Q} 250$. 
a)

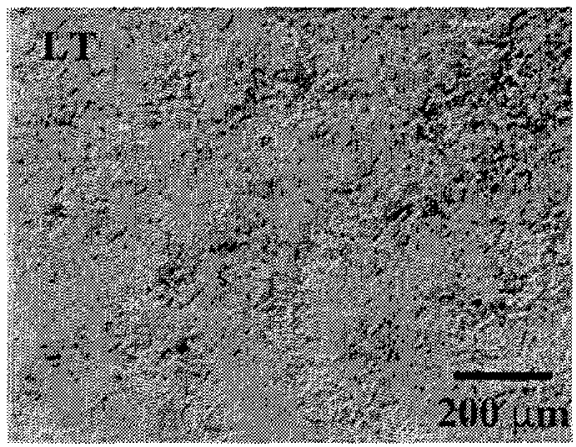

c)

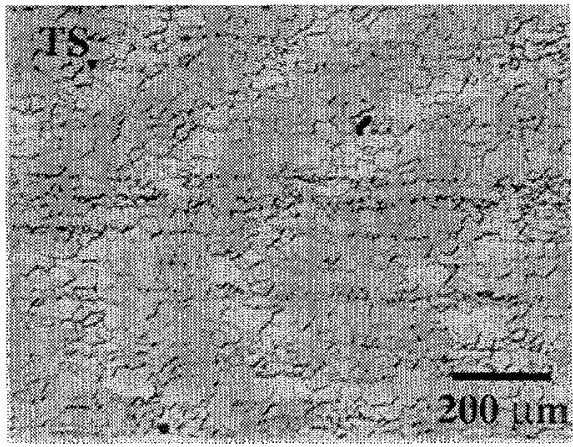

e)

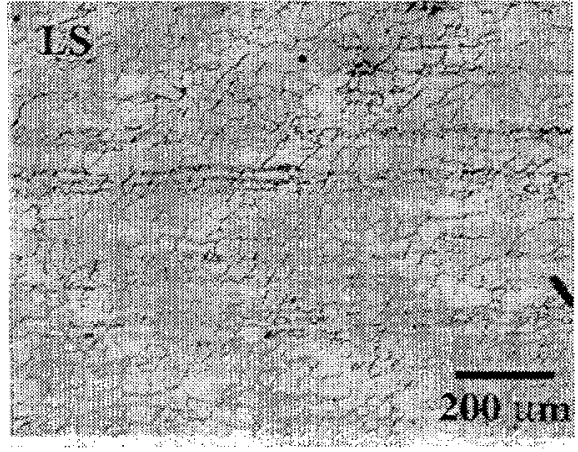

b)

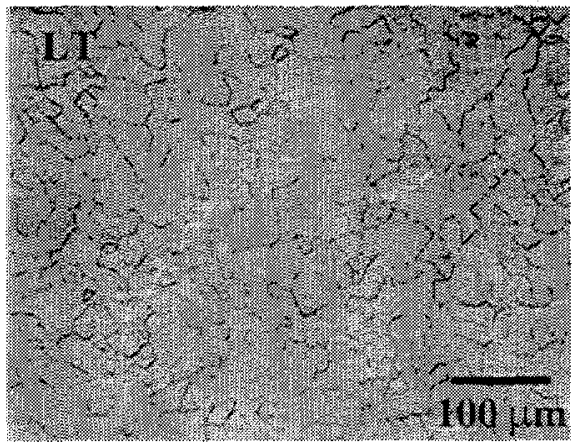

d)

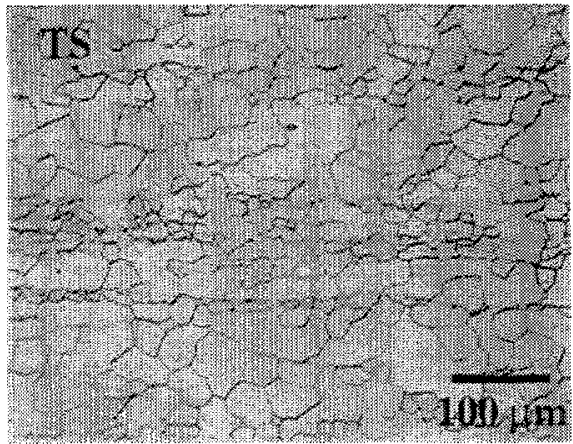

f)

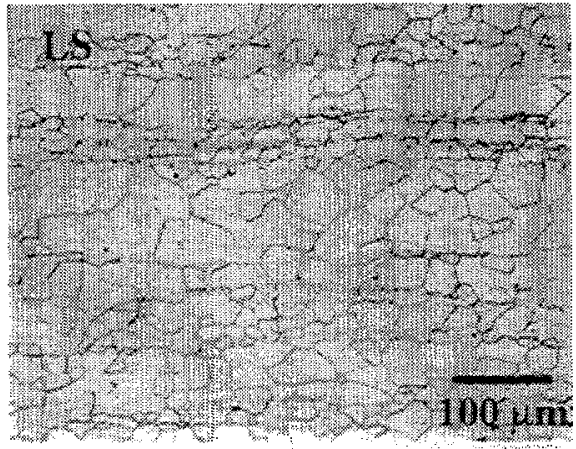

Figure 5. Low- and higher-magnification optical micrographs of M150. The LT view (a, b) shows uniform grain sizes while the TS (c, d) and LS $(e, f)$ views show a banded grain size distribution associated with a nonuniform, banded distribution of particles. The banding is more severe than in Q150, and is similar to that seen in Q250. 
a)

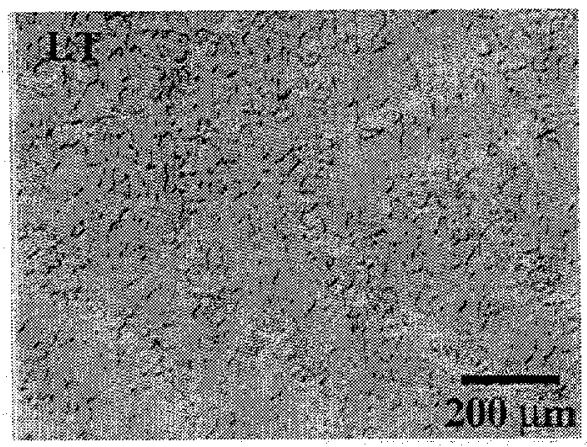

c)

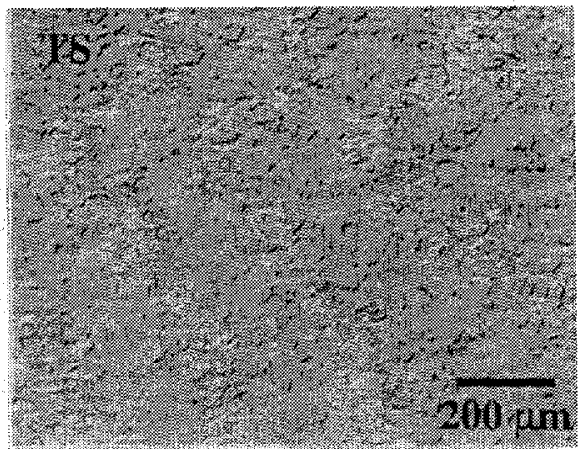

e)

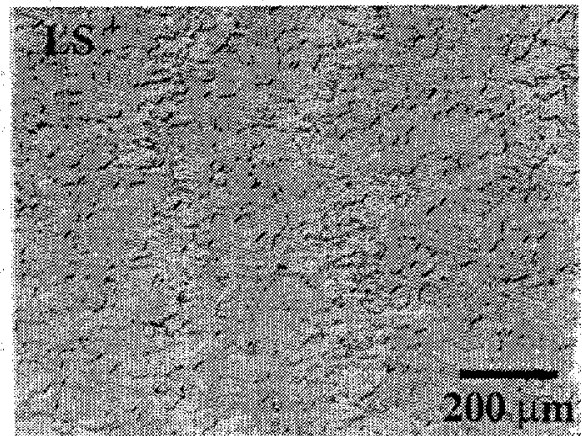

b)

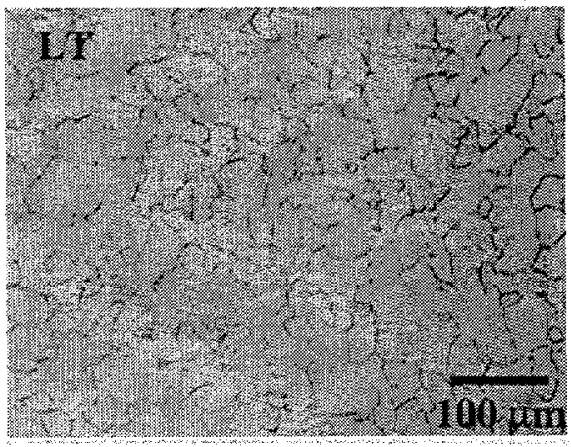

d)

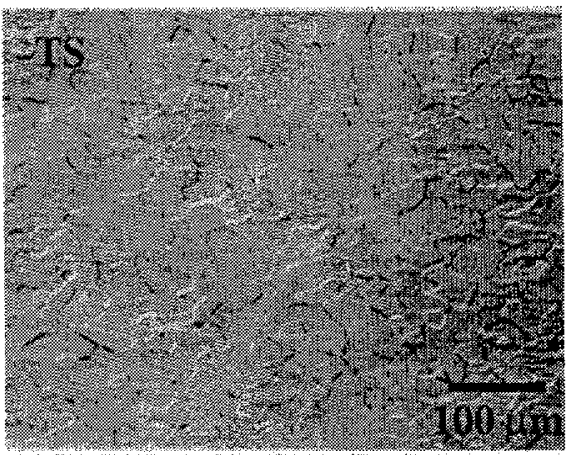

f)

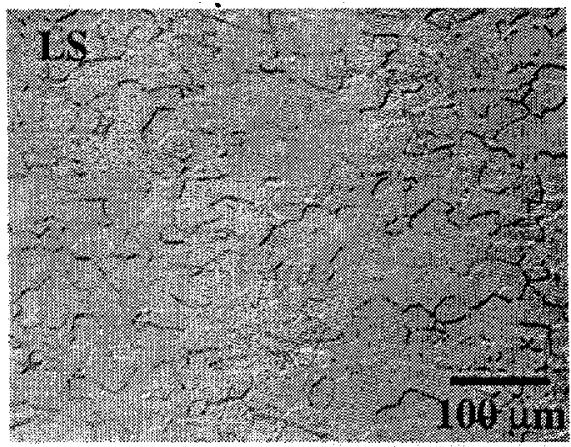

Figure 6. Low- and higher-magnification optical micrographs of V150. The LT view $(a, b)$ shows a homogeneous grain size distribution, as in the other four plates. However, the TS ( $c$ and $d$ ) and LS (e and f) views show a much more uniform distribution of Ti-OCN particles and, consequently, a much more uniform grain size distribution than in the other plates. 


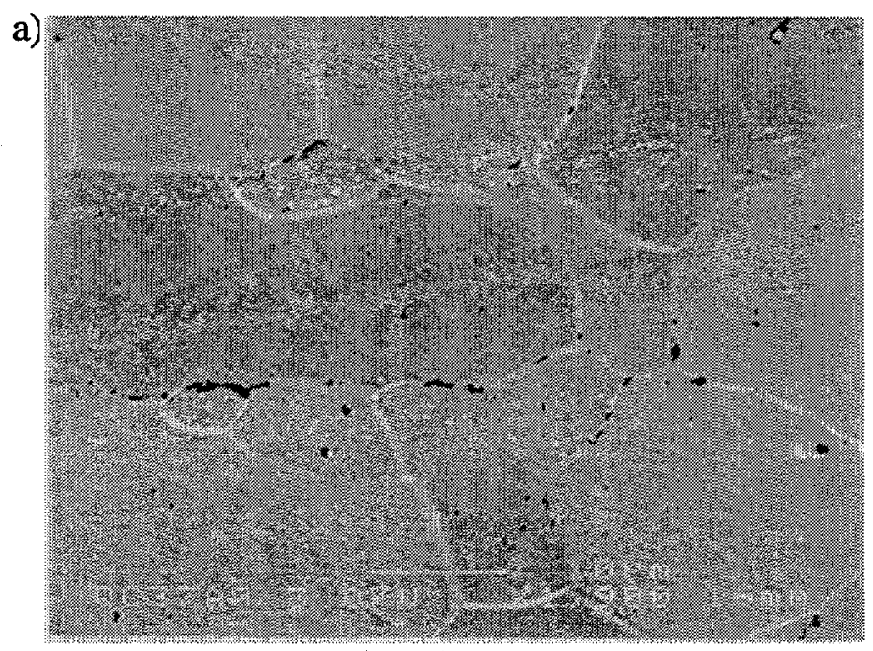

b)

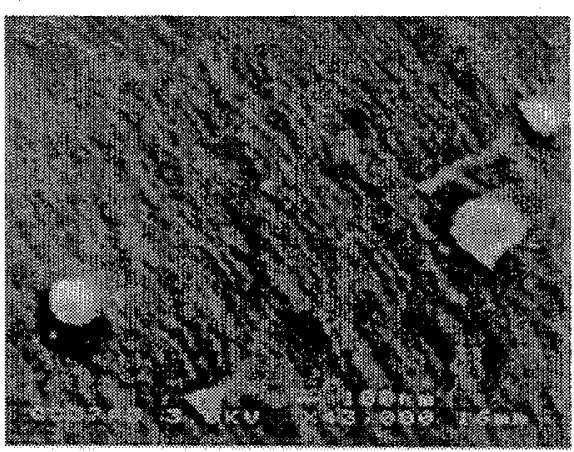

c)

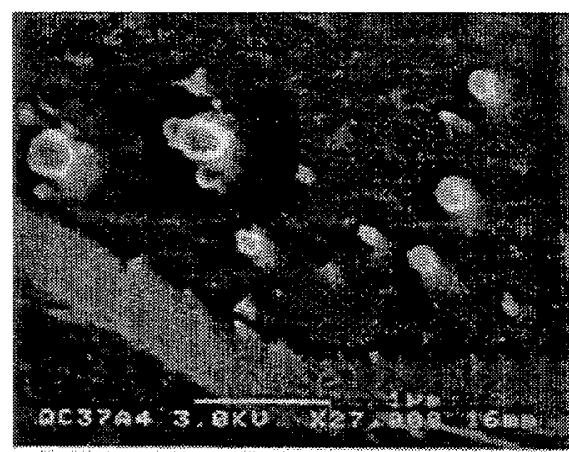

Figure 7. SEM micrographs of the LT view of Q250 showing: a) a region of small grains in the vicinity of Ti-OCN particles which are in a band from left to right: b) and c) high magnification micrographs of representative particles in this region.

SEM micrographs of the TS view of a representative sample from plate Q250 are presented in Figure 7. Figure 7 a shows a region of small grains in the vicinity of the particles, and higher magnification images of the Ti-OCN particles are shown in Figure 7 b and c. The Ti-OCN particles range in size from -0.1 to $0.3 \mu \mathrm{m}$. The structure and content of these particles was analyzed by Hoelzer at ORNL, who determined that they are based on the fcc TiC phase with $\mathrm{O}$ and $\mathrm{N}$ in solid solution.

\section{Discussion}

A summary of metallography results is given in Table 2. Metallography on plates Q250, $\mathrm{Q} 150$, and $\mathrm{M} 150$ has been reported previously [5], and the results are in general agreement with the findings here. All plates had similar bulk, equiaxed grain sizes in the range $25-50 \mu \mathrm{m}$, but differed in the extent of banding and the size and number of the 
small grains in the bands. Plates V250 and Q250 had similar processing histories and microstructures. The extra high-temperature anneal at $1050^{\circ} \mathrm{C}$ for $2 \mathrm{~h}$ for $\mathrm{Q} 250$ appeared to have little affect on the microstructure. The additional cross roll given to plate Q150 appeared to decrease the band spacing and thickness. However, the additional reduction given to plate M150 (compared to plate Q250) appeared to have little effect on the band spacing; and indeed, the band thickness appeared to be somewhat larger. Finally, the microstructure of V150 was quite different than M150, even though both plates received the same reduction and M150 received an additional vacuum anneal after specimen fabrication.

Table 2. Summary of metallography results.

\begin{tabular}{|c|c|c|c|c|c|}
\hline \multirow{2}{*}{$\begin{array}{l}\text { Plate } \\
\text { I.D. }\end{array}$} & \multirow{2}{*}{$\begin{array}{l}\text { Degree of } \\
\text { Banding }\end{array}$} & \multicolumn{2}{|c|}{ Grain Diameters $(\mu \mathrm{m})$} & \multirow{2}{*}{$\begin{array}{c}\text { Band Spacing } \\
(\mu \mathrm{m})\end{array}$} & \multirow{2}{*}{$\begin{array}{c}\text { Band Thickness } \\
(\mu \mathrm{m})\end{array}$} \\
\hline & & Bulk & Band & & \\
\hline $\mathrm{V} 250$ & Moderate & $25-50$ & $10-20$ & $75-100$ & $0-25$ \\
\hline Q250 & Moderate & $25-50$ & $10-20$ & $100-125$ & $25-50$ \\
\hline Q150 & Slight & $25-50$ & $10-20$ & 50 & 25 \\
\hline M150 & Severe & $25-50$ & $10-20$ & $100-125$ & $50-100$ \\
\hline $\mathrm{V} 150$ & None & $25-50$ & - & $\therefore-$ & - \\
\hline
\end{tabular}

It has been previously suggested that the Ti-OCN precipitates during extrusion when the temperature falls below $1125^{\circ} \mathrm{C}$; and because of temperature variation throughout the extrusion, the precipitates are inhomogeneously distributed throughout the extrusion [5]. The precipitate clusters appear to flatten in the rolling plane during warm rolling. Intermediate anneals after warm rolling result in recrystallization; but the precipitates do not dissolve, and their presence hinders grain growth - hence the bimodal grain size distribution. The difference between V150 and M150 is probably due to this inhomogeneous distribution of Ti-OCN - plate M150 coming from a piece of the extrusion that fell below $1125^{\circ} \mathrm{C}$, and plate V150 coming from a piece that largely remained above $1125^{\circ} \mathrm{C}$. Since only limited sampling was done in this study, the degree to which these microstructures represent the entire plate is not known at this time.

Figures 8 and 9 show plots of effective toughness versus temperature obtained on several of these plates and reported previously [1-4]. Figure 8 shows effective toughnesstemperature curves for the Q250 (Figure 8a) and Q150 (Figure 8b) plates obtained from MCVN specimens with the crack plane parallel to the TS view. Hence, the planes of the bands of precipitates and small grains would lie orthogonal to the crack plane and parallel to the crack direction. Both plates exhibit fracture by cleavage pop-ins (open circles) at the lower temperatures and stable crack growth (open squares) at the higher temperatures. The transition temperature delineating this behavior is about $-160^{\circ} \mathrm{C}$ for the $\mathrm{Q} 250$ plate and about $-180^{\circ} \mathrm{C}$ for the Q150 plate. Since the banding was somewhat smaller in the Q150 plate, this may play a role in the lower transition temperature. 
a)

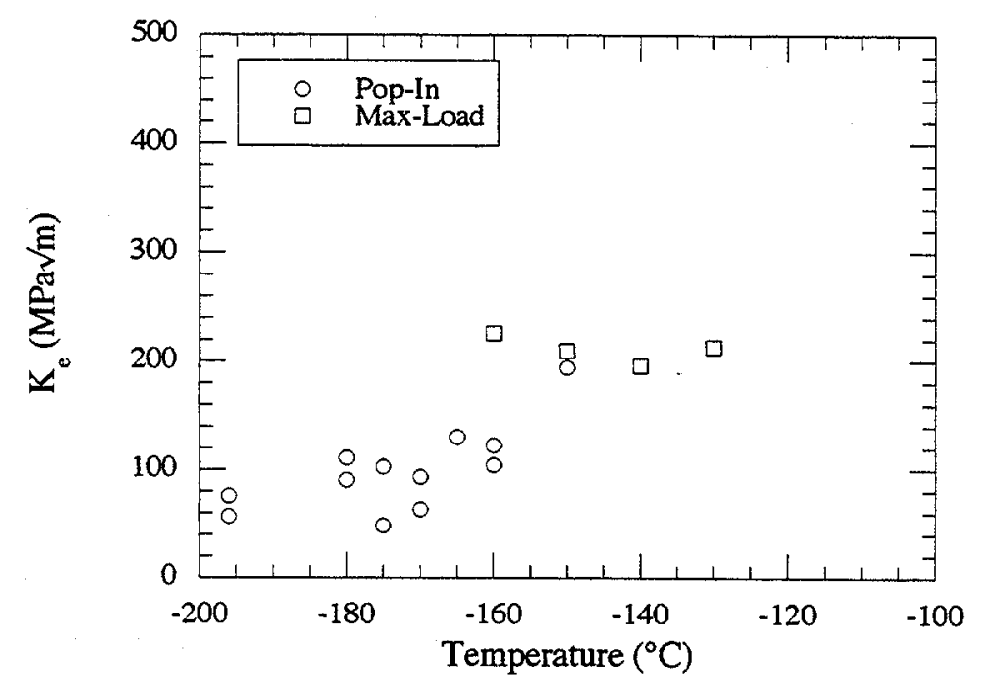

b)

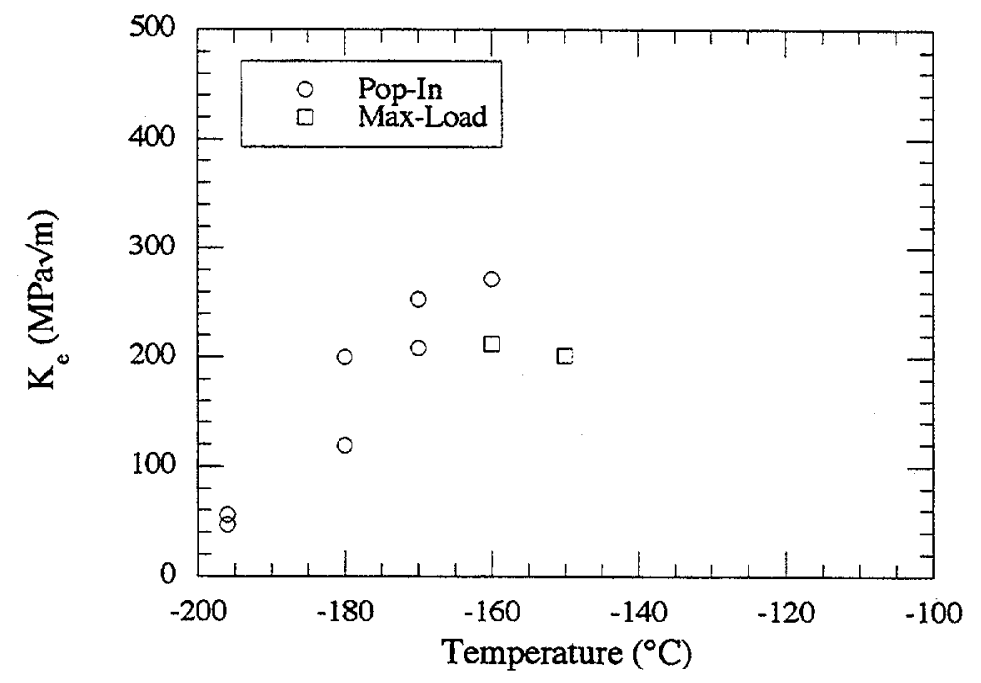

Figure 8. Effective toughness temperature curves for a) Q250 and b) Q150.

Figure 9 shows the effective toughness temperature curves for plates V250 (Figure 9a) and V150 (Figure 9b). The data for V250 were obtained from $0.26 \mathrm{~T}$ CT specimens and the data for V150 were obtained from $0.16 / 0.26 \mathrm{~T}$ CT specimens $(0.26 \mathrm{~T}$ CT in all dimensions except thickness which was $0.16 \mathrm{~T}$ ) as well as pre-cracked $0.16 \mathrm{~T} 3$-point bend specimens. In both cases, specimens were tested in two orientations: one in which the crack plane ran parallel to the TS view (LT orientation) and one in which the crack plane ran parallel to the LS view (TL orientation). In both cases, the planes of the bands of precipitates and small grains would lie orthogonal to the crack plane and parallel to the crack direction. Again the material exhibits fracture by cleavage pop-ins at lower temperatures transitioning to stable ductile fracture at the higher temperatures. For both 
a)

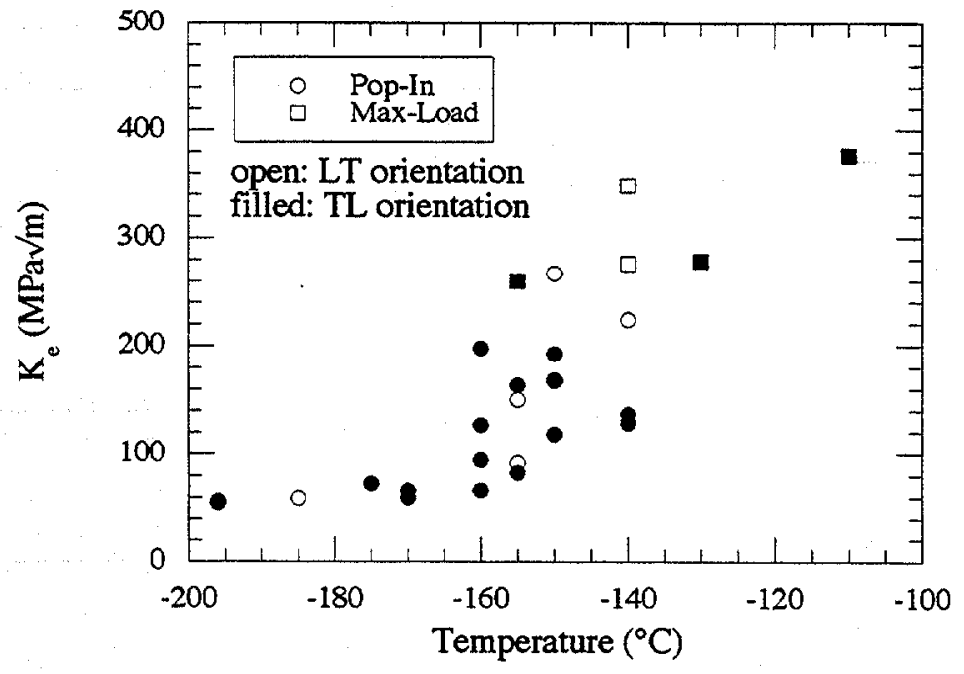

b)

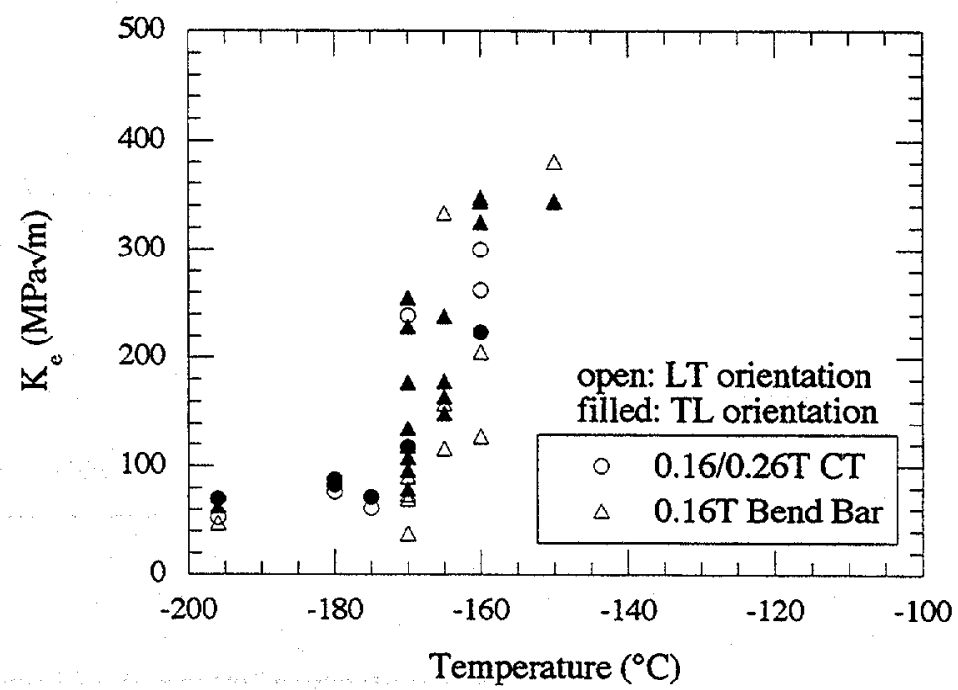

Figure 9. Effective toughness-temperature curves for a) V250 and b) V150.

$\mathrm{V} 250$ and V150 there is little effect of specimen orientation, consistent with the similar microstructures observed in the TS and LS views. For V150 there was also little difference in the data obtained for the two specimen types. The Q250 data show a transition temperature of roughly $-150^{\circ} \mathrm{C}$, while the $\mathrm{V} 150$ data show a sharper transition at about $-165^{\circ} \mathrm{C}$. Again the lower transition temperature seems to correlate with the lesser degree of banding and smaller density of visible Ti-OCN in the V150, although the thinner specimens for this data set currently confound this comparison.

Cleavage fracture in $\mathrm{V}-4 \mathrm{Cr}-4 \mathrm{Ti}$ is believed to occur by the nucleation of numerous cleavage microcracks ahead of the loaded crack, which coalesce and propagate as an unstable macrocrack when a critical area $A^{*}$ ahead of the crack is stressed above a 
critical value $\sigma^{*}[1-2]$. Cleavage microcracks can be nucleated by brittle particles, and the magnitude of $\sigma^{*}$ can scale inversely with the size of the trigger particles. Hence, a larger trigger particle density could increase the temperature for the transition from ductile to brittle cleavage fracture. This suggests that the large Ti-OCN particles may play a direct role in cleavage fracture, and hence control of these particles may improve the fracture behavior.

\section{FUTURE WORK}

Scanning electron microscopy will be performed to look for direct evidence of Ti-OCN particle affiliation with cleavage microcracking. Since only limited metallographic sampling was performed here, and since it is apparent that different plates can have significantly different microstructures, it is important that continued systematic microstructual investigations be pursued in the fusion program.

\section{REFERENCES}

1. Odette, G. R., Lucas, G. E., Donahue, E., Sheckherd, J. W., J. Nucl. Mater., 233-237 (1996) 502-506.

2. Odette, G. R., Donahue, E., Lucas, G. E., Sheckherd, J. W., Effects of Radiation on Materials: 18th International Symposium, ASTM-STP-1325, American Society for Testing and Materials (1999) 1089-1108.

3. E.G. Donahue, G.R. Odette, G.E. Lucas, Fusion Materials Semiannual Progress Report, DOE/ER-0313/27 (2000)

4. E.G. Donahue, G.R. Odette, G.E. Lucas, Journal of Nuclear Materials, in Press.

5. A. F. Rowcliffe, D. T. Hoelzer, Fusion Materials Semiannual Progress Report, DOE/ER-0313/25 (1999) 42.

6. D.T. Hoelzer, Fusion Materials Semiannual Progress Report, DOE/ER-0313/25 (1999) 59.

7. S.J. Zinkle, H. Matsui, D.L. Smith, A.F. Rowcliffe, E. van Osch, K. Abe, V.A. Kazakov, Journal of Nuclear Materials, 258-263 (1998) 205.

8. "Standard Practice for Preparation of Metallographic Specimens," ASTM E3, Annual Book of ASTM Standards vol, 3.01, (1998). 


\subsection{COPPER ALLOYS AND HIGH HEAT FLUX MATERIALS}




\section{TENSILE PROPERTIES OF HIGH-STRENGTH, HIGH-CONDUCTIVITY COPPER ALLOYS AT HIGH TEMPERATURES - S. J. Zinkle (Oak Ridge National Laboratory)}

\section{OBJECTIVE}

The objective of this report is to summarize recent tensile measurements on several different unirradiated commercial high-strength, high-conductivity copper alloys that are being considered for fusion energy applications.

\section{SUMMARY}

The unirradiated tensile properties of wrought GlidCop AL25 (ITER grade zero, IG0), solutionized and aged $\mathrm{CuCrZr}$, and wrought and aged $\mathrm{CuCrNb}$ have been measured at temperatures up to $700^{\circ} \mathrm{C}$ at strain rates between $4 \times 10^{-4} \mathrm{~s}^{-1}$ and $0.02 \mathrm{~s}^{-1}$. GlidCop Al25 exhibited rapid softening with increasing test temperature $\geq 300^{\circ} \mathrm{C}$, whereas the $\mathrm{CuCrZr}$ and $\mathrm{CuCrNb}$ precipitation hardened alloys decreased more slowly with increasing temperature. The difference in tensile behavior of the GlidCop and precipitation-hardened alloys is attributed to the small grain size in GlidCop, which allows grain boundary sliding (Coble creep) to become the dominant deformation mode at temperatures above $\sim 400^{\circ} \mathrm{C}$.

\section{PROGRESS AND STATUS}

\section{Introduction}

High-strength, high-conductivity copper alloys are being considered for first wall heat sink and divertor structural applications in the proposed International Thermonuclear Experimental Reactor (ITER), and are also under consideration for the center post magnet of spherical tokamaks [1-3]. Copper alloys under consideration for fusion energy high heat flux applications include dispersion strengthened copper $\left(\mathrm{Cu}-\mathrm{Al}_{2} \mathrm{O}_{3}\right), \mathrm{CuCrZr}$ and $\mathrm{CuNiBe}$. We have recently examined the tensile and electrical properties of a CuCrNb alloy developed by NASA [4]. Although Nb poses problems for waste disposal in fusion systems, the strategy was to determine whether any high strength, high conductivity copper ally exhibits a superior combination of conductivity and elevated temperature $\left(200-400^{\circ} \mathrm{C}\right)$ strength. A reduced activation version of the CuCrNb alloy could presumably be developed by substituting $V$ or other elements for $\mathrm{Nb}$ if favorable tensile and conductivity results were obtained.

The purpose of the present report is to summarize the completion of a series of tensile measurements performed on unirradiated specimens of copper alloys at various temperatures and strain rates. The tests were performed on as-wrought dispersion-strengthened copper, solutionized and aged $\mathrm{CuCrZr}$, and extruded and annealed CuCrNb. The results of previous tensile and electrical resistivity tests on these alloys and CuNiBe are summarized elsewhere .[4-7].

\section{Experimental Procedure}

The dispersion strengthened (DS) copper specimens were cut from a $2.5 \mathrm{~cm}$ thick plate of GlidCop Al25 DS copper produced by SCM Metal Products (now known as OMG Americas), which was fabricated according to "ITER grade 0 " [8] specifications (heat \#C-8064). This alloy contains $0.25 \mathrm{wt} \% \mathrm{Al}$ in the form of finely dispersed aluminum oxide particles. The copper cladding on the plate surface was machined off prior to specimen fabrication. The tensile axis of the specimens were oriented along the longitudinal direction of the wrought plate. The Cu-0.65\% $\mathrm{Cr}-0.10 \% \mathrm{Zr}$ specimens were obtained from a $2 \mathrm{~cm}$ thick plate that was originally fabricated under the trade name of Elbrodur G by KM-Kabelmetal, Osnabrück, Germany as an F37 (cold-worked and aged) temper, heat \#AN4946. A $2 \times 3 \times 5 \mathrm{~cm}$ piece from this plate was solution annealed in flowing argon for 1 hour at $980^{\circ} \mathrm{C}$, water quenched, then aged in flowing helium at $475^{\circ} \mathrm{C}$ for 2 hours (furnace 
cool) at ORNL, in accordance with ITER heat treatment specifications for $\mathrm{CuCrZr}$. The nominal $\mathrm{Cu}$ $8 a t . \% \mathrm{Cr}-4$ at.\% Nb alloy was extruded at NASA-Lewis (heat NHB920396) and then exposed to a simulated brazing cycle of $925^{\circ} \mathrm{C}$ for $1 \mathrm{~h}$. A chemical analysis of this heat indicated the composition was $6.3 w t . \% \mathrm{Cr}, 5.75 \mathrm{wt} \% \mathrm{Nb}$ with $267 \mathrm{wt}$. ppm oxygen. Type SS3 sheet tensile specimens in both longitudinal and transverse orientations were machined from the $0.71 \times 2.8 \times$ $10.7 \mathrm{~cm}$ strip. Miniature SS-3 sheet tensile specimens with nominal gage dimensions $0.76 \mathrm{~mm} x$ $1.5 \mathrm{~mm} \times 7.6 \mathrm{~mm}$ were electro-discharge machined from the bulk heat treated sheets and tested without any subsequent heat treatment.

The tensile properties of the SS-3 sheet tensile specimens were determined at temperatures between 150 and $700^{\circ} \mathrm{C}$ at crosshead speeds ranging from 0.0016 to $0.17 \mathrm{~mm} / \mathrm{s}$, which corresponds to initial strain rates of $2.1 \times 10^{-4}$ to $0.022 \mathrm{~s}^{-1}$ in the gage region. The tensile tests were performed in vacuum $\left(10^{-6}\right.$ to $10^{-5}$ torr). The specimens were held at the test temperature for 0.25 h prior to the start of each tensile test. A single specimen was tested in an Instron servohydraulic machine for each experimental condition. The tensile properties were determined from graphical analysis of the load versus crosshead displacement curves, which were recorded as both digital data and as chart recorder graphs. A plastic deformation offset of $0.2 \%$ was used for measuring the yield strength.

\section{Results and Discussion}

Table 1 summarizes the results of the room temperature electrical resistivity and ultimate strength measurements performed at ORNL on GlidCop Al25, CuCrZr, CuNiBe and CuCrNb, which have been previously reported [4-7]. Recent resistivity results obtained on 48 pure copper (JohnsonMatthey Puratronic) SS-3 tensile specimens are also included in this table. The relation 17.241 $\mathrm{n} \Omega-\mathrm{m}=100 \%$ IACS (international annealed copper standard) was used to convert the resistivity measurements to normalized conductivity values. GlidCop Al25 exhibited the highest conductivity, followed by $\mathrm{CuCrZr}$, CuCrNb and CuNiBe. The room temperature ultimate tensile strength was highest for $\mathrm{CuNiBe}(700-800 \mathrm{MPa})$, with values of $\sim 400 \mathrm{MPa}$ obtained for the remaining three types of alloys.

The tensile properties obtained in the present study are summarized in Table 2. Figure 1 compares the ultimate tensile strength of the 4 different copper alloys as a function of test temperature, and Figure 2 shows the corresponding uniform elongation results. All of the data in these two plots were obtained at an initial strain rate of 1.1 to $2.2 \times 10^{-3} \mathrm{~s}^{-1}$. The $\mathrm{CuCrZr}, \mathrm{CuCrNb}$ and GlidCop Al25 alloys exhibited similar temperature dependence in their strengths over the temperature range of $20-700^{\circ} \mathrm{C}$, whereas both the AT and $\mathrm{HT} 1$ CuNiBe heats had much higher strengths (by about a factor of two). The strengths of CuCrZr and CuCrNb determined from these short-term tensile tests were higher than that of GlidCop Al25 at temperatures $>300^{\circ} \mathrm{C}$. The strength of GlidCop dropped off more rapidly with increasing test temperature than any of the other alloys. Similar temperature-dependent tensile behavior has been reported by other investigators $[9,10]$. The tensile strength of GlidCop also exhibited a strong strain rate sensitivity at elevated temperatures compared to $\mathrm{CuCrZr}$ and CuCrNb. For example, the yield strength of GlidCop at $600^{\circ} \mathrm{C}$ decreased by a factor of two as the strain rate was decreased from $0.022 \mathrm{~s}^{-1}$ to $2.1 \times 10^{-4} \mathrm{~s}^{-1}$. In contrast, the yield strength of $\mathrm{CuCrNb}$ decreased by less than $50 \%$ over the same range of test conditions.

All of the materials tested exhibited good ductility at temperatures up to $200^{\circ} \mathrm{C}$. However, the behavior at temperatures above $200^{\circ} \mathrm{C}$ was significantly different for each of the different alloys. The uniform elongation at a strain rate of 1 to $2 \times 10^{-3} \mathrm{~s}^{-1}$ of $\mathrm{CuCrZr}$ varied from 10 to $15 \%$ over the entire investigated temperature range $\left(20-700^{\circ} \mathrm{C}\right)$. The uniform elongation of CuCrNb decreased gradually with increasing temperature, falling below $5 \%$ at a test temperature of $700^{\circ} \mathrm{C}$. In contrast, the uniform elongations of GlidCop and both CuNiBe heats decreased strongly with increasing test temperature above $200^{\circ} \mathrm{C}$. The uniform elongation of GlidCop Al25 decreased from $-13 \%$ at room temperature to $\sim 2 \%$ at $400^{\circ} \mathrm{C}$, and then increased with increasing test temperature. The GlidCop Al25 total elongation remained high at all temperatures, with values between 25 and 
Table 1. Summary of Cu alloy room temperature ultimate tensile strength (UTS) and electrical conductivities measured at ORNL [4-7]. The tensile data were obtained at $1-2 \times 10^{-3} \mathrm{~s}^{-1}$.

\begin{tabular}{|l|c|c|c|}
\hline Alloy & $\begin{array}{c}\text { UTS at } 20^{\circ} \mathrm{C} \\
(\mathrm{MPa})\end{array}$ & $\begin{array}{c}\text { Resistivity } \\
\text { at } 20^{\circ} \mathrm{C}\end{array}$ & $\begin{array}{c}\text { Electrical } \\
\text { conductivity }\end{array}$ \\
\hline Copper (99.999\% J-M Puratronic) & -- & $17.19 \mathrm{n} \Omega-\mathrm{m}$ & $100.3 \%$ IACS \\
\hline GlidCop Al25 (IG0) & 410 & $19.12 \mathrm{n} \Omega-\mathrm{m}$ & $90 \%$ IACS \\
\hline Kabelmetal CuCrZr, heat AN4946 & & & \\
\hline ITER solution quenched \& aged & 414 & $20.67 \mathrm{n} \Omega-\mathrm{m}$ & $83 \%$ IACS \\
\hline Zollern CuCrZr, heat Z822 & & & \\
\hline solution quenched \& aged & 418 & $22.55 \mathrm{n} \Omega-\mathrm{m}$ & $76 \%$ IACS \\
\hline solution quenched & 243 & $48.29 \mathrm{n} \Omega-\mathrm{m}$ & $36 \%$ IACS \\
\hline HIP furnace cool & - & $25.41 \mathrm{n} \Omega-\mathrm{m}$ & $68 \%$ IACS \\
\hline HIP furnace cool \& aged & 217 & $24.94 \mathrm{n} \Omega-\mathrm{m}$ & $69 \%$ IACS \\
\hline HIP fast cool & 216 & $39.57 \mathrm{n} \Omega-\mathrm{m}$ & $44 \%$ IACS \\
\hline HIP fast cool \& aged & 328 & $25.91 \mathrm{n} \Omega-\mathrm{m}$ & $66 \%$ IACS \\
\hline Hycon 3HP CuNiBe & & & \\
\hline heat \#46546, sol'n quenched \& aged (AT2) & 723 & $26.78 \mathrm{n} \Omega-\mathrm{m}$ & $64 \%$ IACS \\
\hline heat \#33667, cold worked \& aged (HT1) & 810 & $26.27 \mathrm{n} \Omega-\mathrm{m}$ & $66 \%$ IACS \\
\hline heat \#46546, cold worked \& aged (HT2) & 695 & $24.05 \mathrm{n} \Omega-\mathrm{m}$ & $72 \%$ IACS \\
\hline heat 28626, solution quenched \& aged (AT3) & - & $25.62 \mathrm{n} \Omega-\mathrm{m}$ & $67 \%$ IACS \\
\hline heat 28626, cold-worked \& aged (HT3) & - & $25.45 \mathrm{n} \Omega-\mathrm{m}$ & $68 \%$ IACS \\
\hline heat 35562, cold-worked \& aged (HT4) & - & $25.41 \mathrm{n} \Omega-m$ & $68 \%$ IACS \\
\hline CuCrNb (longitudinal and transverse) & 392 & $23.55 \mathrm{n} \Omega-\mathrm{m}$ & $73 \%$ IACS \\
\hline
\end{tabular}

* the AT2 plate was prepared by subsequent heat treating of the cold-worked and aged HT2 (heat \#46546) plate.

Table 2. Summary of tensile data from the present study.

\begin{tabular}{|c|c|c|c|c|c|}
\hline & Temperature & $\sigma_{\mathrm{Y}}$ (MPa) & UTS (MPa) & $e_{\mathrm{u}}(\%)$ & $e_{\text {tot }}(\%)$ \\
\hline GlidCop Al25 (IGO) & & & & & \\
\hline $2.1 \times 10^{-4} \mathrm{~s}^{-1}$ & $400^{\circ} \mathrm{C}$ & 152 & 172 & 1.2 & 34.2 \\
& $600^{\circ} \mathrm{C}$ & 48 & 66 & 13.6 & 28.5 \\
\hline & $400^{\circ} \mathrm{C}$ & 173 & 182 & 1.3 & 20.3 \\
$1.1 \times 10^{-3} \mathrm{~s}^{-1}$ & $600^{\circ} \mathrm{C}$ & 67 & 74 & 3.7 & 19.5 \\
& $700^{\circ} \mathrm{C}$ & 53 & 63 & 7.6 & 15.2 \\
\hline $0.022 \mathrm{~s}^{-1}$ & $600^{\circ} \mathrm{C}$ & 102 & 121 & 2.1 & 29.2 \\
\hline CuCrZr (ITER SAA) & & & & & \\
\hline $2.1 \times 10^{-4} \mathrm{~s}^{-1}$ & $150^{\circ} \mathrm{C}$ & 291 & 372 & 13.9 & 22.4 \\
\hline & $400^{\circ} \mathrm{C}$ & 228 & 266 & 9.2 & 17.9 \\
& $600^{\circ} \mathrm{C}$ & 132 & 155 & 11.3 & 33.0 \\
& $700^{\circ} \mathrm{C}$ & 77 & 88 & 14.0 & 40.3 \\
\hline CuCrNb (longitudinal) & & & & & \\
\hline $2.1 \times 10^{-4} \mathrm{~s}^{-1}$ & $600^{\circ} \mathrm{C}$ & 99 & 133 & 4.8 & 30.9 \\
\hline $1.1 \times 10^{-3} \mathrm{~s}^{-1}$ & $700^{\circ} \mathrm{C}$ & 48 & 72 & 5.1 & 38.1 \\
\hline $0.022 \mathrm{~s}^{-1}$ & $600^{\circ} \mathrm{C}$ & 122 & 151 & 6.0 & 36.7 \\
\hline & $700^{\circ} \mathrm{C}$ & 71 & 99 & 3.7 & 45.2 \\
\hline CuCrNb (transverse) & $600^{\circ} \mathrm{C}$ & 127 & 178 & 11.2 & 32.3 \\
\hline & & & & & \\
\hline $2.1 \times 10^{-4} \mathrm{~s}^{-1}$ & $300^{\circ} \mathrm{C}$ & 180 & 228 & 9.9 & 18.0 \\
& $600^{\circ} \mathrm{C}$ & 82 & 114 & 3.3 & 33.7 \\
\hline $1.1 \times 10^{-3} \mathrm{~s}^{-1}$ & $700^{\circ} \mathrm{C}$ & 52 & 74 & 4.2 & 26.0 \\
\hline & $600^{\circ} \mathrm{C}$ & 106 & 138 & 6.4 & 30.0 \\
\hline
\end{tabular}




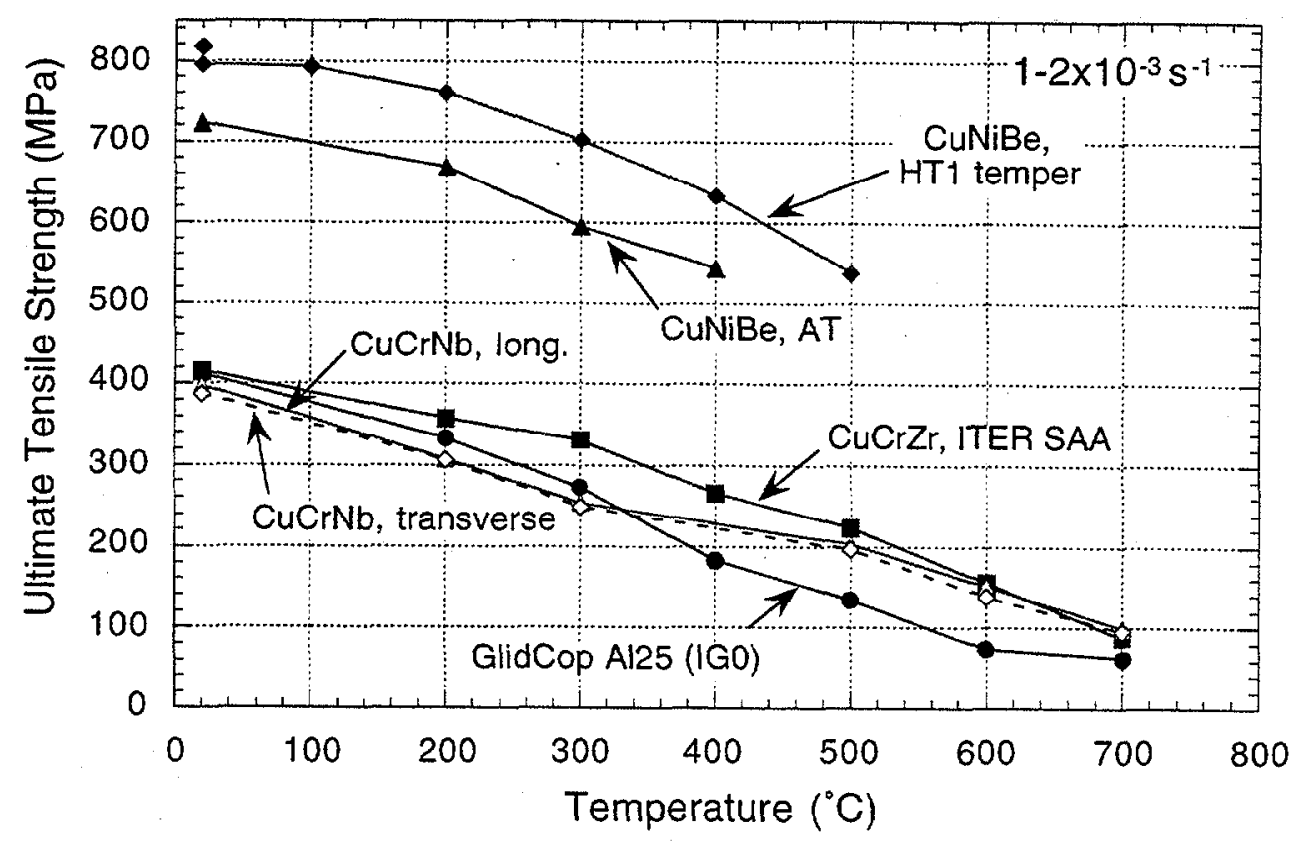

Fig. 1. Comparison of the temperature-dependent ultimate tensile strengths of the four highstrength, high-conductivity copper alloys.

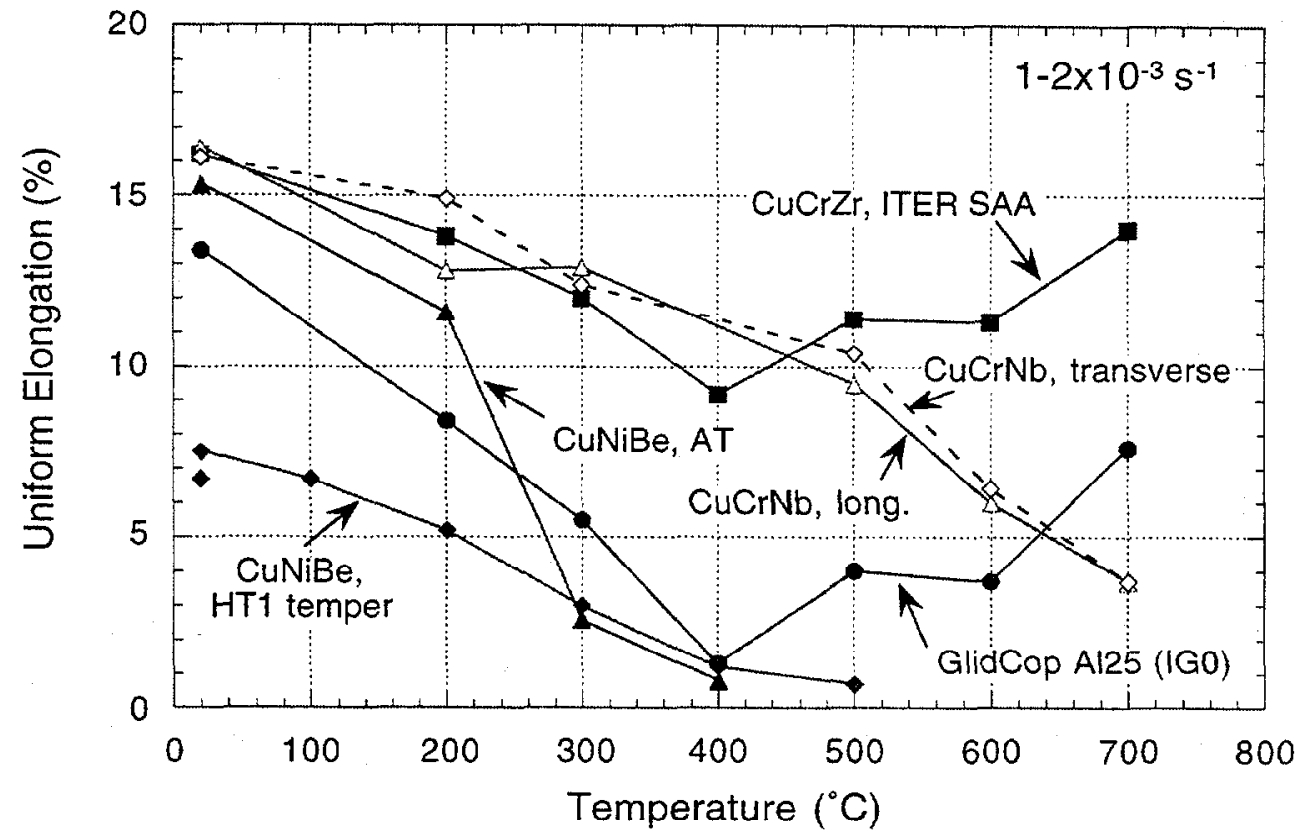

Fig. 2. Comparison of the temperature-dependent uniform elongations of the four high-strength, high-conductivity copper alloys. 
$45 \%$ at temperatures of $300-700^{\circ} \mathrm{C}$ (Table 2 and refs. [5,6]). The GlidCop elongation data indicate that necking (localized deformation) occurred at lower deformation levels with increasing test temperature, but high ductility was present in the necked region at all temperatures. The most severe elevated temperature embrittlement behavior occurred in the CuNiBe alloys, where the uniform elongation was reduced to $<5 \%$ at a temperature of $-250^{\circ} \mathrm{C}$ [5-7]. The decrease in uniform elongation in the CuNiBe alloys at elevated temperatures was accompanied by a pronounced decrease in the total elongation as well. Scanning electron microscopy of the CuNiBe fracture surfaces showed a transition from ductile transgranular failure at room temperature to intergranular failure (with localized ductile deformation) at elevated temperatures [5].

Analysis of the temperature-dependent strengths indicates that a distinct change in slope occurs in all of the $\mathrm{Cu}$ alloys at a temperature of $\sim 300^{\circ} \mathrm{C}$, which corresponds to a homologous temperature of $0.42 T_{M}$ where $T_{M}$ is the melting temperature. According to an Ashby map analysis of the deformation mechanisms (S. Zinkle and G.E. Lucas, to be published), the decrease is strength at temperatures above $300^{\circ} \mathrm{C}$ is due to thermal creep occurring during the tensile testing. Several different creep mechanisms were predicted to be dominant in the different copper alloys. The fine grain size in GlidCop enabled grain boundary sliding (Coble creep) to be the dominant deformation mode in this alloy at temperatures above $\sim 400^{\circ} \mathrm{C}$. In $\mathrm{CuCrZr}$ and CuCrNb, the calculated dominant deformation mechanism was dislocation creep (power law creep).

\section{Acknowledgements}

The GlidCop Al25 plate for this study was provided by D.J. Edwards, Pacific Northwesl National Lab. The CuCrNb sheet and CuCrZr plate were supplied by K. Slattery, Boeing. The author thanks R.G. Sitterson for performing the tensile tests.

\section{References}

1. S.J. Zinkle and S.A. Fabritsiev, Atomic and Plasma-Material Interaction Data for Fusion (supplement to Nuclear Fusion) 5 (1994) 163.

2. S.A. Fabritsiev, S.J. Zinkle and B.N. Singh, J. Nucl. Mater. 233-237 (1996) 127.

3. G.M. Kalinin and R. Matera, J. Nucl. Mater. 258-263 (1998) 345.

4. S.J. Zinkle and W.S. Eatherly, in Fusion Materials Semiannual Progress Report for Period ending June 30, 1998, DOE/ER-0313/24 (Oak Ridge National Lab, 1998) p. 189.

5. S.J. Zinkle and W.S. Eatherly, in Fusion Materials Semiannual Progress Report for Period ending June 30, 1996, DOE/ER-0313/20 (Oak Ridge National Lab, 1996) p. 207.

6. S.J. Zinkle and W.S. Eatherly, in Fusion Materials Semiannual Progress Report for Period ending Dec. 31, 1996, DOE/ER-0313/21 (Oak Ridge National Lab, 1996) p. 165.

7. S.J. Zinkle and W.S. Eatherly, in Fusion Materials Semiannual Progress Report for Period ending June 30, 1997, DOE/ER-0313/22 (Oak Ridge National Lab, 1997) p. 143.

8. R.R. Solomon, J.D. Troxell and A.V. Nadkarni, J. Nucl. Mater. $233-237$ (1996) 542.

9. D.J. Edwards, in Fusion Materials Semiannual Progress Report for Period ending Dec. 31 , 1997, DOE/ER-0313/23 (Oak Ridge National Lab, 1997) p. 213.

10. D.J. Edwards, S.J. Zinkle, S.A. Fabritsiev and A.S. Pokrovsky, in Fusion Materials Semiannual Progress Report for Period ending June 30, 1998, DOE/ER-0313/24 (Oak Ridge National Lab, 1998) p. 193. 
OVERAGING OF OUTOKUMPU CUCRZR - D.J. Edwards (Pacific Northwest National Laboratory)* and B.N. Singh (Risø National Laboratory)

\section{OBJECTIVE}

The objective of this work is to study the effect of overaging on the microstructure of CuCrZr, its effects on mechanical properties, and how it affects performance under neutron irradiation.

\section{SUMMARY}

Aging at $850^{\circ} \mathrm{C}$ for 4 hours essentially removed the fine-scale precipitates produced during the prime aging treatment. Aging at $700^{\circ} \mathrm{C}$ lead to large scale coarsening that produced denuded zones along grain and twin boundaries, grain boundary precipitates, and removed all of the fine-scale defects to produce precipitates $20 \mathrm{~nm}$ in size or larger. Aging at $600^{\circ} \mathrm{C}$ lead to somewhat similar microstructure compared to the $700^{\circ} \mathrm{C}$ aged specimens, however the average size of the precipitates was not quite as large and the density appears to be somewhat higher. Denuded zones formed along all boundaries, but the grain boundary precipitation was not as extensive as in the case of the specimens aged at $700^{\circ} \mathrm{C}$. Further characterization will be conducted to determine the identity and chemistry of the precipitates observed in the aged microstructures.

\section{PROGRESS AND STATUS}

\section{introduction}

Over the past 6 years a series of studies [1-5] have been conducted exploring the effects of neutron irradiation on pure copper and various copper alloys, most notably the precipitation strengthened $\mathrm{CuCrZr}$ and CuNiBe alloys and the ODS alloy GlidCop $\mathrm{Cu}-\mathrm{Al}_{2} \mathrm{O}_{3}$. . Depending on the irradiation and operating conditions, each of these alloys has problems that limit their current applicability for service in advanced fusion power system designs. From a fracture toughness perspective, $\mathrm{CuCr} \mathrm{Cr}$ is an alloy that may possess potential since it retains a greater fraction of its fracture toughness at elevated temperatures and after irradiation. Seppo et. al. [6] found the room temperature fracture toughness of unirradiated Outokumpu CuCrZr to be more than double that of the GlidCop Al25 and CuNiBe alloys $\left(220 \mathrm{~kJ} / \mathrm{m}^{2}\right.$ vs $80-100 \mathrm{~kJ} / \mathrm{m}^{2}$ ), and at temperatures in the range of $200-350^{\circ} \mathrm{C}$ the toughness still remains at roughly $80 \%$ of the ambient values. Neutron irradiation to 0.3 dpa over the same temperature range produces some degradation in toughness, but even at $350^{\circ} \mathrm{C}$, the toughness of the irradiated $\mathrm{CuCrZr}$ is near $100 \mathrm{~kJ} / \mathrm{m}^{2}$, whereas for both the GlidCop and CuNiBe it is near zero. The latter two materials begin to exhibit intergranular failure at temperatures above $250^{\circ} \mathrm{C}$, whereas the $\mathrm{CuCrZr}$ alloy fails in a ductile manner.

The one limitation to the CuCrZr alloy is that in the absence of cold working, it is difficult to heat treat the alloy to produce the same levels of strength as compared to the other two alloys. Under irradiation, however, the $\mathrm{CuCrZr}$ hardens dramatically when irradiated below $250^{\circ} \mathrm{C}$, but this hardening is accompanied by loss of uniform ductility and work hardening and can produce a tensile instability in the most extreme case. Given the fracture toughness behavior, this tensile behavior does not appear to be important since the toughness remains reasonably high, and may be related to the fact that despite the hardening and loss of uniform ductility, it exhibits good reduction in area and ductile failure at elevated

\footnotetext{
"Pacific Northwest National Laboratory (PNNL) is operated for the U.S. Department of
} Energy by Battelle Memorial Institute under contract DE-AC06-76RLO-1830. 
temperatures and after irradiation. One final point is that precipitate stability can be an issue when the irradiation temperature exceeds $280^{\circ} \mathrm{C}$, which can lead to loss of strength, and at high enough temperatures, the material begins to swell from void formation. The CuNiBe alloy also suffers from this problem. The ODS GlidCop by comparison exhibits excellent stability with respect to the microstructure and appears to be swelling resistant even when irradiated at $430^{\circ} \mathrm{C}$ to doses as high as $150 \mathrm{dpa}$ [7].

The CuCrZr alioy will likely be joined to other materials depending on its application since it may not possess the strength to be a standalone structural material. Therefore it is wise to consider the potential effect of heat treatments that may produce less than optimum properties and see how these different microstructural states affect the performance under irradiation. In this report, we describe a set of heat treatments given to CuCrZr and briefly describe the microstructure. These materials will be tested in the near future in the unirradiated condition and will be placed in an irradiation experiment in the DR-3 reactor at Risø in Denmark.

\section{Experimental}

Tensile specimens fabricated from Outokumpu CuCrZr (produced by Outokumpu Oy) were given four separate heat treatments to study the effect of overaging on the microstructure and mechanical properties. The heat treatments are listed below in Table 1. All heat treatments were done in vacuum $\left(<10^{-4}\right.$ torr). The microstructure was examined by transmission electron microscopy using a JEOL 2000FX.

TABLE 1 Heat treatments used to study overaging in Outokumpu $\mathrm{CuCrZr}$

\begin{tabular}{|c|}
\hline Prime Aged: Solution annealed at $960^{\circ} \mathrm{C} / 3 \mathrm{hrs} / \mathrm{WQ}+$ aged $460^{\circ} \mathrm{C} / 3 \mathrm{hrs} / \mathrm{WQ}$ \\
\hline $850^{\circ} \mathrm{C}$ treatment: $\mathrm{PA}+850^{\circ} \mathrm{C} / 4 \mathrm{hrs} / \mathrm{WQ}$ \\
\hline $700^{\circ} \mathrm{C}$ treatment: $\mathrm{PA}+700^{\circ} \mathrm{C} / 4 \mathrm{hrs} / \mathrm{WQ}$ \\
\hline $600^{\circ} \mathrm{C}$ treatment: $\mathrm{PA}+600^{\circ} \mathrm{C} / 4 \mathrm{hrs} / \mathrm{WQ}$ \\
\hline
\end{tabular}

Results

Prime aging (Figure 1)

The microstructure of this condition is comprised of a high density of small precipitates that appear similar to those measured in earlier studies $[1,3,4]$. Though the precipitate reactions that occur in $\mathrm{CuCrZr}$ are not clearly understood, it appears that at least two types of small precipitates are formed during the prime aging treatment, and larger precipitates of a much lower density. Small Gunier-Preston zones (G-P) are present that exhibit a lobe-lobe appearance with a line of no contrast perpendicular to the operating $(200) \mathrm{Cu}$ reflection, an appearance known to occur for very small, coherent spherical particles. There were other precipitates present in the microstructure that differed from the G-P zones in both size and appearance. These precipitates tended to exhibit Moiré fringes when imaged using a $\mathrm{g}$ $=200 \mathrm{Cu}$ reflection, however, not all precipitates were clearly visible. These fringed precipitates are thought to be incoherent Cr-rich precipitates because of the lack of any strain 


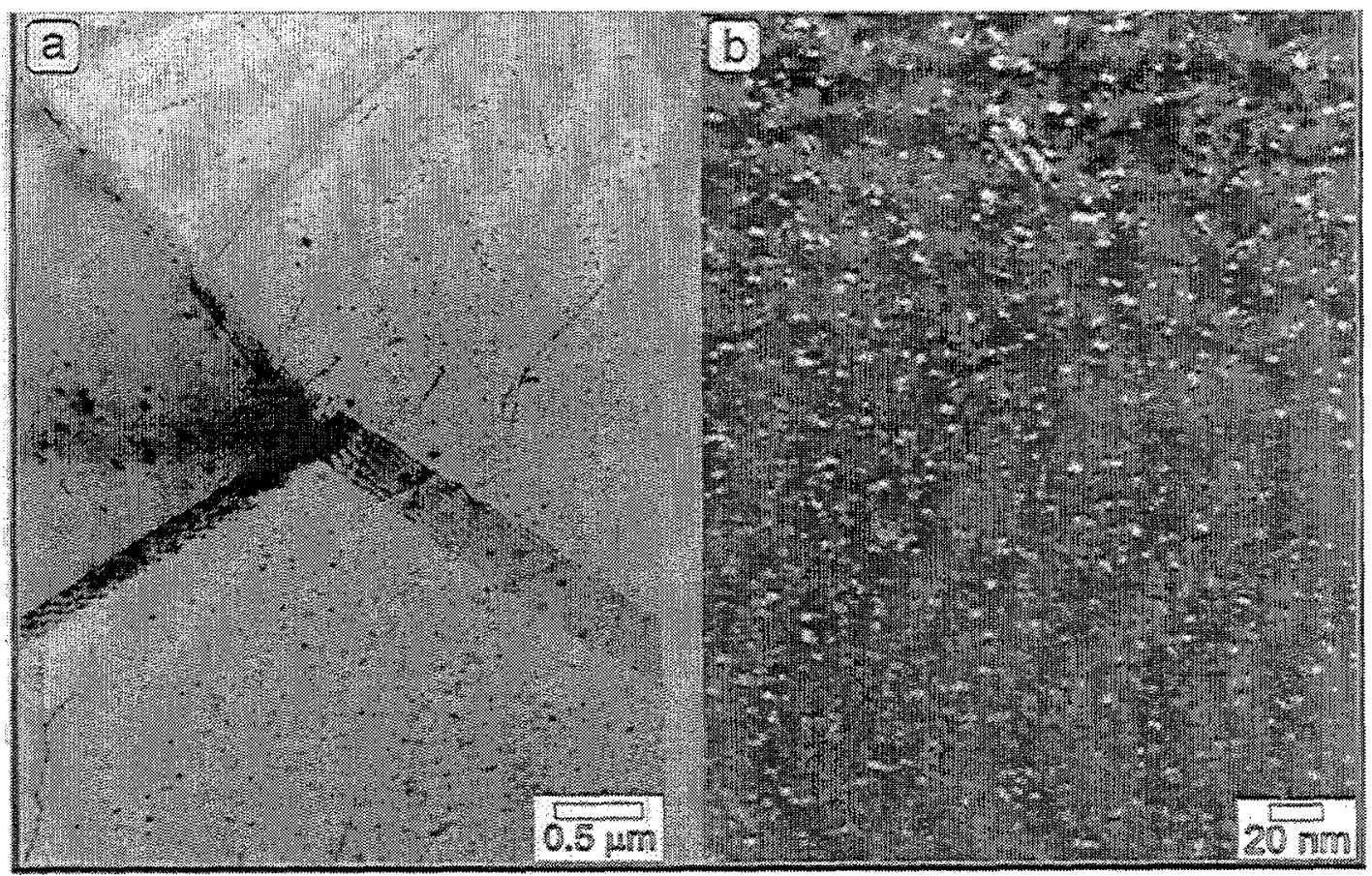

Figure 1. The prime aging treatment leads to (a) precipitation denuding along grain boundaries, dislocations, and twin boundaries. A low density of large inclusions are present, and some grain boundary precipitation occurs at the grain boundaries. A close-up of the fine scale precipitation is shown in (b).

fields around them. The fringed precipitates were oriented in 3 different directions, suggesting that they may be the same type of precipitate but with more than one orientation relationship or habit plane visible in the image. It is not clear whether they are a BCC or a metastable FCC as has been proposed in the literature [8-10]. Large precipitates were also found in a lower density and much larger size than the G-P zones. Selected area diffraction patterns revealed no discrete reflections that would permit identification of any the phases present, so further work is planned on high resolution analytical TEM's to study the precipitation. The grain boundaries contain a low density of small precipitates, and denuding is present along dislocations and boundaries. Large inclusions are scattered about in the matrix, and are assumed to be large $\mathrm{Cr}$ particles formed during the solution annealing or original processing that did not dissolve.

\section{$850^{\circ} \mathrm{C}$ Treatment (Figure 2)}

The microstructure in this case is much simpler since the aging heat treatment removed the fine-scale precipitation. A few stacking fault tetrahedra can be found that formed during the water quenching from $850^{\circ} \mathrm{C}$. The severe overaging produced large-scale grain boundary precipitates that formed when the small scale dispersion either coarsened or dissolved. 


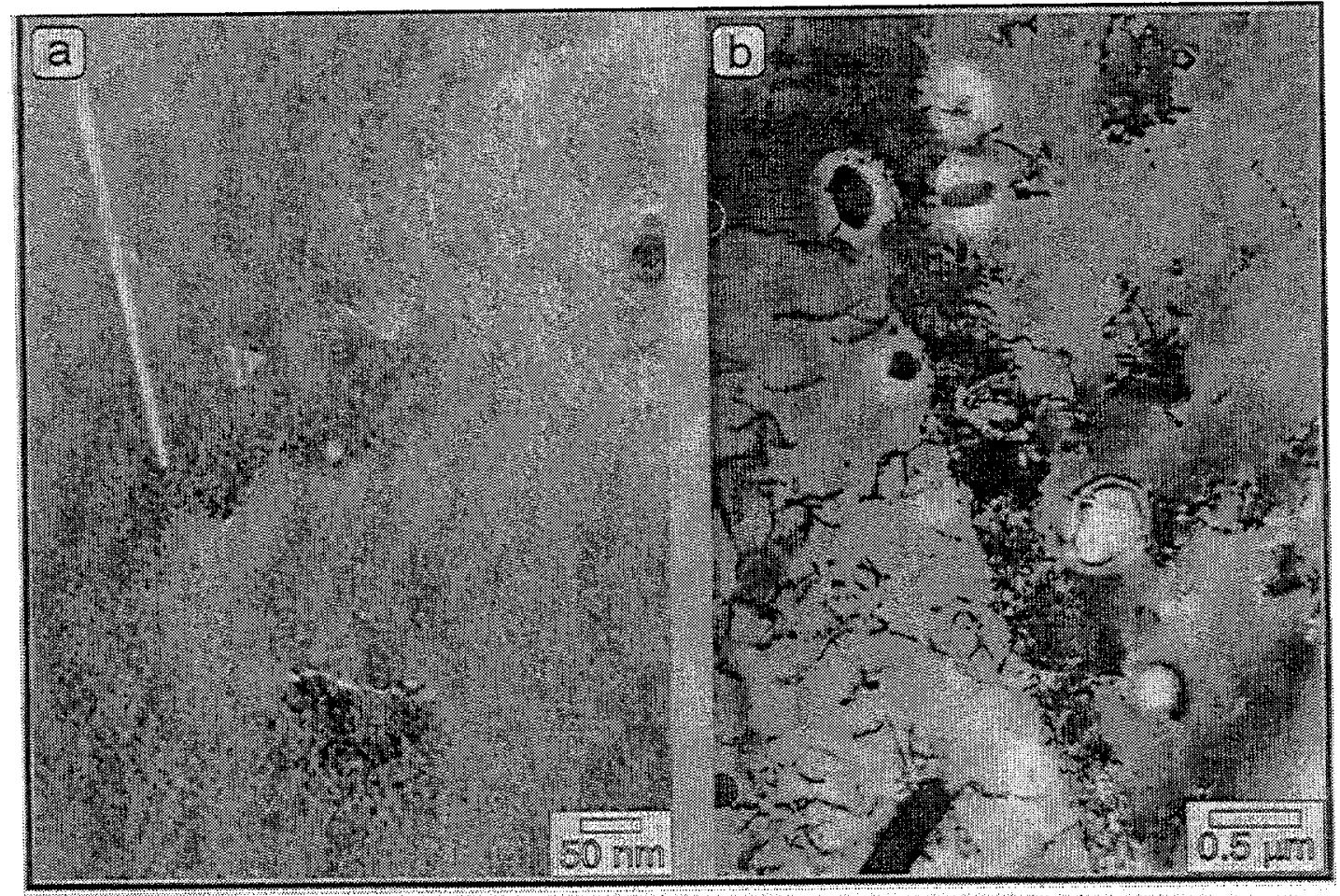

Figure 2. The overaging appears to have reverted the material back to an annealed condition, forming the stacking fault tetrahedra shown in (a) during the water quenching. Other than dislocations the matrix is free of any the fine-scale defects shown in Figure 1a. The extensive grain boundary precipitation formed in this condition (b) may point to where the solute went during the overaging.

\section{$700^{\circ} \mathrm{C}$ Treatment (Figure 3)}

This treatment causes severe coarsening of the fine-scale precipitates, effectively removing the G-P zones and other precipitates shown in Figure 1a. Larger precipitates have formed or coarsened in the matrix to produce an overaged condition of lower overall precipitate density. Grain boundary precipitation and denuding occurs in this condition also, as well as at twin boundaries. The identity of the different phases remains to be determined, requiring careful analysis of their composition.

\section{$6000^{\circ}$ Treatment (Figure 4)}

The overaging that occurs at this temperature is not as severe as shown for the $700^{\circ} \mathrm{C}$ treatment. However, there is still extensive precipitation and denuding along the grain boundaries and twins as shown in Figure 4a. The fine-scale precipitates have been replaced by a much coarser dispersion of particles, the composition and identity of which will be determined in future work. 


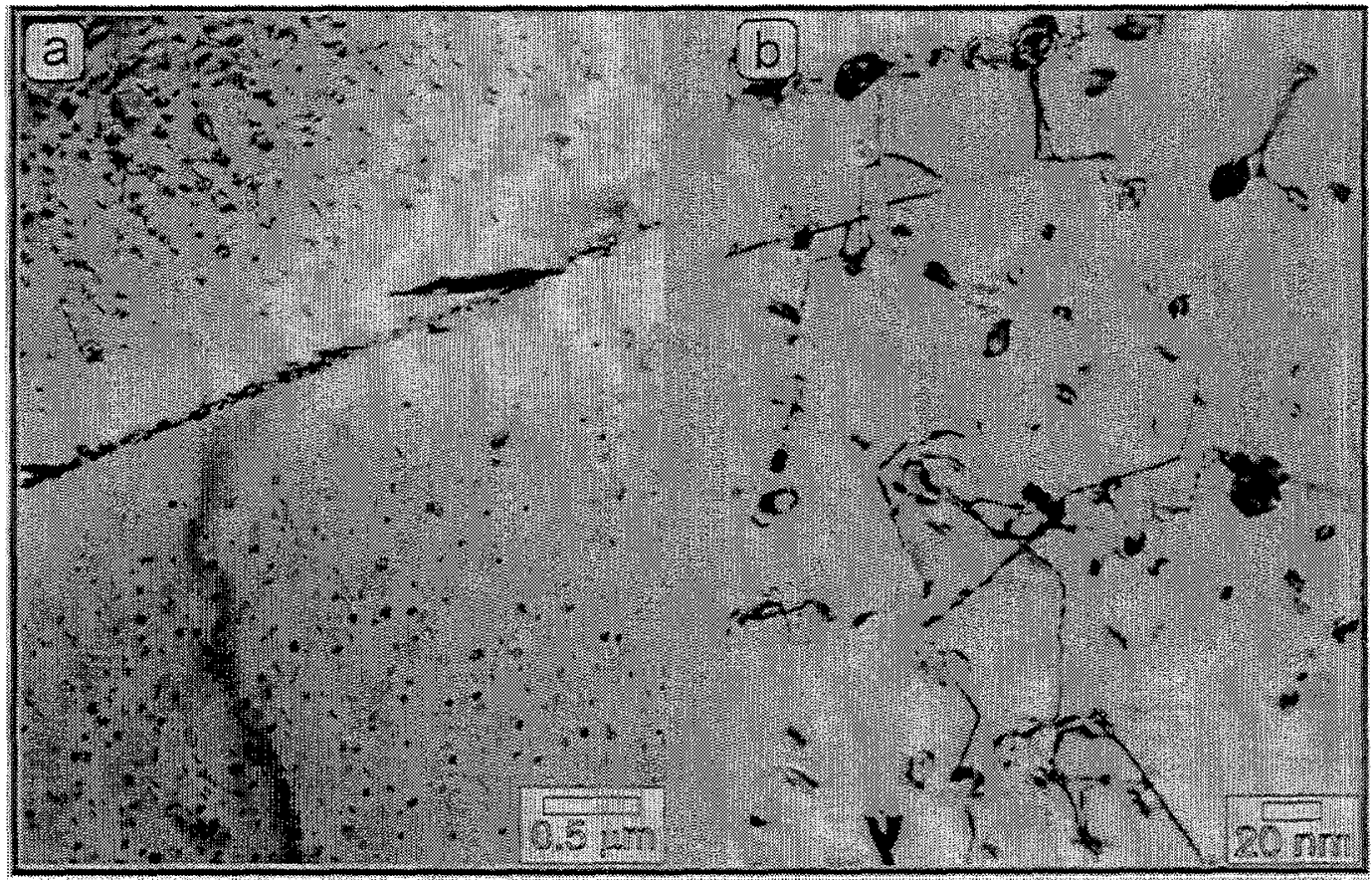

Figure 3. Strong denuding occurs at the boundaries with the material as shown in (a). This denuding is also accompanied by grain boundary precipitation that occurs equally on twin boundaries and grain boundaries. The fine-scale G-P zones and other precipitates shown in Figure 1a have disappeared to be replaced by the larger precipitates shown in (b). Their identity remains to be determined.

\section{FUTURE WORK}

Further work is necessary to characterize the precipitate types that have formed in the different aging treatments. Samples of the unirradiated material will be shipped to PNNL to be characterized in 2010 Field Emission Gun ATEM. Tensile testing and electrical resistivity measurements will be conducted at Ris $\varnothing$ on the unirradiated samples to determine the effect of the aging treatments and how it relates to the observed microstructure. Samples will also be included in future irradiation experiments to study the effect of irradiation on the microstructure, mechanical and physical properties.

\section{ACKNOWLEDGEMENTS}

The present work was partly funded by the European Fusion Technology Programme. The authors wish to thank B. F. Olsen, N.J. Pederson and J.L. Lindbo. DJ Edwards would like to thank Risø National Laboratory for the support and assistance during his visit. His work was also partly supported by the U.S. Department of Energy under contract DE-AC06-76RLO 1830 with the Battelle Memorial Institute at the Pacific Northwest National Laboratory. 


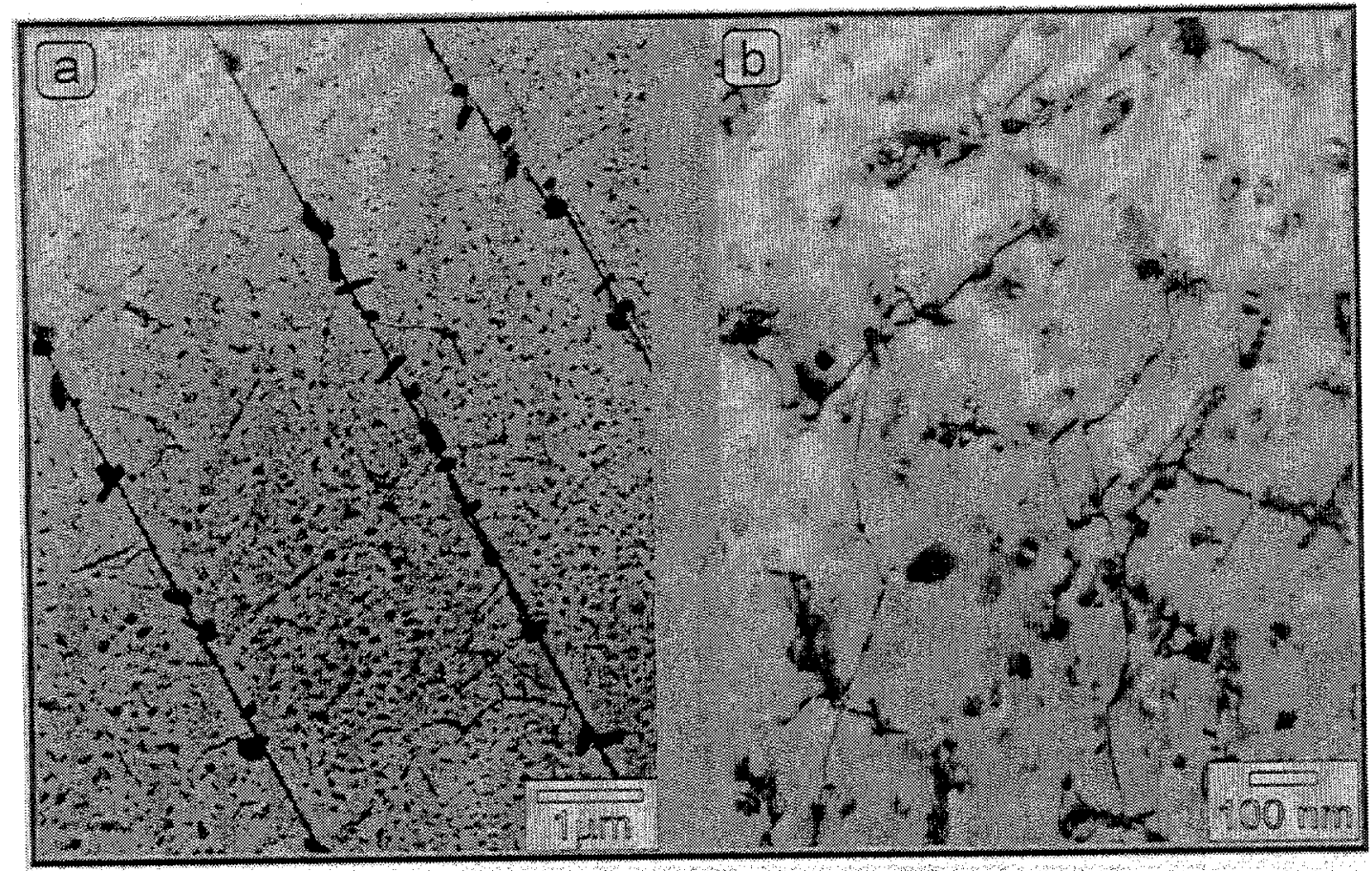

Figure 4. Denuding and precipitation (a) on twin and grain boundaries occurs on a finer scale than that observed in the specimens given the $700^{\circ} \mathrm{C}$ treatment. As in the $700^{\circ} \mathrm{C}$, though, the G-P zones and other small precipitates have been replaced with the coarser distribution of precipitates shown in (b).

\section{REFERENCES}

[1] B. N. Singh, D. J. Edwards and P. Toft, J. Nucl. Mater. 238 (1996) 244.

[2] S. A. Fabritsiev, A. S. Pokrovsky, S. J. Zinkle, D. J. Edwards, J. Nucl. Mater. 233-237 (1996) 513.

[3] B. N. Singh, D. J. Edwards, M. Eldrup and P. Toft, Effect of Bonding and Bakeout Thermal Cycies on the Properties of Copper Alloys Irradiated at $350^{\circ} \mathrm{C}$, Ris $\varnothing-R-971$ (EN), Risø National Laboratory, Roskilde, Denmark, September (1997).

[4] D. J. Edwards, B. N. Singh, P. Toft, and M. Eldrup, J. Nucl. Mater. 258-263 (1998) 978.

[5] A. F. Rowcliffe, S. J. Zinkle, J. F. Stubbins, D. J. Edwards, and D. J. Alexander, J. Nucl. Mater. 258-263 (1998) 183.

[6] S. J. Tähtinen, M. T. Pyykkönen, B. N. Singh and P. Toft, Proceedings of the $19^{\text {th }}$ international Symposium on the Effects of Radiation on Materials, ASTM STP 1366, eds. M. L. Hamilton, A. S. Kumar, S. T. Rosinski and M. L. Grossbeck, (2000), p. 1243.

[7] D. J. Edwards, J. W. Newkirk, F. A. Garner, M. L. Hamilton, A. Nadkarni and P. Samal, Proceedings of the $16^{\text {th }}$ International Symposium on the Effects of Radiation on Materials, ASTM STP 1175, eds. A. S. Kumar, D. S. Gelles, R. K. Nanstad and E. A Little, (1993), p. 1041. 
[8] N. Y. Tang, D. M. R. Taplin, and G. L. Dunlop, Mater. Sci. and Tech., 1 (1985) 270

[9] Z. Rdzawski and J. Strobrawa, Scripta Metall., 20 (1986) 341.

[10] R. W. Knights and P. Wilkes, Metall. Trans., 4 (1973) 2389. 


\subsection{AUSTENITIC STAINLESS STEELS}

No contributions. 


\subsection{INSULATING CERAMICS AND OPTICAL MATERIALS}


GAS ASSISTED CAVITY FORMATION AND BLISTERING IN CERAMICS S. J. Zinkle (Oak Ridge National Laboratory)

\section{SUMMARY}

Single- or poly-crystalline specimens of $\mathrm{SiC}, \mathrm{Si}_{3} \mathrm{~N}_{4}, \mathrm{MgO}, \mathrm{Al}_{2} \mathrm{O}_{3}$ and $\mathrm{MgAl}_{2} \mathrm{O}_{4}$ were implanted with $0.4-1 \mathrm{MeV} \mathrm{H}^{+}$or $0.4-1 \mathrm{MeV} \mathrm{He}{ }^{+}$ion beams at room temperature and $650^{\circ} \mathrm{C}\left(\sim 0.1\right.$ and $\left.0.4 \mathrm{~T}_{\mathrm{M}}\right)$ up to fluences of $\sim 1 \times 10^{22} / \mathrm{m}^{2}$. This produced peak implanted gas and displacement damage levels as high as $\sim 50$ at. $\%$ and 21 displacements per atom (dpa). The specimens were subsequently examined optically, and in cross-section using transmission electron microscopy. Subsurface blistering occurred for specimens irradiated to $\mathrm{H}^{+}$or $\mathrm{He}^{+}$fluences greater than about $3 \times 10^{21} / \mathrm{m}^{2}$ $(\sim 15$ at. \% implanted gas concentration), and surface exfoliation occurred for fluences above $\sim 1 \times 10^{22} / \mathrm{m}^{2}$. Helium was more effective at inducing blistering and exfoliation than $\mathrm{H}$ on an atomic basis. The threshold blistering and exfoliation fluences for both ions decreased with increasing temperature. Both $\mathrm{H}^{+}$and $\mathrm{He}^{+}$were found to be very effective in inducing matrix cavity formation, due to their low solubility in these ceramics. Cavity formation was observed to initiate at the periphery of dislocation loops in several cases. The bubble formation and blistering behavior of the ceramics was similar to that observed for metals irradiated at comparable homologous temperatures.

\section{Introduction}

Due to their low atomic number, ceramics such as $\mathrm{Al}_{2} \mathrm{O}_{3}$ and $\mathrm{SiC}$ produce high concentrations of gaseous $(\mathrm{H}, \mathrm{He})$ transmutation products when exposed to high energy neutrons. Calculations suggest that the helium transmutation rate in $\mathrm{Al}_{2} \mathrm{O}_{3}$ and $\mathrm{SiC}$ exposed to $14 \mathrm{MeV}$ neutrons is about 60-200 appm/dpa, whereas the corresponding transmutation rate in a fission reactor is only about 1-5 appm/dpa [1-3]. It has been recognized for many years that helium can enhance cavity formation in materials due to its limited solubility. Hydrogen has limited solubility in most ceramics and therefore might be more easily trapped in ceramics than in metals. In addition, hydrogen may react chemically with some ceramics [4]. The purpose of this report is to summarize some of the surface and bulk microstructural changes observed in $\mathrm{H}$ and $\mathrm{He}$ implanted $\mathrm{MgO}$, $\mathrm{Al}_{2} \mathrm{O}_{3}, \mathrm{MgAl}_{2} \mathrm{O}_{4}, \mathrm{Si}_{3} \mathrm{~N}_{4}$, and $\mathrm{SiC}$, including the threshold fluences for blistering and exfoliation.

\section{Experimental Procedure}

Polycrystalline blocks of $\mathrm{Al}_{2} \mathrm{O}_{3}$ (GE Lucalox or Wesgo Al995), MgO (Ube UMP-0505), $\mathrm{MgAl}_{2} \mathrm{O}_{4}$ (Ceradyne) $\mathrm{B}$-SiC (Cercom) and $\mathrm{Si}_{3} \mathrm{~N}_{4}$ (Kyocera SN733) and (0001)-oriented single crystal wafers of $\alpha$-SiC (Cree) were machined into transmission electron microscope (TEM) samples using a combination of diamond sawing and ultrasonic cutting. The grain sizes of the polycrystalline specimens ranged from $\sim 1 \mu \mathrm{m}$ for the hot isostatically pressed $\mathrm{Si}_{3} \mathrm{~N}_{4}$ to $\sim 30 \mu \mathrm{m}$ for the sintered oxide specimens. The polycrystalline samples were mechanically polished using $0.05 \mu \mathrm{m}$ diamond paste, whereas the SiC single crystals were polished by the manufacturer. The specimens were bombarded in a $3 \times 3$ target array at room temperature or $650^{\circ} \mathrm{C}$ in the triple ion beam accelerator facility at Oak Ridge National Laboratory [5]. These temperatures correspond to $\sim 0.15$ and $\sim 0.4 T_{M}$ for all of the materials except $\mathrm{MgO}$, where $T_{M}$ is the melting temperature (sublimation temperature for $\mathrm{SiC}$ and $\mathrm{Si}_{3} \mathrm{~N}_{4}$ ). The irradiation temperatures corresponded to 0.1 and $0.3 \mathrm{~T}_{\mathrm{M}}$ for $\mathrm{MgO}$. The $\mathrm{H}$ and $\mathrm{He}$ irradiations were performed as part of a larger irradiation program on the effect of irradiation spectrum on dislocation loop formation and growth.

The specimens were exposed to $\mathrm{H}$ or $\mathrm{He}$ ion beams with energies ranging from 0.4 to $1 \mathrm{MeV}$. Typical particle fluxes for the irradiation ranged from $0.8-6 \times 10^{17} \mathrm{H} / \mathrm{m}^{2}-\mathrm{s}$ and $0.4-4 \times 10^{17} \mathrm{He} / \mathrm{m}^{2}-\mathrm{s}$. Some specimens were also exposed to simultaneous dual beams of $\mathrm{H}$ and $\mathrm{He}$ ions with $\mathrm{H} / \mathrm{He}$ flux ratios ranging from 3 to 10 . The maximum fluences were $1.7 \times 10^{22} \mathrm{H} / \mathrm{m}^{2}$ and $1 \times 10^{22} \mathrm{He} / \mathrm{m}^{2}$, which correspond to calculated peak damage and implanted gas ion concentrations of $3 \mathrm{dpa}$ and 60 
at.\% $\mathrm{H}$ and $21 \mathrm{dpa}$ and 50 at.\% He for $1 \mathrm{MeV} \mathrm{H}$ and $1 \mathrm{MeV} \mathrm{He}$ ions, respectively, assuming an average displacement energy of $40 \mathrm{eV}$. The implanted ion depths were $\sim 10 \mu \mathrm{m}$ and $\sim 2 \mu \mathrm{m}$ for 1 $\mathrm{MeV} \mathrm{H}$ and $1 \mathrm{MeV} \mathrm{He}$ ions, respectively.

Following irradiation, the samples were examined with an optical microscope to detect blistering and surface exfoliation. Selected samples were prepared for cross-section TEM using techniques that are described elsewhere [6]. The TEM specimens were examined in a Philips CM-12 or CM30 electron microscope, operating at 120 and $300 \mathrm{keV}$, respectively.

\section{Results and Discussion}

\section{Threshold fluences for blistering and surface exfoliation}

Figure 1 shows the low-magnification optical microstructures of several specimens following highfluence $\mathrm{H}$ or $\mathrm{He}$ ion irradiation at $650^{\circ} \mathrm{C}$. The dark regions correspond to surface exfoliation. Pronounced surface exfoliation occurred in the proton-irradiated oxide specimens after $1.7 \times 10^{22} / \mathrm{m}^{2}$, with the largest percentage exfoliation occurring in $\mathrm{MgAl}_{2} \mathrm{O}_{4}$. Blistering was observed in proton-irradiated $\mathrm{Si}_{3} \mathrm{~N}_{4}$ at $0.4-1 \times 10^{22} / \mathrm{m}^{2}$, but surface exfoliation did not occur. Surface exfoliation occurred in all of the oxide specimens irradiated with $1 \mathrm{MeV} \mathrm{He}$ ions to $1 \times 10^{22} / \mathrm{m}^{2}$, as well as in B-SiC irradiated to $0.4 \times 10^{22} / \mathrm{m}^{2}$.

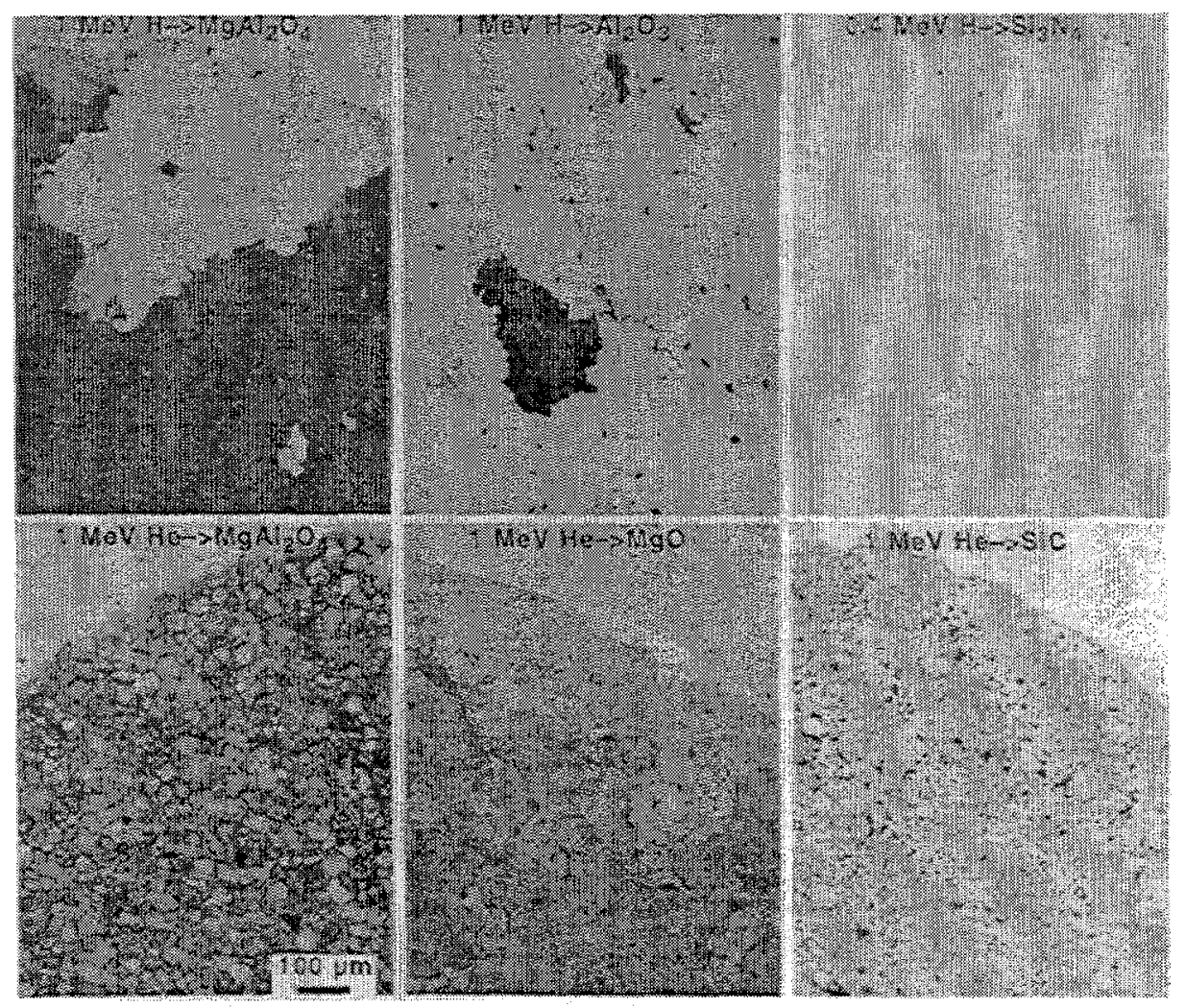

Fig. 1. Optical micrographs of polycrystalline $\mathrm{Al}_{2} \mathrm{O}_{3}, \mathrm{MgO}, \mathrm{MgAl}_{2} \mathrm{O}_{4}, \mathrm{Si}_{3} \mathrm{~N}_{4}$ and $\mathrm{B}-\mathrm{SiC}$ implanted at $650^{\circ} \mathrm{C}$ with $1 \mathrm{MeVH}\left(1.7 \times 10^{22} / \mathrm{m}^{2}\right), 0.4 \mathrm{MeVH}\left(1.0 \times 10^{22} / \mathrm{m}^{2}\right)$, or $1 \mathrm{MeV} \mathrm{He}\left(1.0 \times 10^{22} / \mathrm{m}^{2}\right.$ for the oxides and $0.4 \times 10^{22} / \mathrm{m}^{2}$ for $\mathrm{SiC}$ ). 
Optical examination of the irradiated samples indicated that blister formation and surface exfoliation generally occurred in specimens irradiated to fluences above $-3 \times 10^{21} / \mathrm{m}^{2}$ and $\sim 1 \times 10^{22} / \mathrm{m}^{2}$, respectively. As discussed later in this section, blister formation was preceded by the formation of small cavities in the subsurface gas-implanted region. Hydrogen implantation generally required a higher fluence than the helium implantations to produce blistering or surface exfoliation. Table 1 summarizes the threshold $\mathrm{H}$ and $\mathrm{He}$ ion fluences for producing blistering and surface exfoliation at room temperature and $650^{\circ} \mathrm{C}$. The threshold dose to produce blistering and surface exfoliation decreased with increasing temperature, in agreement with results previously obtained on metals [7]. Silicon nitride and single crystal SiC had the highest resistance to blistering and exfoliation, although most of the materials exhibited roughly comparable behavior. It is worth noting that the single crystal SiC specimens exhibited similar threshold doses for blistering and exfoliation, whereas the polycrystalline $\mathrm{SiC}$ and other ceramics typically blistered at doses two to three times lower than the dose required to produce surface exfoliation.

The present observations are in general agreement with previous extensive studies on metals $[7,8]$ and limited data on ceramics [9-17] that the threshold fluence for blister formation occurs near 2 to $5 \times 10^{21} / \mathrm{m}^{2}$. The size of the blisters was noticeably smaller for $\mathrm{He}$ compared to $\mathrm{H}$ implantation, in agreement with previous studies on ceramics $[10,11,13]$. Surface exfoliation was generally limited to individual grains in the He-implanted specimens, whereas the blister formation and exfoliation extended over several grains in the $\mathrm{H}$-implanted specimens (Fig. 1). These differences may be attributable to the deeper range of the $\mathrm{H}$ ions compared to the $\mathrm{He}$ ions $(\sim 10$ vs. $\sim 2 \mu \mathrm{m}$ for $1 \mathrm{MeV}$ ions in ceramics). Previous studies on metals have reported that the blister size increases with increasing implantation depth, with a roughly linear relationship of $r / R \sim 5$ where $r$ is the blister radius and $R$ is the ion range [8].

Table 1. Summary of threshold fluences to produce blistering and surface exfoliation in $\mathrm{H}$ and $\mathrm{He}$ implanted ceramics. The parentheses denote conditions where blistering or exfoliation were not observed up to the maximum investigated fluence.

\begin{tabular}{|c|c|c|c|}
\hline Ion and $T_{\text {irr }}$ & Material & Blistering $\phi t\left(10^{22} \mathrm{~m}^{-2}\right)$ & Exfoliation $\phi \mathrm{t}\left(10^{22} \mathrm{~m}^{-2}\right)$ \\
\hline $\mathrm{H}, 50^{\circ} \mathrm{C}$ & $\alpha-\operatorname{SiC}$ & $(>1)$ & $(>1)$ \\
\hline " & $\mathrm{Si}_{3} \mathrm{~N}_{4}$ & $(>0.3)$ & $(>0.3)$ \\
\hline$"$ & $\mathrm{Al}_{2} \mathrm{O}_{3}$ & $\sim 0.3$ & $(>1)$ \\
\hline " & $\mathrm{MgAl}_{2} \mathrm{O}_{4}$ & $\sim 0.3$ & $(>1)$ \\
\hline $\mathrm{H}, 650^{\circ} \mathrm{C}$ & $\alpha-\operatorname{SiC}$ & $\sim 0.8$ & $\sim 0.8$ \\
\hline " & $\mathrm{Si}_{3} \mathrm{~N}_{4}$ & -0.4 & $(>1)$ \\
\hline$"$ & $\mathrm{MgO}$ & -0.3 & $\sim 1$ \\
\hline$\pi$ & $\mathrm{Al}_{2} \mathrm{O}_{3}$ & $\sim 0.3$ & -1 \\
\hline " & $\mathrm{MgAl}_{2} \mathrm{O}_{4}$ & $\sim 0.2$ & -1 \\
\hline $\mathrm{He}, 50^{\circ} \mathrm{C}$ & $\alpha-\operatorname{SiC}$ & $(>0.5)$ & $(>0.5)$ \\
\hline " & $\mathrm{Si}_{3} \mathrm{~N}_{4}$ & $\sim 0.3$ & $(>0.3)$ \\
\hline “ & $\mathrm{Al}_{2} \mathrm{O}_{3}$ & $\sim 0.4$ & $(>0.5)$ \\
\hline " & $\mathrm{MgAl}_{2} \mathrm{O}_{4}$ & $\sim 0.2$ & $(>0.5)$ \\
\hline $\mathrm{He}, 650^{\circ} \mathrm{C}$ & B-SiC & $\sim 0.2$ & $\sim 0.4$ \\
\hline " & $\alpha-\mathrm{SiC}$ & $\sim 0.8$ & $\sim 0.8$ \\
\hline " & $\mathrm{Si}_{3} \mathrm{~N}_{4}$ & $(>0.2)$ & $(>0.2)$ \\
\hline 4 & $\mathrm{MgO}$ & $\sim 0.3$ & -0.8 \\
\hline “ & $\mathrm{Al}_{2} \mathrm{O}_{3}$ & -0.3 & -1 \\
\hline " & $\mathrm{MgAl}_{2} \mathrm{O}_{4}$ & $\sim 0.1$ & $\sim 0.4$ \\
\hline
\end{tabular}


Although numerous studies have been performed on metals $[18,19]$, relatively little is known about the microstructural effects of simultaneous high displacement damage and gas concentration in ceramics $[16,20-25]$. Therefore, cross-section transmission electron microscopy was performed on the $\mathrm{H}$ and $\mathrm{He}$ ion irradiated ceramic specimens to determine the physical processes responsible for the blistering and surface exfoliation. The cross-section technique allowed the microstructure of regions containing between zero and the maximum implanted gas concentration to be studied, in order to differentiate between displacement damage and implanted gas atom effects. Comparisons between specimens irradiated to different fluences provided a cross-check on the effect of implanted gas on the cavity evolution.

\section{Effects of He on cavity formation}

Helium implantation had a profound effect on cavity formation in $\mathrm{MgAl}_{2} \mathrm{O}_{4}$, where cavity formation is rare in the absence of gases [24,26-28]. The injected helium promoted cavity formation in the grain interior and at grain boundaries. Figure 2 compares the microstructures of $\mathrm{MgAl}_{2} \mathrm{O}_{4}$ irradiated with $1 \mathrm{MeV} \mathrm{He}$ ions at $650^{\circ} \mathrm{C}$ to fluences of $1 \times 10^{21}$ and $1 \times 10^{22} \mathrm{~m}^{-2}$. The latter fluence corresponds to $21 \mathrm{dpa}$ and 50 at. \% He in the peak implanted region and $\sim 2 \mathrm{dpa}$ and $~ 0.08$ at\% He at a depth of $1.5 \mu \mathrm{m}(0.5 \mu \mathrm{m}$ from the peak implanted region). Small cavities $(\sim 2.5 \mathrm{~nm}$ average diameter) and a few extended microcracks were visible within a $-150 \mathrm{~nm}$ band (corresponding to the peak damage and injected He region) in the lower-dose specimen. Irradiation to an order of magnitude higher fluence produced only a slight increase in the average cavity diameter to $-5 \mathrm{~nm}$ within the peak implanted region, indicating that the cavity growth rate was slow (Fig. 2). Extensive cracking occurred within the He implanted region at the higher fluence.

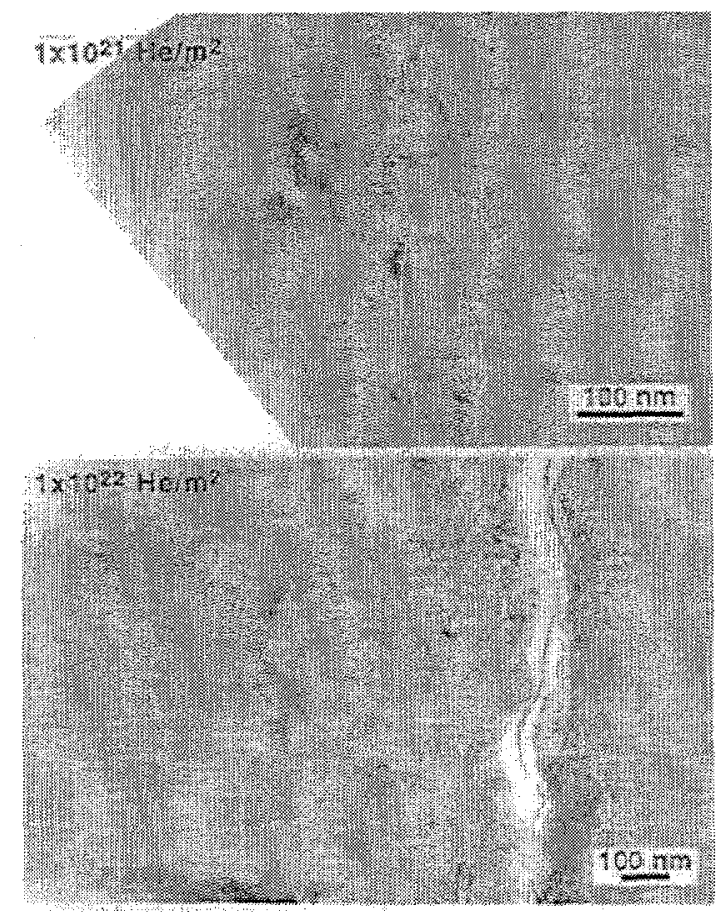

Fig. 2. Comparison of the cross-section microstructures of $\mathrm{MgAl}_{2} \mathrm{O}_{4}$ implanted with $1 \mathrm{MeV} \mathrm{He}$ ions at $650^{\circ} \mathrm{C}$ to fluences of 0.1 and $1 \times 10^{22} \mathrm{~m}^{-2}$. 
Cavities were visible at all depths from the bombarded surface $(0.5 \mathrm{dpa})$ to the implanted ion region (21 dpa) at the higher fluence. The cavity size was nearly constant in irradiated regions outside the peak implanted region ( $d=3.0 \mathrm{~nm}$ at the surface and $d=3.3 \mathrm{~nm}$ at a depth of $1.5 \mu \mathrm{m}$ ) in the higher fluence spinel specimen. The corresponding cavity density increased from $4 \times 10^{21} / \mathrm{m}^{3}$ at the surface to $1.5 \times 10^{22} / \mathrm{m}^{3}$ at a depth of $1.5 \mu \mathrm{m}$.

A previous simultaneous dual-beam (He plus heavy ion) irradiation study on $\mathrm{MgAl}_{2} \mathrm{O}_{4}$ found that cavity formation was enhanced at dislocation loops and adjacent to grain boundaries [23]. At high dual-beam doses, the cavities completely envelop the grain boundary during irradiation at $650^{\circ} \mathrm{C}$ [23].

In agreement with previous ion irradiation studies on $\mathrm{Al}_{2} \mathrm{O}_{3}[20,21,23,29]$ and $\mathrm{SiC}[30,31]$ performed at temperatures above $500^{\circ} \mathrm{C}$, the main effect of $\mathrm{He}$ implantation in $\alpha-\mathrm{SiC}$ and $\mathrm{Al}_{2} \mathrm{O}_{3}$ was to enhance the formation of cavities along (0001) basal plane dislocation loops. Irradiation to high fluence $\left(-1 \times 10^{21} / \mathrm{m}^{2}\right)$ produced cracking in the helium-implanted region. The threshold dose for cavity formation was not determined in the present high-dose study, where cavity formation was observed in all specimens irradiated at $650^{\circ} \mathrm{C}$ (minimum investigated fluence of $1 \times 10^{21} / \mathrm{m}^{2}$ ). The results from previous studies suggest the threshold dose for cavity formation in $\mathrm{He}$ ion irradiated $\mathrm{SiC}$ and $\mathrm{Al}_{2} \mathrm{O}_{3}$ at $500-800^{\circ} \mathrm{C}$ is $\sim 1 \times 10^{20} / \mathrm{m}^{2}[20,24,31,32]$.

The threshold doses for cavity formation in $\mathrm{SiC}, \mathrm{Al}_{2} \mathrm{O}_{3}, \mathrm{MgAl}_{2} \mathrm{O}_{4}$, and $\mathrm{Si}_{3} \mathrm{~N}_{4}$ irradiated with $\mathrm{He}$ ions at room temperature were found to be $\sim 1.0,1.0,1.0$, and $1.5 \times 10^{21} / \mathrm{m}^{2}$, respectively. The formation of bubbles in $\mathrm{He}$ ion irradiated $\mathrm{SiC}$ was preceded by amorphization in the peak damage region. These observations agree with previous work on $\mathrm{SiC}$ [33] and $\mathrm{Al}_{2} \mathrm{O}_{3}$ [17] irradiated at room temperature. Chen et al. [25] observed He platelet formation on (0001) habit planes in $\alpha$-SiC after room temperature implantation of 0.025 at. $\% \mathrm{He}(0.15 \mathrm{dpa})$, where a degrader wheel was used to produce a uniform depth distribution of implanted He $\left(2.3 \times 10^{22} / \mathrm{m}^{2}\right.$ total fluence). The lack of amorphization prior to bubble formation in the latter study may be attributable to a slightly higher irradiation temperature, since the amorphization dose for $\mathrm{SiC}$ is very sensitive to temperature near $300-350 \mathrm{~K}[34,35]$.

\section{Effects of $H$ on cavity formation}

Hydrogen stimulates cavity formation in ceramics via impurity (gas pressure) effects, and may also exert chemical effects. However, higher hydrogen fluences were generally required to produce visible cavities compared to helium ion irradiation. The threshold fluence to produce visible cavities at $650^{\circ} \mathrm{C}$ ranged from $\sim 1 \times 10^{21} \mathrm{~m}^{-2}$ for $\mathrm{MgAl}_{2} \mathrm{O}_{4}$ to $\sim 1 \times 10^{22} \mathrm{~m}^{-2}$ for $\mathrm{Si}_{3} \mathrm{~N}_{4}$, with the other ceramics lying at intermediate fluences. The threshold fluence to produce visible cavities at room temperature was $\sim 5$ to $10 \times 10^{21} \mathrm{~m}^{-2}$ for $\mathrm{MgAl}_{2} \mathrm{O}_{4}$. Hojou et al. [33] found that formation of cavities in $\alpha-\mathrm{SiC}$ at room temperature required a $15-\mathrm{keV} \mathrm{H}$ ion fluence of $\sim 5 \times 10^{22} \mathrm{~m}^{-2}$, i.e., fifty times higher than the corresponding fluence for low energy He ion irradiation.

Figure 3 shows an example of small ( 5 to $10 \mathrm{~nm}$ diameter) platelet cavities associated with (0001) dislocation loops in $\mathrm{SiC}$ implanted with $0.4 \mathrm{MeV} \mathrm{H}$ at $650^{\circ} \mathrm{C}$. The original surface spalled off during the irradiation, so the fluence in the region shown in Fig. 3 is less than the specimen exposure fluence of $1 \times 10^{22} \mathrm{H} / \mathrm{m}^{2}$. The microstructure in the $\mathrm{H}$-implanted region (gas-filled platelets) is similar to that observed in He-implanted $\mathrm{SiC}[25,30,31]$.

Figure 4 shows the microstructure of $\mathrm{MgO}$ after high-fluence implantation with $1 \mathrm{MeV} \mathrm{H}$ ions. Cavity formation in the implanted hydrogen region was preferentially associated with dislocation loops lying on $\{001\}$ and $\{110\}$ habit planes. Since hydrogen diffusion has been reported to be 


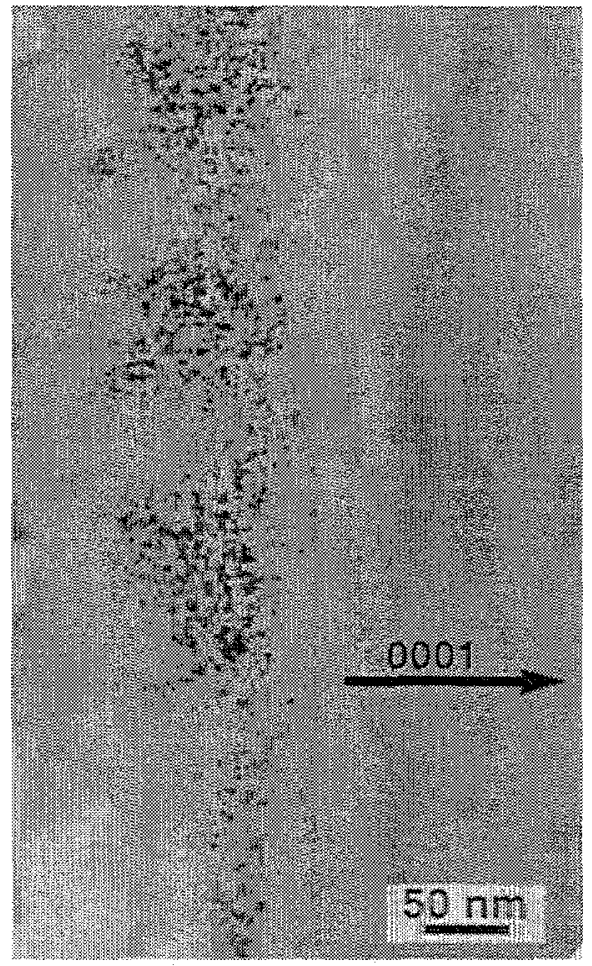

Fig. 3. Over focused cross-section microstructure of $\alpha$-SiC implanted with $0.4 \mathrm{MeV} \mathrm{H}$ ions at $650^{\circ} \mathrm{C}$. Due to surface exfoliation during the irradiation, the fluence in the displayed region is less than the specimen exposure fluence of $1 \times 10^{22} \mathrm{H} / \mathrm{m}^{2}$.

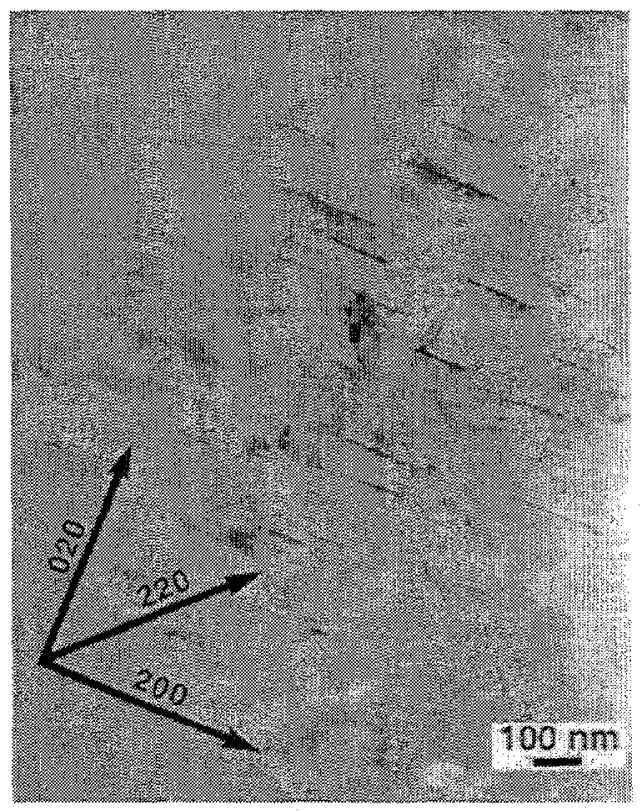

Fig. 4. Microstructure of MgO near the damage peak after irradiation with $1 \mathrm{MeV} \mathrm{H}$ ions at $650^{\circ} \mathrm{C}$ to a fluence of $1.7 \times 10^{22} \mathrm{~m}^{-2}$. The zone axis is near (001). 
considerably enhanced by the ionizing radiation associated with proton irradiation [36], it is possible that much of the implanted hydrogen may have diffused away from the bombarded region during the irradiation.

Hydrogen implantation in $\mathrm{Al}_{2} \mathrm{O}_{3}$ at $650^{\circ} \mathrm{C}$ induced the formation of a high density of heterogeneously nucleated cavities. Figure 5 shows the cross-section microstructure of the peak damage region in $\mathrm{Al}_{2} \mathrm{O}_{3}$ following $1 \mathrm{MeV} \mathrm{H}$ ion irradiation at $650^{\circ} \mathrm{C}(3 \mathrm{dpa}, 60$ at.\% implanted hydrogen at peak). The cavities were spatially segregated into regions containing high and low densities of cavities, with a mean cavity diameter of $\sim 7 \mathrm{~nm}$. The volume-averaged cavity density in the peak damage region was $\sim 6 \times 10^{22} / \mathrm{m}^{3}$ and the mean diameter was $\sim 5 \mathrm{~nm}$. Examination of the irradiated regions adjacent to the peak damage region suggested that the heterogeneous grouping of individual cavities was due to their association with dislocation loops, as shown in Fig. 6. The two arrows in Fig. 6 point to dislocation loops which have 7 to 8 cavities associated with the periphery of the loops. The calculated damage level and implanted hydrogen concentration in this region are $0.3 \mathrm{dpa}$ and 0.1 at.\% $\mathrm{H}$, respectively. Other loops depicted in Fig. 6 have cavities distributed along the entire face of the loop. Preferential nucleation of cavities at dislocation loops in $\mathrm{H}$ ion irradiated $\mathrm{Al}_{2} \mathrm{O}_{3}$ has been observed in another recent study [37].

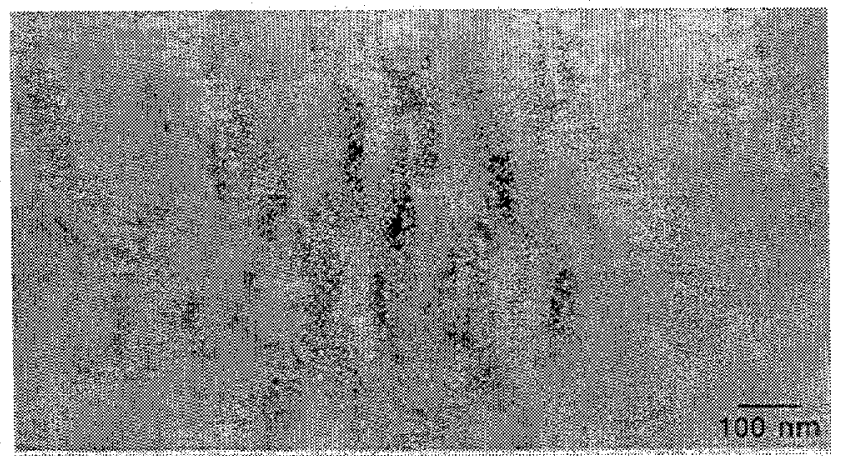

Fig. 5. Cavity formation in the peak damage region of $\mathrm{Al}_{2} \mathrm{O}_{3}$ irradiated with $1 \mathrm{MeV} \mathrm{H}$ ions at $650^{\circ} \mathrm{C}$ to a fluence of $1.7 \times 10^{22} \mathrm{H} / \mathrm{m}^{2}$.

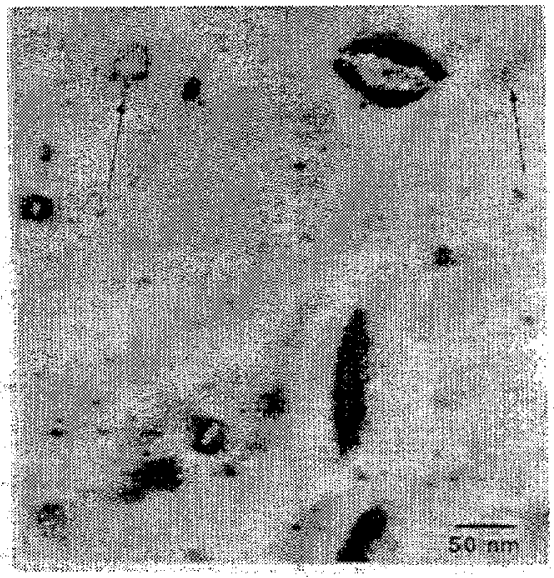

Fig. 6. Cavity formation at dislocation loops in $\mathrm{Al}_{2} \mathrm{O}_{3}$ irradiated with $1 \mathrm{MeV} \mathrm{H}$ ions at $650^{\circ} \mathrm{C}$ to 1.7 $\times 10^{22} \mathrm{H} / \mathrm{m}^{2}$. The microstructure corresponds to an irradiation depth of $\sim 9 \mu \mathrm{m}(1 \mu \mathrm{m}$ from the peak implanted region). 
As shown in Fig. 7 , irradiation of $\mathrm{MgAl}_{2} \mathrm{O}_{4}$ with $1 \mathrm{MeV} \mathrm{H}$ ions at $650^{\circ} \mathrm{C}$ produced a low to moderate density of cavities in the peak implanted region for a fluence of $1.5 \times 10^{21} \mathrm{~m}^{-2}(0.28 \mathrm{dpa}$, 5.6 at. $\% \mathrm{H})$. The cavity density in the hydrogen-implanted regions of $\mathrm{MgAl}_{2} \mathrm{O}_{4}\left(\sim 1.5 \times 10^{21} / \mathrm{m}^{3}\right)$ was considerably lower and the cavity size $(\sim 10 \mathrm{~nm})$ was higher than that in $\mathrm{Al}_{2} \mathrm{O}_{3}$ irradiated at comparable conditions. Irradiation of $\mathrm{MgAl}_{2} \mathrm{O}_{4}$ with $1 \mathrm{MeV} \mathrm{H}$ ions to an order of magnitude higher fluence produced matrix cavity growth and extensive cavitation along grain boundaries. The matrix cavities were faceted along $\{111\}$ planes and were as large as $300 \mathrm{~nm}$ diameter. Figure 8 shows an example of the grain boundary cavities in $\mathrm{MgAl}_{2} \mathrm{O}_{4}$ irradiated with $1 \mathrm{MeV} \mathrm{H}$ ions to high fluence.

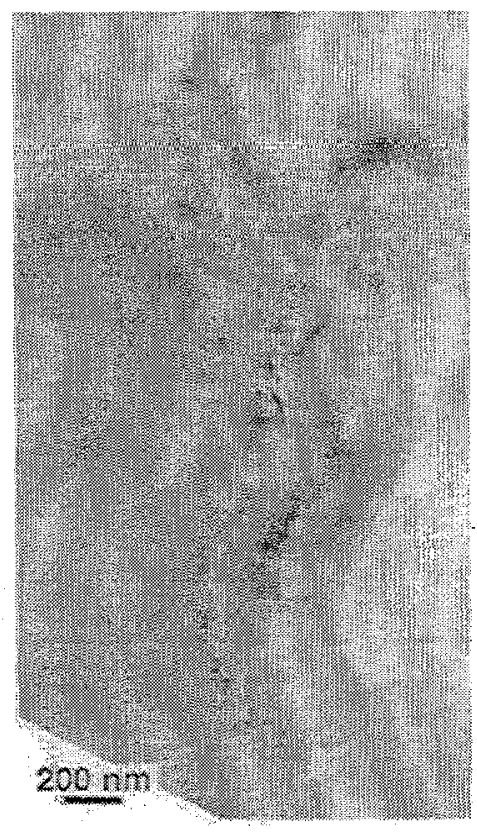

Fig. 7. Cross-section microstructure of $\mathrm{MgAl}_{2} \mathrm{O}_{4}$ irradiated with $1 \mathrm{MeV} \mathrm{H}$ ions at $650^{\circ} \mathrm{C}$ to a fluence of $1.5 \times 10^{21} \mathrm{~m}^{-2}(0.28 \mathrm{dpa}, 5.6$ at. $\% \mathrm{H}$ at peak).

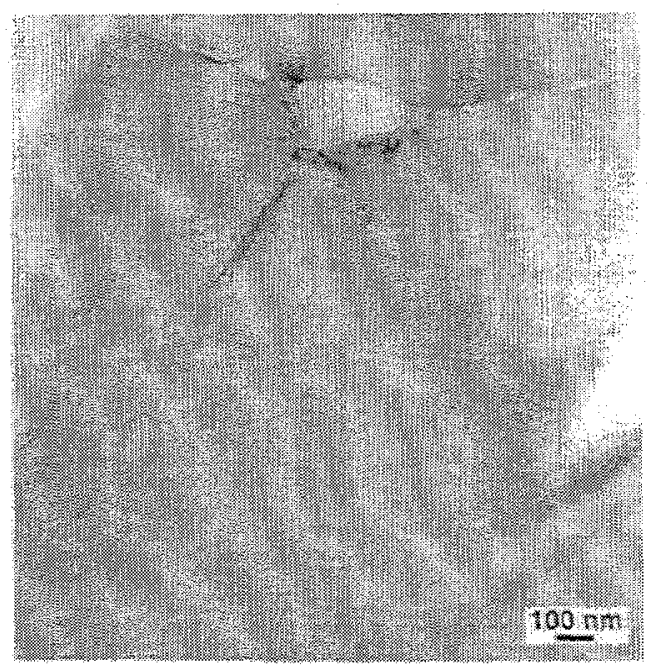

Fig. 8. Grain boundary cavities in $\mathrm{MgAl}_{2} \mathrm{O}_{4}$ irradiated with $1 \mathrm{MeV} \mathrm{H}$ ions at $650^{\circ} \mathrm{C}$ to a fluence of $1.7 \times 10^{22} \mathrm{~m}^{-2}$. 
Figure 9 shows the low-magnification microstructure for $\mathrm{MgAl}_{2} \mathrm{O}_{4}$ irradiated with simultaneous beams of $0.4 \mathrm{MeV} \mathrm{H}$ and $0.36 \mathrm{MeV} \mathrm{He}$ ions at $650^{\circ} \mathrm{C}$. In addition to the extensive matrix cavitation associated with the implanted $H$ ions at a depth of $\sim 2.7 \mu \mathrm{m}$, cavities were observed along the grain boundaries of the unirradiated region to depths in excess of $20 \mu \mathrm{m}$ from the implanted region. The inset photo in Fig. 9 shows the grain boundary cavities observed at a depth of $\sim 15 \mu \mathrm{m}$. It appears that the hydrogen had a chemical reaction with the non-spinel grain boundary phase present in the sintered polycrystalline $\mathrm{MgAl}_{2} \mathrm{O}_{4}$ specimen. Using a typical bulk diffusion coefficient for hydrogen in single crystal ceramics of $D_{H}-1 \times 10^{-18} \mathrm{~m}^{2} / \mathrm{s}$ at $650^{\circ} \mathrm{C}$ [38], hydrogen diffusion distances of only $\sim 0.2 \mu \mathrm{m}$ would be anticipated for the $8 \mathrm{~h}$ ion irradiation. Conversely, the apparent high grain boundary diffusivity suggested by Fig. 9 is consistent with effective diffusion coefficients of $D_{H} \sim 1 \times 10^{-14} \mathrm{~m}^{2} / \mathrm{s}$ at $650^{\circ} \mathrm{C}$ measured for polycrystalline ceramics [38].

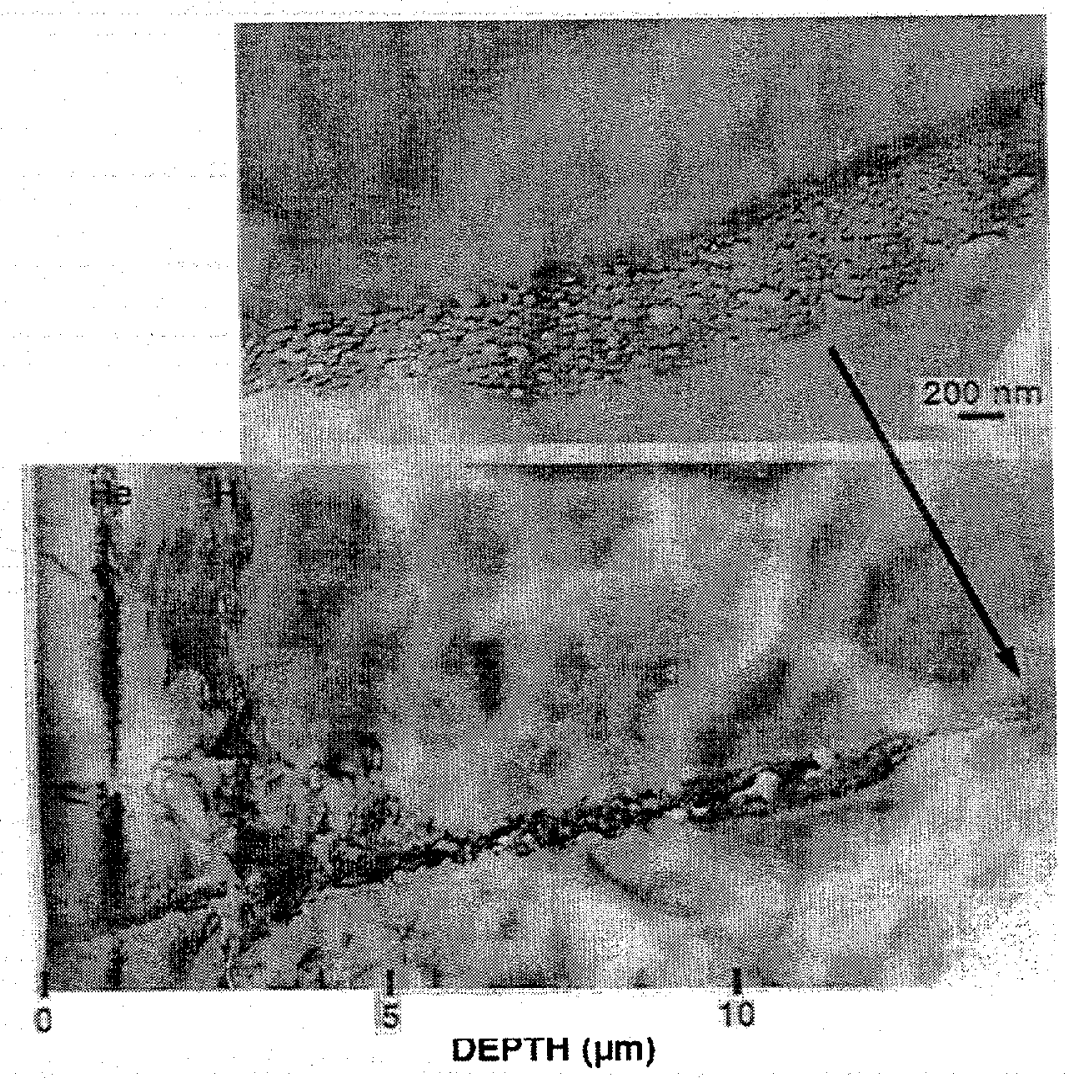

Fig. 9. Cross-section microstructure of $\mathrm{MgAl}_{2} \mathrm{O}_{4}$ irradiated at $650^{\circ} \mathrm{C}$ with simultaneous dual beams of $0.4 \mathrm{MeV} \mathrm{H}$ and $0.36 \mathrm{MeV} \mathrm{He}$ at a $\mathrm{H} / \mathrm{He}$ flux ratio of 10 and a cumulative $\mathrm{H}$ fluence of 1 $\times 10^{22} \mathrm{~m}^{-2}$.

\section{Blistering mechanisms}

The TEM observations indicate that blistering and surface exfoliation in $\mathrm{H}$ and $\mathrm{He}$ irradiated ceramics at 50 and $650^{\circ} \mathrm{C}$ is due to progressive cracking at the ligatures between highly pressurized gas bubbles that form in the implanted ion region. The blistering is not associated with coarsening of gas bubbles, as proposed in an early gas pressure model [10]. The present observations are consistent with the lateral compressive stress model [39], which predicts that blistering occurs when internal stresses at the implantation-produced cavities exceed the yield strength. The observations are also consistent with the pressurized gas platelet model proposed by Chen et al. [25]. 


\section{Conclusions}

In all of the $\mathrm{H}$ and $\mathrm{He}$ implanted specimens, blistering and surface exfoliation occurred at $650^{\circ} \mathrm{C}$ above a critical fluence of $\sim 3$ and $\sim 10 \times 10^{21} \mathrm{~m}^{-2}$, respectively $(\sim 15$ and $\sim 40$ at.\% implanted gas concentration, respectively). The threshold fluence for blistering and surface exfoliation was generally lower for helium irradiation compared to hydrogen irradiation. The behavior of the ceramic specimens is similar to that of metals which have limited $\mathrm{H}$ and $\mathrm{He}$ solubility. The experimental observations are qualitatively consistent with the lateral compressive stress model for blistering.

Cavity formation was generally of higher density and more spatially uniform for $\mathrm{He}$ compared to $\mathrm{H}$ irradiation. The cavities were often associated with dislocation loops, particularly for $\mathrm{H}$ ion irradiation. In the case of proton-irradiated $\mathrm{Al}_{2} \mathrm{O}_{3}$ at $650^{\circ} \mathrm{C}$, cavity nucleation appears to occur on dislocation loops created previously during the irradiation. For proton-irradiated $\mathrm{SiC}$ and $\mathrm{MgO}$, there is insufficient evidence to determine whether the dislocation loop formation or cavity formation occurs first. Long range diffusion of hydrogen along grain boundaries was observed in $\mathrm{MgAl}_{2} \mathrm{O}_{4}$.

\section{References}

[1] L.H. Rovner, G.R. Hopkins, Nucl. Tech. 29 (1976) 274.

[2] G.P. Pells, J. Nucl. Mater. 155-157 (1988) 67.

[3] R.J. LaBauve, R. Livak, F.W. Clinard, Jr., Adv. Ceramic Mater. 3 (1988) 353.

[4] K. Hojou, S. Furuno, T. Soga, K. Izui, J. Nucl. Mater. 179-181 (1991) 411.

[5] M.B. Lewis, W.R. Allen, R.A. Buhl, N.H. Packan, S.W. Cook, L.K. Mansur, Nucl. Instr. Meth. B $43(1989) 243$.

[6] S.J. Zinkle, C.P. Haltom, L.C. Jenkins, C.K.H. DuBose, J. Electron Microsc. Tech. 19 (1991) 452.

[7] K.L. Wilson, Nuclear Fusion special issue (1984) 85.

[8] G.M. McCracken, Rep. Prog. Phys. 38 (1975) 241.

[9] W. Primak, J. Appl. Phys. 34 (1963) 3630.

[10] W. Primak, J. Luthra, J. Appl. Phys. 37 (1966) 2287.

[11] W. Primak, J. Appl. Phys. 48 (1977) 1556.

[12] W. Primak, J. Nucl. Mater. 74 (1978) 84.

[13] D.M. Gruen, B. Siskund, R.B. Wright, J. Chem. Phys. 65 (1976) 363.

[14] C.J. McHargue, G.C. Farlow, M.B. Lewis, J.M. Williams, Nucl. Instr. Meth. B 19/20 (1987) 809.

[15] L. Romana, G. Fuchs, G. Massouras, P. Thevenard, Radiat. Eff. Def. Solids 115 (1990) 139.

[16] E.L. Fleischer, M.G. Norton, Heterogeneous Chemistry Reviews 3 (1996) 171.

[17] S. Furuno et al., Nucl. Instr. Meth. B 127/128 (1997) 181.

[18] H. Schroeder, H. Ullmaier, J. Nucl. Mater. 179-181 (1991) 118.

[19] B.N. Singh, H. Trinkaus, J. Nucl. Mater. 186 (1992) 153.

[20] W.R. Allen, S.J. Zinkle, J. Nucl. Mater. 191-194 (1992) 625.

[21] W.E. Lee, M.L. Jenkins, G.P. Pells, Philos. Mag. A 51 (1985) 639.

[22] K. Hojou, S. Furuno, K.N. Kushita, N. Sasajima, K. Izui, Nucl. Instr. Meth. B 141 (1998) 148.

[23] S.J. Zinkle, S. Kojima, J. Nucl. Mater. 179-181 (1991) 395.

[24] R. Yamada, S.J. Zinkle, G.P. Pells, J. Nucl. Mater. 209 (1994) 191.

[25] J. Chen, P. Jung, H. Trinkaus, Phys. Rev. Lett. 82 (1999) 2709.

[26] F.W. Clinard, Jr., G.F. Hurley, L.W. Hobbs, J. Nucl. Mater. $108 \& 109$ (1982) 655.

[27] S.J. Zinkle, J. Nucl. Mater. 191-194 (1992) 645.

[28] C. Kinoshita, K. Fukumoto, K. Fukuda, F.A. Garner, G.W. Hollenberg, J. Nucl. Mater. 219 (1995) 143.

[29] M.D. Rechtin, Radiat. Eff. 42 (1979) 129.

[30] K. Hojou, K. Izui, J. Nucl. Mater. 160 (1988) 147. 
[31] K. Nakata, S. Kasahara, S. Shimanuki, Y. Katano, H. Ohno, J. Kuniya, J. Nucl. Mater. 179-181 (1991) 403.

[32] Y. Katano, H. Ohno, H. Katsuta, J. Nucl. Mater. 155-157 (1988) 366.

[33] K. Hojou, S. Furuno, K.N. Kushita, H. Otsu, K. Izui, J. Nucl. Mater. 191-194 (1992) 583.

[34] S.J. Zinkle, L.L. Snead, Nucl. Instr. Meth. B 116 (1996) 92.

[35] L.L. Snead, S.J. Zinkle, W.S. Eatherly, D.K. Hensley, N.L. Vaughn, J.W. Jones, in: Microstructural Processes During Irradiation, eds. S.J. Zinkle et al., MRS Symposium Proceedings vol. 540 (Materials Research Society, Warrendale, PA, 1999) p. 165.

[36] Y. Chen, M.M. Abraham, H.T. Tohver, Phys. Rev. Lett. 37 (1976) 1757.

[37] S. Furuno, N. Sasajima, K. Hojou, K. Izui, H. Otsu, T. Matsui, J. Nucl. Mater. 258-263 (1998) 1817.

[38] J.D. Fowler, R.A. Causey, D. Chandra, T.S. Elleman, K. Verghese, in: Radiation Effects and Tritium Technology for Fusion Reactors, CONF-750989, eds. J.S. Watson, F.W. Wiffen, vol. II (USERDA, Gatlinburg, TN, 1975) p. 423.

[39] E.P. EerNisse, S.T. Picraux, J. Appl. Phys. 48 (1977) 9. 


\subsection{BREEDING MATERIALS}

No contributions. 
8.0 RADIATION EFFECTS, MECHANISTIC STUDIES, AND EXPERIMENTAL METHODS 
COMPOSITIONAL AND TEMPERATURE DEPENDENCE OF VOID SWELLING IN MODEL FE-CR BASE ALLOYS IRRADIATED IN THE EBR-II FAST REACTOR - B. H. Sencer and F. A. Garner (Pacific Northwest National Laboratory*)

\section{OBJECTIVE}

The objective of this work is to evaluate the void swelling in model $\mathrm{Fe}-\mathrm{Cr}$ base alloys irradiated in the EBR-Il fast reactor.

\section{SUMMARY}

A series of annealed and aged $\mathrm{Fe}-\mathrm{xCr}, \mathrm{Fe}-12 \mathrm{Cr}-\mathrm{yC}$ and $\mathrm{Fe}-12 \mathrm{Cr}-0.1 \mathrm{C}-\mathrm{zMo}$ model alloys were irradiated in EBR-II at eight temperatures between 400 and $650^{\circ} \mathrm{C}$ and dose levels ranging from 35 to $131 \mathrm{dpa}$. Swelling-induced density changes observed in the binary alloys generally peaked at mid-chromium levels, with the chromium and temperature dependence expressed primarily in the duration of the transient regime. The steady state swelling rate at the lower irradiation temperatures was much higher than previous estimates, reaching $-0.2 \% / \mathrm{dpa}$ and possibly still climbing at higher neutron exposures.

The dependence of swelling on molybdenum and carbon was more complex, depending on whether the temperature was relatively low or high. At temperatures of $482^{\circ} \mathrm{C}$ and above the effect of carbon additions was very pronounced, with swelling of $\mathrm{Fe}-12 \mathrm{Cr}$ jumping dramatically from near zero at $0.002 \% \mathrm{C}$ to $6-10 \%$ at $0.1 \% \mathrm{C}$. This indicates that the major determinant of the composition and temperature dependence probably lies in the duration of the nucleation-dominated transient regime of swelling and not primarily in the steady-state swelling rate as previously envisioned. This raises the possibility that significant swelling may occur earlier in fusion and spallation neutron spectra where high gas.generation rates may assist void nucleation.

\section{Introduction}

Until recently, it was thought that the steady-state swelling rate of iron-base bcc alloys was not only strongly dependent on composition but was also very temperature-dependent. In all cases, however, the steady-state swelling rate was thought to be lower by an order of magnitude compared to that of iron-based fcc alloys, which exhibit a steady state swelling rate of $\sim 1 \% / \mathrm{dpa}$, independent of composition and temperature in the range studied. The origin of these perceptions originally arose from irradiation in EBR-ll of simple $\mathrm{Fe}-\mathrm{Cr}-\mathrm{Ni}$ ternaries examined by Garner and coworkers [1-5] and simple $\mathrm{Fe}-\mathrm{Cr}$ binaries examined by Gelles [6-8], with both alloy series irradiated side-by-side in the very same packets. Gelles and coworkers carried this work further, irradiating these alloys to much higher exposures in the FFTF fast reactor [9-11], but in general preserving his previous EBR-11 based conclusions.

In a recent review article by Garner, Toloczko and Sencer, however, it was shown that an error in dose assignments for bcc specimens in EBR-II at lower irradiation temperatures was responsible for the misperception of very low and variable swelling rates for bcc alloys [12]. When the dose assignments were corrected, the bcc binary alloys were found to exhibit the same general dependence on temperature and composition exhibited by the fcc ternary alloys in the same packets. The steady-state swelling rate of bcc alloys were observed to

\footnotetext{
* Pacific Northwest National Laboratory is operated for the U.S Department of Energy by Battelle Memorial Institute under contract DE-AC06-76RLO-1830.
} 
reach at least $-0.2 \% / \mathrm{dpa}$. In the review other evidence was shown that suggested that the swelling rate might still be climbing to higher values.

Additional conclusions reached in the review article were that the transient regimes of bcc alloys were in general much longer than those of fcc alloys, especially at higher irradiation temperatures and higher dpa rates. In particular, it was shown that even complex structural alloys such as HT9 and $9 \mathrm{Cr}-1 \mathrm{Mo}$ would eventually overcome nucleation difficulties and swell at higher rates [12-13]. A summary of many of these results is shown in Figure 1.

Since these conclusions represent a significant departure from the previous perception of bcc behavior and have some potentially important implications for fusion applications of ferritic alloys, it is important to separately confirm these conclusions. It is also important to see if they extend to higher temperatures and to compositions more representative of structural bcc alloys. Therefore, similar but previously unexamined sets of specimens irradiated in the same EBR-II series were measured to determine their change in density.

\section{Experimental details}

Three series of Fe-xCr $(x=3,6,9,12,15,18 w t \%)$, Fe-12Cr-yC $(y=0.002,0.1,0.2$ wt\% $)$ and Fe$12 \mathrm{Cr}-0.1 \mathrm{C}-\mathrm{zMo}(\mathrm{z}=0,1,2,3 \mathrm{wt} \%)$ model alloys were prepared in the form of $0.3 \mathrm{~mm}$ thick, $3.0 \mathrm{~mm}$ diameter microscopy disks in the annealed and aged $\left(1040^{\circ} \mathrm{C} / 1 \mathrm{~h} / \mathrm{AC}+760^{\circ} \mathrm{C} / 2\right.$ $\mathrm{h} / \mathrm{AC}$ ) condition. These alloys were irradiated in stainless steel "weeper" packets in contact with coolant sodium in EBR-II at eight temperatures between $400^{\circ} \mathrm{C}\left( \pm 10^{\circ} \mathrm{C}\right)$ and $650^{\circ} \mathrm{C}$ $\left( \pm 20^{\circ} \mathrm{C}\right)$. Gelles and coworkers [6-8] have published more details of alloy preparation and irradiation technique.

Dose levels examined in this series depended on the temperature and ranged from 35-48 $\mathrm{dpa}$ at $400-454^{\circ} \mathrm{C}, 74-101 \mathrm{dpa}$ at $482-510^{\circ} \mathrm{C}$, and $121-131 \mathrm{dpa}$ at $538-650^{\circ} \mathrm{C}$, as shown in Figure 2. Swelling measurements were performed using an immersion density technique known to be accurate to $\pm 0.2 \%$ change in density.

\section{$\underline{\text { Results }}$}

As shown in Figure 2, swelling tends to peak at intermediate chromium levels, in agreement with the results of Gelles and coworkers [6-11]. The sometimes negative swelling values most likely represent densification associated with combined effects of segregation and formation of $\alpha^{\prime}$ and $\sigma$ precipitates $[6-11,14]$, with precipitation most pronounced at higher dpa levels and higher chromium levels. Note that swelling appears to be occurring at all temperatures except $650^{\circ} \mathrm{C}$. Preliminary microscopy examination of these specimens finds no voids at $650^{\circ} \mathrm{C}$ for any chromium level [14].

Figure 3 shows that the addition of carbon to $\mathrm{Fe}-12 \mathrm{Cr}$ at temperatures below $454^{\circ} \mathrm{C}$ and doses below $48 \mathrm{dpa}$ tends to monotonically decrease the swelling. At $482-650^{\circ} \mathrm{C}$, however, an increase to $0.1 \% \mathrm{C}$ leads to very large increases in swelling, although a subsequent increase to $0.2 \% \mathrm{C}$ at $593-650^{\circ} \mathrm{C}$ then reduces swelling.

Figure 4 indicates that addition of molybdenum to $\mathrm{Fe}-12 \mathrm{Cr}-0.1 \mathrm{C}$ tends to decrease swelling strongly at low Mo levels, with some hint of smaller subsequent increases in swelling at higher Mo levels. 


\section{Figure captions}

Figure 1 (a) Compilation of swelling data of Fe-(3-15) Cr binary alloys irradiated in EBR-II (with corrected dpa levels) showing swelling rates on the order of $-0.2 \% / \mathrm{dpa}$, following transient regimes that are somewhat dependent on composition) (b) similar compilation in FFTF, showing swelling rates on the order of $\sim 0.2 \% / \mathrm{dpa}$, following transient regimes that at low temperature are also somewhat dependent on composition, but which are very dependent on the different flux-temperature histories of the two reactors [12]. (c) At higher temperatures and the transient regimes are longer in EBR-II. (d) Also shown are HT9 $(12 \% \mathrm{Cr})$ and $9 \mathrm{Cr}-1 \mathrm{Mo}$ irradiated in FFTF, showing that their swelling is relatively close to their binary equivalents [13]. The range of swelling values for these two alloys demonstrates the effect of stress to increase swelling, with the lowest swelling at zero stress and monotonically increasing with stress.

Figure 2. Swelling of $\mathrm{Fe}-\mathrm{Cr}$ binary alloys as a function of $\mathrm{Cr}$ level for various irradiation conditions in EBR-II.

Figure 3. Effect of carbon additions on swelling of $\mathrm{Fe}-12 \mathrm{Cr}$.

Figure 4. Effect of molybdenum additions on swelling of $\mathrm{Fe}-12 \mathrm{Cr}-0.1 \mathrm{C}$.

Figure 5. Swelling of Fe-Cr binary alloys in EBR-ll as a function of temperature and dpa level, showing similar trends to those in Figs. $1 \mathrm{a}$ and $1 \mathrm{~b}$, but with swelling extending to much higher temperatures. The dotted lines at higher temperatures are used only for emphasis to separate the various data sets, with no explicit swelling rate implied. 

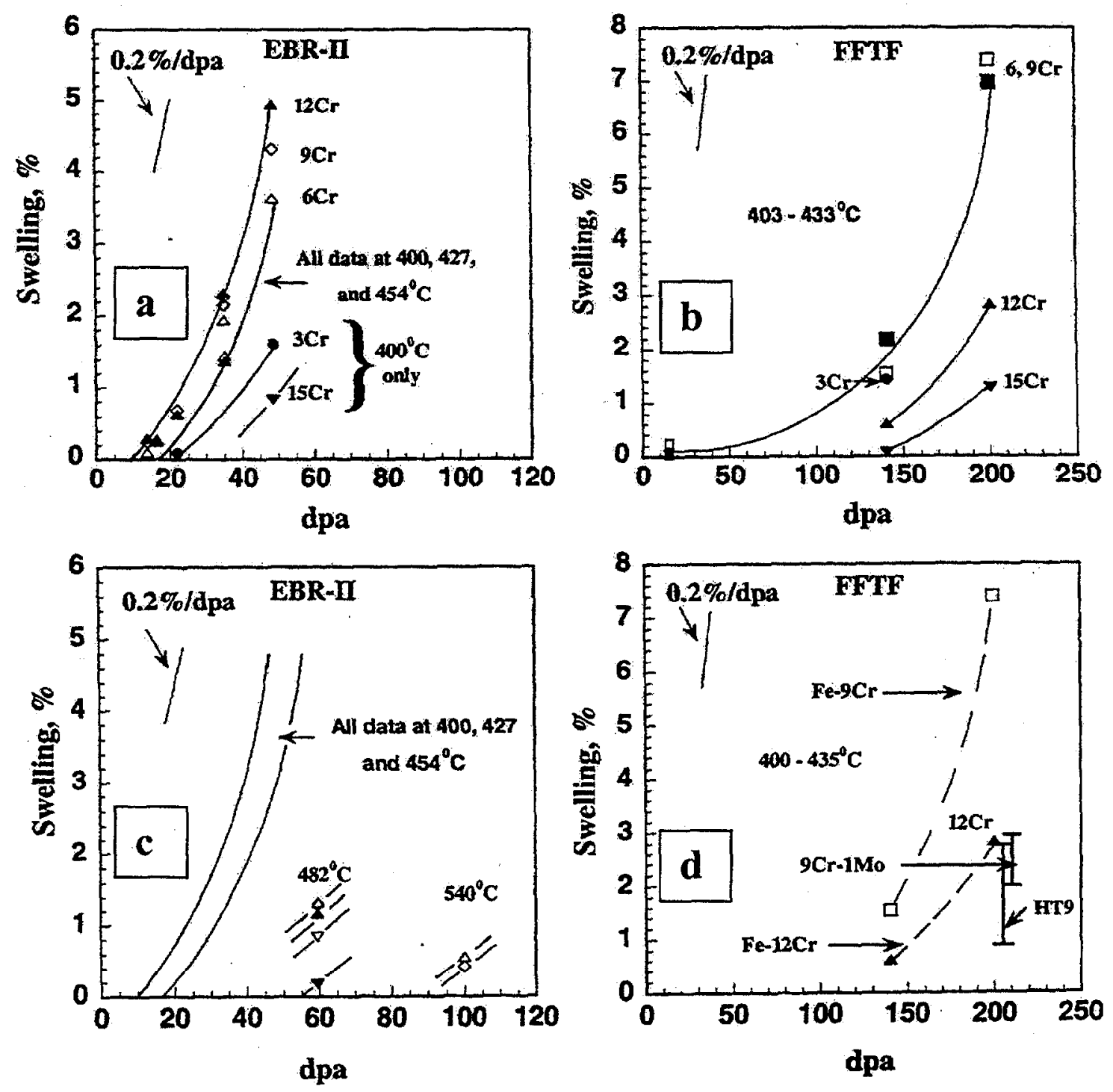

Figure 1. (a) Compilation of swelling data of $\mathrm{Fe}-(3-15) \mathrm{Cr}$ binary alloys irradiated in EBR-II (with corrected dpa levels) showing swelling rates on the order of $\sim 0.2 \% / \mathrm{dpa}$, following transient regimes that are somewhat dependent on composition) (b) similar compilation in FFTF, showing swelling rates on the order of $\sim 0.2 \% / \mathrm{dpa}$, following transient regimes that at low temperature are also somewhat dependent on composition, but which are very dependent on the different flux-temperature histories of the two reactors [12]. (c) At higher temperatures and the transient regimes are longer in EBR-II. (d) Also shown are HT9 $(12 \% \mathrm{Cr})$ and $9 \mathrm{Cr}-1 \mathrm{Mo}$ irradiated in FFTF, showing that their swelling is relatively close to their binary equivalents [13]. The range of swelling values for these two alloys demonstrates the effect of stress to increase swelling, with the lowest swelling at zero stress and monotonically increasing with stress. 

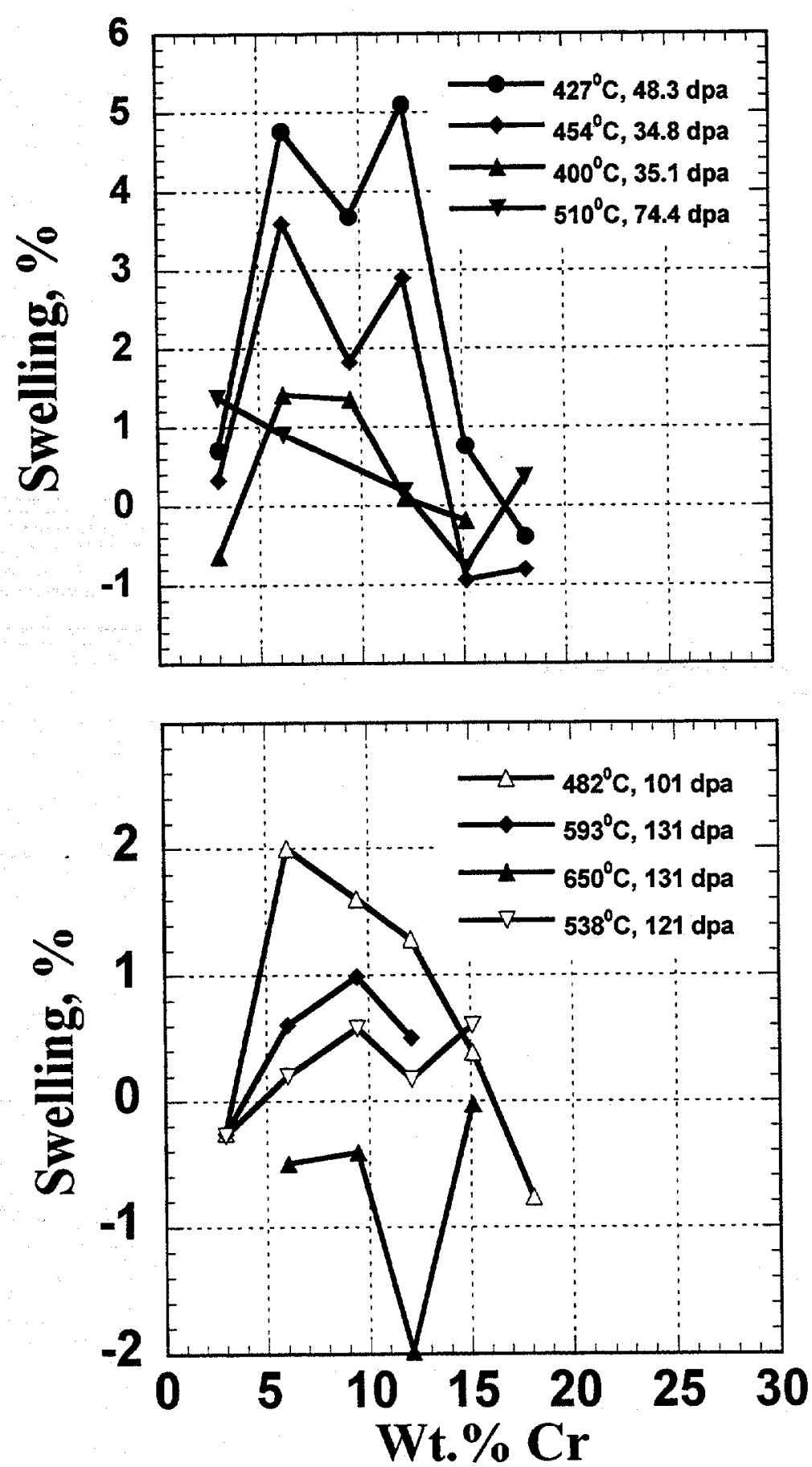

Figure 2. Swelling of $\mathrm{Fe}-\mathrm{Cr}$ binary alloys as a function of $\mathrm{Cr}$ level for various irradiation conditions in EBR-11. 

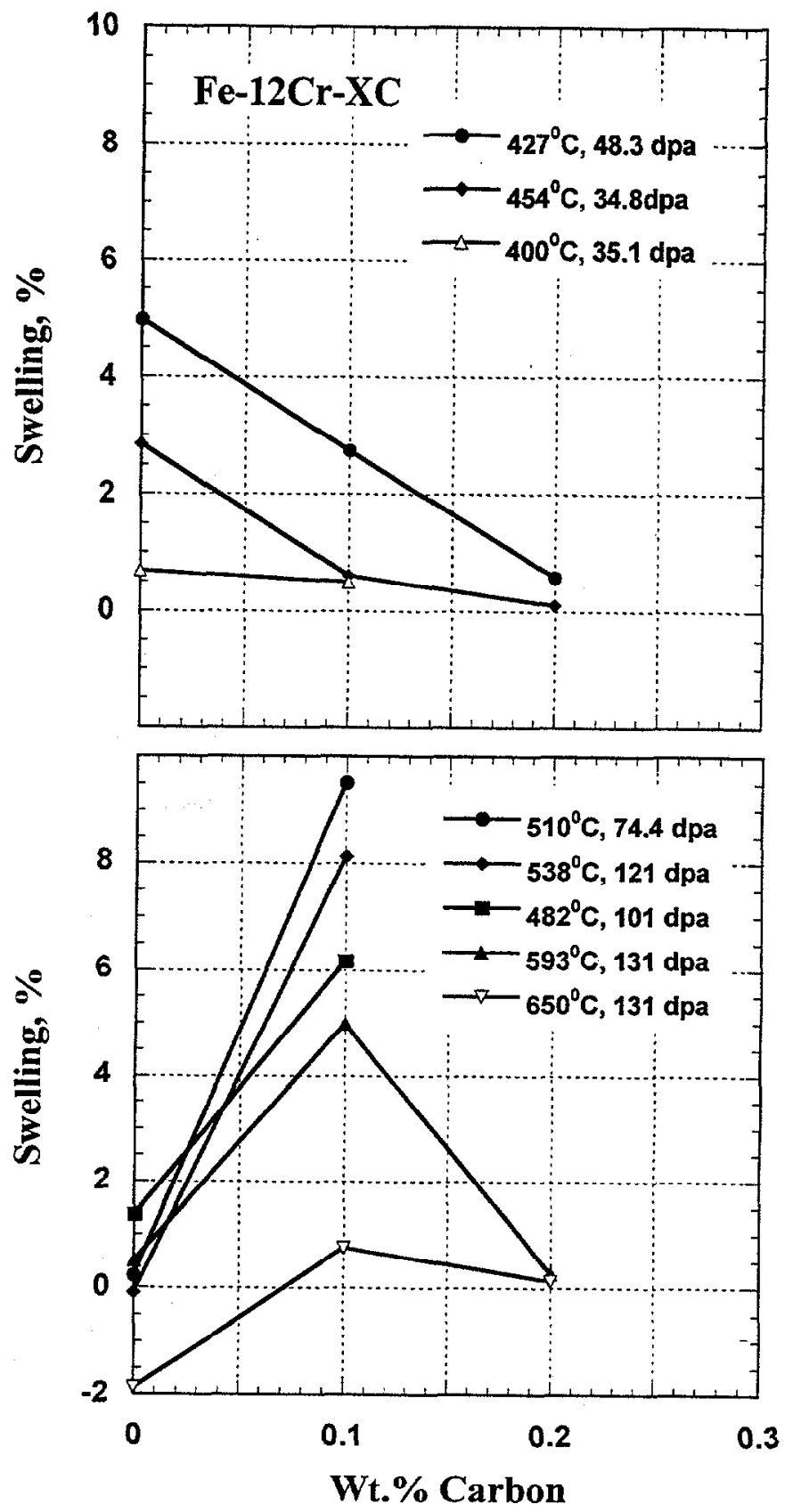

Figure 3. Effect of carbon additions on swelling of Fe-12Cr. 

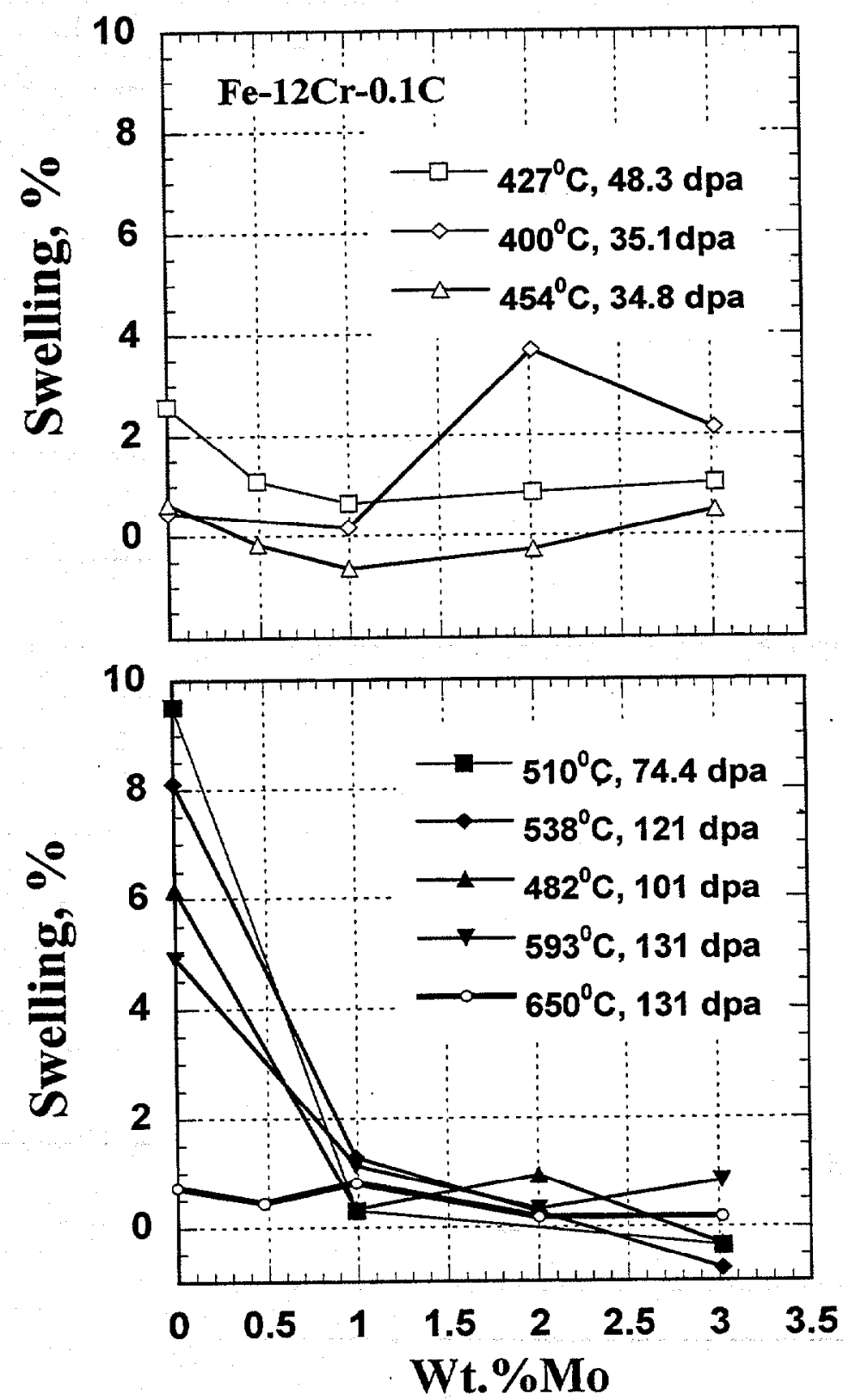

Figure 4. Effect of molybdenum additions on swelling of $\mathrm{Fe}-12 \mathrm{Cr}-0.1 \mathrm{C}$. 


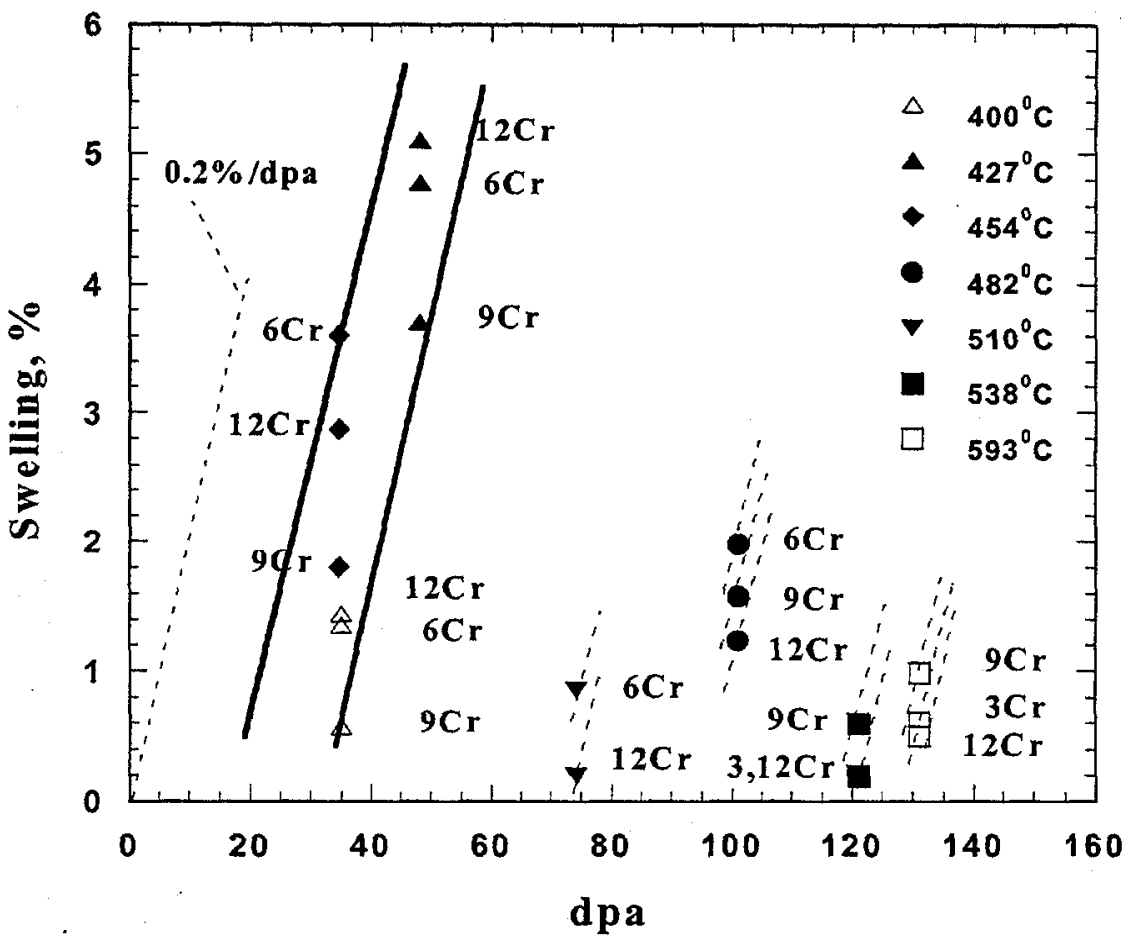

Figure 5. Swelling of $\mathrm{Fe}-\mathrm{Cr}$ binary alloys in EBR-Il as a function of temperature and dpa level, showing similar trends to those in Figs. $1 \mathrm{a}$ and $1 \mathrm{~b}$, but with swelling extending to much higher temperatures. The dotted lines at higher temperatures are used only for emphasis to separate the various data sets, with no explicit swelling rate implied.

\section{Discussion}

Garner and coworkers earlier showed that over a range of $\mathrm{Cr}(12-22 \%)$ and $\mathrm{Ni}(12-24 \%)$ levels and a range of relatively low temperatures the annealed fcc $\mathrm{Fe}-\mathrm{Cr}$-Ni ternary alloys irradiated in this same EBR-II experimental series could be considered to swell in a narrow band as if they were almost independent of temperature and composition [1-3]. Changes in composition or temperature outside these ranges yielded strong increases in the transient regime of swelling but no change in the steady-state swelling rate. It was later shown that the swelling data of Gelles for bcc Fe-Cr alloys could be treated in the same way [12].

As shown in the binary alloys examined in this experiment indeed appear to confirm this conclusion and once again support a steady-state swelling rate on the order of $\sim 0.2 \% / \mathrm{dpa}$. A surprising result is that if one is prepared to wait long enough, swelling in these fast reactors will eventually accelerate in bcc alloys at very high temperatures where swelling was never before anticipated. Only at $650^{\circ} \mathrm{C}$ has swelling not yet started. 
Note, however, that the transient regime does not appear to increase monotonically with increasing temperature in Figure 5. This is an illusion resulting from the differences in dpa rate at each temperature and arises from the large gradients in dpa rate across the relatively small EBR-Il core. Garner and coworkers showed earlier that higher dpa rates and more stable temperatures found in FFTF strongly extend the transient regime of swelling $[4,12]$. When compared at comparable dpa rates, the transient duration of $\mathrm{Fe}-\mathrm{Cr}$ in EBR-II indeed increases monotonically with temperature.

Figure 3 shows that addition of $0.1 \% \mathrm{C}$ to $\mathrm{Fe}-12 \mathrm{Cr}$ causes a dramatic increase in swelling at high temperatures compared with that of the binary alloy which strongly resists swelling. Even though the data are relatively sparse in this figure, it is difficult to visualize this increase except as a reduction in transient duration. Unfortunately, Gelles did not examine irradiated $\mathrm{Fe}-\mathrm{Cr}$ alloys at such high temperatures, although his data at lower temperatures confirm the carbon-induced suppression of swelling for alloys observed in the low temperature portion of our study [8].

The earlier low-temperature and lower-dpa results of Gelles also confirm the suppressive effect of molybdenum on swelling $[6,8]$. It is important to remember, however, that HT9 and $9 \mathrm{Cr}-1 \mathrm{Mo}$ both eventually began to swell at accelerated rates in FFTF at low temperature [13], as shown in Figure 1d. Even more importantly, significant precipitation accompanies swelling in these alloys, removing and redistributing elements such as $C$ and Mo $[8,13]$. The relatively strong effect of stress on swelling of $\mathrm{HTO}$ and $9 \mathrm{Cr}-1 \mathrm{Mo}$ alloys also suggests a transient-dominated behavior $[15,16]$.

The realization that the swelling resistance of bcc alloys resides primarily in delay of void nucleation, rather than an inherently low steady-state swelling rate has some strong potential implications for their future application to fusion devices and especially accelerator-driven spallation neutron devices. Irradiation testing of these alloys has proceeded only in neutron spectra that produce very low levels of helium and moderately low levels of hydrogen. The He/dpa ratios in fusion spectra are expected to be on the order of 5-15 appm/dpa and $~ 150$ appm/dpa in high-energy (>100 MeV) proton beams. The hydrogen generation rates are an order of magnitude greater in each case.

Given the demonstrated strong sensitivity of the transient duration of these binary alloys to the differences in flux and temperature history between EBR-ll and FFTF (both low gas generation devices) shown in Figure 1 , it is prudent to anticipate that the temperature, flux and gas history experienced in unexplored high gas generation devices may lead to swelling behavior significantly different from that obtained in any currently used fission spectrum. Based on the known effects of gaseous transmutants, the onset of swelling will most likely be accelerated in fusion and spallation neutron environments.

\section{Conclusions}

The neutron-induced swelling of $\mathrm{Fe}-\mathrm{Cr}$ binary alloys in fast reactors is characterized for the first time by a transient regime whose duration depends on temperature, composition and dpa rate, and second a steady-state swelling rate that is at least $\sim 0.2 \% / \mathrm{dpa}$ and possibly still climbing to higher levels as swelling continues. The relatively long transient duration at high temperatures is abruptly shortened by the addition of carbon, however. Subsequent addition of molybdenum tends to return the transient to higher dose levels. Since the relative swelling resistance of bcc steels is now known to arise primarily from nucleation-dominated transient behavior, it appears that irradiation in spectra with high gaseous transmutation 
rates might lead to significantly higher than expected swelling levels in both model and structural alloys.

\section{ACKNOWLEDGEMENTS}

This work was supported by the Office of Fusion Energy Sciences, U. S. Department of Energy under Contract DE-AC06-76RLO-1830.

\section{REFERENCES}

[1] F. A. Garner and H. R. Brager, in Effects of Radiation on Materials: 12th Inter. Symp., ASTM STP 870, 1985, pp. 187-201.

[2] F. A. Garner and A. S. Kumar, in Radiation-Induced Changes in Microstructure: 13th Inter. Symp.; Part 1, ASTM STP 955, 1987, pp. 289-314.

[3] F. A. Garner, J. Nucl. Mater. 122 \& 123 (1984) 459-471.

[4] F. A. Garner and C. A. Black, Proc. 19th ASTM Symp. on Effects of Radiation on Materials, ASTM STP 1366, Seattle, WA, June 16-18, 1998, in press.

[5] F. A. Garner, C. A. Black and D. J. Edwards, J. Nucl. Mater. 245 (1997) 124-130.

[6] D. S. Gelles and R. L. Meinecke, in Alloy Development for Irradiation Performance Semiannual Progress Report, DOE/ER-045/11, 1984, pp. 103-107.

[7] . D. S. Gelles and L. E. Thomas, in Proc. Topical Conf. on Ferritic Alloys for Use in Nuclear Energy Technologies, AIME, 1984, pp. 559-568.

[8] D. S. Gelles, J. Nucl. Mater. 108-109 (1982) 515-526.

[9] D. S. Gelles, in Effects of Radiation on Materials: 14th Inter. Symp. vol. 1, ASTM STP 1046, 1989, pp. 73-97.

[10] Y. Katoh, A. Kohyama and D. S. Gelles, J. Nucl. Mater. 225 (1995) 154162.

[11] D. S. Gelles, J. Nucl. Mater. 225 (1995) 163-174.

[12] F. A. Garner, M. B. Toloczko, B. H. Sencer, J. Nucl. Mater., $276(2000)$ 123-142.

[13] M. B. Toloczko, F. A. Garner and C. R. Eiholzer, J. Nucl. Mater. 212-215 (1994) 604-607.

[14] S. Ohnuki and F. A. Garner, work in progress.

[15] F. A. Garner, W. G. Wolfer and H. R. Brager, "A Reassessment of the Role of Stress on Development of Radiation Induced Microstructure," in Proceedings, International Symposium on Effect of Radiation on Structural Materials ASTM STP 683, July 1014, 1978, Richland, WA, p. 160. 
[16] F. A. Garner, Chapter 6: "Irradiation Performance of Cladding and Structural Steels in Liquid Metal Reactors," Vol. 10A of Materials Science and Technology: A

Comprehensive Treatment, VCH Publishers, 1994, pp. 419-543. 
RADIATION HARDENING IN HCP TITANIUM ALLOYS - D. J. EDWARDS (PACIFIC NORTHWEST NATIONAL LABORATORY)", B. N. SINGH AND P. TOFT (RIS $\varnothing$ NATIONAL LABORATORY)

\section{OBJECTIVE}

The objective of this work is to further our understanding of the fundamentals of radiation hardening due to neutron irradiation as they apply to pure metals and their alloys.

\section{SUMMARY}

Two titanium alloys were irradiated at 50 and $350^{\circ} \mathrm{C}$ to $\sim 0.3 \mathrm{dpa}$. Tensile properties were determined for both alloys and related to the observed microstructure before and after deformation. Radiation hardening occurred in both alloys when irradiated at $50^{\circ} \mathrm{C}$ due to the presence of fine-scale defects, whereas at $350^{\circ} \mathrm{C}$ only the Ti-6Al-4V alloy showed significant hardening. Radiation-induced precipitation occurred in this alloy, yielding a high strength, lower ductile condition compared to the unirradiated condition.

\section{PROGRESS AND STATUS}

\section{Introduction}

Radiation hardening is known to occur in a wide range of crystal structures and alloy compositions when these materials are irradiated at low enough temperatures (see Ref. 1 for a recent review on this topic). Depending on the irradiation temperature, dose, dose rate, and material composition, irradiation hardening can arise from radiation-induced precipitation, void swelling, and/or defects produced during irradiation. In the case of neutron irradiation at temperatures lower than the annealing Stage $\mathrm{V}$, the source of the radiation hardening in pure metals is derived from the cascade damage that yields single interstitials, vacancies, and small clusters of these defects that can be sessile or glissile depending on their size and nature. The defects can evolve as a function of dose to yield dislocation networks and larger loops. The presence of these defect clusters and the features that eventually evolve can cause substantial changes in the mechanical and physical behavior of the material, including the loss of uniform ductility and work hardening, large increases in yield strength, formation of a yield drop, and overall loss of conductivity. In alloys the situation can be even more complex if second phases are produced or altered by irradiation in addition to the defect produced during irradiation.

Hexagonal close-packed materials have not been studied nearly as extensively as facecentered cubic or even body-centered systems, but early work by Makin [2] demonstrated that radiation hardening occurs in zirconium and its alloys. Debate still continues regarding the actual source of radiation hardening in pure metals and alloys, and fundamental work is required to elucidate the mechanisms involved. In this study we have initiated a radiation experiment aimed at looking at radiation effects in titanium alloys and eventually pure titanium when the specimens become available.

\footnotetext{
"Pacific Northwest National Laboratory (PNNL) is operated for the U.S. Department of Energy by Battelle Memorial Institute under contract DE-AC06-76RLO-1830.
} 


\section{Experimental}

Tensile specimens of an $(\alpha+\beta)$ titanium alloy (Ti-6Al-4V, proprietary heat treatment) and an $\alpha$-titanium alloy (Ti-5Al-2.5Sn, proprietary heat treatment) have been irradiated in the DR-3 reactor at Risø to a fluence level $1.5 \times 10^{24} \mathrm{n} / \mathrm{m}^{-3}$ (E>1 MeV), which corresponds to a displacement level of approximately $0.3 \mathrm{dpa}$ (NRT). The irradiations were carried out with a neutron flux of $2.5 \times 10^{17} \mathrm{n} / \mathrm{m}^{-2}$ corresponding to a displacement rate of $-5 \times 10^{-8} \mathrm{dpa} / \mathrm{s}$. Multiple tensile specimens were irradiated at $\sim 50$ and $350^{\circ} \mathrm{C}$, then tested at the same temperature as they were irradiated. Tests were conducted in vacuum $\left(<10^{-4}\right.$ torr) at a strain rate of $1.2 \times 10^{-3} \mathrm{~s}^{-1}$. Preliminary characterization of the as-supplied material and asirradiated and tested samples were conducted by transmission electron microscopy in a JEOL 2000FX. Fractography was performed on the tested samples in a JEOL 840 scanning electron microscope.

\section{Results}

\section{(a) Ti-5Al-2.5Sn}

The microstructure of this alloy consists of equiaxed grains of HCP alpha substitutionally strengthened by the aluminum and tin additions. Subgrains are present in some areas, but in general no dislocations are present in a high density. The Al and $\mathrm{Sn}$ are both alphastabilizers and do not promote any precipitation strengthening in the unirradiated condition, so the material is essentially single phase. As shown in Figure $1 \mathrm{a}$, irradiation at $50^{\circ} \mathrm{C}$ produces a high density of small defect clusters or loops that have not yet been


Figure 1. The small clusters or loops shown in (a) form in the $\alpha$-titanium alloy Ti-5Al-2.5Sn during irradiation at $50^{\circ} \mathrm{C}$. The clusters are present in a density on the order of $10^{23} \mathrm{~m}^{-3}$ and range in size from $<1 \mathrm{~nm}$ to $3 \mathrm{~nm}$. Irradiation of the same alloy at $350^{\circ} \mathrm{C}$ produces a much larger type of loop (b) that appears to coalesce to form rafts or line segments. 


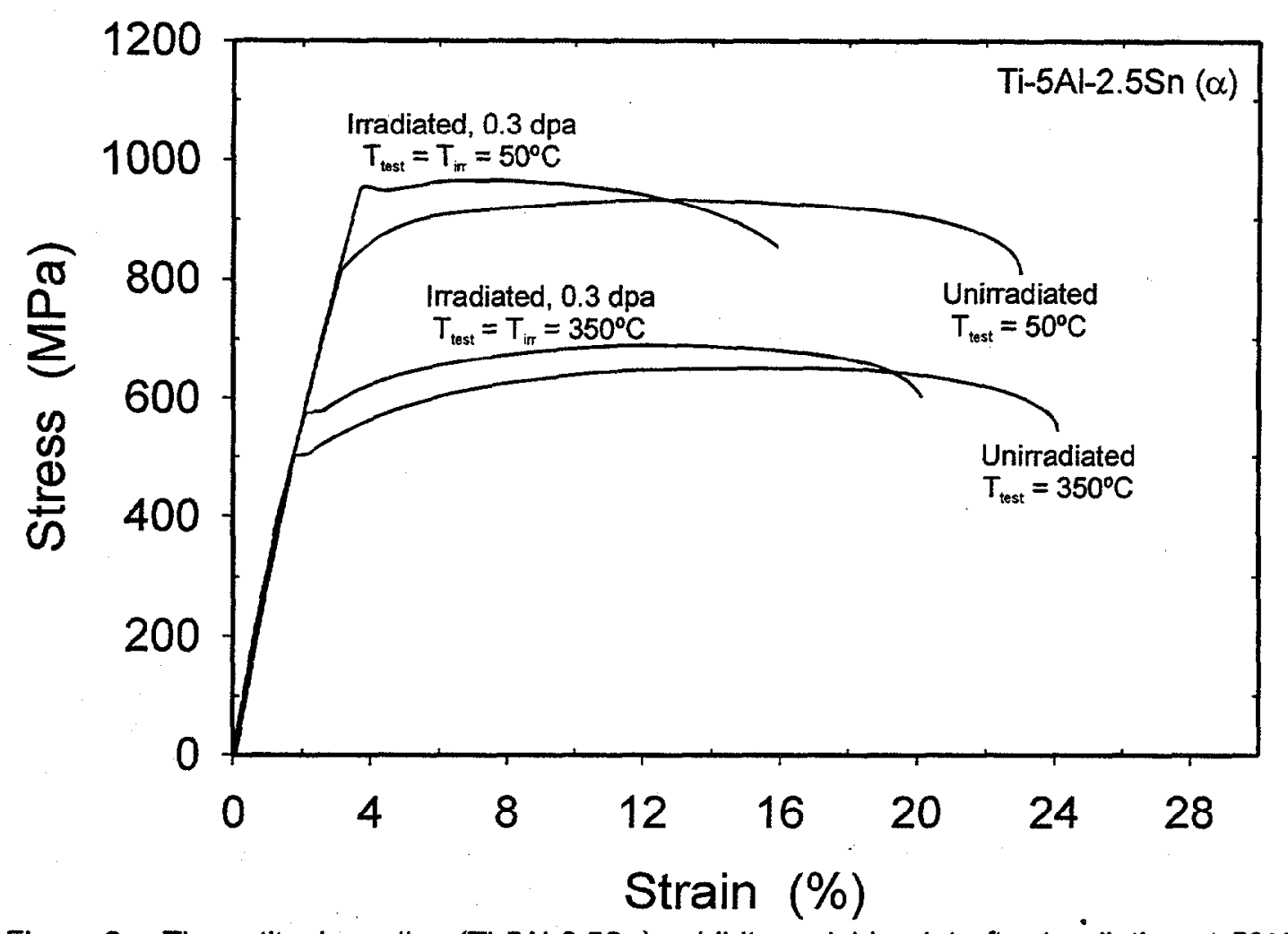

Figure 2. The $\alpha$-titanium alloy (Ti-5Al-2.5Sn) exhibits a yield point after irradiation at $50^{\circ} \mathrm{C}$ as well a loss of uniform and total elongation. There is only a slight hardening after irradiation at $350^{\circ} \mathrm{C}$.

identified. The size of these defects ranges from 0.5 to $3 \mathrm{~nm}$, and their density is estimated to be on the order of $10^{23} \mathrm{~m}^{-3}$, similar to that measured in pure copper. No dislocation network is present in the unirradiated samples and none forms after irradiation to this dose. Irradiation at $350^{\circ} \mathrm{C}$ produces a much coarser size and spatial distribution of dislocation loops (see Figure 1b). These loops are on the order of 10-20 nm in size, and there is some evidence to suggest that they are beginning to coalesce to form either a raft microstructure or dislocation line segments.

The tensile curves shown in Figure 2 reveal that relative to the strength at $50^{\circ} \mathrm{C}$, the unirradiated alloy loses a large fraction of its strength when tested at $350^{\circ} \mathrm{C}$. Work hardening remains minimal for both test temperatures with a uniform elongation on the order of $10-15 \%$. The failure mode is ductile at both test temperatures in the unirradiated conditions. Irradiation at $50^{\circ} \mathrm{C}$ produces an upper/lower yield point approximately $130 \mathrm{MPa}$ higher than the sharp yield point observed in the unirradiated specimens tested at $50^{\circ} \mathrm{C}$. Additionally, the UTS has increased, but it is near the same level as the upper yield point, which corresponds to the lack of work hardening present in the irradiated samples. In addition both the uniform and total elongation are lower compared to the unirradiated condition. TEM examination of the deformed samples near the fracture surface reveals some disiocation channeling, slip bands and twins, with the dislocation channels cleared of the defect clusters.

The samples irradiated and tested at $350^{\circ} \mathrm{C}$ exhibit the same yield plateau as exhibited in the unirradiated samples, however, there is a modest increase in both the yield and ultimate strength accompanied by some reduction in elongation. Deformation occurs homogenously within individual grains and was characterized by narrow slip bands aligned along 
crystallographic directions. A small number of the grains appear to be free of deformation and usually contain the long segments of dislocations or agglomeration of loops shown in Figure $1 \mathrm{~b}$. SEM of the fracture surface reveals no evidence of brittle fracture in either the 50 or the $350^{\circ} \mathrm{C}$ specimens. Overall irradiation at $350^{\circ} \mathrm{C}$ to $-0.3 \mathrm{dpa}$ leads to only a minor shift in mechanical properties, whereas the effect of irradiation is more noticeable at $50^{\circ} \mathrm{C}$.

\section{$(\alpha+\beta) T i-6 \mathrm{Al}-4 \mathrm{~V}$}

This near-alpha titanium alloy is characterized by a two phase microstructure in the unirradiated condition. The microstructure consists of large equiaxed grains of alpha phase (HCP) surrounded by Widmanstätten colonies of acicular platelets of alpha with beta phase (BCC) separating the alpha platelets. Irradiation at both 50 and $350^{\circ} \mathrm{C}$ causes no changes in the overall appearance of the individual phases, so the micrograph shown in Figure $3 a$ is representative of the unirradiated and irradiated microstructure. Irradiation at $50^{\circ} \mathrm{C}$ produces essentially the same kind of defect structure in the alpha phase as shown earlier in the case of the Ti-5Al-2.5 Sn alloy. No defect clusters or loops are observed in the beta phase, perhaps because the narrow platelets and close boundaries do not permit the formation of a stable loop structure. At $350^{\circ} \mathrm{C}$ significant precipitation occurs during irradiation, as
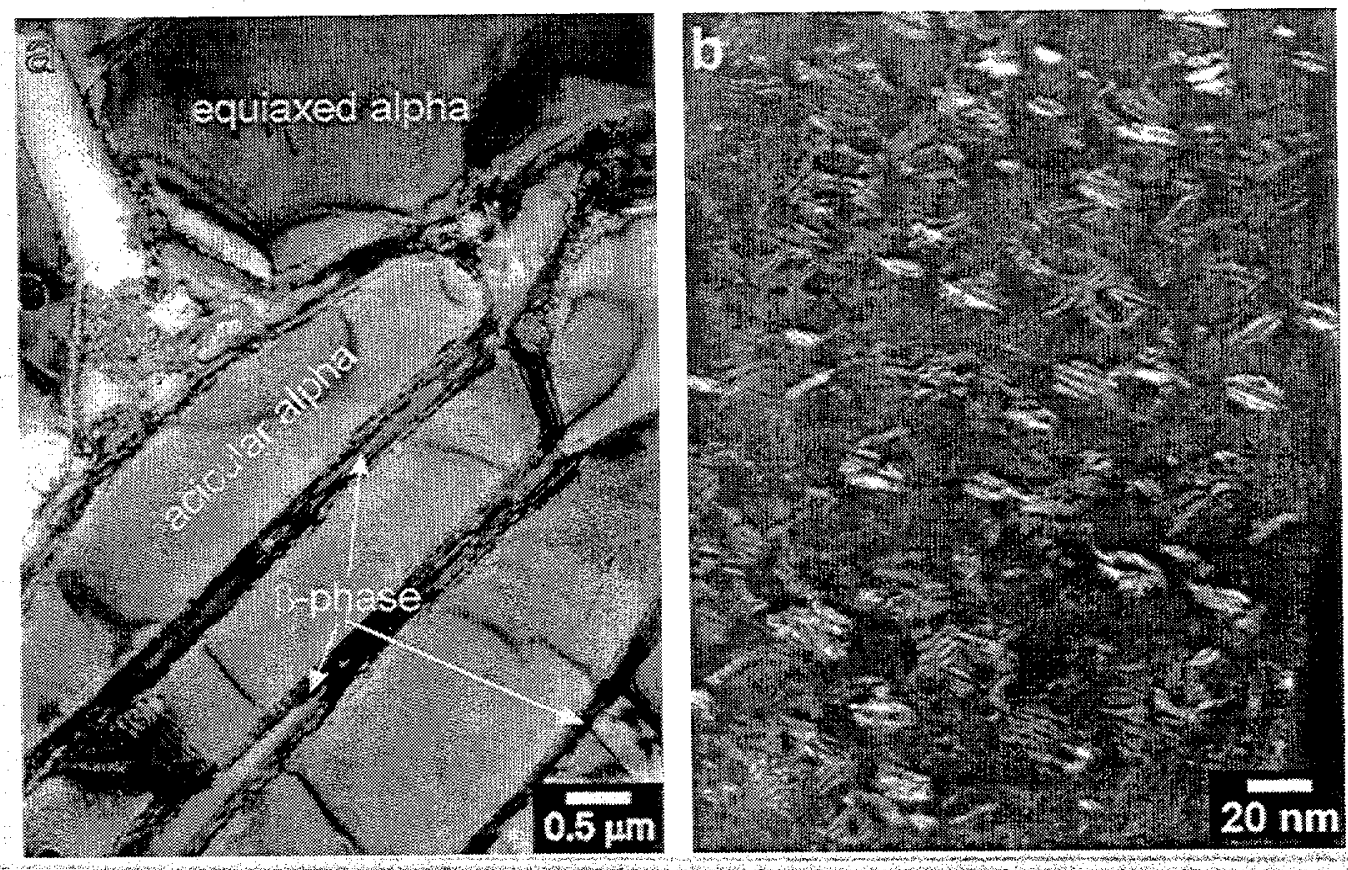

Figure 3. The microstructure of the $(\alpha+\beta)$ titanium alloy (Ti-6Al-4V) shown in (a) consists of equiaxed grains of hcp alpha-phase with Widmanstätten colonies of acicular alpha and $\mathrm{BCC}$ beta phase. Irradiation at $350^{\circ} \mathrm{C}$ leads to the irradiation-induced precipitation in (b) that produces a strong increase in yield and ultimate strength. 


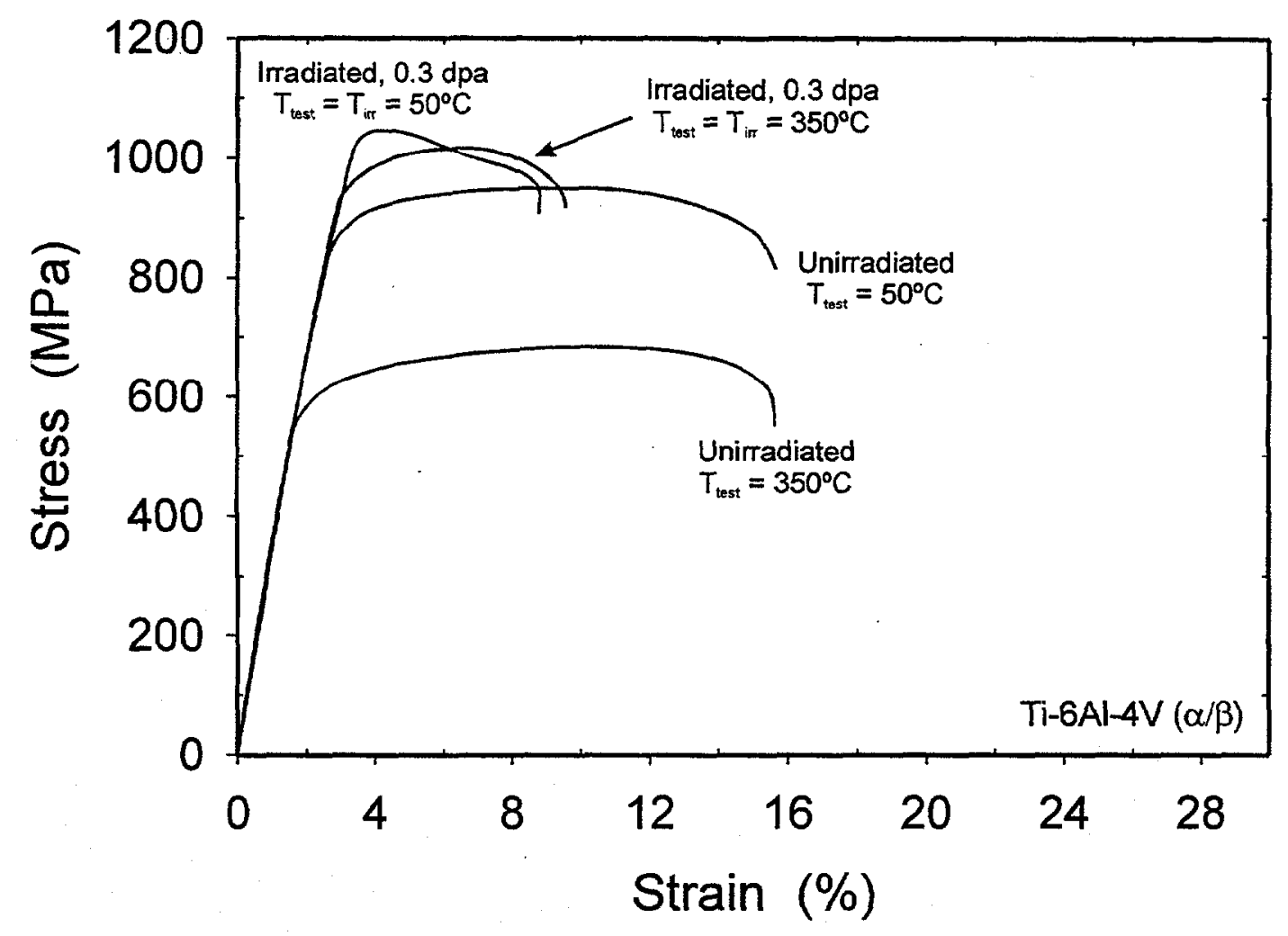

Figure 4. The $\alpha-\beta$ titanium alloy (Ti-6Al-4V) experienced a loss of ductility and increase in strength after irradiation at both 50 and $350^{\circ} \mathrm{C}$. Radiation-induced precipitation is responsible for the changes in properties at $350^{\circ} \mathrm{C}$, whereas fine-scale defects produced by irradiation are responsible at $50^{\circ} \mathrm{C}$.

illustrated in Figure $3 \mathrm{~b}$. The type of precipitates, their chemistry and orientation relationship remain to be determined, but they are present in a sufficiently high density to cause substantial changes in the tensile properties. Precipitation-denuded zones are observed along the grain boundaries in addition. Defect clusters or loops within the alpha phase couid not be detected because of the extensive precipitation.

The Ti-6Al-4V alloy in the as-supplied condition is slightly stronger and less ductile than the $\alpha$-titanium alloy Ti-5Al-2.5Sn in the unirradiated condition (see Figure 4). However, irradiation at $50^{\circ} \mathrm{C}$ produces an increase in yield and ultimate strength almost $100 \mathrm{MPa}$ higher than that observed in the alpha titanium alloy. The two phase material shows no evidence of a yield drop, but work hardening is minimal and the uniform elongation is very low $(<0.5 \%)$. No significant dislocation interactions are observed, but the TEM sample may not have been taken close enough to the fracture surface. Though the tensile curve exhibits no plastic instability, uniform elongation is negligible in these samples, so it is unlikely that there is much evidence of deformation away from the necked region and fracture surface. SEM reveals that the failure mode remains ductile and that significant reduction in area occurs. The strong irradiation-induced precipitation at $350^{\circ} \mathrm{C}$ produces a remarkable increase in strength rivaling that of the $50^{\circ} \mathrm{C}$ irradiated and tested samples. Despite this, it exhibits more uniform elongation and work hardening ability than that of the specimens irradiated at $50^{\circ} \mathrm{C}$, and possesses a uniform elongation of several percent. SEM of the 
fracture surfaces in this condition reveal that the failure mode is again ductile and accompanied by some reduction in area.

\section{Discussion}

It is clear from this work that titanium alloys are as susceptible to radiation hardening and loss of ductility as zirconium and its alloys [2]. The work further illustrates that at temperatures below annealing Stage $V$ both alloys are prone to extreme hardening due to the presence of the fine scale defects produced during irradiation. The behavior illustrated here for the $\alpha$-titanium is similar in many respects to that exhibited by pure copper and $\mathrm{CuCrZr}$, both of which develop a tensile instability immediately upon yielding [3-7]. Similar behavior has been observed in pure BCC Iron, as well as molybdenum alloys $[8,9]$. Radiation hardening is therefore a fundamental problem that is independent of crystal systems, at least in FCC, BCC, and HCP metals and alloys.

It is worth noting that the single phase $\alpha$-titanium alloy behaves differently in tension compared to the two phase $(\alpha+\beta)$ titanium alloy after irradiation at $50^{\circ} \mathrm{C}$. Although both exhibit a large increase in strength, loss of ductility, and negligible work hardening, the $(\alpha+\beta)$ titanium alloy does not exhibit the yield drop observed in the Ti-5Al-2.5 Sn alloy. At this time we can only speculate that the presence of the Widmanstätten structure interferes with the propagation of the channels and formation of twins in some manner, perhaps by promoting a more homogenous source for dislocations or twinning within the nearby alpha grains. The oxide dispersion strengthened copper alloy GlidCop Al25, with its fine grain size and moderate to high dislocation density, behaves similarly after irradiation at low temperatures, but it also has little in the way of uniform elongation.

The respective behavior of the two titanium alloys and that of the ODS copper alloy reveals a possible method to mitigate the yield drop and tensile instability. One can introduce a high density of obstacles that interfere with the motion of moving dislocations, and that are inherently stronger than the small defects produced during irradiation. Oxide particles are one such obstacle, and coupled with a high dislocation density from cold working or extrusion, they can prevent the formation of channeling if present in a high enough density. However, the volume fraction of particles necessary to do this may leave the material in a state that is only marginally better given its high strength and low ductility. The $(\alpha+\beta)$ titanium alloy offers a different solution in that the presence of a sufficient number of phase boundaries (equiaxed alpha intermixed with the Widmanstätten colonies in this case) can interfere with the channel or twinning. This raises the possibility that varying the heat treatment to produce different volume fractions of one phase versus another could alter the response of the material to radiation hardening by virtue of changing the density of phase and/or grain boundaries.

One final issue to keep in mind when considering radiation hardening is that the fracture toughness may not necessarily be degraded despite the tensile instability, which is an important consideration for structural applications. This was recently shown for irradiated $\mathrm{CuCrZr}$ by Tähtinen and coworkers [10], who found that the toughness remained as high or higher after irradiation to $0.3 \mathrm{dpa}$ at $50^{\circ} \mathrm{C}$ despite the presence of tensile instability, i.e. work softening. Presumably this is related to the materials ability to fail in a ductile manner and shows significant reduction in area despite the tensile instability, highlighting the importance of measuring the reduction in area for radiation hardened materials to determine the materials sensitivity to radiation hardening or embrittlement at after irradiation.

Finally, the $(\alpha+\beta)$ titanium alloy irradiated at $350^{\circ} \mathrm{C}$ provides a different perspective on radiation hardening in that radiation-induced precipitation can also produce substantial 
increases in the strength. This serves to illustrate that the microstructure needs to be examined carefully before drawing conclusions on what contributes to strengthening.

\section{Conclusions}

The two titanium alloys irradiated at 50 and $350^{\circ} \mathrm{C}$ show that they are both susceptible to radiation hardening at $50^{\circ} \mathrm{C}$, but only the $(\alpha+\beta)$ titanium alloy hardens significantly when irradiated at $350^{\circ} \mathrm{C}$. While the hardening at $50^{\circ} \mathrm{C}$ appears to be related to the formation of fine-scale defects in both alloys, the hardening observed in the Ti-6Al-4V alloy at $350^{\circ} \mathrm{C}$ is related primarily to radiation-induced precipitation. The solid solution strengthened $\alpha-$ titanium alloy exhibits a yield drop after irradiation at $50^{\circ} \mathrm{C}$, but this is not seen in the case of the $(\alpha+\beta)$ titanium alloy, presumably due to the two-phase nature of the microstructure. Despite the radiation hardening that leads to very high yield and ultimate stresses, both materials fail in a ductile manner. Future work will study how the two alloys compare to pure titanium in their microstructure and tensile behavior after irradiation.

\section{ACKNOWLEDGEMENTS}

The present work was partly funded by the European Fusion Technology Programme. The authors wish to thank B. F. Olsen, N.J. Pederson and J.L. Lindbo. DJ Edwards would like to thank Risø National Laboratory for the support and assistance during his visit. His work was also partly supported by the U.S. Department of Energy under contract DE-AC06-76RLO 1830 with the Battelle Memorial Institute at the Pacific Northwest National Laboratory.

\section{REFERENCES}

[1] B. N. Singh, A.J.E. Foreman and H. Trinkaus, J. Nucl. Mater. $\underline{249}$ (1997) 103.

[2] M. J. Makin, Radiation Effects, ed. W. F. Sheely, Metallurgical Society Conference, Ashville, NC, 1965, p. 627B.N. Singh, D.J. Edwards and P. Toft, J. Nucl. Mater. 238 (1996) 244.

[3] B. N. Singh, D. J. Edwards and P. Toft, J Nucl.Mater. 238 (1996) 244.

[4] B. N. Singh, D.J. Edwards, A. Horsewell and P. Toft, Dose Dependence of Microstructural Evolution and Mechanical Properties of Neutron Irradiated Copper and Copper Alloys, Risø-R-839 (EN) ,Ris $ø$ National Laboratory, Roskilde, Denmark, September (1995).

[5] S. A. Fabritsiev, A. S. Pokrovsky, S. J. Zinkle, D. J. Edwards, J. Nucl. Mater. 233-237 (1996) 513.

[6] A. F. Rowcliffe, S. J. Zinkle, J. F. Stubbins, D. J. Edwards, and D. J. Alexander, J. Nucl. Mater. 258-263 (1998) 183.

[7] D. J. Edwards, B. N. Singh, P. Toft, and M. Eldrup, J. Nucl. Mater. 258-263 (1998) 978.

[8] B. N. Singh, A. Horsewell and P. Toft, J. Nucl. Mater. 271-273 (1999) 97.

[9] B. N. Singh, J. H. Evans, A. Horsewell, P. Toft, and D.J. Edwards, J. Nucl. Mater. 223 (1995) 95.

[10] S. J. Tähtinen, M. T. Pyykkönen, B. N. Singh and P. Toft, Proceedings of the $19^{\text {th }}$ International Symposium on the Effects of Radiation on Materials, ASTM STP 1366, eds. M. L. Hamilton, A. S. Kumar, S. T. Rosinski and M. L. Grossbeck, (2000), p. 1243. 
PASSIVE TEMPERATURE MONTORS FOR THE HFIR METS EXPERIMENT - S. D. CONnEY (Rensselaer Polytechnic Institute), L. L. Snead (Oak Ridge National Laboratory) and D. Steiner (Renssolaer Polytechnic Institute)

\section{SUMMARY}

The purpose of this work is to provide a method of indicating the maximum temperature in the uninstrumented Mapping Elevated Temperature Swelling (METS) capsules. Small heats of selected alloys and pure metals ("melt blocks") were fabricated with a range of melting temperatures to be included in the METS capsules. Visual inspection and/or radiography of the melt blocks after irradiation will indicate the maximum temperature attained to within $\sim 20^{\circ} \mathrm{C}$. METS subcapsules expected to remain below $1000^{\circ} \mathrm{C}$ will also include SiC temperature monitors. Post-irradiation annealing and dimensional analysis of the SiC temperature monitors will provide an estimate of the temperature at the end of irradiation to within $\sim 45^{\circ} \mathrm{C}$.

\section{PROGRESS AND STATUS}

\section{Introduction}

Three uninstrumented METS capsules, containing single crystal SiC and other ceramics, will be irradlated to at least $4.5 \mathrm{dpa}$ in the temperature range of $780-1650^{\circ} \mathrm{C}$. Limited data to date suggests that irradiation-induced swelling of $\mathrm{SiC}$ changes from point defect swelling to void swelling at approximately $1000^{\circ} \mathrm{C}$ [1]. Because point defect swelling saturates at a low irradiation dose while void swelling continues to increase with dose, fusion reactors must be designed so that SiC components operate below the transition temperature from point defect to void swelling. The primary purpose of the METS capsules is to help determine this transition temperature, but the specimens will also be subjected to other post-irradiation physical characterization.

Since the METS capsules are uninstrumented, the only method to determine the temperature at which the specimens have been irradiated is to include passive temperature monitors in the capsule. Usually, SiC bars with precisely known dimensions are used in capsules to be irradiated to low doses within SiC's point defect swelling temperature regime $\left(<1000^{\circ} \mathrm{C}\right)$. Post-irradiation annealing of the SiC over a range of temperatures anneals out the point defects and associated swelling at the irradiation temperature experienced by the capsule at the end of the irradiation [271. The elevated temperatures of most segments of the METS capsules preclude the exclusive use of SiC temperature monitors, so melt blocks with melting temperatures spanning the expected maximum temperatures have been created. Visual and/or radiographic inspection of the blocks in a hot cell after irradiation will indicate the maximum irradiation temperature of each capsule segment.

\section{Experimental Procedure}

Alloys and pure metals were selected with melting temperatures in the range of $660-1769^{\circ} \mathrm{C}$ (Table 1). Preference was given in alloy selection to binary systems with minimal $\left(\sim 20^{\circ} \mathrm{C}\right)$ temperature gaps between their solidus and liquidus phase diagram lines and with low constituent vapor pressures $\left(<0.0003 \mathrm{~Pa}\right.$ at $\left.1100^{\circ} \mathrm{C}\right)$. For the purposes of this work, the liquidus temperature for non-utectic alloy compositions was treated as the melting temperature and this has not presented a problem in visually assessing melting in post-fabrication melting tests. Of the alloy components, only $\mathrm{Ni}$ and $\mathrm{Pt}$ met the vapor pressure criteria, and significant evaporation was observed in a vacuum (<8.0 × $10^{-6}$ torr) for melts containing other elements. No significant melt evaporation has been obsenved in an environment similar to the internal environment of the METS capsules, static Ar gas at a slight positive pressure $(\sim 1$ psi at room temperature, 
Table 1. Alloys and Pure Metals Selected for METS Capsule Melt Blocks

\begin{tabular}{|c|c|}
\hline Material $(w t \%)$ & $T_{m}\left({ }^{\circ} \mathrm{C}\right)$ \\
\hline $\mathrm{Al}$ & 660 \\
\hline $\mathrm{Ge}$ & 938 \\
\hline $18 \mathrm{Ni}-82 \mathrm{Au}$ & 955 \\
\hline $\mathrm{Ag}$ & 962 \\
\hline $7.7 \mathrm{Ni}-92.3 \mathrm{Au}$ & 980 \\
\hline $5.2 \mathrm{Ni}-94.8 \mathrm{Au}$ & 1000 \\
\hline $3.5 \mathrm{Ni}-96.5 \mathrm{Au}$ & 1020 \\
\hline $1.8 \mathrm{Ni}-98.2 \mathrm{Au}$ & 1040 \\
\hline $\mathrm{Au}$ & 1064 \\
\hline $\mathrm{Cu}$ & 1084 \\
\hline $19 \mathrm{Pd}-81 \mathrm{Cu}$ & 1100 \\
\hline
\end{tabular}

\begin{tabular}{|c|c|}
\hline Materla $(w \%)$ & $\left.T_{m}{ }^{\circ} \mathrm{C}\right)$ \\
\hline $39 \mathrm{Pd}-61 \mathrm{Cu}$ & 1140 \\
\hline $50 \mathrm{Pd}-50 \mathrm{Cu}$ & 1180 \\
\hline $59 \mathrm{Pd}-41 \mathrm{Cu}$ & 1220 \\
\hline $60.1 \mathrm{Pd}-39.9 \mathrm{Ni}$ & 1237 \\
\hline $49 \mathrm{Pd}-51 \mathrm{Ni}$ & 1260 \\
\hline Pure Be & 1289 \\
\hline $36 \mathrm{Pd}-64 \mathrm{Ni}$ & 1300 \\
\hline $26 \mathrm{Pd}-74 \mathrm{NI}$ & 1340 \\
\hline $17 \mathrm{Pd}-83 \mathrm{Ni}$ & 1380 \\
\hline Pure Si & 1414 \\
\hline & \\
\hline
\end{tabular}

\begin{tabular}{|c|c|}
\hline Material $(w / \%)$ & $T_{m}\left({ }^{\circ} \mathrm{C}\right)$ \\
\hline 9Pd-91Ni & 1420 \\
\hline Pure Ni & 1455 \\
\hline 94Pd-6Ni & 1475 \\
\hline $77 \mathrm{Pt}-23 \mathrm{Ni}$ & 1495 \\
\hline Pure Co & 145 \\
\hline 96Pd-4Ni & 1500 \\
\hline $81 \mathrm{Pt}-19 \mathrm{Ni}$ & 1540 \\
\hline 86.5Pt-13.5Ni & 1550 \\
\hline Pure Pd & 1555 \\
\hline 90Pt-10Ni & 1580 \\
\hline & \\
\hline
\end{tabular}

* Eutectic composition

increasing to $\sim 7 \mathrm{psi}$ at $1600^{\circ} \mathrm{C}$ ). Therefore, fabrication and melting temperature verification were conducted in Ar.

Fabrication of the alloyed melt blocks was straightforward. The appropriate amounts of each metal were melted together in an alumina crucible at $-90^{\circ} \mathrm{C}$ above the greater melting temperature of the two components for 40 minutes to produce an ingot $\sim 0.25 \mathrm{~cm}^{3}$ in volume. Each ingot was compressed to $\sim 1.1 \mathrm{~mm}$ thick between two SiC platens at $65 \mathrm{kips}$ in an Instron test machine at a crosshead speed of 0.001-0.005 in/min. The resulting disks were sectioned with a low speed diamond saw to form blocks with the dimensions $\sim 1.1 \mathrm{~mm} \times \sim 1.5 \mathrm{~mm} \times \sim 2.0$ $\mathrm{mm}$.

Scanning electron microscopy was used to inspect selected alloyed melt blocks for phase separation. Series of melt blocks were "calibrated" in graphite holders over a range of temperatures in $\sim 20^{\circ} \mathrm{C}$ increments for $1-3$ hours per increment to ensure melting at the assumed temperatures. A Type-S thermocouple and an optical pyrometer were used to verify the temperatures. Melting was visually assessed after each temperature interval.

\section{Resulte}

Some degree of micro-nucleation occurred in the melt blocks while cooling from their respective melts during fabrication, as shown in Figure 1 for a 9 wt\% Pd-91 wt\% Ni alloy. The $10 \mu \mathrm{m}$ wide Pd-rich bands exhiblt an elongated structure due to the $-400 \%$ cold working. The alloys in Table 1 were selected to avoid the formation of secondary phases, and no secondary phases have been observed. Several melt blocks were annealed at $100^{\circ} \mathrm{C}$ below their melting points for up to 6 hours to improve their homogeneity, but calibration has shown no difference in melting temperature between as-fabricated and annealed melt blocks.

Other factors that could impact the accuracy of the melt blocks include irradiation effects, surface oxidation, differences in constituent vapor pressures and reaction with the graphite holders. Transmutation of the base metals in an alloy could increase or decrease the melting temperature, and the potential severities of this and other irradiation effects are currently unknown. Surface oxidation tends to increase melting temperature, but no significant increase has been observed during calibration in an Ar environment similar to the internal environment of the METS capsules. Alloy composition changes due to differences in base metal vapor pressures or interdiffusion/reaction with the graphite substrate have also proven insignificant in Ar. 


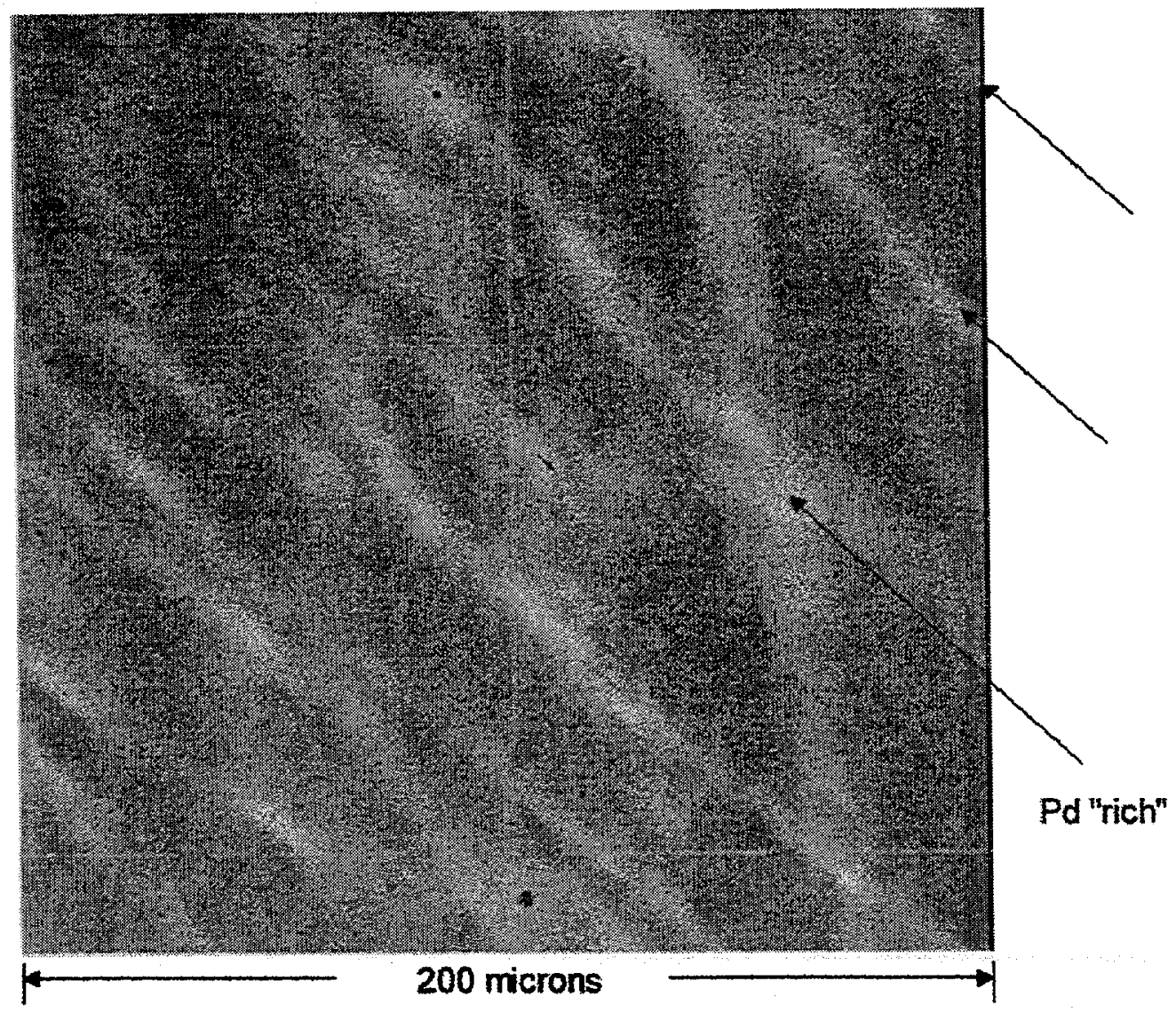

Figure 1. Backscattered SEM image of $9 w \%$ Pd-91 wt\% Ni alloy after $~ 400 \%$ cold working

Each of the three METS capsules contains ten subcapsules, and each subcapsule has been designed to accommodate a graphite holder for melt blocks at each end. Up to eight melt blocks and up to three SiC temperature monitors will be sealed in each graphite holder, selected according to the calculated maximum temperature to be experienced within the subcapsule (Table 2). Post-irradiation visual and/or radiographic inspection of the holders in a hot cell should show that some, but not all, of the blocks in each holder have melted, indicating the maximum temperature reached (to within $\sim 20^{\circ} \mathrm{C}$ in most cases). For the lower temperature subcapsules, annealing and dimensional analysis of SiC temperature monitors will provide a supplemental estimate of the temperature at the end of irradiation with an accuracy of $\sim 30-45^{\circ} \mathrm{C}[6,7]$. 
Table 2. METS Capsule Melt Block Loading List

\begin{tabular}{|c|c|c|c|c|c|c|c|c|c|c|}
\hline $\begin{array}{l}\text { Sub- } \\
\text { capsule }\end{array}$ & $\begin{array}{l}T\left({ }^{\circ} \mathrm{C}\right) \\
\text { Range }\end{array}$ & $\begin{array}{l}\text { Posi- } \\
\text { tion }\end{array}$ & \multicolumn{8}{|c|}{$T_{m}$ of Selected Melt Blocks $\left({ }^{\circ} \mathrm{C}\right)$} \\
\hline \multirow[b]{2}{*}{1} & \multirow{2}{*}{$\begin{array}{l}780- \\
860 \\
\end{array}$} & top & $\mathrm{SiC}^{*}$ & $\mathrm{SiC}^{*}$ & $\mathrm{SiC}^{*}$ & 660 & 938 & 955 & 962 & \\
\hline & & bottom & $\mathrm{SiC}^{*}$ & $\mathrm{SiC}^{*}$ & $\mathrm{SiC}^{*}$ & 600 & 938 & 955 & 962 & \\
\hline \multirow{2}{*}{10} & \multirow{2}{*}{$\begin{array}{l}790- \\
920\end{array}$} & top & $\mathrm{SiC}^{*}$ & 660 & 938 & 955 & 962 & 980 & 1000 & 1020 \\
\hline & & bottom & $\mathrm{SiC}^{\star}$ & 660 & 938 & 955 & 802 & 980 & 1000 & 1020 \\
\hline \multirow[b]{2}{*}{3} & \multirow{2}{*}{$\begin{array}{c}820 \\
1100\end{array}$} & top & $\mathrm{SiC}^{\star}$ & 938 & 962 & 1000 & 1020 & 1084 & 1140 & 1220 \\
\hline & & bottom & $\mathrm{SiC}^{*}$ & 938 & 980 & 1040 & 1084 & 1100 & 1180 & 1220 \\
\hline \multirow{2}{*}{2} & \multirow{2}{*}{$\begin{array}{c}850 \\
1000\end{array}$} & top & $\mathrm{SiC}^{*}$ & 938 & 955 & 962 & 1000 & 1020 & 1064 & 1100 \\
\hline & & bottom & $\mathrm{SiC}^{*}$ & 938 & 962 & 980 & 1000 & 1040 & 1084 & 1100 \\
\hline \multirow{2}{*}{9} & \multirow{2}{*}{$\begin{array}{c}920 \\
1075\end{array}$} & top & $\mathrm{SiC}^{*}$ & 938 & 955 & 980 & 1020 & 1064 & 1100 & 1180 \\
\hline & & bottom & Sic & 938 & 962 & 1000 & 1040 & 1084 & 1140 & 1180 \\
\hline \multirow[b]{2}{*}{8} & \multirow{2}{*}{$\begin{array}{l}1030- \\
1200 \\
\end{array}$} & top & 938 & 980 & 1020 & 1064 & 1100 & 1180 & 1237 & 1300 \\
\hline & & bottom & 938 & 1000 & 1040 & 1084 & 1140 & 1220 & 1260 & 1300 \\
\hline \multirow[b]{2}{*}{4} & \multirow{2}{*}{$\begin{array}{l}1150 \\
1290\end{array}$} & top & 1040 & 1084 & 1140 & 1180 & 1237 & 1289 & 1340 & 1420 \\
\hline & & bottom & 1040 & 1100 & 1140 & 1220 & 1260 & 1300 & 1380 & 1420 \\
\hline \multirow[b]{2}{*}{7} & \multirow{2}{*}{$\begin{array}{l}1290 \\
1390\end{array}$} & top & 1180 & 1220 & 1289 & 1340 & 1380 & 1420 & 1455 & 1495 \\
\hline & & bottom & 1180 & 1260 & 1300 & 1340 & 1380 & 1420 & 1475 & 1495 \\
\hline \multirow{2}{*}{5} & \multirow{2}{*}{$\begin{array}{l}1440 \\
1540\end{array}$} & top & 1340 & 1380 & 1455 & 1475 & 1500 & 1555 & 1580 & 1769 \\
\hline & & bottom & 1340 & 1420 & 1455 & 1495 & 1540 & 1555 & 1580 & 1769 \\
\hline \multirow[b]{2}{*}{6} & \multirow{2}{*}{$\begin{array}{l}1520 \\
1650\end{array}$} & top & 1420 & 1455 & 1475 & 1495 & 1540 & 1555 & 1580 & 1769 \\
\hline & & bottom & 1420 & 1455 & 1475 & 1500 & 1540 & 1555 & 1580 & 1769 \\
\hline
\end{tabular}

*SiC temperature monitor [2-7]

\section{ACKNOWLEDGEMENTS}

Part of S. D. Connery's research was performed under appointment to the Fusion Energy Sciences Fellowship program administered by the Oak Ridge Institute for Science and Education under a contract between the U. S. Department of Energy and the Oak Ridge Associated Universities.

\section{REFERENCES}

[1] R. J. Price, J. Nucl. Mater. 48 (1973) 47.

[2] N. F. Pravdyuk, V. A. Nicolaenco, V. I. Karpuchin and V. K. Kusnetosov, in Property of Reactor Materials and the Effect of Radiation Damage, ed. D. J. Littler (Butterworths, London, 1962) 57.

[3] R. P. Thorne and V. C. Howard, Proc. Brit. Cer. Soc. 7 (1967) 439.

[4] J. I. Bramman, A. S. Fraser and W. H. Martin, J. Nucl. Energy 25 (1971) 223.

[5] R. J. Price, Nucl. Tech. 16 (1972) 536.

[6] J. E. Palentine, J. Nucl. Mater. 61 (1976) 243.

[7] J. E. Palentine, J. Nucl. Mater. 92 (1980) 43. 

AND ACTIVATION CALCULATIONS 
SIMULATION OF PRIMARY DAMAGE FORMATION IN IRRADIATED MATERIALS - Roger E. Stoller (Oak Ridge National Laboratory) and Lawrence R. Greenwood (Pacific Northwest National Laboratory)

\section{OBJECTIVE}

The goal of this work is to develop an improved description of primary damage formation to help assess the effects of differences in neutron energy spectra, and to provide integral radiation damage source term parameters for use in the kinetic radiation damage models that are used to predict microstructural evolution and mechanical property changes.

\section{SUMMARY}

An extensive database of atomic displacement cascades in iron has been developed using the method of molecular dynamics (MD). More than 300 simulations have been completed at $100 \mathrm{~K}$ with energies between 0.1 and $100 \mathrm{keV}$, with a more limited range of simulations at 600 and $900 \mathrm{~K}$. This encompasses nearly all energies relevant to fission and fusion reactor irradiation environments since a $100 \mathrm{keV}$ MD cascade corresponds to the average event following a collision with a $5.1 \mathrm{MeV}$ neutron and an iron atom. Extensive statistical analysis of the database has determined representative average values for several primary damage parameters: the total number of surviving point defects, the fraction of the surviving point defects contained in clusters formed during cascade cooling, and a measure of the size distribution of the in-cascade point defect clusters. The energy dependence of the MD-based primary damage parameters has been used to obtain spectrum-averaged defect production cross sections for typical fission and fusion reactor neutron energy spectra. Total point defect survival and the total fraction of either interstitials or vacancies in clusters exhibit little dependence on neutron energy spectrum, while the fraction of point defects in large clusters exhibits a potentially-significant spectrum dependence.

\section{PROGRESS AND STATUS}

\section{Introduction}

Currently, most researchers correlate radiation effects data either on the basis of fast neutron fluence (i.e. fluence with $\mathrm{E}>0.1 \mathrm{MeV}$ or $\mathrm{E}>1.0 \mathrm{MeV}$ ) or atomic displacements per atom (dpa). The use of fast fluence is rationalized by the assumption that most atomic displacements are generated by the high energy portion of the spectrum. However, it is well known that neutrons of lower energy also contribute to microstructural and mechanical property changes, and dpa has been recommended $[1,2]$ as an improved correlation parameter, particularly when differences in neutron energy spectrum must be accounted for. The differences between fission and DT fusion neutron energy spectra is an important example of this situation.

Differences in neutron energy spectra are manifested as differences in the energy spectra of the primary knockon atoms (PKA) produced in elastic collisions with these neutrons. Neutron energy spectra and corresponding PKA energy spectra for relevant fission and fusion irradiation environments have been shown previously [3]. Since low and high energy PKA can produce damage structures that are both qualitatively and quantitatively different from each other, a systematic investigation of the energy dependence of primary damage formation should provide some insight into fission-fusion damage correlation. The potential impact of differences in PKA energy spectra are amenable to investigation by displacement cascade simulations using the method of molecular dynamics (MD). MD simulations provide a detailed picture of the formation 
and evolution of displacement cascades, and recent advances in computing equipment permit the simulation of high energy displacement events involving several million atoms [4-8]. The results presented below encompass MD cascade simulation energies from near the displacement threshold to as high as $100 \mathrm{keV}$.

An initial statistical analysis of the MD displacement cascade database up to $50 \mathrm{keV}$ has been published previously [4], and the energy dependence of total defect survival and interstitial clustering values are discussed in Ref. [9]. Since that time, a series of eight $100 \mathrm{keV}$ simulations has been completed and the vacancy cluster analysis has been carried out on the complete database. In addition, analysis 10 and $20 \mathrm{keV}$ cascades at 600 and $900 \mathrm{~K}$ has been completed. These new results will be discussed below.

\section{Cascade Simulations}

The MD displacement cascade simulations were carried out using the MOLDY code [10], and the interatomic potential for iron that is described in Refs. [11 and 12]. The MOLDY code simply describes elastic collisions between atoms and does not account for energy loss mechanisms such as electronic excitation and ionization. Therefore, the cascade energy $E_{M D}$ is analogous to the damage energy in the secondary displacement model by Norgett, Robinson, and Torrens (NRT) [13]. PKA energies that correspond to a given $E_{M D}$ can be calculated using the procedure described in Ref. [13], and the neutron energy required to generate PKA with a given average energy can be calculated for an elastic collision. These parameters are summarized in Table 1. Since the $100 \mathrm{keV}$ damage energy corresponds to the average recoil energy from a collision with a $5.1 \mathrm{MeV}$ neutron, these simulations encompass most of the neutron energy range of interest for fission and fusion irradiation conditions.

The last two columns in Table 1 are relevant to a statistical analysis of the cascade database. Based on the number of simulations completed, the mean values and standard errors about the mean have been obtained for various primary damage parameters. The error bars shown in the figures discussed below are set by the standard error. Standard statistical techniques can be used to determine the degree of confidence in a given mean $[14,15]$. Typically this can be expressed as a factor times the standard error, with the factor being determined by the number of events used to compute the mean. The last column in Table 1 is the required factor for a $90 \%$ confidence limit.

As discussed previously [6], the energy dependence of several primary damage parameters can be obtained from the MD simulations to evaluate neutron energy spectrum effects. First is the total number of stable displacements created, with vacancies and interstitials being formed in equal numbers. This includes all surviving defects present after in-cascade recombination is complete and the simulation cell has returned to thermal equilibrium. This requires a simulation time of about 15 to 20 ps at the highest energies. Second, since many of the surviving point defects are contained in small clusters, rather than as isolated defects, the fraction of surviving vacancies and interstitials contained in clusters is determined. It is convenient to express these parameters as a fraction of the displacements predicted by the NRT model [13].

Finally, the energy dependence observed in the vacancy and interstitial cluster size distributions suggested that some method of accounting for their spectrum dependence should also be included in this analysis. A single parameter was chosen for both types of defect size distribution for this initial investigation, the number of defects in clusters above a specified size. Clusters containing 5 or more vacancies were observed only at cascade energies of $2 \mathrm{keV}$ and higher, and interstitial clusters of 10 or more were observed only at $20 \mathrm{keV}$ and above. These apparent thresholds made the values of 5 and 10 convenient choices to evaluate the effect of energy on the 
Table 1: Summary of completed iron cascade database at 100,6000, and $900 \mathrm{~K}$

\begin{tabular}{|c|c|c|c|c|c|}
\hline $\begin{array}{l}\text { MD cascade } \\
\text { Temperature } \\
(\mathrm{K}) \text { and } \\
\text { energy (keV) }\end{array}$ & $\begin{array}{l}\text { Equivalent } \\
\text { PKA energy } \\
\text { (keV) }\end{array}$ & $\begin{array}{l}\text { Neutron energy } \\
\text { required for } \\
\text { specified } \\
\text { average PKA } \\
\text { energy }(\mathrm{MeV})(1)\end{array}$ & $\begin{array}{c}\text { NRT } \\
\text { displacements }\end{array}$ & $\begin{array}{l}\text { Number of MD } \\
\text { simulations } \\
\text { completed (2) }\end{array}$ & $\begin{array}{c}\text { Multiple of } \\
\text { standard error } \\
\text { to obtain } 90 \% \\
\text { confidence } \\
\text { band }\end{array}$ \\
\hline $100-0.1$ & 0.116 & 0.00335 & 1 & 40 & 1.685 \\
\hline $100-0.2$ & 0.236 & 0.00682 & 2 & 32 & 1.696 \\
\hline $100-0.3$ & 0.357 & 0.0103 & 3 & 128 & 1.660 \\
\hline $100-0.5$ & 0.605 & 0.0175 & 5 & 20 & 1.729 \\
\hline $100-1.0$ & 1.24 & 0.0358 & 10 & 12 & 1.796 \\
\hline $100-2.0$ & 2.54 & 0.0734 & 20 & 10 & 1.833 \\
\hline $100-5.0$ & 6.61 & 1.191 & 50 & 9 & 1.860 \\
\hline $100-10.0$ & 13.7 & .0 .397 & 100 & 15 & 1.761 \\
\hline $600-10.0$ & 13.7 & 0.397 & 100 & 8 & 1.895 \\
\hline $900-10.0$ & 13.7 & 0.397 & 100 & 7 & 1.942 \\
\hline $100-20.0$ & 28.8 & 0.832 & 200 & 10 & 1.833 \\
\hline $600-20.0$ & 28.8 & 0.832 & 200 & 8 & 1.895 \\
\hline $900-20.0$ & 28.8 & 0.832 & 200 & 10 & 1.833 \\
\hline $100-30.0$ & 44.7 & 1.29 & 300 & 10 & 1.833 \\
\hline $100-40.0$ & 61.3 & 1.77 & 400 & 8 & 1.895 \\
\hline $100-50.0$ & 87.7 & 2.28 & 500 & 9 & 1.860 \\
\hline $100-100$ & 176. & 5.09 & 1000 & 8 & 1.895 \\
\hline \multicolumn{6}{|c|}{$\begin{array}{l}\text { (1) The average recoil energy from elastic collisions between neutrons of this energy and an } \\
\text { iron atom is the value listed in the previous column } \\
\text { (2) In some cases, more simulations have been completed. This is the number used to obtain } \\
\text { the average values reported here }\end{array}$} \\
\hline
\end{tabular}

vacancy and interstitial defect cluster size distributions, respectively. In-cascade clustering is significant because such clusters provide nuclei for the growth of larger defects and their formation directly within the cascade means that extended defects can evolve more quickly than if the clusters were formed only by the much slower process of classical nucleation. The presence of relatively large incascade clusters could disproportionately contribute to the nucleation of defects such as interstitial loops and microvoids. The number of vacancies and interstitials in "large" clusters is also expressed as a fraction of the NRT displacements at each energy. 


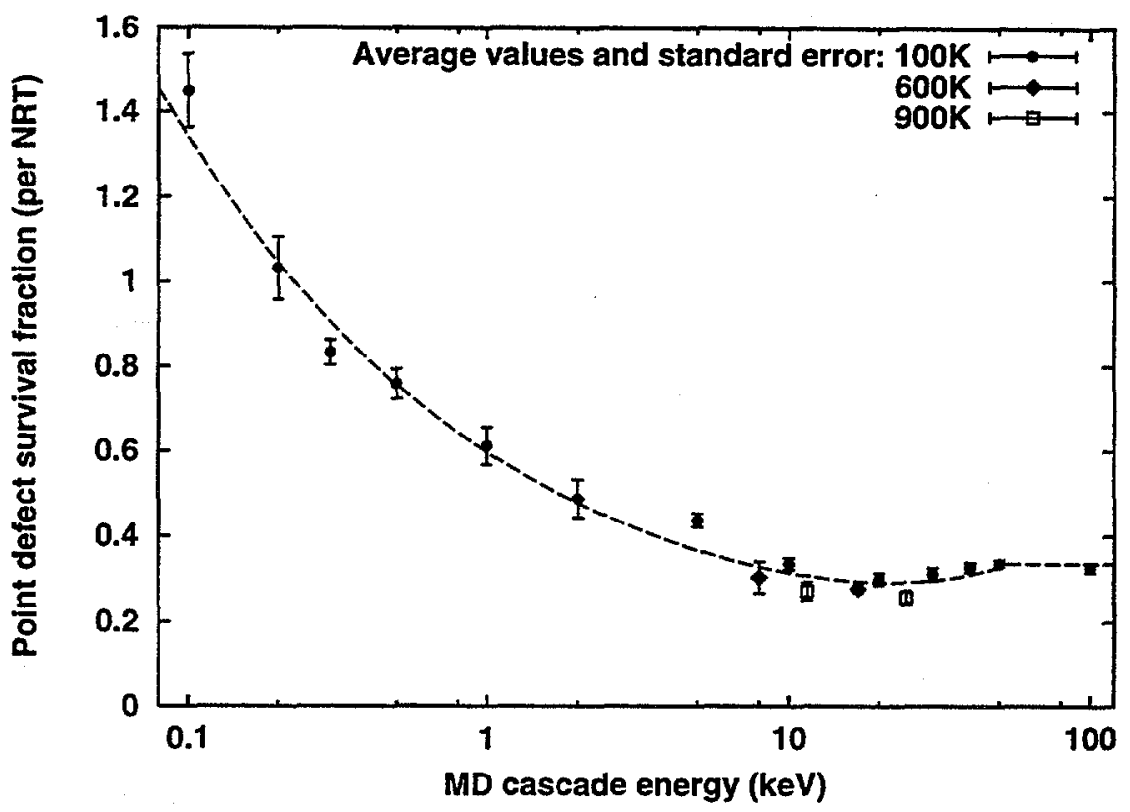

Figure 1. Energy dependence of total point defect survival obtained from MD cascade simulations, MD defect survival divided by NRT [13] displacements.

The $100 \mathrm{keV}$ results fall on a smooth extrapolation of the lower energy data, as shown in Fig. 1 for the total defect survival fraction. At each energy, the data point is an average of between 8 and 128 cascades, with error bars shown indicating the standard error on the mean. These error bars almost too small to be observed at the higher energies in Fig. 1, indicating that the minimum observed in the curve near $20 \mathrm{keV}$ is statisticaliy significant. The minimum arises from the extensive subcascade formation that occurs above $10 \mathrm{keV}[3,4,6-8]$. Note that the point defect survival values at 600 and $900 \mathrm{~K}$ are not substantially different than those at $100 \mathrm{~K}$.

The interstitial clusters formed in these iron cascade simulations tend to be very well defined, with most clusters consisting of nearest neighbor arrangements of $\langle 111\rangle$ or $\langle 110\rangle$ dumbbells, or $<111>$ crowdions. Occasionally, interstitials may be added to a cluster in the second nearest neighbor location or the atomic arrangements can be more complex [16]. The use of computer visualization and animation software enables such interstitials to be clearly identified as part of the cluster. However, the vacancy clusters produced in these iron cascades tend to be diffuse, with clearly correlated arrangements out to the fourth nearest neighbor distance $[7,8]$. As a result, the vacancy cluster analysis was carried out using two different criteria for defining what constitutes a vacancy cluster. The criterion were that all vacancies in the cluster be within either: (1) the second $\left(d_{2 n n}=0.2867 \mathrm{~nm}\right)$ or, $(2)$ the fourth $\left(d_{4 n n}=0.4754 \mathrm{~nm}\right)$ nearest neighbor distance of another vacancy in the cluster. Using the fourth nearest neighbor criterion nearly doubles the fraction of vacancies in clusters, but is supported by Monte Carlo aging studies of cascade debris [8,20].

The total fraction of vacancies in clusters for both the $2 \mathrm{nn}$ and $4 \mathrm{nn}$ clustering criteria is shown in Fig. 2(a) and the fraction of vacancies in clusters of 5 or more using the same criteria is shown in Fig. 2(b). For purposes of comparison, the previously derived trend lines for the interstitial clustering parameters from Ref. [10] are also shown in Figs. 2(a) and (b). At low energies, the dependence of vacancy clustering on cascade energy is noticeably different from that of the interstitials. The fraction of vacancies (per NRT displacement) continues to increase down to the lowest energies, while the interstitial clustering fraction decreases below about $300 \mathrm{eV}$. A much 

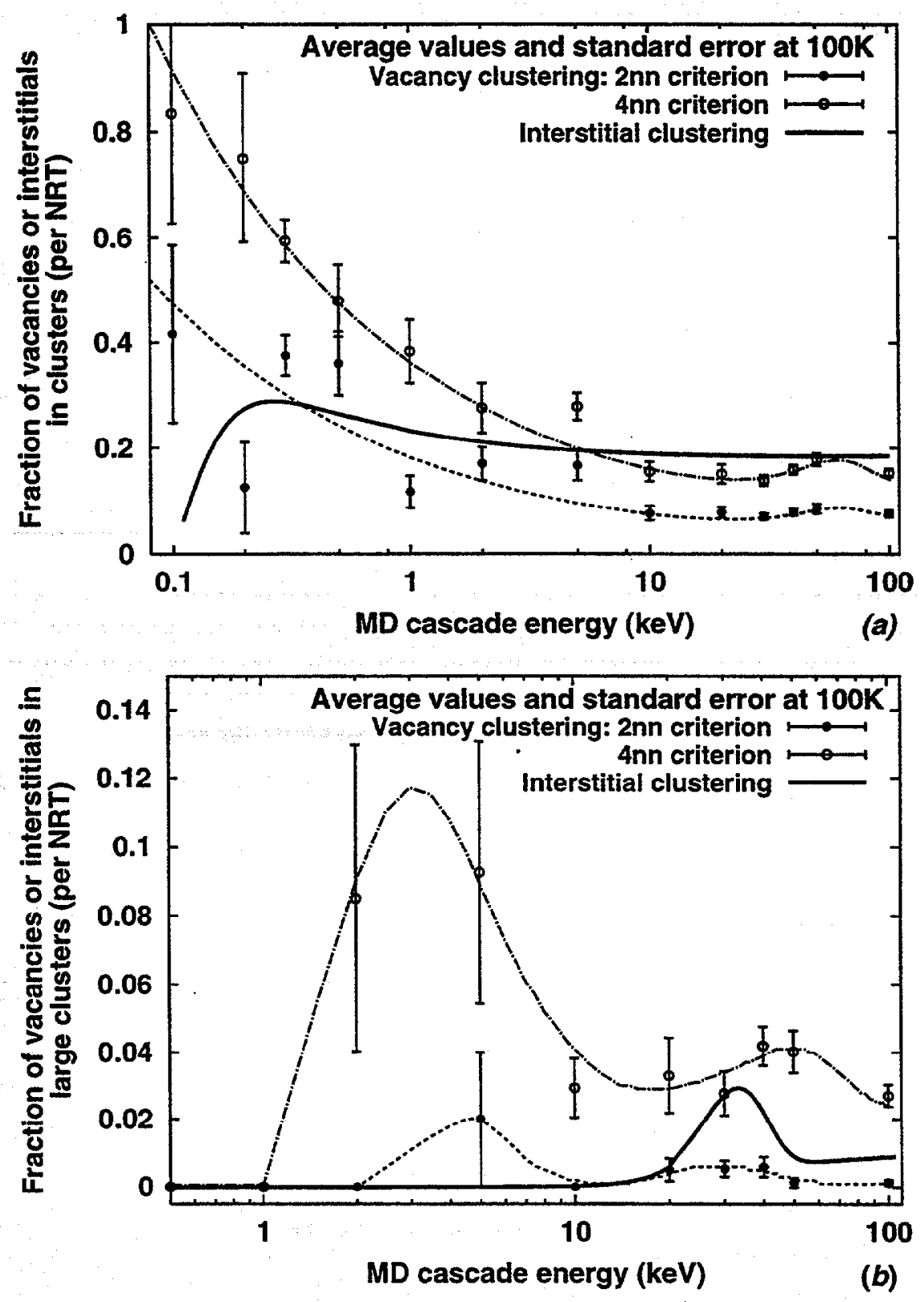

Figure 2. Energy dependence of normalized primary damage parameters from MD cascade simulations: (a) total vacancies and interstitial in clusters, and (b) vacancies in clusters of 5 or more and interstitials in clusters of 10 or more. MD defect clustering values divided by NRT [13] displacements

larger fraction of the vacancies than interstitials are in clusters at low energies, and the decrease with energy is much more rapid for the vacancies. At high energies, the clustering fraction for both defect types becomes nearly asymptotic, with a some indication of a peak in the vacancy clustering curve near $50 \mathrm{keV}$. A somewhat larger fraction of the interstitials are in clusters at high energies, even for the less restrictive 4 nn vacancy clustering criterion.

The analysis of the cluster size distributions revealed further differences between the clustering 
behavior of vacancies and interstitials. Fewer large vacancy clusters are observed than interstitials, and interstitial clusters containing as many as 33 defects have been observed, but the largest vacancy cluster in the database is 14 . . This contributed to the decision to choose a smaller cluster size of 5 as the cutoff for the "large" cluster designation for vacancies while 10 was used for the interstitials. As shown in Flg. 2(b), the fraction of interstitials in large clusters appears to peak near $30 \mathrm{keV}[8,9]$. Two peaks are observed for the vacancy cluster parameter near 3 and $40 \mathrm{keV}$. The peaks are small for the $2 \mathrm{nn}$ criterion but well developed for the $4 \mathrm{nn}$ case. No simple explanation has been found for the structure in the curves in Fig. 2(b). The high-energy peaks may arise from a maximum energy density that is associated with the breakup of the cascade into subcascades.

\section{Neutron Energy-spectrum-averaged Parameters}

In order to use the MD results to evaluate the effect of differences between neutron energy spectra, energy dependent functions were obtained by fitting the data in Figs. 1 and 2 . These energy-dependent functions were employed in the SPECOMP code [17] to compute effective production cross sections for point defect survival, total vacancy and interstitial clustering, and vacancies and interstitials in large clusters. Based on the asymptotic behavior shown in Figs. 1 and 2, the values at $50 \mathrm{keV}$ were used for all higher energy cascades. PKA spectra for iron were obtained from SPECTER [18] and used to weight these MD-based cross sections in order to calculate spectrum-averaged values for various irradiation environments. More details on how the SPECOMP/SPECTER calculations were done can be found in Refs. [3,9,19].

The spectrum-averaged values of total defect survival and total interstitial clustering have been reported previously [3], and very little difference was observed. In particular, the total fraction of interstitials in clusters (per NRT) was nearly identical for all the neutron spectra examined. The fraction of interstitials in large clusters exhibits more sensitivity to neutron energy spectrum as shown in Fig. 3 for six relevant irradiation environements: the ITER first wall, midcore and below

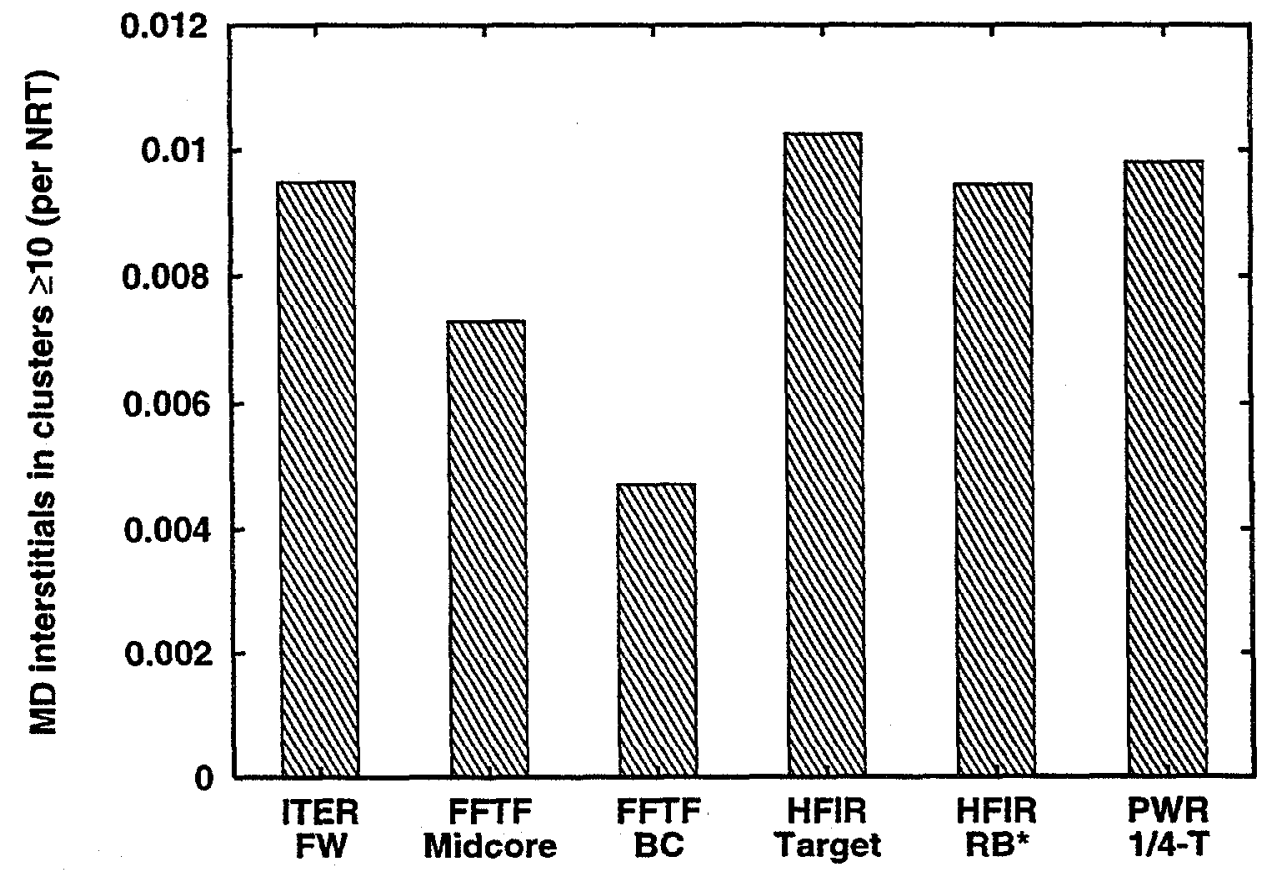

Figure 3. Spectrum-averaged fraction (per NRT) of MD interstitials in clusters of 10 or more. 
core locations in the FFTF, the HFIR target and removable beryllium positions, and the postion $1 / 4$ of the way through a commercial pressurized water reactor pressure vessel. The total clustering fraction in Fig. 3 varies by about a factor of 2 . The impact of this difference is not clear since the number of defects involved is relatively small, $1 \%$ of the NRT displacements or less. However, these large clusters could have an impact that is more than proportional to their numbers. For example, such clusters are more likely to survive and contribute to the nucleation of dislocation loops.

Vacancy clustering appears to be more dependent of neutron energy spectrum than does interstitial clustering. This is shown in Figs. 4 and 5 for the $2 \mathrm{nn}$ and $4 \mathrm{nn}$ clustering criteria, respectively. The total vacancy clustering fraction is shown in part (a) and the fraction of vacancies in clusters of 5 or more is shown in part (b) of Figs. 4 and 5 . In both figures, the fraction of vacancies in large clusters is seen to be more sensitive to neutron spectrum than is the total fraction of vacancies in clusters. This is similar to the behavior of interstitial clustering discussed above, and can be understood by noting that the energy dependence shown in Fig. 2(b) is more complex than that shown in Fig. 2(a) for either defect type.

The total number of vacancies involved in clusters is small for the 2 nn clustring criterion. The total number of vacancies is less than $10 \%$ of the NRT displacements and less than $1 \%$ in clusters of 5 or more. About twice as many total vacancies are involved if the $4 \mathrm{nn}$ criterion is applied, while the number in large clusters increases by about a factor of ten. Comparing Figs 4(b) and 5(b) indicates that the spectral dependence of vacancies in large clusters is reduced if the $4 \mathrm{nn}$ clustering criterion is assumed. The potential impact of these clusters on microstructural evolution can be evaluated further by accounting for variations in the primary damage formation parameters used in kinetic (rate theory) microstructural models.

\section{Conclusions and Future Work}

It is now possible to simulate the atomic displacement cascades generated by nearly the complete fission neutron spectrum. The results presented above include cascade energies as high as 100 $\mathrm{keV}$, corresponding to a $176 \mathrm{keV}$ PKA, which is the average iron recoil from a neutron with an energy of $5.1 \mathrm{MeV}$. Thus, these results are fully relevant to materials irradiated in any fission or fusion reactor environment. Note that the average PKA energy obtained from SPECTER [18] for an FFTF mid-core location, the HFIR target region, and the ITER first wall were only $6.88,14.7$, and $48.0 \mathrm{keV}$, respectively. This extensive database of cascade simulations can now be used to derive statistically-relevant primary damage parameters and provide a basis for analyzing differences in radiation environments.

The total defect survival fraction, and the total fraction of interstitials and vacancies contained in incascade clusters exhibit a relatively smooth. nearly monotonic dependence on cascade energy. Results of the new simulations are consistent with work reported previously [3], indicating that the dependence of these parameters on neutron energy spectrum will probably be relatively weak. However, the energy dependence of the fraction of vacancies or interstitials in large clusters is more complex. If the production of large clusters contributes disproportionately to microstructural evolution by enhancing the nucleation rate of extended defects, this could give rise to an effect of neutron energy spectrum. However, it is not possible to predict microstructural evolution or mechanical property changes simply on the basis of primary damage formation. These results will be analyzed further and used to develop an improved description of the radiation damage source terms for kinetic models that have been used to predict radiation-induced mechanical property changes based on microstructural evolution. 


\section{Acknowledgments}

This research was also sponsored in part by the Office of Nuclear Regulatory Research, U.S. Nuclear Regulatory Commission under inter-agency agreement DOE 1886-N695-3W with the U.S. Department of Energy and by the Division of Materials Sciences and Engineering, U.S. Department of Energy under contract DE-AC05-00OR22725 with UT-Battelle, LLC.
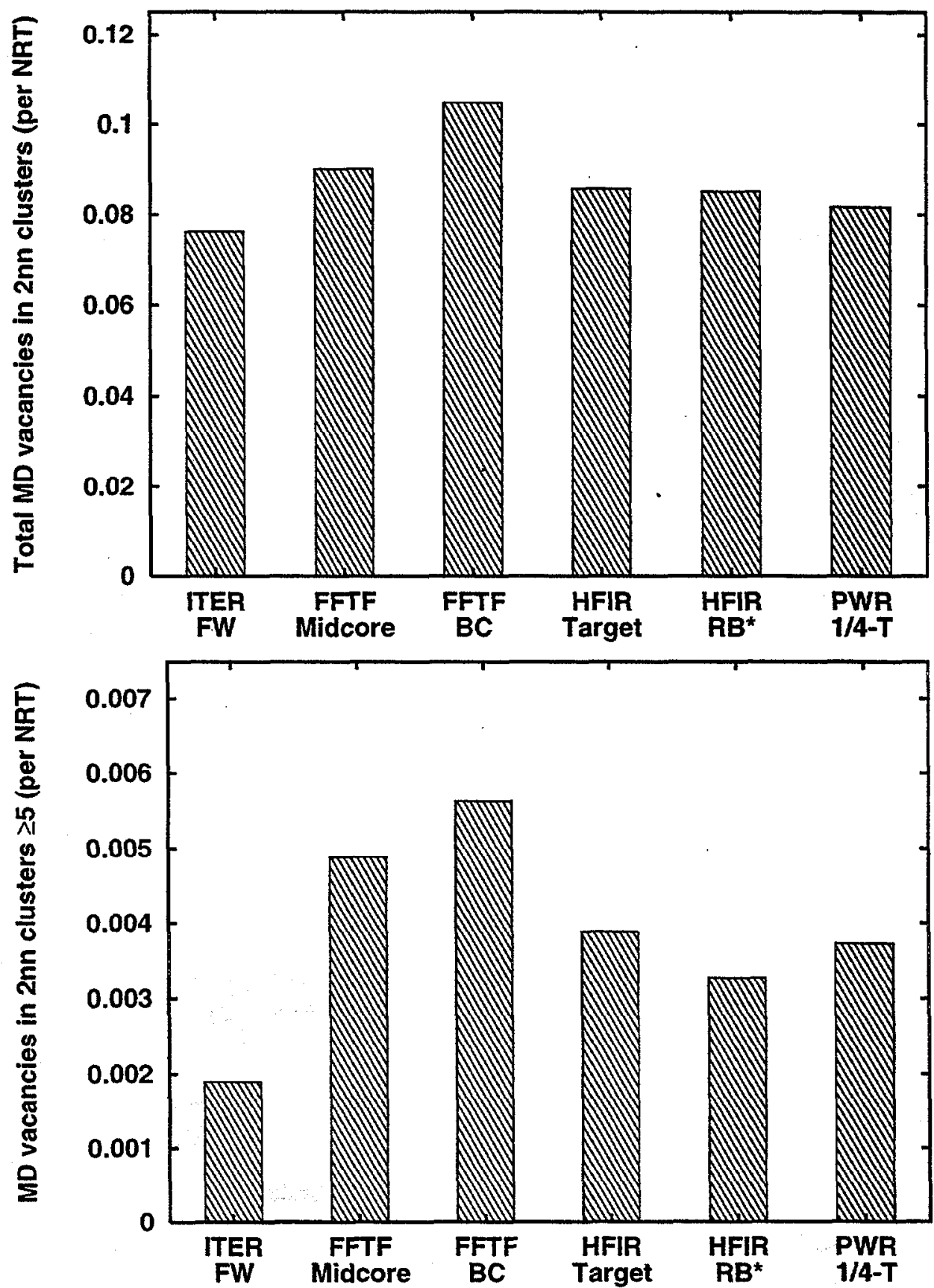

Figure 4. Spectrum-averaged fraction (per NRT) of MD vacancies in clusters, based on: (a) total number in clusters, and (b) number in clusters of 5 or more. 2 nn clustering criterion. 

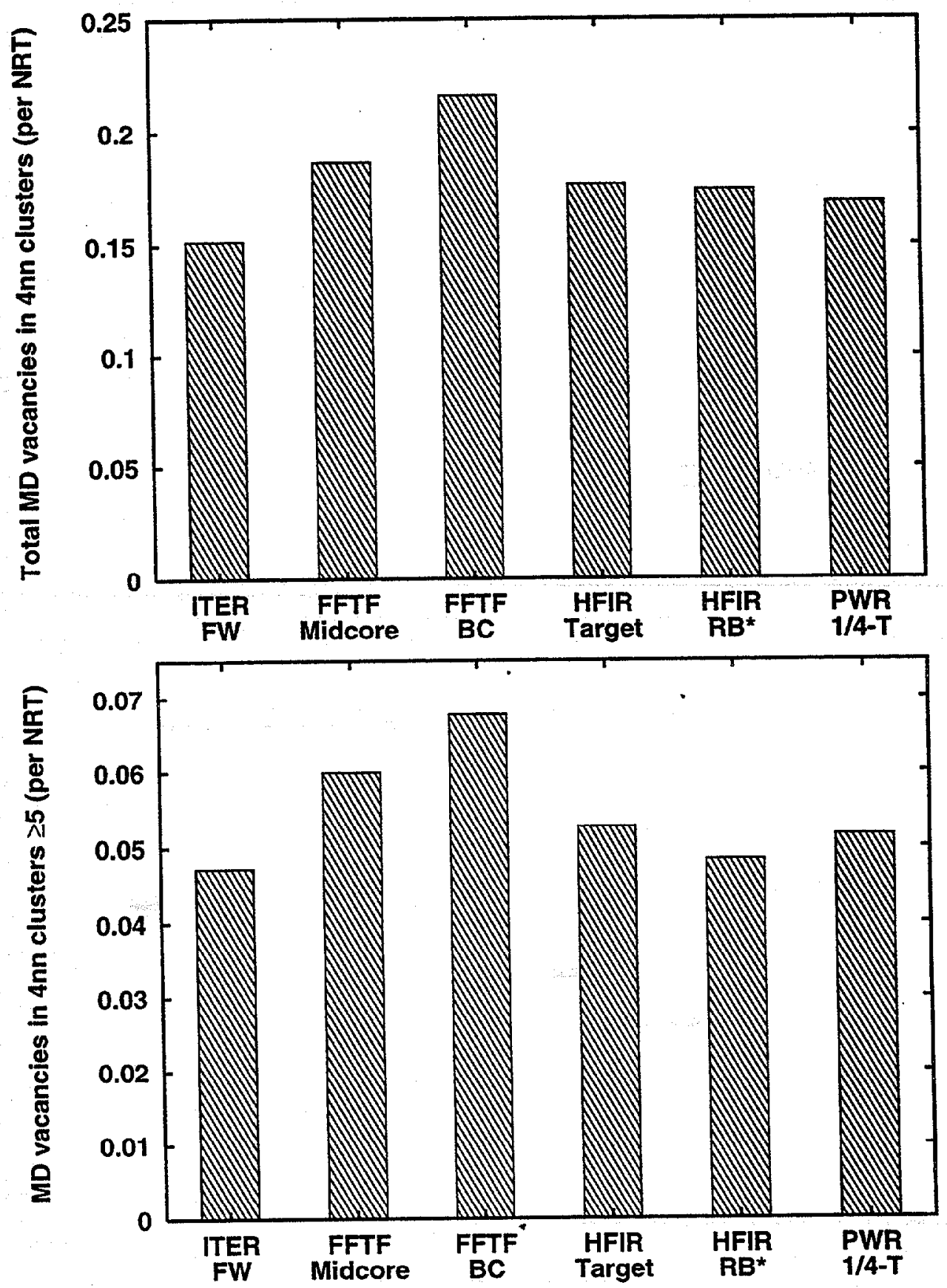

Figure 5. Spectrum-averaged fraction (per NRT) of MD vacancies in clusters, based on: (a) total number in clusters, and (b) number in clusters of 5 or more. 4 nn clustering criterion.

\section{References}

1. Recommendations of IAEA Specialists Meeting on Radiation Damage Units in Graphite and Ferritic and Austenitic Steels, Nuclear Engineering and Design 33 (1975) 48.

2. Stoller, R.E. and Odette, G.R., Journal of Nuclear Materials 186 (1992) 203-205.

3. Stoller, R.E. and Greenwood, L.R.," Journal of Nuclear Materials 271 \&272 (1999) 57-62. 
4. Stoller, R.E. and Calder, A.F., "Statistical Analysis of a Library of Molecular Dynamics Cascade Simulations in Iron at 100K,"presented at the Ninth International Conference on Fusion Reactor Materials, Colorado Springs, CO., 11-16 October 1999, Journal of Nuclear Materials (in press).

5. W. J. Phythian, Stoller, R.E., A. J. E. Foreman, A. F. Calder, and D. J. Bacon, Journal of Nuclear Materials 223 (1995) 245-261.

6. Stoller, R.E., Journal of Nuclear Materials 233-237 (1996) 999-1003.

7. Stoller, R.E., Odette G.R., and Wirth, B. D., Journal of Nuclear Materials 251 (1997) 49-69.

8. Stoller, R.E., Journal of Nuclear Materials 276 (2000) 22-32.

9. Stoller, R.E. and Greenwood, L.R., "A Comparison of the NRT Displacement Model and Primary Damage Formation Observed in Molecular Dynamics Cascade Simulations, presented at the 10th International Symposium on Reactor Dosimetry, 12-17 September 1999, Osaka, Japan, ASTM STP 1398, American Society of Testing and Materials, West Conshohocken, PA, 2000 (in press).

10. Finnis, M.W., "MOLDY6-A Molecular Dynamics Program for Simulation of Pure Metals," AERE R-13182, UK AEA Hanwell Laboratory (1988).

11. Finnis, M.W. and Sinclair, J.E., Philosophical Magazine A50 (1984) $45-55$ and Erratum, Philosophical Magazine A53 (1986) 161.

12. Calder, A.F. and Bacon, D.J., Journal of Nuclear Materials 207 (1993) 25-45.

13. Norgett, M.J., Robinson, M.T., and Torrens, I.M., Nuclear Engineering and Design 33 (1975) 50-54.

14. Kendall's Advanced Theory of Statistics, Volume 1, A. Stuart and J. K. Ord, Charles Griffin and Company, Ltd., London, 1987.

15. Manual on Presentation of Data and Chart Control Analysis, Sixth Edition, American Society for Testing and Materials, West Conshohocken, PA, 1992.

16. Stoller, R.E., "Molecular Dynamics Simulations of High Energy Cascades in Iron," Microstructure of Irradiated Materials, I. M. Robertson, L. E. Rehn, S. J. Zinkle, and W. J. Phythian, Editors, Materials Research Society, Pittsburgh, PA, 1995, pp. 21-26.

17. Greenwood, L.R., "SPECOMP Calculations of Radiation Damage in Compounds," Reactor Dosimetry: Methods, Applications, and Standardization, ASTM STP 1001, H. Farrar IV and E. P. Lippincott, Eds., American Society of Testing and Materials, West Conshohocken, PA, 1989, pp. 598-602.

18. Greenwood, L.R. and Smither, R.K., "SPECTER: Neutron Damage Calculations for Materials Irradiations," ANL/FPP/TM-197, Argonne National Laboratory, Argonne, IL, January 1985.

19. Stoller, R.E. and Greenwood, L.R., "An Evaluation of Neutron Energy Spectrum Effects Based on Molecular Dynamics Displacement Cascade Simulations," Effects of Radiation on Materials, STP 1366, M. L. Hamilton, A. S. Kumar, S. T. Rosinski, and M. L. Grossbeck, Editors, American Society for Testing and Materials, West Conshohocken, PA, 2000, pp. 548559.

20. B. D. Wirth and G. R. Odette, "Kinetic Lattice Monte Carlo Simulations of Cascade Aging in Iron and Dilute Iron-Copper Alloys," Multiscale Modeling of Materials, V. V. Butalov, T. Diaz de la Rubia, P. Phillips, E. Kaxiras, and N. Ghoniem, Editors, Materials Research Society, Pittsburgh, PA, 1999, pp. 211-216. 


\subsection{MATERIALS ENGINEERING AND DESIGN REQUIREMENTS} No contributions. 

11.0 IRRADIATION FACILITIES, TEST MATRICES 
HFIR-MFE-RB-14J SPECIMEN LOADING LISTING AND OPERATIONAL SUMMARY A. L. Qualls (Oak Ridge National Laboratory

\section{OBJECTIVE}

The objective of this experiment is to irradiate metal and ceramic specimens at temperature of $300^{\circ} \mathrm{C}, 500^{\circ} \mathrm{C}$ and $800^{\circ} \mathrm{C}$ in an unshielded Removable Beryllium (RB) position of the High Flux Isotope Reactor. This report describes the specimen loading arrangement for the Fusion Materials Irradiation portion of the RB-14J irradiation experiment (regions $B, C$ and $D$ ) and describes its operation to date.

\section{SUMMARY}

The specimens are housed in three cylindrical holders within the experiment. The holders are centered about the HFIR mid-plane in a large unshielded RB irradiation location (approximately $21 \mathrm{~cm}$ from the reactor centerline) during irradiation.

The three holders are the main components of three independently controlled temperature regions. The upper region is positioned from $21.1 \mathrm{~cm}$ to $12.9 \mathrm{~cm}$ above the reactor centerline and is controlled to irradiate the specimens at $500^{\circ} \mathrm{C}$. The middle region irradiates the specimens at $800^{\circ} \mathrm{C}$. It is twice as long as the other two zones and is centered on the reactor mid-plane extending from $8.8 \mathrm{~cm}$ above the reactor centerline to $-9.2 \mathrm{~cm}$ below the reactor centerline. The lower region is controlled to irradiate the specimens at approximately $300^{\circ} \mathrm{C}$ and is positioned from $-12.4 \mathrm{~cm}$ to $-21.4 \mathrm{~cm}$ below the reactor centerline. A schematic of the experimental region of the capsule is shown in Figure 1.

\section{CAPSULE DESCRIPTION}

The $500^{\circ} \mathrm{C}$ and $300^{\circ} \mathrm{C}$ holders are similar in design and relative position within the flux. They are fabricated from Dispal (an oxide-strengthened aluminum alloy). The $800^{\circ} \mathrm{C}$ holder is fabricated from $\mathrm{H} 451$ graphite. The specimens are located in axial slots in the perimeter of the cylinders and in holes drilled into the upper or lower face of the holders. Each distinctive angular location for which there is either a hole or a slot (or both) is designated as a row and each hole is assigned a distinct alphanumeric character, as shown in Figure 2 . The specimen holes can be described as being either on an inner radius of $1.68 \mathrm{~cm}$ or an outer radius of $2.81 \mathrm{~cm}$ or $2.72 \mathrm{~cm}$.

Specimens are located in three dimensions within a holder: axial location, radial position and angular location. The angular position relates a specimen's orientation with respect to the dosimetry and thermometry within the holder. Each holder has an angular location designated $0^{\circ}$, which corresponds to the Row 1 . The three holder's $0^{\circ}$ locations are not perfectly aligned. The capsule is rotated $180^{\circ}$ for each successive cycle of operation. The rotation varies the temperature distribution within the holder and places specimens in different fluxes. Specimens located on a line passing through the reactor centerline will be irradiated at the highest and lowest successive fluxes while those specimens located perpendicular to that line will encounter a more consistent flux throughout the irradiation. Because of the rotation however, all of the specimens at a given axially location will receive the same total dose during the irradiation. An additional interior hole located inside the inner specimen hole radius at $193^{\circ}$ houses a thermocouple array tube (TCAT) in each holder. Individual thermocouples within the TCATs measure each holder's temperature at seven equally spaced axial locations. The average indicated temperature from the thermocouples is the controlling variable for each zone's operation. Two small screw holes on the upper and lower face of the holders are in line with the TCAT hole and are used to secure end caps on the ends of the holders to keep specimens from falling out. 


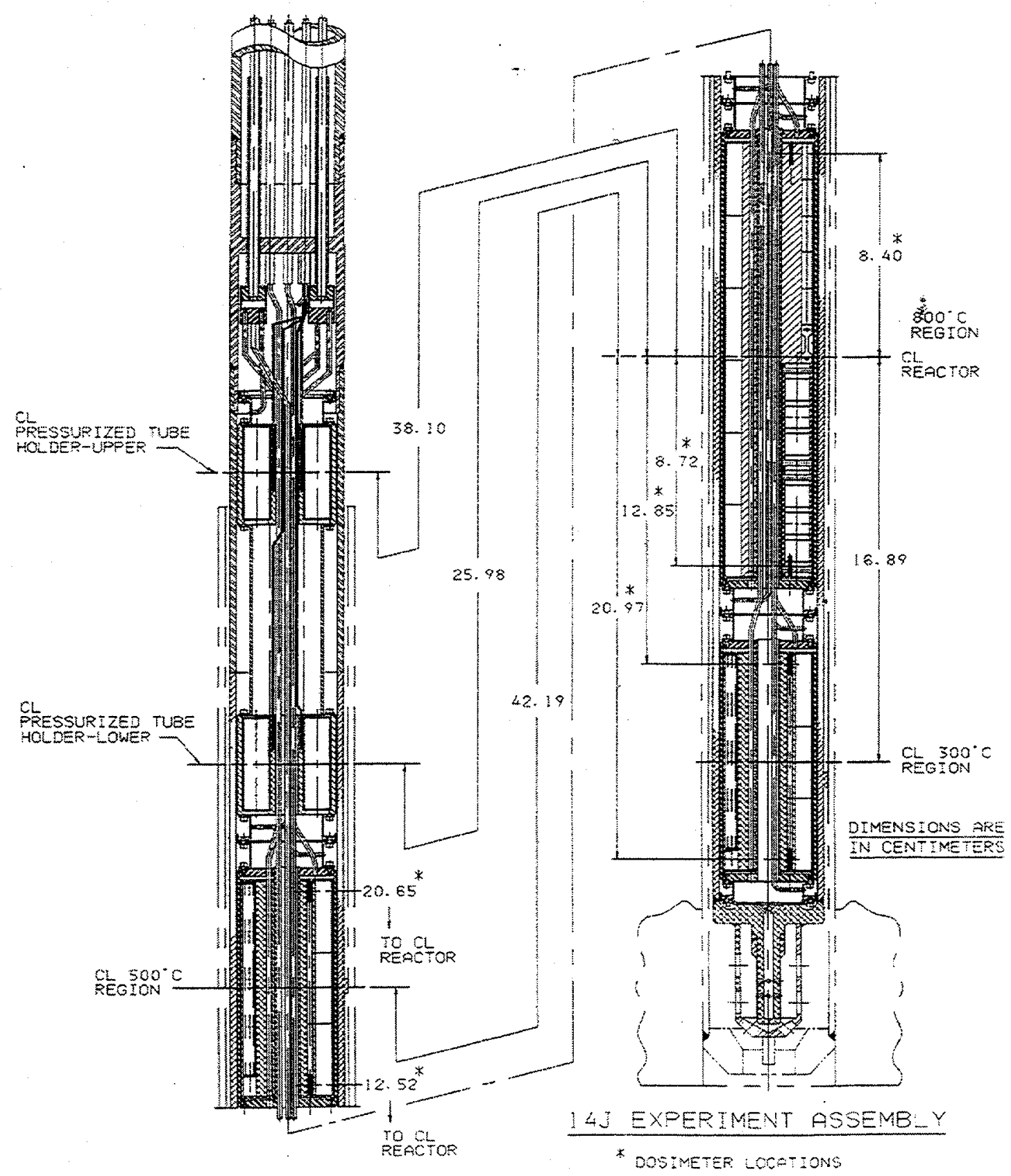

Figure 1. Schematic of the experimental region of the RB-14J irradiation capsule. 

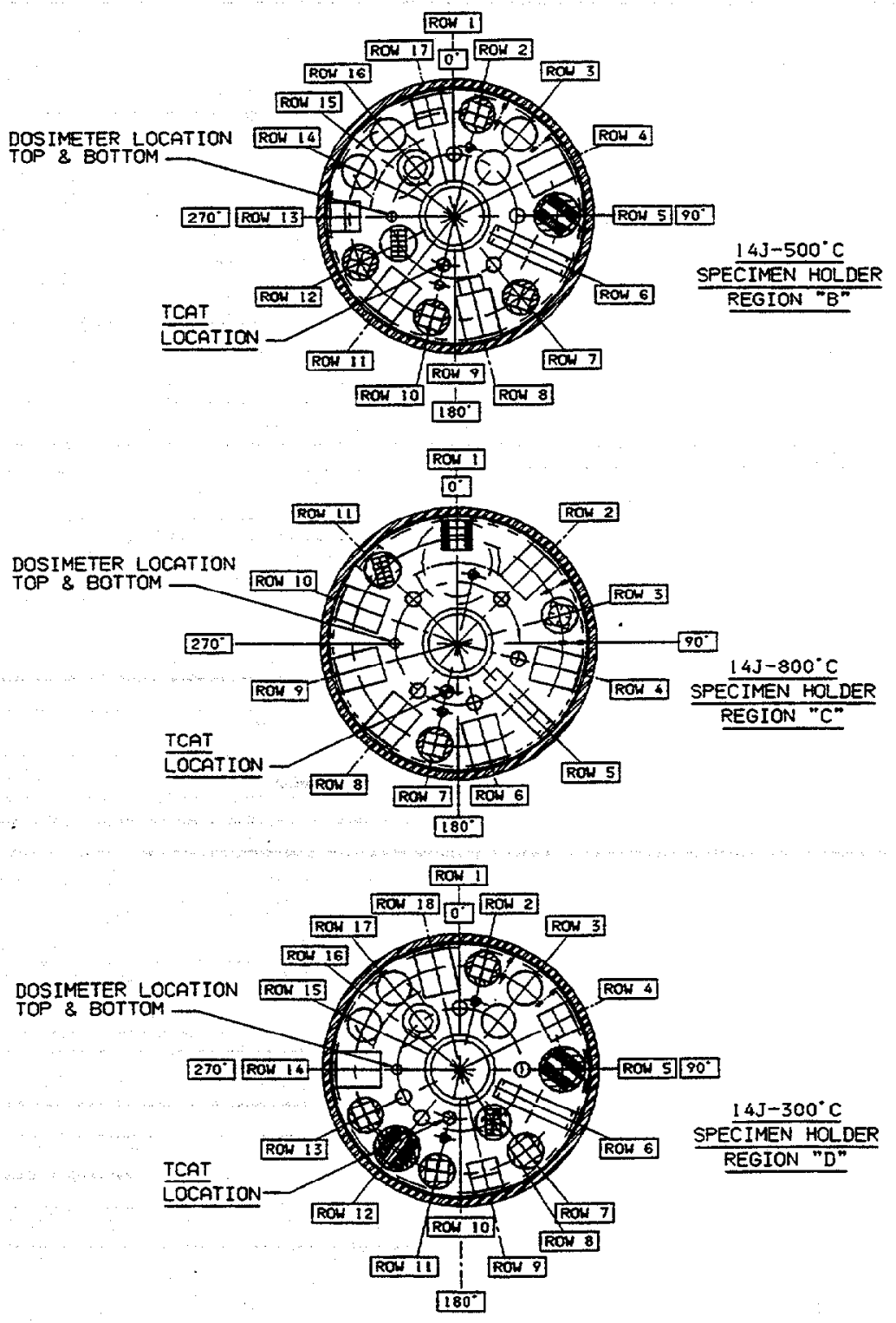

Figure 2. Cross sectional view of the three specimen holders in the $14 \mathrm{~J}$ experiment. 
Each specimen holder has a unique arrangement (number of rows and holes, etc.) and some specimen locations designed for one type of specimen were actually filled with another type. The actual loading of the specimen holders therefore differs from that represented in the capsule drawings. Specimen locations are described in the text below and/or are listed in chart form within the body of the text. The deciding factor is (hopefully) clarity in describing the angular, axial and radial location of the specimens.

\section{DCT Specimens and Thermal Diffusivity Specimens}

The hole originally designated for DCT specimens can be seen as a hidden line in the upper left portion of the $300^{\circ} \mathrm{C}$ and $500^{\circ} \mathrm{C}$ holders shown in Figure 2. The holes were machined for a $9.6-$ $\mathrm{mm}$ OD specimen, however the specimens were $12.5-\mathrm{mm}$ OD specimens. The perimeter slots originally intended for thermal diffusivity specimens (Row 6) were widened to accommodate the larger specimens. The slot was opened near the top of the $500^{\circ} \mathrm{C}$ holder and near the bottom of the $300^{\circ} \mathrm{C}$ holder, and two DCT specimens were stacked vertically in the slot of each holder. The original DCT hole (on the bottom of the holders) was filled with two spare thermal diffusivity specimens.

\section{Dosimetry}

A total of six dosimetry packages are housed in holes drilled into the two faces of the three cylindrical holders at $270^{\circ}$. Their axial locations can be seen in Figure 1 and are listed below. The packages are uniquely identified with small scribed letters.

$\begin{array}{llc}\text { Location } & \text { ID } & \text { Distance from HFIR Mid-plane (cm) } \\ \text { Top of } 500 & \text { HF } & +20.65 \\ \text { Bottom of } 500 & \text { X7 } & +12.52 \\ \text { Top of } 800 & \text { RL } & +8.40 \\ \text { Bottom of } 800 & \text { OV } & -8.72 \\ \text { Top of } 300 & 8 A & -12.85 \\ \text { Bottom of } 300 & \text { BC } & -20.97\end{array}$




\section{SPECIMEN LOADING}

\section{The $500^{\circ} \mathrm{C}$ Holder}

The $500^{\circ} \mathrm{C}$ holder is located above the reactor mid-plane. Spacers are used to fill holes that were not fully occupied. The spacers are placed at the top of the $500^{\circ} \mathrm{C}$ holder to place them in the lowest available flux and place the specimens in the highest available flux. The axial locations of specimens are noted in $\mathrm{cm}$. When only one dimension is given the specimen is centered at that distance from the reactor centerline. Negative numbers are for locations below the reactor centerline. The designation (b) implies that a specimen is in the bottom of the specimen sleeve slot and the designation ( $t$ ) implies that a specimen is on top of that when only two specimens are stacked to fill the sleeve. When more than two specimens are stacked in a slot (Bar-7 for example) the layers are numbered sequentially from the bottom to the top.

\section{$500^{\circ} \mathrm{C}$ Bar- 1 Specimens}

\begin{tabular}{|c|c|c|c|c|c|c|}
\hline Axial Location & & Row 13 & & & Row 1 & \\
\hline $\begin{array}{l}20.4 \\
20.4\end{array}$ & $\begin{array}{l}\text { (b) } \\
\text { (t) }\end{array}$ & $\begin{array}{l}\text { spacer } \\
\text { spacer }\end{array}$ & & $\begin{array}{l}\text { (b) } \\
\text { (t) }\end{array}$ & $\begin{array}{l}\text { FTA4 } \\
\text { FTA7 }\end{array}$ & $\begin{array}{l}\text { FTA5 } \\
\text { FTA6 }\end{array}$ \\
\hline $\begin{array}{l}18.8 \\
18.8\end{array}$ & $\begin{array}{l}\text { (b) } \\
\text { (t) }\end{array}$ & $\begin{array}{l}\text { DA17 } \\
\text { DA04 }\end{array}$ & $\begin{array}{l}\text { DA11 } \\
\text { DA10 }\end{array}$ & $\begin{array}{l}\text { (b) } \\
\text { (t). }\end{array}$ & $\begin{array}{l}\text { FTB4 } \\
\text { FTB6 }\end{array}$ & $\begin{array}{l}\text { FTB5 } \\
\text { FTB7 }\end{array}$ \\
\hline $\begin{array}{l}17.3 \\
17.3\end{array}$ & $\begin{array}{l}\text { (b) } \\
\text { (t) }\end{array}$ & $\begin{array}{l}\text { DA27 } \\
\text { DA25 }\end{array}$ & $\begin{array}{l}\text { DA26 } \\
\text { DA18 }\end{array}$ & $\begin{array}{l}\text { (b) } \\
\text { (t) }\end{array}$ & $\begin{array}{l}\text { FTD4 } \\
\text { FTD6 }\end{array}$ & $\begin{array}{l}\text { FTD5 } \\
\text { FTD7 }\end{array}$ \\
\hline $\begin{array}{l}15.8 \\
15.8\end{array}$ & $\begin{array}{l}\text { (b) } \\
(t)\end{array}$ & $\begin{array}{l}\text { DA42 } \\
\text { DA35 }\end{array}$ & $\begin{array}{l}\text { DA36 } \\
\text { DA34 }\end{array}$ & $\begin{array}{l}(b) \\
(t)\end{array}$ & $\begin{array}{l}\text { FTF4 } \\
\text { FTF6 }\end{array}$ & $\begin{array}{l}\text { FTF5 } \\
\text { FTF7 }\end{array}$ \\
\hline $\begin{array}{l}14.3 \\
14.3\end{array}$ & $\begin{array}{l}(b) \\
(t)\end{array}$ & $\begin{array}{l}\text { DA48 } \\
\text { N607 }\end{array}$ & $\begin{array}{l}\text { DA45 } \\
\text { N608 }\end{array}$ & $\begin{array}{l}\text { (b) } \\
(t)\end{array}$ & $\begin{array}{l}\text { FTG4 } \\
\text { FTG6 }\end{array}$ & $\begin{array}{l}\text { FTG5 } \\
\text { FTG7 }\end{array}$ \\
\hline $\begin{array}{l}12.8 \\
12.8\end{array}$ & $\begin{array}{l}\text { (b) } \\
\text { (t) }\end{array}$ & $\begin{array}{l}\text { N612 } \\
\text { N610 }\end{array}$ & $\begin{array}{l}\text { N611 } \\
\text { N609 }\end{array}$ & $\begin{array}{l}\text { (b) } \\
\text { (t) }\end{array}$ & $\begin{array}{l}\text { FTD8 } \\
\text { FTDA }\end{array}$ & $\begin{array}{l}\text { FTD9 } \\
\text { FTDB }\end{array}$ \\
\hline
\end{tabular}

\section{$500^{\circ} \mathrm{C}$ Thermal Diffusivity Specimens}

A hole in the base of the holder houses two specimens.

$\begin{array}{lll}\text { upper specimen } & \mathrm{N} 4 & 12.3 \mathrm{~cm} \\ \text { lower specimen } & \mathrm{N} 5 & 12.7 \mathrm{~cm}\end{array}$

\section{$500^{\circ} \mathrm{C}$ DCT Specimens}

Specimens are stacked vertically in a widened portion of the perimeter slot in Row 6 at the top of the holder.

$$
\begin{array}{lll}
\text { Top of slot } & \text { LFK2 } & 20.5 \mathrm{~cm} \\
\text { Bottom of slot } & \text { LFK1 } & 19.2 \mathrm{~cm}
\end{array}
$$




\section{$500^{\circ} \mathrm{C}$ Bar-9 Specimens}

No Bar-7 specimens were delivered for irradiation in the $300^{\circ} \mathrm{C}$ or the $500^{\circ} \mathrm{C}$ zones. Two of the Bar-9 specimens delivered for the $500^{\circ} \mathrm{C}$ zone would not fit into the Bar-9 slot, and were installed in the $500^{\circ} \mathrm{C}$ Bar-7 holder and installed in the position originally slated for the Bar-7. The other Bar-9 specimens are in a single layer, two-wide, in a slot machined into the base of the Bar- 8 perimeter slot of Row 8.

\begin{tabular}{ccc}
$\begin{array}{c}\text { Axial Location } \\
\text { (cm) }\end{array}$ & \multicolumn{2}{c}{ Specimens } \\
& & \\
19.1 & $15-2$ & $15-3$ \\
17.1 & $14-5$ & $15-1$ \\
15.1 & $14-3$ & $14-4$ \\
13.1 & $14-1$ & $14-2$
\end{tabular}

The Bar-9 specimens 15-4 and 15-5 in the Bar-7 specimen sleeve are loaded in Row 2 centered at $15.6 \mathrm{~cm}$.

\section{$500^{\circ} \mathrm{C}$ Bar-5 specimens}

The Bar-5 specimens are housed in a single short holder centered at $17.4 \mathrm{~cm}$ in Row 12 on the inner radius. The specimens are grouped into two stacks of four specimens at a single axial location and are arranged as follows:

$\begin{array}{lllll}\text { Top stack } & L & M & V & * \\ \text { Bottom stack } & 2 & 5 & 6 & \text { B }\end{array}$

\section{$500^{\circ} \mathrm{C}$ Fiber Bundle Tubes}

The fiber bundle tubes are $6 \mathrm{~cm}$ long and $3 \mathrm{~cm}$ less than the full length of the $300^{\circ} \mathrm{C}$ or $500^{\circ} \mathrm{C}$ specimen holders. Spacers are placed at the top of the $500^{\circ} \mathrm{C}$ holder. The fiber bundle holes are on the inner circle and the specimens are centered at $15.1 \mathrm{~cm}$.

$\begin{array}{lll}\text { Row } 1 & \text { Row } 5 & \text { Row } 7 \\ \text { J24C } & \text { J17C } & \text { J2C }\end{array}$




\section{$500^{\circ} \mathrm{C} \mathrm{CVN}$ specimens}

The CVN specimens are housed in cylindrical sleeves. A square slot in the sleeve accommodates four CVN specimens per axial location, and there are four axial locations per sleeve. All four CVN sleeves in the $500^{\circ} \mathrm{C}$ holder are in the outer circle.

$\begin{array}{ccccc}\text { Axial location }(\mathrm{cm}) & \text { Row } 2 & \text { Row } 7 & \text { Row } 9 & \text { Row } 12 \\ 19.2 & & & & \\ 19.2 & \text { L1K5 } & \text { L2K3 } & \text { LHK1 } & \text { LHK5 } \\ 19.2 & \text { L1K6 } & \text { L2K4 } & \text { LHK2 } & \text { LHK6 } \\ 19.2 & \text { L2K1 } & \text { L2K5 } & \text { LHK3 } & \text { BLANK } \\ 17.2 & \text { L2K2 } & \text { L2K6 } & \text { LHK4 } & \text { BLANK } \\ 17.2 & \text { LFK1 } & \text { LFK5 } & \text { LBK3 } & \text { L1K1 } \\ 17.2 & \text { LFK2 } & \text { LFK6 } & \text { LBK4 } & \text { L1K2 } \\ 17.2 & \text { LFK3 } & \text { LBK1 } & \text { LBK5 } & \text { L1K3 } \\ 15.2 & \text { LFK4 } & \text { LBK2 } & \text { LBK6 } & \text { L1K4 } \\ 15.2 & \text { G53K } & \text { G57K } & \text { G5BK } & \text { G54P } \\ 15.2 & \text { G54K } & \text { G58K } & \text { G51P } & \text { G55P } \\ 15.2 & \text { G55K } & \text { G59K } & \text { G52P } & \text { G56P } \\ 13.2 & \text { G56K } & \text { G5AK } & \text { G53P } & \text { G57P } \\ 13.2 & \text { G51C } & \text { G55C } & \text { G52E } & \text { G56E } \\ 13.2 & \text { G52C } & \text { G56C } & \text { G53E } & \text { G57E } \\ 13.2 & \text { G53C } & \text { G57C } & \text { G54E } & \text { G51K } \\ & \text { G54C } & \text { G51E } & \text { G55E } & \text { G52K }\end{array}$

\section{$500^{\circ} \mathrm{C}$ Tensile Specimens}

The $500^{\circ} \mathrm{C}$ tensile specimens were grouped into 5 stacks, each held at a specific axial location in the outer hole of Row 5.

$\begin{array}{llllll}\text { Axial Location }(\mathrm{cm}) & 19.3 & 17.7 & 16.1 & 14.5 & 12.9 \\ & & & & & \\ & \text { BLANK } & \text { TO15 } & \text { G53C } & \text { L2K1 } & \text { LFK1 } \\ & \text { BLANK } & \text { TO16 } & \text { G54C } & \text { L2K2 } & \text { LFK2 } \\ \text { BLANK } & \text { TO17 } & \text { G55C } & \text { L2K3 } & \text { LFK3 } \\ & \text { BLANK } & \text { TO25 } & \text { G51E } & \text { L2K4 } & \text { LFK4 } \\ \text { BLANK } & \text { TO26 } & \text { G52E } & \text { L2K5 } & \text { LFK5 } \\ & \text { F4L3 } & \text { TO27 } & \text { G53E } & \text { LHK1 } & \text { LBK1 } \\ & \text { F4L4 } & \text { AB40 } & \text { G54E } & \text { LHK2 } & \text { LBK2 } \\ & \text { F4L5 } & \text { AB41 } & \text { G55E } & \text { LHK3 } & \text { LBK3 } \\ \text { F7K2 } & \text { AB42 } & \text { G51K } & \text { LHK4 } & \text { LBK4 } \\ & \text { F7K4 } & \text { AB43 } & \text { G52K } & \text { LHK5 } & \text { LBK5 } \\ & \text { F7K5 } & \text { AB44 } & \text { G53K } & \text { G51A } & \text { L1K1 } \\ & \text { BLANK } & \text { AB45 } & \text { G51P } & \text { G52A } & \text { L1K2 } \\ & \text { BLANK } & \text { AB46 } & \text { G52P } & \text { G53A } & \text { L1K3 } \\ & \text { BLANK } & \text { AB47 } & \text { G53P } & \text { G51C } & \text { L1K4 } \\ & \text { BLANK } & \text { AB48 } & \text { G51S } & \text { G52C } & \text { L1K5 } \\ & \text { AB49 } & \text { G52S } & & \end{array}$




\section{$500^{\circ} \mathrm{C}$ Pressurized Tube Loading}

The diameters of the pressurized tube holes were varied to accommodate increased swelling expected with increased pressurization and irradiation temperature. Also, the stacked specimens did not completely fill the holes and spacers were used to fill the remainder of the hole. The spacers were placed at the top of the $500^{\circ} \mathrm{C}$ holder.

$\begin{array}{cllll}\begin{array}{c}\text { Axial Location } \\ \text { cm }\end{array} & \begin{array}{l}\text { Row 16 } \\ \text { inner } \\ \text { OMpa } \\ \text { Dia.184" }\end{array} & \begin{array}{l}\text { Row 16 } \\ \text { outer } \\ 120 \mathrm{MPa} \\ \text { Dia.191" }\end{array} & \begin{array}{l}\text { Row 3 } \\ \text { outer } \\ 190 \mathrm{MPa} \\ \text { Dia .196" }\end{array} & \begin{array}{l}\text { Row } 3 \\ \text { inner } \\ 250 \mathrm{MPa} \\ \text { Dia .196" }\end{array} \\ 18.6 & \text { LBK1 } & \text { LBK2 } & \text { LBK3 } & \text { LBK4 } \\ 16.0 & \text { LIK1 } & \text { L1K2 } & \text { LBK3 } & \text { L1K4 } \\ 13.4 & \text { LFK1 } & \text { LFK2 } & \text { L1K3 } & \text { LFK4 }\end{array}$

\section{$500^{\circ} \mathrm{C}$ Bar-8 Specimen Slot Loading}

The large perimeter slots were designed to hold Bar-8 specimens, some of which were below nominal dimensions. In some places small specimens were installed with the Bar-8 specimens to fill the space, in other instances, specimens of different shapes were included instead of Bar-8 specimens and are noted below.

$\begin{array}{clll}\begin{array}{c}\text { Axial location } \\ \mathrm{cm}\end{array} & \text { Row } 4 & \text { Row } 8 & \text { Row } 11 \\ & & & \\ 19.6 & \text { S25 S26 } & \text { C46 C47 } & \begin{array}{l}6 \text { monolithic SiC } \\ \text { in } 2 \text { groups of } 3 \\ 5275 \times 1.5\end{array} \\ & 22-1 \times 1 \times 25 \text { SiC } & & \begin{array}{l}4 \text { lon implanted bar specimens } \\ 1.5 \times 4 \times 50\end{array} \\ 16.6 & \text { F51 F52 } & \text { F53 C39 } & \text { P55 P56 }\end{array}$

\section{$500^{\circ} \mathrm{C}$ TEMS}

The TEMs are held in hollow cylindrical holders. The location range specified for each tube begins with the first specimen listed and ends with the last. The approximate location of other specimens can be found by interpolating between these points. 
Sleeve \#1
Row 16
Inner radius
16.7 to $21.1 \mathrm{~cm}$

$\begin{array}{lll}1 & \text { G5P1 } & \text { FLM2 } \\ 2 & \text { G5P2 } & \text { FLM3 } \\ 3 & \text { G5P3 } & \text { FLMD } \\ 4 & \text { G5S1 } & \text { FLMR }\end{array}$

G5S1

$6 \quad$ G5S3

7 G5S4

8 G5A1.

9 G5A2

10 G5K3

11 G5K4

12 G5C1

13 G5C2

14 G5C3

15 G5C4

16 G5C5

17 G5C7

18 G5E1

19 G5E2

20 G5E3

21 G5E4

22. G5E5

23 G5E6

24 G5E7

25 G5B5

26 G5B4

$27 \quad$ G5C6

28 G5B3

29 G5A6

$30 \quad$ G5B1

31 G5A5

32 G5A1

33 G5A2

$34 \quad$ G5A7

$35 \quad$ G5B7

$36 \quad \mathrm{G} 5 \mathrm{~A} 3$

$37 \quad$ G5B6

$38 \quad$ G5A4

39 G5B2

40 G5N5

$41 \quad \mathrm{G} 5 \mathrm{H} 3$

42 G5N2

$43 \quad \mathrm{G} 5 \mathrm{H} 1$

$44 \quad \mathrm{G} 5 \mathrm{H} 6$

45 G5N6

46 G5N4

$47 \quad \mathrm{G} 5 \mathrm{H}_{2}$

48 G5N3

$49 \quad \mathrm{G} 5 \mathrm{H} 4$

50 G5N1
Sleeve \#2

Row 16

Inner radius

12.1 to $16.5 \mathrm{~cm}$

FLR2

FLR3

FLRD

FLRF

FLS2

FLS3

FLSD

FLSF

FLT2

FLT3

FLTD

FLTF

FLV2

FLV3

FLVD

FLVF

$F L X 2$

FLX3

FLXF

FLY2

FLY3

FLYD

FLYE

LFK1

LFK2

LFK3

LFK4

LFK5

LBK1

LBK2

LBK3

LBK4

LBK5

L1K1

L1K2

L1K3

LIK4

L1K5

L2K1

$\mathrm{L} 2 \mathrm{~K} 2$

$\mathrm{L} 2 \mathrm{~K} 3$

L2K4

L2K5

LHK1

LHK2

LHK3
Sleeve \#3

Row 12

Outer Radius

$16.7 \mathrm{~cm}$ to $21.1 \mathrm{~cm}$

YM01

BLANK

YM02

BLANK

YMO3

BLANK

YM04

BLANK

YM05

BLANK

YMO6

BLANK

YM07

BLANK

YM08

BLANK

YM09

BLANK

YM10

BLANK

YM11

BLANK

YM12

BLANK YN30

YM13

BLANK

YM14

BLANK

YM15

BLANK

YM16

BLANK

YM17

BLANK

YM18

BLANK

YM19

BLANK

YM20

BLANK

YM21

BLANK

YM22

BLANK

YM23

BLANK

YM24

BLANK

YM25

BLANK 
Sleeve \#1

Inner radius

16.7 to $21.1 \mathrm{~cm}$

$51 \quad \mathrm{G} 5 \mathrm{H} 7$

52 G5H5

53 TMA5

54 TMAG

55 TMA7

56 TMA8

57 TMA9

58 TMH5

59 TMH6

60 TMH7

61 TMH8

62 TMHO

63 TMJ5

64 TMJ6

65 TMJ7

66 TMJ8

67 TMJ6

68 TMM5

69 TMM6

$70 \quad$ TMM7

71 TMM8

72 TMM9

73 TMD5

74 TMD6

75 TMD7

76 TMD8

77 TMD9

78 TME5

79 TME6

80 TME7

81 TME8

82 TME9

83 TMK5

84 TMK6

85 TMK7

86 TMK8

87 TMK9

88 TMG5

89 TMG6

90 TMG7

91 TMG8

92 TMG9

93 TML5

94 TML6

95 TML7

96 TML8

97 TML9

98 TMB5

99 TMB6

100 TMB7

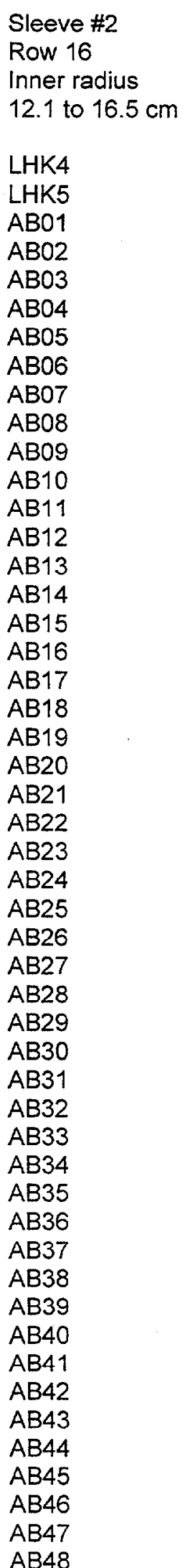

Sleeve \#3

Row 12

Outer Radius

$16.7 \mathrm{~cm}$ to $21.1 \mathrm{~cm}$

YM26

BLANK

YM27

BLANK

YM28

BLANK

YM29

BLANK

YM30

BLANK

YM31

BLANK

YM32

BLANK

YM33

BLANK

YM34

BLANK

YM35

BLANK

YM36

BLANK

YM37

BLANK

YM38

BLANK

YM39

BLANK

YM40

BLANK

YM41

BLANK

YM42

BLANK

YM43

BLANK

YM44

BLANK

YM45

BLANK

YM46

BLANK

YM47

BLANK

YM48

BLANK

YM49

BLANK

YM50

BLANK 
Sleeve \#1

Row 16

Inner radius

16.7 to $21.1 \mathrm{~cm}$

101 TMB8

102 TMB9

103 TM35

104 TM36

105 TM37

106 TM38

107 TM39

108 TM15

109 TM16

110 TM17

111 TM18

112 TM19

113 TM25

114 TM26

115 TM27

116 TM28

117 TM29

118 TM45

119 TM46

120 TM47

121 TM48

122 TM49

123 AV02

124 AV03

125 AV52

126 AV53

127 AV82

128 AV83

129 AL02

130 AL03

131 AT22

132 AT23

133 AH42

$134 \quad \mathrm{AH} 43$

$135 \quad$ AZ62

136 AZ63

$137 \mathrm{KHO}$

$138 \mathrm{KHO2}$

$139 \mathrm{KHO} 4$

$140 \quad \mathrm{KHO5}$

$141 \mathrm{KHO}$

142 KHO9

$143 \mathrm{KH} 11$

$144 \mathrm{KH} 12$

145 KWO4

$146 \quad$ KW05

147 KW06

148 KTO3

149 KTO4

150
Sleeve \#2

Row 16

Inner radius

12.1 to $16.5 \mathrm{~cm}$

AB49

AB50

$A B 51$

$A B 52$

AB53

AB54

AB55

AB56

$A B 57$

AB58

AB59

AB60

AB61

F4L6

F4LG

F4LZ

F6L8

F6LB

F6MO

F7L2

F7LB

F7M6

F5L7

F5LF

F8LF

F8M4

F3L9

F3LK

F2LG

F2LK

F2L5

F4MO

F4MA

F7M9

F7MA

JY15

JY21

FS1F

FS1G

FS3F

FS3G

FS5F

FS5G

FS7F

FS7G

FS9F

FS9G
Sleeve \#3

Row 12

Outer Radius

$16.7 \mathrm{~cm}$ to $21.1 \mathrm{~cm}$

YM51

BLANK

YM52

BLANK

YM53

BLANK

YM54

BLANK

YM55

BLANK

YM56

BLANK

YM57

BLANK

YM58

BLANK

YM59

BLANK

YM60

BLANK

YM61

BLANK

YM62

BLANK

YM63

$14 T 8$

$14 \mathrm{Tg}$

$14 \mathrm{~T} 10$

$15 T 8$

$15 T 9$

$15 \mathrm{~T} 10$ 


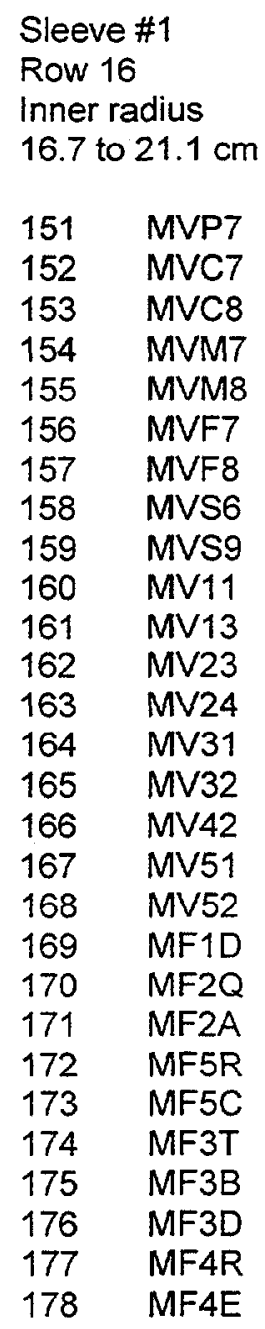

Sleeve \#2

Row 16

Inner radius

12.1 to $16.5 \mathrm{~cm}$
Sleeve \#3

Row 12

Outer Radius

$16.7 \mathrm{~cm}$ to $21.1 \mathrm{~cm}$

The $800^{\circ} \mathrm{C}$ Holder

$800^{\circ} \mathrm{C}$ Bar-5 specimens

The Bar- 5 specimens are housed in a short holder centered at $-8.6 \mathrm{~cm}$ in Row 7 . The specimens are grouped into two stacks of four specimens and are arranged as follows:

$\begin{array}{lllll}\text { Top stack } & \text { E } & \text { N } & \text { W } & \% \\ \text { Bottom stack } & 3 & 7 & 8 & \text { X }\end{array}$


$800^{\circ} \mathrm{C}$ Perimeter Slot Loading

The $800^{\circ} \mathrm{C}$ holder has 6 perimeter slots originally designated for $12 \mathrm{Bar}-8$ specimens. Specimens other than Bar- 8 were included in some of the space and are noted in the table below.

\begin{tabular}{|c|c|c|c|c|c|c|c|c|c|}
\hline & Row 2 & \multirow{2}{*}{$\begin{array}{|ll|}\text { Row 4 } & \\
\text { CVI } & \text { CVI } \\
12283 & 12284 \\
\end{array}$} & Row 6 & \multicolumn{2}{|l|}{ Row 8} & \multicolumn{2}{|l|}{ Row 9} & \multicolumn{2}{|l|}{ Row 10} \\
\hline $7.3 \mathrm{~cm}$ & \multirow{5}{*}{$\begin{array}{l}12 \text { LLS } \\
50 \mathrm{~mm} \\
\text { Pos. } 1 \\
\text { Through } \\
\text { Pos. } 5\end{array}$} & & $\begin{array}{ll}C V 1 & C V I \\
12142 & 12144 \\
\end{array}$ & $\begin{array}{l}\mathrm{CVI} \\
12146\end{array}$ & $\begin{array}{l}\mathrm{CVI} \\
12148\end{array}$ & $\begin{array}{l}C V 1 \\
12062\end{array}$ & $\begin{array}{l}\mathrm{CVI} \\
12064 \\
\end{array}$ & $\begin{array}{l}\text { CVI } \\
12086\end{array}$ & $\begin{array}{l}\mathrm{CVI} \\
12088\end{array}$ \\
\hline $4.3 \mathrm{~cm}$ & & $\begin{array}{ll}\mathrm{CV} & \mathrm{CV} \\
12096 & 12098\end{array}$ & $\begin{array}{ll}\text { CVI } & \text { CVI } \\
12132 & 12134\end{array}$ & $\begin{array}{l}\text { CVI } \\
12136\end{array}$ & $\begin{array}{l}\text { CVI } \\
12138\end{array}$ & $1-1$ & $1-2$ & $\begin{array}{l}\text { CVI } \\
12066\end{array}$ & $\begin{array}{l}\mathrm{CV!} \\
12068\end{array}$ \\
\hline $1.3 \mathrm{~cm}$ & & $\begin{array}{ll}\mathrm{CV} & \mathrm{CVI} \\
12281 & 12282\end{array}$ & $\begin{array}{l}\text { CV } \\
120510\end{array}$ & P82 & P83 & $1-3$ & $2-3$ & P86 & P87 \\
\hline$-1.7 \mathrm{~cm}$ & & F84 & F85 & P88 & P89 & $2-1$ & $2-2$ & $x 2$ & $\times 3$ \\
\hline$-4.7 \mathrm{~cm}$ & & $\mathrm{C} 35$ & C36 $\quad$ C37 & C38 & N5 & N6 & N7 & N8 & N9 \\
\hline$-7.7 \mathrm{~cm}$ & $\begin{array}{l}\text { M1 M2 } \\
91 \times 1 \times 25 \\
\text { SiC }\end{array}$ & $\begin{array}{l}\text { M3 M4 } \\
91 \times 1 \times 25 \\
\text { SiC }\end{array}$ & $\begin{array}{l}\text { M5 S1 } \\
21 \times 1 \times 25 \\
\text { SiC }\end{array}$ & S3 & S2 & \$5 & S4 & $\begin{array}{l}241 \times 1 \times 2 \\
35 \times 5 \times 1\end{array}$ & \\
\hline
\end{tabular}

\section{$800^{\circ} \mathrm{C}$ Fiber Bundle Tubes}

$\begin{array}{ccccc}\begin{array}{c}\text { Axial Location } \\ \mathrm{Cm}\end{array} & \text { Hole A } & \text { Hole B } & \text { Hole C } & \text { Hole D } \\ 5.8 & \mathrm{~J} 7 \mathrm{~B} & \mathrm{~J} 2^{*} \mathrm{~A} & \mathrm{~J} 24 \mathrm{~B} & \mathrm{~J} 2 \mathrm{~B} \\ -0.2 & \mathrm{~J} 17 \mathrm{~A} & \mathrm{~J} 2^{*} \mathrm{~B} & \mathrm{~J} 22 \mathrm{~A} & \mathrm{~J} 2 \mathrm{~A} \\ -6.2 & \mathrm{~J} 17 \mathrm{~B} & \mathrm{~J} 7 \mathrm{~A} & \mathrm{~J} 22 \mathrm{~B} & \mathrm{~J} 24 \mathrm{~A}\end{array}$

\section{$800^{\circ} \mathrm{C}$ BSR}

Two large BSR specimen assemblies are installed into a hole at Row 1 open on the bottom face of the $800 \mathrm{C}$ holder.

Upper specimen Lower specimen
$-2.5 \mathrm{~cm} \mathrm{~A}$ $-6.9 \mathrm{~cm}$ B 


\section{$800^{\circ} \mathrm{C}$ Bar-1 Specimens}

In the $800^{\circ} \mathrm{C}$ holder a perimeter slot was included for Bar- 1 specimens directly above the BSR specimen hole at Row 1 . Four axial locations are used for the Bar-1 specimens and four small Bar specimens are included on top of those specimens.

\begin{tabular}{cll}
$\begin{array}{c}\text { Axial Location } \\
(\mathrm{cm})\end{array}$ & Specimens \\
& \multicolumn{3}{l}{$\begin{array}{l}4 \text { ion implanted } \\
\text { Bar specimens } \\
1 \times 1 \times 4\end{array}$} \\
& DA19(b) & DA20(b) \\
5.2 & DA21(t) & DA28(t) \\
5.0 & DA29(b) & DA30(b) \\
3.5 & DA12(t) & DA13(t) \\
3.5 & DA14(b) & DA05(b) \\
2.0 & DA06(t) & DA39(t) \\
2.0 & DA37(b) & DA38(b) \\
0.47 & DA07(t) & FTF9(t)
\end{tabular}

\section{$800^{\circ} \mathrm{C}$ Thermal Diffusivity Specimens}

A thin perimeter slot at Row 5 was included for 14 thermal diffusivity specimens. Nine specimens were delivered for irradiation, so the specimen sleeve was shortened and the space was filled with other specimens as noted below.

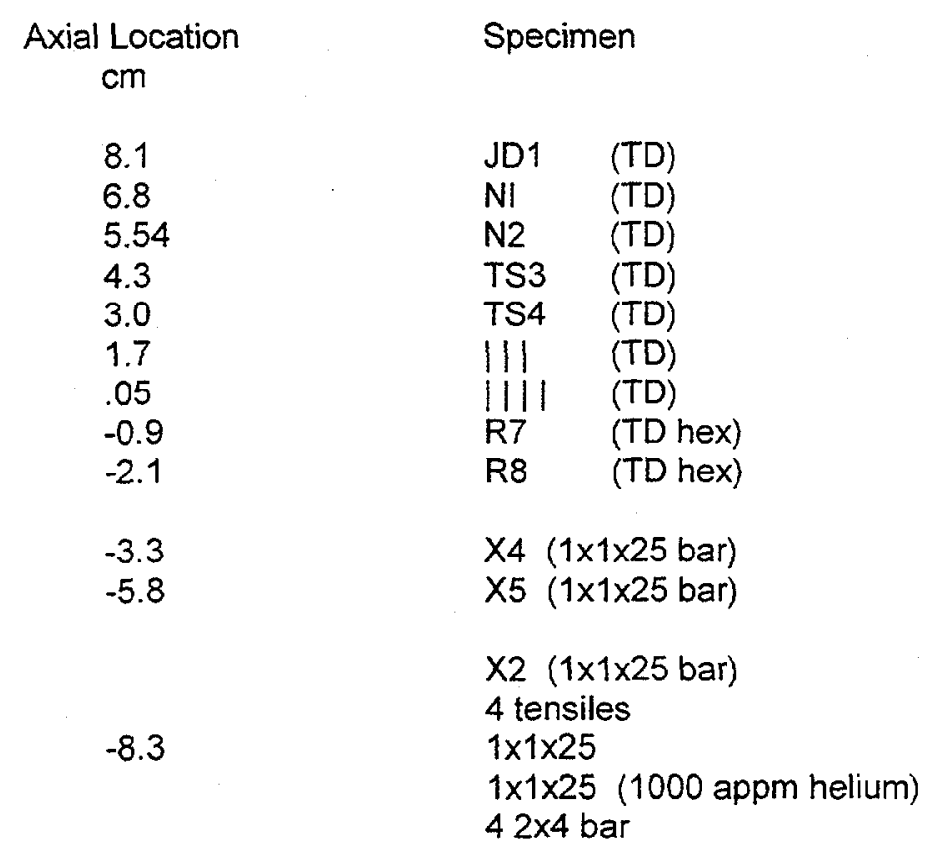




\section{$800^{\circ} \mathrm{C}$ CVN specimens}

An unfilled CVN specimen sleeve was loaded with two unmarked sleeves of fibers supplied by Snead of ORNL and is in an outer hole of row 3 centered at $-3.2 \mathrm{~cm}$. The other CVN specimens are in two sleeves located in an outer hole of Row 7.

Sleeve 1

Axial Location

Specimen

$\mathrm{cm}$

$\begin{array}{lllll}7 \mathrm{~cm} & G 81 K(b) & G 82 K(b) & G 83 K(t) & \text { G84K(t) } \\ 5 \mathrm{~cm} & \text { G85K(b) } & \text { G86K(b) } & \text { G87K(t) } & \text { G88K(t) } \\ 3 \mathrm{~cm} & \text { G89K(b) } & \text { G8AK(b) } & \text { G8BK(t) } & \text { BLANK } \\ 1 \mathrm{~cm} & \text { W109(b) } & \text { W100(b) } & \text { BLANK } & \text { BLANK }\end{array}$

Sleeve 2

$\begin{array}{lllll}-1 \mathrm{~cm} & W 206(b) & W 206(b) & W 207(t) & W 207(t) \\ -3 \mathrm{~cm} & W 208(b) & W 208(b) & W 209(t) & W 209(t) \\ -5 \mathrm{~cm} & W 200(b) & W 200(b) & W 211(t) & W 211(t) \\ -7 \mathrm{~cm} & W 105(b) & W 106(b) & W 107(t) & W 108(t)\end{array}$

\section{$800^{\circ} \mathrm{C}$ Bar-7 Specimens}

All of the planned Bar-7 specimens would not fit inside the sleeve and instead of the originally planned stack of 5 deep, only a stack of 4 could be accommodated, therefore several of the supplied specimens were rejected. Those rejected were generally either too wide or were part of a large group of specimens made of the same alloy. The specimens were stacked two wide, four deep in three axial positions within two specimen sleeves, and the sleeves are in an outer hole of row 11.

Axial Location

Specimen

$\mathrm{cm}$

Sleeve 1

Layer 1

$5.2 \quad$ KSL1 KS11

4.2

KS25 KS02

3.2

$\mathrm{KSZ1} \mathrm{KS} 43$

Sleeve 2

8.2

Layer 1

KS21 KSX1

Layer 2

KSX2 KS22

KS35 KSA1

KSH2 KS71
Layer 3

KSL3 KS13

KS32 KS51

KSZ3 KS52

Layer 3

KS23 KSX3

KSA2 KS41

KS72 KSF1
Layer 4

KS14 KSL4

KS52 KS33

KS53 KSZ4

Layer 4

KS01 KS24

$\mathrm{KS} 42 \mathrm{KSA} 3$

KSF2 KS73 


\section{$800^{\circ} \mathrm{C}$ TEMS}

The TEMs are held in a single hollow cylindrical holder. The location range specified for the tube begins with the first specimen listed and ends with the last. The approximate location of other specimens can be found by interpolating between these points.

Row 3 Outer Hole

\section{$4.7 \mathrm{~cm}$ to $0.6 \mathrm{~cm}$}

\begin{tabular}{|c|c|c|c|c|c|}
\hline 1 & KS61 & 42 & KSZ8 & 83 & FLV8 \\
\hline 2 & KSL6 & 43 & KS82 & 84 & FLX4 \\
\hline 3 & KS62 & 44 & $\mathrm{KSH} 3$ & 85 & $F L X 6$ \\
\hline 4 & KSL7 & 45 & KS83 & 86 & $F L X G$ \\
\hline 5 & KS63 & 46 & KSH4 & 87 & FLX8 \\
\hline 6 & KSL8 & 47 & KS56 & 88 & FLY4 \\
\hline 7 & KS64 & 48 & KS58 & 89 & FLY5 \\
\hline 8 & $\mathrm{KS} \times 6$ & 49 & $\mathrm{KSH} 7$ & 90 & FLY8 \\
\hline 9 & KS65 & 50 & KS75 & 91 & FLY9 \\
\hline 10 & $\mathrm{KSX7}$ & 51 & KSH8 & 92 & G8K1 \\
\hline 11 & KS66 & 52 & KS76 & 93 & G8K2 \\
\hline 12 & $\mathrm{KS} \times 7$ & 53 & KSL3 & 94 & G8K3 \\
\hline 13 & KS67 & 54 & KS77 & 95 & G8K4 \\
\hline 14 & $\mathrm{KS} \times 8$ & 55 & KSL4 & 96 & G8S1 \\
\hline 15 & KS68 & 56 & KS78 & 97 & G8S2 \\
\hline 16 & KSO4 & 57 & KSL5 & 98 & G8S3 \\
\hline 17 & KS69 & 58 & KS79 & 99 & G8S4 \\
\hline 18 & KSO5 & 59 & KSE1 & 100 & JY06 \\
\hline 19 & KS70 & 60 & KSE2 & 101 & JY12 \\
\hline 20 & KS06 & 61 & KSE3 & 102 & 9R04 \\
\hline 21 & KS44 & 62 & KSE6 & 103 & 9R05 \\
\hline 22 & KSS4 & 63 & KSE7 & 104 & 9R12 \\
\hline 23 & KS45 & 64 & KSE8 & 105 & 9R07 \\
\hline 24 & KSS5 & 65 & FLM4 & 106 & 9R08 \\
\hline 25 & KS46 & 66 & FLM5 & 107 & FS1A \\
\hline 26 & KSS6 & 67 & FLM6 & 108 & FS1B \\
\hline 27 & KS91 & 68 & FLM8 & 109 & FS1D \\
\hline 28 & KSA4 & 69 & FLR5 & 110 & FS3A \\
\hline 29 & KS91 & 70 & FLR8 & 111 & FS3B \\
\hline 30 & KSA5 & 71 & FLR9 & 112 & FS3D \\
\hline 31 & KS92 & 72 & FLS4 & 113 & FS5A \\
\hline 32 & KSA6 & 73 & FLS5 & 114 & FS5B \\
\hline 33 & KS93 & 74 & FLS6 & 115 & FS5D \\
\hline 34 & KSA7 & 75 & FLS8 & 116 & FSTA \\
\hline 35 & KS94 & 76 & FLT4 & 117 & FS7B \\
\hline 36 & KSA8 & 77 & FLT5 & 118 & FS7D \\
\hline 37 & KS95 & 78 & FLT6 & 119 & FS9A \\
\hline 38 & KSZ6 & 79 & FLT8 & 120 & FS9B \\
\hline 39 & KS96 & 80 & FLV4 & 121 & FS9D \\
\hline 40 & KSZ7 & 81 & FLV5 & & \\
\hline 41 & KS81 & 82 & FLV6 & & \\
\hline
\end{tabular}


The $300^{\circ} \mathrm{C}$ Holder

\section{$300^{\circ} \mathrm{C}$ Bar-1 Specimens}

The Bar-1 specimens are in the smaller perimeter slots of the $300^{\circ} \mathrm{C}$ holder.

Axial Location Row 9 $\mathrm{cm}$

Row 4

\begin{tabular}{|c|c|c|c|c|c|c|c|}
\hline $\begin{array}{l}-13.15 \\
-13.15\end{array}$ & $\begin{array}{l}\text { (b) } \\
\text { (t) }\end{array}$ & $\begin{array}{l}\text { FTG8 } \\
\text { FTGA }\end{array}$ & $\begin{array}{l}\text { FTG9 } \\
\text { FTGB }\end{array}$ & $\begin{array}{l}-13.15 \\
-13.15\end{array}$ & $\begin{array}{l}\text { (b) } \\
\text { (t) }\end{array}$ & $\begin{array}{l}\text { N603 } \\
\text { N605 }\end{array}$ & $\begin{array}{l}\text { N604 } \\
\text { N606 }\end{array}$ \\
\hline-14.65 & (b) & Go & G1 & -14.65 & (b) & DA46 & DA47 \\
\hline-14.65 & $(t)$ & G2 & G3 & -14.65 & (t) & N601 & N602 \\
\hline-16.15 & (b) & FO & $F 1$ & -16.15 & (b) & DA40 & DA41 \\
\hline-16.15 & $(t)$ & F2 & F3 & -16.15 & $(\mathrm{t})$ & DA33 & DA44 \\
\hline-17.65 & (b) & DO & D1 & -17.65 & (b) & DA24 & DA31 \\
\hline-17.65 & $(t)$ & $\mathrm{D} 2$ & D3 & -17.65 & $(t)$ & DA32 & DA33 \\
\hline-19.15 & (b) & BO & B1 & -19.15 & (b) & DA15 & DA16 \\
\hline-19.15 & $(t)$ & B2 & B3 & -19.15 & $(t)$ & DA22 & DA23 \\
\hline-20.65 & (b) & $\begin{array}{l}\text { FTAO } \\
\text { FTA? }\end{array}$ & FTA1 & -20.65 & (b) & DA02 & DA09 \\
\hline-20.65 & $(\mathrm{t})$ & FTA2 & FTA3 & -20.65 & (t) & DA01 & DA08 \\
\hline
\end{tabular}

$300^{\circ} \mathrm{C}$ Thermal Diffusivity Specimens

Thermal diffusivity specimens are housed in a sleeve in a perimeter slot on Row 6 . Two additional specimens are in the DCT specimen hole on the base of the holder.

Axial Location

$\mathrm{cm} \quad$ Row 6

$-13.2 \quad J D 2$

$-14.415-\mathrm{C}-2$

$-15.715-\mathrm{C}-1$

$-17.0 \quad 14-\mathrm{C}-2$

$-18.214-\mathrm{C}-1$

$\begin{array}{ll}-21.2 & \text { Base of holder } \\ -21.0 & \text { TS1 } \\ & \text { TS2 }\end{array}$

$300^{\circ} \mathrm{C}$ DCT Specimens

The DCT specimens are near the bottom of the holder in a widened portion of the perimeter slot in Row 6 .

Axial Location

$\mathrm{cm}$

$-19.5 \quad$ LFH1

$-20.8 \quad \mathrm{LFH} 2$ 
$300^{\circ} \mathrm{C}$ CVN specimens

In the $300^{\circ} \mathrm{C}$ holder the CVN specimens are housed in 5 sleeves, one of which holds half the number of specimens as the others. A square slot accommodates four CVN specimens in four axial locations in the four longer sleeves and 2 axial locations in the fifth sleeve.

$\begin{array}{ccllll}\begin{array}{c}\text { Axial location } \\ \text { cm }\end{array} & \text { Row 2 } & \text { Row 7 } & \text { Row 11 } & \text { Row 13 } & \text { Row 8 } \\ -13.25 & & & & & \\ -13.25 & \text { G31C } & \text { G35C } & \text { G32E } & \text { G36E } & \\ -13.25 & \text { G32C } & \text { G36C } & \text { G33E } & \text { G37E } & \\ -13.25 & \text { G33C } & \text { G37C } & \text { G34E } & \text { G31K } & \\ & \text { G34C } & \text { G31E } & \text { G35E } & \text { G32K } & \\ -15.25 & \text { G33K } & \text { G37K } & \text { G3BK } & \text { G31P } & \\ -15.25 & \text { G34K } & \text { G38K } & \text { G3DK } & \text { G32P } & \\ -15.25 & \text { G35K } & \text { G39K } & \text { G3EK } & \text { G33P } & \\ -15.25 & \text { G36K } & \text { G3AK } & \text { G3GK } & \text { G34P } & \\ -17.25 & \text { G35P } & \text { LFH2 } & \text { LFH6 } & \text { LBH3 } & \text { LBH7 } \\ -17.25 & \text { G36P } & \text { LFH3 } & \text { LFH7 } & \text { LBH4 } & \text { L1H1 } \\ -17.25 & \text { G37P } & \text { LFH4 } & \text { LBH1 } & \text { LBH5 } & \text { L1H2 } \\ -17.25 & \text { LFH1 } & \text { LFH5 } & \text { LBH2 } & \text { LBH6 } & \text { L1H3 } \\ & & & & & \\ -19.25 & \text { L1H4 } & \text { L1H8 } & \text { L2H4 } & \text { L2H8 } & \text { LHH4 } \\ -19.25 & \text { L1H5 } & \text { L2H1 } & \text { L2H5 } & \text { LHH1 } & \text { LHH5 } \\ -19.25 & \text { L1H6 } & \text { L2H2 } & \text { L2H6 } & \text { LHH2 } & \text { LHH6 } \\ -19.25 & \text { L1H7 } & \text { L2H3 } & \text { L2H7 } & \text { LHH3 } & \text { LHH7 }\end{array}$

\section{$300^{\circ} \mathrm{C}$ Bar- 5 specimens}

The Bar-5 specimens are housed in a short holder centered at $-20.1 \mathrm{~cm}$ in Row 12 on an outer radius. The specimens are grouped into two stacks of four specimens and are arranged as follows:

$\begin{array}{lllll}\text { Top stack } & \text { A } & \text { C } & \text { K } & \text { T } \\ \text { Bottom stack } & 0 & 1 & \text { H } & 9\end{array}$

\section{$300^{\circ} \mathrm{C}$ Pressurized Tubes}

The diameters of the pressurized tube holes were varied to accommodate increased swelling expected with increased pressurization and irradiation temperature. Also, the stacked specimens did not completely fill the holes and spacers were used to fill the remainder of the hole. The spacers were placed at the bottom of the $300^{\circ} \mathrm{C}$ holder.

\begin{tabular}{|c|c|c|c|c|}
\hline $\begin{array}{l}\text { Axial Location } \\
\mathrm{cm}\end{array}$ & $\begin{array}{l}\text { hole P } \\
\text { O MPa } \\
\text { Dia.184" }\end{array}$ & $\begin{array}{l}\text { hole } \mathrm{R} \\
150 \mathrm{MPa} \\
\mathrm{Dia} .191 "\end{array}$ & $\begin{array}{l}\text { hole C } \\
230 \mathrm{MPa} \\
\text { Dia .196" }\end{array}$ & $\begin{array}{l}\text { hole } \mathrm{D} \\
300 \mathrm{MPa} \\
\text { Dia .196" }\end{array}$ \\
\hline-13.7 & LFH1 & LFH2 & LFH3 & LFH4 \\
\hline-16.9 & LIH1 & L1H2 & L1H3 & $\mathrm{L} 1 \mathrm{H} 4$ \\
\hline-19.9 & LBH1 & $\mathrm{LBH} 2$ & LBH3 & LBH4 \\
\hline
\end{tabular}




\section{$300^{\circ} \mathrm{C}$ Bar-8 Specimens}

The Bar- 8 specimens are housed in the larger perimeter slots.

Axial Location

$\mathrm{cm}$

Row $14 \quad$ Row 18

$-13.9$

CVI CVI

C48 449

$-13.9$

1206512067

$-16.9$

CVI CVI CVI CVI

$-16.9$

1205312055

1205712063

$-19.9$

\section{CVI}

1208512286

CVI CVI

1214312147

\section{$300^{\circ} \mathrm{C}$ Fiber Bundle Tubes}

The fiber bundle tubes are not the full length of the $300^{\circ} \mathrm{C}$ holder. Spacers are used to make up the difference and the specimens are centered at $-15.4 \mathrm{~cm}$ in holes on the inner circle.

$\begin{array}{llll}\text { Row } 0 & \text { Row } 5 & \text { Row } 12 & \text { Row } 13 \\ \text { J7D } & \text { J22D } & \text { J2D } & \text { J24D }\end{array}$

\section{$300^{\circ} \mathrm{C}$ Tensile Specimens}

The $300^{\circ} \mathrm{C}$ tensile specimens were grouped into 6 stacks of specimens. Each stack is held at a specific axial location. Five of the stacks are in the outer hole of Row 5 and the sixth stack is in the outer circle of Row 12, near the top of the holder.

Row 5

$\begin{array}{cccccc}\text { Axial Location }(\mathrm{cm}) & -13.2 & -14.8 & -16.4 & -18.0 & -19.6 \\ & \text { LFH1 } & \text { L2H1 } & \text { G36A } & \text { G37E } & \text { TO10 } \\ & \text { LFH2 } & \text { L2H2 } & \text { G37A } & \text { G31K } & \text { TO11 } \\ & \text { LFH3 } & \text { L2H3 } & \text { G31C } & \text { G32K } & \text { TO12 } \\ \text { LFH4 } & \text { L2H4 } & \text { G32C } & \text { G33K } & \text { TO13 } \\ & \text { LFH5 } & \text { L2H5 } & \text { G33C } & \text { G34K } & \text { TO14 } \\ \text { LBH1 } & \text { LHH1 } & \text { G34C } & \text { G35K } & \text { TO20 } \\ & \text { LBH2 } & \text { LHH2 } & \text { G35C } & \text { G31P } & \text { TO21 } \\ & \text { LBH3 } & \text { LHH3 } & \text { G36C } & \text { G32P } & \text { TO22 } \\ \text { LBH4 } & \text { LHH4 } & \text { G37C } & \text { G33P } & \text { TO23 } \\ & \text { LBH5 } & \text { LHH5 } & \text { G31E } & \text { G31S } & \text { TO24 } \\ & \text { L1H1 } & \text { G31A } & \text { G32E } & \text { G32S } & \text { TO30 } \\ & \text { L1H2 } & \text { G32A } & \text { G33E } & \text { G33S } & \text { TO31 } \\ \text { L1H3 } & \text { G33A } & \text { G34E } & \text { G34S } & \text { TO32 } \\ \text { L1H4 } & \text { G34C } & \text { G35E } & \text { G35S } & \text { TO33 } \\ \text { LIH5 } & \text { G35C } & \text { G36E } & & \text { TO34 }\end{array}$


Axial Location (cm) $\quad-13.2 \mathrm{~cm}$

TO40
TO41
TO42
TO43
TO44
AA40
AA41
AA42
AA43
AA44
AA45
AA46
AA47
AA48
AA49
AA50
AA51

$300^{\circ} \mathrm{C}$ Bar-7 Specimen Holder

The $300^{\circ} \mathrm{C}$ Bar- 7 holder was loaded into the inner circle of Row 8 centered at $-14.8 \mathrm{~cm}$ with the following bar specimens:

$\begin{array}{ll}\text { S-23 } & 1 \times 1 \times 15 \\ \text { S- } 24 & 1 \times 1 \times 15 \\ \text { S- } 21 & 1 \times 1 \times 15 \\ \text { S-25 } & 1 \times 1 \times 15 \\ 3 \text { LLS } & 1 \times 1 \times 25\end{array}$

$300^{\circ} \mathrm{C}$ TEMs

The TEMs are held in hollow cylindrical holders. The location range specified for each tube begins with the first specimen listed and ends with the last. The approximate location of other specimens can be found by interpolating between these points.

$\begin{array}{lll}\begin{array}{ll}\text { Sleeve \#1 } \\ \text { Row } 17\end{array} & \text { Sleeve \#2 } & \begin{array}{l}\text { Sleeve \#3 } \\ \text { Inner radius }\end{array} \\ -12.4 \text { to }-16.4 \mathrm{~cm} & \begin{array}{l}\text { Row } 17 \\ \text { Inner radius }\end{array} & \begin{array}{l}\text { Outer Radius } \\ \text {-15.6 to }-19.6 \mathrm{~cm}\end{array} \\ \text { G3S1 } & -16.6 \mathrm{~cm} \text { to }-20.0 \mathrm{~cm} & -15.6 \\ \text { G3S2 } & \text { FLMO } & \text { YN01 } \\ \text { G3S3 } & \text { FLM1 } & \text { YN02 } \\ \text { G3S4 } & \text { FLMA } & \text { YN03 } \\ \text { G3S5 } & \text { FLMB } & \text { YN04 } \\ \text { G3S6 } & \text { FLMO } & \text { YN05 } \\ \text { G3K1 } & \text { FLRO } & \text { YN06 } \\ \text { G3K2 } & \text { FLR1 } & \text { YN07 } \\ \text { G3K3 } & \text { FLRB } & \text { YN08 } \\ \text { G3K4 } & \text { FLSO } & \text { YN09 } \\ \text { G3K5 } & \text { FLS1 } & \text { YN10 } \\ \text { G3K6 } & \text { FLSA } & \text { YN11 } \\ & \text { FLSB } & \text { YN12 }\end{array}$




$$
\begin{aligned}
& \text { Sleeve \#1 } \\
& \text { Row } 17 \\
& \text { Inner radius } \\
& -12.4 \text { to }-16.4 \mathrm{~cm}
\end{aligned}
$$

\begin{tabular}{ll}
13 & G3P1 \\
14 & G3PK33 \\
15 & G3PK36 \\
16 & G3A1 \\
17 & G3A2 \\
18 & G3A3 \\
19 & G3A4 \\
20 & G3A5 \\
21 & G3A6 \\
22 & G3A7 \\
23 & G3B1 \\
24 & G3B2 \\
22 & G3B3 \\
23 & G3B4 \\
27 & G3B5 \\
28 & G3B6 \\
29 & G3B7 \\
30 & G3B8 \\
31 & G3B9 \\
32 & G3N1 \\
33 & G3H1 \\
34 & G3H2 \\
35 & G3H3 \\
36 & G3H3 \\
37 & G3H5 \\
38 & G3H6 \\
39 & G3H7 \\
40 & G3H8 \\
41 & G3C5 \\
42 & G3C7 \\
43 & G3C6 \\
44 & G3C4 \\
45 & G3C2 \\
46 & G3C1 \\
47 & G3C3 \\
48 & G3E3 \\
49 & G3E4 \\
50 & G3E1 \\
51 & G3E6 \\
52 & G3E7 \\
53 & G3E5 \\
54 & G3232 \\
55 & TMB4 \\
56 & TME1 \\
57 & TMM3 \\
58 & TMB3 \\
59 & TMK3 \\
60 & TME3 \\
61 & TMK2 \\
63 & TME2 \\
\hline & TME4 \\
&
\end{tabular}

$\begin{array}{ll}\text { Sleeve \#2 } & \text { Sleeve \#3 } \\ \text { Row } 17 & \text { Row } 12 \\ \text { Inner radius } & \text { Outer Radius } \\ -16.6 \mathrm{~cm} \text { to }-20.0 \mathrm{~cm} & -15.6 \text { to }-19.6 \mathrm{~cm}\end{array}$

FLTO

FLT1

FLTA

FLTB

FLVO

FLV1

FLVA

FLVB

FLXO

FLX1

FLXA

FLXB

FLYO

FLY1

FLYA

FLYB

LFH1

LFH2

LFH3

LFH4

LFH5

LFH6

LBH1

$\mathrm{LBH} 2$

$\mathrm{LBH} 3$

LBH4

LBH5

LBH6

L1H1

L1H2

$\mathrm{L} 1 \mathrm{H} 3$

L1H4

L1H5

L1H6

$\mathrm{L} 2 \mathrm{H} 1$

$\mathrm{L}_{2} \mathrm{H}_{2}$

$\mathrm{L} 2 \mathrm{H} 3$

$\mathrm{L} 2 \mathrm{H} 4$

L2H5

L2H6

LHH1

$\mathrm{LHH} 2$

LHH3

LHH4

LHH5

LHH6

AA01

$\mathrm{AAO} 2$

$\mathrm{AAO} 3$

AAO4

AA05
YN13

YN14

YN15

YN16

YN17

YN18

YN19

YN20

YN21

YN22

YN23

YN24

YN25

YN26

YN27

YN28

YN29

YN30

YN31

YN32

YN33

YN34

YN35

YN36

YN37

YN38

YN39

YN40

YN41

YN42

YN43

YN44

YN45

YN46

YN47

YN48

YN49

YN50

YN51

YN52

YN53

YN54

YN55

YN56

YN57

YN58

YN59

YN60

YN61

YN62

YN63 


\author{
Sleeve \#1 \\ Row 17 \\ Inner radius \\ -12.4 to $-16.4 \mathrm{~cm}$
}

$\begin{array}{ll}64 & \text { TMMO } \\ 65 & \text { TMKO } \\ 66 & \text { TMM2 } \\ 67 & \text { TMM4 }\end{array}$

Sleeve \#2

Row 17

Inner radius

$-16.6 \mathrm{~cm}$ to $-20.0 \mathrm{~cm}$
Sleeve \#3

Row 12

Outer Radius

-15.6 to $-19.6 \mathrm{~cm}$

$\begin{array}{ll}\text { AA06 } & \text { 12YWTA } \\ \text { AA07 } & \text { 12YWTA } \\ \text { AA08 } & \text { 12YWTA } \\ \text { AA09 } & \text { 12YWTA } \\ \text { AA10 } & 12 Y W T A \\ \text { AA11 } & 12 Y 1 Y Q 1 \\ \text { AA12 } & 12 Y 1 Y Q 1 \\ \text { AA13 } & 12 Y 1 Y Q 1 \\ \text { AA14 } & 12 Y 1 Y Q 1 \\ \text { AA15 } & 12 Y 1 Y Q 1 \\ \text { AA16 } & 17 Y 3 C \\ \text { AA17 } & 17 Y 3 C \\ \text { AA18 } & 17 Y 3 C \\ \text { AA19 } & 17 Y 3 C \\ \text { AA20 } & 17 Y 3 C\end{array}$

AA21

AA22

AA23

AA24

AA25

AA26

AA27

AA28

AA29

AA30

AA31

AA32

AA33

AA34

AA35

AA36

AA37

AA38

AA39

AA49

AA50

AA51

AA52

AA53

AA54

AA55

AA56

AA57

AA58

AA59

AA60

AA61

F4L3

F4L4

F4L5 
Sleeve \#1

Row 17

Inner radius

-12.4 to $-16.4 \mathrm{~cm}$

114 TM30

115 TM21

116 TM33

117 TM14

118 TM44

119 TM11

120 TMJO

121 TMJ1

122 TMJ2

123 TMJ4

124 TMJ3

125 AVOO

126 AV01

127 AV50

128 AV51

129 AV80

130 AV81

131 ALOO

132 ALO1

133 AT20

134 AT21

135 AH4O

136 AH41

137 AZ60

138 AZ61

$139 \quad \mathrm{~K} 101$

$140 \quad \mathrm{~K} 102$

$141 \mathrm{~K} 103$

$142 \quad \mathrm{~K} 104$

$143 \mathrm{~K} 105$

$144 \quad K 106$

$145 \quad \mathrm{~K} 107$

$146 \quad K 108$

$147 \quad \mathrm{~K} 109$

$148 \quad \mathrm{~K} 110$

$149 \quad \mathrm{~K} 111$

$150 \quad \mathrm{~K} 112$

$151 \quad \mathrm{~K} 113$

$152 \quad \mathrm{~K} 114$

$153 \mathrm{~K} 115$

$154 \mathrm{~K} 116$

$155 \mathrm{~K} 117$

$156 \mathrm{~K} 118$

$157 \quad K W 01$

$158 \quad \mathrm{KWO2}$

$159 \mathrm{KWO3}$

160 KTO1

161 KTO2

162 MVP1

163 MVP2

164 MVC2

165 MVC3
Sleeve \#2

Row 17

Inner radius

$-16.6 \mathrm{~cm}$ to $-20.0 \mathrm{~cm}$

F7K2

F7K4

F4K5

F4L1

F4L2

F6L2

F6L6

F7LO

F7L1

F5L2

F5L5

F8L1

F8LA

F3L2

F3L5

F2L3

F2LF

14T1

$14 \mathrm{~T} 2$

$14 T 3$

15T1

$15 \mathrm{~T} 2$

$15 T 3$ 
Row 17

Inner radius

-12.4 to $-16.4 \mathrm{~cm}$

$\begin{array}{ll}166 & \text { MVM1 } \\ 167 & \text { MVM4 } \\ 168 & \text { MVS1 } \\ 169 & \text { MVS2 } \\ 170 & \text { MF1S } \\ 171 & \text { MF2R } \\ 172 & \text { MF2D } \\ 173 & \text { MF5Q } \\ 174 & \text { MF5B } \\ 175 & \text { MF3P } \\ 176 & \text { MF3A } \\ 177 & \text { MF3E } \\ 178 & \text { MF4D } \\ 179 & \text { MF4C }\end{array}$

\section{Operational History}

The average indicated temperature of the three holders is shown in Figure 3. Irradiation began at Cycle 370 on 6/03/1999 and has completed $62 / 3$ cycles or 14293 MWD.

The capsule was removed from operation during HFIR cycles 373,374 and 375 . It was removed again at the end of cycle 379 after unexpected contamination was discovered in the capsule effluent system. The capsule is presently being evaluated to determine if it can undergo additional irradiation. 


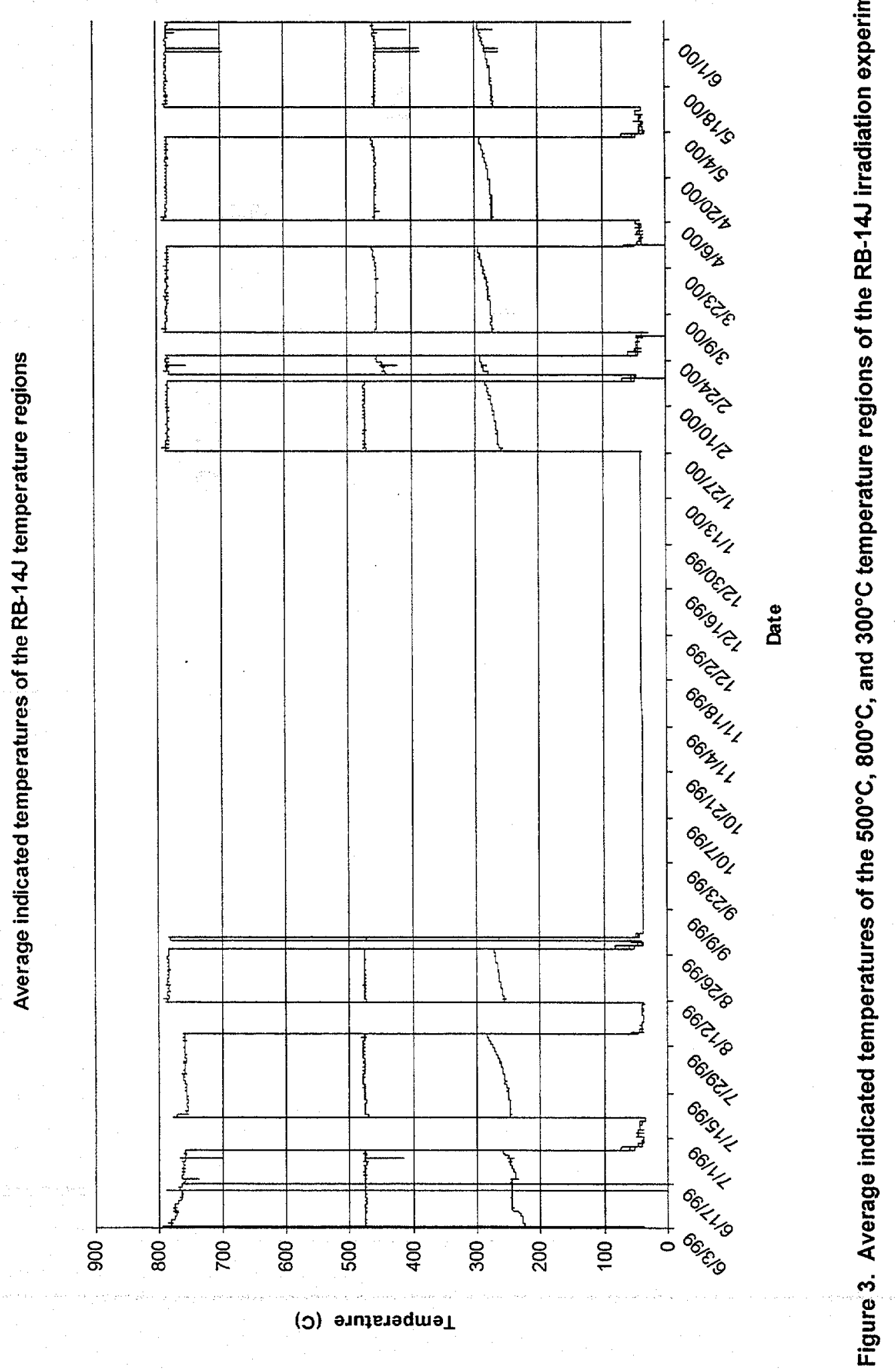


SUMMARY OF THE OPERATION OF THE VARYING TEMPERATURE EXPERIMENT A. L. Qualls (ORNL), T. Muroga (NIFS)

\section{OBJECTIVE}

The objective of this work is to determine experimentally the effects of variable irradiation temperature on physical properties and microstructure of structural materials being considered for fusion reactor applications. In this experiment [1] matched specimen sets were irradiated in similar gamma and neutron fluxes with independent temperature control. Ten percent of the irradiation time of one of the matched sets was at reduced temperature. Heaters within the experiment maintained specimen temperatures close to the normal operating temperatures during reactor startups to minimize the impact of dose received at off-normal temperature.

\section{SUMMARY}

The Varying Temperature Experiment (HFIR-MFE-RB-13J) ended irradiation after eight cycles in a europium shielded Removable Beryllium position in the HFIR reactor. The irradiation was terminated two cycles short of a planned ten-cycle irradiation due to a break in one of the capsule's gas supply lines, which occurred while the capsule was being handled during an outage. The break made it impossible to maintain constant operating pressure and steady temperature control could not be guaranteed. It was considered prudent to terminate the irradiation after 8 cycles, rather than risk a temperature excursion with $80 \%$ of the irradiation complete.

\section{PROGRESS AND STATUS}

The Varying Temperature Experiment began operation on July 22, 1998 (Cycle 362) and operated 195.1 effective full power days (EFPDs) full power days before ending operation on $5 / 16 / 99$ at the end of Cycle 369. During approximately ten percent of the irradiation (17.8 EFPDs) the two varying temperature zones (Zones $C$ and $D$ ) were at reduced temperature. The experiment was controlled at temperature during 9 reactor startups (Cycle 364 had a mid-cycle shutdown and restart). The average indicated temperature of the four temperature zones during the experiment is shown in Figure 1.

Within this experiment, individual specimens were grouped together and the groups were stacked axially into aluminum alloy cylindrical sleeves. The loaded sleeves were irradiated inside axial holes in aluminum alloy holders, four of which formed the experimental region of the capsule. During reactor operation, the heat generated within the specimen groupings was transferred by conduction to the holder establishing a temperature difference. The temperature distribution within the holder and the temperature differences from the groupings to the holder determines the actual operating temperature of the specimens.

Five thermocouples located in three Thermocouple Array Tubes (TCATS) measured the temperature of each holder at distinct axial locations distributed angularly at three locations. The angular locations were referenced to a common angular location on each holder designated as Top-Dead-Center (TDC) and were $10^{\circ}, 150^{\circ}$ and $250^{\circ}$ from TDC in the counter clockwise (CCW) direction (viewing the holders from the top) and the five axial locations were $1.3 \mathrm{~cm}, 2.9 \mathrm{~cm}, 4.5$ $\mathrm{cm}, 6.1 \mathrm{~cm}$ and $7.7 \mathrm{~cm}$ from the top of the holder as shown in Figure 2.

Individual thermocouples measured the temperature of dummy specimen groupings in an unsealed specimen hole located $30^{\circ} \mathrm{CCW}$ from the TDC mark in each holder. These dummy specimen thermocouples were in close proximity to the holder thermocouples in the $10^{\circ}$ angular location and this proximity provides accurate measurements of the temperature difference from the specimen groupings to the holder. 


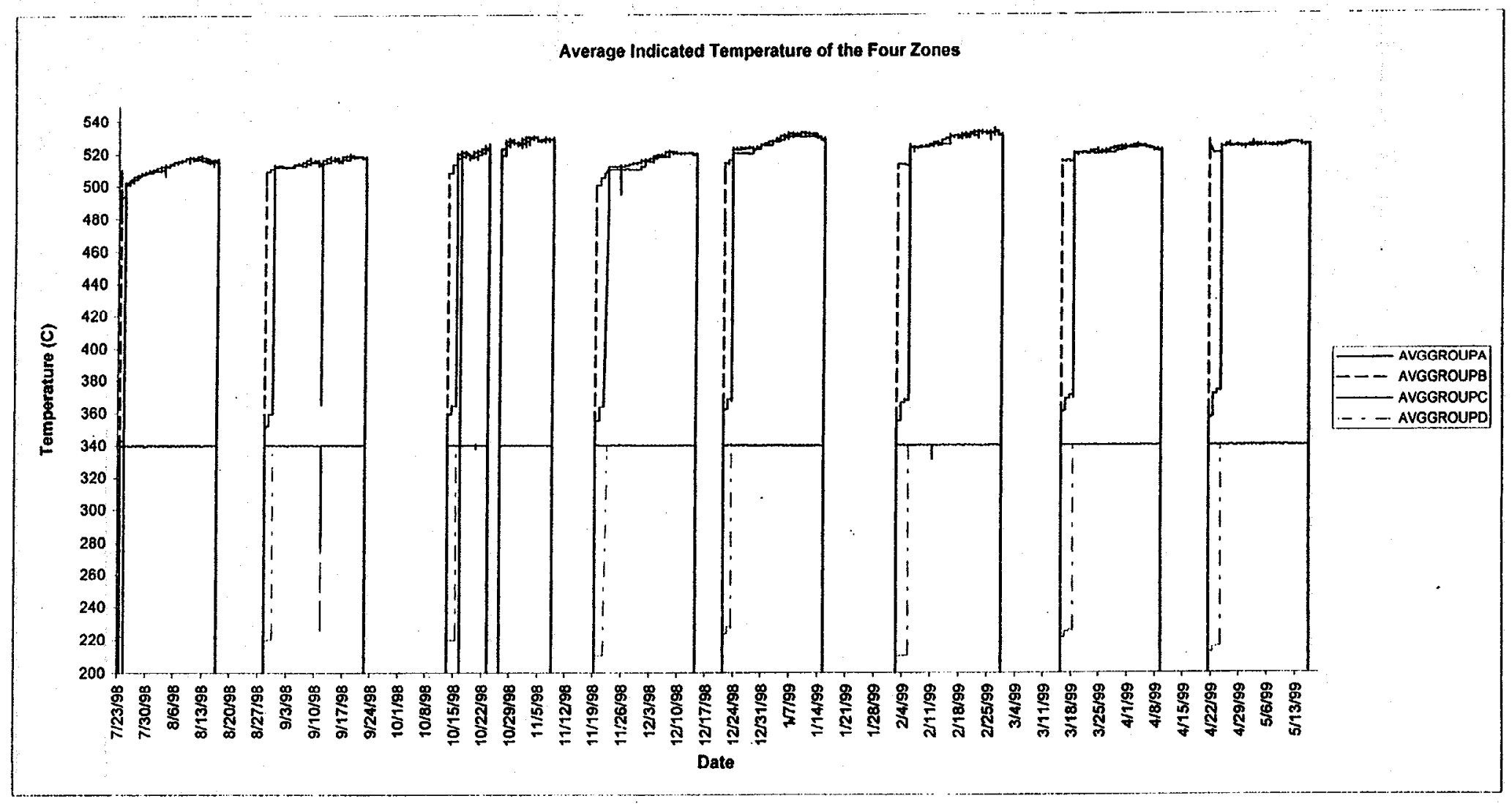

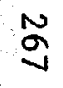

Fig. 1. Average indicated temperature of the four zones in the Varying Temperature Experiment during eight cycles of operation. 


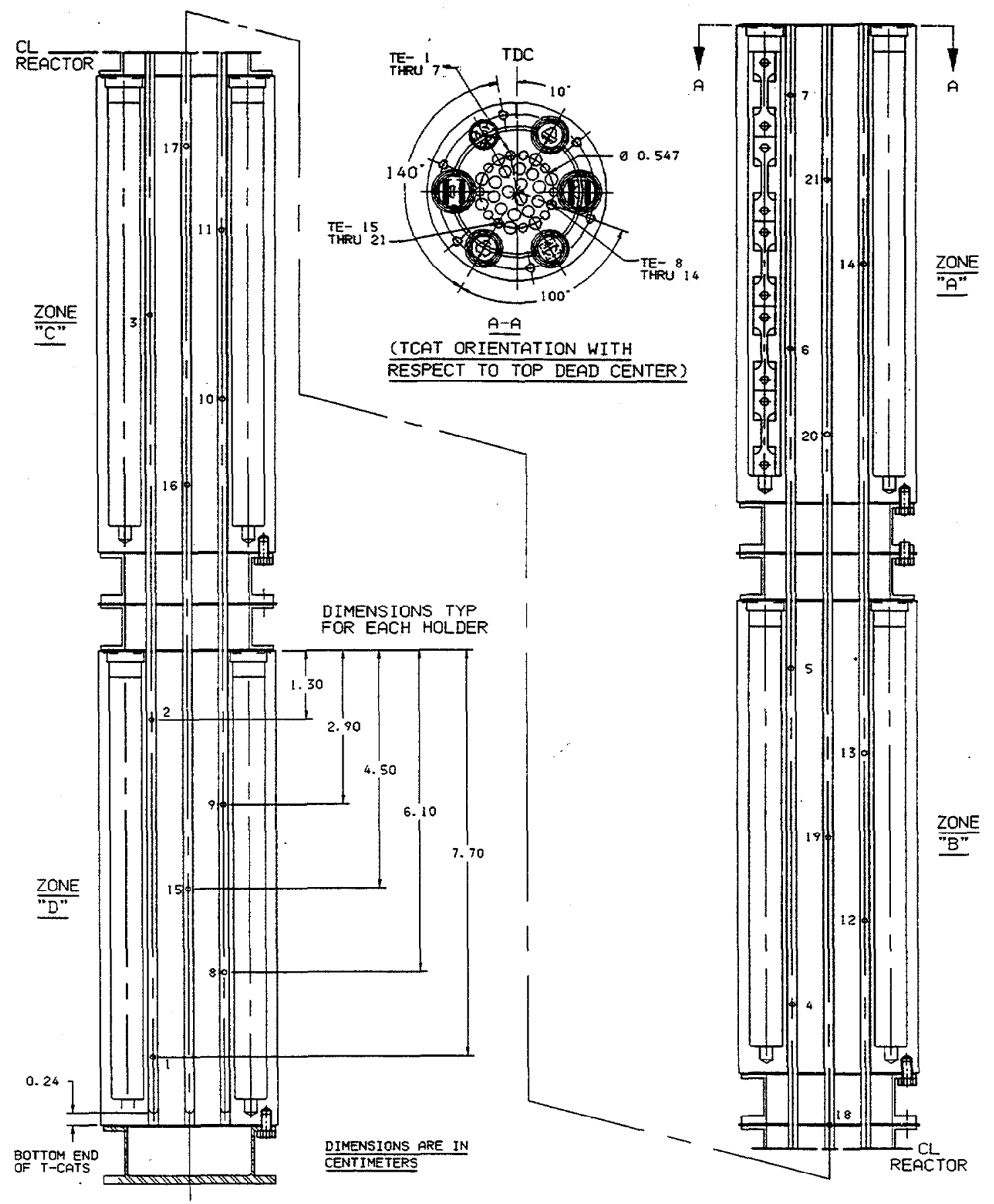

Figure 2. Thermocouple locations within the experimental region of the Varying Temperature Experiment. 
All thermocouple indications were recorded at 7 to 10 second intervals during the experiment. The averages of the holder temperature indications were the controlling variables of the experiment. Actual specimen temperatures must be estimated from the indicated holder temperatures using guidance from the dummy specimen thermocouples. The specimen-to-holder temperature differences are dependent upon specimen shape, material (a factor in determining the amount of heat generated within them) and location within the experiment. All combinations of specimen groupings could not be measured; therefore, the dummy specimen measurements may not be indicative of all specimen groupings.

The combination of varying gas thermal conductivity and electrical heater output proved to be a responsive and reliable control strategy. Temperature changes in response to changes in reactor power were effectively maintained below $0.2^{\circ} \mathrm{C}$ (see Zone A average indicated temperature in Figure 3). Only two pieces of control system hardware failed during the irradiation. A relay in the watchdog system failed and the memory board of the primary control computer failed. Of the 32 heaters operating at the initiation of the irradiation, two heaters were removed from service when lower than normal electrical resistance was detected from the element to ground during routine surveillance. No thermocouples failed during the experiment.

Three temperature excursions occurred during operation, excluding any off-normal temperatures that occurred during reactor startups. On September 11, 1998 the control system placed the capsule into emergency cooling due to a momentary power interruption at the control cabinet. On October 16, 1998 (early in the third cycle of operation) the memory board failure coupled with the previously undetected relay failure produced a no flow condition within the capsule. The only high temperature excursion of the experiment occurred during this event and the temperature increased only in Zone B. The peak temperature in Zone B increased approximately $50^{\circ} \mathrm{C}$ reaching $575^{\circ} \mathrm{C}$, before corrective action was taken [4]. All other zones cooled during the event. The other off-normal temperature event occurred on November 25, 1998 when the reactor was operated at $90 \%$ power for approximately 30 minutes due to a problem with a secondary pump. Zones $\mathrm{B}$ and $\mathrm{C}$ operated approximately $15^{\circ} \mathrm{C}$ below normal operating temperatures for 45 minutes during this event.

\section{SPECIMEN TEMPERATURE}

Specimens were located in essentially two dimensions within the experiment: axial location and angular location. All specimens in this experiment were within $0.25 \mathrm{~cm}$ of the same radial position within the capsule. The angular position relates a specimen's orientation with respect to the dosimetry and thermometry within the holder. The capsule was rotated $180^{\circ}$ for each successive cycle of operation, alternatively placing the holder TDC marks towards and away from the reactor. During cycles ending in an even number $(362,364,366$ and 368$)$ the holder TDC marks were oriented away from the face of the reactor.

The cycle-to-cycle rotation placed specimens and thermocouples at different distances from the centerline of the reactor, which varied the temperature distribution within the holders and placed specimens in different fluxes. Specimens located at or opposite the TDC location were irradiated at the highest and lowest successive temperatures and fluxes while those specimens located $90^{\circ}$ (in either the clockwise or counterclockwise direction) from the TDC location encountered a more consistent flux and temperature throughout the irradiation. Because of the rotation however, all of the specimens at a given axially location received essentially the same total dose during the 8 cycle irradiation. The analysis of the temperature is a bit more complicated.

The actual amount of specimen temperature variation must be estimated from the indicated holder temperatures and the estimated specimen-to-holder temperature difference. Depending upon thermocouple positioning within a holder, the indicated temperature distribution and average 
indicated temperature changed due to the cycle-to-cycle rotation. The reason can be demonstrated by an example. If an angular location with two thermocouples were closest to the reactor during one cycle of operation, the next cycle those thermocouples would be on the other side of the capsule and would indicate a lower temperature. If the angular position with only one thermocouple were originally on the cooler side of the holder, that thermocouple would indicate a higher temperature upon being rotated closer to the fuel. The effect of the change on the calculated average would be dominated by the two thermocouples and the average indicated temperature of the holder would decrease, although the actual temperature may have not changed.

Figure 3 shows the Zone A thermocouple indications at daily intervals for cycles 365 and 366 (the fourth and fifth cycles of operation). The average of the Zone $A$ holder thermocouples was controlled at $340^{\circ} \mathrm{C}$ during these cycles, however the relative values of the thermocouples changed during each cycle and from cycle to cycle. Zone A is located at the top of the experimental region and was near the edge of the fuel plates during irradiation. The heat generation rate within materials at this location is a strong function of axial location, producing a three dimensional temperature distribution within the holder. Thermocouples at the base of the zone (TE-706 and TE-720) indicate higher temperatures than their angular counterparts (TE-707 and TE-721) positioned higher in the holder.

Like the thermocouples, specimens that were moved from the hot side to the cool side of a holder also experienced temperature changes. The dummy specimen sets were fitted with thermocouples to measure this effect. Measured specimen groupings were located $30^{\circ}$ from TDC and therefore experienced some of the largest anticipated temperature swings (the specimens in the adjacent hole where actually the closest to TDC, but the difference in radial displacement between the two holes is small). The individual thermocouple measuring a dummy specimen set in Zone A (TE-722) indicates a temperature below that indicated by the lower holder thermocouples, but above that indicated by TE-707, which is the holder thermocouple closest to the dummy specimens. Specimens that are hotter than the local holder temperature can be cooler than the average indicated temperature of the holder.

Specimen groupings that generate the most internal heat during irradiation typically have the largest temperature difference with respect to the holder. Tungsten specimens should have an increased temperature difference compared to stainless steel specimens of the same size. Specimens that have higher heat generation rates should also experience larger temperature changes due to capsule rotation if all other factors remain the same. The amount of variation is dependent upon the angular location within the holder and the heat generated within the specimens (dependent upon the axial location within the experiment, with increasing heat generation closer to the reactor mid-plane). Specimen groupings closer to the TDC line and $180^{\circ}$ from the TDC line and closer to the reactor centerline should experience the largest changes due to rotation, while those at $90^{\circ}$ and $270^{\circ}$ and towards the edges of the experimental regions should experience smaller changes.

The Zone A dummy specimen thermocouple (TE-722) measured a solid cylindrical aluminum alloy specimen that had the same $O D$ as the specimen sleeves within the experiment. Specimens were expected to operate at temperatures above the local holder temperature surrounding them, so TE-722 was expected to indicate a higher temperature than TE-707. The difference between TE-722 and TE-707 represents the lowest expected specimen to holder temperature difference within the experiment because 1) it has a lower mass than the specimen groupings, 2) it is a solid sample with one less gas gap to inhibit heat loss, and 3 ) it is in the lowest heat generation location within the experiment. This temperature difference was less than $10^{\circ} \mathrm{C}$. 
During Cycle 366, the lower holder thermocouples again indicated a higher temperature than their upper counterparts, however the relative difference between thermocouples at different angular locations changed. TE-720 and TE-721 decreased relative to TE-706 and TE-707 and the dummy specimen thermocouple decreased from the fourth to the fifth cycle. These effects were the result of the capsule being rotated.

The indications from TE-720 and TE-707 illustrate the extremities of the local temperature variations within a temperature zone for this experiment, because Zones $A$ and $D$ were located in a region with strong heating gradients. The holder temperature can vary as much as $25^{\circ} \mathrm{C}$ from the lowest point facing towards the reactor to the highest point facing away from the reactor. It is important to note that even though the average indicated temperature of the holder was controlled during the experiment, the actual temperature of the specimens changed during a cycle and from cycle-to-cycle.

Figure 4 shows the temperature indications from Zone $B$ thermocouples on corresponding days during the fourth (Cycle 365) and fifth (Cycle 366) cycles of operation. The Zone B temperature gradually increased throughout each cycle. The Zone $B$ temperature variability is the highest in the experiment and was approximately $28^{\circ} \mathrm{C}$. TE-724 is the indicated temperature of a grouping of tungsten Bar-7specimens in Zone B.

The measured temperature difference between the tungsten dummy specimens and TE705 in Zone B conservatively bounds the largest expected specimen-to-holder temperature difference within the experiment. During Cycle 365, this temperature difference was approximately $25^{\circ} \mathrm{C}$, but it reduced to less than $15^{\circ} \mathrm{C}$ during Cycle 366 , when the dummy specimens were rotated away from the reactor. In the experimental specimen sets, the tungsten Bar-7 specimens were mixed with the molybdenum Bar-7 specimens and the grouping size was decreased to mitigate the specimen-to-holder temperature difference by reducing the total heat generated within the grouping. Also, the Bar- 7 specimens were located $60^{\circ}$ from TDC. The actual maximum temperature difference from the Bar-7 specimens to the holder is estimated to be $20^{\circ} \mathrm{C}$. This is based on a $5^{\circ} \mathrm{C}$ reduction due to the mixing of molybdenum specimens with the tungsten specimens, which results in approximately a $25 \%$ reduction in the heat being generated.

The indicated temperatures within Zone $C$ are shown on corresponding days of the fourth and fifth cycle in Figure 5. Zone $C$ is held at reduced temperature during the first two days of each cycle, however the heat generation rate within the central regions of the reactor core increase during this time, which resulted in increasing Zone $C$ temperatures. After the initial low temperature operation, the average indicated temperature of Zone $C$ was controlled to match that of Zone $B$.

The dummy specimens in Zone $C$ were stainless steel TEMs (TE-726) and CVN (TE-727) specimens. The temperature difference to the stainless steel specimens is less than that of the tungsten specimens of Zone $B$ and is in fact within the readings of the holder thermocouples during Cycle 366 when the holder TDC mark is rotated away from the reactor. The temperature response of the Zone $\mathrm{C}$ dummy specimens are representative of (and in fact bound) that of the vast majority of the specimens within the experiment and the actual cycle-to-cycle temperature change for the measured specimen sets was less than $5^{\circ} \mathrm{C}$.

Figure 6 shows the thermocouples from Zone $D$ during the fourth and fifth cycle of operation. The Zone $D$ temperature was reduced during the first two days of each cycle and was increased to match that of Zone A for the remainder of the cycle. The variation in the average indicted temperature of Zone D was similar to that of Zone $A$ as were the variations of the actual specimen temperatures. 


\section{SUMMARY OF SPECIMEN TEMPERATURES}

The indicated temperatures of the dummy specimens are shown for all four holders during the fourth and fifth cycle of operation in Figure 7 and the operating temperatures and temperature variability of specimens can be qualitatively estimated from the plot. Figures 8 and 9 show the histogram for the average indicated temperature of the four holders throughout the 8-cycle irradiation (sampled at 1-hr intervals).

The average indicated temperatures of Zone $A$ and Zone $D$ were precisely controlled during the high temperature phase of operation however the resulting temperature variation for specimens in the top of Zone $A$ and the bottom of Zone $B$ is estimated to be $7^{\circ} \mathrm{C}$. The maximum temperature variation for CVN, tensile and TEM specimens due to cycle-to-cycle rotation of the experiment is estimated to be $10^{\circ} \mathrm{C}$. The estimated total variation of specimen temperature within Zone $A$ and Zone $\mathrm{D}$ is estimated to be $17^{\circ} \mathrm{C}$. $\left(10^{\circ} \mathrm{C}\right.$ due to rotation plus $7^{\circ} \mathrm{C}$ due to variation).

Zone A Thermocouples during Cycle 365

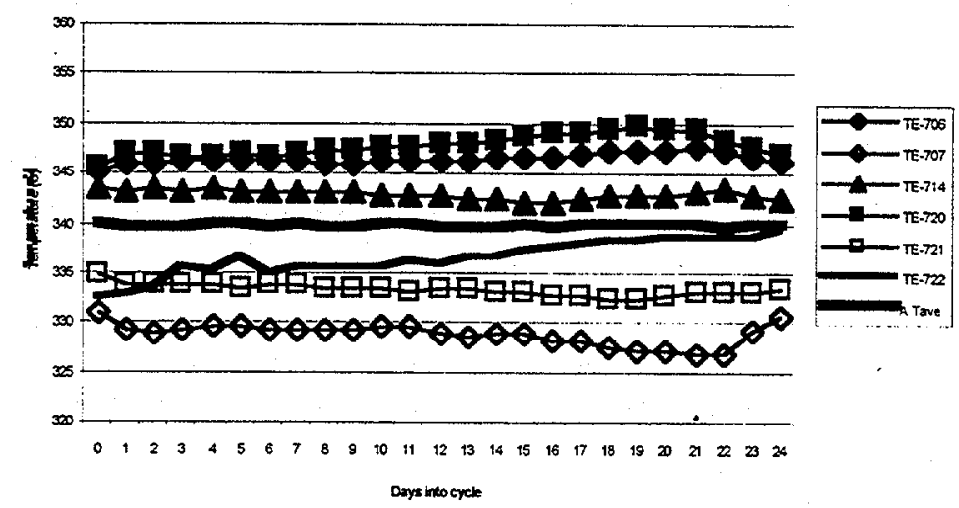

Zone A Thermocouples during Coxcte 366

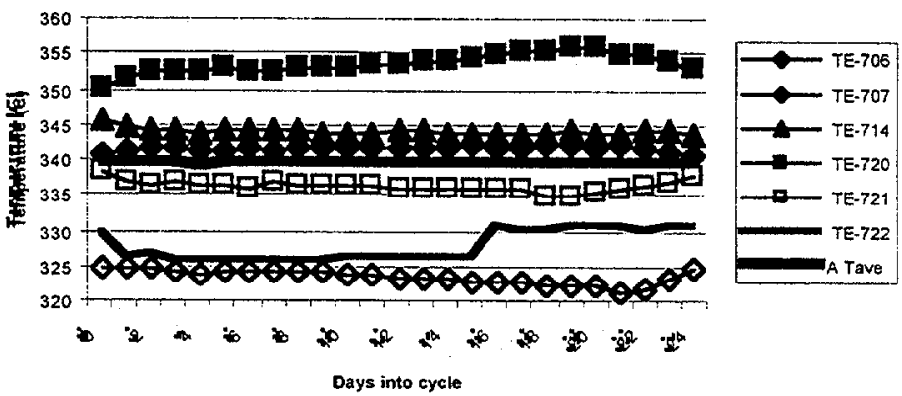

Figure 3. The indicated temperatures of Zone $A$ on corresponding days of the fourth and fifth cycle. The average temperature of Zone A was precisely controlled throughout the experiment, however the relative temperature indications changed during each cycle and due to capsule rotation from cycle-to-cycle. The temperature of a solid aluminum specimen was measured with TE-724 and represents the smallest expected specimen-toholder temperature difference within the experiment. 
Zone $\mathrm{B}$ thermocouples during cycle 365
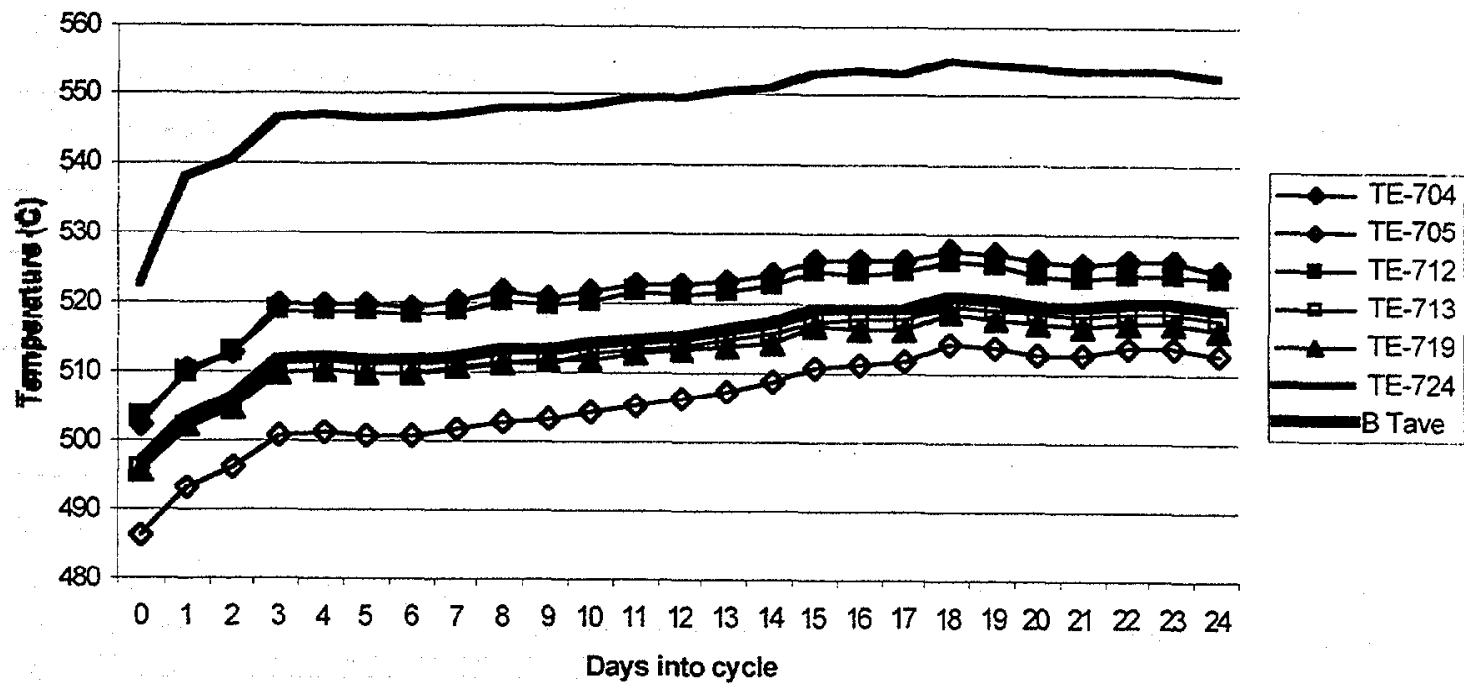

Zone B thermocouples during cycle 366

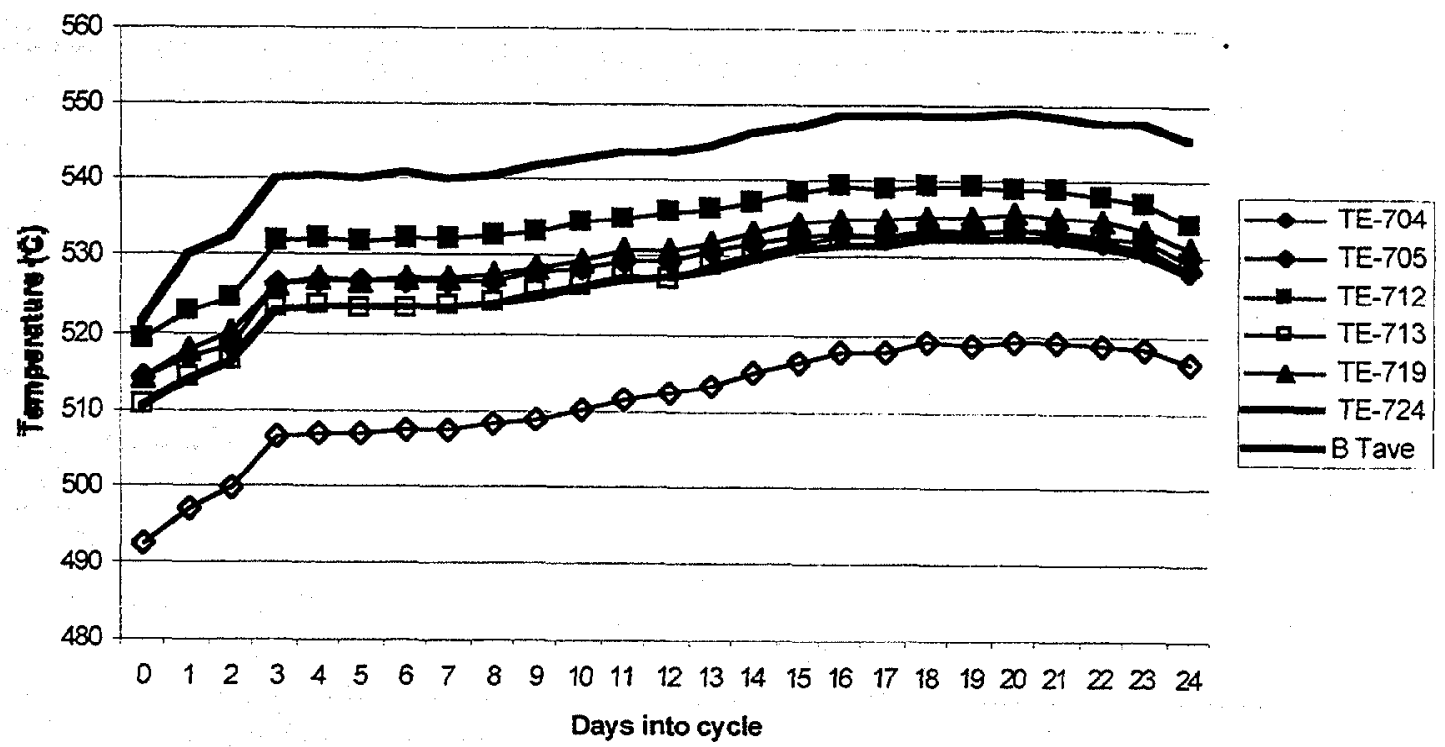

Figure 4. The indicated temperatures of Zone $B$ on corresponding days of the fourth and fitth cycle. Zone $B$ was operated without temperature control because it operated above design temperature. The variation in the temperature of Zone $B$ represents the largest variations over a cycle. The temperature of a grouping of tungsten Bar-7 specimens was measured with TE-724 and represents the largest expected specimen to holder temperature difference within the experiment. 


\section{Zone $\mathrm{C}$ thermocouples during Cycle 365}

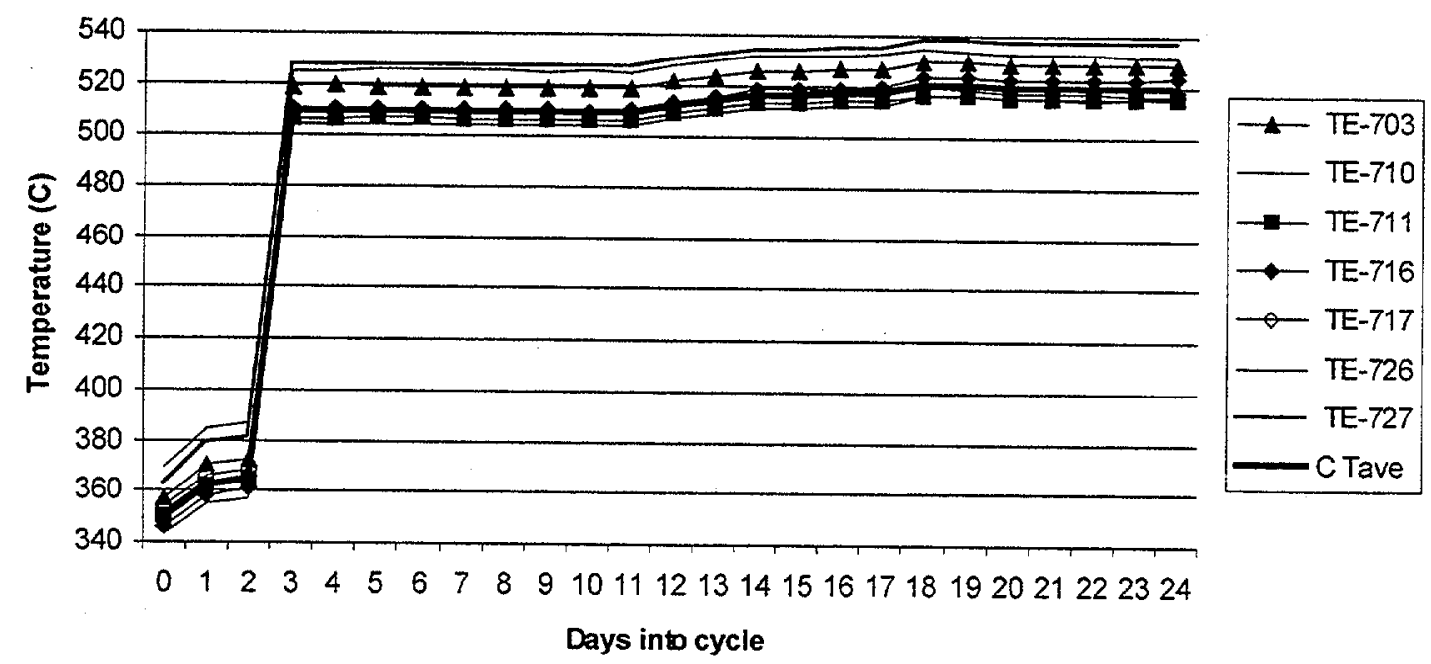

Zone $\mathrm{C}$ thermocouples during Cycle 366

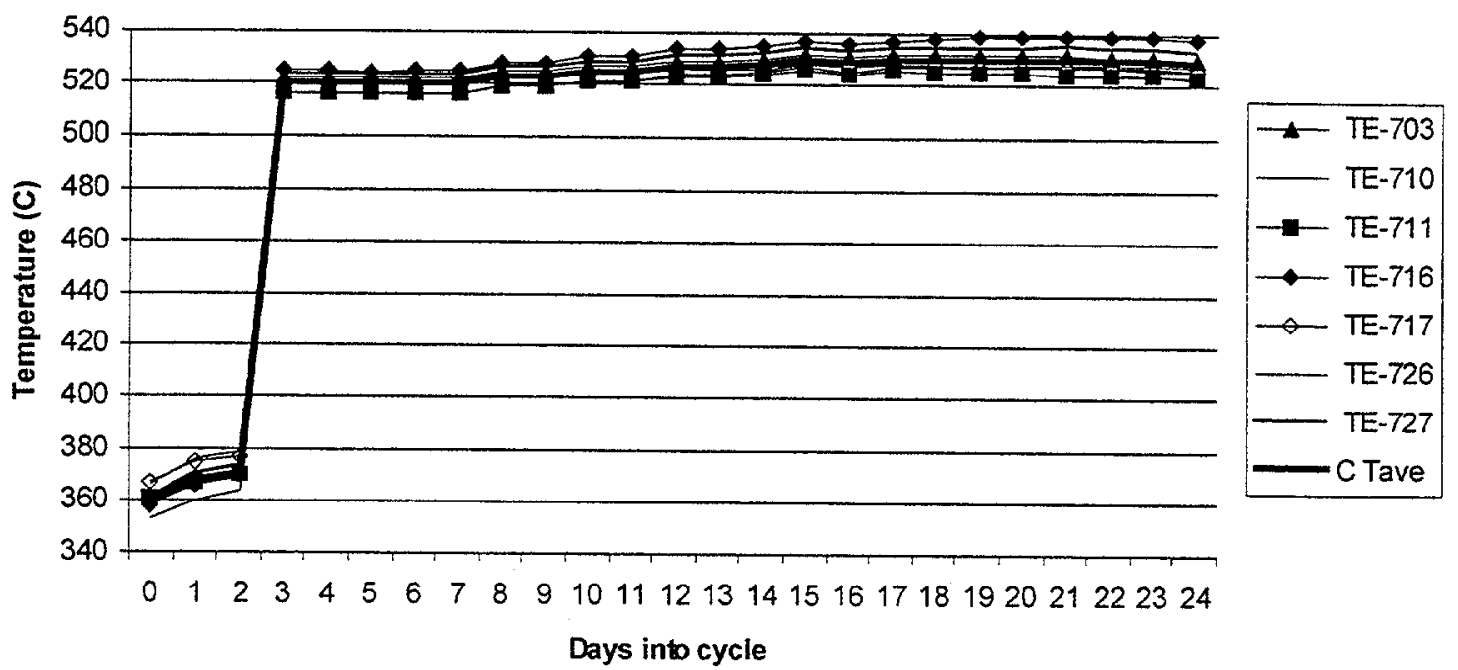

Figure 5. The average indicated temperature of Zone $C$ on corresponding days of the fourth and fifth cycle. The indicated temperature of a stainless steel grouping of CVN specimens (TE-726) and TEM specimens (TE-727) are typical of the specimen to holder temperature differences within the experiment. While the average indicated temperature of the holder increased $10^{\circ} \mathrm{C}$ from one cycle to the next, the actual change in the CVN specimen grouping temperature was less than $5^{\circ} \mathrm{C}$. 
Zone D thermocouples during Cycle 365

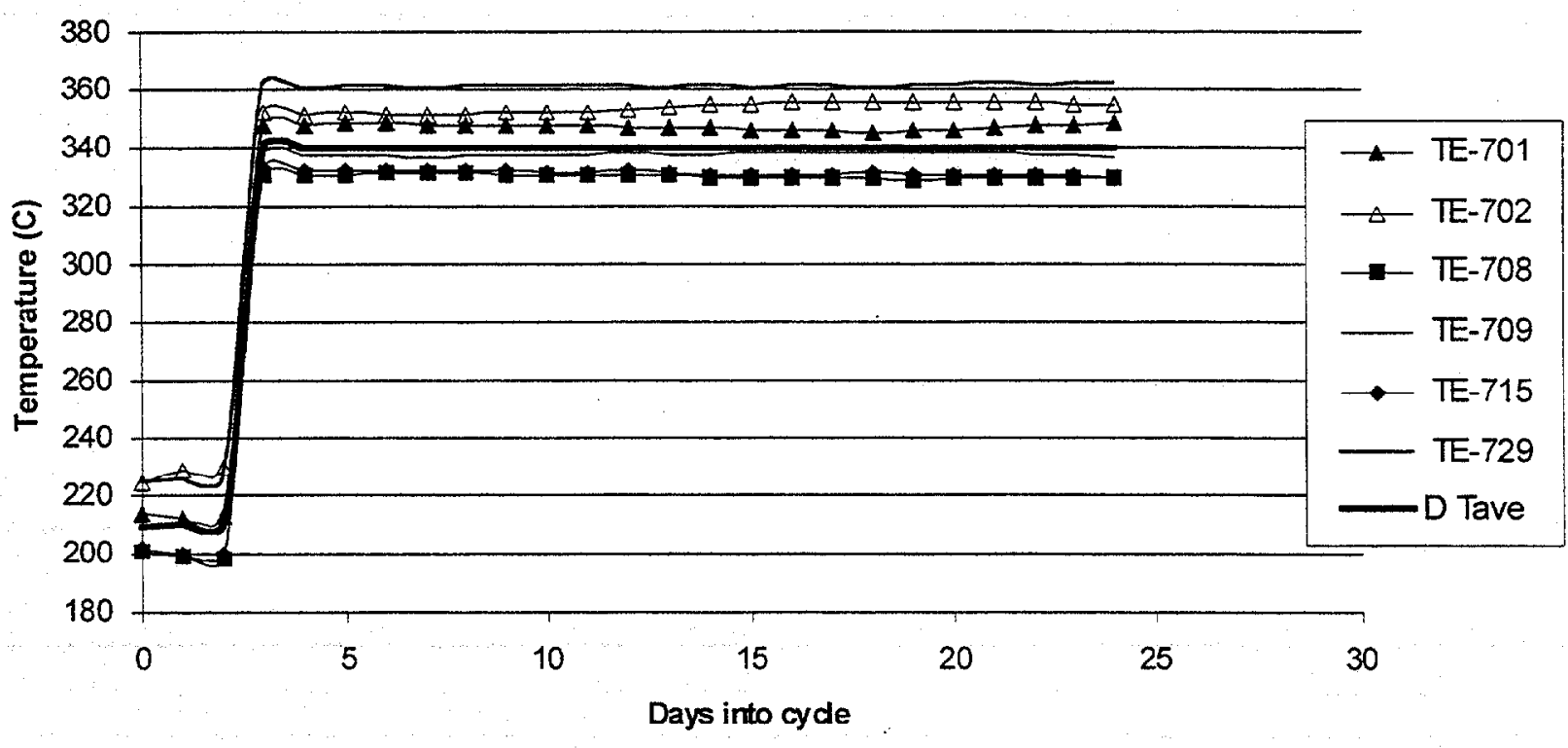

Zone D thermocouples during Cycle 366

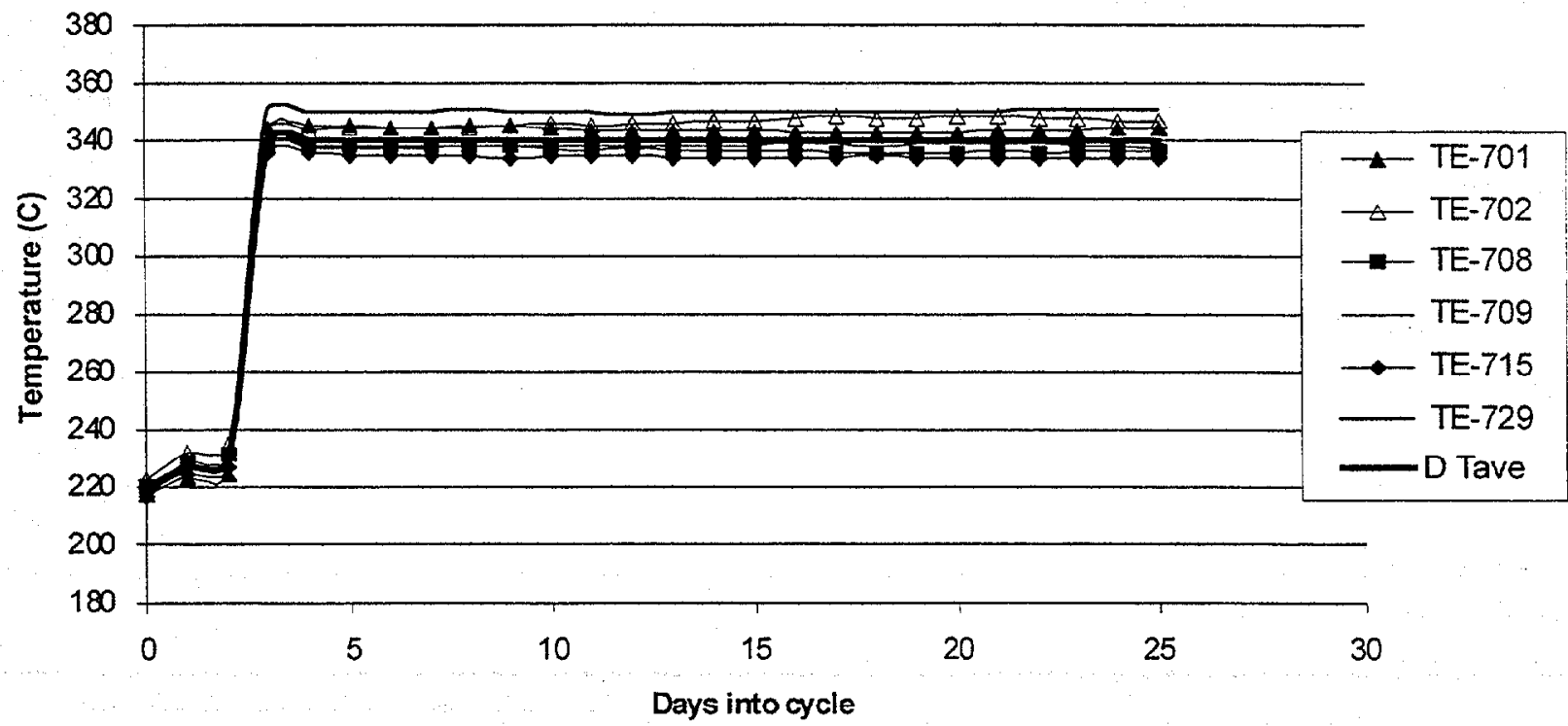

Figure 6. The average indicated temperature of Zone $D$ on corresponding days of the fourth and fifth cycle. 


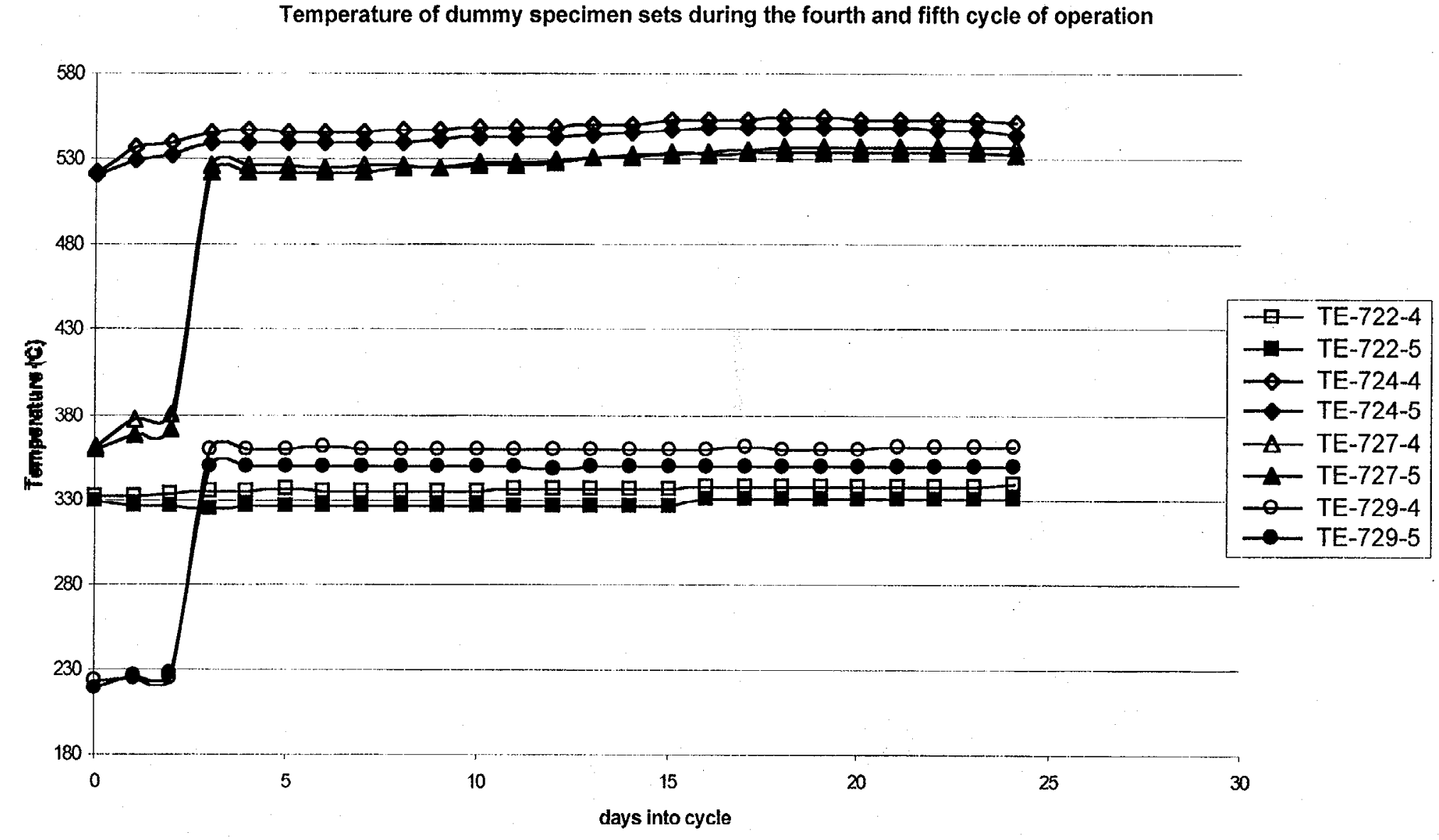

Figure 7. The indicated temperature of the dummy specimen sets for the fourth (hollow symbols) and fifth (solid symbols) cycles. 
The average temperature of specimens in Zone $A$ and Zone $D$ during the high temperature phase of the irradiation are estimated to range from $335^{\circ} \mathrm{C}$ at the top of Zone $A$ and the bottom of Zone $D$ to $355^{\circ} \mathrm{C}$ at the bottom of Zone $A$ and the top of Zone D. Specimens are estimated to have been within $+/-9 \mathrm{C}$ of the average irradlation temperature.

The average indicated temperature of Zones B was not actively controlled during the experiment. Ironically, this resulted in a reduction of the variation of the irradiation temperature due to cycleto-cycle rotation compared to that of the actively controlled zones, $A$ and $D$. The estimated variation in operating temperature of the Zone $B$ and Zone $C$ specimens during the high temperature phase of operation of due changes in the heat generation rate is $10^{\circ} \mathrm{C}$. The Zone $B$ specimens experienced an increased temperature variation during the entire cycle because increasing the temperature of Zone $\mathrm{C}$ resulted in a sudden $5^{\circ} \mathrm{C}$ increase in the temperature of Zone $B$. The total variation of the Zone $B$ specimens during the fourth and fifth cycles was $25^{\circ} \mathrm{C}$, with the majority of the change occurring during the first two days of each cycle including the transition of the varying temperature zones to their high temperatures.

\section{Low Temperature Operation}

Zones $C$ and $D$ were operated at lower temperatures during the first two days of operation. The maximum temperature of the specimens in Zone $D$ is estimated to have been $225^{\circ} \mathrm{C}$ during this period. The maximum temperature of the specimens in Zone $\mathrm{C}$ is estimated to have been $375^{\circ} \mathrm{C}$ and the variation in Zone $\mathrm{C}$ was higher during this period than that of Zone $D$.

The temperature history of an individual specimen is dependent upon its location (holder, hole number and axial position within the hole), which is given in the specimen loading list [3]. The following tables, when used with an individual specimen's axial location within the capsule can be used to estimate the specimens average irradiation temperature and the maximum variation of that temperature.

\begin{tabular}{|l|l|l|lr|lr|}
\hline & Zone A & Zone B & \multicolumn{2}{|l|}{ Zone C } & & \multicolumn{2}{|l|}{ Zone D } \\
\hline $\begin{array}{l}\text { Average Indicated } \\
\text { Temperature }\left({ }^{\circ} \mathrm{C}\right)\end{array}$ & 340 & 510 & $\begin{array}{l}\text { LTP* } \\
350\end{array}$ & $\begin{array}{r}\text { HTP } \\
510\end{array}$ & $\begin{array}{l}\text { LTP } \\
225\end{array}$ & $\begin{array}{r}\text { HTP } \\
340\end{array}$ \\
\hline $\begin{array}{l}\text { Temperature } \\
\text { Variation }\left({ }^{\circ} \mathrm{C}\right)\end{array}$ & $339 / 341$ & $490 / 520$ & $334 / 362$ & $500 / 520$ & $222 / 230$ & $339 / 340$ \\
\hline $\begin{array}{l}\text { Maximum Variation } \\
\left({ }^{\circ} \mathrm{C}\right)\end{array}$ & 2 & 30 & 28 & 20 & 8 & 2 \\
\hline
\end{tabular}

*LTP-low temperature phase *HTP-high temperature phase

Table 1: The average indicated temperatures of the four zones and the variation of the average indicated temperature estimated from the histograms in Figure 8 and 9. 


\section{Zone A Histogram}
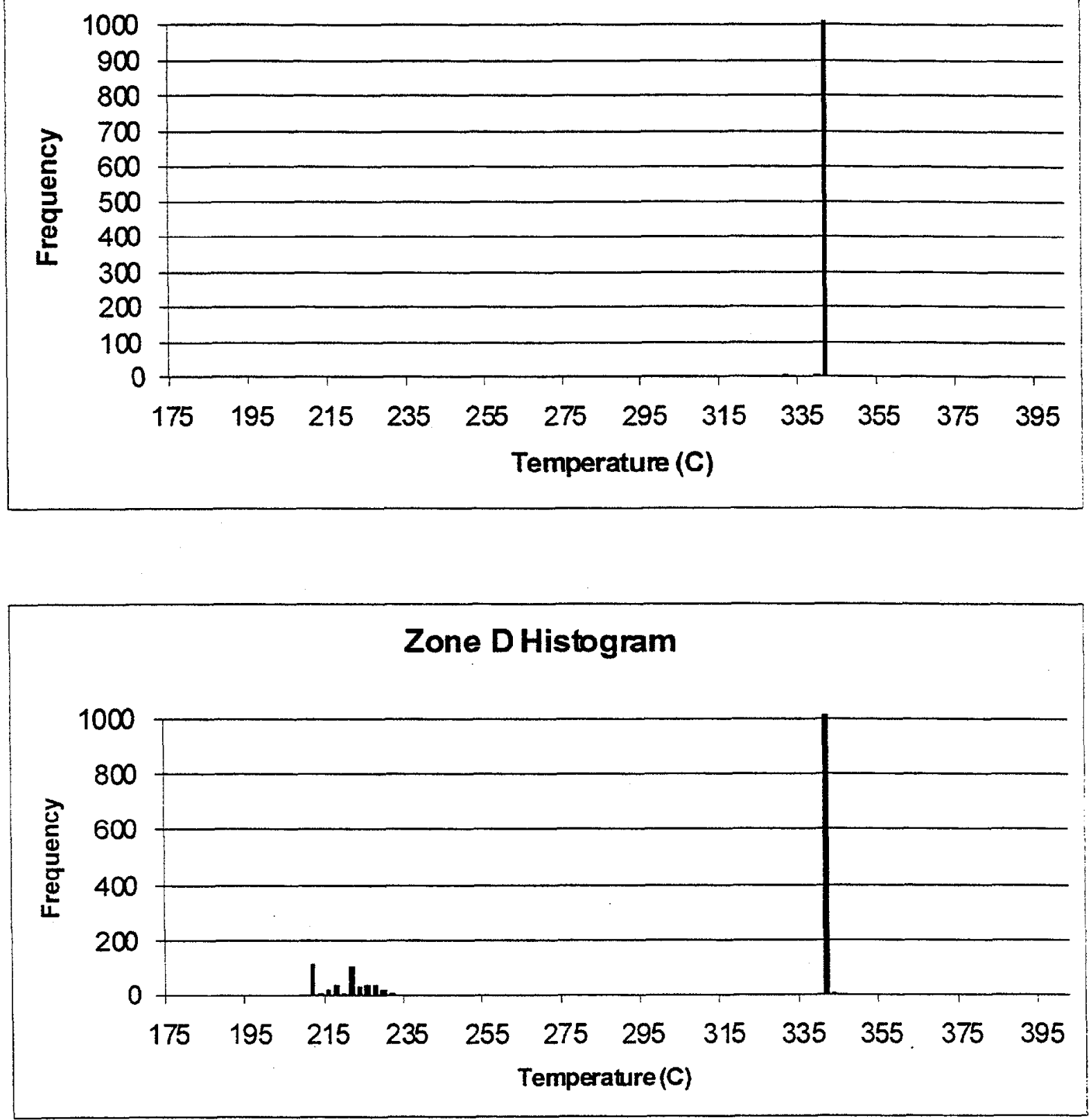

Figure 8

Histogram of the average indicated temperatures of Zone $A$ and Zone $D$ for samples taken at one-hour intervals during the irradiation. The ordinate scale is reduced from 5000 to 1000 to allow temperatures other than $340^{\circ} \mathrm{C}$ to be visible. 


\section{Zone B Histogram}
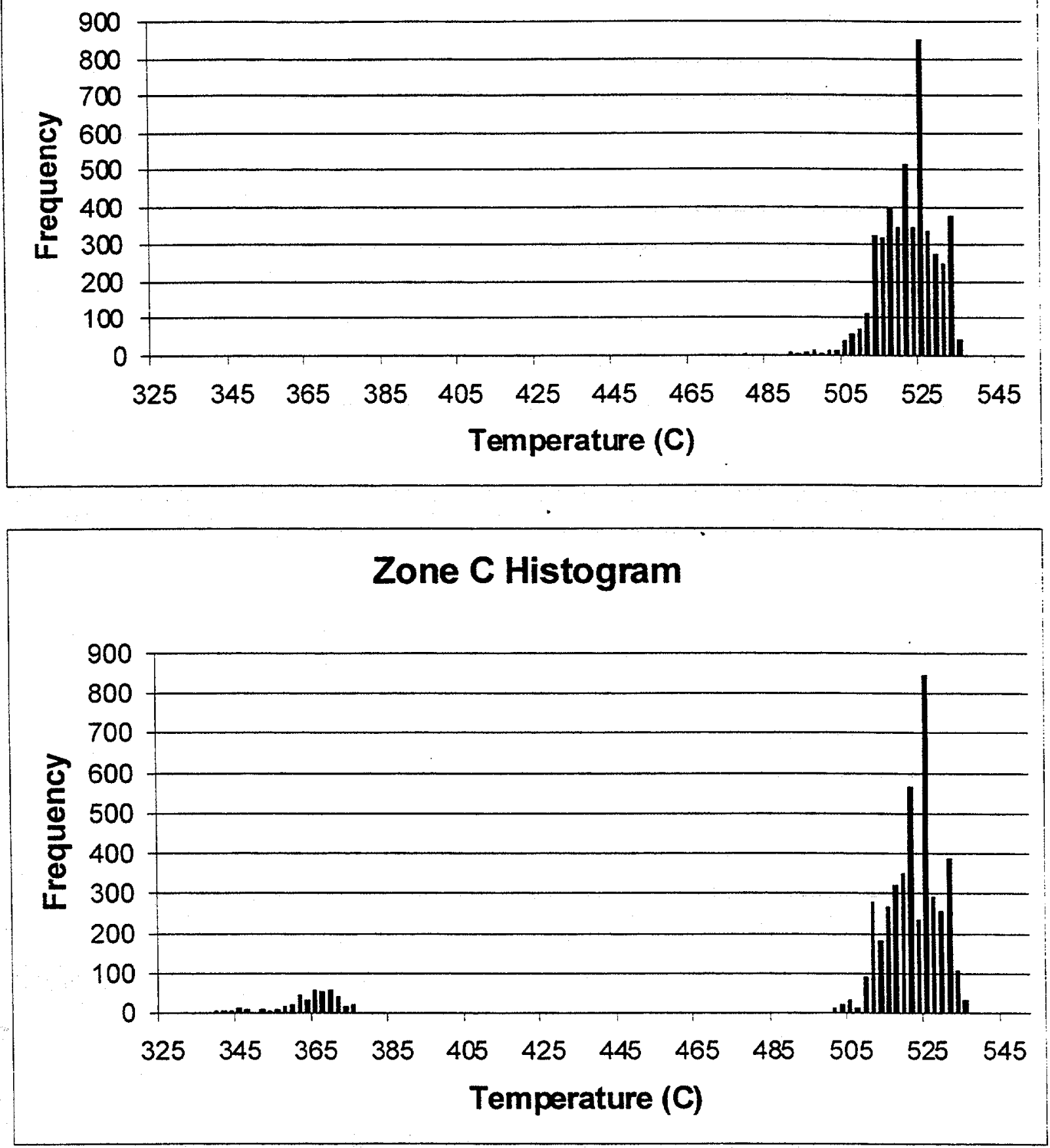

Figure 9

Histograms of the Zone $D$ and Zone $C$ temperatures sampled at hour intervals during the irradiation. 


\begin{tabular}{|l|l|l|l|l|}
\hline & Zone A & Zone B & Zone C & Zone D \\
\hline $\begin{array}{l}\text { Variation during } \\
\text { cycle }\left({ }^{\circ} \mathrm{C}\right)\end{array}$ & 7 & 30 & 29 & 7 \\
\hline $\begin{array}{l}\text { Variation due to } \\
\text { rotation }\left({ }^{\circ} \mathrm{C}\right)\end{array}$ & 9 & 5 & 5 & 9 \\
\hline $\begin{array}{l}\text { Maximum } \\
\text { Variation }\left({ }^{\circ} \mathrm{C}\right)\end{array}$ & 16 & 35 & 34 & 16 \\
\hline
\end{tabular}

Table 2: The estimated maximum temperature variation of specimens in each zone.

\begin{tabular}{|c|c|c|c|c|c|c|}
\hline & \multicolumn{2}{|c|}{ Zone A } & \multirow[t]{2}{*}{ Zone B } & \multirow[t]{2}{*}{ Zone C } & \multicolumn{2}{|c|}{ Zone D } \\
\hline & (top) & (bottom) & & & (top) & (bottom) \\
\hline $\begin{array}{l}\text { Specimen-to- } \\
\text { holder } \\
\text { temperature } \\
\text { difference }\left({ }^{\circ} \mathrm{C}\right)\end{array}$ & -8 to 0 & 0 to +10 & +5 to +15 & +5 to +15 & +0 to +10 & -8 to 0 \\
\hline $\begin{array}{l}\text { Specimen } \\
\text { temperature } \\
\left({ }^{\circ} \mathrm{C}\right)\end{array}$ & $331 / 341$ & $339 / 351$ & $495 / 535$ & $\begin{array}{l}\text { 339/377 LTP } \\
505 / 535 \text { HTD }\end{array}$ & $\begin{array}{l}222 / 230 \text { LTP } \\
339 / 350 \text { HTP }\end{array}$ & $\begin{array}{l}214 / 220 \text { LTP } \\
331 / 340 \text { HTP }\end{array}$ \\
\hline
\end{tabular}

Table 3: Estimated temperature difference from the average indicated temperature to the specimens and the estimated specimen temperature range.

The tables and plots may not be indicative of actual operating conditions of individual specimen groupings. They are indicative of the average operating temperature and the maximum expected variation of the majority of specimens within the experiment. Additional analyses are required to estimate the temperature of individual specimen groupings, and the accuracy of the analyses will be dependent upon the closeness of approximation afforded by one or more of the dummy specimen measurements

\section{FUTURE PLANS}

The capsule has been disassembled and the specimens are being delivered for testing. 


\section{REFERENCES:}

1. A. L. Qualls and T. Muroga, "Progress on the Design of a Varying Temperature Irradiation Experiment of Operation in HFIR, "Fusion Materials Semiannual Progress Report for Period Ending December 31, 1996, p. 255.

2. A. L. Qualls, M. T. Hurst, D. G. Raby, D. W. Sparks and T. Muroga, "Progress Report on the Varying Temperature, "Fusion Materials Semiannual Progress Report for Period Ending June 30, 1997, p. 243.

3. A. L. Qualls and R. G. Sitterson, "Specimens Loading List for the Varying Temperature," Fusion Materials Semiannual Progress Report for period ending June 30, 1998, p. 260.

4. A. L. Qualls and T. Muroga, "Progress Report on the Operations of the Varying Temperature Experiment (HFIR-MFE-RB-13J), Fusion Materials Semiannual Progress Report for period ending December 31, 1998, p. 302. 


\section{Distribution}

1. Advanced Micro Devices, Inc., 5204 E. Ben White Blvd., MS-613, PCAL-Analytical TEM Section, Austin TX 78741
J. Gazda

2-15. Argonne National Laboratory, 9700 South Cass Avenue, Argonne, IL 60439
M. C. Billone
C. E. Johnson
C. B. Reed
T. S. Bray
S. Majumdar
D. L. Smith
O. K. Chopra
R. F. Mattas
H. C. Tsai
H. M. Chung
K. Natesan
Y. Yan
A. B. Hull
J. H. Park

16-17. Argonne National Laboratory, EBR-II Division, P.O. Box 2528, Idaho Falls, ID 83403-2528
H. P. Planchon
D. L. Porter

18. Auburn University, Department of Mechanical Engineering, 201 Ross Hall, Auburn, AL 36849 B. A. Chin

19. Bechtel-Bettis, ZAP 08D/MT, P.O. Box 79, West Mifflin, PA 15122-0079

B. Cockeram

20-21. Boeing, Mail Code S 106 7220, P.O. Box 516, St. Louis, MO 63166-0516
J. W. Davis
G. W. Wille

22. Carnegie Institute of Technology, Carnegie-Mellon University, Schenley Park, Pittsburgh, PA 15213 W. M. Garrison, Jr.

23. Commissariat à l'Energie Atomique, Direction des Technologies Advancées, M2R1/DECM Cen-Saclay, Gif Sur Yvette, Cedex, France
F. Tavassoli

24. Dow Corning Corporation, 3901 S. Saginaw Rd., MS-500, Midland, MI 48686-0995 R. E. Jones

25-27. General Atomics, P.O. Box 85608, San Diego, CA 92138
W. R. Johnson
K. R. Schultz
C. Wong

28. Georgia Institute of Technology, Fusion Research Center, 0225, Atlanta, GA 30332 W. M. Stacey

29. Grand Canyon University, Department of Natural Science, 3300 W. Camelback Rd., Phoenix, AZ 85017

W. A. Coghlan

30-32. Idaho National Engineering Laboratory, Fusion Safety Program, P.O. Box 1625, Idaho Falls, ID 83415-3523
G. Longhurst
K. McCarthy
D. Petti

33. Knolls Atomic Power Laboratory, P.O. Box 1072, Schenectady, NY 12301

G. Newsome 
34-36. Lawrence Livermore National Laboratory, P.O. Box 808, Livermore, CA 94550
T. Diaz de la Rubia
W. G. Wolfer
J. Perkins

37-43. Los Alamos National Laboratory, Los Alamos, NM 87545
J. L. Anderson
E. H. Farnum
W. F. Sommer
R. G. Castro
R. E. Siemon
K. E. Sickafus
D. W. Cooke

44-46. Massachusetts Institute of Technology, Department of Metallurgy and Materials Science, Cambridge, MA 02139
L. W. Hobbs
N. J. Grant
K. C. Russell

47. Massachusette Institute of Technology, Plasma Fusion Center Headquarters, Cambridge, MA 02139

D. B. Montgomery

48. McMaster University, Engineering Physics, Hamilton, Ontario, Canada L8S 4L7

D. P. Jackson

49 MER Corp., 7960 South Kolb Rd., Tucson, AZ 85706

W. Kowbel

50. Merrimack College, Dept. of Physics, 315 Turnpike Street, North Andover, MA 01845 D. P. White

51-52. NASA Lewis Research Center, MS-106-5, Cleveland, OH 44135
J. DiCarlo
G. Morscher

53-54. National Institute of Standards and Technology, Boulder, CO 80302
F. R. Fickett
R. P. Reed

55-56. Naval Research Laboratory, Code 6506, Washington, DC 20375
D. L. Griscom
J. A. Sprague

57-95. Oak Ridge National Laboratory, P.O. Box 2008, Oak Ridge, TN 37831
Central Research Library
Document Reference Section
N. Hashimoto
B. A. Pint
Laboratory Records-RC
D. T. Hoelzer
A. L. Qualls
J. Bentley
E. E. Bloom
N. Igawa
J. P. Robertson
T. D. Burchell
J. F. King
R. L. Klueh
A. F. Rowcliffe (10)
T. S. Byun
E. H. Lee
J. Sheffield
S. D. Connery
L. K. Mansur
L. L. Snead
J. R. DiStefano
P. J. Maziasz
R. H. Goulding
S. Milora
T. C. Reuther
R. E. Stoller
K. R. Thoms
M. L. Grossbeck
S. J. Zinkle

96-111. Pacific Northwest National Laboratory, P.O. Box 999, Richland, WA 99352
D. J. Edwards
F. A. Garner (5)
M. L. Hamilton
R. J. Kurtz
D. S. Gelles
H. L. Heinisch
C. A. Lewinsohn
L. R. Greenwood
G. W. Hollenberg
B. Oliver
R. H. Jones
J. Youngblood

112. Oregon Graduate Institute, Dept. of Materials Science \& Engineering, 19600 N.W.

Von Neumann Drive, Beaverton, OR 97006

J. M. McCarthy 
113-115. Princeton University, Princeton Plasma Physics Laboratory, P.O. Box 451, Princeton, NJ 08540
R. Goldston
Long-Poe Ku
D. M. Meade

116-117. Rensselaer Polytechnic Institute, Troy, NY 12181
D. Duquette
D. Steiner

118-120. Sandia National Laboratories, Fusion Technology Dept., Dept. No 6531, P.O. Box 5800 , Albuquerque, NM 87185-5800
M. J. Davis
M. Ulrickson
R. D. Watson

121-122. Sandia National Laboratories, Livermore Division 8316, Livermore, CA 94550
W. Bauer
K. Wilson

123. Sandia National Laboratories, P.O. Box 969, MS-9402, Livermore, CA 94551-0969 C. Cadden

124. San Diego State University, Mechanical Engineering Dept., San Diego, CA $92182-$ 0191
L. D. Thompson

125. Texas A\&M University, Box 397, Prairie View, TX 77446

D. Baker

126. TSI Research, 225 Stevens Ave., \#110, Solana Beach, CA 92075

E. T. Cheng

127. University of California at San Diego, U.S. ITER Project Office, 9500 Gilman Drive, Bldg. 302, La Jolla, CA 92093-0035

C. C. Baker

128. University of California at San Diego, Fusion Energy Research Program, 9500 Gilman Drive, MC0417, La Jolla, CA 92093-0417

M. Tillack

129-130. University of California at Santa Barbara, Dept. of Mechanical and Environmental Engineering, Engineering II, Room 2355, Santa Barbara, CA 93106-5070
G. E. Lucas
G. R. Odette

131-133. University of California at Los Angeles, Dept. of Chemical, Nuclear, and Thermal Engineering, Los Angeles, CA 90024
M. A. Abdou
N. M. Ghoniem
S. Sharafat

134. University of Illinois, Dept. of Nuclear Engineering, Urbana, IL 61801 J. Stubbins

135. University of Michigan, Dept. of Nuclear Engineering, Ann Arbor, MI 48109 T. Kammash

136. University of Missouri, Department of Nuclear Engineering, Rolla, MO 65401

$$
\text { A. Kumar }
$$

137-138. University of Tennessee, Dept. of Materials Science and Engineering, 427-B Dougherty Bldg., Knoxville, TN 37996-2200
P. K. Liaw
C. J. McHargue 
139-140. University of Wisconsin, Nuclear Engineering Dept., 1500 Engineering Drive, Madison, WI 53706
J. B. Blanchard
G. L. Kulcinski

141. Helsinki University of Technology, Laboratory of Engineering Materials, Puumiehenkuja 3, SF-02150 Espoo, Finland

H. Hänninen

142-143. Hokkaido University, Center for Advanced Research of Energy Technology, Kita 13, Nishi 8, Kita-ku, Sapporo 060-8628, Japan

Tamaki Shibayama Heischichiro Takahashi

144-146. Hokkaido University, Faculty of Engineering, Kita 13, Nishi 8, Kita-ku, Sapporo 060-8628, Japan

Somei Ohnuki

Akira Okada

Seiichi Watanabe

147-151. Japan Atomic Energy Research Institute, Tokai Research Establishment, Tokai-mura, Naka-gun, Ibaraki-ken 319-1195, Japan
Akimichi Hishinuma
Tatsuo Kondo
R. Yamada

S. Jitsukawa

152. Japan Atomic Energy Research Institute, 801-1 Mukouyama, Naka-machi, Naka-gun, Ibaraki-ken 311-0693, Japan
S. Ueda

153-155. Kyoto University, Institute of Advanced Energy, Gokasho, Uji, Kyoto 611-0011, Japan Yutai Katoh Akihiko Kimura Akira Kohyama

156-157. Kyushu University, Dept. of Nuclear Engineering, Faculty of Engineering, Hakozaki, Fukuoka 812-8582, Japan Chiken Kinoshita

Kenichi Shiiyama

158-159. Kyushu University, Research Institute for Applied Mechanics, Kasuga, Fukuoka 816-8580, Japan Hideo Watanabe

Naoaki Yoshida

160-161. Muroran Institute of Technology, Dept. of Materials Science and Engineering, Mizumoto 27-1, Mororan, Hokkaido 050-8585, Japan Yutaka Kohno Toshihei Misawa

162. Nagoya University, Dept. of Nuclear Engineering, Furo-Cho, Chikusa-ku, Nagoya 464-8603, Japan

Tetuo Tanabe

163-165. National Institute for Fusion Science, Oroshi, Toki, Gifu 509-5292, Japan Takeo Muroga Chusei Namba Nobuaki Noda

166-169. National Research Institute for Metals, Tsukuba Branch, Sengen, Tsukuba-shi, Ibaraki-ken, 305-0047, Japan

Fujio Abe

Josei Nagakawa

Tetsuji Noda Haruki Shiraishi

170. PNC Oarai, 4002 Narita, Oarai, Ibaraki 311-1393, Japan S. Ukai 
171. Science University of Tokyo, Dept. of Materials Science \& Technology, 2641

Yamazaki, Noda-shi, Chiba 278-8510, Japan

Naohiro Igata

172-173. Shimane University, Dept. of Materials Science, 1060 Nishikawatsu, Matsue, 6908504, Japan
K. Arakawa
K. Ono

174-175. Tohoku University, Institute for Materials Research, Katahira 2-2-1, Aoba-ku, Sendai 980-8577, Japan

K. Fukumoto

Hideki Matsui

176-177. Tohoku University, Institute for Materials Research, Oarai Branch, Oarai-machi, Ibaraki 311-13, Japan

Hiroaki Kurishita Tatsuo Shikama

178-180. Tohoku University, Dept. of Quantum Science \& Energy Engineering, Aoba, Aramaki, Sendai 980-8579, Japan

Katsunori Abe Akira Hasegawa Manabu Satou

181. Tokai University, Dept. of Nuclear Engineering, 1117 Kitakaname, Hiratsuka-shi, Kanagawa-ken 259-1292, Japan Shiori Ishino

182. University of Tokyo, Dept. of Nuclear Engineering, 3-1, Hongo 7-Chome, Bunkyo-Ku, Tokyo 113-8654, Japan Naoto Sekimura

183. University of Tokyo, Dept. of Materials Science, 3-1, Hongo 7-Chome, Bunkyo-ku, Tokyo 113-8654, Japan Yutaka Kohno

184. University of Tokyo, Dept. of Quantum Engineering and Systems Science, 7-3-1 Hongo, Tokyo 113-8656, Japan T. Terai

185. VTT Manufacturing Technology, P.O. Box 1704, FIN-02044 VTT, Finland P. Aaltonen

186. Commission of European Communities, Directorate-General for Research Science and Education, Fusion Programme, RUE De La Loi 200, B-1049 Brussels, Belgium S. Paidassi

187-188. Southwestern Institute of Physics, P.O. Box 432, Chengdu 610041, Sichuan, P.R. China Chen Jiming Zeng Yu Xu

189. Southwestern Institute of Physics, P.O. Box 9819, Beijing 100029, P.R. China J. P. Qian

190. Institute of Atomic Energy, Academia Sinica, P.O. Box 275-51, Beijing 102413, P.R. China

J. Yu

191. Riso National Laboratory, Materials Dept., P.O. Box 49, DK-4000, Roskilde, Denmark B. N. Singh 
192. CEA-CEREM-CEA, Saclay, CE2M/LECMA, Commissariat a l'Energie Atomique, 91191 Gif-Sur-Yvette, Cedex, France

N. Roux

193. Commission for European Communities, Joint Research Centre, I.A.M. Ispra

Establishment, 21020 Ispra (Varese), Italy

P. Fenici

194. ENEA Fusion Division, CR Brasimone, 40032, Camugnano, Bologna, Italy

G. Benamati

195. EURATOM/CIEMAT Fusion Association, Avenida Complutense 22, 28040, Madrid, Spain

E. R. Hodgson

196. Netherlands Energy Research Foundation ECN, Westerduinweg 3, P.O. Box 1, NI 1755 LE Petten, Netherlands

B. Van der Schaaf

197. Paul Scherrer Institute, $\mathrm{CH}-5232$ Villigen, Wuerenlingen PSI, Switzerland M. Victoria

198. Harwell Laboratory, B393, Radiation Damage Dept., Oxfordshire, OX11 ORA, United Kingdom

C. A. English

199. Metallurgical and Nuclear Consultant, 9A Cumnor Rise Road, Cumnor Hill, Oxford OX2 9HD, United Kingdom

D. R. Harries

200. UKAEA Fusion, Fusion Technology Division, Culham Science Centre, Abingdon, Oxon, OX14 3DB, United Kingdom

P. Karditsas

201. Hahn-Mietner-Institut fur Kernforschung Berlin, Postfach 390128, Glienicker Str. 100, D-14109, Germany

H. Wollenberger

202. Institut fur Festkorperforschung Forschungszentrum Jülich, Postfach 1913, D-52425 Jülich, Germany

H. Ullmaier

203-206. ITER Garching Joint Work Site, Max-Planck-Institute für Plasmaphysik,

Boltzmannstrasse 2, D-85748 Garching bei München, Germany
M. Baiden
R. Behrisch
V. Barabash
G. Kalinin

207. Kazakh State University, 96 Tole Bi Str, 480012, Almaty, Republic of Kazakhstan V. Shestakov 
208-209. ITER Naka Joint Work Site, 801-1 Mukouyama, Naka-machi, Naka-gun, Ibaraki-Ken, 311-01, Japan

M. Huguet (2)

210. Forschungszentrum Juelich, IWV-2, 52425 Juelich, Germany, J. Linke

211-213. Kernforschungszentrum Karlsruhe, Postfach 3640, 75 Karlsruhe 1, Germany M. Dalle-Donne (INR) A. Moeslang

K. Ehrlich (IMF-II)

214. Max-Planck-Institut für Plasmaphysik, Boltzmannstrasse 2, D-85748 Garching bei München, Germany

Patrick Lorenzetto

215. A. A. Baikov Institute of Metallurgy, USSR Academy of Sciences, Leninsky Prospect 49, Moscow, Russia

L. I. Ivanov

216-217. Bochvar Institute, P.O. Box 369, 123060 Moscow, Russia

V. Chernov M. Solonin

218. CRISM "Prometey," Naberezhnava r. Monastyrick 1, 193167, St. Petersburg, Russia V. V. Rybin

219. D. V. Efremov Institute of Electro-Physical Apparatus, Scientific Technical Center "Sintez,"189631, St. Petersburg, Russia

S. A. Fabritsiev

220. ENES, P.O. Box 788, Moscow 101000, Russia

A. Ivanov

221-222. Kharkov Institute of Physics \& Technology, Radiation Damage and Materials Dept., Akademicheskaya 1, 310108 Kharkov, Ukraine

I. M. Neckludov V. Voyevodin

223-225. V. I. Lenin Research Institute of Atomic Reactors, 433510 Dimitrovgrad-10, Ulyanovsk Region, Russia
V. Kazakov
A. S. Pokrovsky
V. K. Shamardin

226. Korea Advanced Institute of Science and Technology, Department of Nuclear Engineering, DaeDukDanji, Taejon, 305-701, Korea I-S. Kim

227. Korean Atomic Energy Research Institute, P.O. Box 105, Yusung, Taejon, 305-600, Korea

Jun Hwa Hong

228. Seoul National University, Dept. of Nuclear Engineering, 56-1 Shinrim-Dong, Kwanak-Ku Seoul, 151-742, Korea

K. H. Chung

229. Sung Kyun Kwan University, Dept. of Metallurgical Engineering, 300 Chunchun-dong, Jangan-gu, Suwon, 440-746, Korea

J. G. Han 
230. KAERI, 150 Dukin-Dong, Yusong-Gu, Taejon, 305-353, Korea Dr Ji Yeon Park

231. Department of Energy, DOE Oak Ridge Field Office, P.O. Box 2008, Oak Ridge, TN 37831-6269 Assistant Manager for Energy Research and Development

232. Department of Energy, DOE Oak Ridge Field Office, P.O. Box 2008, Oak Ridge, TN $37831-6269$

S. D. Frey

233. Department of Energy, Office of Basic Energy Sciences, Washington, D.C. 20585 R. J. Gottschall

234-237. Department of Energy, Office of Fusion Energy, Germantown, MD 20874

S. E. Berk

N. A. Davies
W. Marton

R. McKnight

238. Department of Energy, Richland Operations Office, P.O. Box 550, MS-K850, Richland, WA 99352

J. Turner 
. 